DEVELOPMENT OF ION EXCHANGE MODELS FOR WATER TREATMENT AND APPLICATION TO THE INTERNATIONAL SPACE STATION WATER PROCESSOR

David Robert Hokanson

Michigan Technological University

Follow this and additional works at: https://digitalcommons.mtu.edu/etds

Copyright 2004 David Robert Hokanson

Recommended Citation

Hokanson, David Robert, "DEVELOPMENT OF ION EXCHANGE MODELS FOR WATER TREATMENT AND APPLICATION TO THE INTERNATIONAL SPACE STATION WATER PROCESSOR", Dissertation, Michigan Technological University, 2004.

https://doi.org/10.37099/mtu.dc.etds/708 
DEVELOPMENT OF ION EXCHANGE MODELS FOR WATER TREATMENT AND APPLICATION TO THE

INTERNATIONAL SPACE STATION WATER PROCESSOR

By

David Robert Hokanson

\author{
A DISSERTATION \\ Submitted in Partial Fulfillment of \\ the Requirements for the Degree of \\ DOCTOR OF PHILOSOPHY IN ENGINEERING \\ (ENVIRONMENTAL ENGINEERING)
}

MICHIGAN TECHNOLOGICAL UNIVERSITY 
Copyright @ 2004 Michigan Technological University All rights reserved.

No part of this publication may be reproduced, stored in a retrieval system, or transmitted, in any form or by any means, electronic, mechanical, photocopying, recording, on the internet, or otherwise, without written permission of the author. 
This dissertation, "Development of Ion Exchange Models for Water Treatment and Application to the International Space Station Water Processor," is hereby approved in partial fulfillment of the requirements for the Degree of DOCTOR OF PHILOSOPHY IN ENGINEERING (ENVIRONMENTAL ENGINEERING).

DEPARTMENT: Civil and Environmental Engineering MICHIGAN TECHNOLOGICAL UNIVERSITY

Dissertation Advisor:

Dr. David W. Hand

Date

Non-Departmental

Program Chair:

Dr. Neil J. Hutzler

Date 



\title{
DEVELOPMENT OF ION EXCHANGE MODELS FOR WATER TREATMENT \\ AND APPLICATION TO THE \\ INTERNATIONAL SPACE STATION WATER PROCESSOR
}

\author{
David Robert Hokanson \\ Department of Civil and Environmental Engineering \\ Michigan Technological University \\ 1400 Townsend Drive \\ Houghton, Michigan 49931
}

\begin{abstract}
The International Space Station (ISS) requires a substantial amount of potable water for use by the crew. The economic and logistic limitations of transporting the vast amount of water required onboard the ISS necessitate onboard recovery and reuse of the aqueous waste streams. Various treatment technologies are employed within the ISS water processor to render the waste water potable, including filtration, ion exchange, adsorption, and catalytic wet oxidation. The ion exchange resins and adsorption media are combined in multifiltration beds for removal of ionic and organic compounds.

A mathematical model (MFBMODEL ${ }^{\mathrm{TM}}$ ) designed to predict the performance of a multifiltration (MF) bed was developed. MFBMODEL consists of ion exchange models for describing the behavior of the different resin types in a MF bed (e.g., mixed bed, strong acid cation, strong base anion, and weak base anion exchange resins) and an adsorption model capable of predicting the performance of the adsorbents in a MF bed. Multicomponent ion exchange
\end{abstract}


equilibrium models that incorporate the water formation reaction, electroneutrality condition, and degree of ionization of weak acids and bases for mixed bed, strong acid cation, strong base anion, and weak base anion exchange resins were developed and verified. The equilibrium models developed use a tanks-inseries approach that allows for consideration of variable influent concentrations. The adsorption modeling approach was developed in related studies and application within the MFBMODEL framework was demonstrated in the Appendix to this study. MFBMODEL consists of a graphical user interface programmed in Visual Basic and Fortran computational routines. This dissertation shows MF bed modeling results in which the model is verified for a surrogate of the ISS waste shower and handwash stream.

In addition, a multicomponent ion exchange model that incorporates mass transfer effects was developed, which is capable of describing the performance of strong acid cation (SAC) and strong base anion (SBA) exchange resins, but not including reaction effects. This dissertation presents results showing the mass transfer model's capability to predict the performance of binary and multicomponent column data for SAC and SBA exchange resins.

The ion exchange equilibrium and mass transfer models developed in this study are also applicable to terrestrial water treatment systems. They could be applied for removal of cations and anions from groundwater (e.g., hardness, nitrate, perchlorate) and from industrial process waters (e.g. boiler water, ultrapure water in the semiconductor industry). 


\section{ACKNOWLEDGMENTS}

I wish to thank my advisor, Dr. David W. Hand, for helping create this project and for continued support throughout this effort. I am grateful to Dr. John C. Crittenden for supplying valuable insight throughout the endeavor. I wish to thank Drs. Tony N. Rogers and James R. Mihelcic for serving on my committee to evaluate this work. I would also like to thank Dr. Judith N. Perlinger for her role in evaluating the work. Thanks to project officers Layne Carter at NASA MSFC and Charles Martin at ION Corporation.

Funding was provided by: (1) ION Corporation, (2) U.S. Environmental Protection Agency, (3) National Center for Clean Industrial and Treatment Technologies (CenCITT), (4) MTU Graduate School, (5) MTU Research Excellence Fund.

A very special thanks to Eric Oman for assistance with programming, as well as Richard Hossli and Jason Maclean. I wish to thank the entire NASA/ION Corporation MFB/VRA project team of Brooke Clancey, John Bulloch, Louis Kindt, Changlin Huang, Anisa Ali, Mike DeBraske, Eric Oman, Dinorah Audeves, and Ji Yang for their camaraderie. Thanks to Shelle Sandell, David Perram and Jacqueline Popko for experimental and analytical work. I wish to thank Ken Palosaari and Robert Landsparger for keeping the civil and environmental engineering (CEE) computer network afloat. Thanks also to Shelle Sandell, Corrine Leppen, and Mitzi Johnson for their help at the CEE departmental level. I would like to thank all my fellow graduate students who made this experience more rewarding.

I am also grateful to my parents, Bob and Marcia Hokanson, and to my wife's parents, Frank and Sally Verbos, for their encouragement. I want to thank my daughters, Natalie and Ella, for bringing so much joy into my life.

Most importantly, I would like to thank my wife, Jill, whose love, support, and patience made this accomplishment possible. 



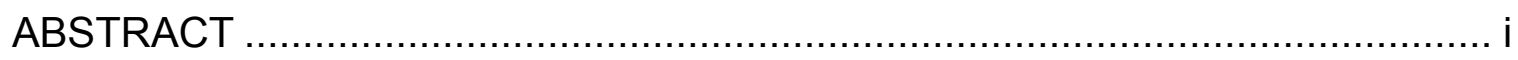

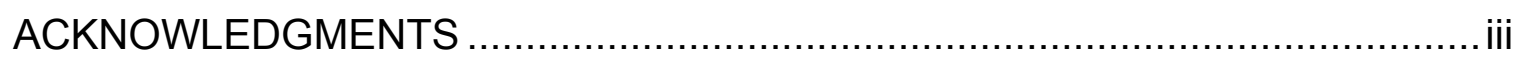

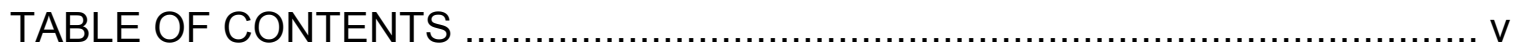

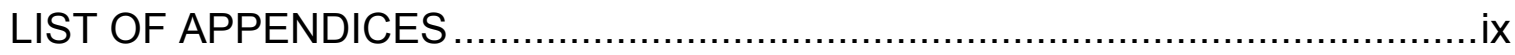

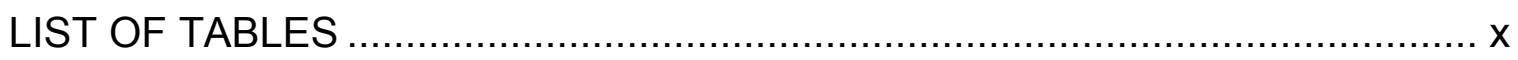

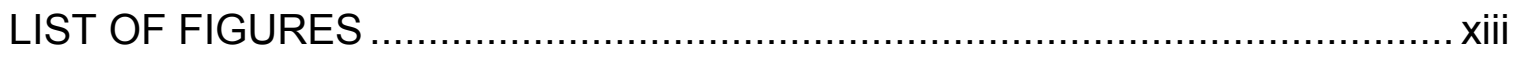

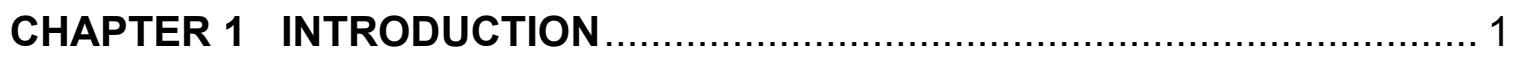

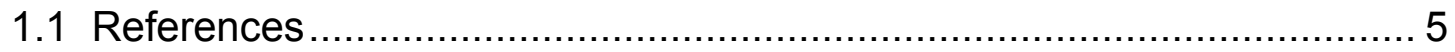

\section{CHAPTER 2 BINARY DESCRIPTION AND}

MULTICOMPONENT PREDICTION OF ION

EXCHANGE EQUILIBRIUM FOR THE

INTERNATIONAL SPACE STATION WATER

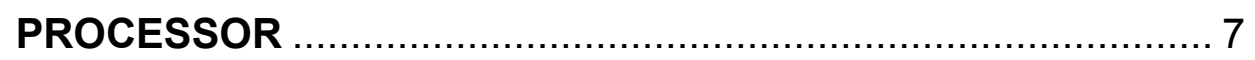

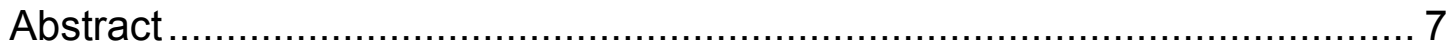

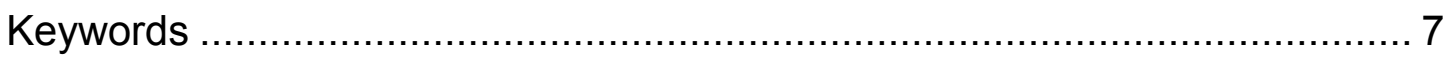

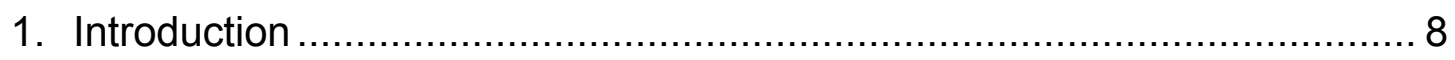

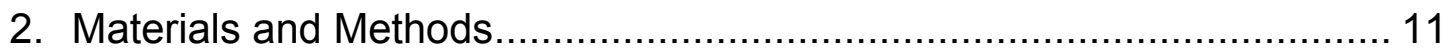

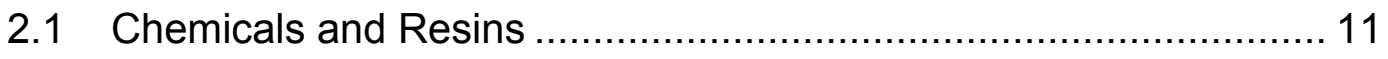

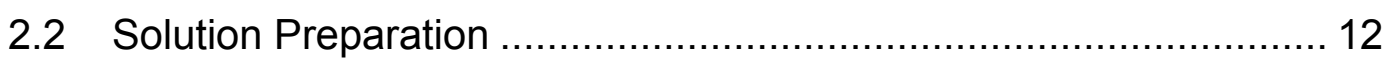

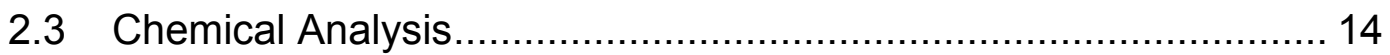

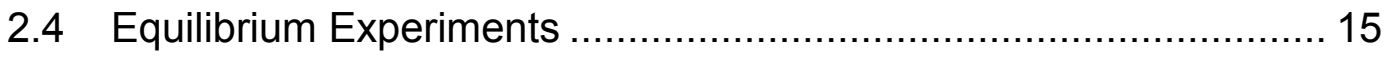

2.4.1 IRN-77 SAC Exchange Resin ........................................ 15

2.4.2 IRN-78 SBA Exchange Resin .......................................... 15

2.4.3 IRN-150 Mixed Bed lon Exchange Resin ........................... 16

2.4.4 IRA-68 WBA Exchange Resin .......................................... 16

2.4.5 Resin Physical Properties and Total Resin

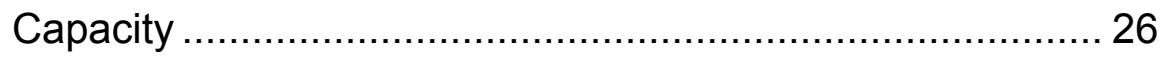


CHAPTER 2 continued

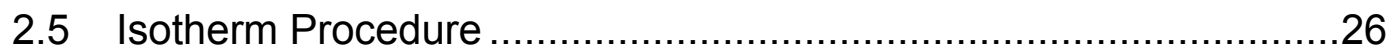

3. Equilibrium Description Development............................................28

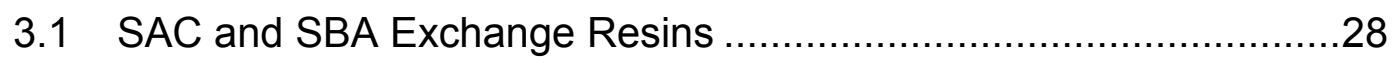

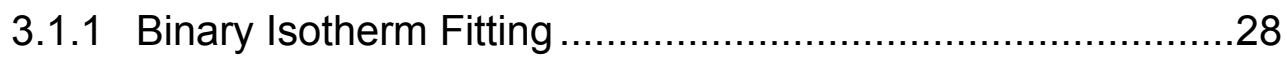

3.1.2 Multicomponent Isotherm Prediction ..................................30

3.2 Mixed Bed Ion Exchange Resins .............................................. 31

3.2.1 Multicomponent Isotherm Prediction ...................................31

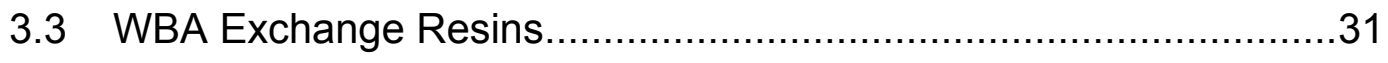

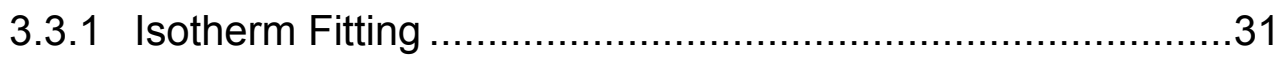

3.2.2 Multicomponent Isotherm Prediction...................................33

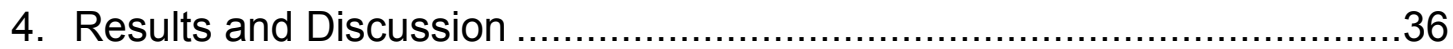

4.1 IRN-77 SAC and IRN-78 SBA Exchange Resins ............................36

4.2 IRN-150 Mixed Bed Ion Exchange Resin ....................................40

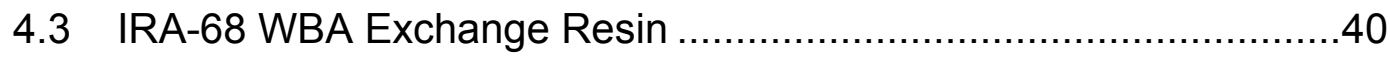

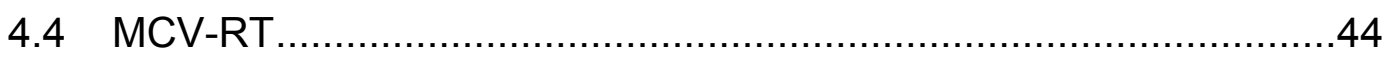

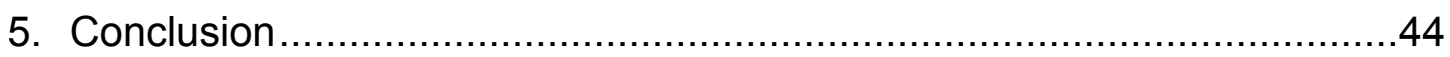

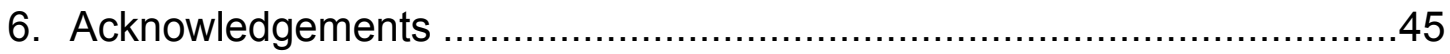

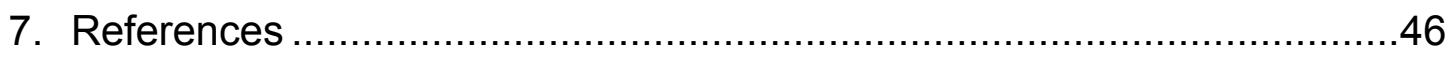

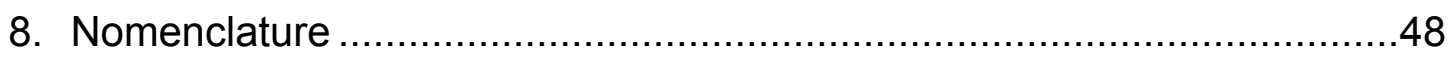

\section{CHAPTER 3 DYNAMIC MATHEMATICAL MODELING OF}

ION EXCHANGE PROCESSES FOR THE

INTERNATIONAL SPACE STATION WATER

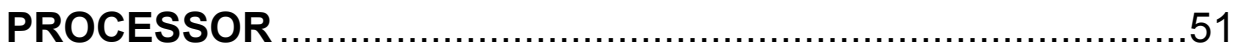

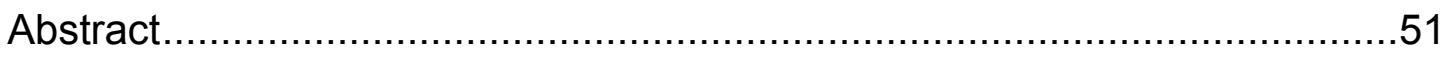

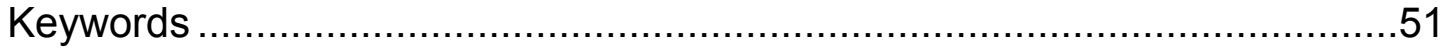

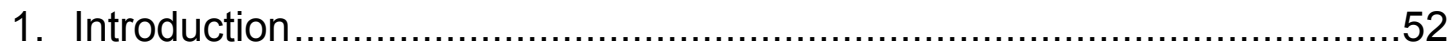

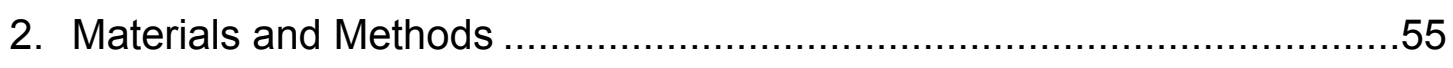

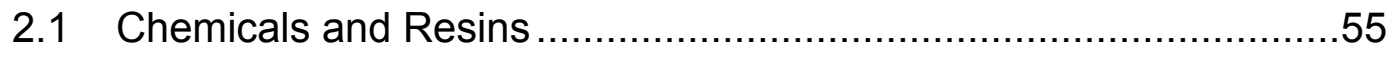

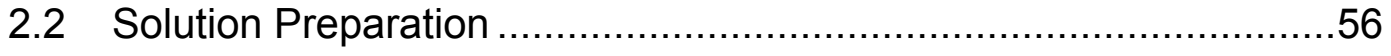


CHAPTER 3 continued

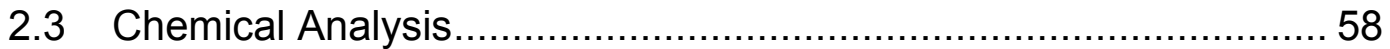

2.4 Multifiltration Bed Model Verification Experiment ............................6 60

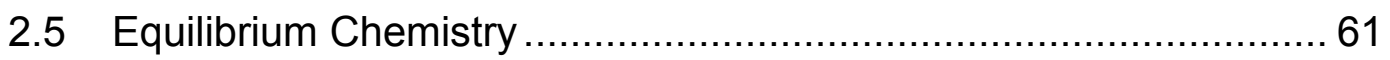

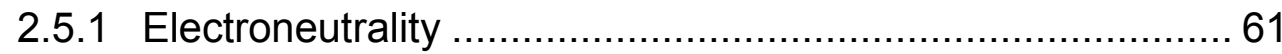

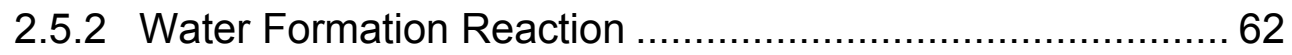

2.5.3 Degree of Ionization of Weak Acids and

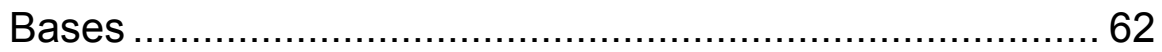

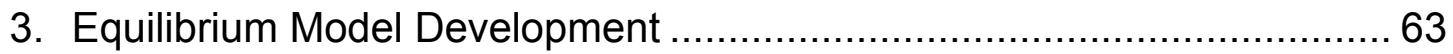

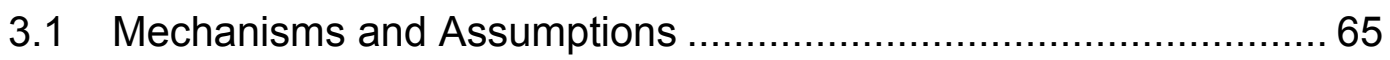

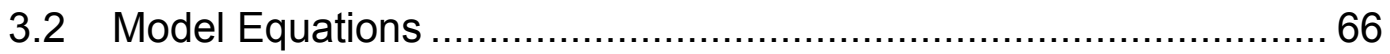

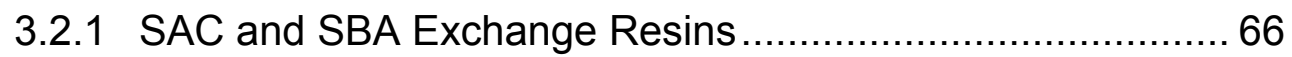

3.2.2 Mixed Bed Ion Exchange Resins .................................... 70

3.2.3 WBA Exchange Resins ................................................... 73

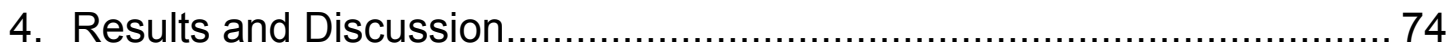

4.1 Mixed Bed lon Exchange Resin: Rohm \& Haas

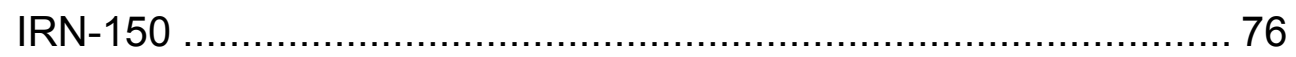

4.2 Strong Acid Cation (SAC) Exchange Resin: Rohm

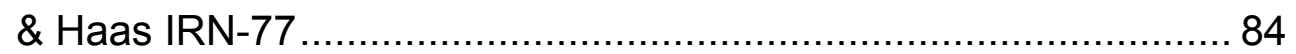

4.3 Weak Base Anion (WBA) Exchange Resin: Rohm \&

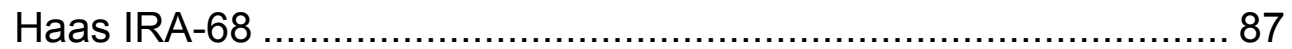

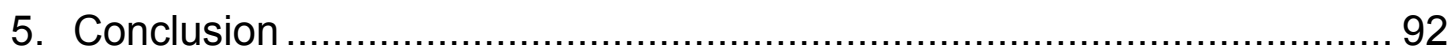

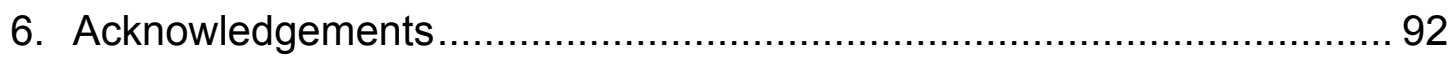

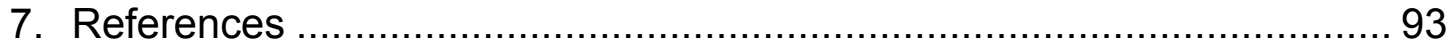

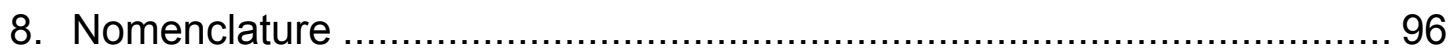




\section{CHAPTER 4 DEVELOPMENT OF A MULTICOMPONENT \\ MASS TRANSFER MODEL FOR ION \\ EXCHANGE}

Abstract. 101

Keywords 101

1. Introduction 102

2. Materials and Methods 106

2.1 Chemicals and Resins 106

2.2 Solution Preparation 106

2.3 Chemical Analysis 107

2.4 Resin Physical Properties, Total Resin Capacities, and Separation Factors 108

2.5 Kinetic Experiments 110

2.6 Statistical Methods 111

2.6.1 Parameter Fitting

2.6.1.1 Binary lon Exchange

2.6.1.2 Multicomponent lon Exchange

2.6.2 95\% Confidence.

2.7 Equilibrium Model 113

3. Mass Transfer Model Development.

3.1 Mechanisms and Assumptions ...................................................114

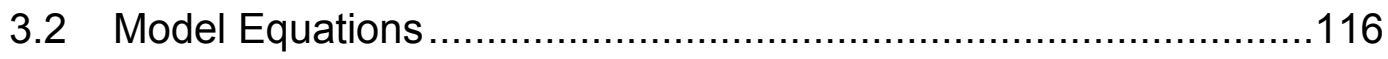

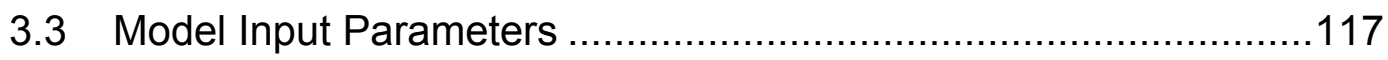

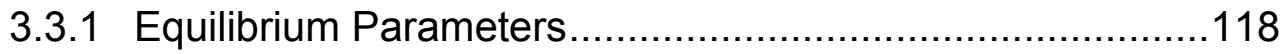

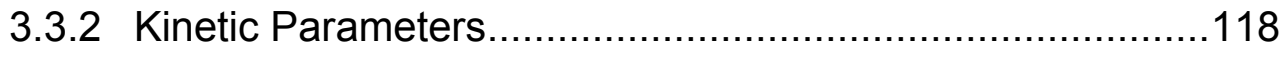

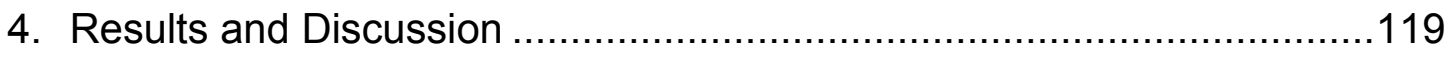

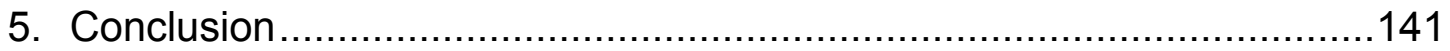

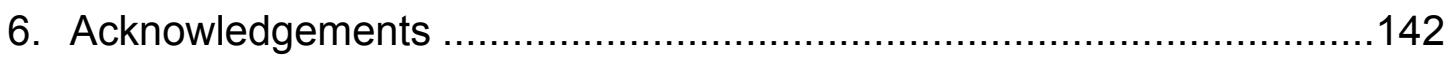

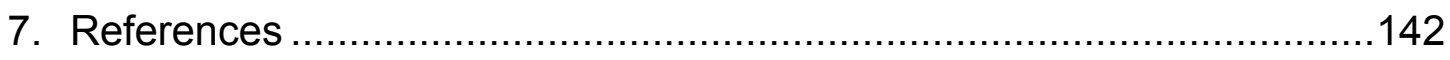

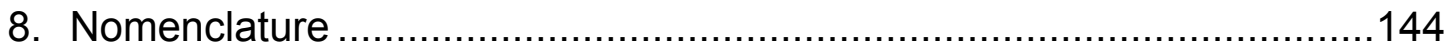




\section{List of Appendices}

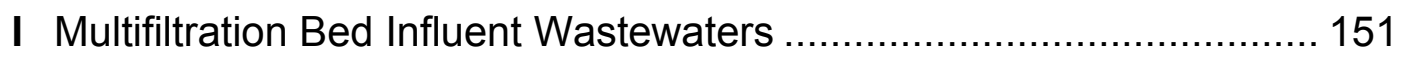

II Example Ion Exchange Equilibrium Calculations ................................ 159

III Development of the Tanks in Series Equilibrium Model (TISEqM) for SAC, SBA and Mixed Bed Resins

IV Equilibrium Approach Accounting for Water Formation Reaction, Charge Balance, and Degree of Ionization Adopted for Mixed Bed Ion Exchange, Strong Acid Cation Exchange, Strong Base Anion Exchange, and Weak Base Anion Exchange.

V Algorithm for Determining SAC and SBA properties within a Mixed Bed Ion Exchange Resin

VI Development of the Tanks in Series Equilibrium Model (TISEqM) for WBA Resins

VII Explanation of MFBMODEL Software Use.................................... 249

VIII Column Procedure for Kinetic Studies ............................................. 269

IX Ion Exchange Results for MFBMODEL Prediction of Experimental Data

X Adsorption Results for MFBMODEL Prediction of Experimental Data

XI Development of the Pore Diffusion Model for SAC and SBA Resins. 


\section{LIST OF TABLES}

Table 1-1 lon Exchange Resins and Adsorbents in an ISS

Multifiltration Bed

Table 2-1 Physical Properties of the lon Exchange Resins in

the Multifiltration Beds.

Table 2-2 Representative lons for the Various Resins ................................14

Table 2-3 lons Present in the Shower/Handwash Water .............................14

Table 2-4 Initial Concentrations for Isotherms Performed on

IRN-77 SAC Exchange Resin .

Table 2-5 Initial Concentrations for Isotherms Performed on

IRN-78 SBA Exchange Resin

Table 2-6 Initial Concentrations for Chloride Isotherms

Performed on IRA-68 WBA Exchange Resin

Table 2-7 Initial Concentrations for Sulfate Isotherms

Performed on IRA-68 WBA Exchange Resin

Table 2-8 Initial Concentrations for Acetate Isotherms

Performed on IRA-68 WBA Exchange Resin

Table 2-9 Initial Concentrations for Lactate Isotherms

Performed on IRA-68 WBA Exchange Resin

Table 2-10 Initial Concentrations for SCMT Isotherms

Performed on IRA-68 WBA Exchange Resin .............................25

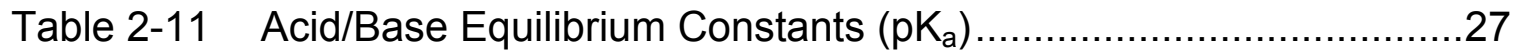

Table 2-12 Total Capacities for Each Resin in Various Forms........................34

Table 2-13 Comparison of Experimental Total Capacities and

Fitted Apparent Capacities with Manufacturer's

Reported Capacity for Each Resin in Various

Forms.

Table 2-14 Separation Factors for IRN-77 SAC Exchange

Resin 
Table 2-15 Separation Factors and Apparent Capacities for IRN-78 SBA Exchange Resin

Table 2-16 Langmuir Equilibrium Ion Exchange Rate

Constants $\left(b_{i}\right)$ and Separation Factors $\left(\alpha_{C l}^{i}\right)$ for

IRA-68 WBA Exchange Resin and Acid $\mathrm{pK}_{\mathrm{a}}$

Values

Table 3-1 Ion Exchange Resins in an ISS Multifiltration Bed

Table 3-2 Organic and Inorganic Ersatz Shower/Handwash

Water Constituents

Table 3-3 Properties of Mixed Bed Resin Column Used in

MFBMODEL Verification Experiment..... 76

Table 3-4 Properties of First Strong Acid Cation Exchange

Resin Column Used in MFBMODEL Verification

Experiment 85

Table 3-5 Properties of Weak Base Anion Exchange Resin

Column Used in MFBMODEL Verification

Experiment 87

Table 4-1 Representative lons for the Various Resins 107

Table 4-2 Physical Properties and Total Resin Capacities of the Ion Exchange Resins 109

Table 4-3 Separation Factors for Cations on the Hydrogen

Form of IRN-77 SAC Exchange Resin and for Anions on the Hydroxide or Chloride Form of IRN-

78 SBA Exchange Resin 110

Table 4-4 Resin Properties for Each of the PDM Simulations 120

Table 4-5 Bed Parameters for Each of the PDM Simulations 121

Table 4-6 Properties of the lons Used in Each of the PDM

Simulations 
Table 4-7 Mass Transfer Parameters and Dimensionless

Groups for Each of the PDM Simulations

Table 4-8 Sensitivity Analysis for the Binary IRN-77 SAC Fit

on the Effect of Varying Pore Diffusion

Coefficient, $D_{p}$, and Film Transfer Coefficient, $k_{f}$,

by plus or minus $50 \%$ of Their PDM Fit Values

Shown in Table 7 and Observing the Impact on

the Objective Function, $\mathrm{f}_{\mathrm{obj}}$, Compared to the PDM

Fit $\left(\mathrm{f}_{\mathrm{obj}}=0.000844\right)$

Table 4-9 Summary of Values of Objective Function $\left(f_{\text {obj }}\right)$ and

Average Sum of the Squares of the Residuals $\left(\mathrm{s}^{2}\right)$

for Each PDM and TISEqM Simulation for the

Multicomponent Case of Sodium, Potassium,

Ammonium, and Calcium Exchanging IRN-77 SAC

Exchange Resin in the Hydrogen Form

Table 4-10 Sensitivity Analysis for the Binary IRN-78 SBA Fit

on the Effect of Varying Pore Diffusion

Coefficient, $D_{p}$, and Film Transfer Coefficient, $k_{f}$,

by plus or minus $50 \%$ of Their PDM Fit Values

Shown in Table 7 and Observing the Impact on

the Objective Function, $\mathrm{f}_{\mathrm{obj}}$, Compared to the PDM

Fit $\left(f_{o b j}=0.00128\right)$

Table 4-11 Summary of Values of Objective Function $\left(f_{\text {obj }}\right)$ and

Average Sum of the Squares of the Residuals $\left(\mathrm{s}^{2}\right)$

for each PDM Simulation for the Multicomponent

Case of Acetate, Butyrate, Chloride, Bicarbonate

and Sulfate Exchanging IRN-78 SBA Exchange

Resin in the Hydroxide Form 


\section{LIST OF FIGURES}

Figure 1-1 Schematic of a Multifiltration Bed .......................................... 1

Figure 2-1 Schematic of the Multifiltration Beds ….................................... 9

Figure 2-2 Sodium Ion Exchange Equilibrium Isotherms with

IRN-77 SAC Exchange Resin for the Following

Conditions: (a) Binary and Multicomponent Data

from IRN-77 in the $\mathrm{H}^{+}$form (b) Ersatz Data from

IRN-77 in the $\mathrm{Na}^{+}$form

Figure 2-3 Chloride Ion Exchange Equilibrium Isotherms with

IRN-78 SBA Exchange Resin in the Hydroxide

Form.

Figure 2-4 Sodium and Chloride Ion Exchange Equilibrium

Isotherm with IRN-150 Mixed Bed Ion Exchange

Resin $\left(\mathrm{H}^{+} / \mathrm{OH}^{-}\right.$Form) Using Equilibrium

Parameters from IRN-77 SAC and IRN-78 SBA

Exchange Resins

Figure 2-5 Lactate Ion Exchange Equilibrium Isotherm with

Freebase Form of IRA-68 WBA Exchange Resin

and Selected $\mathrm{pH}$ Isopleths

Figure 2-6 Comparison of Measured Liquid Phase

Concentrations to Predicted Liquid Phase

Concentrations for the Multicomponent Isotherm

with Freebase Form of IRA-68 WBA Exchange

Resin. Initial Total Acetate Concentration was

$8.11 \mathrm{meq} / \mathrm{L}$ and Initial Total Chloride

Concentration was $1.02 \mathrm{meq} / \mathrm{L}$ 
Figure 2-7 Comparison of Measured Solid Phase

Concentrations to Predicted Solid Phase

Concentrations for the Multicomponent Isotherm

with the Freebase Form of IRA-68 WBA Exchange

Resin

Figure 3-1 Schematic of the Multifiltration Beds ........................................54

Figure 3-2 Schematic of the Multifiltration Bed Employed in

the Multifiltration Bed Verification Experiment. .75

Figure 3-3 Multicomponent MFBMODEL Verification

Experiment Results for Sodium Exchanging the

First IRN-150 Mixed Bed Exchange Resin

$(\mathrm{EBCT}=120 \mathrm{~min}$ )

Figure 3-4 Multicomponent MFBMODEL Verification

Experiment Results for Potassium Exchanging the

First IRN-150 Mixed Bed Exchange Resin

(EBCT=120 $\mathrm{min}$ )

Figure 3-5 Multicomponent MFBMODEL Verification

Experiment Results for Presaturant Ion Hydrogen

(expressed as $\mathrm{pH}$ ) for the First IRN-150 Mixed

Bed Exchange Resin (EBCT=120 min)

Figure 3-6 Multicomponent MFBMODEL Verification

Experiment Results for Sensitivity Analysis on

$\mathrm{Vc} / \mathrm{Vr}$ and $\mathrm{Va} / \mathrm{Vr}$ for Potassium for the First IRN-

150 Mixed Bed Exchange Resin (EBCT=120 min) .79

Figure 3-7 Multicomponent MFBMODEL Verification

Experiment Results for Chloride Exchanging the

First IRN-150 Mixed Bed Exchange Resin

(EBCT=120 $\mathrm{min}$ ).... 
Figure 3-8 Multicomponent MFBMODEL Verification

Experiment Results for Acetate Exchanging the

First IRN-150 Mixed Bed Exchange Resin

$($ EBCT $=120 \mathrm{~min}$ )

Figure 3-9 Multicomponent MFBMODEL Verification

Experiment Results for Sensitivity Analysis on

$V_{c} / V_{r}$ and $V_{a} / V_{r}$ for Acetate for the First IRN-150

Mixed Bed Exchange Resin (EBCT=120 min)

Figure 3-10 Multicomponent MFBMODEL Verification

Experiment Results for Bicarbonate Exchanging

the First IRN-150 Mixed Bed Exchange Resin

$(\mathrm{EBCT}=120 \mathrm{~min})$

Figure 3-11 Multicomponent MFBMODEL Verification

Experiment Results for Sulfate Exchanging the

First IRN-150 Mixed Bed Exchange Resin

$(\mathrm{EBCT}=120 \mathrm{~min})$

Figure 3-12 Multicomponent MFBMODEL Verification

Experiment Results for CMT Exchanging the First

IRN-150 Mixed Bed Exchange Resin (EBCT=120

$\min )$

Figure 3-13 Multicomponent MFBMODEL Verification

Experiment Results for Sodium Exchanging the

First IRN-77 SAC Exchange Resin (EBCT $=8.8$

$\min )$.

Figure 3-14 Multicomponent MFBMODEL Verification

Experiment Results for Potassium Exchanging the

First IRN-77 SAC Exchange Resin (EBCT=8.8

$\min )$ 86 
Figure 3-15 Multicomponent MFBMODEL Verification

Experiment Results for Presaturant lon Hydrogen

(expressed as $\mathrm{pH}$ ) for the First IRN-77 SAC

Exchange Resin (EBCT=8.8 $\mathrm{min}$ )

Figure 3-16 Multicomponent MFBMODEL Verification

Experiment Results for Acetate Exchanging the

IRA-68 WBA Exchange Resin (EBCT=59 min).

Figure 3-17 Multicomponent MFBMODEL Verification

Experiment Results for Chloride Exchanging the

IRA-68 WBA Exchange Resin (EBCT=59 min).

Figure 3-18 Multicomponent MFBMODEL Verification

Experiment Results for Bicarbonate Exchanging

the IRA-68 WBA Exchange Resin (EBCT=59 min).

Figure 3-19 - Multicomponent MFBMODEL Verification

Experiment Results for Sulfate Exchanging the

IRA-68 WBA Exchange Resin (EBCT=59 min)

Figure 3-20 - Multicomponent MFBMODEL Verification

Experiment Results for CMT Exchanging the IRA-

68 WBA Exchange Resin (EBCT=59 min)

Figure 3-21 Multicomponent MFBMODEL Verification

Experiment Results for Hydroxide (represented as

$\mathrm{pH})$ for the IRA-68 WBA Exchange Resin

$(\mathrm{EBCT}=59 \mathrm{~min})$

Figure 4-1 Binary lon Exchange Column Results for Sodium

Exchanging IRN-77 SAC Exchange Resin in the

Hydrogen Form: PDM Prediction, PDM Fit and

TISEqM Fit versus Experimental Data for Sodium

126

Figure 4-2 95\% Confidence Contour for Binary lon Exchange

Column Results for Sodium Exchanging IRN-77

SAC Exchange Resin in the Hydrogen Form 
Figure 4-3 Comparison of Ion Exchange PDM and TISEqM

Prediction and Fitting Results for Potassium for

Multicomponent Column Run with Sodium,

Potassium, Ammonium and Calcium Exchanging

onto IRN-77 SAC Exchange Resin in the

Hydrogen Form. PDM Prediction, PDM Fit and

TISEqM Best Fit

Figure 4-4 Comparison of Ion Exchange PDM and TISEqM

Prediction and Fitting Results for Calcium for

Multicomponent Column Run with Sodium,

Potassium, Ammonium and Calcium Exchanging

onto IRN-77 SAC Exchange Resin in the

Hydrogen Form. PDM Prediction, PDM Fit and

TISEqM Best Fit.

Figure 4-5 Binary lon Exchange Column Results for lodide

Exchanging IRN-78 SBA Exchange Resin in the

Chloride Form: PDM Prediction and PDM Fit

versus Experimental Data for lodide and Chloride

Figure 4-6 95\% Confidence Contour for Binary Ion Exchange

Column Results for lodide Exchanging IRN-78

SBA Exchange Resin in the Chloride Form

Figure 4-7 Comparison of Ion Exchange PDM Prediction with

Experimental Data for Chloride for Multicomponent

Column Run with Acetate, Butyrate, Chloride,

Bicarbonate, and Sulfate Exchanging onto IRN-78

SBA Exchange Resin in the Hydroxide Form.

Figure 4-8 Comparison of Ion Exchange PDM Prediction with

Experimental Data for Sulfate for Multicomponent

Column Run with Acetate, Butyrate, Chloride,

Bicarbonate, and Sulfate Exchanging onto IRN-78

SBA Exchange Resin in the Hydroxide Form 138 



\section{Chapter 1 - Introduction}

The International Space Station (ISS), developed for long term manned space missions, requires a substantial amount of potable water for use by the crew. Water for drinking, food preparation, and hygiene accounts for over $90 \%$ by weight of the basic consumables (water, oxygen, and food) required for survival aboard the ISS. Support of a four-person crew would require transport of approximately $46,100 \mathrm{lbs}$ of water per year. The economic and logistic limitations of transporting this amount of water to the ISS requires onboard recovery and reuse of the aqueous waste streams (Carter et al., 1992; Carter et al., 1991).

Recycling the water aboard the ISS involves a series of treatment processes to render the water potable. Four treatment technologies are utilized in the ISS Water Processor. Water first passes through a 0.5 -micron filter to remove particulate matter. Next in the sequence, ion exchange resins and adsorption media are combined in multifiltration beds for removal of ionic and organic compounds. A schematic of a multifiltration (MF) bed is shown in Figure 1-1.

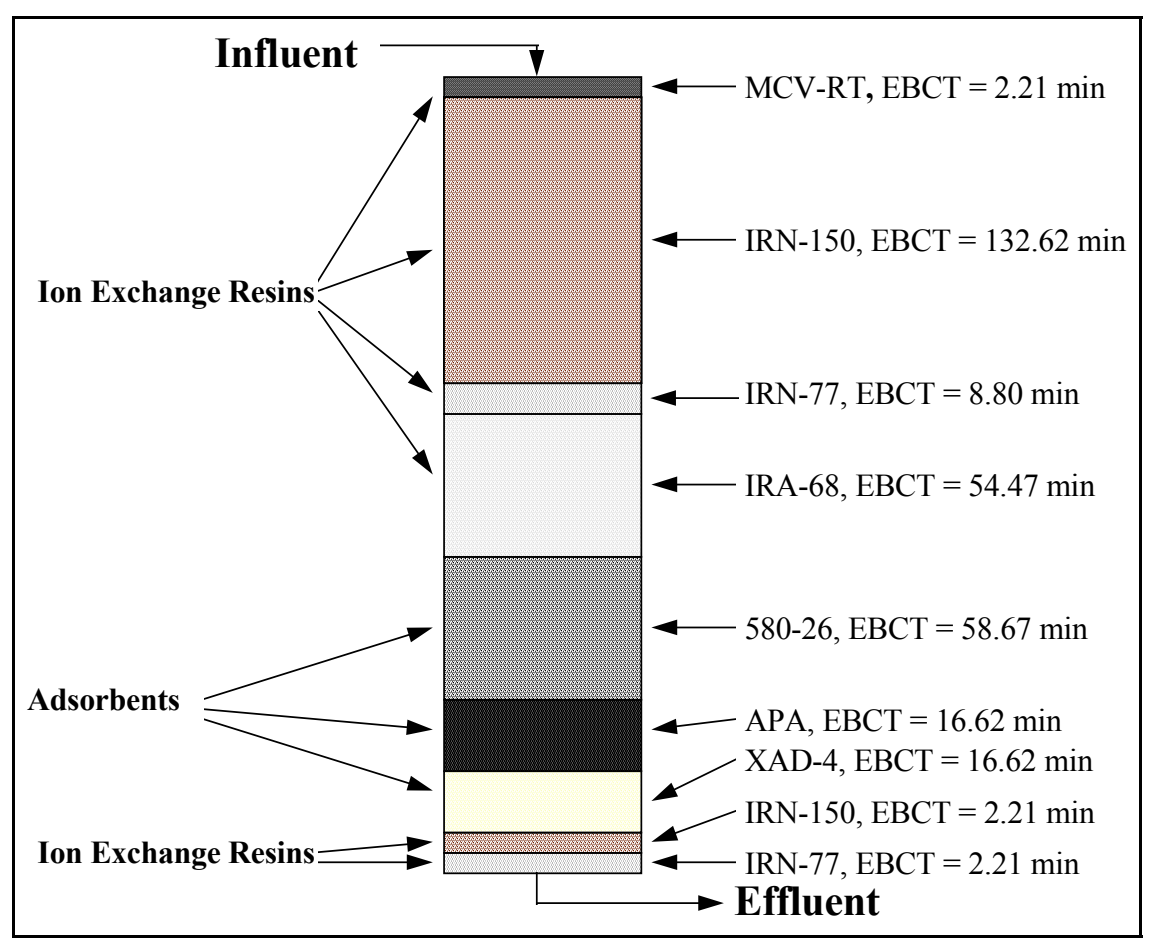

Figure 1-1 - Schematic of a Multifiltration Bed 
Table 1-1 describes the MF bed components and their functions. Catalytic oxidation technology follows the MF beds to remove low molecular weight organics not efficiently eliminated via adsorption. The various waste streams processed by the ISS water processor include; 1) urine distillate, 2) waste and shower handwash water, 3) humidity condensate, 4) oral hygiene and wet shave waste and 5) a mixture of humidity condensate and evaporated urine from the Research Animal Holding Facility (RAHF). Appendix I lists the major waste streams including their known inorganic and organic compositions and expected concentrations (Carter et al., 1992).

Table 1-1 - lon Exchange Resins and Adsorbents in an ISS Multifiltration Bed

\begin{tabular}{|c|c|c|}
\hline Media & Function & Media Description \\
\hline MCV-RT & Disinfection & $\begin{array}{l}\text { iodinated strong base anion, SBA, } \\
\text { exchange resin }\end{array}$ \\
\hline IRN-150 & $\begin{array}{l}\text { Removal of anions } \\
\text { and cations }\end{array}$ & $\begin{array}{l}\text { mixture of gel types strong acid cation, } \\
\text { SAC, (IRN-77, } \mathrm{H}^{+} \text {form) and SBA (IRN-78, } \\
\mathrm{OH}^{-} \text {form) }\end{array}$ \\
\hline IRN-77 & Removal of cations & SAC gel exchange resin in the $\mathrm{H}^{+}$form \\
\hline IRA-68 & $\begin{array}{l}\text { Removal of strong } \\
\text { and weak acids }\end{array}$ & $\begin{array}{l}\text { weak base anion, WBA, gel exchange resin } \\
\text { in the free base form }\end{array}$ \\
\hline $580-26$ & $\begin{array}{l}\text { Removal of } \\
\text { nonpolar organics }\end{array}$ & coconut-shell based activated carbon \\
\hline APA & $\begin{array}{l}\text { Removal of } \\
\text { nonpolar organics }\end{array}$ & bituminous-coal based activated carbon \\
\hline XAD-4 & $\begin{array}{l}\text { Removal of } \\
\text { nonpolar organics }\end{array}$ & polymeric adsorbent \\
\hline IRN-150 & $\begin{array}{l}\text { Removal of anions } \\
\text { and cations }\end{array}$ & $\begin{array}{l}\text { mixture of gel types SAC (IRN-77, } \mathrm{H}^{+} \text {form) } \\
\text { and SBA (IRN-78, } \mathrm{OH}^{-} \text {form) }\end{array}$ \\
\hline IRN-77 & Removal of cations & SAC gel exchange resin in the $\mathrm{H}^{+}$form \\
\hline
\end{tabular}


A mathematical model (MFBMODEL ${ }^{\mathrm{TM}}$ ) designed to predict the performance of a multifiltration (MF) bed was developed. MFBMODEL is a unified engineering design tool capable of assessing the performance of a MF bed. MFBMODEL consists of ion exchange models for describing the behavior of the different resin types in a MF bed (e.g., mixed bed, strong acid cation, strong base anion, and weak base anion exchange resins) and an adsorption model capable of predicting the performance of the adsorbents in a MF bed. The ion exchange equilibrium description for each of the ion exchange resin types within a MF bed is presented in Chapter 2. Langmuir ion exchange equilibrium constants were fit using binary isotherm data and verified with multicomponent isotherm predictions, as shown in Chapter 2.

Multicomponent ion exchange equilibrium models that incorporate the water formation reaction, electroneutrality condition, and degree of ionization of weak acids and bases for mixed bed, strong acid cation, strong base anion, and weak base anion exchange resins were developed and verified, as discussed in Chapter 3. The adsorption modeling approach was developed in related studies (Bulloch et al., 1998; Hand et al., 1999) and application within the MFBMODEL framework is demonstrated in Appendix X of this study.

This dissertation presents MF bed modeling results in which the model was verified for a surrogate of the waste shower and handwash stream. Waste shower and handwash water is the most prevalent and most contaminated waste stream aboard the ISS. Consequently, it was assumed that if the performance of the ion exchange and adsorption processes could be predicted using the MFBMODEL for this stream, then the model should be able to predict the performance of the MF bed in treating other waste water streams or their mixtures. A full scale multifiltration bed column experiment was performed using the surrogate waste shower and handwash water stream, which is termed an "ersatz" shower and handwash wastewater. MFBMODEL, which combines the ion exchange and adsorption models, was verified by comparing the model predictions to this full scale data. Ion exchange equilibrium modeling results for the ersatz shower and handwash wastewater are presented in Chapter 3. Adsorption results are 
presented in Appendix X. MFBMODEL has been designed for the Microsoft Windows $^{\mathrm{TM}}$ environment with a graphical user interface (GUI) in order to maximize user-friendliness. The GUI consists of a front-end shell written in Visual Basic ${ }^{\mathrm{TM}}$ that utilizes FORTRAN sub-programs in order to perform calculations. The GUI for MFBMODEL is demonstrated in Appendix VII.

MFBMODEL was developed to enable engineers to predict the impact of changing process variables on the performance of a multifiltration bed. The model can also be used to simulate laboratory and pilot scale experiments and save the time and cost of performing them. MFBMODEL is useful for determining the most efficient design of a multifiltration bed by evaluating process variables such as the time variable influent contaminant concentrations (including number and type of contaminants), empty bed contact time (EBCT), sequence of the ion exchange resins and adsorbents (including number and type) within a multifiltration bed or multiple beds, and competitive interactions among ions and adsorbates.

MFBMODEL is able to simulate system performance when unexpected changes in the feed streams occur (e.g., when a crew member is sick and a pharmaceutical product is introduced into the system). This multifiltration bed model may be extended to study a wide variety of terrestrial systems. For example, the model could be applied in the fields of municipal drinking water treatment, industrial and hazardous waste remediation, and pollution prevention.

There are situations in which it is necessary to account for mass transfer effects when describing ion exchange resin performance. For this reason, a mass transfer model capable of describing the performance of strong acid cation and strong base anion exchange resins, but not including reaction effects, was developed. This multicomponent mass transfer model, which is not included within the MFBMODEL framework, was verified with binary and multicomponent column data for strong acid cation and strong base anion exchange resins. The multicomponent mass transfer model, termed the pore diffusion model (PDM), is presented in Chapter 4. 


\subsection{References}

Bulloch, J.L., D.W. Hand and J.C. Crittenden. "Model for predicting contaminant removal by adsorption within the International Space Station water processor: 1. Multicomponent equilibrium modeling," Water Environment Research, 70, 1, 14-26 (1998).

Carter, D.L., D.W. Holder, Jr., K. Alexandre, R.G. Shaw, and J.K. Hayase, "Preliminary ECLSS Waste Water Model," Presented at the Twenty-first International Conference on Environmental Systems, San Francisco, CA (July 1991).

Carter, D.L., H. Cole, M. Habercom, G. Griffith, "Determination of Organic Carbon and Ionic Accountability of Various Waste and Product Waters Derived from ECLSS Water Recovery Tests and Spacelab Humidity Condensate," Presented at the Twenty-second International Conference on Environmental Systems, Seattle, WA (July 1992).

Hand, D.W., A.N. Ali, J.L. Bulloch, M.L. DeBraske, J.C. Crittenden, and D.R. Hokanson. "Adsorption Equilibrium Modeling of Space Station Wastewaters," ASCE Journal of Environmental Engineering, 125, 6, 540-547 (1999). 



\title{
Chapter 2 - Binary Description and Multicomponent Prediction of Ion Exchange Equilibrium for the International Space Station Water Processor ${ }^{*}$
}

\begin{abstract}
An equilibrium description was developed for the ion exchange beds in the International Space Station (ISS) Water Processor. Binary isotherm data were fit to determine separation factors for strong acid cation (SAC) and strong base anion (SBA) exchange resins and Langmuir ion exchange equilibrium constants for weak base anion (WBA) exchange resin in the freebase form. Separation factors determined from binary isotherms were used in a Langmuir multicomponent equilibrium equation to predict multicomponent isotherms in distilled/deionized water and in a multicomponent mixture consisting of an ersatz water designed to mimic the ISS shower/handwash waste stream. The separation factors determined for SAC and SBA exchange resins were able to predict a mixed bed ion exchange isotherm.

lons studied are representative of the inorganics observed in the ISS waste streams. Cations inlcuded in the study were sodium, potassium, calcium, ammonium, and triethanolamine. Anions included in the study were chloride, acetate, butyrate, bicarbonate, sulfate, an ionic soap (SCMT), lactate and iodide.
\end{abstract}

\section{Keywords}

ion exchange, equilibrium description, Langmuir equation, strong acid cation, SAC, strong base anion, SBA, mixed bed, weak base anion, WBA, mixed bed resin, multicomponent prediction, space, space station

\footnotetext{
* This chapter consists of a paper that will be submitted as part 1 of a two-part series of papers to the Journal of Environmental Engineering. The work was completed by a team of David Hokanson and Brooke Clancey. Clancey performed many of the the experiments that generated the data used in the study.
} 


\section{Introduction}

Water for drinking, food preparation, and hygiene accounts for over $90 \%$ by weight of the basic consumables (water, oxygen, and food) required for survival aboard the ISS. Support of a four person crew aboard the ISS would require transport of approximately $46,100 \mathrm{lbs}$ of water per year with an additional 4,400 lbs per year required for payloads. The technical and economic limitations of this water transport require onboard recovery and reuse of the ISS aqueous waste streams (Carter et al., 1991; Carter et al., 1992).

Recycling the water aboard the ISS involves various treatment processes to render the water potable. Four treatment technologies, filtration, ion exchange, adsorption, and catalytic oxidation are utilized in the ISS Water Processor. Water first passes through a 0.5 micron filter to remove particulate matter. Ion exchange and adsorption media are combined in multifiltration beds for removal of ionic and organic compounds. A schematic of the multifiltration bed is shown in Figure 2-1. Catalytic oxidation technology follows the multifiltration beds to remove low molecular weight organics not efficiently eliminated via adsorption. The various waste streams processed by the ISS Water Processor include waste shower and handwash, humidity condensate, urine distillate, waste from oral hygiene and wet shaves, and a mixture of humidity condensate and evaporated urine from the Research Animal Holding Facility (RAHF). 


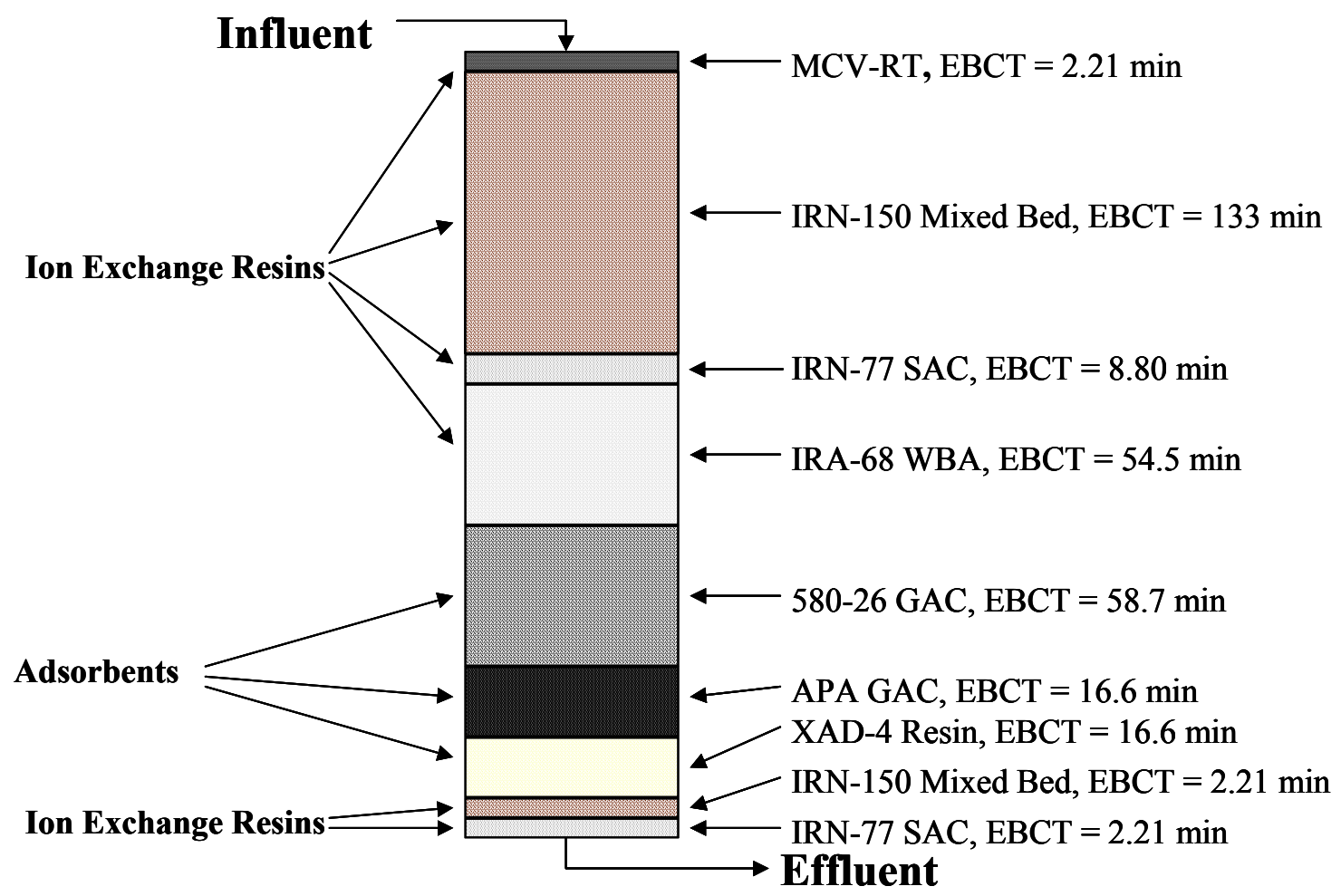

Figure 2-1 - Schematic of the Multifiltration Beds

A mathematical model designed to predict the performance of the multifiltration bed was developed. Chapters 2 and 3 specifically address the modeling of ion exchange processes in the multifiltration beds for removal of ions in the waste shower and handwash streams. Waste shower and handwash water is the most prevalent and most contaminated waste stream. Consequently, it was assumed that if the performance of the ion exchange processes could be predicted using a mathematical model for the shower/handwash water, then the model would be able to describe the ion exchange performance for other waste water streams. In conjunction with the development of the ion exchange model, a model has been developed to predict the performance of the adsorption media in the multifiltration beds (Bulloch et al., 1998; Hand et al., 1999). The ion exchange and adsorption models were integrated in order to predict the overall performance of the multifiltration unit. This integrated model of the multifiltration unit in the ISS Water Processor may 
be extended to model a wide variety of terrestrial systems. For example, the model could be applied in the fields of municipal drinking water treatment, industrial and hazardous waste remediation, and pollution prevention (Hand et al., 1995).

The ion exchange resins in the multifiltration unit are shown in Figure 2-1 and include (1) an iodinated strong base anion (SBA) exchange resin (MCV-RT) to control microbial growth within the multifiltration unit, (2) a strong acid cation (SAC) gel type exchange resin (IRN-77), (3) a mixed bed resin (IRN-150) consisting of a mixture of SAC (IRN-77) and SBA (IRN-78) gel type resins, and (4) a weak base anion (WBA) gel type exchange resin (IRA-68). This chapter will present equilibrium results for the IRN-77 SAC, IRN-78 SBA, IRN-150 mixed bed, and IRA-68 WBA exchange resins and will verify a multicomponent equilibrium description for these resins. Resin physical properties, equilibrium constants and total resin capacities were determined for each ion exchange resin.

Binary equilibrium data were used to determine equilibrium constants (i.e., separation factors) for sodium, potassium, calcium, ammonium and triethanolamine for the IRN-77 SAC exchange resin; and chloride, acetate, butyrate, sulfate, bicarbonate, an ionic soap and iodide for the IRN-78 SBA exchange resin. The separation factors determined from binary equilibrium data for IRN-77 SAC and IRN-78 SBA exchange resins were combined with a multicomponent Langmuir equilibrium description and appropriate acid/base chemistry to predict multicomponent competition in a distilled-deionized matrix and in an ersatz (surrogate) shower/handwash waste stream. An IRN-150 mixed bed ion exchange equilibrium isotherm with sodium and chloride was conducted to verify that the separation factors of sodium and chloride determined from binary IRN-77 SAC and IRN-78 SBA exchange isotherms could predict the performance of IRN-150 mixed bed resin.

Binary equilibrium data were used to determine Langmuir ion exchange equilibrium constants for chloride, acetate, butyrate, sulfate, lactate and an ionic soap for the IRA-68 WBA exchange resin. A multicomponent isotherm with 
acetate and chloride was conducted and used to validate the multicomponent equilibrium description for IRA-68 WBA exchange resin. The ion exchange equilibrium description material presented in Chapter 2 builds upon the work of Clancey (1995).

\section{Materials and Methods}

\subsection{Chemicals and Resins}

All chemicals were reagent grade or better. Sodium bicarbonate, calcium chloride, potassium chloride, ammonium chloride, sulfuric acid, sodium chloride, sodium acetate, acetic acid, hydrochloric acid, sodium hydroxide, sodium nitrate and potassium iodide were obtained from Fisher Scientific (Fair Lawn, NJ). The Aldrich Chemical Company (Milwaukee, $\mathrm{WI}$ ) supplied: m-xylene, naphthalene, toluene, trichloroethylene (TCE), 1,2,4-trichlorobenzene (1,2,4-TCB), triethanolamine, sodium butyrate, sodium lactate, butyric acid, acetic acid (sodium salt), and lactic acid. NASA Whole Body Shampoo, Formula \#6503.45.4 was obtained from Ecolab Inc. (Mendota Hts., MN). The major constituent of NASA Whole Body Shampoo is Sodium-N-methyl-N-"coconut oil acid" taurate (SCMT). The manufacturer reports NASA Whole Body Shampoo is $98 \%$ pure, $24 \%$ by weight SCMT, $6.4 \%$ by weight $\mathrm{NaCl}$, and SCMT's molecular weight is between 357 and 360. There is one fixed anionic charge per SCMT molecule.

The ion exchange resins for this study came from various sources. UMQUA Research Company (Beaverton, OR) provided the MCV-RT, the IRN150 mixed bed and some of the IRN-77 SAC exchange resins. Additional IRN77 SAC and IRA-68 WBA exchange resins were purchased from Rohm and Haas (Cherry Hill, PA). The IRN-78 SBA exchange resin was obtained directly from multifiltration columns opened by NASA. IRN-150 mixed bed ion exchange resin consists of $40 \%$ IRN-77 SAC exchange resin and $60 \%$ IRN-78 SBA exchange resin by volume. The resins and their physical properties are listed in Table 2-1. Distilled-deionized water was produced by distilling tap water and further purifying it with a Milli-Q UV Plus Water System (Millipore Corp., Bedford, $M A)$. 
Prior to use, the resins were conditioned and converted to the forms listed in Table 2-1 following procedures outlined by Rohm and Haas (1990). The MCV-RT resin was used in the iodinated form as received. For the equilibrium experiments, IRN-150 mixed bed resin was used as received from UMQUA. The Amberlite IRN-78 SBA exchange resin was conditioned and converted with solutions prepared under nitrogen to minimize the amount of atmospheric bicarbonate contacting the resin.

\subsection{Solution Preparation}

Distilled-deionized water and salts of the exchanging ions were used to make solutions of approximately $10 \mathrm{meq} / \mathrm{L}$, which is representative of the approximate ion concentration in the International Space Station water processor. Table 2-2 lists the ions used for the equilibrium experiments. These ions are representative of those found in the actual shower/handwash water. For the WBA resin (IRA-68), the acid solutions of the ions were used to maintain the operational $\mathrm{pH}$ of IRA-68 WBA exchange resin. Multicomponent solutions were made with equal equivalent concentrations of the ions listed in Table 2-2. An ersatz shower/handwash water, designed to mimic the adsorption potential of the actual shower/handwash water, was made from ionic constituents which are listed in Table 2-3 and from various organics (TCE, SCMT, m-xylene, toluene, $1,2,4-$ TCB and naphthalene) to obtain a TOC concentration equal to the average TOC of the actual shower/handwash water.

The ersatz water was developed by applying a fictive component analysis (FCA) to the actual shower/handwash water (Hand et al., 1999). Substitute compounds and their concentrations were determined from adsorption isotherms with the actual water. Large quantities of the ersatz water were needed. Therefore, saturated solutions of the individual organic compounds were made. These solutions were pumped into Tedlar bags (SKC Inc., Eighty Four, PA) to minimize volatilization and the ionic species were injected directly into the bags. For individual ersatz isotherms, the ion of interest was spiked to $10 \mathrm{meq} / \mathrm{L}$ while the remaining ions were maintained at the concentrations given in Table 2-3. 
Table 2-1 - Physical Properties of the Ion Exchange Resins in the Multifiltration Beds

\begin{tabular}{|c|c|c|c|c|c|c|c|c|c|}
\hline \multirow[b]{2}{*}{ Resin } & \multirow{2}{*}{$\begin{array}{l}\text { Manu- } \\
\text { facturer }\end{array}$} & \multirow[b]{2}{*}{ Type } & \multirow[b]{2}{*}{ Form } & \multicolumn{4}{|c|}{ Density $(\mathrm{g} / \mathrm{mL})$} & \multicolumn{2}{|c|}{ Porosity } \\
\hline & & & & Bulk & $\begin{array}{l}\text { Apparent } \\
\text { Dry }\end{array}$ & $\begin{array}{l}\text { Apparent } \\
\text { Wet }\end{array}$ & Resin Matrix & $\begin{array}{c}\text { Intra- } \\
\text { particle }\end{array}$ & Bulk \\
\hline \multirow{2}{*}{$\begin{array}{l}\text { Amberlite } \\
\text { IRN-77 }\end{array}$} & \multirow{2}{*}{$\begin{array}{c}\text { Rohm \& } \\
\text { Haas }\end{array}$} & \multirow{2}{*}{$\begin{array}{l}\text { Strong } \\
\text { Acid } \\
\text { Cation } \\
\text { (SAC) } \\
\text { Gel } \\
\end{array}$} & $\mathrm{H}^{+}$ & 0.89 & 0.63 & 1.24 & 1.50 & 0.58 & 0.28 \\
\hline & & & $\mathrm{Na}^{+}$ & 0.81 & 0.61 & 1.15 & 1.34 & 0.55 & 0.30 \\
\hline \multirow{2}{*}{$\begin{array}{l}\text { Amberlite } \\
\text { IRN-78 }\end{array}$} & \multirow{2}{*}{$\begin{array}{c}\text { Rohm \& } \\
\text { Haas }\end{array}$} & \multirow{2}{*}{$\begin{array}{c}\text { Strong } \\
\text { Base } \\
\text { Anion } \\
\text { (SBA) } \\
\text { Gel } \\
\end{array}$} & $\mathrm{OH}^{-}$ & 0.79 & 0.56 & 1.1 & 1.11 & 0.49 & 0.28 \\
\hline & & & $\mathrm{Cl}^{-}$ & 0.71 & 0.56 & 1.00 & 1.01 & 0.44 & 0.30 \\
\hline \multirow{2}{*}{$\begin{array}{c}\text { Amberlite } \\
\text { IRA-68 }\end{array}$} & \multirow{2}{*}{$\begin{array}{c}\text { Rohm \& } \\
\text { Haas }\end{array}$} & \multirow{2}{*}{$\begin{array}{c}\text { Weak } \\
\text { Base } \\
\text { Anion } \\
\text { (WBA) } \\
\text { Gel } \\
\end{array}$} & $\begin{array}{l}\text { Free- } \\
\text { base }\end{array}$ & 0.72 & 0.39 & 1.02 & 0.94 & 0.58 & 0.29 \\
\hline & & & $\mathrm{Cl}^{-}$ & 0.67 & 0.36 & 1.02 & 1.07 & 0.66 & 0.35 \\
\hline $\begin{array}{l}\text { Amberlite } \\
\text { IRN-150 }\end{array}$ & $\begin{array}{c}\text { Rohm \& } \\
\text { Haas }\end{array}$ & $\begin{array}{l}\text { Mixed } \\
\text { Bed } \\
\text { (SAC / } \\
\text { SBA) Gel }\end{array}$ & $\begin{array}{l}\mathrm{H}^{+} / \\
\mathrm{OH}^{-}\end{array}$ & 0.79 & 0.53 & 1.08 & 1.19 & 0.55 & 0.27 \\
\hline
\end{tabular}


Table 2-2 - Representative lons for the Various Resins

\begin{tabular}{|l|l|}
\hline Resin & lons Studied \\
\hline IRN-77 & sodium, potassium, calcium, ammonium, triethanolamine \\
\hline IRN-78 & $\begin{array}{l}\text { chloride, acetate, butyrate, bicarbonate, sulfate, SCMT, } \\
\text { iodide }\end{array}$ \\
\hline IRN-150 & sodium, potassium, chloride, acetate \\
\hline IRA-68 & chloride, acetate, butyrate, sulfate, lactate, SCMT \\
\hline
\end{tabular}

Table 2-3 - Ions Present in the Shower/Handwash Water

\begin{tabular}{|l|c|l|c|}
\hline \multicolumn{3}{|c|}{ Ionic organic and inorganic constituents (concentration in meq/L) } \\
\hline Cation & Concentration & Anion & Concentration \\
\hline Sodium & 10.86 & Chloride & 5.86 \\
\hline Triethanolamine & 0.09 & Butyrate & 0.73 \\
\hline Ammonium & 0.37 & Acetate & 0.75 \\
\hline Calcium & 0.18 & Sulfate & 0.46 \\
\hline Potassium & 0.60 & SCMT & 2.14 \\
\cline { 3 - 4 } & & Bicarbonate & 0.67 \\
\hline
\end{tabular}

${ }^{*}$ Differences in charge concentration are due to analytical error, anionic charge of SCMT and pH.

\subsection{Chemical Analysis}

Total organic carbon (TOC) and inorganic carbon (IC) measurements for SCMT and bicarbonate were made with a Sievers Total Organic Carbon Analyzer (Sievers, Inc., Boulder, CO). In the ersatz water the SCMT concentration was defined by the difference between the actual TOC concentration and the TOC contributions of the individual organic constituents. The $\mathrm{pH}$ was determined using an Orion (Cambridge, MA) model $501 \mathrm{pH}$ meter. An Orion Sodium probe was used to determine some sodium concentrations down to 10 ppm with the ion selective electrode (ISE) method outlined by Orion. A Dionex ion chromatograph, DX500 (Sunnyvale, CA) was used for the majority of ion measurements. Cations were analyzed with the lonPac CS12 $4 \mathrm{~mm}$ 
analytical column and the anions were analyzed with the lonPac AS11 $4 \mathrm{~mm}$ analytical column and the lonPac AG11 guard column.

The iodine and iodide exchanged or leached from the MCV-RT were measured with a residual chlorine probe (model 97-70) and an iodide probe (model 94-53), both from Orion, based on the ISE chlorine determination method outlined by Orion. Triiodide concentrations were measured spectrophotometrically using a Perkin-Elmer 552 spectrophotometer (Norwalk, $\mathrm{CT})$.

\subsection{Equilibrium Experiments}

\subsubsection{IRN-77 SAC Exchange Resin}

Binary, multicomponent, and ersatz shower/handwash isotherms were conducted with the ions listed in Table 2-2. Separation factors were determined from the binary isotherms. The multicomponent and ersatz isotherms were predicted using the separation factors. For individual ersatz isotherms, the ion of interest was spiked to a level between 8 and $13 \mathrm{meq} / \mathrm{L}$, which is higher than that shown in Table 2-3 for each ion, while the remaining ions were maintained at a level near the values reported in Table 2-3. Table 2-4 shows the initial concentrations of all ions in the binary, multicomponent, and individual ersatz isotherms for IRN-77 SAC exchange resin.

\subsubsection{IRN-78 SBA Exchange Resin}

Binary, multicomponent, and ersatz shower/handwash isotherms were conducted with the ions listed in Table 2-2. Separation factors were determined from the binary isotherms. The multicomponent and ersatz isotherms were predicted using the separation factors. SCMT was not included in the multicomponent isotherms. lodide was not included in the multicomponent or ersatz isotherms. For individual ersatz isotherms, the ion of interest was spiked to a level between 8.5 and $10.5 \mathrm{meq} / \mathrm{L}$, which is higher than that shown in Table 2-3 for each ion, while the remaining ions were maintained at a level near the values reported in Table 2-3. Table 2-5 shows the initial concentrations of all 
ions in the binary, multicomponent, and individual ersatz isotherms for IRN-78 SBA exchange resin.

The equilibrium and kinetic experiments for the MCV-RT indicated that the resin does not participate in ion exchange. Since there was very little ion exchange observed, the MCV-RT was not modeled as an ion exchange resin. MCV-RT releases iodide species while acting as a disinfectant. Consequently, iodide was investigated with the IRN-78 resin.

\subsubsection{IRN-150 Mixed Bed lon Exchange Resin}

Equilibrium isotherms were performed on IRN-150 mixed bed resin for the ions listed in Table 2-2. A multicomponent equilibrium isotherm was conducted with sodium and chloride. The initial concentrations of sodium and chloride were $9.60 \mathrm{meq} / \mathrm{L}$ and $8.92 \mathrm{meq} / \mathrm{L}$, respectively. The initial $\mathrm{pH}$ was 6.27 . A binary isotherm with acetate was conducted with initial acetate concentration of 1.19 $\mathrm{meq} / \mathrm{L}$ and initial $\mathrm{pH}$ of 6.72 . A binary isotherm with potassium was conducted with initial potassium concentration of $1.53 \mathrm{meq} / \mathrm{L}$ and initial $\mathrm{pH}$ of 6.56 .

\subsubsection{IRA-68 WBA Exchange Resin}

Binary isotherms were performed on IRA-68 WBA exchange resin in the freebase form for the ions listed in Table 2-2. A multicomponent isotherm was performed on IRA-68 WBA exchange resin in the freebase form for acetate and chloride. Table 2-6 shows the initial concentrations corresponding to each resin dosage for the chloride isotherms. Table 2-7 shows the initial concentrations corresponding to each resin dosage for the sulfate isotherms. Table 2-8 shows the initial concentrations corresponding to each resin dosage for the acetate isotherms. The butyrate isotherms were performed with a constant initial butyrate concentration of $3.76 \mathrm{meq} / \mathrm{L}$ and initial $\mathrm{pH}$ of 4.40 . Table 2-9 shows the initial concentrations corresponding to each resin dosage for the lactate isotherms. Table 2-10 shows the initial concentrations corresponding to each resin dosage for the SCMT isotherms. 
Table 2-4 - Initial Concentrations for Isotherms Performed on IRN-77 SAC Exchange Resin

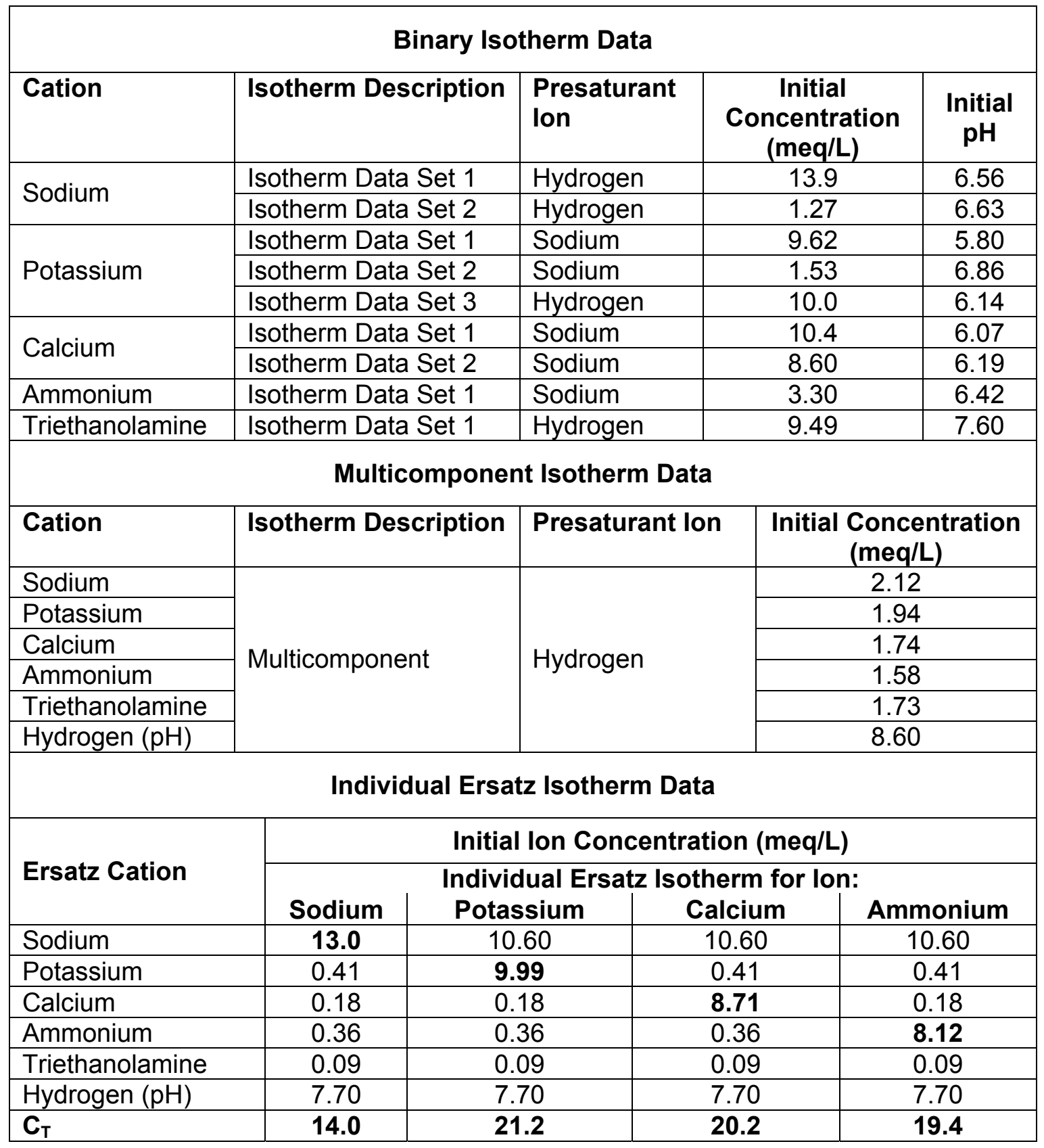


Table 2-5 - Initial Concentrations for Isotherms Performed on IRN-78 SBA Exchange Resin

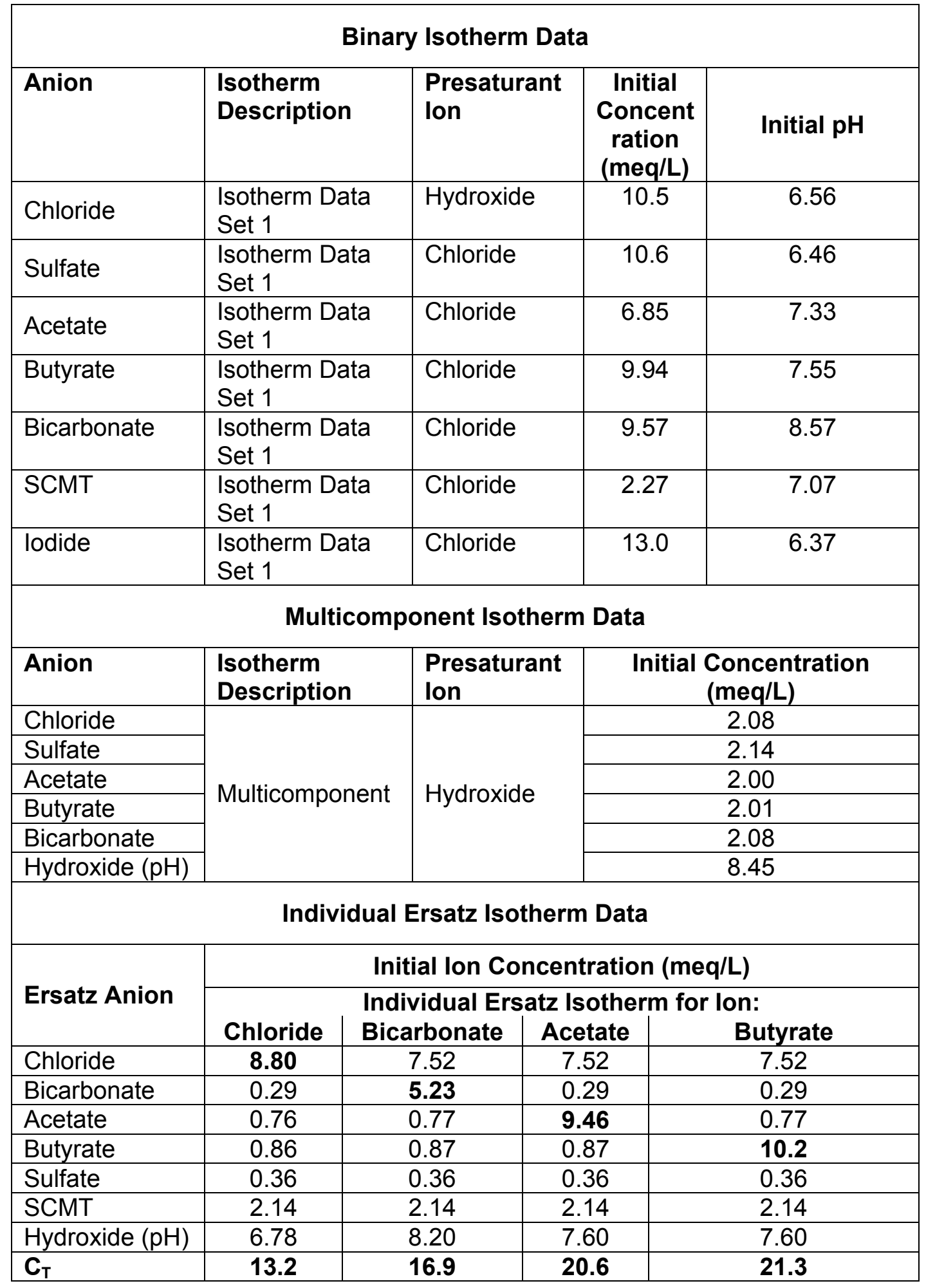


Table 2-6 - Initial Concentrations for Chloride Isotherms Performed on IRA68 WBA Exchange Resin

\begin{tabular}{|c|c|c|c|}
\hline \multicolumn{4}{|c|}{ Isotherm Data Set 1: Desired Equilibrium $\mathrm{pH}=5$} \\
\hline $\begin{array}{l}\text { Bottle } \\
\text { Volume } \\
\text { (L) }\end{array}$ & $\begin{array}{l}\text { Mass of Resin } \\
\text { (g dry) }\end{array}$ & $\begin{array}{c}\text { Initial } \\
\text { Concentration } \\
\text { (meq/L) }\end{array}$ & Initial pH \\
\hline 0.0418 & 0.0170 & 10.1 & 3.23 \\
\hline 0.0426 & 0.0349 & 8.35 & 2.99 \\
\hline 0.0422 & 0.0557 & 6.64 & 2.80 \\
\hline 0.0425 & 0.0729 & 5.07 & 2.74 \\
\hline 0.0425 & 0.0908 & 4.52 & 2.69 \\
\hline 0.0417 & 0.108 & 4.29 & 2.69 \\
\hline 0.0432 & 0.124 & 3.96 & 2.68 \\
\hline 0.0423 & 0.143 & 4.09 & 2.68 \\
\hline 0.0426 & 0.178 & 4.04 & 2.69 \\
\hline 0.0425 & 0.214 & 3.99 & 2.69 \\
\hline 0.0422 & 0.287 & 3.92 & 2.67 \\
\hline 0.0420 & 0.355 & 3.93 & 2.68 \\
\hline \multicolumn{4}{|c|}{ Isotherm Data Set 2: Desired Equilibrium pH = 6.0} \\
\hline $\begin{array}{l}\text { Bottle } \\
\text { Volume } \\
\text { (L) }\end{array}$ & $\begin{array}{l}\text { Mass of Resin } \\
\text { (g dry) }\end{array}$ & $\begin{array}{c}\text { Initial } \\
\text { Concentration } \\
(\text { meq/L) }\end{array}$ & Initial pH \\
\hline 0.0421 & 0.0168 & 10.3 & 3.28 \\
\hline 0.0427 & 0.0348 & 8.71 & 3.05 \\
\hline 0.0427 & 0.0541 & 7.31 & 2.89 \\
\hline 0.0418 & 0.0711 & 6.45 & 2.81 \\
\hline 0.0424 & 0.0889 & 5.54 & 2.77 \\
\hline 0.0433 & 0.110 & 5.33 & 2.75 \\
\hline 0.0428 & 0.125 & 4.87 & 2.73 \\
\hline 0.0414 & 0.143 & 4.79 & 2.71 \\
\hline 0.0421 & 0.161 & 4.52 & 2.70 \\
\hline 0.0417 & 0.196 & 4.63 & 2.70 \\
\hline 0.0425 & 0.268 & 4.33 & 2.69 \\
\hline 0.0423 & 0.357 & 4.15 & 2.69 \\
\hline
\end{tabular}


Table 2-6 (continued)

\begin{tabular}{|c|c|c|c|}
\hline \multicolumn{2}{|c|}{ Isotherm Data Set 3: Desired Equilibrium pH = 6.5 } \\
\hline $\begin{array}{c}\text { Bottle } \\
\text { Volume } \\
\text { (L) }\end{array}$ & $\begin{array}{c}\text { Mass of Resin } \\
\text { (g dry) }\end{array}$ & $\begin{array}{c}\text { Initial } \\
\text { Concentration } \\
\text { (meq/L) }\end{array}$ & Initial pH \\
\hline 0.0427 & 0.0178 & 10.5 & 3.40 \\
\hline 0.0434 & 0.0378 & 9.22 & 3.12 \\
\hline 0.0424 & 0.0551 & 8.27 & 3.00 \\
\hline 0.0425 & 0.0718 & 7.81 & 2.92 \\
\hline 0.0419 & 0.0920 & 6.86 & 2.84 \\
\hline 0.0417 & 0.108 & 5.94 & 2.80 \\
\hline 0.0430 & 0.125 & 6.52 & 2.79 \\
\hline 0.0432 & 0.144 & 5.65 & 2.76 \\
\hline 0.0421 & 0.161 & 5.58 & 2.74 \\
\hline 0.0424 & 0.197 & 5.13 & 2.73 \\
\hline 0.0425 & 0.271 & 4.88 & 2.72 \\
\hline 0.0426 & 0.356 & 4.48 & 2.70 \\
\hline
\end{tabular}

Table 2-7 - Initial Concentrations for Sulfate Isotherms Performed on IRA-68 WBA Exchange Resin

\begin{tabular}{|c|c|c|c|}
\hline \multicolumn{3}{|c|}{ Isotherm Data Set 1: Desired Equilibrium pH = 6.0 } \\
\hline $\begin{array}{c}\text { Bottle } \\
\text { Volume } \\
\text { (L) }\end{array}$ & $\begin{array}{c}\text { Mass of Resin } \\
\text { (g dry) }\end{array}$ & $\begin{array}{c}\text { Initial } \\
\text { Concentration } \\
\text { (meq/L) }\end{array}$ & Initial pH \\
\hline 0.245 & 0.191 & 9.63 & 2.68 \\
\hline 0.250 & 0.385 & 9.26 & 2.41 \\
\hline 0.249 & 0.481 & 8.92 & 2.38 \\
\hline 0.252 & 0.574 & 9.16 & 2.36 \\
\hline 0.249 & 0.673 & 9.28 & 2.35 \\
\hline 0.251 & 0.765 & 9.40 & 2.34 \\
\hline 0.250 & 0.958 & 9.42 & 2.34 \\
\hline 0.250 & 1.15 & 9.16 & 2.35 \\
\hline 0.252 & 1.53 & 8.96 & 2.36 \\
\hline 0.251 & 1.92 & 9.21 & 2.35 \\
\hline
\end{tabular}


Table 2-7 (continued)

\begin{tabular}{|c|c|c|c|}
\hline \multicolumn{4}{|c|}{ Isotherm Data Set 2: Desired Equilibrium $\mathrm{pH}=7.0$} \\
\hline $\begin{array}{c}\text { Bottle } \\
\text { Volume } \\
\text { (L) }\end{array}$ & $\begin{array}{l}\text { Mass of Resin } \\
\text { (g dry) }\end{array}$ & $\begin{array}{c}\text { Initial } \\
\text { Concentration } \\
(\mathrm{meq} / \mathrm{L})\end{array}$ & Initial pH \\
\hline 0.255 & 0.0969 & 10.1 & 2.97 \\
\hline 0.250 & 0.196 & 10.0 & 2.74 \\
\hline 0.250 & 0.292 & 9.71 & 2.58 \\
\hline 0.251 & 0.393 & 9.85 & 2.49 \\
\hline 0.247 & 0.490 & 9.21 & 2.45 \\
\hline 0.251 & 0.588 & 9.36 & 2.42 \\
\hline 0.249 & 0.686 & 9.14 & 2.41 \\
\hline 0.249 & 0.787 & 9.45 & 2.38 \\
\hline 0.249 & 0.882 & 9.37 & 2.38 \\
\hline 0.247 & 1.08 & 9.40 & 2.37 \\
\hline 0.252 & 1.47 & 8.65 & 2.39 \\
\hline 0.250 & 1.97 & 9.49 & 2.36 \\
\hline \multicolumn{4}{|c|}{ Isotherm Data Set 3: Desired Equilibrium $\mathrm{pH}=7.5$} \\
\hline $\begin{array}{l}\text { Bottle } \\
\text { Volume } \\
\text { (L) }\end{array}$ & $\begin{array}{l}\text { Mass of Resin } \\
\text { (g dry) }\end{array}$ & $\begin{array}{c}\text { Initial } \\
\text { Concentration } \\
\text { (meq/L) }\end{array}$ & Initial pH \\
\hline 0.250 & 0.0956 & 10.0 & 3.04 \\
\hline 0.250 & 0.194 & 10.2 & 2.81 \\
\hline 0.250 & 0.386 & 9.79 & 2.59 \\
\hline 0.250 & 0.480 & 9.60 & 2.54 \\
\hline 0.254 & 0.577 & 9.83 & 2.48 \\
\hline 0.253 & 0.674 & 10.2 & 2.44 \\
\hline 0.249 & 0.774 & 9.77 & 2.43 \\
\hline 0.251 & 0.960 & 9.40 & 2.42 \\
\hline 0.249 & 1.15 & 9.49 & 2.40 \\
\hline 0.250 & 1.44 & 9.36 & 2.39 \\
\hline 0.252 & 1.91 & 9.78 & 2.36 \\
\hline
\end{tabular}


Table 2-8- Initial Concentrations for Acetate Isotherms Performed on IRA-68 WBA Exchange Resin

\begin{tabular}{|c|c|c|c|}
\hline \multicolumn{2}{|c|}{ Isotherm Data Set 1: Desired Equilibrium pH = 5.0 } \\
\hline $\begin{array}{c}\text { Bottle } \\
\text { Volume } \\
\text { (L) }\end{array}$ & $\begin{array}{c}\text { Mass of Resin } \\
\text { (g dry) }\end{array}$ & $\begin{array}{c}\text { Initial } \\
\text { Concentration } \\
\text { (meq/L) }\end{array}$ & Initial pH \\
\hline 0.252 & 0.100 & 4.49 & 4.65 \\
\hline 0.245 & 0.209 & 3.23 & 4.43 \\
\hline 0.251 & 0.309 & 1.97 & 4.15 \\
\hline 0.249 & 0.420 & 1.16 & 3.87 \\
\hline 0.248 & 0.506 & 0.756 & 3.67 \\
\hline 0.248 & 0.616 & 0.581 & 3.55 \\
\hline 0.249 & 0.834 & 0.504 & 3.49 \\
\hline 0.250 & 1.01 & 0.503 & 3.49 \\
\hline 0.251 & 1.32 & 0.437 & 3.43 \\
\hline 0.250 & 1.68 & 0.448 & 3.43 \\
\hline 0.250 & 2.09 & 0.438 & 3.42 \\
\hline
\end{tabular}

Isotherm Data Set 2: Desired Equilibrium pH = 5.5

\begin{tabular}{|c|c|c|c|}
\hline $\begin{array}{c}\text { Bottle } \\
\text { Volume } \\
\text { (L) }\end{array}$ & $\begin{array}{c}\text { Mass of Resin } \\
\text { (g dry) }\end{array}$ & $\begin{array}{c}\text { Initial } \\
\text { Concentration } \\
\text { (meq/L) }\end{array}$ & Initial pH \\
\hline 0.0421 & 0.0177 & 6.81 & 5.01 \\
\hline 0.0422 & 0.0367 & 5.22 & 4.71 \\
\hline 0.0422 & 0.0548 & 3.63 & 4.47 \\
\hline 0.0424 & 0.0729 & 2.43 & 4.20 \\
\hline 0.0374 & 0.0923 & 1.62 & 4.00 \\
\hline 0.0406 & 0.109 & 1.22 & 3.86 \\
\hline 0.0382 & 0.127 & 1.00 & 3.78 \\
\hline 0.0424 & 0.146 & 0.886 & 3.72 \\
\hline 0.0424 & 0.183 & 0.780 & 3.64 \\
\hline 0.0428 & 0.218 & 0.691 & 3.60 \\
\hline 0.0419 & 0.273 & 0.643 & 3.57 \\
\hline 0.0419 & 0.362 & 0.602 & 3.54 \\
\hline
\end{tabular}


Table 2-8 (continued)

\begin{tabular}{|c|c|c|c|}
\hline \multicolumn{2}{|c|}{ Isotherm Data Set 3: Desired Equilibrium $\mathbf{~ H H}=\mathbf{6 . 0}$} \\
\hline $\begin{array}{c}\text { Bottle } \\
\text { Volume } \\
\text { (L) }\end{array}$ & $\begin{array}{c}\text { Mass of Resin } \\
\text { (g dry) }\end{array}$ & $\begin{array}{c}\text { Initial } \\
\text { Concentration } \\
\text { (meq/L) }\end{array}$ & Initial pH \\
\hline 0.250 & 0.202 & 5.52 & 4.86 \\
\hline 0.251 & 0.301 & 4.13 & 4.61 \\
\hline 0.248 & 0.394 & 3.13 & 4.41 \\
\hline 0.245 & 0.494 & 2.33 & 4.24 \\
\hline 0.251 & 0.595 & 1.90 & 4.13 \\
\hline 0.247 & 0.693 & 1.55 & 4.03 \\
\hline 0.247 & 0.792 & 1.37 & 3.96 \\
\hline 0.253 & 0.989 & 1.02 & 3.81 \\
\hline 0.251 & 1.19 & 0.874 & 3.74 \\
\hline 0.250 & 1.48 & 0.742 & 3.66 \\
\hline 0.252 & 1.97 & 0.607 & 3.58 \\
\hline
\end{tabular}

Table 2-9- Initial Concentrations for Lactate Isotherms Performed on IRA-68 WBA Exchange Resin

\begin{tabular}{|c|c|c|c|}
\hline \multicolumn{2}{|c|}{ Isotherm Data Set 1: Desired Equilibrium pH = 5.0 } \\
\hline $\begin{array}{c}\text { Bottle } \\
\text { Volume } \\
\text { (L) }\end{array}$ & $\begin{array}{c}\text { Mass of Resin } \\
\text { (g dry) }\end{array}$ & $\begin{array}{c}\text { Initial } \\
\text { Concentration } \\
\text { (meq/L) }\end{array}$ & Initial pH \\
\hline 0.250 & 0.0955 & 9.04 & 4.39 \\
\hline 0.250 & 0.214 & 8.12 & 3.96 \\
\hline 0.247 & 0.306 & 7.02 & 3.56 \\
\hline 0.248 & 0.411 & 5.46 & 3.24 \\
\hline 0.249 & 0.507 & 4.65 & 3.06 \\
\hline 0.247 & 0.606 & 4.20 & 2.99 \\
\hline 0.250 & 0.716 & 4.06 & 2.97 \\
\hline 0.250 & 0.804 & 4.05 & 2.96 \\
\hline 0.250 & 1.00 & 4.02 & 2.96 \\
\hline 0.249 & 1.33 & 4.15 & 2.97 \\
\hline 0.250 & 1.60 & 4.11 & 2.97 \\
\hline 0.251 & 2.05 & 3.93 & 2.95 \\
\hline
\end{tabular}


Table 2-9 (continued)

\begin{tabular}{|c|c|c|c|}
\hline \multicolumn{4}{|c|}{ Isotherm Data Set 2: Desired Equilibrium $\mathrm{pH}=5.5$} \\
\hline $\begin{array}{l}\text { Bottle } \\
\text { Volume } \\
\text { (L) }\end{array}$ & $\begin{array}{l}\text { Mass of Resin } \\
\text { (g dry) }\end{array}$ & $\begin{array}{c}\text { Initial } \\
\text { Concentration } \\
\text { (meq/L) }\end{array}$ & Initial pH \\
\hline 0.0428 & 0.0187 & 10.1 & 4.44 \\
\hline 0.0439 & 0.0387 & 9.09 & 4.09 \\
\hline 0.0429 & 0.0576 & 8.42 & 3.80 \\
\hline 0.0426 & 0.0761 & 7.59 & 3.52 \\
\hline 0.0417 & 0.0947 & 6.34 & 3.34 \\
\hline 0.0421 & 0.114 & 5.78 & 3.17 \\
\hline 0.0383 & 0.134 & 5.63 & 3.16 \\
\hline 0.0390 & 0.152 & 5.53 & 3.10 \\
\hline 0.0426 & 0.170 & 5.47 & 3.08 \\
\hline 0.0371 & 0.210 & 5.13 & 3.05 \\
\hline 0.0431 & 0.286 & 5.44 & 3.00 \\
\hline 0.0430 & 0.382 & 5.27 & 3.00 \\
\hline \multicolumn{4}{|c|}{ Isotherm Data Set 3: Desired Equilibrium pH = 6.0} \\
\hline $\begin{array}{l}\text { Bottle } \\
\text { Volume } \\
\text { (L) }\end{array}$ & $\begin{array}{l}\text { Mass of Resin } \\
\text { (g dry) }\end{array}$ & $\begin{array}{c}\text { Initial } \\
\text { Concentration } \\
(\text { meq/L) }\end{array}$ & Initial pH \\
\hline 0.249 & 0.0989 & 9.00 & 4.49 \\
\hline 0.249 & 0.198 & 9.26 & 4.00 \\
\hline 0.253 & 0.301 & 8.38 & 3.78 \\
\hline 0.249 & 0.395 & 7.54 & 3.58 \\
\hline 0.252 & 0.496 & 6.71 & 3.41 \\
\hline 0.249 & 0.597 & 6.03 & 3.30 \\
\hline 0.252 & 0.698 & 5.69 & 3.22 \\
\hline 0.247 & 0.792 & 5.46 & 3.19 \\
\hline 0.251 & 0.893 & 5.47 & 3.16 \\
\hline 0.248 & 1.09 & 4.73 & 3.05 \\
\hline 0.253 & 1.49 & 4.66 & 3.01 \\
\hline 0.249 & 1.99 & 4.27 & 2.96 \\
\hline
\end{tabular}


Table 2-10- Initial Concentrations for SCMT Isotherms Performed on IRA-68 WBA Exchange Resin

\begin{tabular}{|c|c|c|c|c|}
\hline \multicolumn{5}{|c|}{ Isotherm Data Set 1} \\
\hline $\begin{array}{l}\text { Bottle } \\
\text { Volume } \\
\text { (L) }\end{array}$ & $\begin{array}{c}\text { Mass of } \\
\text { IRA-68 Resin } \\
\text { (g dry) }\end{array}$ & $\begin{array}{c}\text { Mass of } \\
\text { IRN-77 Resin } \\
\text { (g dry) }\end{array}$ & $\begin{array}{c}\text { Initial } \\
\text { Concentration } \\
\text { (meq/L) }\end{array}$ & Initial pH \\
\hline 0.222 & 0.0941 & 0.0637 & 1.32 & 7.12 \\
\hline 0.214 & 0.0919 & 0.0718 & 1.32 & 7.12 \\
\hline 0.231 & 0.0947 & 0.0814 & 1.32 & 7.12 \\
\hline 0.232 & 0.0902 & 0.0864 & 1.32 & 7.12 \\
\hline 0.227 & 0.0959 & 0.0912 & 1.32 & 7.12 \\
\hline 0.220 & 0.0957 & 0.0956 & 1.32 & 7.12 \\
\hline 0.221 & 0.0936 & 0.0995 & 1.32 & 7.12 \\
\hline 0.230 & 0.0962 & 0.105 & 1.32 & 7.12 \\
\hline 0.236 & 0.0896 & 0.108 & 1.32 & 7.12 \\
\hline 0.222 & 0.0922 & 0.118 & 1.32 & 7.12 \\
\hline 0.226 & 0.0937 & 0.127 & 1.32 & 7.12 \\
\hline 0.218 & 0.0915 & 0.156 & 1.32 & 7.12 \\
\hline 0.237 & 0.0935 & 0.183 & 1.32 & 7.12 \\
\hline \multicolumn{5}{|c|}{ Isotherm Data Set 2} \\
\hline $\begin{array}{c}\text { Bottle } \\
\text { Volume } \\
\text { (L) }\end{array}$ & $\begin{array}{c}\text { Mass of } \\
\text { IRA-68 Resin } \\
\text { (g dry) }\end{array}$ & $\begin{array}{c}\text { Mass of } \\
\text { IRN-77 Resin } \\
\text { (g dry) }\end{array}$ & $\begin{array}{c}\text { Initial } \\
\text { Concentration } \\
\text { (meq/L) }\end{array}$ & Initial pH \\
\hline 0.228 & 0.0479 & 0.0370 & 1.33 & 7.12 \\
\hline 0.249 & 0.0484 & 0.0464 & 1.33 & 7.12 \\
\hline 0.234 & 0.0495 & 0.0570 & 1.33 & 7.12 \\
\hline 0.226 & 0.0484 & 0.0595 & 1.33 & 7.12 \\
\hline 0.221 & 0.0469 & 0.0635 & 1.33 & 7.12 \\
\hline 0.239 & 0.0483 & 0.0670 & 1.33 & 7.12 \\
\hline 0.225 & 0.0461 & 0.0729 & 1.33 & 7.12 \\
\hline 0.223 & 0.0472 & 0.0777 & 1.33 & 7.12 \\
\hline 0.226 & 0.0491 & 0.0821 & 1.33 & 7.12 \\
\hline 0.215 & 0.0467 & 0.0909 & 1.33 & 7.12 \\
\hline 0.233 & 0.0473 & 0.102 & 1.33 & 7.12 \\
\hline 0.217 & 0.0480 & 0.130 & 1.33 & 7.12 \\
\hline 0.233 & 0.0510 & 0.156 & 1.33 & 7.12 \\
\hline
\end{tabular}




\subsubsection{Resin Physical Properties and Total Resin Capacity}

The resin physical property determination was performed as outlined by Sontheimer et. al. (1988). The total capacity of the resin was determined as outlined by Rohm and Haas (1990). An apparent capacity was determined by globally fitting the equilibrium data for each resin. The physical properties were used to convert mass of resin to volume of resin or bed.

\subsection{Isotherm Procedure}

Bottle point isotherms were used for the equilibrium experiments. For the IRN-77 SAC, IRN-78 SBA and IRN-150 mixed bed ion exchange isotherms, the initial liquid phase concentration (see Tables 2-4 and 2-5) was held constant while resin dosages were varied. The IRA-68 WBA exchange isotherm with butyrate was performed in the same manner. For IRA-68 WBA exchange isotherms with chloride, sulfate, acetate and lactate, the initial ion concentrations (see Tables 2-6 through 2-9) were varied in a manner intended to attain equilibrium $\mathrm{pH}$ values in the operational range of the IRA-68 WBA exchange resin between $\mathrm{pH} 4$ and $\mathrm{pH} 7$. For the SCMT isotherms on IRA-68 WBA exchange resin, the initial concentration was held constant at $1.3 \mathrm{meq} / \mathrm{L}$ (see Table 2-10) and IRN-77 SAC exchange resin in the hydrogen form was placed in the isotherm bottle in addition to IRA-68 WBA exchange resin in the freebase form in order to attain equilibrium $\mathrm{pH}$ values in the operational $\mathrm{pH}$ range of the IRA-68 WBA exchange resin between $\mathrm{pH} 4$ and $\mathrm{pH} 7$.

The amount of presaturant ion not associated with exchange sites was determined from two isotherm points with only distilled-deionized water and resin. This background presaturant concentration was included in the isotherm mass balance when determining solid phase concentrations.

The water content or percent solids was determined by drying samples at $110^{\circ} \mathrm{C}$ for 4 hours with cooling in a desiccator. IRN-78 SBA exchange resin in the hydroxide form was air dried and then placed in a desiccator over phosphorous pentoxide to constant weight to avoid thermal degradation of the resin (Bolto and Pawlowski, 1987). 
The bottles were filled leaving no head space, capped with Teflon septums, and tumbled (14 rpm) at room temperature for 24 hours. After equilibration, the $\mathrm{pH}$ and concentrations of the ions of interest were determined. The solid phase concentrations were determined via mass balances on each bottle.

Ionic equilibria of the weak acids and bases were used to calculate the ionized fraction of the exchanging ions. The liquid and solid phase activity was assumed to equal the molar concentrations. The ionized concentration of the weak acids was calculated from:

$$
\left[\mathrm{A}^{-}\right]=\frac{\left[\mathrm{C}_{\mathrm{T}, \mathrm{A}}\right]}{1+\frac{\left[\mathrm{H}^{+}\right]}{\mathrm{Ka}_{\mathrm{a}}}}
$$

The ionized concentration of ammonium and triethanolamine was calculated from:

$$
\left[\mathrm{A}^{+}\right]=\frac{\left[\mathrm{C}_{\mathrm{T}, \mathrm{A}}\right]}{1+\frac{\mathrm{K}_{\mathrm{a}}}{\left[\mathrm{H}^{+}\right]}}
$$

Table 2-11 lists the acid/base equilibrium constant $\left(K_{a}\right)$ of each species.

\section{Table 2-11 - Acid/Base Equilibrium Constants ( $\left.\mathrm{pK}_{\mathrm{a}}\right)$}

\begin{tabular}{|l|c|}
\hline Acid/Base & $\mathbf{p K}_{\mathbf{a}}$ \\
\hline Acetic Acid & 4.75 \\
\hline Butyric Acid & 4.81 \\
\hline Lactic Acid & 3.08 \\
\hline Ammonium & 9.3 \\
\hline Triethanolamine & 9.5 \\
\hline
\end{tabular}




\section{Equilibrium Description Development}

Complete details on the equilibrium description development are presented in Appendix II.

\subsection{SAC and SBA Exchange Resins}

\subsubsection{Binary Isotherm Fitting}

A Langmuir equation can be used to determine equilibrium constants for SAC and SBA exchange resins, which are represented as separation factors (Helfferich, 1962; Kunin, 1990; Lopez et al., 1992; Clifford, 1976). When only monovalent ions are considered, the separation factor is equal to the selectivity and, at equilibrium, is defined as:

$$
\alpha_{j}^{i}=\frac{q_{i} C_{j}}{C_{i} q_{j}}=\frac{y_{i} x_{j}}{x_{i} y_{j}}
$$

where $q$ represents the equivalent resin phase concentration for ions $\mathrm{i}$ and $\mathrm{j}$ and $\mathrm{C}$ represents the equivalent liquid phase concentration for ions $\mathrm{i}$ and $\mathrm{j}$ (where I denotes the counter ion and $\mathrm{j}$ represents the presaturant ion). Dimensionless equivalent fractions are defined as:

$$
\begin{array}{cr}
x_{i}=\frac{C_{i}}{\sum_{k=1}^{m} C_{k}} & x_{j}=\frac{C_{j}}{\sum_{k=1}^{m} C_{k}} \\
y_{i}=\frac{q_{i}}{q_{T}} & y_{j}=\frac{q_{j}}{q_{T}}
\end{array}
$$

In this study, divalent ions were assumed to have constant separation factors, which does not sacrifice the validity of the equilibrium description (Subramonian and Clifford, 1988).

The separation factors were determined by fitting the binary isotherm data with the following equations, setting the binary Langmuir equation $\left(y_{\text {model, }}\right)$ equal to the mass balance on a bottle point isotherm $\left(\mathrm{y}_{\text {data, }}\right)$ for that ion: 


$$
\begin{gathered}
y_{\text {data,i }}=\left(\frac{C_{T} \times V_{B}}{M \times q_{T}}\right) \times\left(\frac{C_{i, 0}-C_{i}}{C_{T}}\right) \\
y_{\text {model,i }}==\frac{x_{i}}{x_{i}+x_{j} \alpha_{i}^{j}} \\
\left(\frac{C_{T} \times V_{B}}{M \times q_{T}}\right) \times\left(\frac{C_{i, 0}-C_{i}}{C_{T}}\right)=\frac{x_{i}}{x_{i}+x_{j} \alpha_{i}^{j}}
\end{gathered}
$$

An objective function which represents the normalized root mean square error (i.e. each data point is equally weighted) was minimized to fit the binary equilibrium data. The root mean square error (RMSE) is calculated as follows for each isotherm data set:

$$
\operatorname{RMSE}_{\mathrm{i}}=\sqrt{\frac{\sum\left(\frac{\mathrm{y}_{\text {data,i }}-\mathrm{y}_{\text {model } \mathrm{i}}}{\mathrm{y}_{\text {data, }}}\right)^{2}}{\mathrm{~N}_{\text {data }}-1}}
$$

in which $\mathrm{N}_{\text {data }}$ is the number of data points in an individual isotherm. The objective function, $f_{o b j}$, which represents the sample deviation, is defined as:

$$
f_{o b j}=\frac{\sum_{i=1}^{\text {NSET }} \text { RMSE }_{i}}{\text { NSET }}
$$

in which NSET is the number of isotherm sets simultaneously being fit. The objective function was minimized by adjusting the separation factor $(\alpha)$. For the SAC exchange resin isotherm fitting, the total resin capacity was held constant at the experimental value. For the SBA exchange resin isotherm fitting, the total resin capacity was treated as a fitting parameter.

The objective function was minimized using the Microsoft Excel ${ }^{\circledR}$ spreadsheet solver, which was developed by Frontline Systems Inc. (http://www.frontsys.com). The solver nonlinear programming algorithm utilizes 
the generalized reduced gradient (GRG) method as implemented in Lasdon and Waren's GRG2 code (Lasdon et al., 1978; Lasdon and Smith, 1992).

\subsubsection{Multicomponent Isotherm Prediction}

For multicomponent ion exchange, the Langmuir equation was expanded:

$$
y_{i}=\frac{x_{i}}{\sum_{k=i}^{n}\left(x_{i} \alpha_{i}^{k}\right)}
$$

To predict bottle point multicomponent ion exchange, the multicomponent Langmuir equation for each ion is set equal to the mass balance equation for that ion.

$$
\frac{V_{B}}{M}\left(C_{i, o}-C_{i}\right)=\frac{q_{T} C_{i}}{\sum_{k=i}^{m}\left(C_{k} \alpha_{i}^{k}\right)}
$$

The equilibrium liquid phase presaturant ion concentration was determined from a mass balance on the resin solid phase. These equations are solved simultaneously using the Levenberg-Marquardt method within Mathcad 8 Professional (Mathsoft, Inc. 1998).

Separation factors are expressions of the ratio between the solid and liquid phase concentrations of two ions as shown in Equation 2-3. To predict multicomponent ion exchange equilibrium, the separation factors must be expressed in terms of a common reference ion. Separation factors can be converted to different reference ions by use of the following relationship:

$$
\alpha_{j}^{i} \cdot \alpha_{k}^{j}=\alpha_{k}^{i}
$$

The method described above for the multicomponent predictions was also used to predict the individual ersatz shower/handwash water isotherms with Mathcad. 


\subsection{Mixed Bed Ion Exchange Resins}

\subsubsection{Multicomponent Isotherm Prediction}

The IRN-150 mixed bed resin is a mixture of IRN-77 SAC exchange resin in the hydrogen form and IRN-78 SBA exchange resin in the hydroxide form. The hydrogen and hydroxide ions released by IRN-150 mixed bed resin during exchange react to form water which decreases the total liquid phase ionic concentration. The Langmuir equation for IRN-77 SAC and IRN-78 SBA exchange resins (see Equation 2-11) was used to describe IRN-150 mixed bed ion exchange by including the water formation reaction, which is written in terms of molar concentrations as:

$$
\left[\mathrm{H}^{+}\right]\left[\mathrm{OH}^{-}\right]=10^{-14}
$$

and an equation to account for electroneutrality:

$$
\sum \mathrm{C}_{\text {cations }}=\sum \mathrm{C}_{\text {anions }}
$$

These equations were solved simultaneously to describe the ion exchange equilibrium of IRN-150 mixed bed resin in the hydrogen/hydroxide form using the Levenberg-Marquardt method within Mathcad (Mathsoft, Inc. 1998).

\subsection{WBA Exchange Resins}

\subsubsection{Isotherm Fitting}

The WBA isotherms were fit using a similar approach to the method used for the SAC and SBA exchange resins. The Langmuir equilibrium relationship representing resin phase concentration in terms of liquid phase concentration for a WBA exchange resin in the freebase form is presented below for a single ion.

$$
q_{H i}=\frac{q_{T} b_{i} C_{H} C_{i}}{1+C_{H} b_{i} C_{i}}
$$

in which $q_{H i}$ represents resin phase acid concentration (meq/g), $q_{T}$ equals total resin capacity (meq/g), $C_{H}$ equals liquid phase hydrogen ion concentration 
(meq/L), $C_{i}, C_{k}$ represent liquid phase anion concentrations (meq/L), and $b_{i}$ represents Langmuir equilibrium exchange rate constant for ion $\mathrm{i}\left(\mathrm{L}^{2} / \mathrm{meq}^{2}\right)$.

The mass balance equation for an isotherm bottle point in dimensioned form is:

$$
q_{H i}=\frac{V_{B}}{M}\left(C_{i, 0}-C_{i}\right)
$$

where $V_{B}$ is the liquid volume, $M$ is the mass of resin, and $C_{i, 0}$ is the initial equivalent liquid phase concentration of ion $\mathrm{i}$. The Langmuir equilibrium ion exchange rate constants were determined by fitting the single ion isotherm data with the following equation, setting the single ion Langmuir equation (Equation 2-16) equal to the mass balance on a bottle point isotherm for that ion (Equation 2-17):

$$
\frac{V_{B}}{M}\left(C_{0, i}-C_{i}\right)=\frac{q_{T} b_{i} C_{H} C_{i}}{1+C_{H} b_{i} C_{i}}
$$

The objective function used to fit the data was based on sample deviation. The resin phase concentrations determined from Equation 2-16 $\left(q_{\text {model, }}\right)$ were compared to the measured resin phase concentrations from Equation 2-17 $\left(q_{\text {data, }}\right)$ to determine the root mean squared error (RMSE) for each isotherm:

$$
\mathrm{RMSE}_{\mathrm{i}}=\sqrt{\frac{\sum\left(\frac{\mathrm{q}_{\text {data }, \mathrm{i}}-\mathrm{q}_{\text {model }, \mathrm{i}}}{\mathrm{q}_{\text {data, } \mathrm{i}}}\right)^{2}}{\mathrm{~N}_{\text {data }}-1}}
$$

in which $\mathrm{N}_{\text {data }}$ is the number of data points in an individual isotherm. The objective function $\left(f_{o b j}\right)$, which is the sample deviation, is defined in Equation 2-10 above. The objective function was minimized using the Microsoft Excel solver by adjusting the Langmuir equilibrium exchange constant (b). For the WBA exchange resin isotherm fitting, the total resin capacity was held constant at the experimental value. 


\subsubsection{Multicomponent Isotherm Prediction}

For multicomponent ion exchange, the Langmuir equation was expanded:

$$
q_{H i}=\frac{a_{T} b_{i} C_{H} C_{i}}{1+C_{H}\left(\sum_{k=1}^{n} b_{k} C_{k}\right)}
$$

in which $\mathrm{q}_{\mathrm{Hi}}$ represents resin phase acid concentration (meq/g), $\mathrm{q}_{\mathrm{T}}$ equals total resin capacity (meq/g), $C_{H}$ equals liquid phase hydrogen ion concentration (meq/L), $C_{i}, C_{k}$ represent liquid phase anion concentrations (meq/L), and $b_{i}, b_{k}$ represent Langmuir equilibrium exchange rate constants $\left(\mathrm{L}^{2} / \mathrm{meq}^{2}\right)$. To predict bottle point multicomponent ion exchange, the multicomponent Langmuir equation for each ion is set equal to the mass balance equation for that ion.

$$
\frac{V_{B}}{M}\left(C_{i, o}-C_{i}\right)=\frac{a_{T} b_{i} C_{H} C_{i}}{1+C_{H}\left(\sum_{k=1}^{n} b_{k} C_{k}\right)}
$$

These equations are solved simultaneously with Mathcad 8 Professional (Mathsoft, Inc. 1998) using the Levenberg-Marquardt method.

Based on the definition of separation factor, the Langmuir equilibrium exchange rate constant $\left(b_{i}\right)$ can be related to separation factor as follows:

$$
\alpha_{j}^{i}=\frac{b_{i}}{b_{j}}
$$


Table 2-12 - Total Capacities for Each Resin in Various Forms

\begin{tabular}{|c|c|c|c|c|c|c|c|c|c|}
\hline \multirow[b]{2}{*}{ Resin } & \multirow{2}{*}{$\begin{array}{l}\text { Manu- } \\
\text { facturer }\end{array}$} & \multirow[b]{2}{*}{ Type } & \multirow[b]{2}{*}{ Form } & \multicolumn{3}{|c|}{ Experimental Total Capacity } & \multicolumn{3}{|c|}{ Fitted Apparent Capacity } \\
\hline & & & & $\begin{array}{c}\text { meq / } \\
\text { mL bed }\end{array}$ & $\begin{array}{c}\text { meq / } \\
\mathrm{mL} \text { resin }\end{array}$ & $\begin{array}{l}\text { meq / g } \\
\text { dry resin }\end{array}$ & $\begin{array}{c}\text { meq / } \\
\text { mL bed }\end{array}$ & $\begin{array}{c}\mathrm{meq} / \mathrm{mL} \\
\text { resin }\end{array}$ & $\begin{array}{l}\mathrm{meq} / \mathrm{g} \\
\text { dry resin }\end{array}$ \\
\hline \multirow{2}{*}{$\begin{array}{l}\text { Amberlite } \\
\text { IRN-77 }\end{array}$} & \multirow{2}{*}{$\begin{array}{c}\text { Rohm \& } \\
\text { Haas }\end{array}$} & \multirow{2}{*}{$\begin{array}{l}\text { Strong } \\
\text { Acid } \\
\text { Cation } \\
\text { (SAC) } \\
\text { Gel }\end{array}$} & $\mathrm{H}^{+}$ & 2.2 & 3.1 & 5.00 & 2.0 & 3.0 & 4.72 \\
\hline & & & $\mathrm{Na}^{+}$ & 1.9 & 2.7 & 4.50 & \multicolumn{3}{|c|}{$\mathrm{N} / \mathrm{A}$} \\
\hline \multirow{2}{*}{$\begin{array}{l}\text { Amberlite } \\
\text { IRN-78 }\end{array}$} & \multirow{2}{*}{$\begin{array}{c}\text { Rohm \& } \\
\text { Haas }\end{array}$} & \multirow{2}{*}{$\begin{array}{c}\text { Strong } \\
\text { Base } \\
\text { Anion } \\
\text { (SBA) } \\
\text { Gel }\end{array}$} & $\mathrm{OH}^{-}$ & \multicolumn{3}{|c|}{$\mathrm{N} / \mathrm{A}$} & 0.96 & 1.5 & 2.64 \\
\hline & & & $\mathrm{Cl}^{-}$ & 1.4 & 2.0 & 3.56 & 1.4 & 2.0 & 3.58 \\
\hline $\begin{array}{l}\text { Amberlite } \\
\text { IRA-68 }\end{array}$ & $\begin{array}{c}\text { Rohm \& } \\
\text { Haas }\end{array}$ & $\begin{array}{c}\text { Weak } \\
\text { Base } \\
\text { Anion } \\
\text { (WBA) } \\
\text { Gel } \\
\end{array}$ & $\begin{array}{l}\text { Free- } \\
\text { base }\end{array}$ & 1.3 & 1.9 & 4.89 & 1.6 & 2.2 & 5.7 \\
\hline $\begin{array}{l}\text { Amberlite } \\
\text { IRN-150 }\end{array}$ & $\begin{array}{c}\text { Rohm \& } \\
\text { Haas }\end{array}$ & $\begin{array}{l}\text { Mixed } \\
\text { Bed } \\
\text { (SAC / } \\
\text { SBA) Gel }\end{array}$ & $\begin{array}{l}\mathrm{H}^{+} / \\
\mathrm{OH}^{-}\end{array}$ & 0.86 & 1.2 & 2.22 & & $\mathrm{~N} / \mathrm{A}$ & \\
\hline
\end{tabular}


Table 2-13 - Comparison of Experimental Total Capacities and Fitted Apparent Capacities with Manufacturer's Reported Capacity for Each Resin in Various Forms

\begin{tabular}{|c|c|c|c|c|c|c|}
\hline Resin & $\begin{array}{l}\text { Manu- } \\
\text { facturer }\end{array}$ & Type & Form & $\begin{array}{l}\text { Experimental } \\
\text { Total Capacity } \\
\text { (meq/mL resin) }\end{array}$ & $\begin{array}{c}\text { Fitted Apparent } \\
\text { Capacity } \\
\text { (meq/mL resin) }\end{array}$ & $\begin{array}{c}\text { Capacity } \\
\text { Reported by the } \\
\text { Manufacturer } \\
\text { (meq/mL resin) }\end{array}$ \\
\hline \multirow{2}{*}{$\begin{array}{l}\text { Amberlite } \\
\text { IRN-77 }\end{array}$} & \multirow{2}{*}{$\begin{array}{c}\text { Rohm \& } \\
\text { Haas }\end{array}$} & \multirow{2}{*}{$\begin{array}{l}\text { Strong } \\
\text { Acid } \\
\text { Cation } \\
\text { (SAC) } \\
\text { Gel }\end{array}$} & $\mathrm{H}^{+}$ & 3.1 & 3.0 & 2.6 \\
\hline & & & $\mathrm{Na}^{+}$ & 2.7 & $\mathrm{~N} / \mathrm{A}$ & $\mathrm{N} / \mathrm{A}$ \\
\hline \multirow{2}{*}{$\begin{array}{l}\text { Amberlite } \\
\text { IRN-78 }\end{array}$} & \multirow{2}{*}{$\begin{array}{c}\text { Rohm \& } \\
\text { Haas }\end{array}$} & \multirow{2}{*}{$\begin{array}{c}\text { Strong } \\
\text { Base } \\
\text { Anion } \\
\text { (SBA) } \\
\text { Gel } \\
\end{array}$} & $\mathrm{OH}^{-}$ & $N / A$ & 1.5 & 1.7 \\
\hline & & & $\mathrm{Cl}^{-}$ & 2.0 & 2.0 & $\mathrm{~N} / \mathrm{A}$ \\
\hline $\begin{array}{c}\text { Amberlite } \\
\text { IRA-68 }\end{array}$ & $\begin{array}{c}\text { Rohm \& } \\
\text { Haas }\end{array}$ & $\begin{array}{c}\text { Weak } \\
\text { Base } \\
\text { Anion } \\
\text { (WBA) } \\
\text { Gel }\end{array}$ & $\begin{array}{l}\text { Free- } \\
\text { base }\end{array}$ & 1.9 & 2.2 & 2.4 \\
\hline $\begin{array}{l}\text { Amberlite } \\
\text { IRN-150 }\end{array}$ & $\begin{array}{c}\text { Rohm \& } \\
\text { Haas }\end{array}$ & $\begin{array}{l}\text { Mixed } \\
\text { Bed } \\
\text { (SAC / } \\
\text { SBA) Gel }\end{array}$ & $\begin{array}{l}\mathrm{H}^{+} / \\
\mathrm{OH}^{-}\end{array}$ & 1.2 & $\mathrm{~N} / \mathrm{A}$ & 0.82 \\
\hline
\end{tabular}




\section{Results and Discussion}

Table 2-12 shows two different total capacities for each resin in the multifiltration unit: the experimentally determined total capacity and a fitted total capacity. The fitted capacities were determined by globally fitting the equilibrium data for each resin. Table 2-13 compares the experimentally determined total capacities and fitted total capacities with the manufacturers' reported total capacity for each resin in a representative form. In all cases, the capacities compare favorably.

The objective function (see Equation 2-10) determined the sample deviation of the isotherms for each resin. If there were an infinite amount of data, $68 \%$ of it would fall between plus or minus the percent of the reported value determined by the objective function.

\subsection{IRN-77 SAC and IRN-78 SBA Exchange Resins}

Table 2-14 summarizes the separation factors determined for the IRN-77 SAC exchange resin. The separation factors compare well with literature values except for the calcium ion. Variation is to be expected when comparing resins produced by different manufacturers because the site spacing of the resin's exchange sites may be different, which greatly affects the selectivity of divalent ions (Subramonian and Clifford, 1988), such as calcium. Table 2-14 shows the 95\% confidence interval (Draper and Smith, 1981) for each separation factor determined for IRN-77 SAC exchange resin.

Table 2-15 summarizes the separation factors for the IRN-78 SBA exchange resin which were determined from the binary isotherm data using the fitted total capacities given in the Table 2-15. Binary isotherms performed in the hydroxide form showed lower total capacities than the chloride form. This lower capacity for the hydroxide form is supported by literature (Lopez et al., 1992). SCMT also exhibits a lower capacity which may be due to steric hindrance. Table 2-15 shows that the objective function determined from Equation 2-10 is equal to 0.183 for the IRN-78 SBA exchange resin. Except for iodide, the separation factors found in this study compare closely to those reported in the 
Table 2-14 - Separation Factors for IRN-77 SAC Exchange Resin

\begin{tabular}{|l|c|c|c|}
\hline \multirow{2}{*}{ Ion, $\mathbf{i}$} & \multicolumn{3}{|c|}{ Separation Factor $\left(\alpha_{H}^{\mathrm{i}}\right)$} \\
\cline { 2 - 3 } & \multicolumn{2}{|c|}{ Experimental } & \multirow{2}{*}{ Literature $^{*}$} \\
\cline { 2 - 3 } & $\begin{array}{c}\text { Best } \\
\text { Fit }\end{array}$ & $\begin{array}{c}\text { 95\% Confidence } \\
\text { Interval }\end{array}$ & \\
\hline Sodium (Na) & 1.68 & $1.45 \leq \alpha_{H}^{\mathrm{Na}} \leq 1.85$ & 1.5 \\
\hline Potassium (K) & 2.15 & $1.92 \leq \alpha_{H}^{\mathrm{K}} \leq 2.41$ & 2.5 \\
\hline Calcium (Ca) & 59.1 & $44.2 \leq \alpha_{H}^{\mathrm{Ca}} \leq 82.3$ & 2.8 \\
\hline Ammonium (NH & 1.72 & $1.32 \leq \alpha_{H}^{\mathrm{NH}} \leq 1.89$ & 1.9 \\
\hline Triethanolamine (Tri) & 0.979 & $0.761 \leq \alpha_{H}^{\mathrm{Tri}} \leq 1.24$ & N/A \\
\hline
\end{tabular}

\#Literature values from Clifford (1999)

Table 2-15 - Separation Factors and Apparent Capacities for IRN-78 SBA Exchange Resin

\begin{tabular}{|l|c|c|c|}
\hline \multirow{2}{*}{ Ion, $\mathrm{i}$} & \multicolumn{2}{|c|}{ Separation Factor $\left(\alpha_{\mathrm{OH}}^{\mathrm{i}}\right)$} & $\begin{array}{c}\text { Apparent Capacity } \\
\text { (meq/mL bed Cl form) }\end{array}$ \\
\cline { 2 - 4 } & Experimental & Literature & $0.96(\mathrm{OH}$ form) \\
\hline Chloride $(\mathrm{Cl})$ & 16.7 & $16.7-22^{\#}$ & 1.4 \\
\hline Sulfate $\left(\mathrm{SO}_{4}\right)$ & 149 & $152^{*}$ & 1.4 \\
\hline Acetate $(\mathrm{Ac})$ & 1.99 & $2.33-3.2^{\#}$ & 1.4 \\
\hline Butyrate $(\mathrm{But})$ & 3.21 & $4.3^{*}$ & 1.4 \\
\hline $\begin{array}{l}\text { Bicarbonate } \\
\text { (HCO })\end{array}$ & 4.99 & $4.5-6.0^{\#}$ & 1.4 \\
\hline lodide & 638 & $175^{\#}$ & 1.2 \\
\hline SCMT & 214 & $\mathrm{~N} / \mathrm{A}$ & \\
\hline $\begin{array}{l}\text { Objective } \\
\text { Function }\left(\mathrm{f}_{\mathrm{obj}}\right)\end{array}$ & 0.183 & & \\
\hline
\end{tabular}

${ }^{\#}$ Literature values from Diamond Shamrock Chemical Company (1969)

*Literature values from Crittenden et al. (1992) 
literature, as shown in Table 2-15. The amount of iodide exchange exceeded the total capacity of the resin indicating that iodide is highly preferred compared to the other ions. This high preference for iodide is supported by the literature (Hatch et al., 1980; Lambert et al., 1980). However, the amount of iodide contacting the IRN-78 resin will be insignificant compared to the amount of anionic exchange resin (Muckle, 1990).

Figure 2-2 compares the binary, multicomponent, and ersatz data with the model predictions for sodium exchange onto the hydrogen form of IRN-77 SAC exchange resin. Figure 2-2 shows that when using separation factors from Table 2-14, Equation 2-11 (which incorporates the multicomponent Langmuir equilibrium expression) was able to predict the sodium exchange in both the multicomponent and ersatz isotherms. Figure 2-2 is representative of the IRN-77 SAC exchange data and predictions for the other cations listed in Table 2-2.

Figure 2-3 compares the binary, multicomponent, and ersatz data with the model predictions for chloride exchange onto the hydroxide form of IRN-78 SBA exchange resin. Figure 2-3 illustrates that when using separation factors from Table 2-15, Equation 2-11 (which incorporates the multicomponent Langmuir equilibrium expression) was able to predict the chloride exchange for the multicomponent isotherm, but predicted a higher chloride exchange for the ersatz isotherm. A probable cause for the poor prediction of the ersatz isotherm is that the apparent separation factor for SCMT could be larger than the experimentally determined value either because the charge on the SCMT was underestimated or because SCMT fouls the resin. In addition, there are other organics in the ersatz water which could potentially foul the ion exchange resin thereby decreasing the number of exchange sites available. Similar results were obtained for the other anions. 


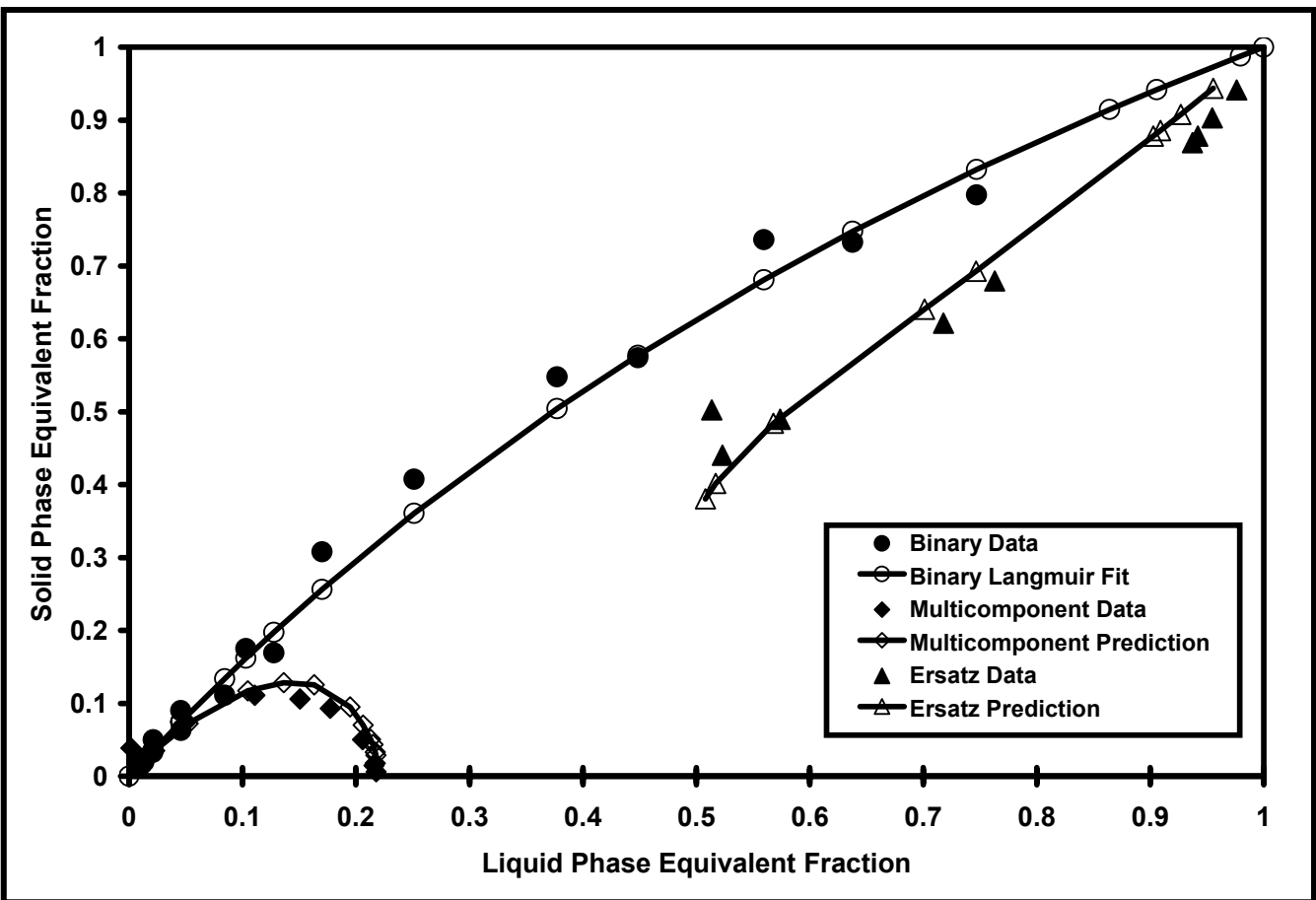

Figure 2-2 - Sodium Ion Exchange Equilibrium Isotherms with IRN-77 SAC Exchange Resin for the Following Conditions: (a) Binary and Multicomponent Data from IRN-77 in the $\mathrm{H}^{+}$form (b) Ersatz Data from IRN77 in the $\mathrm{Na}^{+}$form

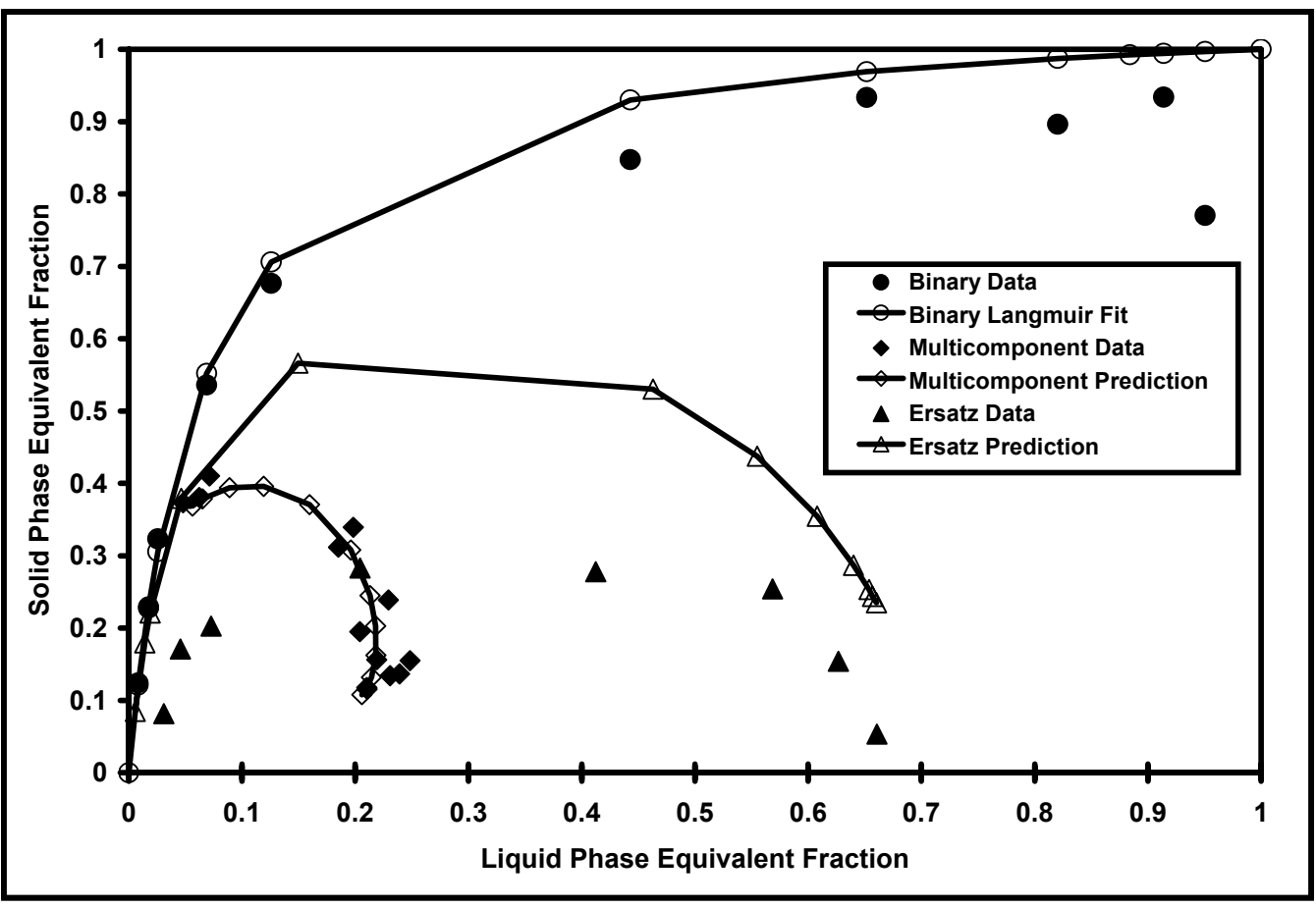

Figure 2-3 - Chloride Ion Exchange Equilibrium Isotherms with IRN-78 SBA Exchange Resin in the Hydroxide Form 


\subsection{IRN-150 Mixed Bed Ion Exchange Resin}

The IRN-150 mixed bed resin is a mixture of IRN-77 SAC exchange resin in the hydrogen form and IRN-78 SBA exchange resin in the hydroxide form. The hydrogen and hydroxide ions released by $\mathrm{IRN}-150$ mixed bed resin during exchange react to form water. The formation of water decreases the total liquid phase ionic concentration and improves the removal of all ions. The separation factors for the IRN-77 SAC and IRN-78 SBA exchange resins (see Tables 2-5 and 2-6, respectively) were used to predict IRN-150 mixed bed ion exchange, in the presence of sodium and chloride only, by including the water formation reaction. Figure 2-4 shows the prediction of the exchange of sodium and chloride with IRN-150 mixed bed resin. The data is plotted in terms of concentrations rather than equivalent fractions since the formation of water keeps the equivalent liquid phase fraction at unity. Figure 2-4 shows that when using the separation factors from the IRN-77 SAC and IRN-78 SBA exchange resins for sodium and chloride, respectively, the Langmuir multicomponent model was able to predict the ion exchange equilibrium for IRN-150 mixed bed resin.

\subsection{IRA-68 WBA Exchange Resin}

Table 2-16 summarizes the Langmuir ion exchange equilibrium constants $\left(b_{i}\right.$ values) determined for the IRA-68 WBA exchange resin. There are no values available in the literature for comparison. However, it is reported that WBA resins prefer acids of higher valence, larger ionic radius (smaller hydrated radius), complex molecular structure and higher strength (Diamond Shamrock Chemical Company, 1969). The Langmuir ion exchange equilibrium constants shown in Table 2-16 follow this sequence except for the weak organic acids (butyrate, acetate, lactate). Table 2-16 shows that the objective function determined from Equation 2-10 is equal to 0.228 for the IRA-68 WBA exchange resin. 


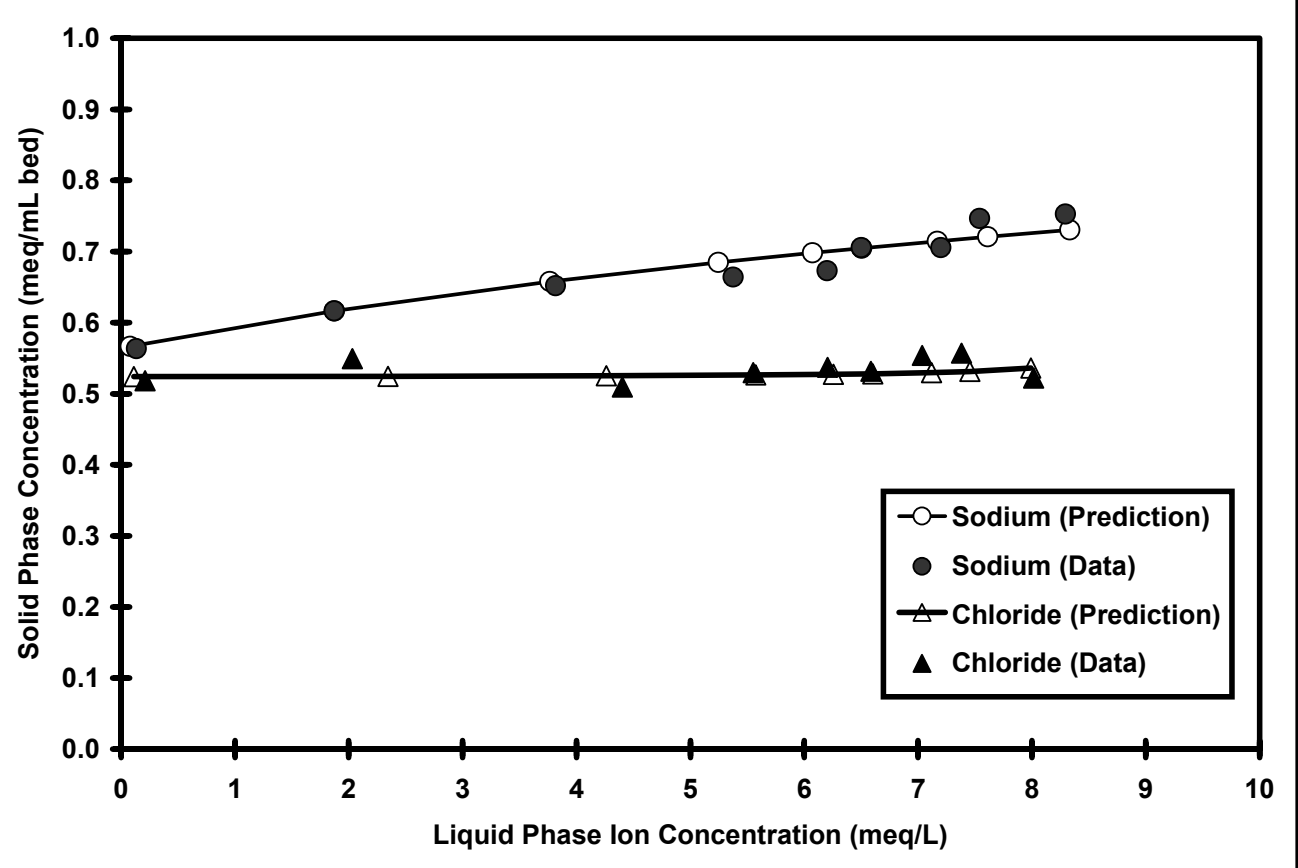

Figure 2-4 - Sodium and Chloride lon Exchange Equilibrium Isotherm with IRN-150 Mixed Bed lon Exchange Resin ( $\mathrm{H}^{+} / \mathrm{OH}^{-}$Form) Using Equilibrium Parameters from IRN-77 SAC and IRN-78 SBA Exchange Resins

Table 2-16 - Langmuir Equilibrium Ion Exchange Rate Constants $\left(b_{i}\right)$ and Separation Factors $\left(\alpha_{C l}^{i}\right)$ for IRA-68 WBA Exchange Resin and Acid $\mathrm{pK}_{\mathrm{a}}$ Values

\begin{tabular}{|l|c|c|c|}
\hline Ion, $\mathrm{i}$ & $\begin{array}{c}\mathrm{b}_{\mathrm{i}} \\
\left(\mathrm{L}^{2} / \mathrm{meq}^{2}\right)\end{array}$ & $\alpha_{\mathrm{Cl}}^{\mathrm{i}}$ & $\mathrm{pK}_{\mathrm{a}}$ \\
\hline Chloride $(\mathrm{Cl})$ & $1.06 \times 10^{3}$ & 1 & -3 \\
\hline Sulfate $\left(\mathrm{SO}_{4}\right)$ & $1.47 \times 10^{4}$ & 13.9 & -3 \\
\hline Acetate (Ac) & 588 & 0.555 & 4.75 \\
\hline Butyrate (But) & 541 & 0.510 & 4.81 \\
\hline Lactate (Lac) & 382 & 0.360 & 3.08 \\
\hline SCMT & $3.44 \times 10^{4}$ & 32.4 & -3 \\
\hline Objective Function $\left(\mathrm{f}_{\mathrm{obj}}\right)$ & 0.228 \\
\hline
\end{tabular}


Figure 2-5 compares the IRA-68 WBA exchange resin in the freebase form isotherm data for lactate with Langmuir model predictions. The Langmuir model predictions are plotted in terms of constant $\mathrm{pH}$ isopleths generated using the Langmuir ion exchange equilibrium constant for lactate $\left(b_{\text {Lac }}=382\right)$ in Table 2-16 in Equation 2-20. Figure 2-5 also shows the equilbrium $\mathrm{pH}$ values of each isotherm data point. The ionized portions of the acids were calculated using Equation 2-1. The equilibrium data is presented in terms of concentrations rather than equivalent fractions because only the anion added to solution was present since the hydroxide concentration is negligible for the freebase form of the resin. Figure 2-5 also shows the approximate $\mathrm{pH}$ at which the exchange capacity begins to decrease for lactate. By comparing the equilibrium $\mathrm{pH}$ values for each data point with the model predictions represented by the constant $\mathrm{pH}$ isopleths, it is clear from Figure 2-5 that the fit value of Langmuir ion exchange equilibrium constant for lactate $\left(b_{\text {Lac }}=382\right)$ results in good agreement between the isotherm data and model predictions for the lactate exchanging with IRA-68 WBA exchange resin in the freebase form. Figure 2-5 is representative of the IRA-68 WBA exchange data and predictions for the other anions listed in Table 2-2.

A multicomponent (chloride and acetate) isotherm with the freebase form of IRA-68 WBA exchange resin was conducted to validate the WBA multicomponent equilibrium description. The initial concentration of chloride was $1.02 \mathrm{meq} / \mathrm{L}$. The initial acetate ion concentration was $0.12 \mathrm{meq} / \mathrm{L}$ compared to the total acetate concentration of $8.11 \mathrm{meq} / \mathrm{L}$. Figure 2-6 compares the measured liquid phase concentrations of chloride and acetate to the values predicted using the exchange constants from Table 2-16 and Equation 2-20. Figure 2-7 compares the measured solid phase data for chloride and acetate to the predicted values. The model predicts a higher solid phase concentration and lower aqueous phase concentration for both chloride and acetate than is observed. When there are more ions in solution than there are sites (low resin dosages), the model is able to predict the data. However, when there is an excess of sites available, the model predicts a higher removal of chloride and acetate than is observed. The solid phase concentrations were determined using 


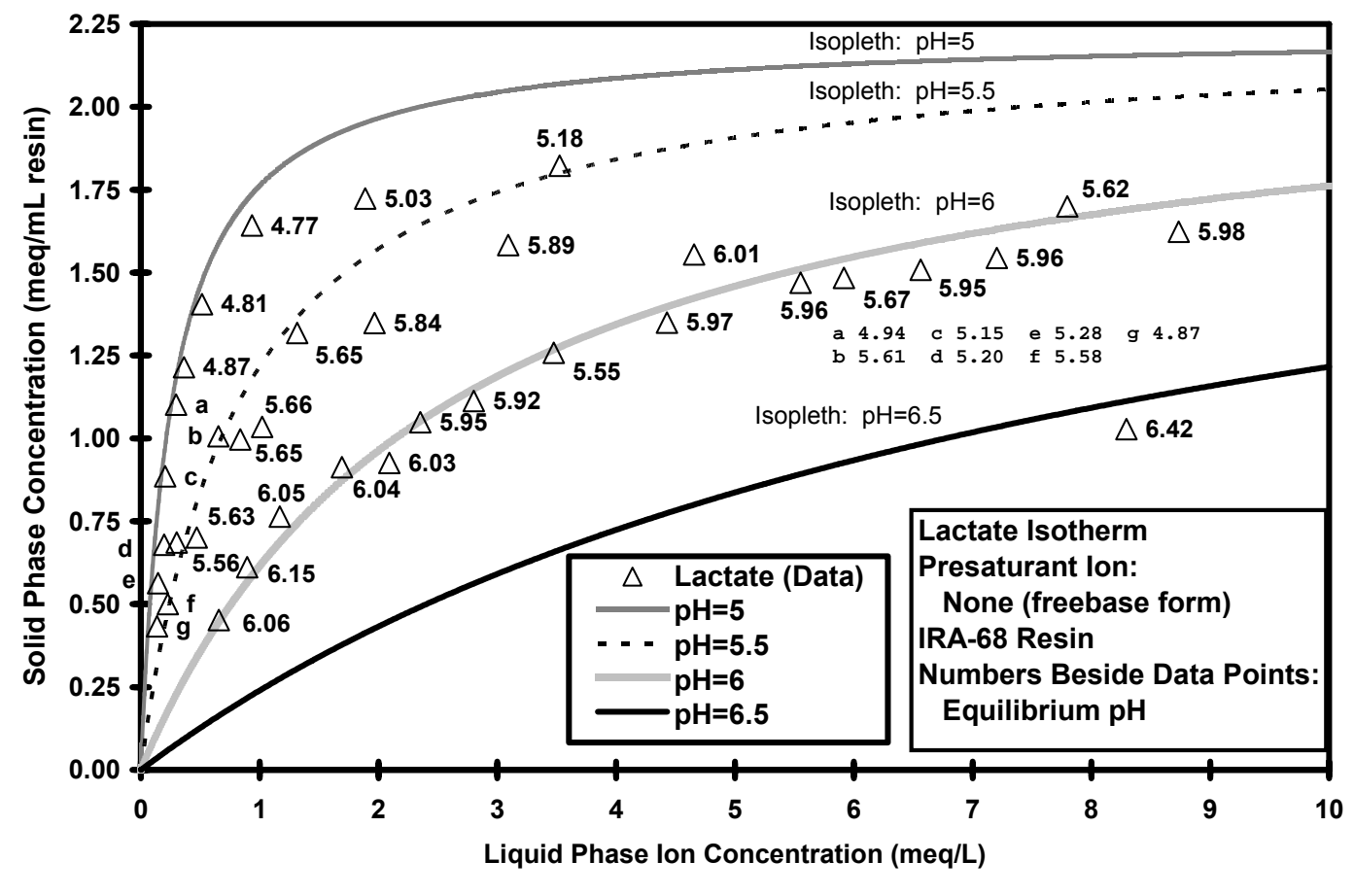

Figure 2-5 - Lactate Ion Exchange Equilibrium Isotherm with Freebase Form of IRA-68 WBA Exchange Resin and Selected pH Isopleths

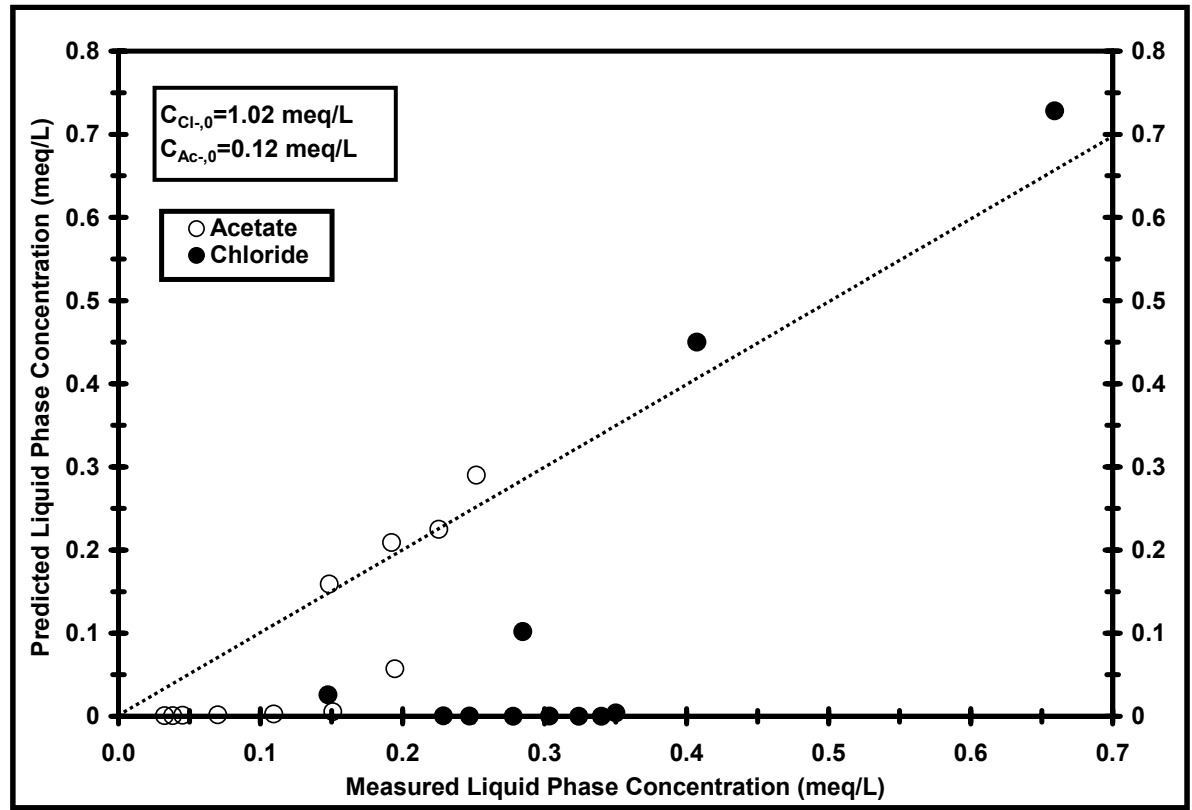

Figure 2-6 - Comparison of Measured Liquid Phase Concentrations to Predicted Liquid Phase Concentrations for the Multicomponent Isotherm with Freebase Form of IRA-68 WBA Exchange Resin. Initial Total Acetate Concentration was $8.11 \mathrm{meq} / \mathrm{L}$ and Initial Total Chloride Concentration was $1.02 \mathrm{meq} / \mathrm{L}$. 


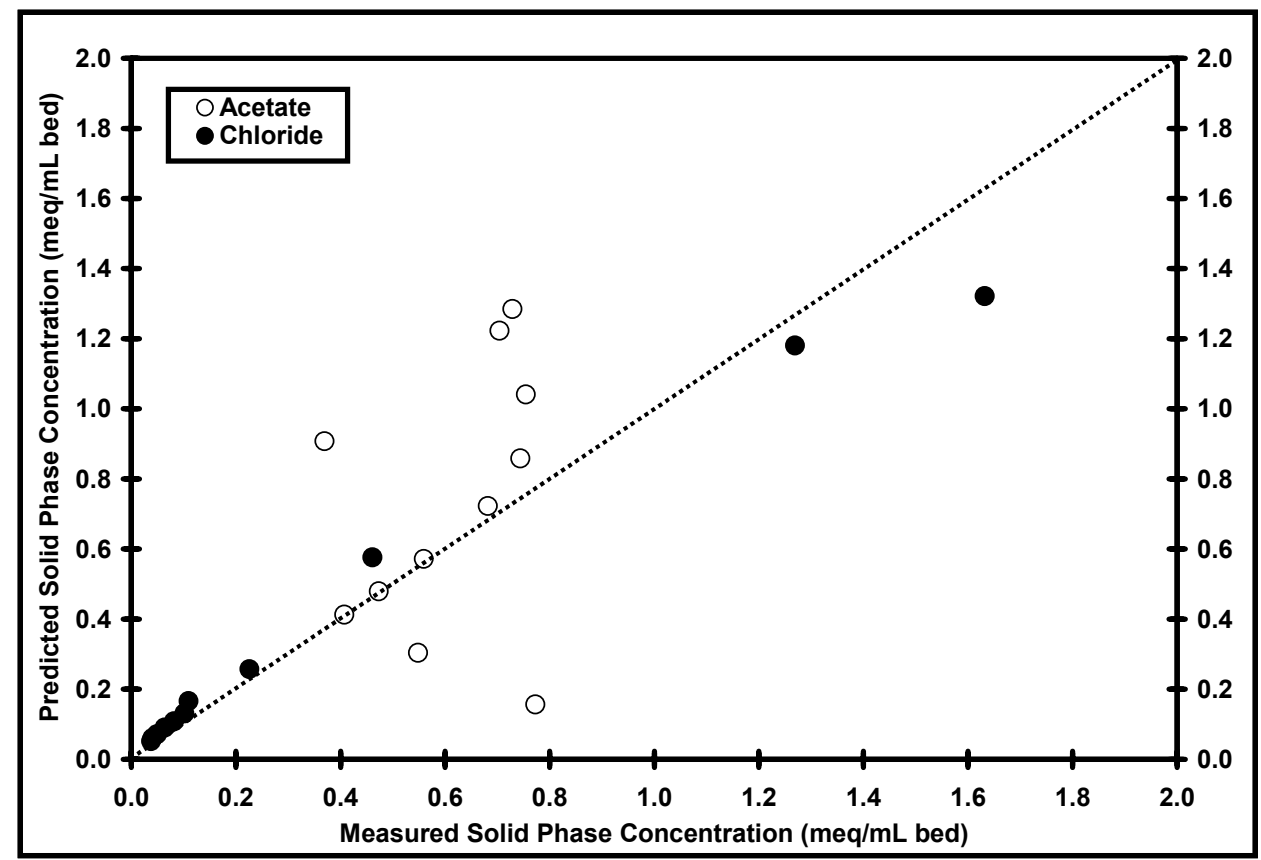

Figure 2-7 - Comparison of Measured Solid Phase Concentrations to Predicted Solid Phase Concentrations for the Multicomponent Isotherm with the Freebase Form of IRA-68 WBA Exchange Resin.

Equation 2-17. For chloride the variation in measured $(0.2 \mathrm{meq} / \mathrm{L})$ and predicted (0.02) equilibrium aqueous phase concentrations is small compared to the initial aqueous phase concentration (1.02 meq/L). Therefore, it appears that the solid phase chloride concentrations are better predicted than the liquid phase chloride concentrations.

\subsection{MCV-RT}

The equilibrium experiments for the MCV-RT indicated that the resin does not participate in ion exchange. Since there was very little ion exchange observed, the MCV-RT was not modeled as an ion exchange resin.

\section{Conclusion}

Binary isotherms were performed on the IRN-77 SAC, IRN-78 SBA, IRA$68 \mathrm{WBA}$, and IRN-150 mixed bed ion exchange resins. Separation factors for the IRN-77 SAC and IRN-78 SBA exchange resins were successfully determined from the binary isotherms. Langmuir ion exchange equilibrium constants have 
been determined for IRA-68 WBA exchange resin from the binary isotherms. Comparisons of the ion exchange equilibrium data for IRA-68 WBA exchange resin with model predictions represented by constant $\mathrm{pH}$ isopleths showed that the Langmuir ion exchange equilibrium constants determined were able to successfully describe the data.

The Langmuir multicomponent equilibrium expression predicted five- and six-component isotherm data for the IRN-77 SAC and IRN-78 SBA exchange resins, respectively. The separation factors determined for the IRN-77 SAC and IRN-78 SBA exchange resins were able to predict equilibrium for the IRN-150 mixed bed resin by coupling the water formation reaction with the binary Langmuir equilibrium expression for each ion.

The Langmuir multicomponent equilibrium expression was able to predict the ion exchange in the ersatz water for IRN-77 SAC exchange resin and overpredicted the ion exchange for IRN-78 SBA exchange resin. The impact of SCMT exchange and possible organic contaminant fouling may cause the overprediction.

The Langmuir multicomponent equilibrium expression predicted a higher solid phase concentration and a lower aqueous phase concentration than was observed in the data for both anions present in a multicomponent isotherm for IRA-68 WBA exchange resin. The Langmuir expression was able to predict the exchange for low resin dosages when there are more ions in solution than sites available, but not when there were excess sites available.

\section{Acknowledgements}

The authors acknowledge ION Corporation, U.S. EPA and CenCITT, Michigan Tech Graduate School, and Michigan Tech Research Excellence Fund for funding this project. The authors are grateful to Shelle Sandell, Jacqueline Popko, Daniel LaCrosse, and David Perram for performing analysis and running the isotherm experiments. 
This work was supported in part by ION Corporation, U.S. EPA, the Center for Clean Industrial and Treatment Technologies, Michigan Tech Graduate School and Michigan Tech Research Excellence Fund, although it does not necessarily reflect their views and no official endorsement should be inferred.

\section{References}

Bolto, B. A., and Pawlowski, L. (1987). Wastewater treatment by ion-exchange. E. \& F. N. Spon, London.

Bulloch, J. L., Hand, D. W., and Crittenden, J. C. (1998). "Model for predicting contaminant removal by adsorption within the International Space Station water processor: 1. Multicomponent equilibrium modeling." Water Environ. Res., 70(1), 14-26.

Carter, D. L., Holder Jr., D. W., Alexandre, K., Shaw, R. G., and Hayase, J. K. (1991). "Preliminary ECLSS waste water model," Presented at the Twentyfirst International Conference on Environmental Systems, San Francisco, CA, July.

Carter, D. L., Cole, H., Habercom, M., and Griffith, G. (1992). "Determination of organic carbon and ionic accountability of various waste and product waters derived from ECLSS water recovery tests and spacelab humidity condensate," Presented at the Twenty-second International Conference on Environmental Systems, Seattle, WA, July.

Clancey, B. L. "Binary Description and Multicomponent Prediction of Ion Exchange Equilibrium," M.S. Thesis in Civil Engineering, Michigan Technological University, 141 pp. (1995).

Clifford, D. A. (1976). "Nitrate removal from water supplies by ion exchange:

Resin selectivity and multicomponent, chromatographic column," PhD Dissertation, University of Michigan, Ann Arbor, Michigan.

Clifford, D. A. (1999). "Chapter 9. Ion exchange and inorganic adsorption," AWWA Water quality and treatment: A handbook of community water supplies, $5^{\text {th }}$ Ed., McGraw-Hill, New York, 9.1-9.91. 
Crittenden, J. C., Hand, D. W., Perram, D. L., Gierke, J. S., Bhuvendralingham, S., Gopakumar, B., and Jayadev, R. (1992). "Development of a mathematical model to evaluate the operation of the multifiltration unit in the space station's drinking water treatment system," Report prepared for McDonnell Douglas Space System Company, Huntsville, Alabama, April 30.

Diamond Shamrock Chemical Company. (1969). Duolite ion-exchange manual, $2^{\text {nd }}$ ed., Prepared and edited by technical staff of Resinous Products Division, $210 \mathrm{pp}$.

Draper, N. R. and Smith, H. (1981). Applied regression analysis, 2nd Ed., John Wiley \& Sons, New York, 709 pp.

Hand, D. W., Crittenden, J. C., Bulloch, J. L., Clancey, B. L., Hokanson, D. R., and Yu, J. (1995). "Bringing water recovery models down to Earth," Presented at the Life Science and Space Medicine Conference and Exhibition '95: Bringing Space Benefits Down to Earth, Houston, TX, April.

Hand, D. W., Ali, A. N., Bulloch, J. L., DeBraske, M. L., Crittenden, J. C., and Hokanson, D. R. (1999). "Adsorption equilibrium modeling of space station wastewaters," ASCE J. Environ. Engrg., ASCE, 125(6), 540-547.

Hatch, G.L., J.L. Lambert, and L.R. Fina, "Some Properties of the Quaternary Ammonium Anion-Exchange Resin-Triiodide Disinfectant for Water," Ind. Eng. Chem. Prod. Res. Dev., 19, 259-263 (1980).

Helfferich, F. (1962). lon exchange, McGraw-Hill Book Co., New York, 624 pp. Unabridged reprint available through Dover Publications, New York (1995). Kunin, R. (1990). "lon exchange resins", Krieger Publishing, Huntington, NY. Lambert, J.L., G.T. Fina, and L.R. Fina, "Preparation and Properties of Triiodide-, Pentaiodide-, and Heptaiodide-Quaternary Ammonium Strong Base Anion Exchange Resin Disinfectants," Ind. Eng. Chem. Prod. Res. Dev., 19, 256258 (1980).

Lasdon, L.S., Waren, A., Jain, A., and Ratner, M. (1978). "Design and testing of a generalized reduced gradient code for nonlinear programming," ACM Trans. Math. Softw. 4(1), 34-50. 
Lasdon, L.S. and Smith, S. (1992). "Solving sparse nonlinear programs using GRG," ORSA J. Comput., 4(1), 2-15.

Lopez, M., Coca, J., and Sastre, H. (1992). "Anion exchange in Amberlite IRA-400 and IRA-410 ion exchange resins." J. Chem. Eng. Data, 37, 274-277.

MathSoft, Inc., "Mathcad 8 Professional," U.S. Patent Nos. 5,469,538 and $5,526,475$ (1998).

Muckle, Susan, "Treatment of Spacecraft Humidity Condensate to Produce Potable Water," M.S. Thesis, University of Houston, Texas (1990).

Rohm and Haas, "Rohm and Haas ion exchange resins: Laboratory guide," Technical Bulletin Fluid Process Chemicals Department, Rohm and Haas, Philadelphia, PA (1990).

Sontheimer, H., Crittenden, J. C., and Summers, R. S. (1988). Activated carbon for water treatment, DVGW-Forschungsstelle, Engler-Bunte-Institut, Univ. of Karlsruhe, Fed. Rep. of Germany.

Subramonian, S. and Clifford, D. (1988). "Monovalent/divalent selectivity and the charge separation concept", React. Polym., 9, 195-209.

\section{Nomenclature}

$b_{i} \quad$ Langmuir equilibrium exchange rate constant for ion $i\left(L^{6} e^{-2}\right)$

$\left[\mathrm{A}^{+}\right],\left[\mathrm{A}^{-}\right]$Cation $\left(\mathrm{A}^{+}\right)$or anion $\left(\mathrm{A}^{-}\right)$concentration $\left(\mathrm{molL}^{-1}\right)$

$\sum \mathrm{C}_{\text {anions }} \quad$ Sum of equivalent liquid phase anion concentrations $\left(\right.$ eq $\left.\mathrm{L}^{-3}\right)$

$\sum \mathrm{C}_{\text {cations }} \quad$ Sum of equivalent liquid phase cation concentrations $\left(\mathrm{eq} \mathrm{L}^{-3}\right)$

$\mathrm{C}_{\mathrm{H}} \quad$ Equivalent liquid phase hydrogen ion concentration $\left(\right.$ eq $\mathrm{L}^{-3}$ )

$\mathrm{C}_{\mathrm{i}}, \mathrm{C}_{\mathrm{j}} \quad$ Equivalent liquid phase concentration of ion $\mathrm{i}$ and ion $\mathrm{j}$ respectively $\left(\right.$ eq $\left.L^{-3}\right)$

$\mathrm{C}_{\mathrm{i}, 0} \quad$ Initial equivalent liquid phase concentration of ion $\mathrm{i}\left(\mathrm{eq} \mathrm{L}^{-3}\right)$

$\mathrm{C}_{\mathrm{T}} \quad$ Total liquid phase equivalent concentration of ions $\left(\right.$ eq $\left.\mathrm{L}^{-3}\right)$ 


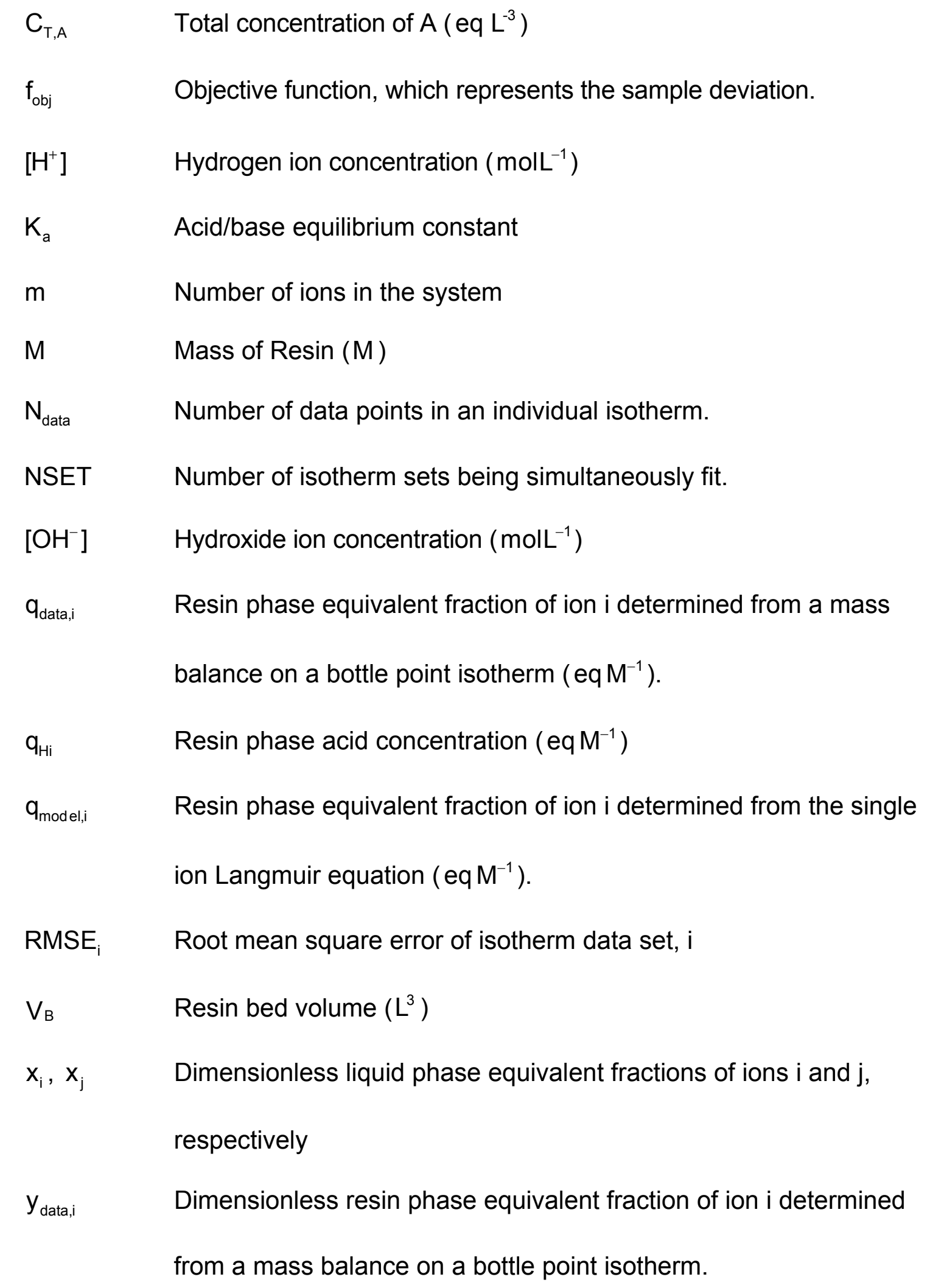


$\mathrm{y}_{\text {model,i }} \quad$ Dimensionless resin phase equivalent fraction of ion i determined

from the binary Langmuir equation.

$y_{i}, y_{j} \quad$ Dimensionless resin phase equivalent fractions of ions $i$ and $j$, respectively.

$\alpha_{j}^{i} \quad$ Separation factor 


\title{
Chapter 3 - Dynamic Mathematical Modeling of lon Exchange Processes for the International Space Station Water Processor ${ }^{*}$
}

\begin{abstract}
A mathematical model is presented for analysis and optimization of the ion exchange beds in the International Space Station (ISS) Water Processor. A tanks-in-series equilibrium model (TISEqM) is applied to binary and multicomponent ion exchange and has the capability to describe strong acid cation, strong base anion, mixed bed, and weak base anion exchange resins within the ISS water processor. A Langmuir equilibrium approach is applied. The ion exchange model was verified for an Ersatz water designed to mimic the ISS shower/handwash waste stream. It was shown that specifying 25 tanks-inseries within the TISEqM to in an attempt to represent plug flow conditions allows for reasonable prediction of the ion exchange bed performance within the ISS water processor.
\end{abstract}

\section{Keywords}

mathematical model, equilibrium model, Langmuir equilibrium approach, separation factor, strong acid cation, SAC, strong base anion, SBA, multicomponent, mixed bed, weak base anion, WBA, freebase form

\footnotetext{
* This chapter consists of a paper that will be submitted as part 2 of a two-part series of papers to the Journal of Environmental Engineering.
} 


\section{Introduction}

Chapter 2 describes the need for recycling the water onboard the International Space Station (ISS) and the treatment technologies employed in the ISS Water Processor. A mathematical model designed to predict the performance of the multifiltration bed within the ISS Water Processor was developed. Chapter 2 addressed the development of the equilibrium description for the ion exchangers employed in the ISS Water Processor. Chapter 3 specifically addresses the modeling of ion exchange processes in the multifiltration beds for removal of ions in the waste shower and handwash streams. The equilibrium constants determined in Chapter 2 are applied to predict the performance of ion exchange beds utilized in the ISS Water Processor. Waste shower and handwash water is the most prevalent and most contaminated waste stream. Consequently, it was assumed that if the performance of the ion exchange processes could be predicted using a mathematical model for the shower/handwash water, then the model should be able to describe the ion exchange performance for other waste water streams

In conjunction with the development of the ion exchange model, a model has been developed to predict the performance of the adsorption media in the multifiltration beds (Bulloch et al., 1998; Hand et al., 1999). The two models will be integrated into the multifiltration bed model, MFBMODEL ${ }^{\mathrm{TM}}$, to predict the overall performance of the multifiltration unit. This integrated model of the multifiltration unit in the ISS Water Processor may be extended to model a wide variety of terrestrial systems. For example, the model could be applied in the 
fields of municipal drinking water treatment, industrial and hazardous waste remediation, and pollution prevention (Hand et al., 1995). An explanation of MFBMODEL software use is presented in Appendix VII.

The ion exchange resins in the multifiltration unit are shown in Figure 3-1 and include (1) an iodinated strong base anion (SBA) exchange resin (MCV-RT), (2) a strong acid cation (SAC) gel type exchange resin (IRN-77), (3) a mixture of SAC (IRN-77) and SBA (IRN-78) gel type resins (IRN-150), and (4) a weak base anion (WBA) gel type exchange resin (IRA-68). This paper will present equilibrium model results for IRN-150, IRN-77, and IRA-68 resins. A more detailed discussion of the complete MFBMODEL is beyond the scope of this paper and is reported elsewhere (Hand et al., 2000). Appendix X presents adsorption results for the MFBMODEL verification experiment with shower/handwash wastewater.

Mathematical models can predict the impact of changing process variables on ion exchange performance. Use of models significantly reduces the time and cost involved in performing laboratory and pilot scale experimental work. Process variables such as the number of exchanging ions, time variable influent concentrations, ion exchange bed size, resin type, ion exchange bed configurations such as multiple beds in series, and competition among exchanging ions can be evaluated with a mathematical model for ion exchange. 


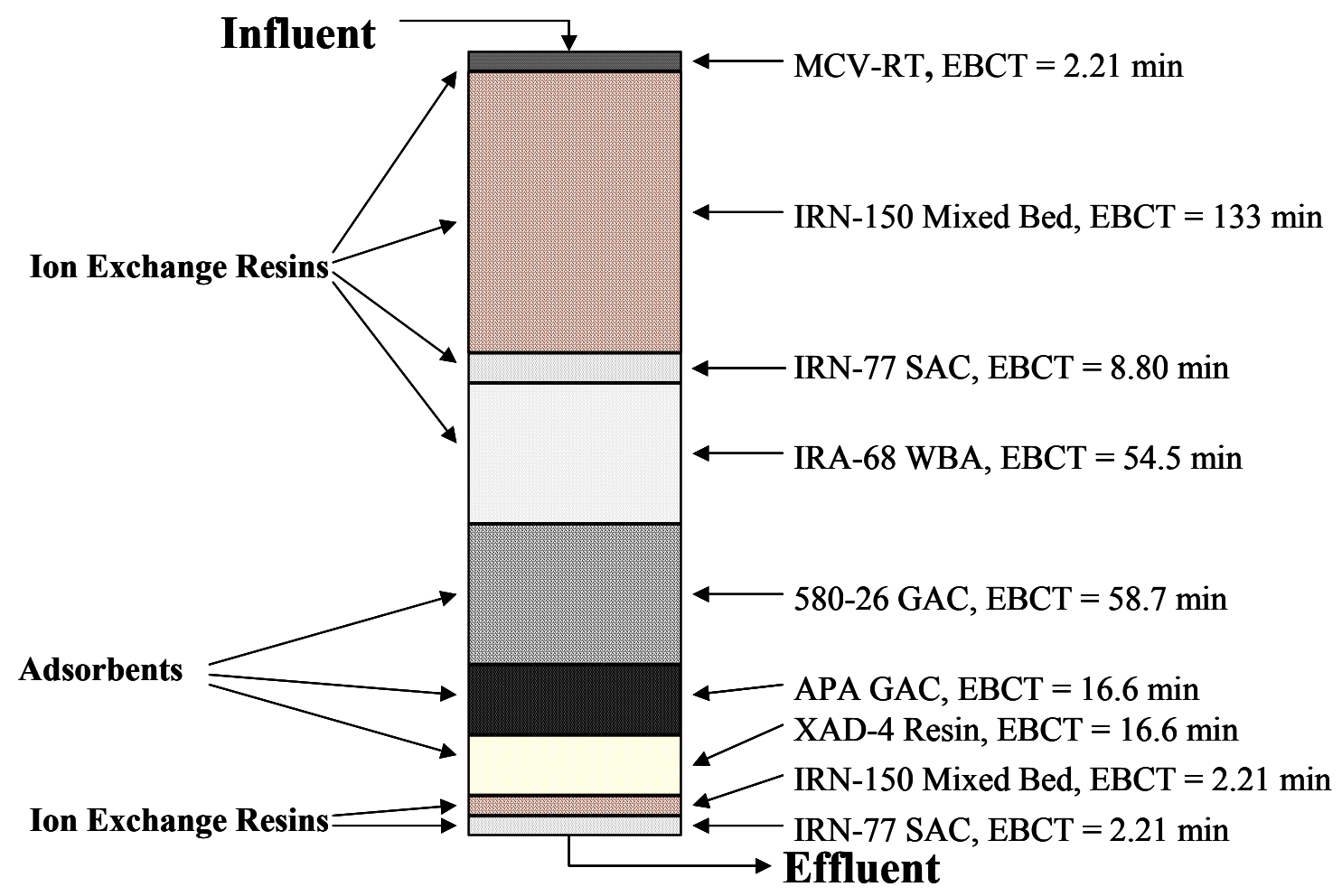

Figure 3-1 - Schematic of the Multifiltration Beds

A mathematical modeling approach to analyze ion exchange in the multifiltration unit is presented in this paper. This ion exchange column model accounts for multicomponent equilibrium and is applicable to SAC, SBA, mixed bed, and WBA exchange resins.

The ion exchange equilibirum modeling approach presented in this paper represents an advancement over past work for the following reasons. The ion exchange equilibrium modeling approach presented in this paper represents an improved numerical solution method over existing multicomponent equilibrium models. The application for multicomponent mixtures to the various types of ion exchange resins within the multifiltration beds, with their long empty bed contact times, is significant. Especially important are the multicomponent results for a 
mixed bed ion exchange resin, as past multicomponent ion exchange equilibrium modeling results have typically been demonstrated for strong base ion exchange resins (e.g., nitrate removal). Also significant is the development of a numerical modeling approach capable of predicting the performance of the water processor onboard the International Space Station (multifiltration bed consisting of ion exchange resins and adsorbents in series and a sophisticated engineering design tool with a GUI in Visual Basic and Fortran computational routines).

\section{Materials and Methods}

\subsection{Chemicals and Resins}

All chemicals were reagent grade or better. Sodium bicarbonate, calcium chloride, potassium chloride, ammonium chloride, sulfuric acid, sodium chloride, sodium acetate, acetic acid, hydrochloric acid, sodium hydroxide, sodium nitrate and potassium iodide were obtained from Fisher Scientific (Fair Lawn, NJ). The Aldrich Chemical Company (Milwaukee, WI) supplied: m-xylene, naphthalene, toluene, trichloroethylene (TCE), 1,2,4-trichlorobenzene (1,2,4-TCB), triethanolamine, sodium butyrate, sodium lactate, butyric acid, acetic acid (sodium salt), and lactic acid. NASA Whole Body Shampoo, Formula \#6503.45.4 was obtained from Ecolab Inc. (Mendota Hts., MN). The major constituent of NASA Whole Body Shampoo is Sodium-N-methyl-N-"coconut oil acid" taurate (SCMT). The manufacturer reports NASA Whole Body Shampoo is $98 \%$ pure, $24 \%$ by weight SCMT, $6.4 \%$ by weight $\mathrm{NaCl}$, and SCMT's molecular weight is between 357 to 360 . There is one fixed anionic charge per SCMT molecule. 
The ion exchange resins for this study came from various sources. UMQUA Research Company (Beaverton, OR) provided the MCV-RT, the IRN150 and some of the IRN-77. Additional IRN-77 and IRA-68 was purchased from Rohm and Haas (Cherry Hill, PA). The IRN-78 was obtained directly from multifiltration columns opened by NASA. The resins and their physical properties are listed in Table 2-1. Distilled-deionized water was produced by distilling tap water and further purifying it with a Milli-Q UV Plus Water System (Millipore Corp., Bedford, MA).

Prior to use, the resins were conditioned and converted to the forms listed in Table 3-1 following procedures outlined by Rohm and Haas (1990). The MCV$\mathrm{RT}$ resin was used in the iodinated form as received. The IRN-150 was produced by mixing IRN-77, hydrogen form, ( $40 \%$ by volume) and IRN-78, hydroxide form ( $60 \%$ by volume). The Amberlite IRN-78 was conditioned and converted with solutions prepared under nitrogen to minimize the amount of atmospheric bicarbonate contacting the resin.

\subsection{Solution Preparation}

An Ersatz shower/handwash water, designed to mimic the adsorption potential of the actual shower/handwash water, was made from ionic constituents which are listed in Table 3-2 and from various organics (TCE, SCMT, m-xylene, toluene, 1,2,4-TCB and naphthalene) to obtain a TOC concentration equal to the average TOC of the actual shower/handwash water. The ions are representative of those found in the actual shower/handwash water. 
Table 3-1 - Ion Exchange Resins in an ISS Multifiltration Bed

\begin{tabular}{|l|l|l|}
\hline Media & Function & Media Description \\
\hline MCV-RT & Disinfection & $\begin{array}{l}\text { iodinated strong base anion, SBA, } \\
\text { exchange resin }\end{array}$ \\
\hline IRN-150 & $\begin{array}{l}\text { Removal of anions } \\
\text { and cations }\end{array}$ & $\begin{array}{l}\text { mixture of gel types strong acid cation, } \\
\text { SAC, }\left(\text { IRN-77, } \mathrm{H}^{+} \text {form) and SBA (IRN-78, }\right. \\
\text { OH form) }\end{array}$ \\
\hline IRN-77 & Removal of cations & SAC gel exchange resin in the $\mathrm{H}^{+}$form \\
\hline IRA-68 & $\begin{array}{l}\text { Removal of strong } \\
\text { and weak acids }\end{array}$ & $\begin{array}{l}\text { weak base anion, WBA, gel exchange resin } \\
\text { in the free base form }\end{array}$ \\
\hline IRN-150 & $\begin{array}{l}\text { Removal of anions } \\
\text { and cations }\end{array}$ & $\begin{array}{l}\text { mixture of gel types SAC }\left(I R N-77, \mathrm{H}^{+} \text {form) }\right. \\
\text { and SBA (IRN-78, OH form) }\end{array}$ \\
\hline IRN-77 & Removal of cations & SAC gel exchange resin in the $\mathrm{H}^{+}$form \\
\hline
\end{tabular}

Table 3-2 - Organic and Inorganic Ersatz Shower/Handwash Water Constituents

Ionic organic and inorganic constituents (concentration in meq/L)

\begin{tabular}{l|l|l|l}
\hline Compound & Concentration & Compound & Concentration \\
\hline Sodium & 10.86 & Chloride & 5.86 \\
\hline Triethanolamine & 0.09 & Butyrate & 0.73 \\
\hline Ammonium & 0.37 & Acetate & 0.75 \\
\hline Calcium & 0.18 & Sulfate & 0.46 \\
\hline Potassium & 0.60 & SCMT & 2.14 \\
\cline { 2 - 4 } & & Bicarbonate & 0.67 \\
\hline
\end{tabular}

Non-ionized organic constituents (concentration in $\mathrm{mg} / \mathrm{L}$ )

\begin{tabular}{l|l|l|l}
\hline Compound & Concentration & Compound & Concentration \\
\hline TCE & 246.43 & $1,2,4-\mathrm{TCB}$ & 15.00 \\
\hline m-xylene & 15.94 & naphthalene & 0.53 \\
\hline toluene & 176.35 & & \\
\hline
\end{tabular}


The Ersatz water was developed by applying a fictive component analysis (FCA) to the actual shower/handwash water. Substitute compounds and their concentrations were determined from adsorption isotherms with the actual water. Large quantities of the Ersatz water were needed for column experiments. Therefore, saturated solutions of the individual organic compounds were made. These solutions were pumped into Tedlar bags (SKC Inc., Eighty Four, PA) to minimize volatilization and the ionic species were injected directly into the bags.

\subsection{Chemical Analysis}

Total organic carbon (TOC) and inorganic carbon (IC) measurements for SCMT and bicarbonate were made with a Sievers Model 800 Portable TOC Analyzer (Sievers, Inc., Boulder, CO). The analyzer utilizes UV-persulfate oxidation. Reagents used in the analyzer include $6 \mathrm{M}$ phosphoric acid and $15 \%$ ammonium persulfate. Two membrane based conductometric $\mathrm{CO}_{2}$ sensors measure the Total Inorganic Carbon (TIC) and Total Carbon (TC) of the sample. TOC is found by taking the difference between the TC and the TIC of the sample. The conductivity electronics are calibrated automatically within the instrument by measuring a precision resistor prior to each conductivity measurement. The increase in conductivity is proportional to the concentration of $\mathrm{CO} 2(\mathrm{aq})$ in the sample stream. The TIC analysis was used to measure bicarbonate concentrations. In the Ersatz water, the SCMT concentration was defined by the difference between the actual TOC concentration and the TOC contributions of the individual organic constituents. 
chromatography and ion selective electrodes were used to measure the ion concentrations. An Orion Sodium probe was used to determine some sodium concentrations down to $10 \mathrm{ppm}$ with the ion selective electrode (ISE) method outlined by Orion (Cambridge, MA). A Dionex ion chromatograph, DX500 (Sunnyvale, CA) was used for the majority of ion measurements. Cations were analyzed with the lonPac CS12 4mm analytical column with a CG12 $4 \mathrm{~mm}$ guard column and a cation self-regenerating suppresser $(4 \mathrm{~mm})$. Dionex Method 7.2 with $20 \mathrm{mM}$ Methanesulfonic acid eluent was used for the cation analyses. The anions were analyzed with an IonPac anion trap column (ATC-1) and an AS11 $4 \mathrm{~mm}$ analytical column with a AG11 $4 \mathrm{~mm}$ guard column and an self-regenerating anion suppresser $(4 \mathrm{~mm})$. Dionex Method 6.2 using sodium hydroxide gradient elution program and method 6.1 using $21 \mathrm{mM}$ sodium hydroxide eluent were used for the anion analyses.

The iodine and iodide exchanged or leached from the MCV-RT was measured with a residual chlorine probe (Model 97-70) and an iodide probe (Model 94-53), both from Orion, based on the ISE chlorine determination method outlined by Orion. Triiodide concentrations were measured spectrophotometrically using a Perkin-Elmer 552 spectrophotometer (Norwalk, CT).

The $\mathrm{pH}$ was determined using an Orion (Cambridge, MA) Model $501 \mathrm{pH}$ meter. 


\subsection{Multifiltration Bed Model Verification Experiment}

A multifiltration bed model verification ersatz shower/handwash column experiment with representative ions (see Table 3-2) was conducted using resins and adsorbents with empty bed contact times similar to those reported in Figure

3-1. The multifiltration verification column experiment with ersatz water involved using ion exchange columns and adsorption columns in series. For beds in series operation, the effluent from one column was the influent to the next column. Sampling was performed between the columns and at the influent and effluent of the entire beds in series apparatus. The beds in series columns were all operated in the downflow mode.

Channeling effects were eliminated by capping glass columns, (Ace Glass Co., Vineland, NJ) with inner diameters of $2.5 \mathrm{~cm}$ or $5.0 \mathrm{~cm}$ with a bored out Teflon end cap filled with glass beads. The glass beads were retained with 150 mesh stainless steel screen. Teflon tubing was used to connect the apparatus to FMI pumps (Oyster Bay, NJ).

Conditioned resin was slurried into the columns with distilled-deionized water. The mass and volume of resin in each column was used to determine individual column properties. Solutions were run downflow through the columns to obtain empty bed contact times (EBCT) similar to the multifiltration unit.

Column effluent was monitored for presaturant ion and exchanging ions until complete exhaustion. The $\mathrm{pH}$ was also monitored. Appendix VIII presents the column procedure. 


\subsection{Equilibrium Chemistry}

Several reactions that affect the ion exchange process were incorporated into the ion exchange models. Conditions that must be considered simultaneously for the water include electroneutrality, degree of ionization of weak acids and bases, and water formation reaction. Simultaneous acid/base equilibria needs to be incorporated in order to consider the degree of ionization of weak acids or bases present in the water matrix. The water formation reaction between the hydrogen $\left(\mathrm{H}^{+}\right)$and the hydroxide $\left(\mathrm{OH}^{-}\right)$ions needs to be considered, especially for the mixed bed ion exchange resin where the presaturant ions for the SAC portion and SBA portion are $\mathrm{H}^{+}$and $\mathrm{OH}^{-}$, respectively. As the water formation reaction and ionization effect are considered, the system must be constrained such that the water remains electrically neutral. More details on the equilibrium chemistry are presented in Appendix IV.

\subsubsection{Electroneutrality}

The electroneutrality condition is written in terms of the charge balance in dimensionless form as:

$$
\sum_{\substack{\mathrm{i}=1 \\ i \neq \mathrm{H}}}^{\text {NumCations }}\left[\left(\overline{\mathrm{C}_{\mathrm{i}}}\right) \times \overline{\mathrm{C}_{0, \mathrm{i}}}\right]+\left(\overline{\mathrm{C}_{\mathrm{H}}}\right) \times \overline{\mathrm{C}_{0, \mathrm{H}}}=\sum_{\substack{\mathrm{j}=1 \\ \mathrm{j} \neq \mathrm{OH}}}^{\text {NumAnions }}\left[\left(\overline{\mathrm{C}_{\mathrm{j}}}\right) \times \overline{\mathrm{C}_{0, \mathrm{j}}}\right]+\left(\overline{\mathrm{C}_{\mathrm{OH}}}\right) \times \overline{\mathrm{C}_{0, \mathrm{OH}}}
$$

in which NumCations represents the number of cations in the system, $\overline{C_{i}}$ represents the dimensionless liquid phase concentration of cation $\mathrm{i}, \overline{\mathrm{C}_{0, \mathrm{i}}}$ is equal to the equivalent time-averaged influent liquid phase concentration of cation i $\left(\right.$ eq L $\left.{ }^{-3}\right), \overline{\mathrm{C}_{\mathrm{H}}}$ represents the dimensionless hydrogen ion concentration, $\overline{\mathrm{C}_{0, \mathrm{H}}}$ equals the equivalent time-averaged influent liquid phase concentration of 
hydrogen $\left(\mathrm{H}^{+}\right)$ion $\left(\right.$eq $\left.\mathrm{L}^{-3}\right)$, NumAnions represents the number of anions in the system, $\overline{C_{j}}$ represents the dimensionless liquid phase concentration of anion $j$, $\overline{\mathrm{C}_{0, j}}$ is equal to the equivalent time-averaged influent liquid phase concentration of anion $\mathrm{j}\left(\mathrm{eq} \mathrm{L}^{-3}\right), \overline{\mathrm{C}_{\mathrm{OH}}}$ represents the dimensionless hydroxide ion concentration, and $\overline{\mathrm{C}_{0, \mathrm{OH}}}$ equals the equivalent time-averaged influent liquid phase concentration of hydroxide $\left(\mathrm{OH}^{-}\right)$ion $\left(\right.$eq $\left.\mathrm{L}^{-3}\right)$.

\subsubsection{Water Formation Reaction}

The water formation reaction written in dimensionless form is:

$$
\overline{\mathrm{C}_{\mathrm{H}}} \times \overline{\mathrm{C}_{\mathrm{OH}}}=\overline{\mathrm{K}_{\mathrm{w}}}
$$

in which $\overline{\mathrm{C}_{\mathrm{H}}}$ represents the dimensionless hydrogen ion concentration, $\overline{\mathrm{C}_{\mathrm{OH}}}$ equals the dimensionless hydroxide ion concentration, and $\overline{\mathrm{K}_{w}}$ is equal to the dimensionless form of the constant for water, $K_{w}$.

\subsubsection{Degree of Ionization of Weak Acids and Bases}

The amount of ionized form of weak acids and weak bases is a function of the $\mathrm{pH}$. lonized weak acid concentrations will be determined with the following relationship:

$$
\mathrm{C}_{\mathrm{j}^{-}}=\frac{\mathrm{C}_{\mathrm{T}, \mathrm{j}}}{1+\frac{\left[\mathrm{H}^{+}\right]}{\mathrm{K}_{\mathrm{a}, \mathrm{j}}}}
$$

Similarly, ionized weak base concentrations can be calculated based on the following relationship:

$$
\mathrm{C}_{\mathrm{Hi}^{+}}=\frac{\mathrm{C}_{\mathrm{T}, \mathrm{i}}}{1+\frac{\mathrm{K}_{\mathrm{a}, \mathrm{i}}}{\left[\mathrm{H}^{+}\right]}}
$$

Acid base equilibrium constants are shown in Table 2-11. 


\section{Equilibrium Model Development}

Helfferich and Klein (1970) developed a model for describing the ion exchange process. This equilibrium model, which ignores mass transfer resistances, was developed for a step-up increase in influent concentration and cannot accommodate variable influent ion concentrations. Clifford (1982) has successfully compared this model to multivalent anion exchange. More recently, Crittenden et al. (1992) used this modeling approach, based on the work of Horng (1983) and Clifford and Majano (1993), for describing the fate of humidity condensate in the MF bed. The model was used to simulate the removal of cations and anions from the humidity condensate water by the MF bed. However, there are several improvements which need to be incorporated into the ion exchange equilibrium modeling approach, especially the incorporation of capability to handle variable influent ion concentrations in order to simulate the series of ion exchange resins in the MF beds.

Höll and his research group have demonstrated the effectiveness of the surface complexation theory for describing equilibrium in various types of ion exchange resins (Höll et al. 1993; Horst, Höll, and Eberle 1990; Höll, Horst, and Wernet 1991; Höll, Horst, and Franzreb 1993). However, this study applies a Langmuir-based equilibrium approach for modeling rather than applying the surface complexation theory because of the unknown nature of the background water. The surface complexation theory is system-specific to those ions present in the system and not easily amenable to a generalized equilibrium expression applicable regardless of which ions are present. The Langmuir multicomponent 
equilibrium expression is amenable to generalization and has been applied successfully by Clifford (Clifford 1976; Clifford 1982; Subramonian and Clifford 1988).

Guter $(1984,1985,1995)$ developed an equilibrium modeling approach describing an ion exchange resin as a number of theoretical plates and solved the ion exchange equilibrium via a method of successive approximations. The model was applied to nitrate removal from groundwater using anion exchange resins (Guter 1984, 1985, 1995; Liang et al., 1999). The equilibrium model developed in this paper is similar conceptually to Guter's model. However, the equilibrium model presented in this paper utilizes Gear's stiff method to solve a system of ordinary differential equations describing the ion exchange equilibrium, which is much more robust than the method of successive approximations. A more robust method is needed given the long empty bed contact times for the ion exchange resins in the multifiltration beds and the required application of the model to three different types of ion exchange resins. A Langmuir equilibrium approach that considers solution chemistry is applied to a mixed bed ion exchange resin and a weak base anion exchange resin in the freebase form, which is a novel application of the equilibrium model presented in this paper.

For the ion exchangers in the MF bed, it is expected that an equilibrium modeling approach will be able to successfully describe system performance. One of the primary beds in the system (IRN-150) is a mixed bed ion exchange resin. In a mixed bed of resin, the feed solution becomes progressively diluted as the hydrogen and hydroxide exchanging from the resin react to form water, 
making equilibrium increasingly favorable (Slater 1991). In addition, the most important resins for removing ions in the MF bed (the mixed bed [IRN-150] and weak base anion [IRA-68] exchange resins) have considerably long empty bed contact times (133 minutes and 54.5 minutes, respectively, as shown in Figure 31), which will drive the system toward equilibrium.

\subsection{Mechanisms and Assumptions}

An ion exchange equilibrium column model was developed to describe the fate of ions within a fixed bed ion exchanger in the absence of mass transfer resistance. The model is based upon mass balance equations for continuous flow stirred tank reactors (CFSTRs) placed in-series. This equilibrium model is

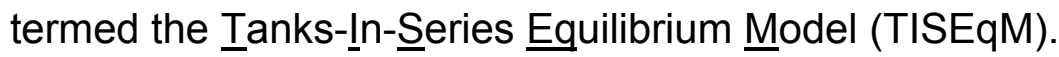

The TISEqM incorporates the following mechanisms and assumptions:

- The fluid is transported through the bed by advective plug flow (axial and radial dispersions are neglected)

- Mass balance equations are derived for continuous flow stirred tank reactors (CFSTRs) placed in-series

- The number of equally sized CFSTRs in series is chosen such that it will simulate plug flow conditions within a fixed bed ion exchanger (to meet this criteria, the number of CFSTRs in series is set equal to 25 within MFBMODEL for all types of resins)

- A Langmuir equilibrium relationship incorporating constant separation factors (for SAC and SBA exchange resins) or Langmuir exchange rate 
constants (for WBA exchange resins) describes the multicomponent ion exchange equilibrium between the liquid- and solid-phases

- The expressions to account for electroneutrality condition, water formation reaction, and degree of ionization, as described in section 2.5, are incorporated into the model.

- Mass transfer effects are neglected.

- Electrical potential effects are neglected.

\subsection{Model Equations}

\subsubsection{SAC and SBA Exchange Resins}

A complete derivation of the TISEqM as applied to SAC and SBA exchange resins is presented in Appendix III. The resultant dimensionless equations are given as:

\section{$\underline{\text { Tank } 1}$}

\section{Cations (SAC Exchange Resin):}

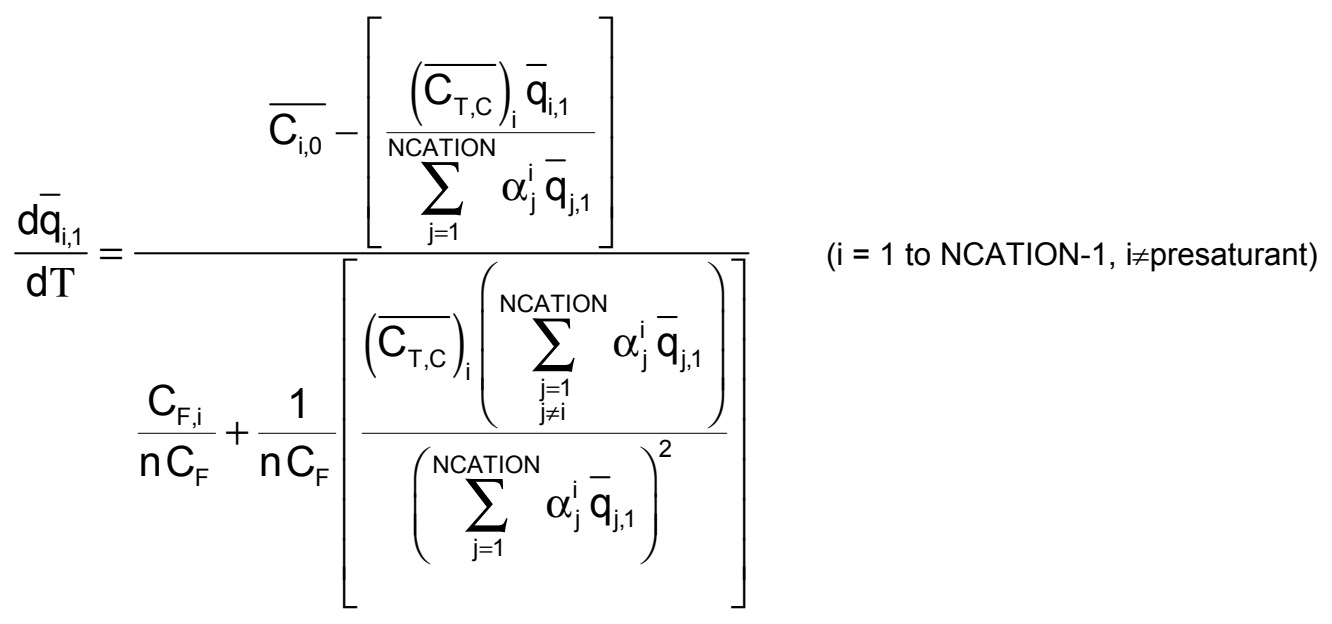


Anions (SBA Exchange Resin):

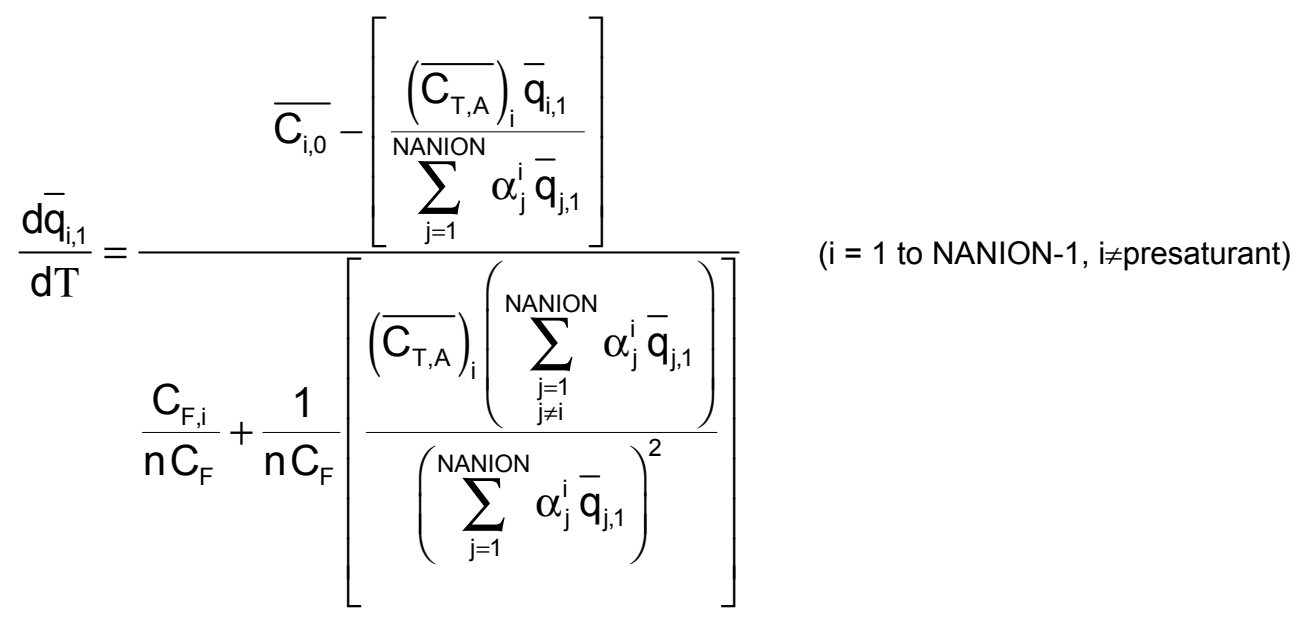

Tanks $2-n(m=$ Number of the tank (2 through $n))$

Cations (SAC Exchange Resin):

$\frac{d \bar{q}_{i, m}}{d T}=\frac{\left[\frac{\left(\overline{C_{T, C}}\right)_{i} \bar{q}_{i, m-1}}{\sum_{j=1}^{N C A T I O N} \alpha_{j}^{i} \bar{q}_{j, m-1}}\right]-\left[\frac{\left(\overline{C_{T, C}}\right)_{i} \bar{q}_{i, m}}{\sum_{j=1}^{N C A T I O N} \alpha_{j}^{i} \bar{q}_{j, m}}\right]}{\frac{C_{F, i}}{n C_{F}}+\frac{1}{n C_{F}}\left[\frac{\left(\overline{C_{T, C}}\right)_{i}\left(\sum_{\substack{j=1 \\ j \neq i}}^{N C A T I O N} \alpha_{j}^{i} \bar{q}_{j, m}\right)}{\left(\sum_{j=1}^{N C A T I O N} \alpha_{j}^{i} \bar{q}_{j, m}\right)^{2}}\right]}$ 


$$
\begin{aligned}
& \text { Anions (SBA Exchange Resin): } \\
& \frac{d \bar{q}_{i, m}}{d T}=\frac{\left[\frac{\left(\overline{C_{T, A}}\right)_{i} \bar{q}_{i, m-1}}{\left.\sum_{j=1}^{\text {NANION }} \alpha_{j}^{i} \bar{q}_{j, m-1}\right]}\left[\frac{\left({\overline{C_{T, A}}}_{i} \bar{q}_{i, m}\right.}{\sum_{j=1}^{\text {NANION }} \alpha_{j}^{i} \bar{q}_{j, m}}\right]\right.}{\frac{C_{F, i}}{n C_{F}}+\frac{1}{n C_{F}}\left[\overline{\left(\bar{C}_{T, A}\right.}\right)_{i}\left(\sum_{\substack{j=1 \\
j \neq i}}^{\text {NANION }} \alpha_{j}^{i} \bar{q}_{j, m}\right)} \\
& \text { (i=1 to NANION-1, } i \neq \text { presaturant) }
\end{aligned}
$$

Once the dimensionless resin phase concentrations of all ions except the presaturant are known from tank $k(k=1-n)$, it is possible to calculate the dimensionless resin phase concentration of the presaturant from tank $k$ as:

$$
\begin{aligned}
& \overline{\mathrm{q}}_{\text {presaturant }, \mathrm{C}, \mathrm{k}}=1-\sum_{\substack{j=1 \\
j \neq \text { presaturant,C }}}^{\text {NCATION-1 }} \overline{\mathrm{q}}_{\mathrm{j}, \mathrm{k}} \\
& \overline{\mathrm{q}}_{\text {presaturant } \mathrm{A}, \mathrm{k}}=1-\sum_{j \neq \text { presaturant,A }}^{\mathrm{j}=1} \overline{\mathrm{q}}_{\mathrm{j}, \mathrm{k}}
\end{aligned}
$$

Note that Equation 3-9 is substituted into Equations 3-5 and 3-7 whenever the term $\overline{\mathrm{q}}_{\text {presaturant,c }}$ is called for in those equations (in the summations from $\mathrm{j}=1$ to NCATION). Note also that Equation 3-10 is substituted into Equations 3-6 and 3-8 whenever the term $\bar{q}_{\text {presaturant,A }}$ is called for in those equations (in the summations from $\mathrm{j}=1$ to NANION). 
Once the dimensionless resin phase concentrations are known in each tank, it is possible to make use of the equilibrium expression and solve for the dimensionless liquid phase effluent concentration out of each tank:

$$
\begin{aligned}
& \overline{C_{i, k}}=\frac{\left(\overline{C_{T, C}}\right)_{i} \bar{q}_{i, k}}{\sum_{j=1}^{\text {NCATIN }} \alpha_{j}^{i} \bar{q}_{j, k}} \quad \text { (for } \mathrm{i}=1 \text { to NCATION-1, i } \neq \text { presaturant ion) } \\
& \overline{C_{i, k}}=\frac{\left(\overline{C_{T, A}}\right)_{i} \bar{q}_{i, k}}{\sum_{j=1}^{\text {NANION }} \alpha_{j}^{i} \bar{q}_{j, k}} \quad \text { (for } i=1 \text { to NANION-1, i } i \neq \text { presaturant ion) }
\end{aligned}
$$

For the presaturant ion, the dimensionless liquid phase effluent concentration out of tank $\mathrm{k}$ can be calculated as (for $\mathrm{k}=1$ to Number of Tanks):

$$
\begin{aligned}
& \overline{\mathrm{C}}_{\text {presaturant }, \mathrm{C}, \mathrm{k}}=\left(\overline{\mathrm{C}_{\mathrm{T}, \mathrm{C}}}\right)_{\text {presaturant }}-\sum_{\substack{\mathrm{j}=1 \\
j \neq \text { presaturant, } \mathrm{C}}}^{\mathrm{NCATION-1}}\left[\left(\overline{\mathrm{C}_{\mathrm{j}, \mathrm{k}}}\right) \times\left(\frac{\mathrm{C}_{\mathrm{F}, \text { presaturant }}}{\mathrm{C}_{\mathrm{F}, \mathrm{j}}}\right)\right] \\
& \overline{\mathrm{C}}_{\text {presaturant, } \mathrm{A}, \mathrm{k}}=\left(\overline{\mathrm{C}_{\mathrm{T}, \mathrm{A}}}\right)_{\text {presaturant }}-\sum_{\substack{\mathrm{j}=1 \\
j \neq \text { presaturant, } \mathrm{A}}}^{\mathrm{NANION-1}}\left[\left(\overline{\mathrm{C}_{\mathrm{j}, \mathrm{k}}}\right) \times\left(\frac{\mathrm{C}_{\mathrm{F}, \text { presaturant }}}{\mathrm{C}_{\mathrm{F}, \mathrm{j}}}\right)\right]
\end{aligned}
$$

The parameters required for TISEqM calculations are: the total resin capacity, the influent aqueous phase ion concentrations to the first tank, the separation factors of the ions, the number of tanks in series, and the capacity factor for each ion.

For a SAC exchange resin, Equations 3-5, 3-7, 3-9, 3-11, and 3-13 make up the set of ordinary differential equations (ODEs) solved. For SBA exchange resin, Equations 3-6, 3-8, 3-10, 3-12, and 3-14 make up the set of ODEs solved. The set of pertinent ODEs is solved using the backward differentiation method formula (up to order five), also called Gear's stiff method (Gear, 1971). The 
equilibrium chemistry expressions shown in section 2.5 for electroneutrality, water formation reaction, and degree of ionization are applied at each time step after the ODEs are solved. The equilibrium chemistry equations are not solved simultaneously with the TISEqM ODEs.

\subsubsection{Mixed Bed Ion Exchange Resins}

A mixed bed ion exchange resin consists of a mixture of a strong acid cation (SAC) exchange resin and a strong base anion (SBA) exchange resin. The TISEqM derived above for SAC and SBA resins can be applied to predict the performance of a mixed bed ion exchange resin. In order to apply the TISEqM for a mixed bed resin, the physical properties of the mixed bed resin must be adjusted such that the mixed bed resin is broken down into its component SAC and SBA portions. An explanation of the algorithm used to adjust the mixed bed ion exchange bed resin's physical properties in this manner is shown below. The physical properties of IRN-77 SAC, IRN-78 SBA, and !RN-150 mixed bed ion exchange resins, as shown in Table 2-1, are used in this calculation.

The mixed bed consists of a SAC exchange resin, a SBA exchange resin, and void space. In order to apply the TISEqM to this situation, the mixed bed must be treated as an SAC exchange resin for the cations and an SBA exchange resin to describe the anions. In order to accomplish this for the cations, the volume of mixed bed resin (volume of SAC exchange resin plus volume of SBA exchange resin in the mixed bed) is treated as occupied by only SAC exchange resin. The empty bed volume is held constant and the volume of resin is treated as completely a SAC exchange resin. The number of equivalents of cations that 
can be removed by the mixed bed ion exchange resin is calculated and held constant as this algorithm is applied in the TISEqM for SAC resins. The mass of cationic exchange resin and the total resin capacity for cationic exchange resin are adjusted such that the number of equivalents removed by the SAC exchange resin portion of the mixed bed $\left(m_{C} \times q_{T, C}\right)$ is equal to the number of equivalents removed by the mixed bed treated as completely occupied by SAC exchange resin $\left(\left[\mathrm{m}_{\mathrm{C}}\right]_{\text {adjusted }} \times\left[\mathrm{q}_{\mathrm{T}, \mathrm{C}}\right]_{\mathrm{adjusted}}\right)$. The fundamental equation for this adjustment is as follows for the SAC portion of the mixed bed resin:

$$
\mathrm{m}_{\mathrm{C}} \times \mathrm{q}_{\mathrm{T}, \mathrm{C}}=\left(\mathrm{m}_{\mathrm{C}}\right)_{\text {adjusted }} \times\left(\mathrm{q}_{\mathrm{T}, \mathrm{C}}\right)_{\text {adjusted }}
$$

In order to apply this algorithm, the following relationships are used. The volume of the mixed bed resin is calculated as follows:

$$
V_{r, \text { mixed }}=\frac{m_{\text {mixed }}}{\rho_{a, \text { mixed }}}
$$

The volume of cationic exchange resin within the mixed bed is calculated:

$$
V_{C}=\left(\frac{V_{C}}{V_{r, \text { mixed }}}\right) \times V_{r, \text { mixed }}
$$

in which $V_{c} / V_{r, \text { mixed }}$ equals the fraction of the mixed bed occupied by the cationic exchange resin, equal to 0.40 for IRN-150 mixed bed ion exchange resin. The mass of cationic exchange resin within the mixed bed resin is calculated:

$$
m_{C}=V_{C} \times \rho_{A, C}
$$

The total resin capacity for $S A C$ exchange resin, $q_{T, C}$, required in Equation 3-15 is known as reported in Table 2-12. In order to adjust the mixed bed such that 
there are only cations in the bed, assume that the mixed bed is occupied completely by cations:

$$
\begin{gathered}
\left(\frac{\mathrm{V}_{\mathrm{C}}}{\mathrm{V}_{\mathrm{r}, \text { mixed }}}\right)_{\text {adjusted }}=1 \\
\left(\mathrm{~V}_{\mathrm{C}}\right)_{\text {adjusted }}=\left(\frac{\mathrm{V}_{\mathrm{C}}}{\mathrm{V}_{\mathrm{r}, \text { mixed }}}\right)_{\text {adjusted }} \times \mathrm{V}_{\mathrm{r}, \text { mixed }} \\
\left(\mathrm{m}_{\mathrm{C}}\right)_{\text {adjusted }}=\left(\mathrm{V}_{\mathrm{C}}\right)_{\text {adjusted }} \times \rho_{\mathrm{A}, \mathrm{C}}
\end{gathered}
$$

In order that the relationship in Equation 3-15 holds true, the value of $\left(q_{T, C}\right)_{\text {adjusted }}$ is determined as follows:

$$
\left(\mathrm{q}_{\mathrm{T}, \mathrm{C}}\right)_{\text {adjusted }}=\frac{\mathrm{m}_{\mathrm{C}} \times \mathrm{q}_{\mathrm{T}, \mathrm{C}}}{\left(\mathrm{m}_{\mathrm{C}}\right)_{\text {adjusted }}}
$$

TISEqM is then executed for SAC exchange resin using the values of $\left(m_{C}\right)_{\text {adjusted }}$ and $\left(\mathrm{q}_{\mathrm{T}, \mathrm{C}}\right)_{\text {adjusted }}$ for the mass of resin and total resin capacity, respectively. Values of $\left(\mathrm{m}_{\mathrm{A}}\right)_{\text {adjusted }}$ and $\left(\mathrm{q}_{\mathrm{T}, \mathrm{A}}\right)_{\text {adjusted }}$ for the SBA exchange resin are determined in an analogous fashion. For complete details on the algorithm for determining SAC and SBA resin properties within a mixed bed ion exchange resin, see Appendix V.

The TISEqM is then run for both SAC and SBA resins simultaneously but not coupled. The equilibrium chemistry expressions for electroneutrality, water formation reaction and degree of ionization are applied in the same manner as for SAC and SBA exchange resins (see section 3.2.1). 


\subsubsection{WBA Exchange Resins}

A complete derivation of the TISEqM as applied to WBA exchange resins is presented in Appendix VI. The resultant dimensionless equations are given as (for $\mathrm{i}=1$ to NANION-1, $i \neq$ presaturant):

\section{$\underline{\text { Tank } 1}$}

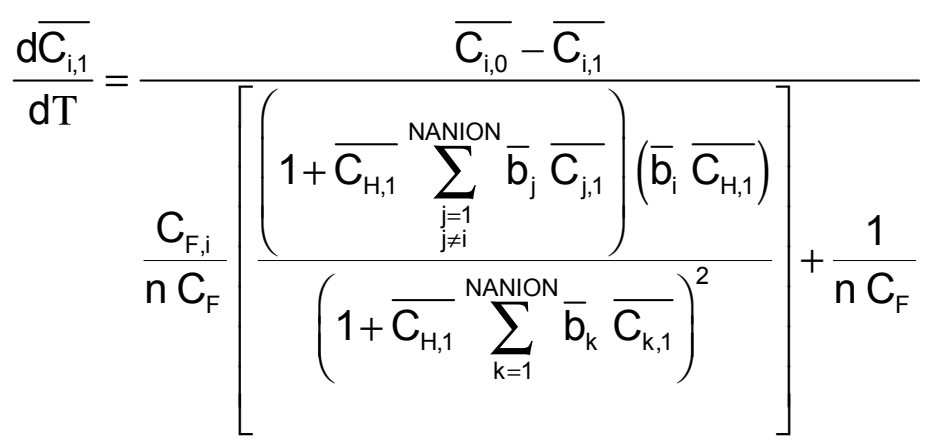

Tanks $2-n(m=$ Number of the tank (2 through $n))$

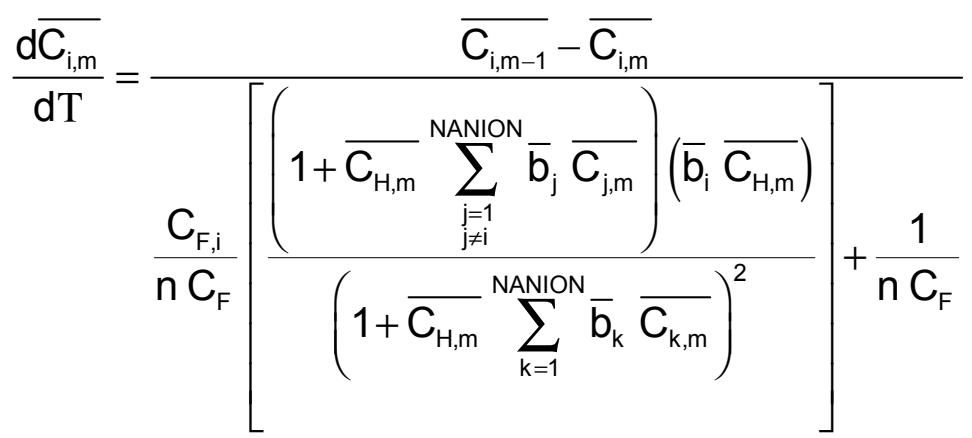

Once the dimensionless liquid phase concentrations are known in each tank, it is possible to make use of the equilibrium expression and solve for the dimensionless resin phase effluent concentration out of each tank:

$$
\overline{\mathrm{q}}_{\mathrm{i}, \mathrm{m}}=\frac{\overline{\mathrm{b}}_{\mathrm{i}} \overline{\mathrm{C}}_{\mathrm{H}, \mathrm{m}} \overline{\mathrm{C}}_{\mathrm{i}, \mathrm{m}}}{1+\overline{\mathrm{C}}_{\mathrm{H}, \mathrm{m}} \sum_{\mathrm{k}=1}^{\text {NANION }} \overline{\mathrm{b}}_{\mathrm{k}} \overline{\mathrm{C}}_{\mathrm{k}, \mathrm{m}}}
$$

The parameters required for TISEqM calculations are: the total resin phase capacity, $q_{T}$, the influent aqueous phase ion concentrations to the first 
tank, $\mathrm{C}_{\mathrm{i}, \mathrm{o}}$ `s, the Langmuir equilibrium exchange rate constants of the ions, $b_{i}{ }^{\prime} s$, the number of tanks in series, and the capacity factor for each ion, $\mathrm{C}_{\mathrm{F}, \mathrm{i}}$.

The set of ordinary differential equations (ODEs) is solved using the backward differentiation method formula (up to order five), also called Gear's stiff method (Gear, 1971). The equilibrium chemistry expressions shown in section 2.5 for electroneutrality, water formation reaction, and degree of ionization are applied at each time step after the ODEs are solved. The equilibrium chemistry equations are not solved simultaneously with the TISEqM ODEs.

\section{Results and Discussion}

Figure 3-2 shows a schematic of the multifiltration bed used in the multifiltration bed verification experiment. The MF bed for this experiment is designed to represent the actual MF bed sizing shown in Figure 3-1 in order to verify the MFBMODEL. The empty bed contact time (EBCT) for each ion exchange and adsorbent bed used in the MFBMODEL verification experiment is shown in Figure 3-2. Note that the EBCTs for the ion exchangers and adsorbents used in the full-scale experiment vary slightly from the EBCTs for the ion exchange beds and adsorbents within the MF bed of the ISS water processor shown in Figure 3-1. 


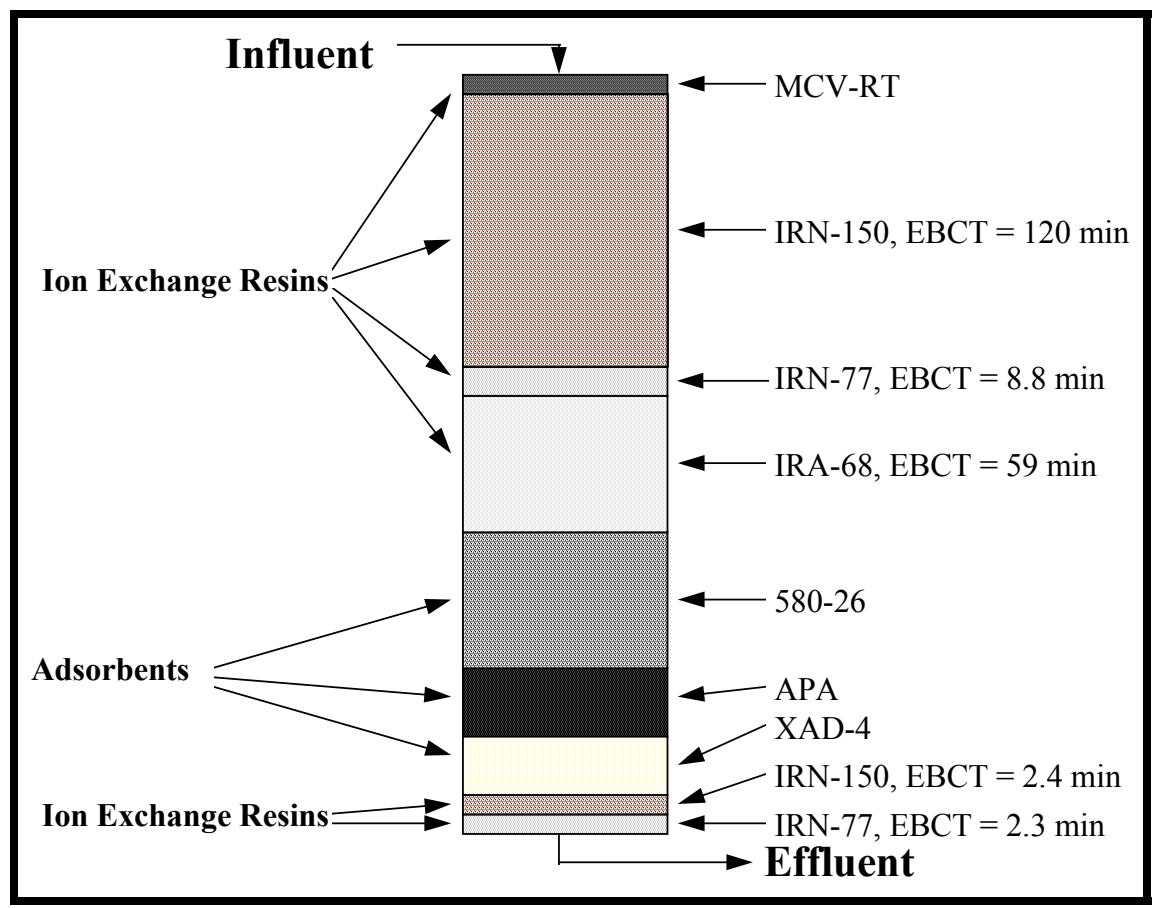

Figure 3-2 - Schematic of the Multifiltration Bed Employed in the Multifiltration Bed Verification Experiment

The first three ion exchange beds in the MFBMODEL verification experiment were simulated in a single MFBMODEL run, consisting of three ion exchange beds in series. The three ion exchange beds included in the simulation were a mixed bed ion exchange resin (Rohm and Haas IRN-150), a strong acid cation (SAC) exchange resin (Rohm and Haas IRN-77) and a weak base anion (WBA) exchange resin (Rohm and Haas IRA-68). This MFBMODEL simulation was performed for eleven ions in the ersatz shower and handwash wastewater:

Cations: Sodium, Potassium, Calcium, Hydrogen

Anions: Acetate, Butyrate, Chloride, Bicarbonate, Sulfate, CMT, Hydroxide A complete set of ion exchange MFBMODEL results for all resins and all ions in various sets of units is presented in Appendix IX. 


\subsection{Mixed Bed Ion Exchange Resin: Rohm \& Haas IRN-150}

Table 3-3 shows the properties of the first mixed bed ion exchange column in the multifiltration bed verification experiment.

Table 3-3 - Properties of Mixed Bed Resin Column Used in MFBMODEL Verification Experiment

\begin{tabular}{l|c}
\hline Property & Value \\
\hline Mass of Resin, g (lb) & $4522(9.969)$ \\
\hline Diameter of Bed, cm (in.) & $5.1(2.01)$ \\
\hline Length of Bed, cm (in.) & $279.75(110.1)$ \\
\hline Flowrate, $\mathrm{mL} / \mathrm{min}(\mathrm{lb} / \mathrm{hr})$ & $47.88(6.33)$ \\
\hline Number of lons Simulated & $11(4$ cations, 7 anions) \\
\hline EBCT, min & 120 \\
\hline
\end{tabular}

Figures 3-3 through 3-5 show the MFBMODEL predictions for cations sodium, potassium, and hydrogen, respectively, exchanging the first IRN-150 mixed bed ion exchange resin employed in the multifiltration bed verification experiment. Breakthrough was not achieved for the calcium ion data before sampling was stopped so the calcium prediction is not presented (see Appendix IX for complete MFBMODEL ion exchange results for the MFB verification experiment). From Figure 3-3, it appears that the TISEqM predicts the sodium data very well. From Figure 3-4, the potassium data is not predicted as well. Because the separation factor for potassium compares favorably to the literature value (see Chapter 2) and because the potassium data is described reasonably by the tanks-in-series equilibrium model for a multicomponent experiment discussed in Chapter 4, it is suggested that there may be error in the 
experimental data for potassium. Another possible explanation is that the simulation of the IRN-150 mixed bed ion exchange resin performance is sensitive to the fraction of the mixed bed occupied by the cationic (design value of $V_{c} / V_{r}$ equal to 0.4 ) exchange resin as well as the fraction of the mixed bed occupied by the anionic exchange resin (design value of $V_{a} / V_{r}$ equal to 0.6 ). When the IRN150 mixed bed ion exchange resin was prepared experimentally, it is possible that the exact design parameters were not obtained. Figure 3-6 shows the effect of varying the fraction of the mixed bed occupied by the SAC and SBA exchange resins on the exchange of potassium. From Figure 3-6, it is clear that the model is sensitive to changes in the fraction of the mixed bed occupied by the SAC and SBA exchange resins and that the potassium data appears to be better described by $V_{c} / V_{r}=0.5$ and $V_{a} / V_{r}=0.5$ than by the design values. Figure 3-5 shows the $\mathrm{pH}$ as a function of bed volumes treated and demonstrates that the MFBMODEL is capable of describing the general trend in $\mathrm{pH}$.

Figure 3-7 shows the MFBMODEL prediction for chloride anion exchanging the first IRN-150 mixed bed ion exchange resin employed in the multifiltration bed verification experiment. From Figure 3-7, it appears that the MFBMODEL prediction for sodium is reasonable. Figure 3-8 shows the MFBMODEL prediction for acetate. It appears from Figure 3-8 that the MFBMODEL predicted breakthrough for acetate occurs subsequent to the acetate breakthrough observed in the data. A possible reason is that the acetate ion is subject to ionization effect as a change in $\mathrm{pH}$ will affect the amount of acetate ion present as compared to the acid form. From Figure 3-5, in order for 


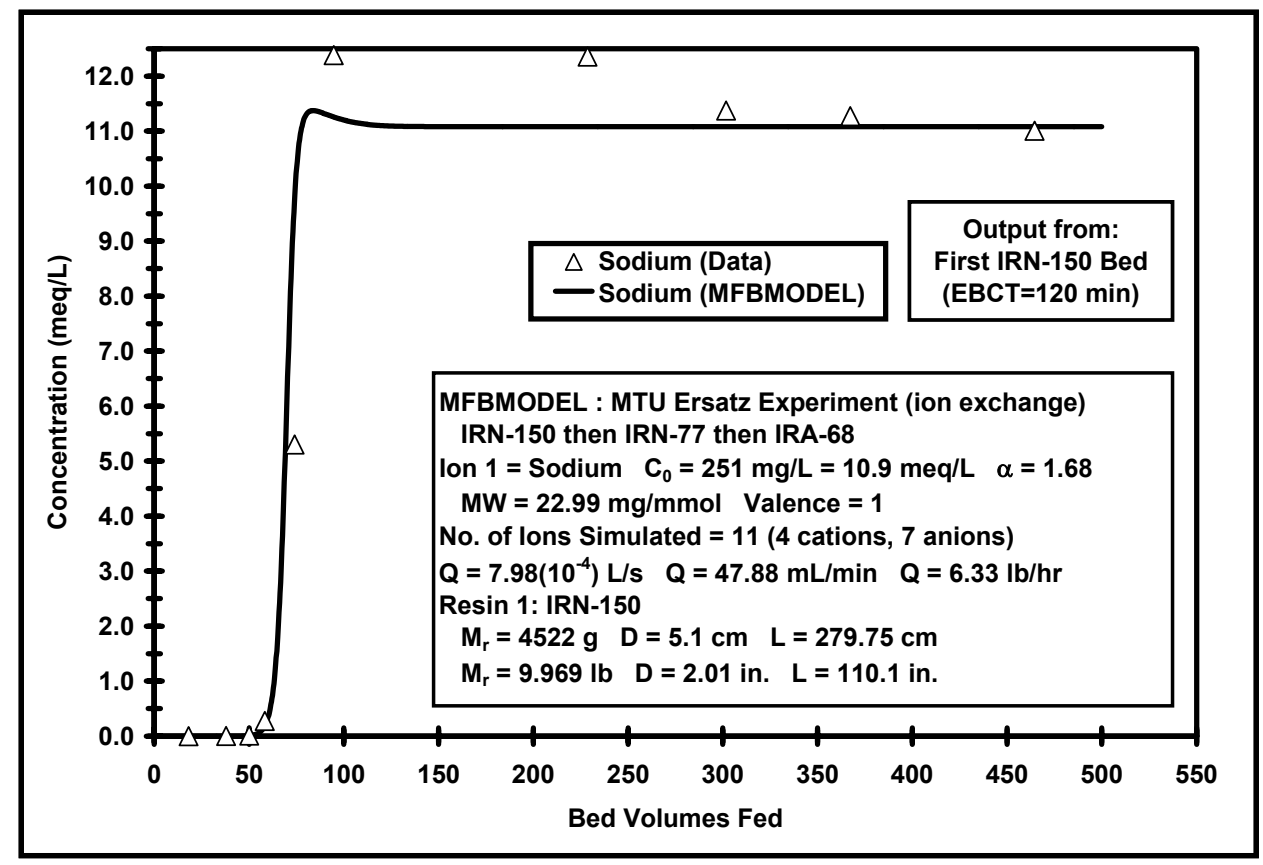

Figure 3-3 - Multicomponent MFBMODEL Verification Experiment Results for Sodium Exchanging the First IRN-150 Mixed Bed Exchange Resin $($ EBCT=120 $\mathrm{min}$ )

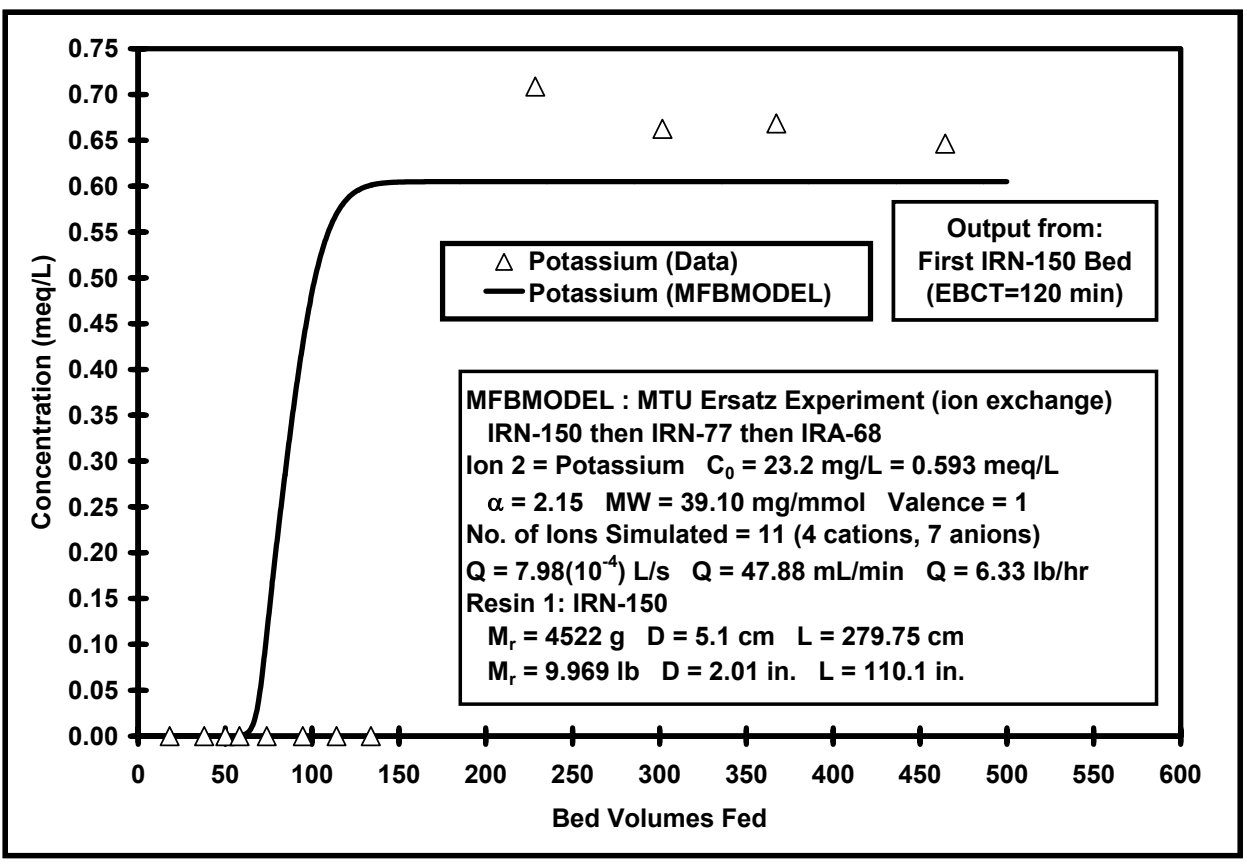

Figure 3-4 - Multicomponent MFBMODEL Verification Experiment Results for Potassium Exchanging the First IRN-150 Mixed Bed Exchange Resin $(\mathrm{EBCT}=120 \mathrm{~min})$ 


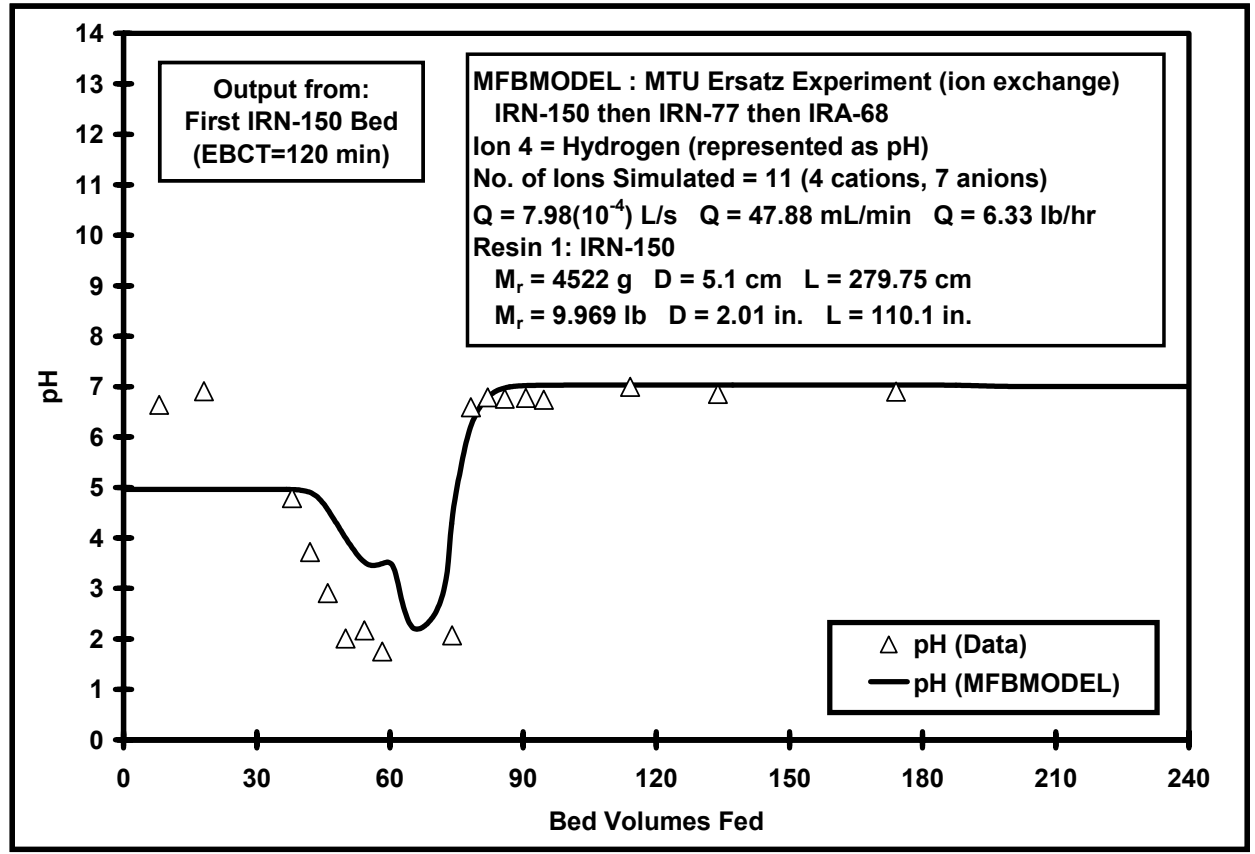

Figure 3-5 - Multicomponent MFBMODEL Verification Experiment Results for Presaturant lon Hydrogen (expressed as pH) for the First IRN-150 Mixed Bed Exchange Resin (EBCT=120 min)

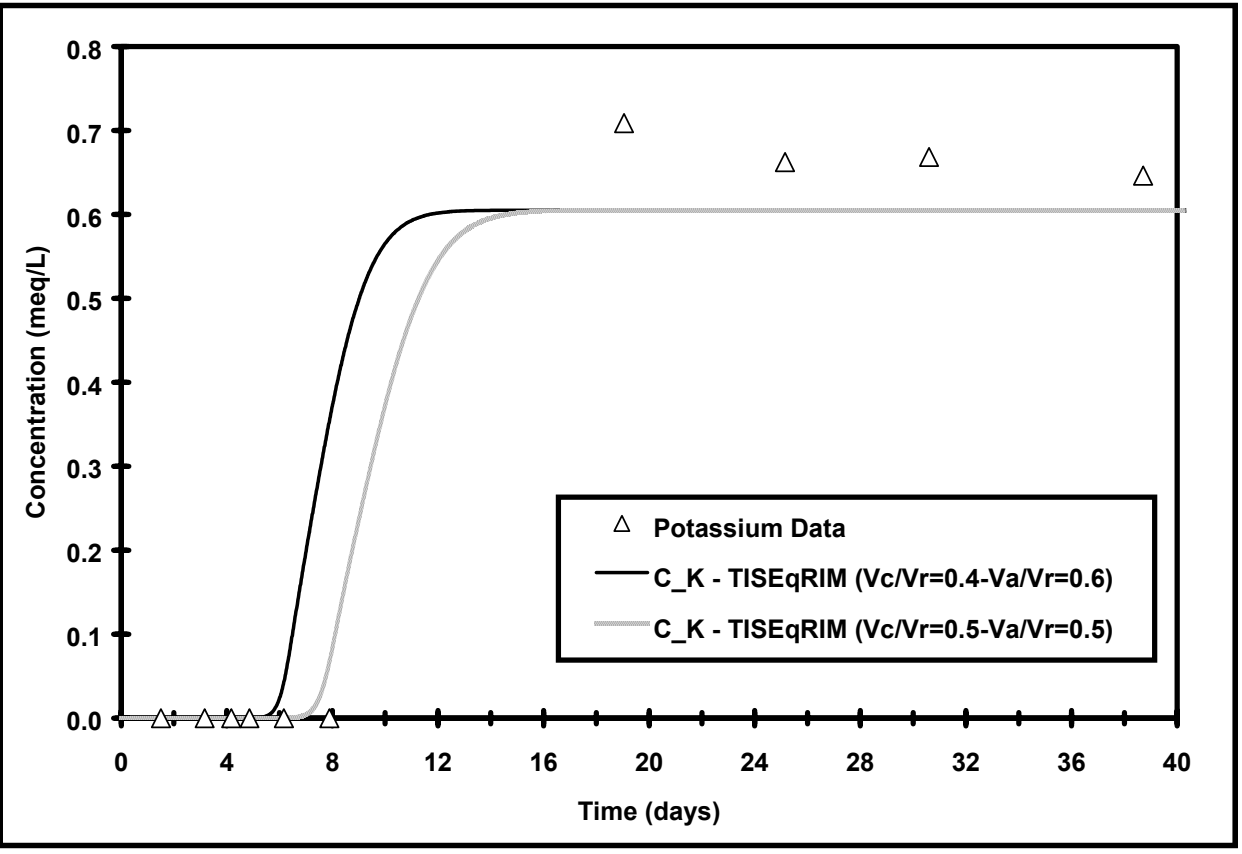

Figure 3-6 - Multicomponent MFBMODEL Verification Experiment Results for Sensitivity Analysis on $V_{c} / V_{r}$ and $V_{a} / V_{r}$ for Potassium for the First IRN150 Mixed Bed Exchange Resin (EBCT=120 min) 


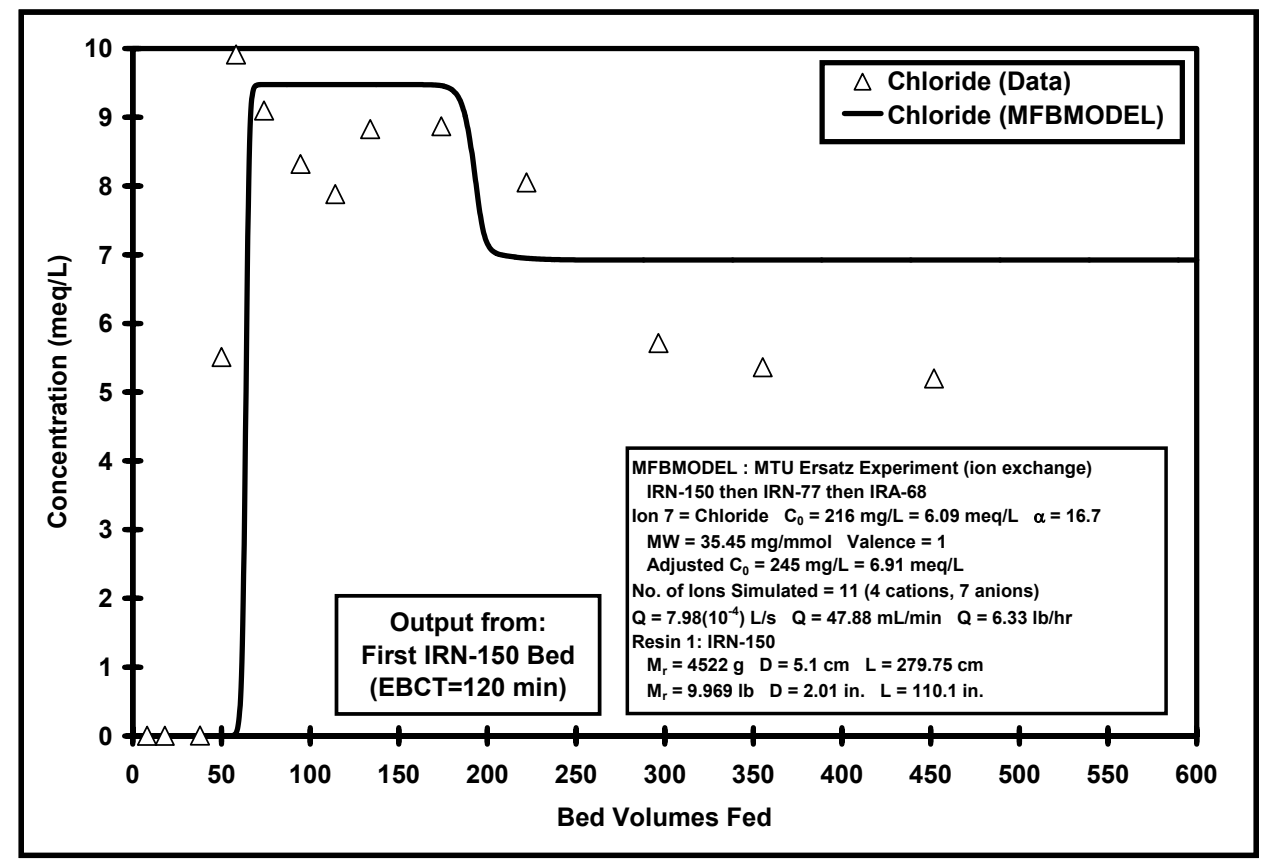

Figure 3-7 - Multicomponent MFBMODEL Verification Experiment Results for Chloride Exchanging the First IRN-150 Mixed Bed Exchange Resin (EBCT=120 $\mathrm{min}$ )

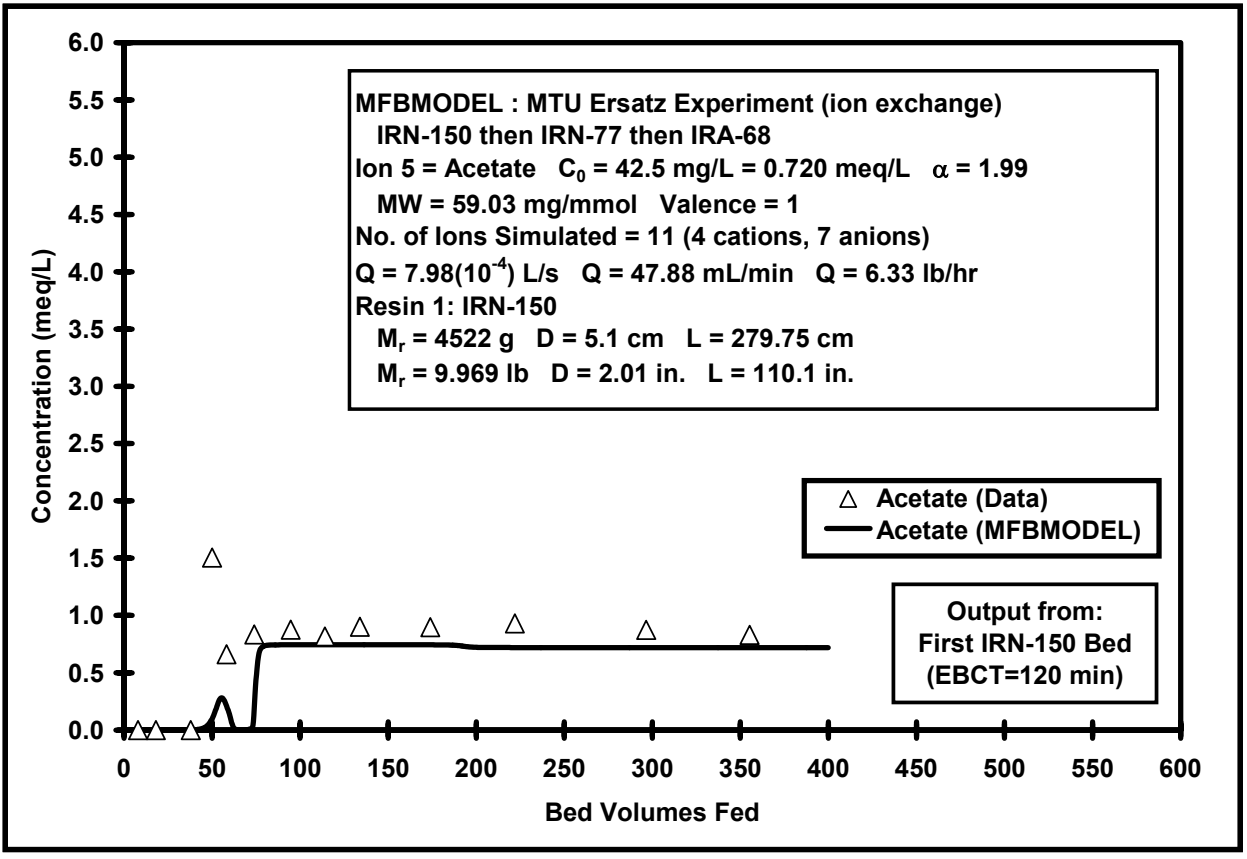

Figure 3-8 - Multicomponent MFBMODEL Verification Experiment Results for Acetate Exchanging the First IRN-150 Mixed Bed Exchange Resin $(\mathrm{EBCT}=120 \mathrm{~min})$ 
the charge balance, water formation reaction, and degree of ionization effects to be handled in the early part of the breakthrough, the MFBMODEL predicts a $\mathrm{pH}$ around 5 in the early part of the breakthrough profile. This $\mathrm{pH}$ is not observed in the data. At a $\mathrm{pH}$ of 5 , less acetate ion is present $\left(\mathrm{pK}_{\mathrm{a}}=4.75\right)$ than at higher $\mathrm{pH}$, which could explain the later breakthrough of acetate ion predicted by the model. Another possible explanation is sensitivity to $V_{c} / V_{r}$ and $V_{a} / V_{r}$ as discussed above.

Figure 3-9 shows the effect of varying the fraction of the mixed bed occupied by the SAC and SBA exchange resins on the exchange of acetate ion. From Figure 3-9, it is clear that the model is sensitive to changes in the fraction of the mixed bed occupied by the SAC and SBA exchange resins and that the acetate data appears to be better described by $V_{c} / V_{r}=0.36$ and $V_{a} / V_{r}=0.64$ than by the design values. It should be observed that the improved fractions, $V_{c} / V_{r}$ and $V_{a} / V_{r}$, for acetate are not the same as the improved fractions for potassium, suggesting that sensitivity to $V_{c} / V_{r}$ and $V_{a} / V_{r}$ may not be the critical issue in the potassium and acetate predictions. The butyrate results are similar to acetate and are not presented here. 


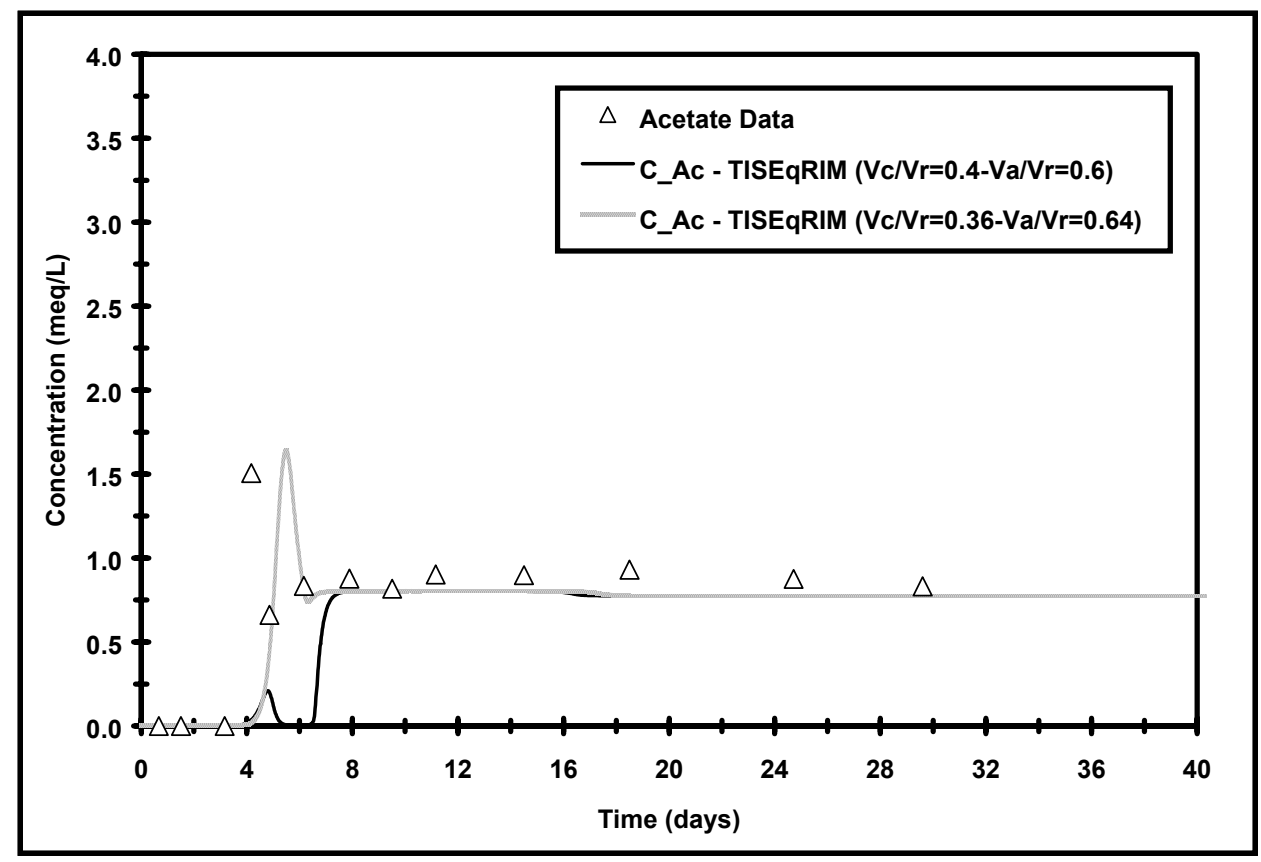

Figure 3-9 - Multicomponent MFBMODEL Verification Experiment Results for Sensitivity Analysis on $V_{c} / V_{r}$ and $V_{a} / V_{r}$ for Acetate for the First IRN-150 Mixed Bed Exchange Resin (EBCT=120 min)

Figures 3-10 through 3-12 show the MFBMODEL predictions for anions bicarbonate, sulfate, and CMT, respectively, exchanging the first IRN-150 mixed bed ion exchange resin employed in the multifiltration bed verification experiment. From Figure 3-10, it appears that the initial breakthrough time for bicarbonate is reasonably predicted. Figure 3-11 shows that the breakthrough of sulfate is predicted by the MFBMODEL prior to the breakthrough time observed in the data. One possible explanation is that the sulfate, which is the secondstrongest exchanging ion (second highest separation factor), breaks through when breakthrough in the strongest exchanging ion, CMT, is observed. While it is possible that the CMT breakthrough shown in Figure 3-12 is correct, it is also possible that the predicted breakthrough of CMT occurs too soon compared to the data. If the CMT predicted breakthrough time is premature, this would explain the early predicted breakthrough of sulfate because the strongest exchanging ion pushes off the next strongest exchanging ion when it breaks through. Difficulty is expected in predicting the CMT results because the CMT is 


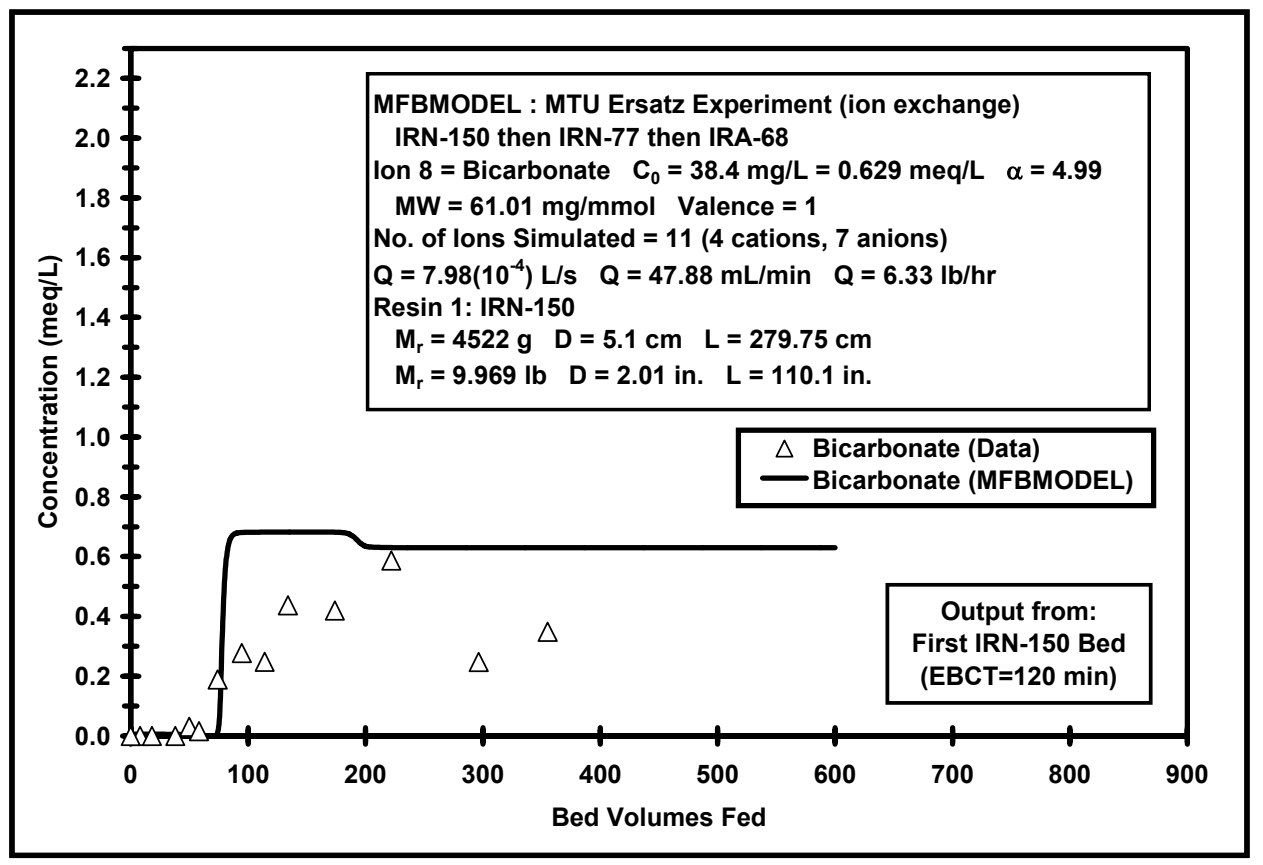

Figure 3-10 - Multicomponent MFBMODEL Verification Experiment Results for Bicarbonate Exchanging the First IRN-150 Mixed Bed Exchange Resin (EBCT=120 $\mathrm{min}$ )

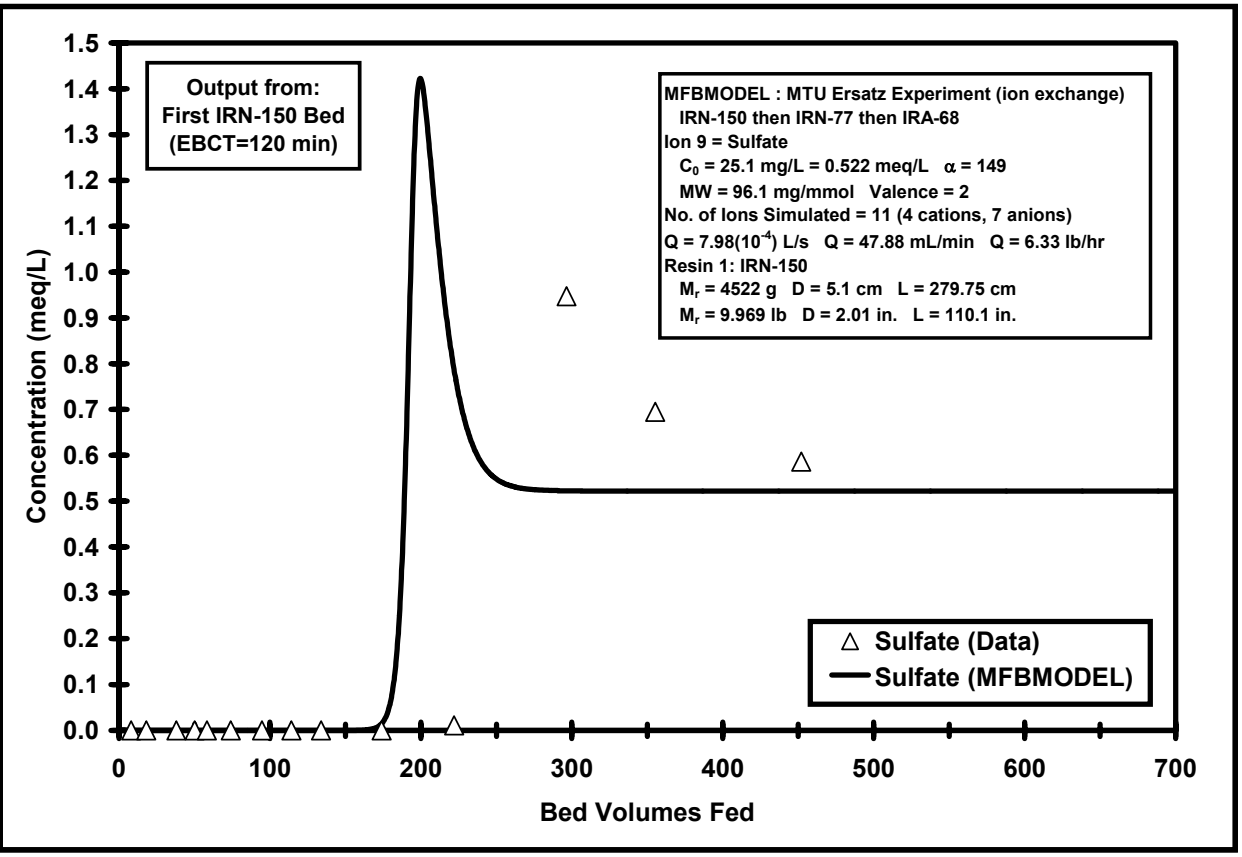

Figure 3-11 - Multicomponent MFBMODEL Verification Experiment Results for Sulfate Exchanging the First IRN-150 Mixed Bed Exchange Resin (EBCT=120 min) 


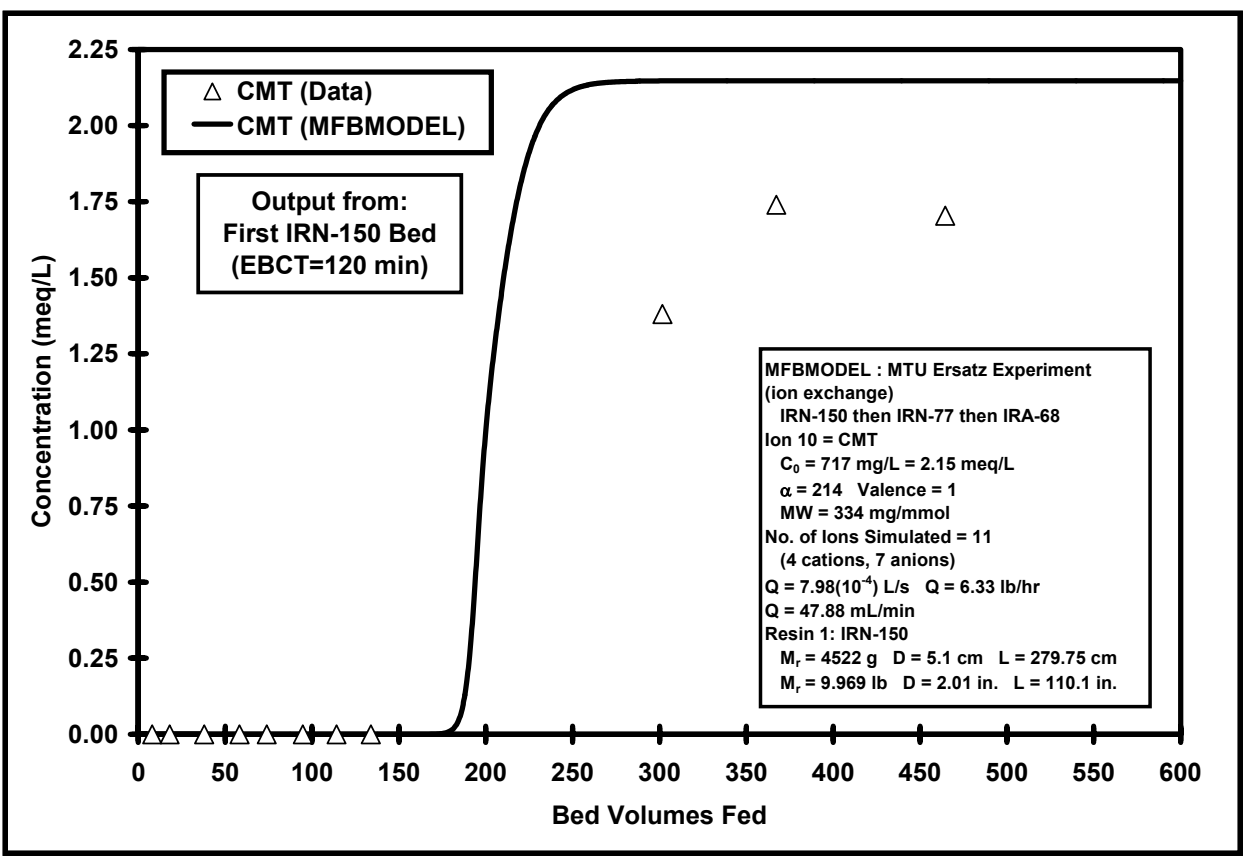

\section{Figure 3-12 - Multicomponent MFBMODEL Verification Experiment Results for CMT Exchanging the First IRN-150 Mixed Bed Exchange Resin (EBCT=120 $\mathrm{min}$ )}

a soap whose surfactant properties make description of its ionic/organic forms more difficult. If less CMT ion were present in the mixed bed than assumed, the breakthrough time for CMT would be later than predicted by the model, possibly explaining the early breakthrough of sulfate ion.

\subsection{Strong Acid Cation (SAC) Exchange Resin: Rohm \& Haas IRN-77}

Table 3-4 shows the properties of the first strong acid cation (SAC) exchange column in the multifiltration bed verification experiment.

Figures 3-13 through 3-15 show the MFBMODEL predictions for cations sodium, potassium, and hydrogen, respectively, exchanging the first IRN-77 SAC exchange resin employed in the multifiltration bed verification experiment. Figure 3-13 shows that the MFBMODEL does a good job predicting the exchange of 
Table 3-4 - Properties of First Strong Acid Cation Exchange Resin Column Used in MFBMODEL Verification Experiment

\begin{tabular}{l|c}
\hline Property & Value \\
\hline Mass of Resin, g (lb) & $374.6(0.826)$ \\
\hline Diameter of Bed, cm (in.) & $4.93(1.94)$ \\
\hline Length of Bed, cm (in.) & $22.1(8.7)$ \\
\hline Flowrate, $\mathrm{mL} / \mathrm{min}(\mathrm{lb} / \mathrm{hr})$ & $47.88(6.33)$ \\
\hline Number of lons Simulated & $11(4$ cations, 7 anions) \\
\hline EBCT, min & 8.8 \\
\hline
\end{tabular}

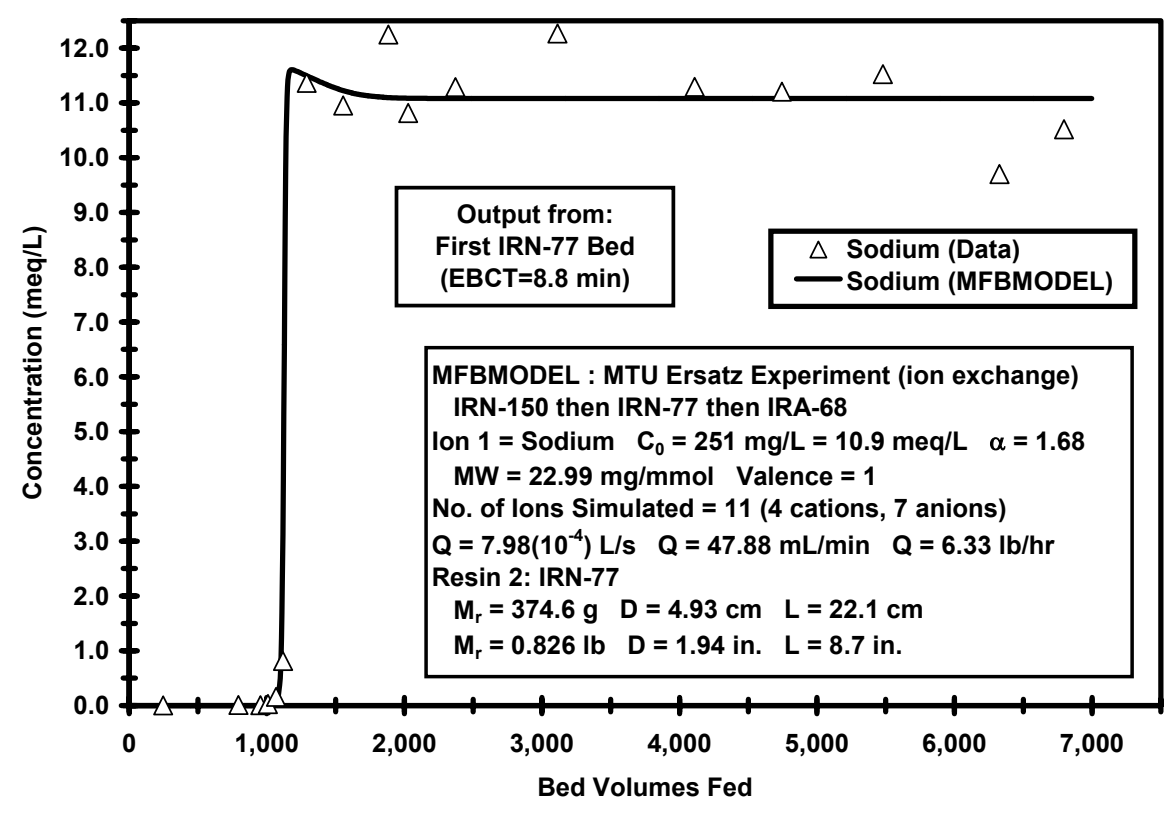

Figure 3-13 - Multicomponent MFBMODEL Verification Experiment Results for Sodium Exchanging the First IRN-77 SAC Exchange Resin (EBCT=8.8 $\min$ ) 


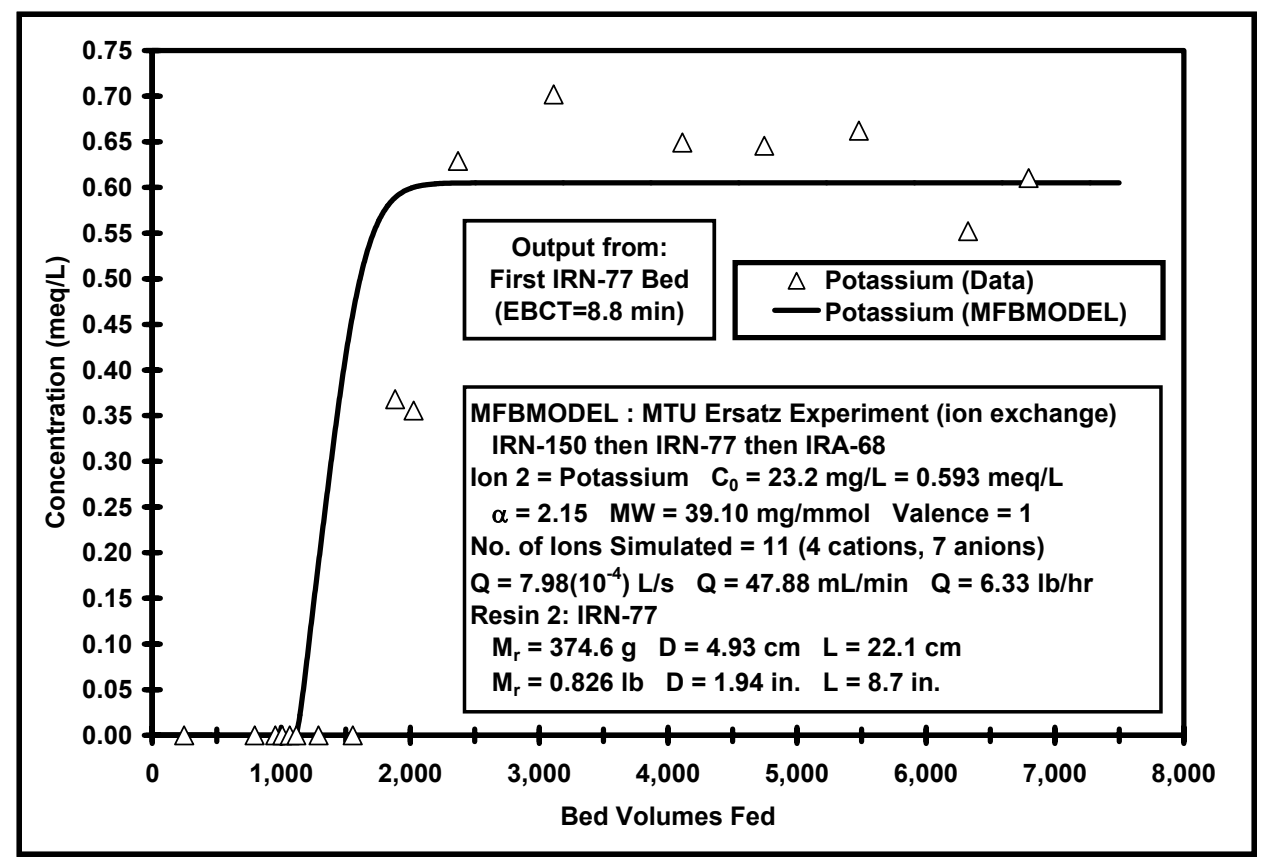

Figure 3-14 - Multicomponent MFBMODEL Verification Experiment Results for Potassium Exchanging the First IRN-77 SAC Exchange Resin (EBCT=8.8 $\min )$

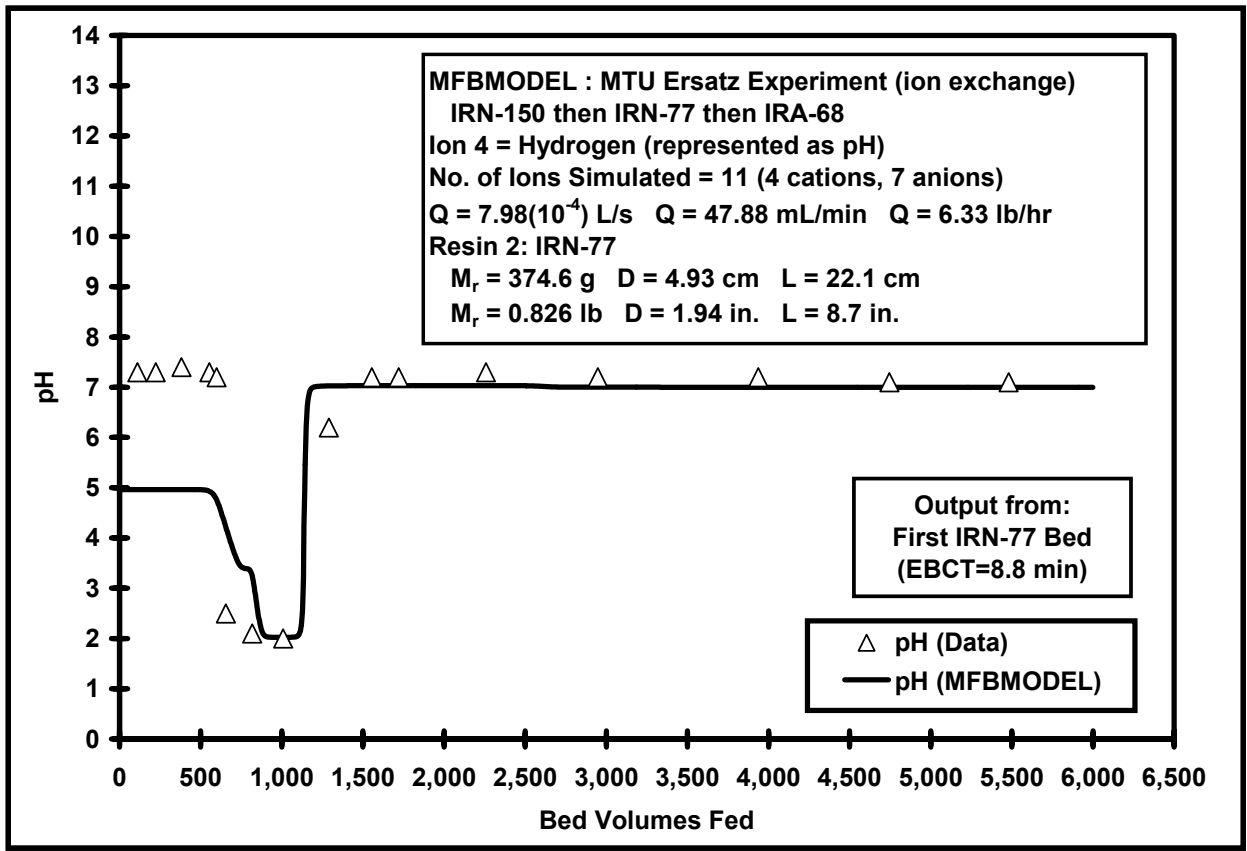

Figure 3-15 - Multicomponent MFBMODEL Verification Experiment Results for Presaturant lon Hydrogen (expressed as pH) for the First IRN-77 SAC Exchange Resin (EBCT=8.8 $\mathrm{min}$ ) 
sodium ion onto the IRN-77 SAC exchange resin. Figure 3-14 shows that the potassium breakthrough predicted by the model occurs earlier than is observed in the data. This is the same result as observed for the IRN-150 resin discussed above and could be an artifact of that result. Figure 3-15 shows that the model can predict the general trend in $\mathrm{pH}$ but that in the early part of the simulation, the model predicts a $\mathrm{pH}$ around 5 that is not observed in the data. The reason for the model prediction of $\mathrm{pH}$ around 5 is such that the water formation reaction, charge balance, and degree of ionization criteria can be met. When the exchange begins and hydrogen comes off the resin, the $\mathrm{pH}$ is low (hydrogen concentration is high) and less ionic form of organic acids (e.g,, acetate, butyrate) is predicted. To make the charge balance work out, the $\mathrm{pH}$ must rise such that the sum of the concentrations of all cations equals the sum of the concentrations of all anions.

\subsection{Weak Base Anion (WBA) Exchange Resin: Rohm \& Haas IRA-68}

Table 3-5 shows the properties of the weak base anion (WBA) exchange column in the multifiltration bed verification experiment.

Table 3-5 - Properties of Weak Base Anion Exchange Resin Column Used in MFBMODEL Verification Experiment

\begin{tabular}{l|c}
\hline Property & Value \\
\hline Mass of Resin, g (lb) & $2042.1(4.50)$ \\
\hline Diameter of Bed, cm (in.) & $5.16(2.03)$ \\
\hline Length of Bed, cm (in.) & $135.8(53.5)$ \\
\hline Flowrate, $\mathrm{mL} / \mathrm{min}(\mathrm{lb} / \mathrm{hr})$ & $47.88(6.33)$ \\
\hline Number of lons Simulated & $11(4$ cations, 7 anions) \\
\hline EBCT, min & 59 \\
\hline
\end{tabular}


Figures 3-16 through 3-21 show the MFBMODEL predictions for anions acetate, chloride, bicarbonate, sulfate, CMT, and hydroxide, respectively, exchanging the IRA-68 weak base anion (WBA) exchange resin employed in the multifiltration bed verification experiment. Figure $3-18$ shows that the acetate breakthrough predicted by the model occurs later than observed in the data, which could be an artifact of the late breakthrough predicted from the first IRN150 mixed bed as explained previously. The butyrate results are similar to acetate and therefore are not presented here. From Figures 3-17 and 3-18, it appears that the MFBMODEL predicts the breakthrough of chloride and bicarbonate, respectively, in a reasonable manner. From Figures 3-19 and 3-20, the breakthrough of sulfate and CMT, respectively, is predicted by the model to occur at a point earlier than is observed in the data, which suggests that the equilibrium constants for CMT and sulfate may not be accurate. Figure 3-21 shows the $\mathrm{pH}$ prediction for the IRA-68 WBA exchange resin. It appears that the fluctuations in $\mathrm{pH}$ caused by satisfying the charge balance, water formation reaction, and degree of ionization in the first two resins cause some major fluctuations in the $\mathrm{pH}$ results for the WBA exchange resin, as shown in Figure 321. The IRA-68 WBA exchange resin is extremely sensitive to $\mathrm{pH}$. A WBA exchange resin must operate in the range between $\mathrm{pH} 4$ and $\mathrm{pH} 7$ or it will shut down. Because of the importance of $\mathrm{pH}$ for WBA resins, it is expected that it may improve the results if it is possible to solve the equilibrium chemistry conditions simultaneously with the ordinary differential equations for the WBA model. This was attempted but proved too complex at the present time. 


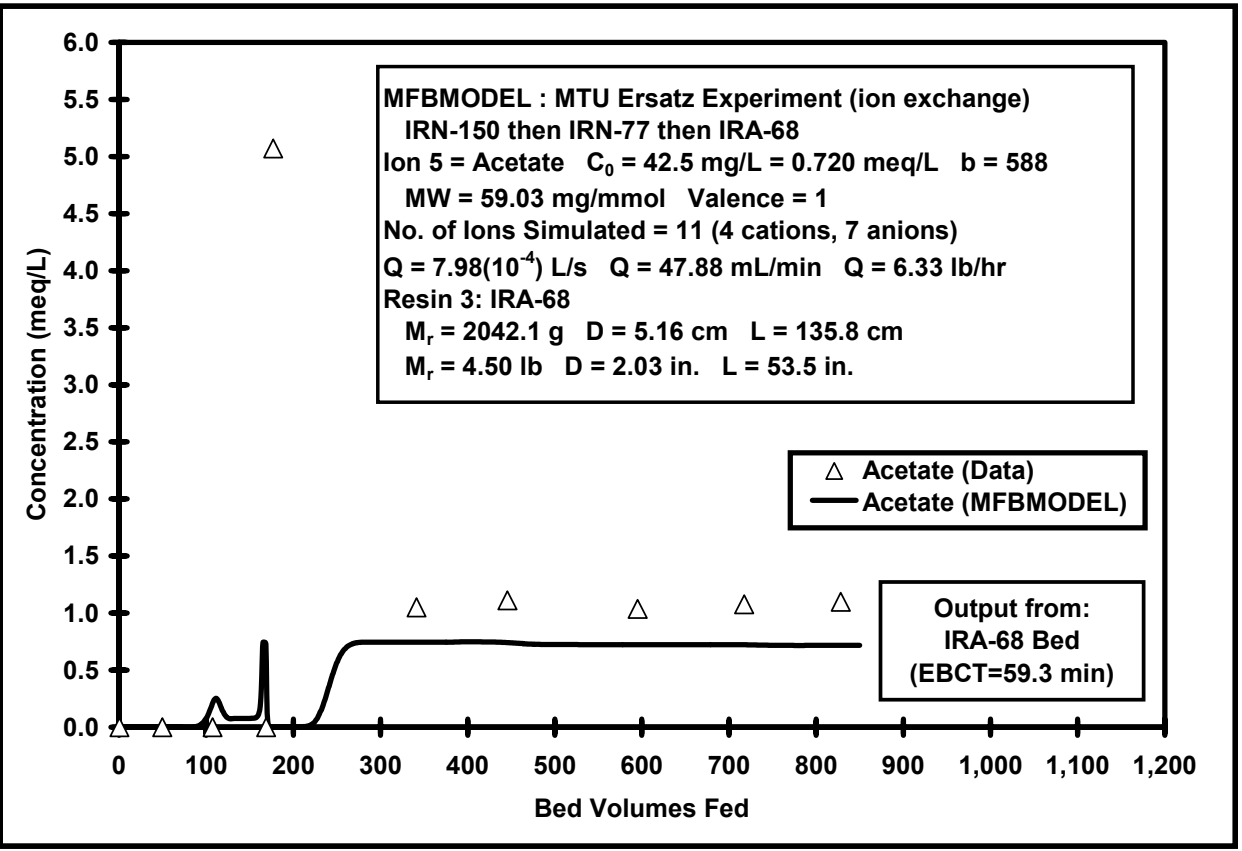

Figure 3-16 - Multicomponent MFBMODEL Verification Experiment Results for Acetate Exchanging the IRA-68 WBA Exchange Resin (EBCT=59 min)

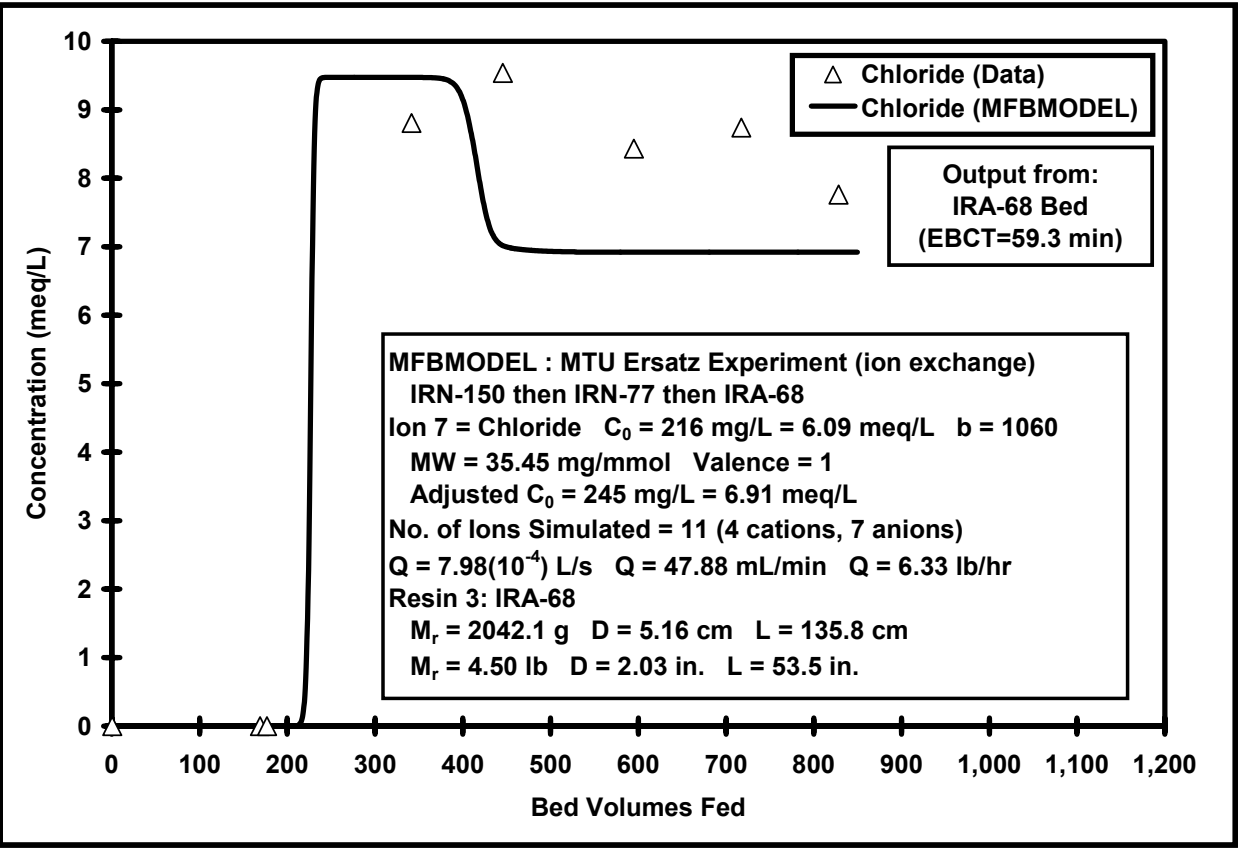

Figure 3-17 - Multicomponent MFBMODEL Verification Experiment Results for Chloride Exchanging the IRA-68 WBA Exchange Resin (EBCT=59 min) 


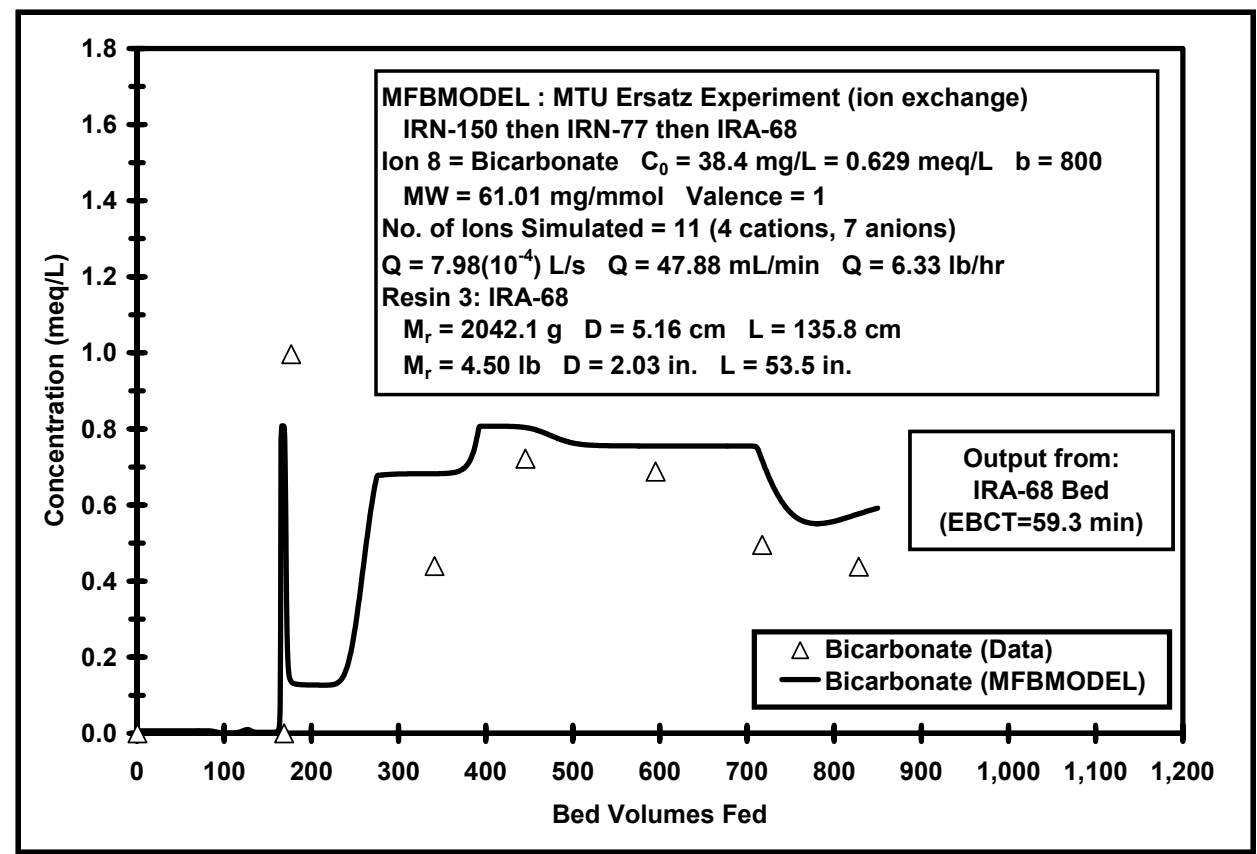

Figure 3-18 - Multicomponent MFBMODEL Verification Experiment Results for Bicarbonate Exchanging the IRA-68 WBA Exchange Resin (EBCT=59 $\min$ )

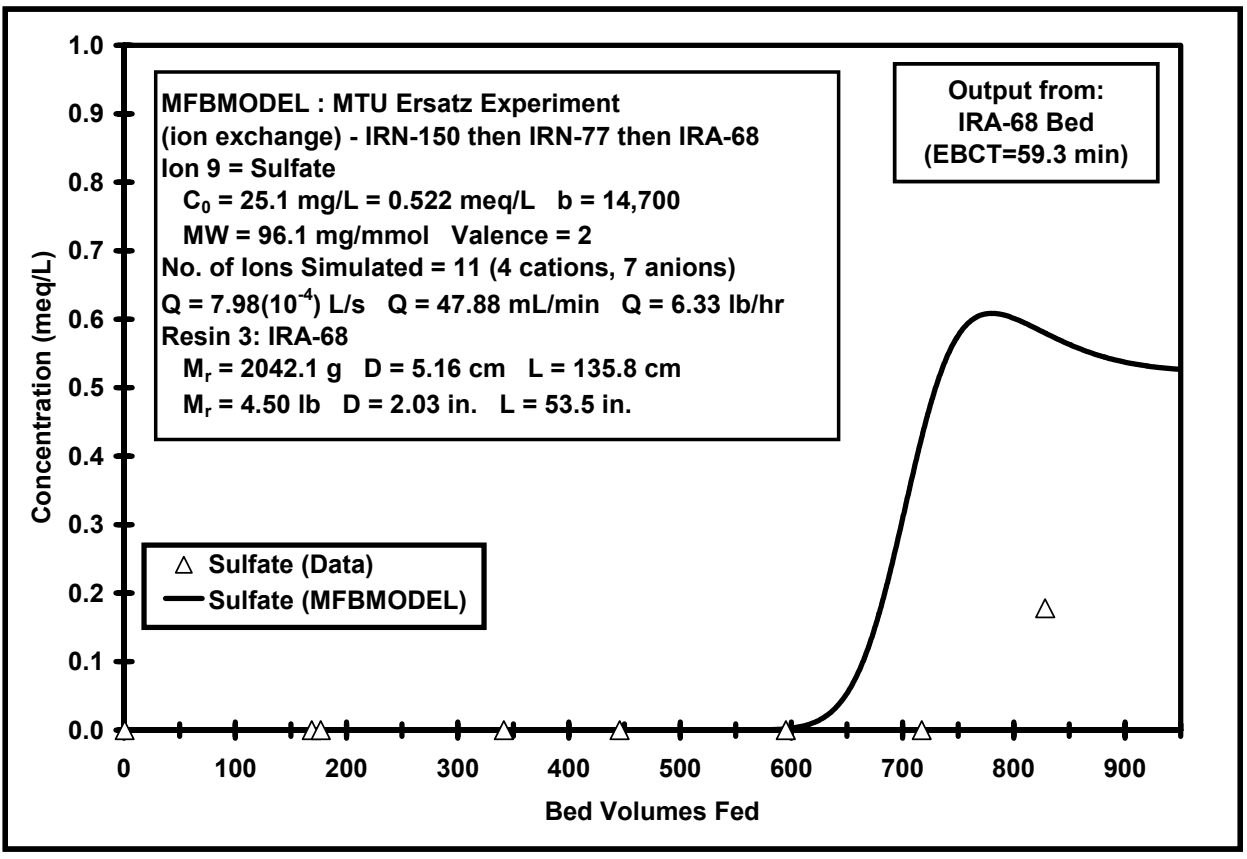

Figure 3-19 - Multicomponent MFBMODEL Verification Experiment Results for Sulfate Exchanging the IRA-68 WBA Exchange Resin (EBCT=59 min) 


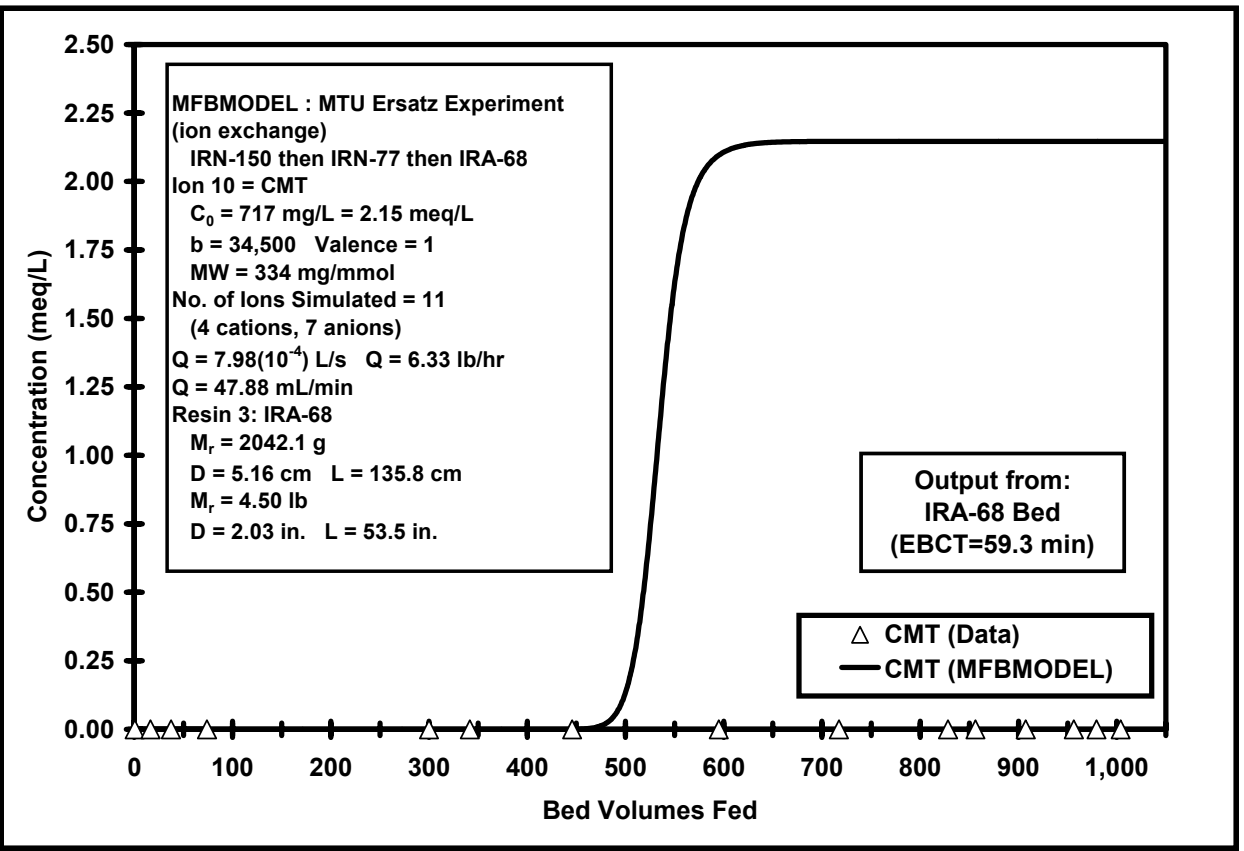

Figure 3-20 - Multicomponent MFBMODEL Verification Experiment Results for CMT Exchanging the IRA-68 WBA Exchange Resin (EBCT=59 min)

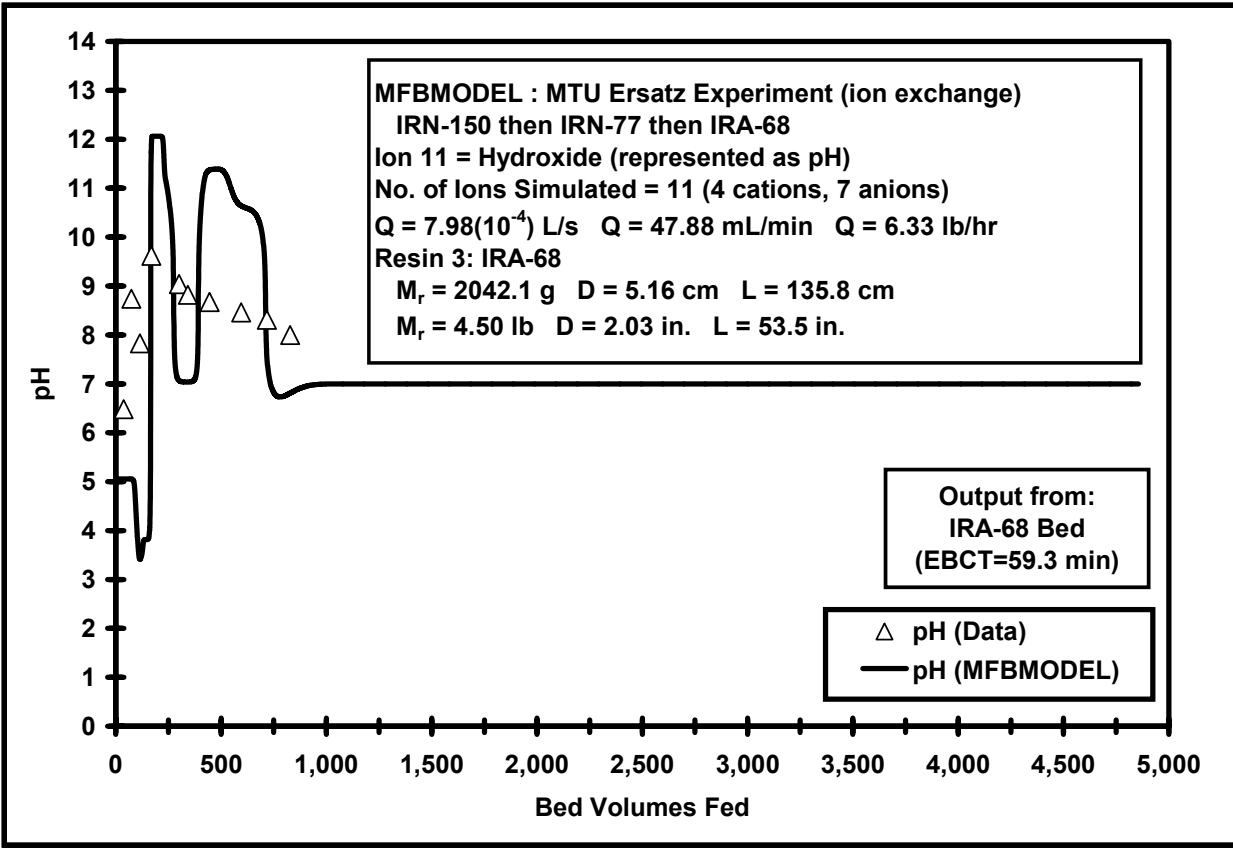

Figure 3-21 - Multicomponent MFBMODEL Verification Experiment Results for Hydroxide (represented as pH) for the IRA-68 WBA Exchange Resin (EBCT=59 min) 


\section{Conclusion}

A tanks-in-series equilibrium model was developed to describe strong acid cation, strong base anion, mixed bed, and weak base anion exchange resins. The model was verified using the ion exchange resins employed in the international space station water processor. The model was shown capable to predict the performance of the different types of resins employed in the ISS water processor. The results were particularly good for mixed bed and strong acid cation resins. The results for WBA resins should be considered preliminary and could be improved by coupling the equilibrium chemistry considerations with the ordinary differential equations.

\section{Acknowledgements}

The authors acknowledge ION Corporation, U.S. EPA and CenCITT, Michigan Tech Graduate School, and Michigan Tech Research Excellence Fund for funding this project. The authors are grateful to Shelle Sandell, Jacqueline Popko, John Bulloch, and David Perram for performing analysis and running the MFBMODEL verification experiment.

This work was supported in part by ION Corporation, U.S. EPA, the Center for Clean Industrial and Treatment Technologies, Michigan Tech Graduate School and Michigan Tech Research Excellence Fund, although it does not necessarily reflect their views and no official endorsement should be inferred. 


\section{References}

Bulloch, J.L., D.W. Hand and J.C. Crittenden. "Model for predicting contaminant removal by adsorption within the International Space Station water processor: 1. Multicomponent equilibrium modeling," Water Environment Research, 70, 1, 14-26 (1998).

Clancey, B. L. “

Clifford, D., "Nitrate Removal from Water Supplies by Ion Exchange: Resin Selectivity and Multicomponent, Chromatographic Column," Ph.D. Dissertation, University of Michigan, Ann Arbor, MI (1976).

Clifford, D.A., "Multicomponent lon-Exchange Calculations for Selected Ion Separations," Ind. Eng. Chem. Fundam., 21(2), 141-153 (1982).

Clifford, D. and R.E. Majano, "Computer Prediction of lon Exchange," Journal AWWA, 85(4), 20 (1993).

Crittenden, J.C., D.W. Hand, D.L. Perram, J.S. Gierke, S. Bhuvendralingham, B. Gopakumar and R. Jayadev, "Development of a Mathematical Model to Evaluate the Operation of the Multifiltration Unit in the Space Station's Drinking Water Treatment System," Report Prepared for McDonnell Douglas Space System Company, Huntsville, Alabama, April 30 (1992).

Gear, C. W. (1971). Numerical initial value problems in ordinary differential equations. Prentice Hall, Upper Saddle River, NJ.

Guter, G.A. "Estimation of Effects of Resin and Water Composition of Column Performance in Nitrate Ion Exchange," Proceedings of the American Water Works Association Annual Conference, Dallas, TX, pp. 1631-1649 (1984). 
Guter, G.A. "Computer Simulation of Nitrate Removal by lon Exchange,"

Proceedings of the American Water Works Association Annual Conference, Washington, D.C., pp. 1293-1325 (1985).

Guter, G.A. "Nitrate Removal from Contaminated Groundwater by lon Exchange," chapter 2, in Sengupta, A.K. (ed.), Ion Exchange Technology: Advances in Pollution Control, pp. 61-113, Technomic Publishing Co., Lancaster, PA (1995).

Hand, D.W., J.C. Crittenden, J.L. Bulloch, B.L. Clancey, D.R. Hokanson, and J. Yu, "Bringing Water Recovery Models Down to Earth," Presented at the Life Science and Space Medicine Conference and Exhibition '95: Bringing Space Benefits Down to Earth, Houston, TX, April (1995).

Hand, D.W., A.N. Ali, J.L. Bulloch, M.L. DeBraske, J.C. Crittenden, and D.R. Hokanson. "Adsorption Equilibrium Modeling of Space Station Wastewaters," ASCE Journal of Environmental Engineering, 125, 6, 540-547 (1999).

Hand, D.W., D.R. Hokanson, M.L. DeBraske, A.N. Ali, and J.C. Crittenden, "Development of the Multifiltration Bed Model for the International Space Station Potable Water System: Phase II Final Report," Prepared for ION Corporation, Huntsville, AL 35806 (2000).

Helfferich, F. and G. Klein, Multicomponent Chromatography: Theory of Interference, Marcel Dekker: New York, 419 pp. (1970).

Hokanson, D.R. "lon Exchange Model Development for the International Space Station Water Processor," Ph.D. Dissertation, Michigan Technological University (2004). 
Höll, W.H., J. Horst, and M. Wernet, "Application of the Surface Complex Formation Model to Exchange Equilibria on Ion Exchange Resins. Part II. Chelating Resins," Reactive Polymers, 14, 251-261 (1991).

Höll, W.H., J. Horst and M. Franzreb, "Application of the Surface Complex Formation Model to Exchange Equilibria on Ion Exchange Resins. Part III: Anion Exchangers," Reactive Polymers, 19, 123-136 (1993).

Höll, W.H., M. Franzreb, J. Horst and S.H. Eberle, "Description of lon-Exchange Equilibria by Means of the Surface Complexation Theory," In Ion Exchange and Solvent Extraction: A Series of Advances, J.A. Marinsky and Y. Marcus (eds.), 11, 151-209 (1993).

Horng, L.L., "Reaction Mechanisms and Chromatographic Behavior of Polyprotic Acid Anions in Multicomponent lon Exchange," Doctoral Dissertation, University of Houston, Texas (1983).

Horst, J., W.H. Höll, and S.H. Eberle, "Application of the Surface Complex Formation Model to Exchange Equilibria on Ion Exchange Resins. Part I. Weak-Acid Resins," Reactive Polymers, 13, 209-231 (1990).

Liang, S., M.A. Mann, G.A. Guter, P.H.-S. Kim and D.L. Hardan. "Nitrate Removal from Contaminated Groundwater: An innovative approach to design of an ion exchange plant using data from bench-scale tests and computer models," Journal AWWA, 91, 2, 79-91 (1999).

Rohm and Haas, "Rohm and Haas Ion Exchange Resins - Laboratory Guide," Technical Bulletin Fluid Process Chemicals Department, Rohm and Haas, Philadelphia, PA (1990). 
Slater, M.J., Principles of lon Exchange Technology; Boston: ButterworthHeinemann, 184 p. (1991).

Subramonian, S. and D. Clifford, "Monovalent/Divalent Selectivity and the Charge Separation Concept", Reactive Polymers, 9, 195-209, (1988).

\section{Nomenclature}

$b_{i} \quad$ Langmuir equilibrium ion exchange rate constant for ion $\mathrm{i}$ applied for weak base anion (WBA) exchange resins $\left(\mathrm{eq}^{-2} \mathrm{~L}^{6}\right)$

$b_{j} \quad$ Langmuir equilibrium ion exchange rate constant for ion $\mathrm{j}$ applied for weak base anion (WBA) exchange resins $\left(\mathrm{eq}^{-2} \mathrm{~L}^{6}\right)$

$\bar{b}_{i} \quad$ Dimensionless Langmuir equilibrium ion exchange rate constant for ion i applied for weak base anion (WBA) exchange resins

$\overline{\mathrm{C}_{0}}$ Equivalent time-averaged influent liquid phase concentration of hydrogen $\left(\mathrm{H}^{+}\right)$ion $\left(\mathrm{eq}^{-3}\right)$.

$\mathrm{C}_{\text {Anions }} \quad$ Total equivalent liquid phase concentration of anions $\left(\mathrm{eq} \mathrm{L}^{-3}\right)$

$\mathrm{C}_{\text {Cations }} \quad$ Total equivalent liquid phase concentration of cations $\left(\mathrm{eq} \mathrm{L}^{-3}\right)$

$\mathrm{C}_{\mathrm{F}} \quad$ Capacity factor (dimensionless)

$\mathrm{C}_{\mathrm{F}, \mathrm{A}} \quad$ Capacity factor for anions (dimensionless)

$\mathrm{C}_{\mathrm{F}, \mathrm{C}} \quad$ Capacity factor for cations (dimensionless)

$\mathrm{C}_{\mathrm{F}, \mathrm{i}} \quad$ Capacity factor for ion $\mathrm{i}$ (dimensionless)

$\mathrm{C}_{\mathrm{H}} \quad$ Effluent liquid phase concentration of hydrogen $\left(\mathrm{H}^{+}\right)$ion $\left(\mathrm{eq} \mathrm{L}^{-3}\right)$.

$\overline{\mathrm{C}_{\mathrm{H}}} \quad$ Dimensionless hydrogen ion concentration, equal to $\mathrm{C}_{\mathrm{H}} / \overline{\mathrm{C}_{0, \mathrm{H}}}$.

$\mathrm{C}_{\mathrm{Hi}^{+}} \quad$ Liquid phase concentration of an ionized weak base, such as $\mathrm{NH}_{4}^{+}$ $\left(\mathrm{eqL}^{-3}\right)$. 
$\overline{\mathrm{C}}_{\mathrm{H}, \mathrm{k}} \quad$ Dimensionless effluent liquid phase concentration of $\mathrm{H}^{+}$from tank number $\mathrm{k}$ (where $\mathrm{k}$ is a number between 1 and $\mathrm{n}$ ) (dimensionless)

$\mathrm{C}_{0, \mathrm{i}} \quad$ Initial equivalent liquid phase concentration of ion $\mathrm{i}\left(\mathrm{eq} \mathrm{L}^{-3}\right)$.

$\overline{\mathrm{C}_{0, \mathrm{i}}} \quad$ Equivalent time-averaged influent liquid phase concentration of ion i $\left(\right.$ eq $\left.\mathrm{L}^{-3}\right)$.

$\mathrm{C}_{\mathrm{i}} \quad$ Effluent liquid phase concentration of ion $\mathrm{i}\left(\mathrm{eq} \mathrm{L}^{-3}\right)$.

$\mathrm{C}_{\mathrm{i}}(\mathrm{z}, \mathrm{t}) \quad$ Equivalent liquid-phase concentration in the bulk solution ( eq $\mathrm{L}^{-3}$ )

$\overline{\mathrm{C}_{i}} \quad$ Dimensionless concentration of ion $\mathrm{i}$, equal to $\mathrm{C}_{\mathrm{i}} / \overline{\mathrm{C}_{0, \mathrm{i}}}$.

$\overline{\mathrm{C}_{i, 0}} \quad$ Dimensionless influent liquid phase concentration of ion $\mathrm{i}$ (dimensionless)

$\overline{\mathrm{C}}_{\mathrm{i}, \mathrm{k}} \quad$ Dimensionless effluent liquid phase concentration of ion i from tank number $\mathrm{k}$ (dimensionless)

$\overline{\mathrm{C}_{0, \mathrm{j}}} \quad$ Equivalent time-averaged influent liquid phase concentration of ion j $\left(e q L^{-3}\right)$.

$\mathrm{C}_{0, \mathrm{i}}(\mathrm{t}) \quad$ Equivalent time-variable influent liquid-phase concentration of ion $\mathrm{i}$ $\left(\right.$ eq $\left.\mathrm{L}^{-3}\right)$

$\mathrm{C}_{\mathrm{j}} \quad$ Effluent liquid phase concentration of ion $\mathrm{j}\left(\mathrm{eq}^{-3}\right)$.

$\overline{C_{j}} \quad$ Dimensionless concentration of ion $j$, equal to $C_{j} / \overline{C_{0, j}}$.

$\overline{\mathrm{C}_{0, \mathrm{OH}}} \quad$ Equivalent time-averaged influent liquid phase concentration of hydroxide $\left(\mathrm{OH}^{-}\right)$ion $\left(\mathrm{eq} \mathrm{L}^{-3}\right)$.

$\mathrm{C}_{\mathrm{OH}} \quad$ Effluent liquid phase concentration of hydroxide $\left(\mathrm{OH}^{-}\right)$ion $\left(\right.$eq $\left.\mathrm{L}^{-3}\right)$.

$\mathrm{C}_{\mathrm{p}, \mathrm{i}}(\mathrm{r}, \mathrm{z}, \mathrm{t}) \quad$ Equivalent liquid-phase concentration in the resin pores $\left(\mathrm{eq} \mathrm{L}^{-3}\right)$

$\overline{\mathrm{C}}_{\text {presaturant,A,k}}$ Dimensionless liquid phase concentration of the presaturant ion for the anionic exchange resin in tank number $k$ (where $k$ is a number between 1 and $\mathrm{n}$ ) (dimensionless) 
$\overline{\mathrm{C}}_{\text {presaturant,C,k}}$ Dimensionless liquid phase concentration of the presaturant ion for the cationic exchange resin in tank number $\mathrm{k}$ (where $\mathrm{k}$ is a number between 1 and $\mathrm{n}$ ) (dimensionless)

$\overline{\mathrm{C}_{\mathrm{T}, \text { avg }}} \quad$ Total equivalent time-averaged influent liquid-phase concentration of all ions (eq $\mathrm{L}^{-3}$ ), equal to $\sum_{\mathrm{j}=1}^{\mathrm{m}} \overline{\mathrm{C}_{0, \mathrm{j}}}$

$\left(\overline{\mathrm{C}_{\mathrm{T}, \mathrm{A}}}\right)_{\mathrm{i}} \quad$ Dimensionless term representing the total liquid phase concentration of all anions at time $t$, equal to $\left[\sum_{\mathrm{j}=1}^{\mathrm{NANION}}\left(\overline{\mathrm{C}_{j, 0}} \times \frac{\mathrm{C}_{\mathrm{F}, \mathrm{i}}}{\mathrm{C}_{\mathrm{F}, \mathrm{j}}}\right)\right]$ (dimensionless)

$\left(\overline{\mathrm{C}_{\mathrm{T}, \mathrm{C}}}\right)_{\mathrm{i}} \quad$ Dimensionless term representing the total liquid phase concentration of all cations at time $t$, equal to $\sum_{j=1}^{\text {NCATION }}\left(\overline{C_{j, 0}} \times \frac{C_{F, j}}{C_{F, j}}\right)$ (dimensionless)

$\mathrm{C}_{\mathrm{T}, \mathrm{i}} \quad$ Total concentration of ionizable cation species (ionic form plus weak base form), equal to $\mathrm{C}_{\mathrm{Hi}^{+}}+\mathrm{C}_{\mathrm{i}}\left(\right.$ eq L $\left.^{-3}\right)$.

$\mathrm{C}_{\mathrm{T}, \mathrm{j}} \quad$ Total concentration of ionizable anion species (ionic form plus weak acid form), equal to $\mathrm{C}_{\mathrm{j}^{-}}+\mathrm{C}_{\mathrm{Hj}}\left(\right.$ eq $\left.\mathrm{L}^{-3}\right)$.

$\mathrm{C}_{\mathrm{T}}(\mathrm{z}, \mathrm{t}) \quad$ Total equivalent time-variable influent liquid-phase concentration of all ions at time $t\left(\right.$ eq $\left.L^{-3}\right)$, equal to $\sum_{j=1}^{m} C_{0, j}\left(t-\frac{z}{V}\right)$

$\overline{\mathrm{C}_{\mathrm{T}}}(\overline{\mathrm{z}}, \mathrm{T}) \quad$ Reduced total equivalent time-variable influent liquid-phase concentration of all ions (dimensionless), equal to $\mathrm{C}_{\mathrm{T}}(\mathrm{z}, \mathrm{t}) / \overline{\mathrm{C}_{\mathrm{T}, \text { avg }}}$ Dimensionless hydroxide ion concentration, equal to $\mathrm{C}_{\mathrm{OH}} / \overline{\mathrm{C}_{0, \mathrm{OH}}}$.

$\mathrm{C}_{\mathrm{p}, \mathrm{i}}(\mathrm{r}, \mathrm{z}, \mathrm{t}) \quad$ Equivalent ion concentration in the resin pores as a function of radial and axial position and time $\left(\mathrm{eq} \mathrm{L}^{-3}\right)$ 


\begin{tabular}{|c|c|}
\hline $\mathrm{C}_{\text {Pr esaturant }}$ & Liquid phase concentration of the presaturant ion $\left(\mathrm{eqL}^{-3}\right)$ \\
\hline$f_{\text {obj }}$ & $\begin{array}{l}\text { Objective function, equal to the sample deviation, used for fitting } \\
\text { the isotherm data }\end{array}$ \\
\hline$\left[\mathrm{H}^{+}\right]$ & Molar hydrogen ion concentration $\left(\mathrm{mol} \mathrm{L}^{-1}\right)$. \\
\hline $\mathrm{K}_{\mathrm{a}}$ & Acid/base equilibrium constant $\left(\mathrm{mol} \mathrm{L}^{-1}\right)$ \\
\hline $\mathrm{K}_{\text {eq }}$ & Selectivity coefficient for either cation or anion exchange reactions \\
\hline $\mathrm{K}_{\mathrm{w}}$ & Constant for water, equal to $10^{-14} \mathrm{~mol}^{2} \mathrm{~L}^{-2}=10^{-08} \mathrm{meq}^{2} \mathrm{~L}^{-2}$. \\
\hline$\overline{\mathrm{K}_{\mathrm{w}}}$ & Dimensionless form of constant for water, equal to $\mathrm{K}_{\mathrm{w}} / \overline{\mathrm{C}_{0, \mathrm{H}}} / \overline{\mathrm{C}_{0, \mathrm{OH}}}$. \\
\hline L & Length of the resin bed $(L)$ \\
\hline M & Mass of resin (M) \\
\hline $\mathrm{n}$ & Number of tanks in series \\
\hline NANION & Number of anions \\
\hline NCATION & Number of cations \\
\hline NumAnions & Number of anions in the system. \\
\hline NumCations & Number of cations in the system. \\
\hline$\left[\mathrm{OH}^{-}\right]$ & Molar hydrogen ion concentration $\left(\mathrm{mol} \mathrm{L}^{-1}\right)$. \\
\hline $\mathrm{pK}_{\mathrm{a}}$ & Acid/base equilibrium constant. \\
\hline$q_{\text {data,i }}$ & $\begin{array}{l}\text { Experimental resin phase concentration determined for an isotherm } \\
\text { point }\left(\text { eq }^{-1} \text { ) }\right.\end{array}$ \\
\hline $\mathrm{q}_{\mathrm{Hi}}$ & $\begin{array}{l}\text { Resin phase concentration of ion i on a weak base anion (WBA) } \\
\text { exchange resin }\left(\mathrm{eq} \mathrm{M}^{-1}\right)\end{array}$ \\
\hline$q_{i}$ & Resin phase concentration of ion $\mathrm{i}\left(\mathrm{eq} \mathrm{M}^{-1}\right)$ \\
\hline$\overline{\mathrm{q}}_{\mathrm{i}, 1}$ & Dimensionless resin phase concentration of ion i in tank number 1 \\
\hline$\overline{\mathrm{q}}_{\mathrm{i}, \mathrm{m}}$ & $\begin{array}{l}\text { Dimensionless resin phase concentration of ion } \mathrm{i} \text { in tank number } \mathrm{m} \\
\text { (where } \mathrm{m} \text { is a number between } 2 \text { and } \mathrm{n} \text { ) (dimensionless) }\end{array}$ \\
\hline$\overline{\mathrm{q}}_{\text {presaturant,A,k}}$ & $\begin{array}{l}\text { Dimensionless resin phase concentration of the presaturant ion on } \\
\text { the anionic exchange resin in tank number } k \text { (dimensionless) }\end{array}$ \\
\hline
\end{tabular}


$\overline{\mathrm{q}}_{\text {presaturant,C,k}}$ Dimensionless resin phase concentration of the presaturant ion on the cationic exchange resin in tank number $\mathrm{k}$ (dimensionless)

$\mathrm{q}_{\mathrm{T}} \quad$ Total resin capacity $\left(\right.$ eq $\left.^{-1}\right)$

$\mathrm{R} \quad$ Universal gas constant in discussion of Fick's law and electrical potential effects, equal to $0.08206 \mathrm{~L} \mathrm{~atm} \mathrm{~mol}^{-1} \mathrm{~K}^{-1}$

T Temperature

V Liquid volume $\left(L^{3}\right)$

$z_{i} \quad$ Valence of ion $i$

$z_{j} \quad$ Valence of ion $j$

\section{Greek Letters}

$\alpha_{j}^{i} \quad$ Separation factor, which measures the preference for ion i with respect to ion $\mathrm{j}$ (dimensionless).

$\varepsilon \quad$ Fraction of volumetric space in exchange column unoccupied by resin, or void fraction (dimensionless)

$\varepsilon_{\mathrm{p}} \quad$ Fraction of volumetric space in resin phase unoccupied by adsorbent (dimensionless)

$\rho_{\mathrm{a}} \quad$ Adsorbent density which includes pore volume $\left(\mathrm{M} \mathrm{L}^{-3}\right)$

$\tau \quad$ Fluid residence time in resin column, or packed bed contact time $(\mathrm{T})$ 


\title{
Chapter 4 - Development of a Multicomponent Mass Transfer Model for Ion Exchange*
}

\begin{abstract}
A multicomponent mass transfer model that incorporates external (film) diffusion and intraparticle (pore) diffusion effects that will predict the performance of ion exchange resins was developed. This pore diffusion model (PDM) for ion exchange accounts for multicomponent equilibrium using a Langmuir approach and is applicable to strong acid cation (SAC) and strong base anion (SBA) exchange resins. External and intraparticle mass transfer parameters were obtained from literature correlations and calibrated using a multiparameter fit of ionic transport coefficient and pore diffusion coefficient. The PDM was verified in binary and multicomponent column experiments using SAC and SBA exchange resins.
\end{abstract}

\section{Keywords}

mass transfer, mathematical model, pore diffusion, intraparticle diffusion, external diffusion, film diffusion, equilibrium description, Langmuir approach, separation factor, strong acid cation, SAC, strong base anion, SBA, multicomponent

\footnotetext{
* This chapter consists of a paper that will be submitted to Water Research.
} 


\section{Introduction}

Helfferich and Plesset (1958) were among the first to incorporate the combined effects of equilibrium thermodynamics and kinetics into mass or equivalent balances to predict fixed-bed ion exchange performance for a binary system. Their model included the combined effects of liquid- and solid-phase transport. It was assumed transport of ions during ion exchange occurs due to the effects of diffusion and ionic migration. Because ions diffuse at different rates, charge separation can arise inducing an electric field, which causes ionic migration to satisfy the local electrical balance. The flux of ions $\left(\mathrm{J}_{\mathrm{i}}\right)$ is given by the Nernst-Planck (N-P) equation, which contains both diffusive and electrical flux terms. Applying the N-P equation, the diffusional flux of ion $i$ in the liquidphase $\left(\mathrm{J}_{1, \mathrm{i}}\right)$ and solid-phase $\left(\mathrm{J}_{\mathrm{s}, \mathrm{i}}\right)$ is given by the following equations, respectively.

$$
\begin{gathered}
J_{\mathrm{l}, \mathrm{i}}=-\mathrm{D}_{\mathrm{l}, \mathrm{i}}\left[\frac{\partial \mathrm{C}_{\mathrm{i}}(\mathrm{z}, \mathrm{t})}{\partial \mathrm{r}}+\frac{\mathrm{Z}_{\mathrm{i}} \mathrm{FC} \mathrm{C}_{\mathrm{i}}(\mathrm{z}, \mathrm{t})}{\mathrm{R}_{\mathrm{gas}} \operatorname{Temp}} \frac{\partial \phi(\mathrm{z}, \mathrm{t})}{\partial \mathrm{r}}\right] \\
\mathrm{J}_{\mathrm{s}, \mathrm{i}}=-\mathrm{D}_{\mathrm{s}, \mathrm{i}}\left[\frac{\partial \mathrm{C}_{\mathrm{p}, \mathrm{i}}(\mathrm{r}, \mathrm{z}, \mathrm{t})}{\partial \mathrm{r}}+\frac{\mathrm{Z}_{\mathrm{i}} \mathrm{F} \mathrm{C}_{\mathrm{p}, \mathrm{i}}(\mathrm{r}, \mathrm{z}, \mathrm{t})}{\mathrm{R}_{\mathrm{gas}} \operatorname{Temp}} \frac{\partial \phi(\mathrm{r}, \mathrm{z}, \mathrm{t})}{\partial \mathrm{r}}\right]
\end{gathered}
$$

in which, $D_{1, i}$ and $D_{s, i}$ are the diffusivities in the liquid- and solid-phase of ion $i$, respectively; $C_{i}(z, t)$ represents the equivalent liquid-phase concentration in the bulk solution; $\mathrm{C}_{\mathrm{p}, \mathrm{i}}(\mathrm{r}, \mathrm{z}, \mathrm{t})$ represents the equivalent liquid-phase concentration in the resin pores and it is assumed that transport in the solid-phase is by pore diffusion; $\phi$ is the electrical potential caused by the migration of the ions in 
solution; $F$ is the Faraday constant; $R_{\text {gas }}$ is the universal gas constant; and Temp is the temperature. The flux terms are simplified by assuming electroneutrality exists within the liquid film surrounding the solid-phase and within the solid phase, and the flux of the non-exchanging co-ion across the solid-liquid interface is negligible.

$$
\begin{gathered}
\sum \mathrm{C}_{\mathrm{i}}(\mathrm{z}, \mathrm{t})=0 \text { (liquid-phase) } \\
\sum \mathrm{C}_{\mathrm{p}, \mathrm{i}}(\mathrm{r}, \mathrm{z}, \mathrm{t})=0 \text { (solid-phase) } \\
\mathrm{J}_{\mathrm{i}}(\text { non-exchanging co-ion })=0
\end{gathered}
$$

Combining these two assumptions leads to the following condition of no net current flow:

$$
\sum \mathrm{J}_{\mathrm{i}}=0 \text { (no net current flow) }
$$

Utilizing these conditions, the N-P equations can be reduced to a form similar to Fick's law, where the flux is expressed as a product of a so-called 'effective' diffusion coefficient and a concentration gradient. The effective diffusivity is not constant, but depends on the concentrations, diffusivities, and charges of all the individual exchanging ions.

Several researchers performed ion exchange model calculations by incorporating various forms of the above modified version Fick's law into mass and equivalent balance expressions for binary and ternary exchange situations in single cation (Wagner and Dranoff 1967), anion (Graham and Dranoff 1972), and mixed-bed (Kataoka et al. 1968; Wildhagen, et al. 1985, and Haub and Foutch 1986) ion exchange processes. Kataoka and Yoshida (1988) showed that for ion 
concentrations less than about $0.5 \mathrm{~N}$, mass transfer was liquid-phase controlled. Kataoka et al. (1976) and Haub and Foutch (1986) used a film diffusion controlled model, which incorporated the bulk phase hydrogen/hydroxide neutralization reaction for a mixed-bed ion exchange system. Most of these studies compared model calculations to a very limited quantity of data obtained for columns with short empty bed contact times (EBCTs) and waters which were free of background organic matter. However, exchange columns with relatively large EBCTs and water containing high concentrations of organic matter may foul exchange sites and block pores within the ion exchange particles causing transport in the solid-phase to become important. As a part of this ion exchange model development, the impact of both liquid- and solid-phase transport were evaluated.

The above studies have only considered ion exchange model development for simple binary and ternary exchange systems and not considered situations where large numbers of ions are present. Incorporating an effective diffusion coefficient, such as the one described above, into mass balance equations for situations where several ions are present will significantly increase the level of model complexity. Therefore, the impact of electrical potential effects will be neglected, and an apparent diffusion coefficient will be used in the Fick's law expression. This assumption may be adequate in describing the ion breakthrough profiles as Haub and Foutch (1986) showed that accounting for the electrical potential in the flux expression only had about a $20 \%$ increase in the rate of exchange of sodium for hydrogen. 
A multicomponent mass transfer model that incorporates external (film) diffusion and pore diffusion effects that will predict the performance of ion exchange resins was developed. Mathematical models can predict the impact of changing process variables on ion exchange performance. Use of models significantly reduces the time and cost involved in performing laboratory and pilot scale experimental work. Process variables such as the number of exchanging ions, time variable influent concentrations, ion exchange bed size, resin type, ion exchange bed configurations such as multiple beds in series, and competition among exchanging ions can be evaluated with a mathematical model for ion exchange.

A mathematical modeling approach to analyze ion exchange processes is presented in this paper. This ion exchange model accounts for multicomponent equilibrium, as well as external and intraparticle mass transfer. External and intraparticle mass transfer parameters were obtained from literature correlations. This multicomponent mass transfer model was verified in binary and multicomponent column experiments using strong acid cation (SAC) and strong base anion (SBA) exchange resins. The multicomponent mass transfer model will be compared to a tanks in series equilibrium model (TISEqM) (Hokanson, 2004) for the IRN-77 SAC exchange results and the advantages of the mass transfer model compared to the equilibrium model will be demonstrated. 


\section{Materials and Methods}

\subsection{Chemicals and Resins}

All chemicals were reagent grade or better. Sodium bicarbonate, calcium chloride, potassium chloride, ammonium chloride, sulfuric acid, sodium chloride, sodium acetate, acetic acid, hydrochloric acid, sodium hydroxide and potassium iodide were obtained from Fisher Scientific (Fair Lawn, NJ). The Aldrich Chemical Company (Milwaukee, WI) supplied: sodium butyrate, butyric acid, and acetic acid (sodium salt).

The ion exchange resins for this study came from various sources. UMQUA Research Company (Beaverton, OR) provided some of the IRN-77 SAC exchange resin. Additional IRN-77 SAC exchange resin was purchased from Rohm and Haas (Cherry Hill, PA). The IRN-78 SBA exchange resin was obtained directly from multifiltration columns opened by NASA. Distilleddeionized water was produced by distilling tap water and further purifying it with a Milli-Q UV Plus Water System (Millipore Corp., Bedford, MA).

Prior to use, the resins were conditioned and converted to the hydrogen (for IRN-77 SAC exchange resin) or hydroxide (for IRN-78 SBA exchange resin) forms following procedures outlined by Rohm and Haas (1990). The Amberlite IRN-78 SBA was conditioned and converted with solutions prepared under nitrogen to minimize the amount of atmospheric bicarbonate contacting the resin.

\subsection{Solution Preparation}

Distilled-deionized water and salts of the exchanging ions were used to make solutions of approximately 10 meq/L. Table $4-1$ lists the ions used for the 
kinetic experiments. These ions are representative of those found in the actual shower/handwash water. Multicomponent solutions were made with equal equivalent concentrations of the ions listed in Table 4-1.

\subsection{Chemical Analysis}

Total organic carbon (TOC) and inorganic carbon (IC) measurements for bicarbonate were made with a Sievers Total Organic Carbon Analyzer (Sievers, Inc., Boulder, CO). The pH was determined using an Orion (Cambridge, MA) model $501 \mathrm{pH}$ meter. An Orion Sodium probe was used to determine some sodium concentrations down to $10 \mathrm{ppm}$ with the ion selective electrode (ISE) method outlined by Orion. A Dionex ion chromatograph, DX500 (Sunnyvale, CA) was used for the majority of ion measurements. Cations were analyzed with the IonPac CS12 $4 \mathrm{~mm}$ analytical column and the anions were analyzed with the IonPac AS11 $4 \mathrm{~mm}$ analytical column and the lonPac AG11 guard column.

The iodine and iodide were measured with a residual chlorine probe (model 97-70) and an iodide probe (model 94-53), both from Orion, based on the ISE chlorine determination method outlined by Orion. Triiodide concentrations were measured spectrophotometrically using a Perkin-Elmer 552 spectrophotometer (Norwalk, CT).

Table 4-1 - Representative lons for the Various Resins

\begin{tabular}{|l|l|}
\hline Resin & lons Studied \\
\hline IRN-77 SAC & sodium, potassium, calcium, ammonium \\
\hline IRN-78 SBA & chloride, acetate, butyrate, bicarbonate, sulfate, iodide \\
\hline
\end{tabular}




\subsection{Resin Physical Properties, Total Resin Capacities, and Separation}

\section{Factors}

Hokanson (2004) presents the determination of resin physical properties and total resin capacities for IRN-77 SAC and IRN-78 SBA exchange resins, as well as separation factors for cations on the hydrogen form of IRN-77 SAC exchange resin and for anions on the hydroxide form of IRN-78 SAC exchange resin. The physical properties and total resin capacities of IRN-77 SAC and IRN78 SBA exchange resins are listed in Table 4-2. The total capacity of each resin was determined as outlined by Rohm and Haas (1990). The resin physical property determination was performed as outlined by Sontheimer et. al. (1988).

Separation factors were determined by fitting binary equilibrium isotherm data for each ion on IRN-77 SAC exchange resin or IRN-78 SBA exchange resin, as described in Hokanson (2004). Table 4-3 shows the separation factors for the cations and anions used in this study (see Table 4-1). The separation factor for iodide on the chloride form of IRN-78 SBA exchange resin can be determined based on the separation factors of iodide and chloride on the hydroxide form of IRN-78 SBA exchange resin:

$$
\alpha_{\mathrm{Cl}}^{\prime}=\frac{\alpha_{\mathrm{OH}}^{\mathrm{I}}}{\alpha_{\mathrm{OH}}^{\mathrm{Cl}}}=\frac{638}{16.7}=38.2
$$


Table 4-2 - Physical Properties and Total Resin Capacities of the Ion Exchange Resins

\begin{tabular}{|c|c|c|c|c|c|c|c|c|c|}
\hline \multirow[b]{2}{*}{ Resin } & \multirow{2}{*}{$\begin{array}{l}\text { Manu- } \\
\text { facturer }\end{array}$} & \multirow[b]{2}{*}{ Type } & \multirow[b]{2}{*}{ Form } & \multicolumn{4}{|c|}{ Density $(\mathrm{g} / \mathrm{mL})$} & \multicolumn{2}{|c|}{ Porosity } \\
\hline & & & & Bulk & $\begin{array}{c}\text { Apparent } \\
\text { Dry }\end{array}$ & $\begin{array}{l}\text { Apparent } \\
\text { Wet }\end{array}$ & $\begin{array}{l}\text { Resin } \\
\text { Matrix }\end{array}$ & $\begin{array}{c}\text { Intra- } \\
\text { particle }\end{array}$ & Bulk \\
\hline $\begin{array}{l}\text { Amberlite } \\
\text { IRN-77 }\end{array}$ & $\begin{array}{c}\text { Rohm \& } \\
\text { Haas }\end{array}$ & $\begin{array}{l}\text { Strong } \\
\text { Acid } \\
\text { Cation } \\
\text { (SAC) } \\
\text { Gel }\end{array}$ & $\mathrm{H}^{+}$ & 0.89 & 0.63 & 1.24 & 1.50 & 0.58 & 0.28 \\
\hline \multirow{2}{*}{$\begin{array}{l}\text { Amberlite } \\
\text { IRN-78 }\end{array}$} & \multirow{2}{*}{$\begin{array}{c}\text { Rohm \& } \\
\text { Haas }\end{array}$} & \multirow{2}{*}{$\begin{array}{c}\text { Strong } \\
\text { Base } \\
\text { Anion } \\
\text { (SBA) } \\
\text { Gel } \\
\end{array}$} & $\mathrm{OH}^{-}$ & 0.79 & 0.56 & 1.1 & 1.11 & 0.49 & 0.28 \\
\hline & & & $\mathrm{Cl}^{-}$ & 0.71 & 0.56 & 1.00 & 1.01 & 0.44 & 0.30 \\
\hline \multirow{2}{*}{ Resin } & \multirow{2}{*}{$\begin{array}{c}\text { Manu- } \\
\text { facturer }\end{array}$} & \multirow{2}{*}{ Type } & \multirow{2}{*}{ Form } & \multicolumn{6}{|c|}{ Total Resin Capacity } \\
\hline & & & & \multicolumn{2}{|c|}{ meq/mL bed } & \multicolumn{2}{|c|}{$\mathrm{meq} / \mathrm{mL}$ resin } & \multicolumn{2}{|c|}{$\mathrm{meq} / \mathrm{g}$ dry resin } \\
\hline $\begin{array}{l}\text { Amberlite } \\
\text { IRN-77 }\end{array}$ & $\begin{array}{c}\text { Rohm \& } \\
\text { Haas }\end{array}$ & $\begin{array}{c}\text { Strong } \\
\text { Acid } \\
\text { Cation } \\
\text { (SAC) } \\
\text { Gel } \\
\end{array}$ & $\mathrm{H}^{+}$ & \multicolumn{2}{|c|}{2.2} & \multicolumn{2}{|l|}{3.1} & \multicolumn{2}{|c|}{5.0} \\
\hline \multirow{2}{*}{$\begin{array}{l}\text { Amberlite } \\
\text { IRN-78 }\end{array}$} & \multirow{2}{*}{$\begin{array}{c}\text { Rohm \& } \\
\text { Haas }\end{array}$} & \multirow{2}{*}{$\begin{array}{c}\text { Strong } \\
\text { Base } \\
\text { Anion } \\
\text { (SBA) } \\
\text { Gel }\end{array}$} & $\mathrm{OH}^{-}$ & \multicolumn{2}{|c|}{0.96} & \multicolumn{2}{|l|}{1.5} & \multicolumn{2}{|c|}{2.6} \\
\hline & & & $\mathrm{Cl}^{-}$ & \multicolumn{2}{|c|}{1.4} & \multicolumn{2}{|l|}{2.0} & \multicolumn{2}{|c|}{3.6} \\
\hline
\end{tabular}


Table 4-3 - Separation Factors for Cations on the Hydrogen Form of IRN-77 SAC Exchange Resin and for Anions on the Hydroxide or Chloride Form of IRN-78 SBA Exchange Resin

\begin{tabular}{|l|c|c|c|}
\hline Ion & Resin & Form & Separation Factor \\
\hline Sodium & IRN-77 SAC & Hydrogen & 1.68 \\
\hline Potassium & IRN-77 SAC & Hydrogen & 2.15 \\
\hline Calcium & IRN-77 SAC & Hydrogen & 59.1 \\
\hline Ammonium & IRN-77 SAC & Hydrogen & 1.72 \\
\hline lodide & IRN-78 SBA & Chloride & 38.2 \\
\hline Chloride & IRN-78 SBA & Hydroxide & 16.7 \\
\hline Sulfate & IRN-78 SBA & Hydroxide & 149 \\
\hline Acetate & IRN-78 SBA & Hydroxide & 1.99 \\
\hline Butyrate & IRN-78 SBA & Hydroxide & 3.21 \\
\hline Bicarbonate & IRN-78 SBA & Hydroxide & 4.99 \\
\hline
\end{tabular}

\subsection{Kinetic Experiments}

Bench scale binary and multicomponent column experiments with representative ions (see Table 4-1) were conducted for IRN-77 SAC and for IRN78 SBA exchange resins. Channeling effects were eliminated by capping glass columns, (Ace Glass Co., Vineland, NJ) with inner diameters of $2.5 \mathrm{~cm}$ or $5.0 \mathrm{~cm}$ with a bored out Teflon end cap filled with glass beads. The glass beads were retained with 150 mesh stainless steel screen. Teflon tubing was used to connect the apparatus to FMI pumps (Oyster Bay, NJ).

Conditioned resin was slurried into the columns with distilled-deionized water. The mass and volume of resin in each column was used to determine individual column properties. Solutions were run downflow through the columns.

Column effluent was monitored for presaturant ion and exchanging ions until complete exhaustion. The $\mathrm{pH}$ was also monitored. 


\subsection{Statistical Methods}

\subsubsection{Parameter Fitting}

Certain parameters (ionic transport coefficient and pore diffusion coefficient for the PDM; number of tanks for the TISEqM) were fit in the ion exchange models by comparing model predictions to experimental data such that an objective function was minimized.

$$
f_{o b j}=\frac{\sum_{j=1}^{\text {Numlons }} s_{j}^{2}}{\text { Numlons }}
$$

\subsubsection{Binary lon Exchange}

For binary SAC and SBA exchange, the average of the sum of the squares of the residuals $\left(\mathrm{s}_{\mathrm{j}}^{2}\right)$ is defined as follows:

$$
\mathrm{s}_{\mathrm{j}}^{2}=\frac{\sum_{\mathrm{i}=1}^{\mathrm{N}_{\mathrm{d}} \text { data }_{\mathrm{j}}}\left(\mathrm{x}_{\text {data }_{\mathrm{j}, \mathrm{i}}}-\mathrm{x}_{\text {}_{\text {ode }} \mathrm{j}_{\mathrm{j}, \mathrm{i}}}\right)}{\mathrm{N}_{\text {data }_{\mathrm{j}}}-1}
$$

Presaturant data was not used in the fitting of binary SAC exchange data. Both exchanging ion and presaturant ion data were used in the fitting of binary SBA exchange data. Both the PDM and the TISEqM were used in the fitting of the binary SAC exchange data for comparative purposes. No TISEqM fitting was performed on SBA exchange data.

The procedure for determining the best fit values of pore diffusion coefficient and ionic transport coefficient for the PDM based on binary SAC or SBA exchange data is as follows. On the first iteration, the pore diffusion coefficient $\left(D_{p}\right)$ is varied in a series of PDM runs until the objective function (see 
Equation 4-8) is minimized for a given value of ionic transport coefficient $\left(\mathrm{k}_{\mathrm{f}}\right)$.

Utilizing the best fit $D_{p}$ from iteration 1 on the second iteration, $k_{f}$ is varied in a series of PDM runs until the objective function is minimized. Using the best fit $k_{f}$

from iteration 2 on the third iteration, $D_{p}$ is varied in a series of PDM runs until the objective function is minimized. This iterative process is continued until the value of the objective function is not further reduced on subsequent iterations on pore diffusion coefficient or ionic transport coefficient. During the iterative process, the $k_{f}$ and $D_{p}$ values, respectively, for both the exchanging ion and the presaturant ion are varied by the same factor compared to the correlated values of $k_{f}$ and $D_{p}$, respectively, during each PDM run.

The procedure for determining the best fit value of number of tanks for the TISEqM based on binary SAC exchange data is as follows. The number of tanks is varied until the objective function is minimized when comparing TISEqM predictions to experimental data.

\subsubsection{Multicomponent lon Exchange}

For multicomponent SAC and SBA exchange, the average of the sum of the squares of the residuals $\left(s_{j}^{2}\right)$ is defined as follows:

$$
\mathrm{s}_{\mathrm{j}}^{2}=\frac{\sum_{\mathrm{i}=1}^{\mathrm{N}_{-} \text {data }}\left(\overline{\mathrm{C}}_{\mathrm{j}_{-} \text {data, }, \mathrm{i}}-\overline{\mathrm{C}}_{\mathrm{j}_{-} \text {model }, \mathrm{i}}\right)}{\mathrm{N}_{-} \text {data } \mathrm{j}_{\mathrm{j}}-1}
$$




\subsubsection{5\% Confidence}

The objective function corresponding to $95 \%$ confidence may be determined from the following equation (see this approach as shown in Draper and Smith, 1981):

$$
\mathrm{OF}_{95 \%}^{2}=\mathrm{OF}_{\text {min }}^{2}\left[1-\frac{\mathrm{P}}{\mathrm{P}-\mathrm{N}} \mathrm{F}(\mathrm{P}, \mathrm{N}-\mathrm{P}, 95 \%)\right]
$$

in which, $\mathrm{OF}_{95 \%}$ is the objective function value that corresponds to the $95 \%$ confidence value. $\mathrm{OF}_{\min }$ is the best-fit value of the objective function. $\mathrm{F}$ is determined from the $F$ table, which is available from many statistics books. $P$ is the number of parameters and $\mathrm{N}$ is number of data points. For the PDM fits, there are two fitting parameters $\left(D_{p}\right.$ and $\left.k_{f}\right)$ and the $95 \%$ confidence limits may be examined graphically by looking at the $95 \%$ confidence contour on a plot of $D_{p}$ versus $\mathrm{k}_{\mathrm{f}}$. Each point on the plot represents a PDM run that resulted in a value of the objective function equal to $\mathrm{OF}_{95 \%}$ when the PDM result is compared to experimental data via Equation 4-8. For the TISEqM fit, there is one fitting parameter (Number of Tanks) and the $95 \%$ confidence interval can be determined by varying Number of Tanks in the TISEqM until OF $=\mathrm{OF}_{95 \%}$.

\subsection{Equilibrium Model}

The multicomponent mass transfer model will be compared to a tanks in series equilibrium model (TISEqM) (see Chapter 2 of Hokanson, 2004) for the IRN-77 SAC exchange results and the advantages of the mass transfer model compared to the equilibrium model will be demonstrated.

The TISEqM incorporates the following mechanisms and assumptions: 
- The fluid is transported through the bed by advective plug flow (axial and radial dispersions are neglected)

- Mass balance equations are derived for continuous flow stirred tank reactors (CFSTRs) placed in-series

- A Langmuir equilibrium relationship incorporating constant separation factors (for SAC and SBA exchange resins) describes the multicomponent ion exchange equilibrium between the liquid- and solid-phases

- Mass transfer effects are neglected.

- Electrical potential effects are neglected.

- The number of equally sized CFSTRs in series will be used as an adjustable parameter to fit the ion exchange data and the approach compared to the mass transfer model.

\section{Mass Transfer Model Development}

\subsection{Mechanisms and Assumptions}

The transport of ions within exchange resin particles can occur by pore diffusion. Pore diffusion is where the exchanging ions will travel to the exchange sites through the fluid void space contained within the resin. Since this fixed-bed model assumes that pore diffusion is the only intraparticle transport mechanism; it is hereafter referred to as the pore diffusion model (PDM). 
The PDM incorporates the following mechanisms:

- The fluid is transported through the bed by advective plug flow (axial and radial dispersions are neglected)

- The liquid phase mass transfer flux at the exterior of the resin particle is described by a linear driving force

- The intraparticle transport is caused by pore diffusion.

- Electrical potential effects on intraparticle transport are neglected

- There are no ion-ion interactions during the diffusion process

- The exchange rate of an ion onto the resin is much faster than the diffusion rate (i.e. local ion exchange equilibrium exists between the ion adsorbed onto the resin particle and the ion in the intraaggregate stagnant fluid)

- A Langmuir equilibrium relationship incorporating constant separation factors and total solution concentration describes the multicomponent ion exchange equilibrium between the liquid- and solid-phases

- The PDM considers the total cation or anion concentration in the system as a constant (hence, the electroneutrality condition holds) and neglects the water formation reaction and degree of ionization of weak acids and bases. Hence, the PDM is only applicable to SAC and SBA exchange resins and does not apply to mixed bed ion exchange resins. 


\subsection{Model Equations}

The development of the PDM follows closely the development of the pore and surface diffusion model (PSDM) available in the literature (Friedman, 1984; Crittenden et al., 1986). A more complete derivation of the PDM is presented in Appendix XI. The PDM was developed by eliminating the effects of surface diffusion from the PSDM and by modifying the coupling equation to use the Langmuir equilibrium approach appropriate for ion exchange rather than the Freundlich equilibrium expression used for adsorption processes. The PDM equations describe the fate of an ion, i, within an exchange column. The liquid phase equivalent balance for each ion in dimensionless form is given as:

$$
-\frac{\partial\left[\bar{X}_{i}(\bar{z}, T)\right]}{\partial \bar{z}}=\frac{1}{\left(D g_{T}+1\right)} \frac{\partial \bar{X}_{i}(\bar{z}, T)}{\partial T}+3 S t_{i}\left[\bar{X}_{i}(\bar{z}, T)-\bar{X}_{p, i}(\bar{r}=1, \bar{z}, T)\right]
$$

The terms that appear in Equation 4-12 account for advective flow, accumulation of ions in the liquid phase, and transport from the liquid- to solid-phase by liquidphase transport. The dimensionless initial and boundary conditions for Equation 4-12 are given by Equations 4-13 and 4-14, respectively.

$$
\begin{aligned}
& \bar{X}_{i}(0 \leq \bar{z} \leq 1, T=0)=0 \\
& \bar{X}_{i}(\bar{z}=0, T \geq 0)=\frac{C_{0, i}(t)}{\overline{C_{T, \text { avg }}}}
\end{aligned}
$$

The dimensionless form of the intraparticle equivalent balance is expressed by:

$$
\frac{1}{\bar{r}} \frac{\partial}{\partial \bar{r}}\left[\bar{r}^{2} E_{d_{p, i}} \frac{\partial \bar{X}_{p, i}(\bar{r}, \bar{z}, T)}{\partial \bar{r}}\right]=\left(\frac{D g_{T}}{D g_{T}+1}\right) \frac{\partial \bar{Y}_{i}(\bar{r}, \bar{z}, T)}{\partial T}
$$


The dimensionless initial and boundary conditions for the intraparticle equivalent balance are shown in Equations 4-16, 4-17, and 4-18, respectively, with the exception that the solid-phase presaturant concentration is equal to the total resin capacity at $T$ equal to zero.

$$
\begin{gathered}
\bar{Y}_{i}(0 \leq \bar{r} \leq 1,0 \leq \bar{Z} \leq 1, T=0)=0 \\
\frac{\partial}{\partial \bar{r}}\left[\bar{Y}_{i}(\bar{r}=0,0 \leq \bar{Z} \leq 1, T)\right]=0 \\
\left(\frac{D g_{T}}{D g_{T}+1}\right) \frac{\partial}{\partial T} \int_{0}^{1} \bar{Y}_{i}(\bar{r}, \bar{Z}, T) r^{2} d \bar{r}=S_{i}\left[\bar{X}_{i}(\bar{Z}, T)-\bar{X}_{p, i}(\bar{r}=1, \bar{z}, T)\right]
\end{gathered}
$$

The coupling equation which relates the equivalent fraction of component $i$ in the liquid in the resin pores to the equivalent fraction exchanged on the resin surface is given in dimensionless form in Equation 4-19.

$$
\bar{X}_{p, i}(\bar{r}, \bar{z}, T)=\frac{\bar{C}_{T}(\bar{z}, T)\left[\bar{Y}_{i}(\bar{r}, \bar{z}, T)\right]}{\sum_{j} \alpha_{j}^{i}\left[\bar{Y}_{j}(\bar{r}, \bar{z}, T)\right]}
$$

The orthogonal collocation method is used to convert the partial differential equations shown above into a set of ordinary differential equations (Finlayson, 1972, 1980; Villadsen and Michelsen, 1978). The set of ordinary differential equations is solved using the backward differentiation method formula (up to order five), also called Gear's stiff method (Gear, 1971).

\subsection{Model Input Parameters}

This model requires separation factors, kinetic parameters, column conditions, and resin properties for input. The model output includes breakthrough profiles for each ion in the system. 


\subsubsection{Equilibrium Parameters}

The equilibrium parameters required for ion exchange model calculations are the separation factors and total resin capacity. Refer to MATERIALS AND METHODS section for a description of these parameters.

\subsubsection{Kinetic Parameters}

External (film) mass transfer coefficients and pore diffusivities of the ions are needed for model calculations. Methods for estimating these values are discussed below.

For the case of ion exchange onto a strong acid cation resin, the film mass transfer coefficient for ion exchange is estimated using a correlation presented by Wildhagen (Wildhagen et al., 1985).

$$
k_{f, i}=\left(\frac{D_{l, i}}{d}\right)\left(\frac{0.86}{\varepsilon}\right) \operatorname{Re}^{1 / 2} \operatorname{Sc}_{i}^{1 / 3}
$$

This correlation was applied to cation exchange because it was developed for cation exchange and it was found to work well for cation exchange in this study.

The above correlation did not work as well for anion exchange. Therefore, the correlation presented by Gnielinski (1978) was used to estimate the film transfer coefficient for anions because it gave better results:

$$
\mathrm{k}_{\mathrm{f}, \mathrm{i}}=\frac{[1+1.5(1-\varepsilon)] \mathrm{D}_{\mathrm{l}, \mathrm{i}}}{\mathrm{d}}\left[2+0.644 \mathrm{Re}^{1 / 2} \mathrm{Sc}_{\mathrm{i}}^{1 / 3}\right]
$$

The pore diffusion coefficient for ion exchange is estimated using the liquid diffusivity of the ion and the resin particle tortuosity:

$$
D_{p, i}=\frac{D_{l, i}}{\tau_{p}}
$$


The liquid diffusivity $\left(D_{l, i}\right)$ for each ion in Equation $4-22$ is calculated by the Nernst-Haskell correlation (Reid et al., 1987). The particle tortuosity was set equal to one, which would yield the largest possible value for the pore diffusion coefficient. This study found that setting the tortuosity equal to one produced good results, which is consistent with a wide open pore space as may be found with gel type resins.

\section{Results and Discussion}

Binary and multicomponent column experiments were performed on the IRN-77 SAC and IRN-78 SBA exchange resins. The PDM was used to predict the ion exchange breakthrough profiles for each of the four cases. For comparative purposes, the tanks in series equilibrium model (TISEqM) was used to predict the binary and multicomponent IRN-77 SAC exchange bed performance (Hokanson, 2004). Table 4-4 shows the resin properties fed to the model for each of the four model simulations. Table $4-5$ summarizes the bed parameters used in each of the four model simulations. Table 4-6 provides the physical properties of each of the ions simulated for each of the four cases.

Table 4-7 gives the mass transfer parameters and dimensionless groups of the ions for each of the same four model simulations. The mass transfer parameters of each ion, $\mathrm{i}$, shown in Table 4-7 $\left(\mathrm{k}_{\mathrm{f}, \mathrm{i}}\right.$ and $\left.\mathrm{D}_{\mathrm{p}, \mathrm{i}}\right)$ were calculated using the methods presented in Equations 4-20 through 4-22. 
Table 4-4 - Resin Properties for Each of the PDM Simulations

\begin{tabular}{|l|c|c|c|c|}
\hline \multirow{2}{*}{ Property } & \multicolumn{4}{|c|}{ Simulation } \\
\cline { 2 - 5 } & $\begin{array}{c}\text { Binary } \\
\text { IRN-77 SAC }\end{array}$ & $\begin{array}{c}\text { Multicomponent } \\
\text { IRN-77 SAC }\end{array}$ & $\begin{array}{c}\text { Binary } \\
\text { IRN-78 SBA }\end{array}$ & $\begin{array}{c}\text { Multicomponent } \\
\text { IRN-78 SBA }\end{array}$ \\
\hline $\begin{array}{l}\text { Average } \\
\text { Diameter (cm) }\end{array}$ & 0.0595 & 0.0595 & 0.0595 & 0.0595 \\
\hline $\begin{array}{l}\text { Apparent Dry } \\
\text { Density (g/cm }\end{array}$ & 0.63 & 0.63 & 0.56 & 0.56 \\
\hline $\begin{array}{l}\text { Apparent Wet } \\
\text { Density (g/cm }\end{array}$ & 1.24 & 1.24 & 1.10 & 1.10 \\
\hline $\begin{array}{l}\text { Particle Void } \\
\text { Fraction (-) }\end{array}$ & 0.58 & 0.58 & 0.49 & 0.49 \\
\hline $\begin{array}{l}\text { Particle } \\
\text { Tortuosity (-) }\end{array}$ & 1.0 & 1.0 & 1.0 & 1.0 \\
\hline $\begin{array}{l}\text { Total Capacity } \\
\text { (meq/mL bed) }\end{array}$ & 2.12 & 2.20 & 1.61 & 1.04 \\
\hline $\begin{array}{l}\text { Total Capacity } \\
\text { (meq/mL resin) }\end{array}$ & 3.15 & 3.15 & 1.99 & 1.5 \\
\hline
\end{tabular}


Table 4-5 - Bed Parameters for Each of the PDM Simulations

\begin{tabular}{|l|c|c|c|c|}
\hline \multirow{2}{*}{ Property } & \multicolumn{4}{|c|}{ Simulation } \\
\cline { 2 - 5 } & $\begin{array}{c}\text { Binary } \\
\text { IRN-77 SAC }\end{array}$ & $\begin{array}{c}\text { Multicomponent } \\
\text { IRN-77 SAC }\end{array}$ & $\begin{array}{c}\text { Binary } \\
\text { IRN-78 SBA }\end{array}$ & $\begin{array}{c}\text { Multicomponent } \\
\text { IRN-78 SBA }\end{array}$ \\
\hline $\begin{array}{l}\text { Hydraulic } \\
\text { Loading } \\
\text { (m/hr) }\end{array}$ & 4.52 & 1.46 & 3.78 & 1.45 \\
\hline $\begin{array}{l}\text { Flowrate } \\
\text { (mL/min) }\end{array}$ & 42.8 & 13.8 & 35.8 & 13.6 \\
\hline EBCT (min) & 1.30 & 3.95 & 0.809 & 8.71 \\
\hline $\begin{array}{l}\text { Bed Length } \\
\text { (cm) }\end{array}$ & 9.80 & 9.60 & 5.10 & 21.0 \\
\hline $\begin{array}{l}\text { Bed } \\
\text { Diameter } \\
\text { (cm) }\end{array}$ & 2.69 & 2.69 & 2.69 & 2.68 \\
\hline $\begin{array}{l}\text { Mass of Dry } \\
\text { Resin (g) }\end{array}$ & 23.6 & 24.0 & 13.1 & 47.5 \\
\hline $\begin{array}{l}\text { Mass of Wet } \\
\text { Resin (g) }\end{array}$ & 46.5 & 47.2 & 23.4 & 93.4 \\
\hline $\begin{array}{l}\text { Bed Density } \\
\left.\text { (g wet/cm }{ }^{3}\right)\end{array}$ & 0.835 & 0.865 & 0.807 & 0.788 \\
\hline $\begin{array}{l}\text { Void Fraction } \\
\text { of Bed (-) }\end{array}$ & 0.327 & 0.302 & 0.266 & 0.284 \\
\hline $\begin{array}{l}\text { Number of } \\
\text { Axial } \\
\text { Elements }\end{array}$ & 1 & 16 & 16 & 4 \\
\hline
\end{tabular}


Table 4-6 - Properties of the lons Used in Each of the PDM Simulations

\begin{tabular}{|c|c|c|c|c|c|c|c|}
\hline \multirow[t]{2}{*}{ Simulation } & \multirow[t]{2}{*}{ Ion, i } & \multirow{2}{*}{$\begin{array}{c}\text { Molecular } \\
\text { Weight } \\
(\mathrm{mg} / \mathrm{mmol})\end{array}$} & \multicolumn{2}{|c|}{$\begin{array}{c}\text { Influent } \\
\text { Concentration }\end{array}$} & \multirow{2}{*}{$\begin{array}{c}\text { Valence } \\
(-)\end{array}$} & \multirow[t]{2}{*}{$\lambda_{+}^{0}$ or $\lambda_{-}^{0 \mathrm{c}, \mathrm{d}}$} & \multirow{2}{*}{$\begin{array}{l}\text { Separation } \\
\text { Factor } \\
\alpha_{\text {presaturant }}^{i}\end{array}$} \\
\hline & & & $\mathrm{meq} / \mathrm{L}$ & $\mathrm{mg} / \mathrm{L}$ & & & \\
\hline \multirow{2}{*}{$\begin{array}{c}\text { Binary } \\
\text { IRN-77 } \\
\text { SAC }\end{array}$} & Sodium & 22.99 & 10.4 & 239 & 1 & 50.1 & 1.68 \\
\hline & Hydrogen $^{a}$ & 1.01 & $2.24 \times 10^{-3}$ & $2.26 \times 10^{-3}$ & 1 & 349.8 & 1.00 \\
\hline \multirow{5}{*}{$\begin{array}{l}\text { Multi- } \\
\text { component } \\
\text { IRN-77 } \\
\text { SAC }\end{array}$} & Sodium & 22.99 & 2.34 & 53.8 & 1 & 50.1 & 1.68 \\
\hline & Potassium & 39.10 & 2.21 & 86.4 & 1 & 73.5 & 2.15 \\
\hline & Ammonium & 18.04 & 2.68 & 48.4 & 1 & 73.4 & 1.72 \\
\hline & Calcium & 40.08 & 2.38 & 47.7 & 2 & 59.5 & 59.1 \\
\hline & Hydrogen $^{a}$ & 1.01 & $1.00 \times 10^{-4}$ & $1.01 \times 10^{-4}$ & 1 & 349.8 & 1.00 \\
\hline \multirow{2}{*}{$\begin{array}{l}\text { Binary } \\
\text { IRN-78 } \\
\text { SBA }\end{array}$} & lodide & 126.90 & 8.99 & $1.14 \times 10^{3}$ & 1 & 76.8 & 38.2 \\
\hline & Chloride $^{a}$ & 35.45 & $5.00 \times 10^{-4}$ & 0.0177 & 1 & 76.3 & 1 \\
\hline \multirow{6}{*}{$\begin{array}{l}\text { Multi- } \\
\text { component } \\
\text { IRN-78 } \\
\text { SBA }^{\mathrm{b}}\end{array}$} & Acetate & 59.03 & 1.93 & 114 & 1 & 40.9 & 1.99 \\
\hline & Butyrate & 87.07 & 2.01 & 175 & 1 & 32.6 & 3.21 \\
\hline & Chloride & 35.45 & 1.96 & 69.6 & 1 & 76.3 & 16.7 \\
\hline & Bicarbonate & 61.01 & 2.02 & 123 & 1 & 44.5 & 4.99 \\
\hline & Sulfate & 96.10 & 2.00 & 96.3 & 2 & 80.0 & 149 \\
\hline & Hydroxide $^{a}$ & 17.01 & $1.00 \times 10^{-4}$ & $1.70 \times 10^{-3}$ & 1 & 197.6 & 1.00 \\
\hline
\end{tabular}

a Denotes presaturant ion

b For this experiment, the resin was presaturated with $71 \%$ hydroxide and $29 \%$ chloride ions

c Limiting ionic conductance of cation $\left(\lambda_{+}^{0}\right)$ or anion $\left(\lambda_{-}^{0}\right)$ in units of $\left\{\left(\mathrm{A} / \mathrm{cm}^{2}\right)(\mathrm{V} / \mathrm{cm})\left(\mathrm{g}-\right.\right.$ equiv $\left.\left./ \mathrm{cm}^{3}\right)\right\}$. Values taken from Reid, Prausnitz and Poling (1987). 
Table 4-7 - Mass Transfer Parameters and Dimensionless Groups for Each of the PDM Simulations

\begin{tabular}{|c|c|c|c|c|c|c|c|c|c|c|}
\hline Simulation & Ion, i & $\begin{array}{c}D_{1, i}^{c, d} \\
\left(\mathbf{c m}^{2} / \mathbf{s}\right)\end{array}$ & $\begin{array}{c}k_{\mathrm{f}, \mathrm{i}} \\
(\mathbf{c m} / \mathbf{s})\end{array}$ & $\begin{array}{c}D_{p, i} \\
\left(\mathbf{c m}^{2} / \mathbf{s}\right)\end{array}$ & $\begin{array}{c}\mathrm{Dg}_{\mathrm{s}} \\
(-)\end{array}$ & $\begin{array}{l}D g_{p} \\
(-)\end{array}$ & $\begin{array}{c}\mathrm{Dg}_{\mathrm{T}} \\
(-)\end{array}$ & $\begin{array}{c}E d_{p, i} \\
(-)\end{array}$ & $\begin{array}{l}S t_{i} \\
(-)\end{array}$ & $\begin{array}{l}\mathrm{Bi}_{\mathrm{p}, \mathrm{i}} \\
(-)\end{array}$ \\
\hline \multirow{2}{*}{$\begin{array}{c}\text { Binary } \\
\text { IRN-77 SAC } \\
\text { Prediction } \\
\end{array}$} & Sodium & $1.59 \times 10^{-5}$ & $9.11 \times 10^{-3}$ & $1.59 \times 10^{-5}$ & \multirow{2}{*}{624} & \multirow{2}{*}{1.20} & \multirow{2}{*}{625} & 0.545 & 16.1 & 29.5 \\
\hline & Hydrogen $^{a}$ & $3.29 \times 10^{-5}$ & $1.48 \times 10^{-2}$ & $3.29 \times 10^{-5}$ & & & & 1.13 & 26.1 & 23.1 \\
\hline \multirow{2}{*}{$\begin{array}{c}\text { Binary } \\
\text { IRN-77 SAC } \\
\text { Fit }\end{array}$} & Sodium & $1.59 \times 10^{-5}$ & $8.96 \times 10^{-3}$ & $1.36 \times 10^{-4}$ & \multirow{2}{*}{624} & \multirow{2}{*}{1.20} & \multirow{2}{*}{625} & 4.66 & 15.8 & 3.39 \\
\hline & Hydrogen $^{a}$ & $3.29 \times 10^{-5}$ & $1.46 \times 10^{-2}$ & $2.81 \times 10^{-4}$ & & & & 9.65 & 25.6 & 2.66 \\
\hline \multirow{5}{*}{$\begin{array}{l}\text { Multi- } \\
\text { component } \\
\text { IRN-77 SAC } \\
\text { Prediction }\end{array}$} & Sodium & $1.59 \times 10^{-5}$ & $5.80 \times 10^{-3}$ & $1.59 \times 10^{-5}$ & \multirow{5}{*}{756} & \multirow{5}{*}{1.34} & \multirow{5}{*}{757} & 1.72 & 32.2 & 18.8 \\
\hline & Potassium & $1.97 \times 10^{-5}$ & $6.69 \times 10^{-3}$ & $1.97 \times 10^{-5}$ & & & & 2.13 & 37.1 & 17.5 \\
\hline & Ammonium & $1.96 \times 10^{-5}$ & $6.68 \times 10^{-3}$ & $1.96 \times 10^{-5}$ & & & & 2.12 & 37.1 & 17.5 \\
\hline & Calcium & $1.32 \times 10^{-5}$ & $5.12 \times 10^{-3}$ & $1.32 \times 10^{-5}$ & & & & 1.42 & 28.4 & 20.0 \\
\hline & Hydrogen $^{a}$ & $3.29 \times 10^{-5}$ & $9.42 \times 10^{-3}$ & $3.29 \times 10^{-5}$ & & & & 3.56 & 52.3 & 14.7 \\
\hline \multirow{5}{*}{$\begin{array}{c}\text { Multi- } \\
\text { component } \\
\text { IRN-77 SAC } \\
\text { Fit }\end{array}$} & Sodium & $1.59 \times 10^{-5}$ & $5.70 \times 10^{-3}$ & $1.36 \times 10^{-4}$ & \multirow{5}{*}{756} & \multirow{5}{*}{1.34} & \multirow{5}{*}{757} & 14.7 & 31.7 & 2.16 \\
\hline & Potassium & $1.97 \times 10^{-5}$ & $6.57 \times 10^{-3}$ & $1.68 \times 10^{-4}$ & & & & 18.2 & 36.5 & 2.01 \\
\hline & Ammonium & $1.96 \times 10^{-5}$ & $6.57 \times 10^{-3}$ & $1.68 \times 10^{-4}$ & & & & 18.2 & 36.5 & 2.01 \\
\hline & Calcium & $1.32 \times 10^{-5}$ & 4.88 & $3.78 \times 10^{-6}$ & & & & 0.409 & $2.71 \times 10^{4}$ & $6.63 \times 10^{4}$ \\
\hline & Hydrogen $^{a}$ & $3.29 \times 10^{-5}$ & $9.26 \times 10^{-3}$ & $2.81 \times 10^{-4}$ & & & & 30.4 & 51.4 & 1.69 \\
\hline \multirow{2}{*}{$\begin{array}{c}\text { Binary } \\
\text { IRN-78 SBA } \\
\text { Prediction }\end{array}$} & lodide & $1.59 \times 10^{-5}$ & $5.82 \times 10^{-3}$ & $1.59 \times 10^{-5}$ & \multirow{2}{*}{927} & \multirow{2}{*}{2.05} & \multirow{2}{*}{929} & 0.343 & 7.66 & 22.3 \\
\hline & Chloride $^{a}$ & $1.58 \times 10^{-5}$ & $5.81 \times 10^{-3}$ & $1.58 \times 10^{-5}$ & & & & 0.342 & 7.64 & 22.3 \\
\hline \multirow{2}{*}{$\begin{array}{c}\text { Binary } \\
\text { IRN-78 SBA } \\
\text { Fit }\end{array}$} & lodide & $1.59 \times 10^{-5}$ & $5.73 \times 10^{-3}$ & $3.60 \times 10^{-5}$ & \multirow{2}{*}{927} & \multirow{2}{*}{2.05} & \multirow{2}{*}{929} & 0.778 & 7.53 & 9.68 \\
\hline & Chloride $^{a}$ & $1.58 \times 10^{-5}$ & $5.72 \times 10^{-3}$ & $3.59 \times 10^{-5}$ & & & & 0.776 & 7.52 & 9.69 \\
\hline
\end{tabular}


Table 4-7 - (continued)

\begin{tabular}{|c|c|c|c|c|c|c|c|c|c|c|}
\hline Simulation & Ion, i & $\begin{array}{c}D_{l, i}{ }^{c, d} \\
\left(\mathbf{c m}^{2} / s\right)\end{array}$ & $\begin{array}{c}k_{f, i} \\
(\mathbf{c m} / \mathbf{s})\end{array}$ & $\begin{array}{c}D_{p, i} \\
\left(\mathbf{c m}^{2} / \mathbf{s}\right)\end{array}$ & $\begin{array}{c}\mathrm{Dg}_{\mathrm{s}} \\
(-)\end{array}$ & $\begin{array}{c}\mathrm{Dg}_{p} \\
(-)\end{array}$ & $\begin{array}{c}\mathrm{Dg}_{\mathrm{T}} \\
(-)\end{array}$ & $\begin{array}{c}E d_{p, i} \\
(-)\end{array}$ & $\begin{array}{l}\mathrm{St}_{\mathrm{i}} \\
(-)\end{array}$ & $\begin{array}{c}B i_{p, i} \\
(-)\end{array}$ \\
\hline \multirow{6}{*}{$\begin{array}{l}\text { Multi- } \\
\text { component } \\
\text { IRN-78 SBA }^{\mathrm{b}} \\
\text { Prediction }\end{array}$} & Acetate & $1.18 \times 10^{-5}$ & $3.13 \times 10^{-3}$ & $1.18 \times 10^{-5}$ & \multirow{6}{*}{371} & \multirow{6}{*}{1.24} & \multirow{6}{*}{372} & 2.44 & 39.3 & 16.1 \\
\hline & Butyrate & $1.04 \times 10^{-5}$ & $2.84 \times 10^{-3}$ & $1.04 \times 10^{-5}$ & & & & 2.14 & 35.6 & 16.6 \\
\hline & Chloride & $1.59 \times 10^{-5}$ & $3.91 \times 10^{-3}$ & $1.59 \times 10^{-5}$ & & & & 3.28 & 49.1 & 15.0 \\
\hline & Bicarbonate & $1.24 \times 10^{-5}$ & $3.24 \times 10^{-3}$ & $1.24 \times 10^{-5}$ & & & & 2.55 & 40.7 & 15.9 \\
\hline & Sulfate & $1.21 \times 10^{-5}$ & $3.19 \times 10^{-3}$ & $1.21 \times 10^{-5}$ & & & & 2.50 & 40.1 & 16.0 \\
\hline & Hydroxide $^{a}$ & $2.10 \times 10^{-5}$ & $4.84 \times 10^{-3}$ & $2.10 \times 10^{-5}$ & & & & 4.33 & 60.8 & 14.0 \\
\hline
\end{tabular}

Denotes presaturant ion

b For this experiment, the resin was presaturated with $71 \%$ hydroxide and $29 \%$ chloride ions

c For cation exchange on IRN-77 SAC exchange resin, counter-anion is set to chloride in the Nernst-Haskell expression.

d For anion exchange on IRN-78 SBA exchange resin, counter-cation is set to sodium in the Nernst-Haskell expression. 
Figure 4-1 shows the pore diffusion model (PDM) prediction using correlated values of pore diffusion coefficient $\left(D_{p}\right)$ and ionic transport coefficient $\left(k_{f}\right)$, as well as two model fits, (1) PDM fit of $D_{p}, k_{f}$ and (2) a tanks in series equilibrium model (TISEqM) fit of number of tanks, compared to experimental data for a binary ion exchange column run for sodium exchanging the hydrogen form of IRN-77 SAC exchange resin. Figure 4-1 demonstrates that the PDM was able to predict the breakthrough profiles for the binary simulation on IRN-77 SAC exchange resin. However, while the column capacities appear to be predicted quite well, the kinetic parameters could be adjusted to more accurately fit the shape of the profiles $\left(f_{o b j}=0.0246\right)$. Figure $4-1$ shows that the mass transfer rate predicted using the correlations for $D_{p}$ and $k_{f}$ is slower than the mass transfer rate effect observed in the experimental data and that the correlated mass transfer parameters appear to overestimate the impact of mass transfer on the binary ion exchange column experiment. Figure 4-1 also shows a PDM fit of the data and a TISEqM fit of the data, as described above. It is clear from Figure 4-1 that the PDM fit of $D_{p}$ and $k_{f}\left(f_{o b j}=8.44 \times 10^{-4}\right)$ and the TISEqM fit $\left(f_{o b j}=7.34 \times 10^{-4}\right)$ are similar and both are capable of fitting the binary IRN-77 SAC ion exchange data and improving on the PDM prediction. The PDM fit values of $D_{p}$ and $k_{f}$ are equal to factors of 8.55 and 0.983 times the correlated $D_{p}$ and $k_{f}$ values determined from Equations 4-20 and 4-22, respectively, and the factors are applied to both ions. The TISEqM fit value of 13 tanks is equal to 13 tanks per 1.3 minutes EBCT, which equals 10 tanks per minute EBCT. 


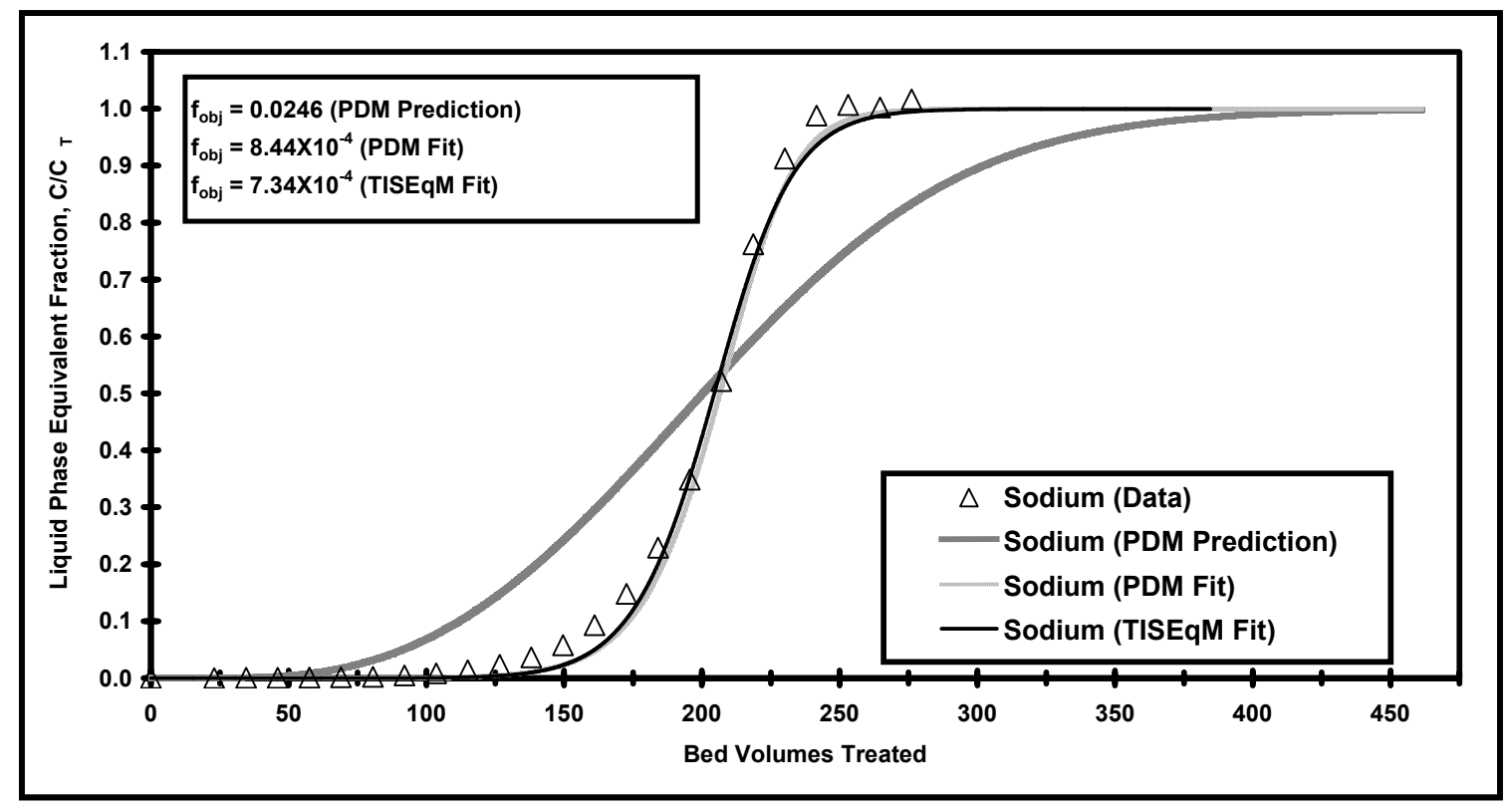

Figure 4-1 - Binary lon Exchange Column Results for Sodium Exchanging IRN-77 SAC Exchange Resin in the Hydrogen Form: PDM Prediction, PDM Fit and TISEqM Fit versus Experimental Data for Sodium.

Figure 4-2 shows the 95\% confidence contour for the PDM fit. Table 4-8 shows a sensitivity analysis on film transfer coefficient, $k_{f}$, and pore diffusion coefficient, $D_{p}$, for the PDM fit. The $95 \%$ confidence contour shown on Figure 42 and the sensitivity analysis shown in Table 4-8 both demonstrate that the PDM is sensitive to both changes in $k_{f}$ and $D_{p}$, but that the PDM is slightly more sensitive to changes in $k_{f}$ than to changes in $D_{p}$. This confirms the necessity of the multiparameter PDM fit of the binary ion exchange data. 


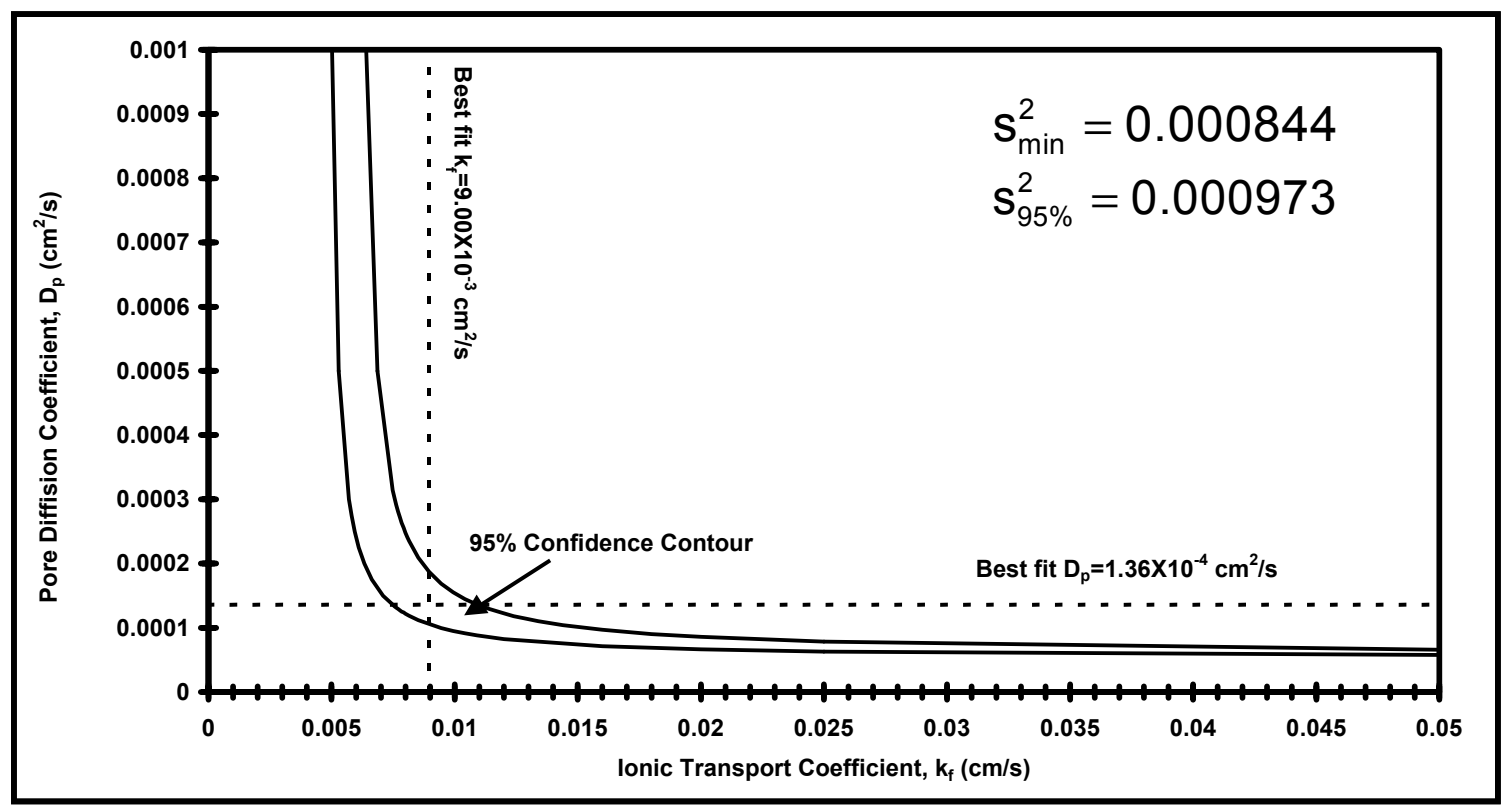

Figure 4-2 - 95\% Confidence Contour for Binary Ion Exchange Column Results for Sodium Exchanging IRN-77 SAC Exchange Resin in the Hydrogen Form.

Table 4-8 - Sensitivity Analysis for the Binary IRN-77 SAC Fit on the Effect of Varying Pore Diffusion Coefficient, $D_{p}$, and Film Transfer Coefficient, $k_{f}$, by plus or minus $50 \%$ of Their PDM Fit Values Shown in Table 7 and Observing the Impact on the Objective Function, $f_{o b j}$, Compared to the PDM Fit $\left(f_{\text {obj }}=0.000844\right)$

\begin{tabular}{|l|c|c|c|c|c|}
\hline Simulation & $\Delta \mathrm{St}$ & $\Delta \mathrm{Ed}_{\mathrm{p}}$ & $\Delta \mathrm{Bi}_{\mathrm{p}}$ & $\mathrm{f}_{\mathrm{obj}}$ & Change in $\mathrm{f}_{\mathrm{obj}}$ \\
\hline$-50 \% \mathrm{D}_{\mathrm{p}}$ & $0 \%$ & $-50 \%$ & $+100 \%$ & 0.00212 & $+251 \%$ \\
\hline$+50 \% \mathrm{D}_{\mathrm{p}}$ & $0 \%$ & $+50 \%$ & $-33.3 \%$ & 0.00104 & $+123 \%$ \\
\hline$-50 \% \mathrm{k}_{\mathrm{f}}$ & $-50 \%$ & $0 \%$ & $-50 \%$ & 0.00332 & $+393 \%$ \\
\hline$+50 \mathrm{k}_{\mathrm{f}}$ & $+50 \%$ & $0 \%$ & $+50 \%$ & 0.00131 & $+155 \%$ \\
\hline
\end{tabular}


Table 4-9 shows a comparison of objective function $\left(\mathrm{f}_{\mathrm{obj}}\right)$ and average sum of the squares of the residuals $\left(s^{2}\right)$ for several PDM and TISEqM predictions and fits of the multicomponent ion exchange column run for IRN-77 SAC exchange resin in the hydrogen form. From Table 4-9, it is observed that the PDM prediction based on correlated $k_{f}$ and $D_{p}$ values $\left(f_{o b j}=0.0429\right)$ can be improved by using a PDM prediction based on adjusting the $D_{p}$ and $k_{f}$ values for each ion by the factors determined from the binary IRN-77 SAC exchange experiment of 8.55 and 0.983 , respectively $\left(\mathrm{f}_{\mathrm{obj}}=0.0340\right)$. However, it is seen from Table 4-9 by comparing the average sum of the squares of the residuals that the predictions for the two strongest exchanging ions (calcium and potassium) are not improved by using the adjusted $k_{f}$ and $D_{p}$ values $\left(s_{\mathrm{Ca}}^{2}=0.0150, \mathrm{~s}_{\mathrm{K}}^{2}=0.00746\right)$ as opposed to the correlated $\mathrm{k}_{\mathrm{f}}$ and $\mathrm{D}_{\mathrm{p}}$ values $\left(\mathrm{s}_{\mathrm{Ca}}^{2}=0.0191, \mathrm{~s}_{\mathrm{K}}^{2}=0.00961\right)$. Figures $4-3$ and $4-4$ show a comparison of the PDM predictions versus experimental data for correlated $D_{p}$ and $k_{f}$ values for potassium and calcium, respectively. From Figure 4-4, it is observed that the PDM does not predict the calcium exchange well based on correlated $D_{p}$ and $k_{f}$ values. From Figure 4-3, it is shown that the potassium data is not predicted well in the tail end of the profile where the calcium exchanging onto the resin causes the potassium ion to be removed from the resin. This suggests that the strongest exchanging ion, calcium, is not well represented by the predictions and that it could be beneficial to fit the $k_{f}$ and $D_{p}$ values for calcium while still calculating the adjusted $D_{p}$ and $k_{f}$ values for other ions based on the factors of 8.55 and 0.983 , respectively, compared to correlated values. It is expected that if the calcium 
Table 4-9 - Summary of Values of Objective Function $\left(f_{\text {obj }}\right)$ and Average Sum of the Squares of the Residuals $\left(s^{2}\right)$ for Each PDM and TISEqM Simulation for the Multicomponent Case of Sodium, Potassium, Ammonium, and Calcium Exchanging IRN-77 SAC Exchange Resin in the Hydrogen Form.

\begin{tabular}{|c|c|c|c|c|c|}
\hline \multicolumn{6}{|c|}{ PDM Simulations of Multicomponent SAC Data } \\
\hline Description & $f_{o b j}$ & $\mathrm{~s}_{\mathrm{Na}}^{2}$ & $s_{K}^{2}$ & $\mathrm{~S}_{\mathrm{NH} 4}^{2}$ & $\mathrm{~s}_{\mathrm{Ca}}^{2}$ \\
\hline $\begin{array}{l}\text { Prediction (Correlated } D_{p} \\
\left.\text { and } k_{f}\right)^{1}\end{array}$ & 0.0429 & 0.118 & 0.00746 & 0.0315 & 0.0150 \\
\hline $\begin{array}{l}\text { Prediction }\left(\mathrm{D}_{\mathrm{p}} \mathrm{X8.55}\right. \\
\left.\mathrm{k}_{\mathrm{f}} \mathrm{X} 0.983\right)^{2}\end{array}$ & 0.0340 & 0.0801 & 0.00961 & 0.0191 & 0.0272 \\
\hline $\begin{array}{l}\text { Fit }\left(D_{p} \times 8.55, k_{f} \times 0.983\right. \\
\text { except Ca best fit })^{3}\end{array}$ & 0.0217 & 0.0647 & 0.00378 & 0.0145 & 0.00393 \\
\hline
\end{tabular}

TISEqM Simulations of Multicomponent SAC Data

\begin{tabular}{|l|c|c|c|c|c|}
\hline Description & $\mathrm{f}_{\mathrm{obj}}$ & $\mathrm{s}_{\mathrm{Na}}^{2}$ & $\mathrm{~s}_{\mathrm{K}}^{2}$ & $\mathrm{~s}_{\mathrm{NH} 4}^{2}$ & $\mathrm{~s}_{\mathrm{Ca}}^{2}$ \\
\hline Best Fit Overall $(68$ tanks) & 0.0287 & 0.0492 & 0.0128 & 0.0207 & 0.0323 \\
\hline $\begin{array}{l}\text { Prediction (No. of Tanks } \\
\text { based on Binary SAC [39 } \\
\text { tanks]) }\end{array}$ & 0.0314 & 0.0689 & 0.00936 & 0.0184 & 0.0290 \\
\hline Fit Na (300 tanks) & 0.0346 & 0.0416 & 0.0268 & 0.0266 & 0.0434 \\
\hline Fit K (22 tanks) & 0.0376 & 0.0940 & 0.00842 & 0.0213 & 0.0267 \\
\hline Fit NH $4(40$ tanks) & 0.0312 & 0.0678 & 0.00946 & 0.0184 & 0.0291 \\
\hline Fit Ca $(2$ tanks) & 0.0754 & 0.173 & 0.0435 & 0.0758 & 0.00955 \\
\hline
\end{tabular}

${ }^{1}$ PDM Prediction (Correlated $D_{p}$ and $\left.k_{f}\right)$. Ionic transport coefficient $\left(k_{f}\right)$ and pore diffusion coefficient $\left(D_{p}\right)$ determined from correlations.

${ }^{2}$ PDM Prediction $\left(D_{p} \times 8.55, k_{f} \times 0.983\right)$. $k_{f}$ determined as 0.983 times the correlated value from (1) above. $D_{p}$ determined as 8.55 times greater than the correlated value from (1) above. The factors of 8.55 times the correlated $D_{p}$ value and 0.983 times the correlated $k_{f}$ value represent the optimum factors determined by fitting binary sodium data for SAC resin in the hydrogen form.

${ }^{3}$ PDM Fit $\left(D_{p} \times 8.55, k_{f} \times 0.983\right.$ except Ca best fit). With the exception of calcium ion, $k_{f}$ determined as 0.983 times the correlated value from (1) above. With the exception of calcium ion, $D_{p}$ determined as 8.55 times greater than the correlated value from (1) above. The factors of 8.55 times the correlated $D_{p}$ value and 0.983 times the correlated $\mathrm{k}_{\mathrm{f}}$ value represent the optimum factors determined by fitting binary sodium data for SAC resin in the hydrogen form. The $k_{f}$ and the $D_{p}$ values for calcium were fit such that $\mathrm{S}_{\mathrm{Ca}}^{2}$ was minimized.

${ }^{4}$ TISEqM Best Fit Overall (68 tanks). Best fit of no. of tanks in TISEqM to minimize $\mathrm{f}_{\text {obj }}$ (equals 68 tanks).

${ }^{5}$ TISEqM Prediction (No. of Tanks based on Binary SAC [39 tanks]). Prediction based on scaling the best fit no. of tanks determined from binary SAC exchange experiment (equals 13 tanks) for EBCT (equals 39 tanks).

${ }^{6}$ TISEqM Fit Na (300 tanks). Fit no. of tanks in TISEqM based on sodium (Na) to minimize $\mathrm{S}_{\mathrm{Na}}^{2}$ (equals 300 tanks).

${ }^{7}$ TISEqM Fit K (22 tanks). Fit no. of tanks in TISEqM based on potassium (K) to minimize $\mathrm{S}_{\mathrm{K}}^{2}$ (equals 22 tanks).

${ }^{8}$ TISEqM Fit $\mathrm{NH}_{4}$ (40 tanks). Fit no. of tanks in TISEqM based on ammonium $\left(\mathrm{NH}_{4}\right)$ to minimize $\mathrm{S}_{\mathrm{NH}_{4}}^{2}$ (equals 40 tanks).

${ }^{9}$ TISEqM Fit Ca (2 tanks). Fit no. of tanks in TISEqM based on calcium (Ca) to minimize $\mathrm{S}_{\mathrm{Ca}}^{2}$ (equals 2 tanks). 


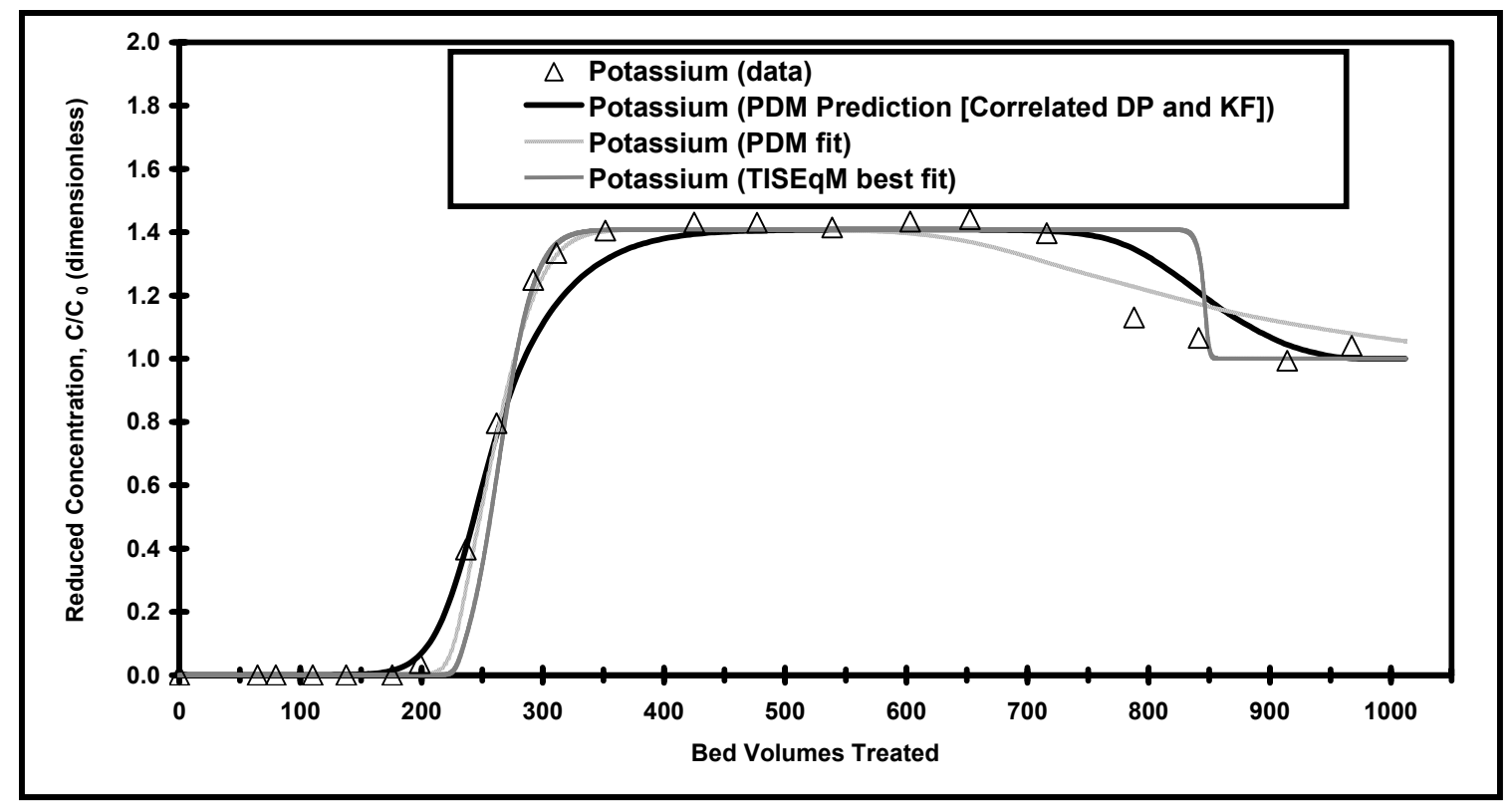

Figure 4-3 - Comparison of Ion Exchange PDM and TISEqM Prediction and Fitting Results for Potassium for Multicomponent Column Run with Sodium, Potassium, Ammonium and Calcium Exchanging onto IRN-77 SAC Exchange Resin in the Hydrogen Form. PDM Prediction, PDM Fit and TISEqM Best Fit.

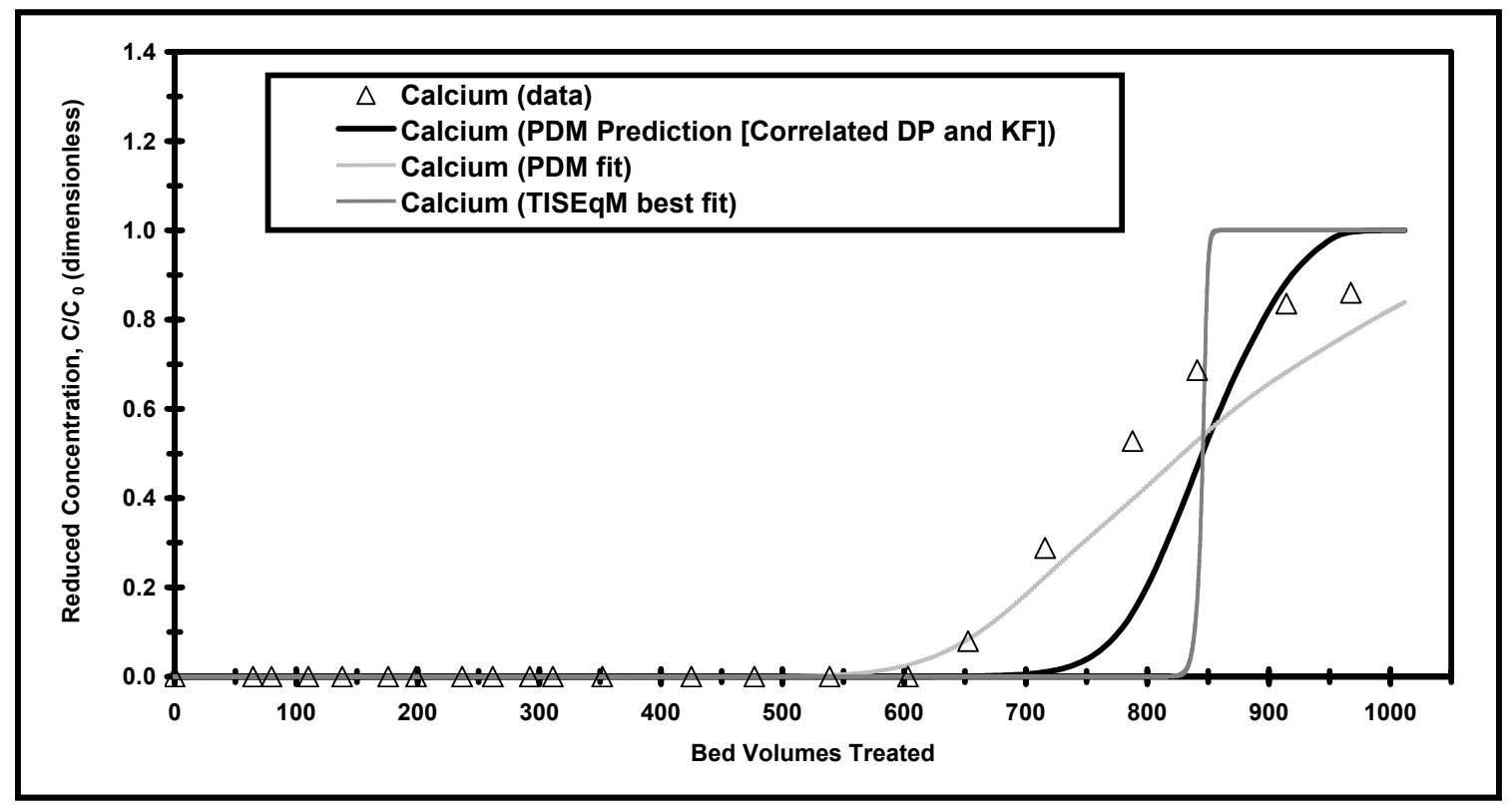

Figure 4-4 - Comparison of Ion Exchange PDM and TISEqM Prediction and Fitting Results for Calcium for Multicomponent Column Run with Sodium, Potassium, Ammonium and Calcium Exchanging onto IRN-77 SAC Exchange Resin in the Hydrogen Form. PDM Prediction, PDM Fit and TISEqM Best Fit. 
exchange profile can be better described, the exchange of the other ions, particularly potassium, will be better described as well.

From Table 4-9, it is observed that the PDM fit $\left(f_{o b j}=0.0217\right)$ of the $D_{p}$ and $k_{f}$ values for calcium compared to the multicomponent IRN-77 SAC exchange experiment results in an improvement on both of the PDM predictions shown in Table 4-9. The PDM fit resulted in improvements for all ions compared to the PDM predictions based on $\mathrm{s}^{2}$ values. The calcium and potassium ions, which are the strongest exchanging ions, are significantly better described by the PDM fit of $D_{p}$ and $k_{f}$ for calcium as shown by the improvement in their $s^{2}$ values compared to the PDM predictions $\left(\mathrm{s}_{\mathrm{Ca}}^{2}=0.00393, \mathrm{~s}_{\mathrm{K}}^{2}=0.00378\right)$. Figures $4-3$ and $4-4$ show a comparison of the PDM fit versus experimental data for potassium and calcium, respectively. From Figure 4-3, it is shown that the potassium data is better described by the simulation employing the results of the PDM fit of $D_{p}$ and $k_{f}$ values for calcium as compared to the PDM prediction based on correlated $D_{p}$ and $\mathrm{k}_{\mathrm{f}}$ values for all ions. It should be noted that the exchange of potassium at the latter portion of the breakthrough profile (after about 550 bed volumes treated) is better described compared to the PDM prediction. This is the region where the breakthrough of the strongest exchanging ion, calcium, is observed, as shown on Figure 4-4. From Figure 4-4, it is shown that the simulation corresponding to the PDM fit of $D_{p}$ and $k_{f}$ values for calcium results in a significant improvement in the description of the experimental data for calcium.

For comparative purposes, simulations of multicomponent IRN-77 SAC exchange column experiment were performed using the equilibrium model, 
TISEqM. Table 4-9 shows the objective function $\left(\mathrm{f}_{\mathrm{obj}}\right)$ and average sum of the squares of the residuals $\left(\mathrm{s}^{2}\right)$ for several TISEqM predictions and fits. From Table 4-9, it is observed that a TISEqM prediction based on scaling the best fit number of tanks for the binary IRN-77 SAC column results based on EBCT (Number of Tanks Predicted for Multicomponent SAC $=$ Best Fit Number of Tanks for Binary SAC [13] times EBCT for multicomponent SAC [3.9 minutes] divided by EBCT for binary SAC [1.3 minutes] = 39) produces a result $\left(f_{o b j}=0.0314\right)$ that is comparable to the PDM prediction based on adjusted $D_{p}$ and $k_{f}$ values $\left(f_{o b j}=0.0340\right)$. The best fit number of tanks to minimize the objective function is equal to 68 and the minimum objective function for the best fit number of tanks is equal to $f_{o b j}=0.287$, as shown in Table 4-9. While this represents an improvement over the TISEqM prediction, it is less of an improvement than the PDM fit described above. The reason is that the number of tanks is a single adjustable parameter that impacts the breakthrough profile for all ions in the same manner. There is no way with the TISEqM to describe the spreading of the wave for each ion individually because diffusivities are different and the various ions would need a different number of tanks to describe the spreading. In contrast, the PDM allows for the description of the spreading of the breakthrough profile for each ion individually based on the mass transfer parameters $D_{p}$ and $k_{f}$.

This is confirmed by examining the $s^{2}$ values for calcium in the TISEqM best fit $\left(\mathrm{s}_{\mathrm{Ca}}^{2}=0.0323\right)$ as well as the TISEqM prediction $\left(\mathrm{s}_{\mathrm{Ca}}^{2}=0.0290\right)$ as compared to the PDM predictions $\left(\mathrm{s}_{\mathrm{Ca}}^{2}=0.0150\right.$ based on correlated $\mathrm{D}_{\mathrm{p}}$ and $\mathrm{k}_{\mathrm{f}}$ values; $\mathrm{s}_{\mathrm{Ca}}^{2}=0.0272$ based on $\mathrm{D}_{\mathrm{p}}$ and $\mathrm{k}_{\mathrm{f}}$ values adjusted by factors of 8.55 and 
0.983, respectively, compared to correlated values) and the PDM fit $\left(s_{\mathrm{Ca}}^{2}=0.00393\right)$. The $\mathrm{s}^{2}$ values for calcium demonstrate that the PDM predictions and fit are able to better describe the calcium data as compared to either the TISEqM prediction or the TISEqM fit. Furthermore, the TISEqM does not allow for fitting the calcium data and improving the overall fit of the multicomponent IRN-77 SAC data. The result of a TISEqM fit of calcium data is shown in the bottom row of Table 4-9 $\left(\mathrm{f}_{\mathrm{obj}}=0.0754\right)$, which demonstrates that the TISEqM fit of calcium is far inferior to the TISEqM prediction $\left(f_{o b j}=0.0314\right)$ or the TISEqM best fit $\left(f_{o b j}=0.0287\right)$. Based on $s^{2}$ values, the TISEqM fit of number of tanks based on minimizing $\mathrm{s}^{2}$ for calcium $\left(\mathrm{s}_{\mathrm{Ca}}^{2}=0.00955\right)$ is also inferior to the PDM fit of $D_{p}$ and $k_{f}$ for calcium $\left(s_{C a}^{2}=0.00393\right)$.

Figures 4-3 and 4-4 show the TISEqM best fit results compared to experimental data, as well as to the PDM fit and PDM prediction based on correlated $D_{p}$ and $k_{f}$ values for potassium and calcium, respectively. From Figures 4-3 and 4-4, it is clear that the TISEqM best fit does not describe the multicomponent IRN-77 SAC experimental data as well as either the PDM fit or the PDM prediction for potassium and calcium, respectively. From Table 4-9, comparing the TISEqM best fit to the PDM fit it is clear from comparing $\mathrm{s}^{2}$ values that the PDM fit represents an improvement over the TISEqM best fit for all ions except sodium. An explanation is that the TISEqM represents a best fit that impacts all ions in the fitting process; whereas, the PDM fit only fit the calcium data and the $D_{p}$ and $k_{f}$ values for sodium were predicted based on the binary ion exchange results. This shows that while fitting the TISEqM for number of tanks 
may represent an improvement for one ion, it is not possible in the fitting exercise to fit the breakthrough profile for multiple ions successfully.

Figure 4-5 shows the pore diffusion model (PDM) prediction using correlated values of pore diffusion coefficient $\left(D_{p}\right)$ and ionic transport coefficient $\left(k_{f}\right)$, as well as a PDM fit of $D_{p}$ and $k_{f}$, compared to experimental data for a binary ion exchange column experiment for iodide exchanging the chloride form of IRN-78 SBA exchange resin. Figure 4-5 shows that the PDM was able to predict the breakthrough profiles for the binary simulation on IRN-78 SBA exchange resin. However, while the column capacities appear to be predicted quite well, the kinetic parameters could be adjusted to more accurately fit the shape of the profiles $\left(f_{o b j}=0.0334\right)$. Figure $4-5$ shows that the mass transfer rate

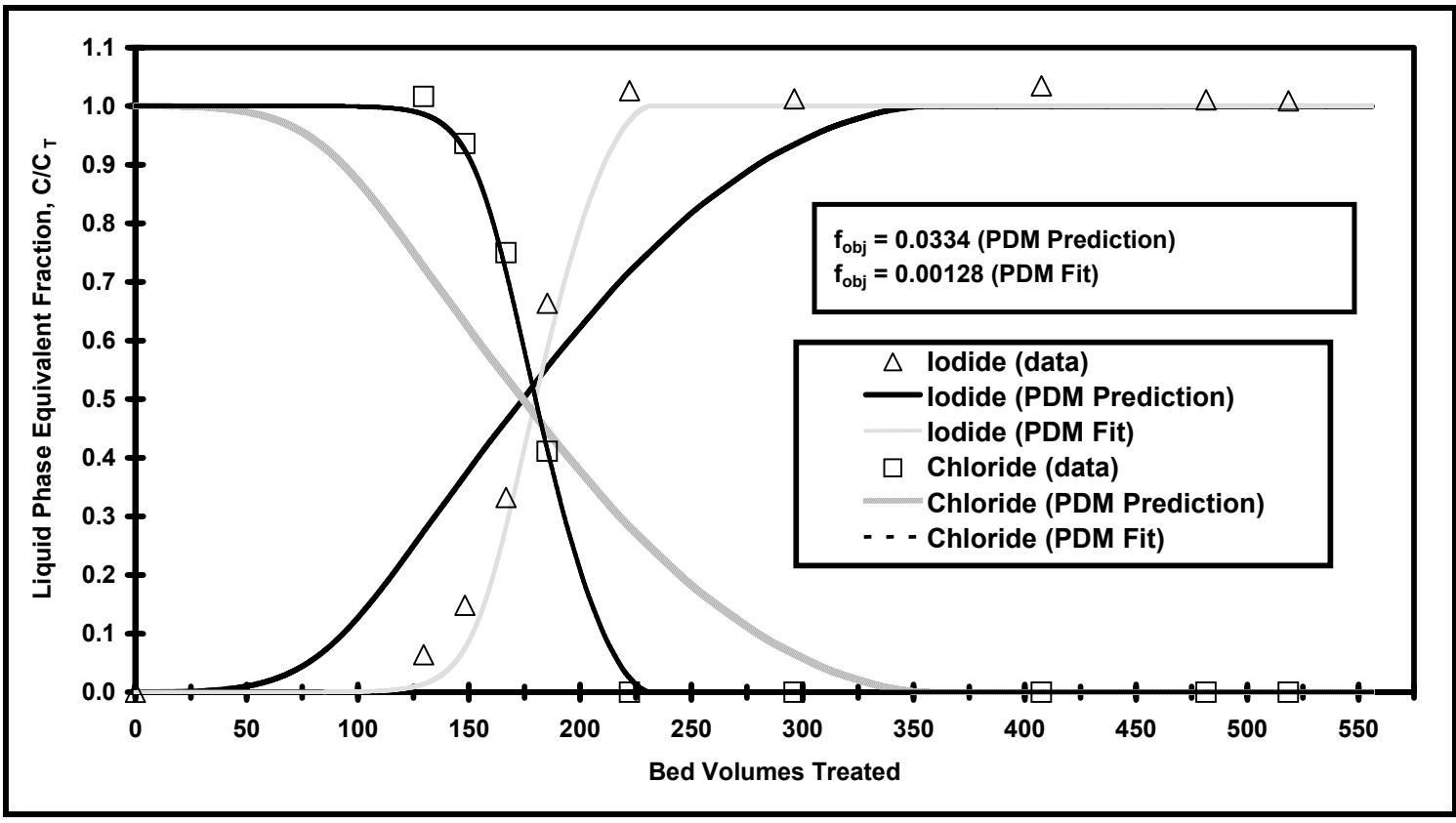

Figure 4-5 - Binary lon Exchange Column Results for lodide Exchanging IRN-78 SBA Exchange Resin in the Chloride Form: PDM Prediction and PDM Fit versus Experimental Data for lodide and Chloride. 
predicted using the correlations for $D_{p}$ and $k_{f}$ is slower than the mass transfer rate effect observed in the experimental data and that the correlated mass transfer parameters appear to overestimate the impact of mass transfer on the binary ion exchange column experiment. This result is consistent with the binary IRN-77 SAC results. Figure 4-5 also shows a PDM fit of the data, as described above. It is clear from Figure 4-5 that the PDM fit of $D_{p}$ and $k_{f}\left(f_{o b j}=0.00128\right)$ is capable of describing the binary IRN-78 SBA ion exchange data and improving on the PDM prediction. The PDM fit values of $D_{p}$ and $k_{f}$ are equal to factors of 2.27 and 0.984 times the correlated $D_{p}$ and $k_{f}$ values determined from Equations 4-20 and 4-22, respectively, and the factors are applied to both ions.

Figure 4-6 shows the 95\% confidence contour for the PDM fit. Table 4-10 shows a sensitivity analysis on film transfer coefficient, $k_{f}$, and pore diffusion coefficient, $D_{p}$, for the PDM fit. The $95 \%$ confidence contour shown on Figure 46 and the sensitivity analysis shown in Table 4-10 both demonstrate that the PDM is sensitive to both changes in $k_{f}$ and $D_{p}$, but that the PDM is more sensitive to changes in $D_{p}$ than to changes in $k_{f}$, which is the opposite result compared to the binary IRN-77 SAC exchange (see Table 4-8). This confirms the necessity of the multiparameter PDM fit of the binary ion exchange data. 


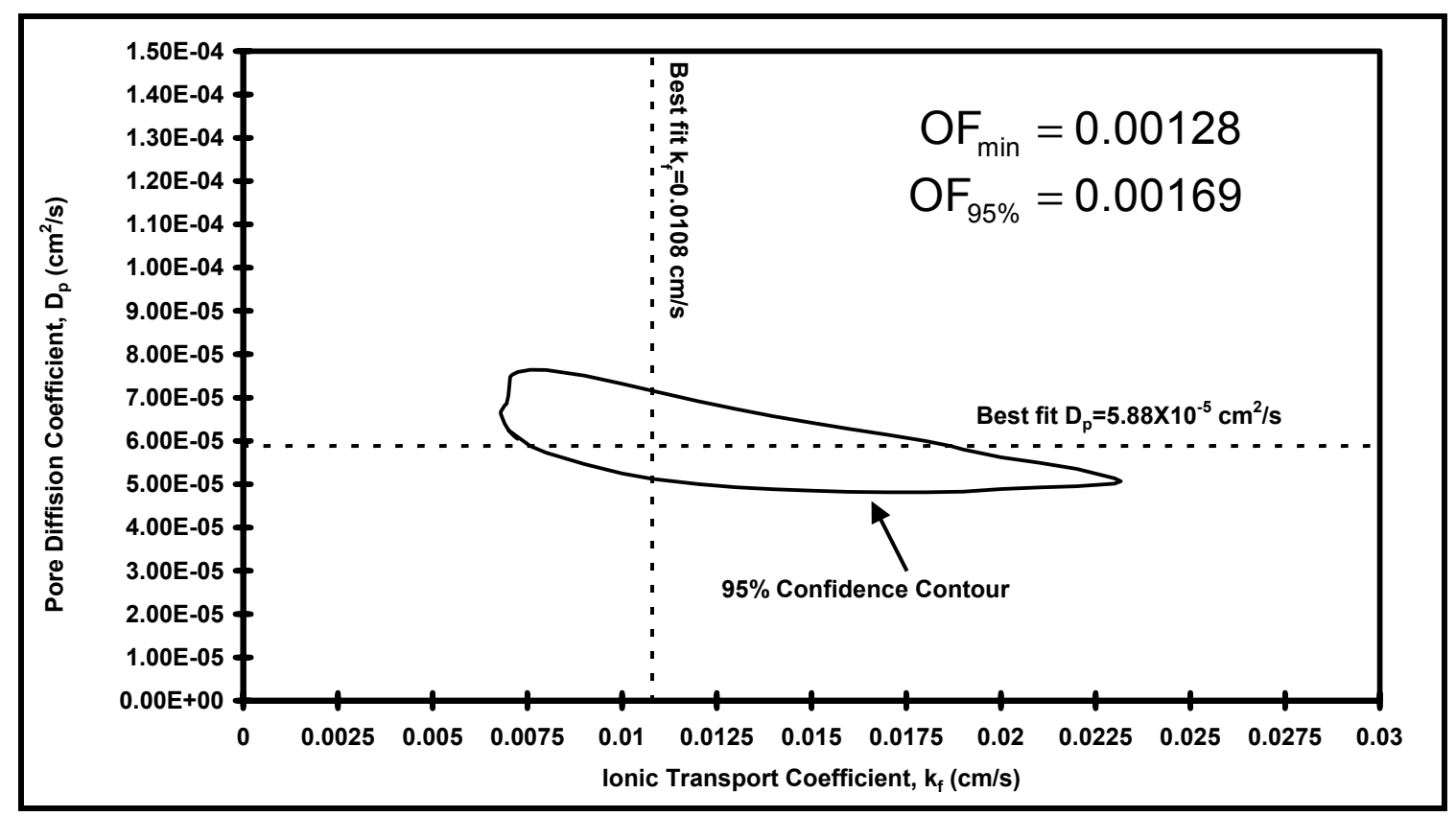

Figure 4-6 - 95\% Confidence Contour for Binary Ion Exchange Column Results for lodide Exchanging IRN-78 SBA Exchange Resin in the Chloride Form

Table 4-10 - Sensitivity Analysis for the Binary IRN-78 SBA Fit on the Effect of Varying Pore Diffusion Coefficient, $D_{p}$, and Film Transfer Coefficient, $k_{f}$, by plus or minus $\mathbf{5 0 \%}$ of Their PDM Fit Values Shown in Table 7 and Observing the Impact on the Objective Function, $f_{o b j}$, Compared to the PDM Fit $\left(f_{\text {obj }}=0.00128\right)$

\begin{tabular}{|l|c|c|c|c|c|}
\hline Simulation & $\Delta \mathrm{St}$ & $\Delta \mathrm{Ed}_{\mathrm{p}}$ & $\Delta \mathrm{Bi}_{\mathrm{p}}$ & $\mathrm{f}_{\mathrm{obj}}$ & Change in $\mathrm{f}_{\mathrm{obj}}$ \\
\hline$-50 \% \mathrm{D}_{\mathrm{p}}$ & $0 \%$ & $-50 \%$ & $+100 \%$ & 0.00683 & $+534 \%$ \\
\hline$+50 \% \mathrm{D}_{\mathrm{p}}$ & $0 \%$ & $+50 \%$ & $-33.3 \%$ & 0.00226 & $+177 \%$ \\
\hline$-50 \% \mathrm{k}_{\mathrm{f}}$ & $-50 \%$ & $0 \%$ & $-50 \%$ & 0.00267 & $+209 \%$ \\
\hline$+50 \mathrm{k}_{\mathrm{f}}$ & $+50 \%$ & $0 \%$ & $+50 \%$ & 0.00159 & $+124 \%$ \\
\hline
\end{tabular}


Table 4-11 shows a comparison of objective function $\left(\mathrm{f}_{\mathrm{obj}}\right)$ and average sum of the squares of the residuals $\left(s^{2}\right)$ for two PDM predictions of the multicomponent ion exchange column run for IRN-78 SBA exchange resin in the hydroxide/chloride form. Figure 4-7 shows chloride ion results comparing experimental data to a PDM prediction (correlated $D_{p}, k_{f}$ ). Figure 4-8 shows sulfate ion results comparing experimental data to a PDM prediction (correlated $D_{p}, k_{f}$ ). From Table 4-11, it appears that the PDM prediction based on $D_{p}$ and $k_{f}$ adjusted by factors of 2.27 and 0.984 , respectively, times the correlated values for all ions $\left(f_{o b j}=0.0983\right)$ does not improve on the PDM prediction based on the correlated $k_{f}$ and $D_{p}$ values from Equations 4-21 and 4-22, respectively $\left(f_{o b j}=0.0927\right)$. This could be because iodide data was used for the binary IRN-78 SBA exchange fitting of $D_{p}$ and $k_{f}$ values. lodide is a unique ion that exists in many forms and has a much greater affinity for the resin phase than the other anions studied, as shown by the separation factor for iodide in the hydroxide form $\left(\alpha_{\mathrm{OH}}^{\mathrm{I}}=\alpha_{\mathrm{Cl}}^{\mathrm{I}} \times \alpha_{\mathrm{OH}}^{\mathrm{Cl}}=38.2 \times 16.7=638\right)$, which is much greater than the separation factor for any of the ions included in the multicomponent IRN-78 SBA exchange experiment. It should also be noted that the binary IRN-78 SBA exchange experiment was performed on the chloride form of the resin. The hydroxide form of an anion exchange resin is more susceptible to shrinking and swelling effects than the chloride form. Therefore, it is expected that a binary column experiment with chloride exchanging the hydroxide form of IRN-78 SBA exchange resin could provide a more representative case for fitting the mass transfer parameters and then applying the results to a multicomponent column experiment. 


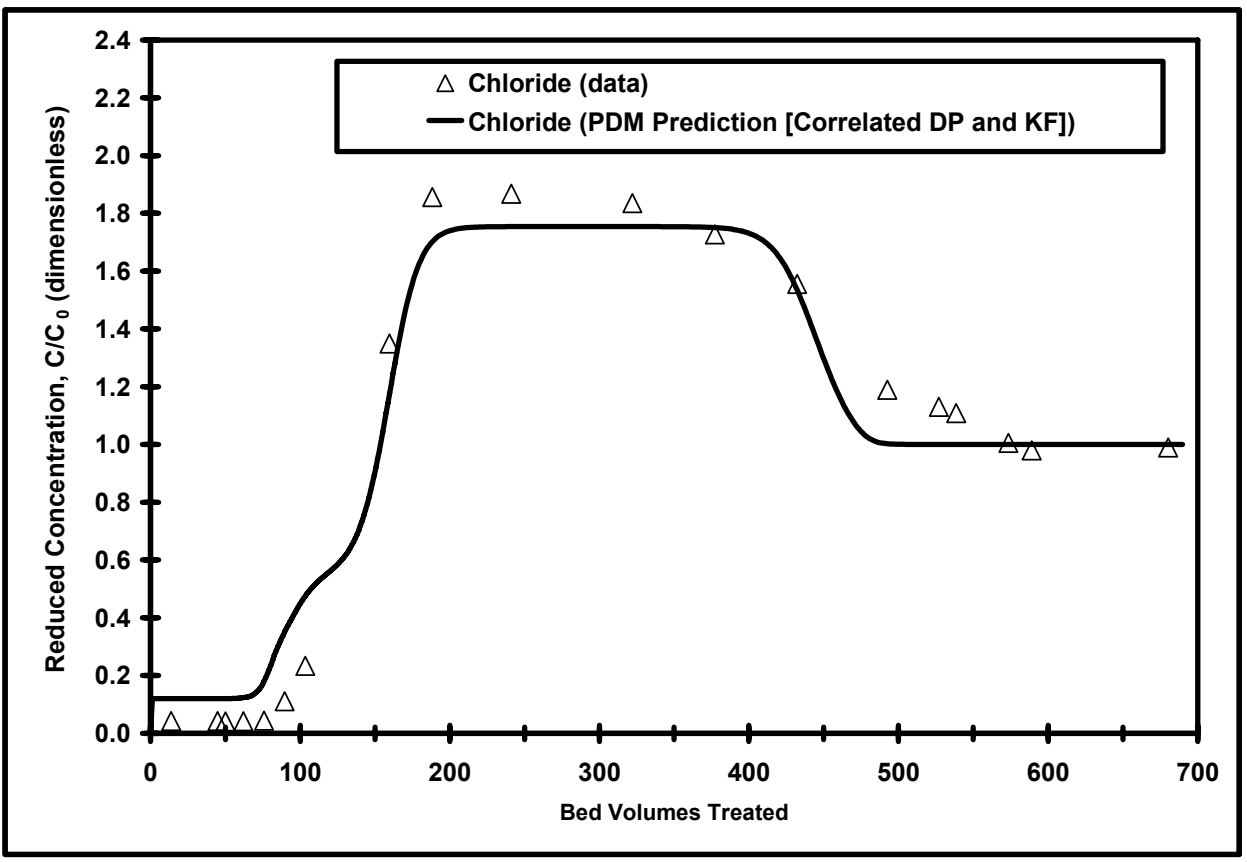

Figure 4-7 - Comparison of lon Exchange PDM Prediction with Experimental Data for Chloride for Multicomponent Column Run with Acetate, Butyrate, Chloride, Bicarbonate, and Sulfate Exchanging onto IRN78 SBA Exchange Resin in the Hydroxide Form.

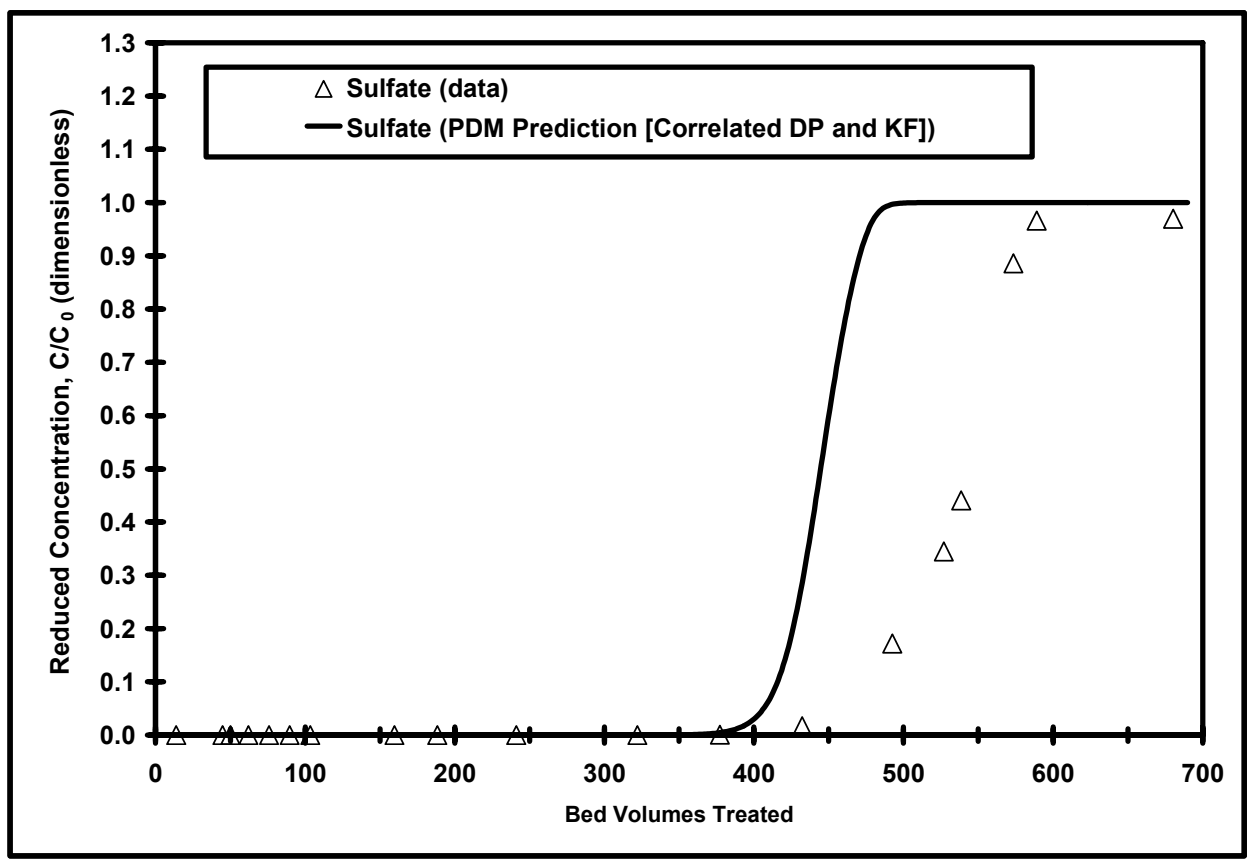

Figure 4-8 - Comparison of lon Exchange PDM Prediction with Experimental Data for Sulfate for Multicomponent Column Run with Acetate, Butyrate, Chloride, Bicarbonate, and Sulfate Exchanging onto IRN78 SBA Exchange Resin in the Hydroxide Form. 
Table 4-11 - Summary of Values of Objective Function $\left(f_{\text {obj }}\right)$ and Average Sum of the Squares of the Residuals $\left(s^{2}\right)$ for each PDM Simulation for the Multicomponent Case of Acetate, Butyrate, Chloride, Bicarbonate and Sulfate Exchanging IRN-78 SBA Exchange Resin in the Hydroxide Form.

\begin{tabular}{|l|c|c|c|c|c|c|}
\hline \multicolumn{7}{|c|}{ PDM Simulations of Multicomponent SBA Data } \\
\hline Description & $\mathrm{f}_{\mathrm{obj}}$ & $\mathrm{s}_{\mathrm{Ac}}^{2}$ & $\mathrm{~s}_{\mathrm{But}}^{2}$ & $\mathrm{~s}_{\mathrm{Cl}}^{2}$ & $\mathrm{~s}_{\mathrm{HCO} 3}^{2}$ & $\mathrm{~s}_{\mathrm{SO} 4}^{2}$ \\
\hline $\begin{array}{l}\text { Prediction } \\
\left(\text { Correlated } \mathrm{D}_{\mathrm{p}}\right. \\
\left.\text { and } \mathrm{k}_{\mathrm{f}}\right)^{1}\end{array}$ & 0.0927 & 0.231 & 0.0513 & 0.0166 & 0.0811 & 0.0839 \\
\hline $\begin{array}{l}\text { Prediction } \\
\left(\mathrm{D}_{\mathrm{p}} \times 2.27,\right. \\
\left.\mathrm{k}_{\mathrm{f}} \mathrm{X} 0.984\right)^{2}\end{array}$ & 0.0983 & 0.246 & 0.0697 & 0.0163 & 0.0779 & 0.0815 \\
\hline
\end{tabular}

${ }^{1}$ PDM Prediction (Correlated $D_{p}$ and $\left.k_{f}\right)$. Ionic transport coefficient $\left(k_{f}\right)$ and pore diffusion coefficient $\left(D_{p}\right)$ determined from correlations.

${ }^{2}$ PDM Prediction ( $\left.D_{p} X 2.27, k_{f} \times 0.0 .984\right) . k_{f}$ determined as 0.984 times the correlated value from (1) above. $D_{p}$ determined as 2.27 times greater than the correlated value from (1) above. The factors of 2.27 times the correlated $D_{p}$ value and 0.984 times the correlated $k_{f}$ value represent the optimum factors determined by fitting binary iodide data for SBA resin in the chloride form.

From Figure 4-7, it appears that the chloride data is reasonably well described by the PDM prediction, but that the PDM breakthrough occurs prior to the breakthrough observed in the experimental data. The chloride prediction also could be improved toward the latter part of the breakthrough profile (after 400 bed volumes fed) when sulfate, the strongest exchaning anion, is exchanging onto the resin and chloride, the next strongest exchanging ion, is being removed. This suggests that a fit of the mass transfer parameters $D_{p}$ and $k_{f}$ for the strongest exchanging ion, sulfate, may better describe the chloride data shown on Figure 4-7 in a manner similar to the effect observed for the PDM fit of multicomponent IRN-77 SAC exchange experimental data. However, it appears from the PDM breakthrough profile for sulfate compared to experimental data shown on Figure 4-8 that the sulfate separation factor determined from binary isotherm data (Hokanson, 2004) does not describe the sulfate data adequately. That is, the centroid of the breakthrough profile $\left(C / C_{0}=0.5\right)$ should occur at the 
same number of bed volumes treated for both the PDM prediction and the experimental data. However, for the PDM prediction, a reduced effluent concentration of $\mathrm{C} / \mathrm{C}_{0}=0.5$ is observed at 445 bed volumes treated compared to $\mathrm{C} / \mathrm{C}_{0}=0.5$ at 546 bed volumes treated for the experimental data. A possible explanation is that the binary isotherm experiment used to fit the separation factor for sulfate was conducted with chloride as the presaturant ion; whereas, the multicomponent IRN-78 SBA exchange column experiment was presaturated with $71 \%$ chloride and $29 \%$ hydroxide. The hydroxide form of the resin is more susceptible to selling and shrinking, which could impact the exchange. A possible way to improve the separation factor calculation for sulfate is collect binary isotherm data for sulfate using the hydroxide form of IRN-78 SBA exchange resin and refitting the separation factor. It would then be logical to verify the sulfate separation factor using a binary column experiment for sulfate exchanging the hydroxide form of IRN-78 SBA exchange resin. Finally, the multicomponent IRN-78 SBA exchange column experiment could be rerun using IRN-78 SBA exchange resin presaturated only with hydroxide. Because the separation factor for sulfate does not appear to describe the data, it is not logical to perform a fitting of the mass transfer parameters, $D_{p}$ and $k_{f}$, for sulfate as was done for calcium in the strong acid cation exchange analysis presented earlier. If the separation factor for sulfate described the data well, it is expected that fitting the mass transfer parameters $D_{p}$ and $k_{f}$ for sulfate exchange onto the IRN-78 SBA exchange resin for the multicomponent column experiment in a similar 
fashion to the calcium fitting performed for the IRN-77 SAC column experiment would improve upon the ability of the PDM to describe the experimental data.

\section{Conclusion}

A fixed-bed model was developed to describe the fate of ions in strong acid cation (SAC) and strong base anion (SBA) exchange systems. The model includes multicomponent equilibrium description, mass transfer by external and intraparticle diffusion, and transient influent capabilities. The model neglects electrical potential effects on intraparticle diffusion. Using film transfer coefficient correlations obtained in the literature and by assuming a tortuosity of one in the determination of the pore diffusion coefficient, the model was able to predict multicomponent column data for the IRN-77 SAC and IRN-78 SBA ion exchange resins. Fitting the mass transfer parameters $\left(k_{f}\right.$ and $\left.D_{p}\right)$ for the strongest exchanging ion (calcium) in a multicomponent strong acid cation exchange experiment was shown to improve upon the PDM results for all the ions in the study when predicting $D_{p}$ and $k_{f}$ for other ions by multiplying correlated values by a factor of 8.55 and 0.983 , respectively, based on results of a binary IRN-77 SAC exchange column experiment. An advantage of the PDM compared to the TISEqM is that the spreading of the waves for each ion can be described independently using the mass transfer parameters $\left(D_{p}\right.$ and $\left.k_{f}\right)$ for each ion separately; whereas, the modifying the spreading of the waves in the TISEqM by adjusting the number of tanks impacts all of the ions in the same manner. 


\section{Acknowledgements}

The authors acknowledge Ion Electronics, USEPA and CenCITT, MTU Graduate School, and MTU Research Excellence Fund for funding this project. The authors are grateful to Shelle Sandell, Jacqueline Popko, Daniel LaCrosse, and David Perram for performing analysis and running the isotherm and column experiments.

This work was supported in part by lon Electronics, USEPA, the Center for Clean Industrial and Treatment Technologies, MTU Graduate School and MTU Research Excellence Fund, although it does not necessarily reflect their views and no official endorsement should be inferred.

\section{References}

Crittenden, J. C., N. J. Hutzler, D. G. Geyer, J. L. Oravitz, and G. Friedman. (1986) Transport of Organic Compounds with Saturated Groundwater Flow: Model development and Parameter Sensitivity. Water Resources Research, $22(3), 271-284$.

Finlayson, B.A. The Method of Weighted Residuals and Variational Principles, Academic Press Inc., New York (1972).

Finlayson, B.A. Non Linear Analysis in Chemical Engineering, McGraw-Hill, NewYork (1980).

Friedman, G., "Mathematical Modeling of Multicomponent Adsorption in Batch and Fixed-Bed Reactors", M.S. Thesis, Michigan Tech. University (1984). 
Gear, C. W. (1971). Numerical initial value problems in ordinary differential equations. Prentice Hall, Upper Saddle River, NJ.

Gnielinski, V. (1978) Gleichungen zur Berechnung des Wärme-und Stoffaustauches in durchströmten ruhenden Kugelschttüngen bei mittleren und grossen Pecletzhalen. VT-verfahrenstechnik, 12, 363-366.

Graham, E.E. and J.S. Dranoff, "Kinetics of Anion Exchange Accompanied by Fast Irreversible Reaction," AIChE Journal, 18(3), 608-613 (1972).

Haub, C.E. and G.L. Foutch, "Mixed-Bed Ion Exchange at Concentrations Approaching the Dissociation of Water. 1. Model Development," Ind. Eng. Chem. Fundam., 25(3), 373-381 (1986).

Helfferich, F. and M.S. Plesset, "lon Exchange Kinetics. A Nonlinear Diffusion Problem," The Journal of Chemical Physics, 28(3), 418-424 (1958).

Hokanson, D.R. "Ion Exchange Model Development for the International Space Station Water Processor," Ph.D. Dissertation, Michigan Technological University (2004).

Kataoka, T., N. Sato and K. Ueyama, "Effective Liquid Phase Diffusivity in Ion Exchange," Journal of Chemical Engineering of Japan, 1(1), 38-42 (1968).

Kataoka, T., H. Yoshida and Y. Shibahara, "Liquid Phase Mass Transfer in Ion Exchange Accompanied by Chemical Reaction," Journal of Chemical Engineering of Japan, 9(2), 130-135 (1976).

Kataoka, T. and H. Yoshida. "Kinetics of lon Exchange Accompanied by Neutralization Reaction," AIChE Journal, 34(6), 1020-1026 (1988). Reid, R.C., J.M. Prausnitz, and B.E. Poling, The Properties of Liquids and Gases, 4th ed., New York: McGraw-Hill Book Company (1987). 
Rohm and Haas, "Rohm and Haas lon Exchange Resins - Laboratory Guide,"

Technical Bulletin Fluid Process Chemicals Department, Rohm and Haas,

Philadelphia, PA (1990).

Sontheimer, H., J.C. Crittenden, and R.S. Summers, Activated Carbon for Water

Treatment, DVGW-Forschungsstelle, Engler-Bunte-Institut, Univ. of

Karlsruhe, Fed. Rep. of Germany (1988).

Villadsen, J. and M.L. Michelsen, Solution of Differential Equation Models by

Polynomial Approximation, Prentice-Hall, Englewood Cliffs, NJ (1978).

Wagner, J.D. and J.S. Dranoff, "The Kinetics of Ion Exchange Accompanied by

Irreversible Reaction. III. Film Diffusion Controlled Neutralization of a Strong

Acid Exchanger by a Weak Base," Journal of Physical Chemistry, 71(13), 4551-4553 (1967).

Wildhagen, G.R.S., R.Y. Qassim and K. Rajagopal, "Effective Liquid-Phase

Diffusivity in lon Exchange," Ind. Eng. Chem. Fundam., 24(4), 423-432 (1985).

\section{Nomenclature}

A Column cross-sectional area $\left(\mathrm{L}^{2}\right)$, equal to $\pi \times \mathrm{D}^{2} / 4$

$A_{p} \quad$ Total external surface area of the resin particle $\left(L^{2}\right)$

$\mathrm{Bi}_{\mathrm{p}, \mathrm{i}} \quad$ Pore Biot number of ion $\mathrm{i}$ (dimensionless), equal to $\mathrm{St}_{\mathrm{i}} / \mathrm{Ed}_{\mathrm{p}, \mathrm{i}}$

$\mathrm{C}_{\mathrm{i}}(\mathrm{z}, \mathrm{t}) \quad$ Equivalent liquid-phase concentration of ion $i\left(\mathrm{eq} \mathrm{L}^{-3}\right)$ 
$\mathrm{C}_{\mathrm{j}_{-} \text {data,i }} \quad$ Experimental data value of the liquid phase concentration of ion $\mathrm{j}$ for data point i (eq $\left.\mathrm{L}^{-3}\right)$

$\overline{\mathrm{C}}_{\mathrm{j}_{\perp} \text { data,i }} \quad$ Experimental data value of the dimensionless liquid phase concentration of ion $\mathrm{j}$ for data point $\mathrm{i}$ (dimensionless), equal to $\mathrm{C}_{\mathrm{j}_{-} \text {data, } \mathrm{i}} / \overline{\mathrm{C}_{0, \mathrm{j}}}$

$\mathrm{C}_{\mathrm{j}_{\perp} \text { model,i }} \quad$ lon exchange model (PDM or TISEqM) value of the liquid phase concentration of ion $\mathrm{j}$ corresponding to data point $\mathrm{i}\left(\mathrm{eq} \mathrm{L}^{-3}\right)$

$\overline{\mathrm{C}}_{\mathrm{j}_{\perp} \text { model, }} \quad$ lon exchange model (PDM or TISEqM) value of the dimensionless liquid phase concentration of ion $\mathrm{j}$ corresponding to data point $\mathrm{i}$ (dimensionless), equal to $\mathrm{C}_{\mathrm{j}_{-} \text {model, } \mathrm{i}} / \overline{\mathrm{C}_{0, \mathrm{j}}}$

$\mathrm{C}_{0, \mathrm{i}}(\mathrm{t}) \quad$ Equivalent time-variable influent liquid-phase concentration of ion $\mathrm{i}$ $\left(\right.$ eq $\left.L^{-3}\right)$

$\overline{\mathrm{C}_{0, \mathrm{i}}} \quad$ Equivalent time-averaged influent liquid-phase concentration of ion $i\left(\right.$ eq $\left.\mathrm{L}^{-3}\right)$, equal to $\frac{1}{\mathrm{t}_{\text {TOTAL }}} \int_{0}^{\mathrm{t}_{\mathrm{TOTAL}}} \mathrm{C}_{0, \mathrm{i}}(\mathrm{t}) \mathrm{dt}$ $\mathrm{C}_{\mathrm{p}, \mathrm{i}}(\mathrm{r}, \mathrm{z}, \mathrm{t}) \quad$ Equivalent ion concentration in the resin pores as a function of radial and axial position and time $\left(\mathrm{eq} \mathrm{L}^{-3}\right)$

$\overline{\mathrm{C}_{\mathrm{T}, \text { avg }}} \quad$ Total equivalent time-averaged influent liquid-phase concentration of all ions (eq $\mathrm{L}^{-3}$ ), equal to $\sum_{\mathrm{j}=1}^{\mathrm{m}} \overline{\mathrm{C}_{0, j}}$ 
$\mathrm{C}_{\mathrm{T}}(\mathrm{z}, \mathrm{t}) \quad$ Total equivalent time-variable influent liquid-phase concentration of

all ions at time $t\left(\right.$ eq $\left.L^{-3}\right)$, equal to $\sum_{j=1}^{m} C_{0, j}\left(t-\frac{z}{V}\right)$

$\overline{\mathrm{C}_{\mathrm{T}}}(\overline{\mathrm{z}}, \mathrm{T}) \quad$ Reduced total equivalent time-variable influent liquid-phase

concentration of all ions (dimensionless), equal to $\mathrm{C}_{\mathrm{T}}(\mathrm{z}, \mathrm{t}) / \overline{\mathrm{C}_{\mathrm{T}, \text { avg }}}$

d $\quad$ Resin particle diameter (L )

D Column diameter ( $\mathrm{L}$ )

$\mathrm{Dg}_{\mathrm{p}} \quad$ Equivalent pore distribution parameter (dimensionless), equal to

$\frac{\varepsilon_{\mathrm{p}}(1-\varepsilon)}{\varepsilon}$

$\mathrm{Dg}_{\mathrm{s}} \quad$ Equivalent surface distribution parameter (dimensionless), equal to

$\frac{\rho_{\mathrm{a}} \mathrm{q}_{\mathrm{T}}(1-\varepsilon)}{\varepsilon \overline{\mathrm{C}_{\mathrm{T}, \mathrm{avg}}}}$

$\mathrm{Dg}_{\mathrm{T}} \quad$ Total equivalent distribution parameter (dimensionless), equals

$\mathrm{Dg}_{\mathrm{s}}+\mathrm{Dg}_{\mathrm{p}}$

$\mathrm{D}_{\mathrm{l}, \mathrm{i}} \quad$ Liquid diffusivity of ion $i\left(\mathrm{~L}^{2} \mathrm{~T}^{-1}\right)$, equal to

$\frac{\mathrm{R}_{\mathrm{gas}} \operatorname{Temp}\left[\left(1 / \mathrm{n}_{+}\right)+\left(1 / \mathrm{n}_{-}\right)\right]}{\mathrm{F}^{2}\left[\left(1 / \lambda_{+}^{0}\right)+\left(1 / \lambda_{-}^{0}\right)\right]}$

$D_{p, i} \quad$ Pore diffusivity of ion $i$ based on pore volume fraction $\left(\mathrm{L}^{2} \mathrm{~T}^{-1}\right)$

$\mathrm{D}_{\mathrm{s}, \mathrm{i}} \quad$ Solid-phase diffusion coefficient of ion $i\left(\mathrm{~L}^{2} \mathrm{~T}^{-1}\right)$

EBCT Empty bed contact time $(T)$, equal to $V_{B} / Q$ 
$\mathrm{Ed}_{\mathrm{p}, \mathrm{i}} \quad$ Pore diffusion modulus of ion i (dimensionless), equal to

$$
D_{p, i} \tau(1-\varepsilon) \varepsilon_{p} / R^{2} \varepsilon
$$

$\mathrm{F}=\quad$ Faraday's constant $(\mathrm{cal} / \mathrm{g} /$ equiv $)$, equal to 96,500

$\mathrm{J}_{\mathrm{i}} \quad$ Equivalent ion flux $\left(\mathrm{eq} \mathrm{L}^{-2} \mathrm{~T}^{-1}\right)$

$\mathrm{J}_{1, \mathrm{i}} \quad$ Equivalent diffusional flux of ion $\mathrm{i}$ in the liquid phase $\left(\right.$ eq $\left.\mathrm{L}^{-2} \mathrm{~T}^{-1}\right)$

$\mathrm{J}_{\mathrm{s}, \mathrm{i}} \quad$ Equivalent diffusional flux of ion $\mathrm{i}$ in the solid phase $\left(\right.$ eq $\left.\mathrm{L}^{-2} \mathrm{~T}^{-1}\right)$

$k_{f, i} \quad$ lonic transport coefficient of ion $i\left(L^{-1}\right)$

$L \quad$ Length of the resin bed $(L)$

$\mathrm{m} \quad$ Number of ions in the system

M Mass of Resin (M)

$\mathrm{n}_{+}=\quad$ Valence of cation

$\mathrm{n}_{-}=\quad$ Valence of anion

$N_{-}$data $_{\mathrm{j}} \quad$ Number of data points for ion $\mathrm{j}$

$\mathrm{q}_{i}(r, z, t) \quad$ Equivalent resin phase concentration of ion $i$ on the resin surface as a function of radial and axial position and time ( eq $\left.\mathrm{M}^{-1}\right)$

$\mathrm{q}_{\mathrm{T}} \quad$ Total resin capacity $\left(\right.$ eq $\left.\mathrm{M}^{-1}\right)$

Q $\quad$ Flowrate $\left(\mathrm{L}^{3} \mathrm{~T}^{-1}\right)$

$r \quad$ Radial coordinate ( $L$ )

$\bar{r} \quad$ Reduced radial coordinate (dimensionless), equal to $r / R$

$\mathrm{R} \quad$ Resin radius ( $\mathrm{L}$ )

$\operatorname{Re} \quad$ Reynolds number (dimensionless), equal to $d V \rho_{1} / \mu_{1}$ 


\begin{tabular}{|c|c|}
\hline $\mathrm{R}_{\text {gas }}$ & Gas constant $(\mathrm{J} / \mathrm{mol} / \mathrm{K})$, equal to 8.314 \\
\hline $\mathrm{Sc}_{\mathrm{i}}$ & Schmidt number of ion i (dimensionless), equal to $\mu_{1} / \rho_{1} / D_{l, i}$ \\
\hline $\mathrm{St}_{\mathrm{i}}$ & Modified Stanton number (dimensionless), equal to $\mathrm{k}_{\mathrm{f}, \mathrm{i}} \tau(1-\varepsilon) / \mathrm{R} \varepsilon$ \\
\hline $\mathrm{t}$ & Elapsed time $(T)$ \\
\hline $\mathrm{t}_{\text {TOTAL }}$ & Total run time $(T)$ \\
\hline $\mathrm{T}$ & Dimensionless time, equal to $t / \tau /\left(\mathrm{Dg}_{T}+1\right)$ \\
\hline Temp $=$ & Temperature $(\mathrm{K})$ \\
\hline V & Interstitial velocity $\left(\mathrm{L} \mathrm{T}^{-1}\right)$, equal to $\mathrm{v}_{\mathrm{F}} / \varepsilon$ \\
\hline $\mathrm{V}_{\mathrm{B}}$ & Resin empty bed volume $\left(L^{3}\right)$, equal to $A \times L$ \\
\hline $\mathrm{V}_{\mathrm{F}}$ & Superficial fluid velocity $\left(\mathrm{LT}^{-1}\right)$, equal to $\mathrm{Q} / \mathrm{A}$ \\
\hline $\mathrm{X}_{\text {data }_{\mathrm{j}, \mathrm{i}}}$ & $\begin{array}{l}\text { Experimental data value of the equivalent fraction in the liquid } \\
\text { phase for data point } i \text { for ion } j \text { (dimensionless) }\end{array}$ \\
\hline$x_{\text {model } j_{j, i}}$ & $\begin{array}{l}\text { Ion exchange model (PDM or TISEqM) value of the equivalent } \\
\text { fraction in the liquid phase corresponding to data point i for ion } j \\
\text { (dimensionless) }\end{array}$ \\
\hline$\overline{\mathrm{X}}_{\mathrm{i}}(\overline{\mathrm{z}}, \mathrm{T})$ & $\begin{array}{l}\text { Reduced equivalent concentration in the liquid phase of ion i as a } \\
\text { function of dimensionless axial position and dimensionless time } \\
\text { (dimensionless), equal to } \mathrm{C}_{\mathrm{i}}(\mathrm{z}, \mathrm{t}) / \overline{\mathrm{C}_{\mathrm{T}, \text { avg }}}\end{array}$ \\
\hline
\end{tabular}


$\bar{X}_{p, i}(\bar{r}, \bar{z}, T) \quad$ Reduced concentration in liquid phase in the resin pores of ion $i$ as a function of dimensionless radial and axial position and dimensionless time (dimensionless), equal to $\mathrm{C}_{\mathrm{p}, \mathrm{i}}(\mathrm{r}, \mathrm{z}, \mathrm{t}) / \overline{\mathrm{C}_{\mathrm{T}, \mathrm{avg}}}$

$Y_{i}(r, z, T) \quad$ Total equivalent resin phase concentration of ion $i$ as a function of radial and axial position and time $\left(\right.$ eq $\left.\mathrm{M}^{-1}\right)$, equal to $\mathrm{q}_{\mathrm{i}}(\mathrm{r}, \mathrm{z}, \mathrm{t})+\left(\varepsilon_{\mathrm{p}} / \rho_{\mathrm{a}}\right) \mathrm{C}_{\mathrm{p}, \mathrm{i}}(\mathrm{r}, \mathrm{z,t})$

$\overline{\mathrm{Y}}_{i}(\overline{\mathrm{r}}, \overline{\mathrm{z}}, \mathrm{T}) \quad$ Reduced total equivalent concentration in the resin phase of ion $\mathrm{i}$ as a function of dimensionless radial and axial position and dimensionless time (dimensionless), equal to $Y_{i}(r, z, t) / Y_{T}$

$\mathrm{Y}_{\mathrm{T}} \quad$ Total equivalent concentration in the resin phase of all ions (eq/M), equal to $\mathrm{q}_{\mathrm{T}}+\left(\varepsilon_{\mathrm{P}} / \rho_{\mathrm{a}}\right) \overline{\mathrm{C}_{\mathrm{T}, \text { avg }}}$

Axial coordinate $(L)$

$\bar{z}$

Reduced axial coordinate (dimensionless), equal to $z / L$

$Z_{i} \quad$ Valence of ion $\mathrm{i}$ (dimensionless)

$\alpha_{j}^{i} \quad$ Separation factor

$\varepsilon$ Fraction of volumetric space in exchange column unoccupied by resin, or void fraction (dimensionless), equal to $1-\rho_{b} / \rho_{a}$

$\varepsilon_{\mathrm{p}} \quad$ Fraction of volumetric space in resin phase unoccupied by adsorbent (dimensionless) 
$\lambda_{+}^{0}=\quad$ Limiting ionic conductance of cation

$$
\left\{\left(\mathrm{A} / \mathrm{cm}^{2}\right)(\mathrm{V} / \mathrm{cm})\left(\mathrm{g}-\text { equiv } / \mathrm{cm}^{3}\right)\right\}
$$

$\lambda_{-}^{0}=\quad$ Limiting ionic conductance of anion

$$
\left\{\left(\mathrm{A} / \mathrm{cm}^{2}\right)(\mathrm{V} / \mathrm{cm})\left(\mathrm{g}-\text { equiv } / \mathrm{cm}^{3}\right)\right\}
$$

$\rho_{\mathrm{a}} \quad$ Resin apparent density which includes pore volume $\left(\mathrm{M} \mathrm{L}^{-3}\right)$

$\rho_{\mathrm{b}} \quad$ Bulk (bed) density $\left(\mathrm{M} \mathrm{L}^{-3}\right)$, equal to $\mathrm{M} / \mathrm{V}_{\mathrm{B}}$

$\rho_{1} \quad$ Density of water $\left(\mathrm{M} \mathrm{L}^{-3}\right)$

$\phi \quad$ Electrical potential caused by the migration of ions in solution.

$\tau \quad$ Fluid residence time in resin column, or packed bed contact time

( $T$ ), equal to $\mathrm{EBCT} \times \varepsilon$

$\tau_{\mathrm{P}} \quad$ Tortuosity (dimensionless)

$\mu_{1} \quad$ Viscosity of water $\left(\mathrm{ML}^{-1} \mathrm{~T}^{-1}\right)$ 


\section{Appendix I - Characterization of Multifiltration Bed Influent Wastewaters}

\begin{tabular}{|c|c|c|c|c|c|}
\hline Compound & $\begin{array}{l}\text { Carbon } \\
\text { Fraction }\end{array}$ & $\begin{array}{c}\text { Humidity } \\
\text { Condensate }\end{array}$ & $\begin{array}{c}\text { Shower } \\
\text { Handwash }\end{array}$ & $\begin{array}{c}\text { Clothes } \\
\text { Wash }\end{array}$ & $\begin{array}{c}\text { Urine } \\
\text { Distillate }\end{array}$ \\
\hline & & $\mathrm{ug} / \mathrm{L}$ & ug/L & ug/L & ug/L \\
\hline Total Organic Carbon (TOC) & & 50000 & 704000 & 101600 & 11100 \\
\hline Acenapthylene & 0.947 & & 10 & 8 & \\
\hline Acetaldehyde & 0.545 & 170 & & 26 & 330 \\
\hline Acetic Acid & 0.4 & 8000 & 10800 & 11000 & 990 \\
\hline Acetone & 0.621 & 500 & 60 & 98 & 353 \\
\hline Acetophenone & 0.8 & & & & 2.2 \\
\hline 7-Acetyl-6-ethyl-1,1,4,4-tetramethyltetralin & 0.837 & & & 47 & \\
\hline 4-Acetyl morpholine & 0.558 & 2100 & & & \\
\hline Acetyloxyoctadecenoic acid, Methyl ester & 0.704 & & & 5 & \\
\hline Adipate & 0.493 & & & & 22 \\
\hline Alphahydroxybenzeneneacetic acid ester & 0.651 & & & & 33 \\
\hline Amine(unknown) & 0.6 & 170 & & & \\
\hline 2-Amino benzoic acid methyl ester & 0.636 & & & & 1 \\
\hline Benzaldehyde & 0.792 & 10 & & & 9 \\
\hline Benzene & 0.923 & 1 & & 1 & \\
\hline Benzeneacetic acid & 0.706 & 4 & 64 & & 24 \\
\hline Benzene ethanol & 0.787 & 50 & & 8 & \\
\hline Benzene methanol & 0.778 & 380 & & & \\
\hline Benzoic Acid & 0.689 & 150 & 50 & 60 & 660 \\
\hline Benzophenone & 0.857 & 5 & & & \\
\hline 2H-1-Benzopyran-2-one & 0.74 & 4 & & & \\
\hline Benzothiazole & 0.622 & 40 & & 8 & \\
\hline Benzyl alcohol & 0.778 & 200 & & 5 & 33 \\
\hline 1,1-Biphenyl-2-ol & 0.847 & 10 & & & \\
\hline Bis(2-ethylhexyl)phthalate & 0.738 & 10 & 150 & 15 & 33 \\
\hline Bis(1-methylethyl)ester hexadecanoic acid & 0.626 & 30 & & & \\
\hline Bis(2-methypropyl)phthalate & 0.691 & 6 & & & \\
\hline 1,3-Butanedoid & 0.533 & 14 & & & 6 \\
\hline Butanoic acid & 0.545 & 70 & 44800 & 3040 & 1320 \\
\hline 2-Butanol & 0.649 & 1000 & 1600 & & \\
\hline 2-Butanone & 0.667 & 50 & & & 34 \\
\hline 2-Butoxyethanol & 0.61 & 900 & 8 & 23 & 9 \\
\hline 2-Butoxyethoxyethanol & 0.593 & 500 & & 18 & \\
\hline Butylated hydroxy anisole & 0.733 & 60 & & 14 & \\
\hline Butylbenzylphthalate & 0.731 & 4 & & & 9 \\
\hline (1-Butylheptl) benzene & 0.879 & & & 23 & \\
\hline (1-Butyloctyl) benzene & 0.878 & & & 40 & \\
\hline Butyraldehyde & 0.666 & 25 & & & \\
\hline Butyrolactone & 0.558 & & & & 22 \\
\hline C12 Alcohol & 0.774 & & & 20 & \\
\hline C12+Aldehyde-methyloxime & 0.723 & & 20 & & \\
\hline C11+ Alkylsubstituted benzene & 0.878 & & & 75 & \\
\hline C4-Substituted cyclohexanol & 0.784 & 20 & & & \\
\hline C5-7 Ketone & 0.697 & & & & 11 \\
\hline Caffeine & 0.495 & & 50 & 25 & \\
\hline Caprolactam & 0.637 & 12000 & 1700 & 17 & 110 \\
\hline Carbon Disulfide & 0.273 & 500 & & & \\
\hline 4-Chloro aniline & 0.565 & & 10 & & \\
\hline Chlorobenzene & 0.352 & & & 14 & \\
\hline 2-Chloroethanol phosphate & 0.135 & 160 & & & \\
\hline Chloroform & 0.101 & & & & 18 \\
\hline 1-Chloro-4-isocyanato benzene & 0.549 & & 9 & & \\
\hline Chloromethylphenol & 0.59 & & & & 21 \\
\hline Chlorophenol & 0.561 & 7 & & & 30 \\
\hline Cholesterol & 0.839 & & 1400 & 310 & \\
\hline Cis-p-menth-2-ene-1,8-diol & 0.706 & & & & 5 \\
\hline Cotinine & 0.682 & & 10 & & \\
\hline Crotonaldehyde & 0.685 & 10 & & & \\
\hline Cyclohexanone & 0.734 & 100 & & & \\
\hline
\end{tabular}




\begin{tabular}{|c|c|c|c|c|c|}
\hline 2-Cyclohexen-1-ol & 0.72 & 1 & & & \\
\hline 2-Cyclohexen-1-one & 0.734 & 5 & & & \\
\hline 1-(1-Cyclohexen-1-yl)ethanone & 0.774 & & & & 25 \\
\hline Cyclopentanone & 0.714 & & & & 5 \\
\hline Decanoic acid & 0.69 & 100 & 40 & 23 & 12 \\
\hline Decanoic acid, Methyl ester & 0.71 & & 10 & & \\
\hline 1-Decanol & 0.759 & & 100 & & \\
\hline 1,4-diacetylbenzene & 0.741 & 12 & & & \\
\hline Butyl amine & 0.744 & 1000 & & & 51 \\
\hline di-n-Butylphthalate & 0.691 & 100 & 5 & 7 & \\
\hline 2,4-Dichloroaniline & 0.445 & & 5 & & \\
\hline Dichlorobenzoic acid & 0.44 & 20 & & & \\
\hline 2,4-Dichlorophenol & 0.442 & & & & 15 \\
\hline \begin{tabular}{|l|} 
Diethylene glycol \\
\end{tabular} & 0.453 & 3 & & & \\
\hline Diethylene glycol diecetate & 0.505 & 400 & & & \\
\hline Diethylphthalate & 0.649 & 320 & 12 & 10 & 22 \\
\hline Dihydroacetic acid & 0.387 & 4 & & & \\
\hline 2,3-Dihydrobenzofuran & 0.8 & & & & 34 \\
\hline Dihydro-5,5-dimethyl-2(3H)-furanone & 0.632 & & & & 97 \\
\hline Dihydro-5-ethenyl-5-methyl-2H-furanone & 0.667 & & & & 72 \\
\hline Dihydro-5-ethyl-2H-furanone & 0.632 & 28 & & & 121 \\
\hline 1,3-Dihydro-2H-indol-2-one & 0.722 & & & & 9 \\
\hline Dihydro-5-methyl-2(3H)-furanone & 0.612 & 33 & 30 & & 212 \\
\hline 2,3-Dihydro-4-methyl-1H-indole & 0.812 & & & & 10 \\
\hline 1-(Dimethylamino)-2-propanol & 0.588 & 85 & & & \\
\hline a,a-Dimethyl benzenemethanol & 0.787 & 150 & & & \\
\hline Dimethylbenzyl alcohol & 0.794 & 100 & & & 7 \\
\hline (3,3-Dimethyldecyl) benzene & 0.878 & & & 28 & \\
\hline Dimethyl disulfate & 0.255 & & & & 14 \\
\hline 4-(1,1-Dimethylethyl)-benzoic acid & 0.741 & 16 & & & \\
\hline 3-(1,1-Dimethylethyl)-phenol & 0.8 & 50 & & & \\
\hline \multicolumn{6}{|l|}{ 2,2-Dimethyl-1-(2-hydroxy-1-methylethyl) } \\
\hline \begin{tabular}{|c|}
-propyl ester propanoic acid \\
\end{tabular} & 0.667 & 73 & & & \\
\hline 3,7-Dimethyl-1,5-octadien-3-ol & 0.779 & 10 & & & 11 \\
\hline \begin{tabular}{|l|l|} 
Dimethylphthalate \\
\end{tabular} & 0.619 & 40 & & & 39 \\
\hline 2,2-dimethyl propanoic acid & 0.448 & 50 & & & \\
\hline 2,3-Dimethylpyrazine & 0.667 & & & & 11 \\
\hline Dimethyl sulfide & 0.387 & & 25 & & \\
\hline Dimethyl sulfone & 0.255 & 140 & 76 & 75 & 75 \\
\hline Dimethylsulfoxide & 0.307 & & 10 & 9 & \\
\hline Dimethyltetrahydropyranone & 0.656 & & & & 8 \\
\hline 2,6-Dinitrotoluene & 0.454 & 80 & & & \\
\hline 1,6-Dioxacyclododecane-7,12-dione & 0.631 & 450 & & & \\
\hline Dipropyleneglycol methyl ether & 0.568 & 50 & & 12 & \\
\hline Docosane & 0.852 & 10 & & & \\
\hline Docosanoic acid & 0.776 & & 80 & & \\
\hline Docosanoic acid, methyl ester & 0.78 & & 190 & & \\
\hline Dodecanal, o-methyloxime & 0.732 & & 440 & & \\
\hline Dodecanoic acid & 0.72 & 50 & 2250 & 160 & 78 \\
\hline Dodecanoic acid, methyl ester & 0.729 & & 900 & & \\
\hline Dodecanol & 0.774 & 6 & 160 & 43 & \\
\hline Eicosane & 0.851 & 21 & & & \\
\hline Eicosanoic acid & 0.769 & & 180 & 41 & \\
\hline Eicosanoic acid, methyl ester & 0.773 & & 250 & & \\
\hline 2,2-[1,2-Ethaneoxybis(oxy)] bis-ethanoldiacetate & 0.513 & 200 & & & \\
\hline Ethanol & 0.522 & 7000 & 2400 & 500 & 3850 \\
\hline Substituted ethanone & 0.65 & 40 & & & \\
\hline 2-Ethoxyethanol & 0.533 & 200 & & & \\
\hline Ethoxyethanol acetate & 0.545 & 100 & & & \\
\hline Ethoxyethoxy ethanol & 0.537 & 500 & & 15 & \\
\hline Ethoxyethoxy ethanol acetate & 0.539 & 25 & & & \\
\hline 1-(2-Ethoxypropoxy)-2-propanol & 0.592 & 130 & & & \\
\hline Ethylacetate & 0.545 & & & & 3 \\
\hline Ethyl benzene & 0.905 & & & 8 & \\
\hline 2-Ethyl-1-butanol & 0.706 & & & & 110 \\
\hline
\end{tabular}




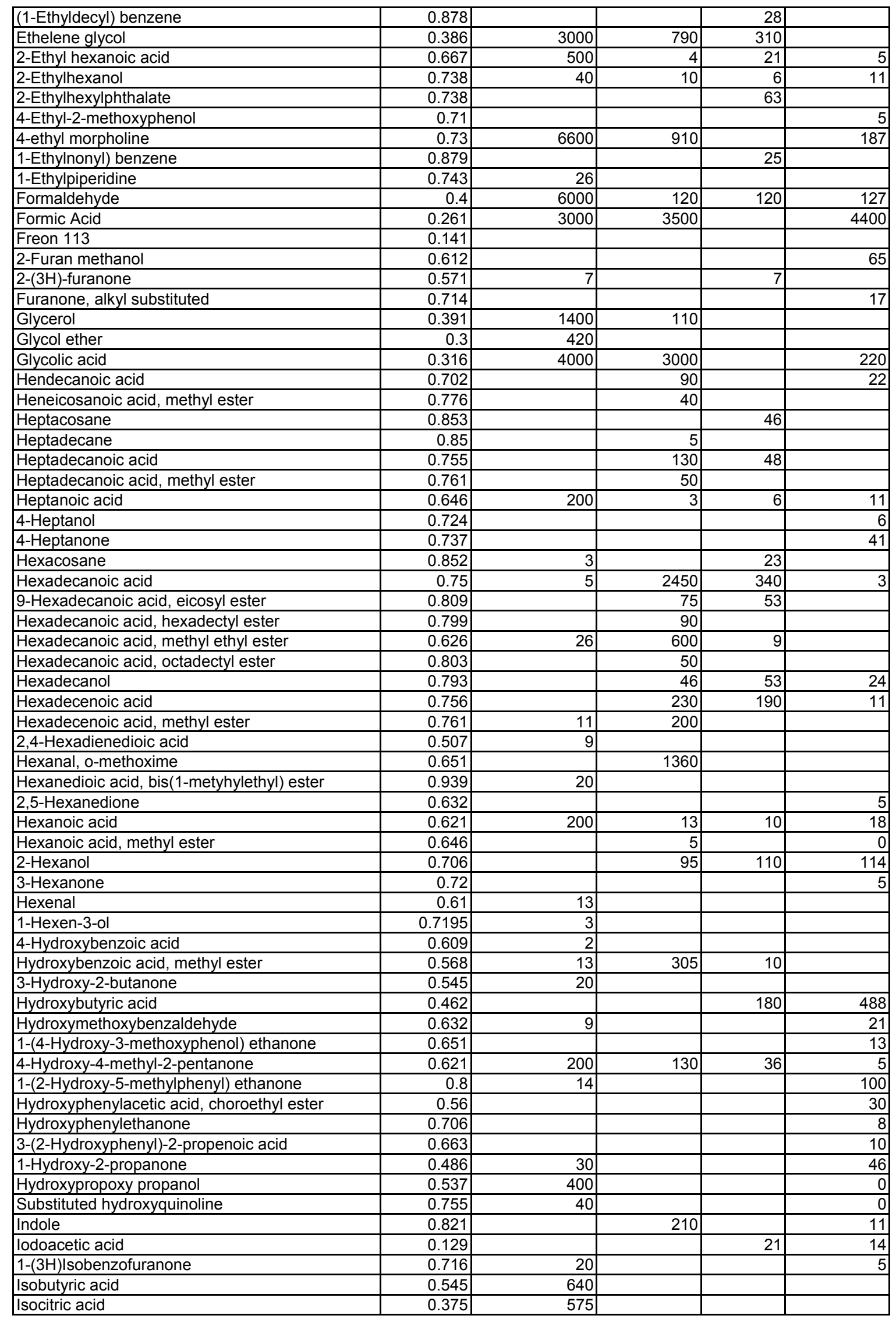




\begin{tabular}{|c|c|c|c|c|c|}
\hline Isophorone & 0.783 & 18 & & & \\
\hline Isoketoglutaric acid & 0.411 & & 80 & & \\
\hline Lactic acid & 0.4 & 3250 & 30000 & 15000 & 154 \\
\hline Methacrylic acid & 0.558 & 5 & & & \\
\hline Methanol & 0.375 & 1000 & 1400 & 434 & 1900 \\
\hline 2-Methoxyethanol & 0.474 & 100 & & & \\
\hline 2-(2-Methoxyethoxy) ethanol & 0.5 & 50 & & & \\
\hline 1-(2-Methoxy-1-methylethoxy)-2-propanol & 0.564 & 100 & & & \\
\hline Methoxymethylpropanol & 0.582 & 100 & & & \\
\hline Methoxy phenol & 0.677 & 150 & & & 32 \\
\hline 1-(4-Methoxyphenol)-ethanone & 0.72 & & & & 58 \\
\hline 3-Methoxy-1,2-propanediol & 0.453 & 70 & & & \\
\hline 2-Methoxy-4-(1-propenyl)-phenol & 0.732 & & & & 13 \\
\hline 1-(2-Methoxypropoxy)-2-propanol & 0.568 & 100 & & 11 & \\
\hline 2-Methyl benzaldehyde & 0.8 & & & & 7 \\
\hline Methylbenzoic acid & 0.706 & 22 & & & \\
\hline 3-Methyl butanoic acid & 0.588 & 25 & & & 190 \\
\hline 3-Methyl-2-butanone & 0.697 & & & & 3 \\
\hline 3-Methylcyclopentanone & 0.735 & & & & 8 \\
\hline (1-Methyldecyl) benzene & 0.879 & & & 40 & 7 \\
\hline \multicolumn{6}{|l|}{ 2-Methyl-2,2-dimethyl-1-(2-hydroxy propyl) } \\
\hline \begin{tabular}{|c} 
\\
- propionic acid
\end{tabular} & 0.667 & 25 & & & \\
\hline \multicolumn{6}{|l|}{ 2-Methyl-2,2-dimethyl-1-(2-hydroxy,1 methylethyl) } \\
\hline $\begin{array}{ll}\text { acid } & \text {-propyl esterpropionic } \\
\end{array}$ & 0.667 & 24 & & 12 & \\
\hline \multicolumn{6}{|l|}{ 2-Methyl-2,2-dimethyl-1-(2-hydroxy,1-methyl) } \\
\hline $\begin{array}{ll}\text { acid } & \text {-propionic } \\
\end{array}$ & 0.667 & 50 & & & \\
\hline \multicolumn{6}{|l|}{ 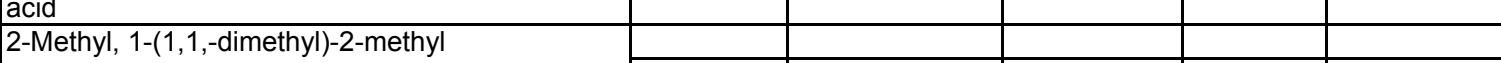 } \\
\hline \begin{tabular}{|c|c|c|} 
& -1,3-propanediyl ester propionic acid \\
\end{tabular} & 0.667 & 25 & & & \\
\hline Methylene chloride & 0.141 & 5 & & & 17 \\
\hline Methyl-2-heptanol & 0.76 & & 20 & & \\
\hline \multicolumn{6}{|l|}{ 2-Methyl-3-hydroxy-2,2,4-trimethylpentyl } \\
\hline \begin{tabular}{|l} 
\\
-ester propionic acid
\end{tabular} & 0.556 & 50 & & 13 & \\
\hline Methylisopropylcyclohexanol & 0.769 & 37 & & & \\
\hline Methyl methacrylate & 0.6 & & & & 11 \\
\hline Methyl-(methylethenyl)-2-cyclohexen-1-one & 0.81 & 10 & & & 12 \\
\hline 5-methyl-2-(1-methylethyl)-phenol & 0.8 & 200 & & & 110 \\
\hline Methyloxime & 0.261 & & 42 & & \\
\hline 14-Methyl-pentadecanoic acid,methyl ester & 0.756 & & 8 & & \\
\hline 2-Methyl-2,4-pentanediol & 0.61 & 425 & & & \\
\hline 4-Methyl pentanoic acid & 0.62 & 6 & & & \\
\hline 2-Methyl-3-pentanone & 0.719 & & & & 18 \\
\hline 4-Methyl-3-penten-2-one & 0.735 & & & 8 & \\
\hline Methyl phenol & 0.778 & 300 & & & 268 \\
\hline 2-Methyl propanoic acid & 0.545 & 25 & 7 & 6 & 105 \\
\hline 2-Methyl-2-propenoic acid & 0.558 & 50 & & & \\
\hline Methyl pyrazine & 0.638 & & & & 12 \\
\hline 1-Methyl-2-pyrrolidinone & 0.606 & 100 & 550 & & \\
\hline 12-Methyl-tetradecanoic acid & 0.744 & & 30 & & \\
\hline (1-Methylundecyl) benzene & 0.877 & & & 3 & \\
\hline Morpholine & 0.551 & 500 & & & \\
\hline Substituted Morpholine & 0.6 & 220 & & & \\
\hline Morpholine ethanamine & 0.549 & 130 & & & \\
\hline $\mathrm{N}, \mathrm{N}$-di-n-butylformamide & 0.688 & 250 & & 10 & \\
\hline $\mathrm{N}, \mathrm{N}$-diethyl-3-methylbenzamide & 0.754 & 20 & & & \\
\hline $\mathrm{N}, \mathrm{N}$-diethyl-m-toluamide & 0.754 & 23 & & & \\
\hline $\mathrm{N}, \mathrm{N}$-dimethylacetamide & 0.552 & 40 & & 4 & \\
\hline $\mathrm{N}, \mathrm{N}$-dimethylbenzylamine & 0.8 & 40 & & & 3 \\
\hline $\mathrm{N}, \mathrm{N}$-dimethylthioformamide & 0.493 & 400 & 4 & 13 & \\
\hline N,N-dimethylthioformamide & 0.404 & 40 & & & \\
\hline n-Butyl ether & 0.738 & 5 & & & \\
\hline N-Butylbenzenesulfonamide & 0.563 & 20 & & & \\
\hline N-Methyl-2-pyrrolidinone & 0.605 & 1200 & 4 & 18 & \\
\hline $\mathrm{N}$-Nitrosodimethyl amine & 0.324 & 30 & & & \\
\hline
\end{tabular}




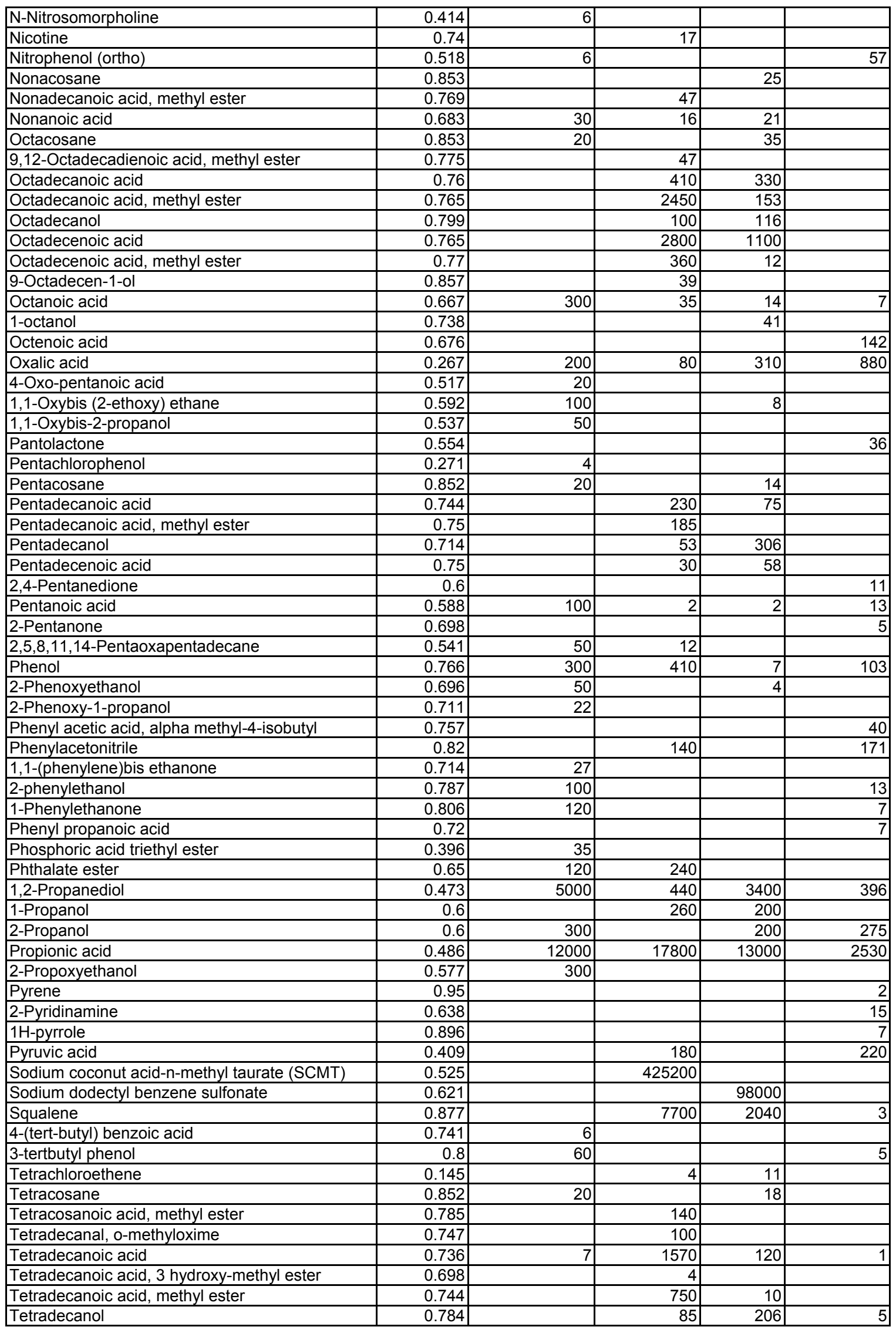




\begin{tabular}{|c|c|c|c|c|c|}
\hline Tetradecene & 0.857 & & & 5 & \\
\hline Tetradecenoic acid & 0.743 & & & 90 & \\
\hline Tetraethylene glycol diacetate & 0.518 & 2 & & & \\
\hline Tetraethylene glycol monoacetate & 0.508 & & 4 & & \\
\hline Tetrahydro-5,6-dimethyl-2H-pyran-2-one & 0.656 & & & & 106 \\
\hline Tetrahydro-6-methyl-2H-pyran-2-one & 0.632 & 45 & & & 75 \\
\hline Tetrahydrothiophene-1,1-dioxide (sulfolane) & 0.4 & 28 & & & \\
\hline 4-(2,2,3,3) Tetramethylbutyl phenol & 0.816 & & & & 7 \\
\hline Tetramethylurea & 0.517 & 31 & & & \\
\hline Tetraoxadodecane & 0.539 & & & & \\
\hline Toluene & 0.913 & 1 & 1000 & 5 & \\
\hline Total Amino Acids & 0.442 & & 275 & 320 & 374 \\
\hline Total Protein & 0.5 & 1300 & 23000 & 19700 & 1100 \\
\hline Tri(2-chlorethoxy)phosphate & 0.254 & 120 & & & \\
\hline Triacontane & 0.853 & & & 96 & \\
\hline Triacotanoic acid & 0.773 & & 95 & & \\
\hline Triacosane & 0.852 & 16 & & 5 & \\
\hline Tri(2-chloroethoxy)phosphate & 0.254 & 150 & & & \\
\hline Trichloropropene & 0.25 & & 3 & 21 & \\
\hline Tricosanoic acid, methyl ester & 0.783 & & 37 & & \\
\hline Tridecanoic acid & 0.729 & & 12 & 16 & \\
\hline Tridecanoic acid, methyl ester & 0.737 & & 42 & & \\
\hline Triethoxyphosphate & 0.396 & 26 & & & \\
\hline Triethylene glycol & 0.5 & 5 & & & \\
\hline Triethylene glycol diacetate & 0.513 & 46 & 3 & & \\
\hline Trimethylbenzylalcohol & 0.8 & & & & 9 \\
\hline Triumethylcyclohexenemethanol & 0.779 & 41 & & & 14 \\
\hline Trimethyl-2-cyclopenten-1-one & 0.787 & & & & 8 \\
\hline 2,2,4-Trimethyl-1,3-pentanediol & 0.738 & 60 & & & \\
\hline 1-(2,4,6-trimethylphenyl)ethanone & 0.761 & 8 & & & \\
\hline Trimethylpyrazine & 0.688 & & & & 8 \\
\hline 1,3,5-Tri-2-propenyl-1,3,5-triazine-2,4,6-trione & 0.578 & 12 & & & \\
\hline Undecanoic acid & 0.709 & 10 & & & \\
\hline 1-Undecene & 0.851 & & 9 & & \\
\hline Urea & 0.2 & 1000 & 15000 & 19600 & 3300 \\
\hline Vanillin & 0.632 & 7 & & & 13 \\
\hline Vinyl benzylalcohol & 0.806 & & & 16 & \\
\hline Aluminum & NA & 25 & & & 25 \\
\hline Ammonium & NA & 14000 & 6723 & 2630 & 1400 \\
\hline Arsenic & NA & & 10.8 & 20 & 3 \\
\hline Barium & NA & & 10.8 & 10 & 12 \\
\hline Bicarbonate & NA & 30000 & 17604 & 22760 & 1700 \\
\hline Bromide & NA & 50 & 54 & 100 & \\
\hline calcium & NA & 55 & 3574.8 & & 100 \\
\hline Carbon dioxide & NA & & & & \\
\hline Chloride & NA & 200 & 125280 & 91880 & 1100 \\
\hline Chromium & NA & & & & 8 \\
\hline Copper & NA & & 75.6 & & 10 \\
\hline Cyanide & NA & & & & 280 \\
\hline Fluoride & $\mathrm{NA}$ & 220 & 2376 & 75 & 160 \\
\hline Iodide & NA & & & & 110 \\
\hline \begin{tabular}{|l|} 
lodine \\
\end{tabular} & NA & & & & \\
\hline Iron & $\mathrm{NA}$ & & 129.6 & 110 & 45 \\
\hline Lead & NA & 10 & & & 3 \\
\hline Magnesium & NA & & 421.2 & 430 & 28 \\
\hline Manganese & NA & & 10.8 & & 3 \\
\hline Mercury & $\mathrm{NA}$ & 3 & & & \\
\hline Nickel & NA & & 21.6 & & 16 \\
\hline Nitrate & NA & 150 & 270 & 140 & 110 \\
\hline Nitrite & NA & 190 & & 100 & 120 \\
\hline Phosphate & NA & & 3375 & 660 & 480 \\
\hline Potassium & NA & 95 & 18122.4 & 9450 & 450 \\
\hline Selenium & NA & & & & 3 \\
\hline Sodium & NA & 665 & 135000 & 78720 & 1070 \\
\hline
\end{tabular}




\begin{tabular}{|l|r|r|r|r|r|}
\hline Sulfate & NA & 240 & 17820 & 6810 & 1240 \\
\hline Zinc & NA & 3 & & 30 & 8 \\
\hline Volume (I/day) & & 9.25 & 27.22 & 49.9 & 8.13 \\
\hline note: all values are in ppb unless noted & & \multicolumn{5}{|l|}{} \\
\hline
\end{tabular}




\section{Appendix II - Example Ion Exchange Equilibrium Calculations}

This ion exchange equilibrium description development is based on the work of Clancey (1995).

\section{Strong Acid Cation (SAC) and Strong Base Anion (SBA) Exchange Resins}

This Langmuir development regards ion exchange as the exchange of an ion for a presaturant ion.

\section{Assumptions:}

(1) Resin sites are occupied by either the exchanging ion or the presaturant ion. There are no empty sites.

(2) All ion exchange is treated as monovalent-monovalent ion exchange, which means that the selectivity $\left(K_{B}^{A}\right)$ is assumed equal to the separation factor $\left(\alpha_{B}^{A}\right)$ regardless of valence.

\section{Development for Resin Phase Concentration as a Function of Liquid Phase Concentration}

Binary Exchange

The ion exchange reaction for Type I strong base anionic exchange resin in the hydroxide form can be written in shorthand notation as:

$$
\mathrm{C}_{\mathrm{A}}+\mathrm{q}_{\mathrm{B}} \leftrightarrow \mathrm{q}_{\mathrm{A}}+\mathrm{C}_{\mathrm{B}}
$$

in which $C_{A}$ is the liquid phase concentration of exchanging ion $A^{-}$in meq/L, $C_{B}$ is the liquid phase concentration of presaturant ion $B^{-}$in meq/L, $q_{A}$ is the resin phase concentration of ion $A^{-}$in $\mathrm{meq} / \mathrm{mL}$ resin, and $q_{B}$ is the resin phase concentration of ion $\mathrm{B}^{-}$in $\mathrm{meq} / \mathrm{mL}$ resin .

The equilibrium constant (selectivity) for this reaction, $K_{A}^{B}$, is defined as:

$$
K_{A}^{B}=\frac{C_{A} q_{B}}{q_{A} C_{B}}
$$

This equation can be rearranged to solve for $q_{B}$ as follows:

$$
q_{B}=\frac{K_{A}^{B} q_{A} C_{B}}{C_{A}}
$$


Assuming that all exchange sites on the resin are occupied by either ion $\mathrm{A}^{-}$or ion $\mathrm{B}^{-}$, the total resin exchange capacity, $\mathrm{q}_{\mathrm{T}}$, can be represented by:

$$
\mathrm{q}_{\mathrm{T}}=\mathrm{q}_{\mathrm{A}}+\mathrm{q}_{\mathrm{B}}
$$

Substituting Equation II-3 into Equation II-4 and solving for $\mathrm{q}_{\mathrm{A}}$ results in an equilibrium expression for a binary (two component) system:

$$
q_{A}=\frac{q_{T} C_{A}}{C_{A}+K_{A}^{B} C_{B}}
$$

Once $q_{A}$ is known, it is possible to determine the resin phase concentration of the presaturant ion, $\mathrm{q}_{\mathrm{B}}$, after rearranging Equation II-4 since $\mathrm{q}_{\mathrm{T}}$ is known and constant for a given resin:

$$
q_{B}=q_{T}-q_{A}
$$

\section{Example: Chloride exchanging SBA resin in the hydroxide form}

The resin phase concentration of chloride can be calculated from Equation II-5:

$$
\mathrm{q}_{\mathrm{Cl}}=\frac{\mathrm{q}_{\mathrm{T}} \mathrm{C}_{\mathrm{Cl}}}{\mathrm{C}_{\mathrm{Cl}}+\mathrm{K}_{\mathrm{Cl}}^{\mathrm{OH}} \mathrm{C}_{\mathrm{OH}}}
$$

Once $q_{C l}$ is known, it is possible to determine the resin phase concentration of the presaturant ion, $\mathrm{q}_{\mathrm{OH}}$, from the relationship shown in Equation II-6:

$$
\mathrm{q}_{\mathrm{OH}}=\mathrm{q}_{\mathrm{T}}-\mathrm{q}_{\mathrm{OH}}
$$

\section{Multicomponent Exchange}

An expression for multicomponent ion exchange is needed to adequately describe ion exchange in complicated water matrices. A generalized ion exchange reaction is expressed below:

$$
C_{i}+q_{j} \leftrightarrow q_{i}+C_{j}
$$

The total exchange capacity of the resin is the sum of all sites occupied by ions $i$ through $j$ :

$$
q_{T}=\sum_{j=1}^{n} q_{j}
$$

in which $\mathrm{n}$ equals the number of ions in the system, including ion $\mathrm{i}$. 
A generalized multicomponent equilibrium expression is presented here, which is used to determine the resin phase concentrations of all ions except the presaturant ion:

$$
q_{i}=\frac{q_{T} C_{i}}{\sum_{j=1}^{n} K_{i}^{j} C_{j}}
$$

It should be noted that the equilibrium constant of an ion with respect to itself is equal to unity. That is, $K_{i}^{i}=1$.

The resin phase concentration of the presaturant ion, $\mathrm{q}_{\text {presaturant }}$, can be determined based on Equation II-10 once the resin phase concentrations of all other ions have been determined from Equation II-11:

$$
q_{\text {presaturant }}=q_{T}-\sum_{j=1}^{n-1} q_{j} \quad j \neq \text { presaturant ion }
$$

\section{Example: Chloride, Acetate, and Butyrate exchanging SBA resin in the hydroxide form}

The resin phase concentrations of chloride, acetate and butyrate can be calculated from Equation II-11:

$$
\begin{aligned}
& \mathrm{q}_{\mathrm{Cl}}=\frac{\mathrm{q}_{\mathrm{T}} \mathrm{C}_{\mathrm{Cl}}}{\mathrm{C}_{\mathrm{Cl}}+\mathrm{K}_{\mathrm{Cl}}^{\mathrm{Ac}} \mathrm{C}_{\mathrm{AC}}+\mathrm{K}_{\mathrm{Cl}}^{\mathrm{Bu}} \mathrm{C}_{\mathrm{But}}+\mathrm{K}_{\mathrm{Cl}}^{\mathrm{OH}} \mathrm{C}_{\mathrm{OH}}} \\
& \mathrm{q}_{\mathrm{AC}}=\frac{\mathrm{q}_{\mathrm{T}} \mathrm{C}_{\mathrm{Ac}}}{\mathrm{C}_{\mathrm{Ac}}+\mathrm{K}_{\mathrm{AC}}^{\mathrm{Cl}} \mathrm{C}_{\mathrm{Cl}}+\mathrm{K}_{\mathrm{AC}}^{\mathrm{But}} \mathrm{C}_{\mathrm{But}}+\mathrm{K}_{\mathrm{AC}}^{\mathrm{OH}} \mathrm{C}_{\mathrm{OH}}} \\
& q_{\text {But }}=\frac{\mathrm{q}_{\mathrm{T}} \mathrm{C}_{\text {But }}}{\mathrm{C}_{\text {But }}+\mathrm{K}_{\text {But }}^{\mathrm{Cl}} \mathrm{C}_{\mathrm{Cl}}+\mathrm{K}_{\text {But }}^{\mathrm{AC}} \mathrm{C}_{\text {Ac }}+\mathrm{K}_{\text {But }}^{\mathrm{OH}} \mathrm{C}_{\mathrm{OH}}}
\end{aligned}
$$

Once $\mathrm{q}_{\mathrm{Cl}}, \mathrm{q}_{\mathrm{AC}}$ and $\mathrm{q}_{\mathrm{But}}$ are known, it is possible to determine the resin phase concentration of the presaturant ion, $\mathrm{q}_{\mathrm{OH}}$, from the relationship shown in Equation II-12:

$$
q_{O H}=q_{T}-q_{C l}-q_{A c}-q_{B u t}
$$




\section{Development for Liquid Phase Concentration as a Function of Resin Phase Concentration}

\section{Binary Exchange}

The ion exchange reaction for Type I strong base anionic exchange resin in the hydroxide form can be written in shorthand notation as:

$$
\mathrm{C}_{\mathrm{A}}+\mathrm{q}_{\mathrm{B}} \leftrightarrow \mathrm{q}_{\mathrm{A}}+\mathrm{C}_{\mathrm{B}}
$$

in which $C_{A}$ is the liquid phase concentration of exchanging ion $A^{-}$in meq/L, $C_{B}$ is the liquid phase concentration of presaturant ion $B^{-}$in meq/L, $q_{A}$ is the resin phase concentration of ion $A^{-}$in meq/mL resin, and $q_{B}$ is the resin phase concentration of ion $\mathrm{B}^{-}$in $\mathrm{meq} / \mathrm{mL}$ resin .

The equilibrium constant (selectivity) for this reaction, $K_{A}^{B}$, is defined as:

$$
K_{B}^{A}=\frac{q_{A} C_{B}}{C_{A} q_{B}}
$$

This equation can be rearranged to solve for $C_{B}$ as follows:

$$
C_{B}=\frac{K_{B}^{A} C_{A} q_{B}}{q_{A}}
$$

The total liquid phase concentration can be represented by:

$$
\mathrm{C}_{\mathrm{T}}=\mathrm{C}_{\mathrm{A}}+\mathrm{C}_{\mathrm{B}}
$$

Substituting Equation II-19 into Equation II-20 and solving for $\mathrm{C}_{\mathrm{A}}$ results in an equilibrium expression for a binary (two component) system:

$$
C_{A}=\frac{C_{T} q_{A}}{q_{A}+K_{B}^{A} q_{B}}
$$

Once $C_{A}$ is known, it is possible to determine the liquid phase concentration of the presaturant ion, $C_{B}$, after rearranging Equation II-20 since $C_{T}$ is known and constant:

$$
\mathrm{C}_{\mathrm{B}}=\mathrm{C}_{\mathrm{T}}-\mathrm{C}_{\mathrm{A}}
$$




\section{Example: Chloride exchanging SBA resin in the hydroxide form}

The liquid phase concentration of chloride can be calculated from Equation II-21:

$$
\mathrm{C}_{\mathrm{Cl}}=\frac{\mathrm{C}_{\mathrm{T}} \mathrm{q}_{\mathrm{Cl}}}{\mathrm{q}_{\mathrm{Cl}}+\mathrm{K}_{\mathrm{OH}}^{\mathrm{Cl}} \mathrm{q}_{\mathrm{OH}}}
$$

Once $\mathrm{C}_{\mathrm{Cl}}$ is known, it is possible to determine the liquid phase concentration of the presaturant ion, $\mathrm{C}_{\mathrm{OH}}$, from the relationship shown in Equation II-22:

$$
\mathrm{q}_{\mathrm{OH}}=\mathrm{q}_{\mathrm{T}}-\mathrm{q}_{\mathrm{OH}}
$$

\section{Multicomponent Exchange}

An expression for multicomponent ion exchange is needed to adequately describe ion exchange in complicated water matrices. A generalized ion exchange reaction is expressed below:

$$
C_{i}+q_{j} \leftrightarrow q_{i}+C_{j}
$$

The total liquid phase concentration is the sum of the liquid phase concentrations of ions $i$ through $j$ :

$$
\mathrm{C}_{\mathrm{T}}=\sum_{\mathrm{j}=1}^{\mathrm{n}} \mathrm{C}_{\mathrm{j}}
$$

in which $\mathrm{n}$ equals the number of ions in the system, including ion $\mathrm{i}$.

A generalized multicomponent equilibrium expression is presented here, which is used to determine the liquid phase concentrations of all ions except the presaturant ion:

$$
C_{i}=\frac{C_{T} q_{i}}{\sum_{j=1}^{n} K_{j}^{i} q_{j}}
$$

It should be noted that the equilibrium constant of an ion with respect to itself is equal to unity. That is, $K_{i}^{i}=1$.

The liquid phase concentration of the presaturant ion, $\mathrm{C}_{\text {presaturant }}$, can determined based on Equation II-22 once the resin phase concentrations of all other ions have been determined from Equation II-27: 


$$
\mathrm{C}_{\text {presaturant }}=\mathrm{C}_{\mathrm{T}}-\sum_{\mathrm{j}=1}^{\mathrm{n}-1} \mathrm{C}_{\mathrm{j}} \mathrm{j} \neq \text { presaturant }
$$

Example: Chloride, Acetate, and Butyrate exchanging SBA resin in the hydroxide form

The liquid phase concentrations of chloride, acetate and butyrate can be calculated from Equation II-27:

$$
\begin{aligned}
& C_{C l}=\frac{C_{T} q_{C l}}{q_{C l}+K_{A C}^{C l} q_{A C}+K_{B u t}^{C l} q_{B u t}+K_{O H}^{C l} q_{O H}} \\
& C_{A C}=\frac{C_{T} q_{A C}}{q_{A C}+K_{C l}^{A C} q_{C l}+K_{B u t}^{A C} q_{B u t}+K_{O H}^{A C} q_{O H}} \\
& C_{B u t}=\frac{C_{T} q_{B u t}}{q_{B u t}+K_{C l}^{B u t} q_{C I}+K_{A C}^{B u t} q_{A C}+K_{O H}^{B u t} q_{O H}}
\end{aligned}
$$

Once $\mathrm{C}_{\mathrm{Cl}}, \mathrm{C}_{\mathrm{Ac}}$ and $\mathrm{C}_{\mathrm{But}}$ are known, it is possible to determine the liquid phase concentration of the presaturant ion, $\mathrm{C}_{\mathrm{OH}}$, from the relationship shown in Equation II-28:

$$
\mathrm{C}_{\mathrm{OH}}=\mathrm{C}_{\mathrm{T}}-\mathrm{C}_{\mathrm{Cl}}-\mathrm{C}_{\mathrm{Ac}}-\mathrm{C}_{\mathrm{But}}
$$

\section{Converting Separation Factors between Reference Ions}

The separation factors used in the equilibrium description must be expressed in terms of a common reference ion. The following relationship is used to convert separation factors to different reference ions:

$$
\alpha_{j}^{i} \times \alpha_{k}^{j}=\alpha_{k}^{i}
$$

Equation II-33 was validated by determining the separation factor for potassium using both the sodium and hydrogen form of IRN-77 resin. The separation factors for potassium were within $11 \%$ of each other when referenced to the same common ion.

\section{Weak Base Anion (WBA) Exchange Resins}

\section{Single Component System}

Assuming only monovalent ions / monoprotic acids, the mass action equation for a weak base anion (WBA) exchanger in the freebase form can be written in shorthand form as: 


$$
\mathrm{q}+\mathrm{C}_{\mathrm{H}}+\mathrm{C}_{\mathrm{i}} \leftrightarrow \mathrm{q}_{\mathrm{Hi}}
$$

in which the resin can be viewed as undergoing sorption rather than ion exchange because the uptake of an anion by the freebase form of the resin occurs without exchange of an ion (Helfferich, 1962; Diamond Shamrock Chemical Co., 1969).

The sorption of an acid by a WBA resin depends on: 1) the $\mathrm{pK}_{\mathrm{a}}$ of the acid which determines the amount of ionized acid; 2) the proton concentration which determines the amount of protonated resin (Helfferich, 1962; Clifford, 1976); and 3) the preference of the resin for the ion.

At equilibrium, an ion exchange constant, $b_{i}$, can be defined as:

$$
b_{i}=\frac{q_{H i}}{C_{H} C_{i} q}
$$

Rearranging Equation II-35 and solving for q results in the following:

$$
q=\frac{q_{H i}}{C_{H} C_{i} b_{i}}
$$

The total capacity of the resin is equal to the sum of the resin phase acid $\left(\mathrm{q}_{\mathrm{Hi}}\right)$ and the non-exchanging resin $(q)$ concentrations:

$$
\mathrm{q}_{\mathrm{T}}=\mathrm{q}+\mathrm{q}_{\mathrm{Hi}}
$$

Substituting Equation II-36 into Equation II-37 and solving for $\mathrm{q}_{\mathrm{Hi}}$ results in:

$$
q_{H i}=\frac{q_{T} C_{H} C_{i} b_{i}}{1+C_{H} C_{i} b_{i}}
$$

in which $C_{i}$ is defined as:

$$
C_{i}=C_{T, i}\left(\frac{10^{-p K_{a}}}{10^{-p K_{a}}+10^{-p H}}\right)
$$

Example: Chloride exchanging WBA resin in the freebase form

The resin phase concentration of chloride can be calculated from Equation II-38:

$$
q_{H C l}=\frac{q_{T} C_{H} C_{C l} b_{C l}}{1+C_{H} C_{C l} b_{C l}}
$$




\section{Multicomponent Exchange}

In a multicomponent system, the total capacity of the resin is the summation of the resin phase concentrations and the non-exchanging portion of the resin:

$$
q_{T}=q+q_{H i}+q_{H j}+\cdots+q_{H n}
$$

\section{Two Component System}

Starting with a two component system with the exchange rates defined by:

$$
b_{i}=\frac{q_{H i}}{C_{H} C_{i} q}
$$

and

$$
b_{j}=\frac{q_{H j}}{C_{H} C_{j} q}
$$

Solving Equation II-42 for q results in:

$$
q=\frac{q_{H i}}{C_{H} C_{i} b_{i}}
$$

Substituting Equation II-44 into Equation II-43 and solving for $\mathrm{q}_{\mathrm{Hj}}$ results in:

$$
q_{H j}=\frac{b_{j} C_{H} C_{j} q_{H i}}{C_{H} C_{i} b_{i}}
$$

Substituting Equations II-44 and II-45 into Equation II-41 for a two component system containing ions $\mathrm{i}$ and $\mathrm{j}$ results in:

$$
\begin{aligned}
q_{T} & =q+q_{H i}+q_{H j} \\
& =\frac{q_{H i}}{C_{H} C_{i} b_{i}}+q_{H i}+\frac{b_{j} C_{H} C_{j} q_{H i}}{C_{H} C_{i} b_{i}}
\end{aligned}
$$

Solving Equation II-46 for $\mathrm{q}_{\mathrm{Hi}}$ results in:

$$
q_{H i}=\frac{q_{T} b_{i} C_{H} C_{i}}{1+b_{i} C_{H} C_{i}+b_{j} C_{H} C_{j}}
$$

The resin phase concentration, $\mathrm{q}_{\mathrm{Hj}}$, can be derived in a similar manner. The result is presented here.

$$
q_{H j}=\frac{q_{T} b_{j} C_{H} C_{j}}{1+b_{i} C_{H} C_{i}+b_{j} C_{H} C_{j}}
$$


Example: Chloride and Acetate exchanging WBA resin in the freebase form

The resin phase concentrations of chloride and acetate can be calculated from Equations II-47 and II-48:

$$
\begin{gathered}
q_{H C l}=\frac{q_{T} b_{C l} C_{H} C_{C l}}{1+b_{C l} C_{H} C_{C l}+b_{A c} C_{H} C_{A c}} \\
q_{H A C}=\frac{q_{T} b_{A c} C_{H} C_{A c}}{1+b_{C l} C_{H} C_{C l}+b_{A c} C_{H} C_{A c}}
\end{gathered}
$$

\section{Multicomponent System with $\mathbf{n}$ components}

For systems containing $\mathrm{n}$ ions, the resin phase concentration of any ion $\mathrm{i}$ can be expressed as:

$$
q_{H i}=\frac{q_{T} b_{i} C_{H} C_{i}}{1+C_{H}\left(\sum_{k=1}^{n} b_{k} C_{k}\right)}
$$

Equation II-51 was developed in terms of concentration because the hydroxide concentration is negligible and the exchanging ion the only anionic species. Therefore the equivalent liquid phase concentration would be unity for all cases. Exchange constants ( $b$ 's) are used in Equation II-51 for the same reason. For multivalent ions, Equation II-51 is assumed to describe the reaction; however the equivalent concentration of multivalent ions is used for the aqueous phase concentration.

\section{Separation Factor for a WBA exchanger}

Based on the definition of separation factor, Equation II-42, and Equation II-43, the separation factor for a WBA exchanger is shown to be the ratio of the rate constants:

$$
\alpha_{j}^{i}=\frac{b_{i}}{b_{j}}=\frac{\frac{q_{H i}}{C_{H} C_{i} q}}{\frac{q_{H j}}{C_{H} C_{j} q}}=\frac{\frac{q_{H i}}{C_{i}}}{\frac{q_{H j}}{C_{j}}}=\frac{q_{H i} C_{j}}{q_{H j} C_{i}}
$$




\section{Appendix III - Development of the Tanks in Series Equilibrium Model} (TISEqM) for SAC, SBA and Mixed Bed Resins

Model Development for Single CSTR for Sodium Exchanging onto IRN77 (SAC) Exchange Resin in the Hydrogen Form and Chloride Exchanging onto IRN-78 (SBA) Exchange Resin in the Hydroxide Form

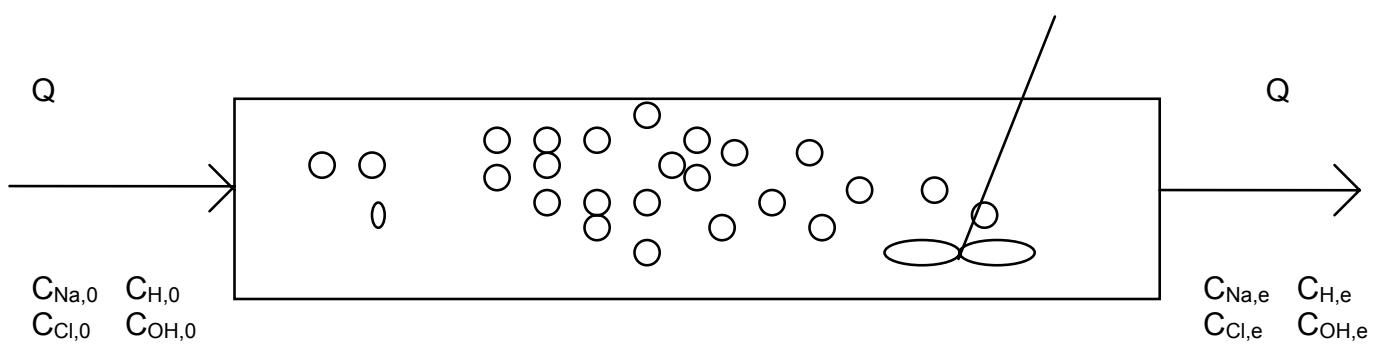

\section{General Mass Balance Equation:}

in - out + generation - loss = accumulation $\Rightarrow$

$$
\text { in }- \text { out }=\text { accumulation }
$$

$$
\mathrm{QC}_{0}-\mathrm{QC}_{\mathrm{e}}=\mathrm{M} \frac{\mathrm{dq}}{\mathrm{dt}}+\varepsilon \mathrm{V} \frac{\mathrm{dC}}{\mathrm{dt}}
$$

The term $\frac{\mathrm{dC}_{\mathrm{e}}}{\mathrm{dt}}$ may be replaced by the following expression:

$$
\frac{d C_{e}}{d t}=\frac{d C_{e}}{d q} \frac{d q}{d t}
$$

Substituting Equation III-3 into Equation III-2 results in the following:

$$
\mathrm{QC}_{0}-\mathrm{QC}_{\mathrm{e}}=\mathrm{M} \frac{\mathrm{dq}}{\mathrm{dt}}+\varepsilon \mathrm{V} \frac{\mathrm{dC}}{\mathrm{dq}} \frac{\mathrm{dq}}{\mathrm{dt}}
$$

Rearranging Equation III-4 and solving for $\frac{\mathrm{dq}}{\mathrm{dt}}$ results in the following:

$$
\frac{d q}{d t}=\frac{{Q C_{0}}_{0}-Q C_{e}}{M+\varepsilon V \frac{d C_{e}}{d q}}
$$




\section{Sodium Exchanging the Hydrogen Form of IRN-77 (SAC) Exchange Resin}

For the case of $\mathrm{Na}^{+}$exchanging on to the $\mathrm{H}^{+}$form of IRN-77 resin, the mass balances on $\mathrm{Na}^{+}$and on $\mathrm{H}^{+}$can be derived using the method shown above, resulting in equations similar to Equation III-5. These equations are shown below:

$$
\begin{aligned}
\frac{d q_{N a}}{d t} & =\frac{Q C_{N a, 0}-Q C_{N a, e}}{M_{C}+\varepsilon V \frac{d C_{N a, e}}{d q_{N a}}} \\
\frac{d q_{H}}{d t} & =\frac{Q C_{H, 0}-Q C_{H, e}}{M_{C}+\varepsilon V \frac{d C_{H, e}}{d q_{H}}}
\end{aligned}
$$

In order to solve Equation III-6 and Equation III-7, it is necessary to have values for the expressions $\frac{\mathrm{dC}_{\mathrm{Na}, \mathrm{e}}}{\mathrm{dq}_{\mathrm{Na}}}$ and $\frac{\mathrm{dC}_{\mathrm{H}, \mathrm{e}}}{\mathrm{dq}_{\mathrm{H}}}$. These expressions are obtained from the equilibrium expressions that relate concentration in the liquid phase to concentration in the resin phase for each ion. These equilibrium expressions are:

$$
\begin{gathered}
C_{\mathrm{Na}}=\frac{\mathrm{C}_{\mathrm{T}, \mathrm{C}} \mathrm{q}_{\mathrm{Na}}}{\mathrm{q}_{\mathrm{Na}}+\alpha_{\mathrm{H}}^{\mathrm{Na}} \mathrm{q}_{\mathrm{H}}} \\
\mathrm{C}_{\mathrm{H}}=\frac{\mathrm{C}_{\mathrm{T}, \mathrm{C}} \mathrm{q}_{\mathrm{H}}}{\mathrm{q}_{\mathrm{H}}+\alpha_{\mathrm{Na}}^{\mathrm{H}} \mathrm{q}_{\mathrm{Na}}}
\end{gathered}
$$

Taking the partial derivative $\frac{\mathrm{dC}_{\mathrm{Na}, \mathrm{e}}}{\mathrm{dq}_{\mathrm{Na}}}$ from Equation III-8 results in the following:

$$
\frac{d C_{\mathrm{Na}, \mathrm{e}}}{d \mathrm{q}_{\mathrm{Na}}}=\frac{\mathrm{C}_{\mathrm{T}, \mathrm{C}} \alpha_{H}^{\mathrm{Na}} \mathrm{q}_{H}}{\left(\mathrm{q}_{\mathrm{Na}}+\alpha_{H}^{\mathrm{Na}} \mathrm{q}_{H}\right)^{2}}
$$

Taking the partial derivative $\frac{\mathrm{dC}_{\mathrm{H}, \mathrm{e}}}{\mathrm{dq}_{\mathrm{H}}}$ from Equation III-9 results in the following:

$$
\frac{d C_{H, e}}{d q_{H}}=\frac{C_{T, C} \alpha_{N a}^{H} q_{N a}}{\left(q_{H}+\alpha_{N a}^{H} q_{N a}\right)^{2}}
$$

Substituting Equation III-10 into Equation III-6 results in the following: 


$$
\frac{d q_{N a}}{d t}=\frac{Q C_{N a, 0}-Q_{\mathrm{Na}^{\mathrm{e}}}}{M_{\mathrm{C}}+\varepsilon V\left[\frac{\mathrm{C}_{\mathrm{T}, \mathrm{C}} \alpha_{\mathrm{H}}^{\mathrm{Na}} \mathrm{q}_{\mathrm{H}}}{\left(\mathrm{q}_{\mathrm{Na}}+\alpha_{\mathrm{H}}^{\mathrm{Na}} \mathrm{q}_{\mathrm{H}}\right)^{2}}\right]}
$$

Substituting Equation III-11 into Equation III-7 results in the following:

$$
\frac{d q_{H}}{d t}=\frac{Q C_{H, 0}-Q C_{H, e}}{M_{C}+\varepsilon V\left[\frac{C_{T, C} \alpha_{N a}^{H} q_{N a}}{\left(q_{H}+\alpha_{N a}^{H} q_{N a}\right)^{2}}\right]}
$$

The term $\mathrm{C}_{\mathrm{Na}, 0}$ in Equation III-12 and the term $\mathrm{C}_{\mathrm{H}, 0}$ in Equation III-13 refer to the liquid phase influent concentrations of sodium and hydrogen ions, respectively. These values are known. In contrast, the term $\mathrm{C}_{\mathrm{Na}, \mathrm{e}}$ in Equation III-12 and the term $\mathrm{C}_{\mathrm{H}, \mathrm{e}}$ in Equation III-13 refer to the liquid phase effluent concentrations of sodium and hydrogen ions, respectively. These values are unknown. In order to solve Equation III-12 and Equation III-13, it is necessary to replace the terms $\mathrm{C}_{\mathrm{Na}, \mathrm{e}}$ and $\mathrm{C}_{\mathrm{H}, \mathrm{e}}$ using the equilibrium expressions given by Equation III-8 and Equation III-9. The resulting equations are given below:

$$
\begin{gathered}
\frac{d q_{N a}}{d t}=\frac{Q_{N a, 0}-Q\left[\frac{C_{T, C} q_{N a}}{q_{N a}+\alpha_{H}^{N a} q_{H}}\right]}{M_{C}+\varepsilon V\left[\frac{C_{T, C} \alpha_{H}^{N a} q_{H}}{\left(q_{N a}+\alpha_{H}^{N a} q_{H}\right)^{2}}\right]} \\
\frac{d q_{H}}{d t}=\frac{Q_{H, 0}-Q\left[\frac{C_{T, C} q_{H}}{q_{H}+\alpha_{N a}^{H} q_{N a}}\right]}{M_{C}+\varepsilon V\left[\frac{C_{T, C} \alpha_{N a}^{H} q_{N a}}{\left(q_{H}+\alpha_{N a}^{H} q_{N a}\right)^{2}}\right]}
\end{gathered}
$$

Because in this case it is known that the total resin phase ion concentration is the sum of the resin phase sodium ion concentration and the resin phase hydrogen ion concentration, solution of Equation III-14 and Equation III-15 simultaneously will result in an overspecification of the problem. Therefore the following relationship will be used in conjunction with either of the ODE's given by Equation III-14 and Equation III-15 for this ion exchange model: 


$$
\mathrm{q}_{\mathrm{T}, \mathrm{C}}=\mathrm{q}_{\mathrm{Na}}+\mathrm{q}_{\mathrm{H}}
$$

For this model, the ODE with respect to sodium will be programmed in order to solve for the effluent profiles of $\mathrm{Na}^{+}$and $\mathrm{H}^{+}$. Therefore, the equations programmed to solve the model will be Equation III-14 and Equation III-16. Equation III-16 will be rearranged to represent a solution for the $\mathrm{H}^{+}$concentration anywhere that it appears in Equation III-14. The rearrangement of Equation III-16 is:

$$
\mathrm{q}_{\mathrm{H}}=\mathrm{q}_{\mathrm{T}, \mathrm{C}}-\mathrm{q}_{\mathrm{Na}}
$$

Substituting Equation III-17 into Equation III-14 results in the single ODE that is solved by GEAR in order to determine $\mathrm{q}_{\mathrm{Na}}$. This equation is shown below:

$$
\frac{\mathrm{dq}_{\mathrm{Na}}}{\mathrm{dt}}=\frac{Q C_{\mathrm{Na}, 0}-Q\left[\frac{C_{\mathrm{T}, \mathrm{C}} \mathrm{q}_{\mathrm{Na}}}{\mathrm{q}_{\mathrm{Na}}+\alpha_{H}^{N a}\left(\mathrm{q}_{\mathrm{T}, \mathrm{C}}-\mathrm{q}_{\mathrm{Na}}\right)}\right]}{\mathrm{M}_{\mathrm{C}}+\varepsilon V\left[\frac{\mathrm{C}_{\mathrm{T}, \mathrm{C}} \alpha_{H}^{\mathrm{Na}}\left(\mathrm{q}_{\mathrm{T}, \mathrm{C}}-\mathrm{q}_{\mathrm{Na}}\right)}{\left(\mathrm{q}_{\mathrm{Na}}+\alpha_{H}^{\mathrm{Na}}\left(\mathrm{q}_{\mathrm{T}, \mathrm{C}}-\mathrm{q}_{\mathrm{Na}}\right)\right)^{2}}\right]}
$$

Once $\mathrm{q}_{\mathrm{Na}}$ is known from Equation III-18, $\mathrm{q}_{\mathrm{H}}$ can be found by substituting back into Equation III-17. The liquid phase effluent concentrations $\left(\mathrm{C}_{\mathrm{Na}, \mathrm{e}}\right.$ and $\left.\mathrm{C}_{\mathrm{H}, \mathrm{e}}\right)$ can be found by substituting the resin phase concentrations $\left(q_{\mathrm{Na}}\right.$ and $\left.\mathrm{q}_{\mathrm{H}}\right)$ into Equation III-8 and Equation III-9, respectively.

\section{Chloride Exchanging the Hydroxide Form of IRN-78 (SBA) Exchange Resin}

For the case of $\mathrm{Cl}^{-}$exchanging on to the $\mathrm{OH}^{-}$form of IRN-78 resin, the mass balances on $\mathrm{Cl}^{-}$and on $\mathrm{OH}^{-}$can be derived using the method shown above, resulting in equations similar to Equation III-5. These equations are shown below:

$$
\begin{aligned}
& \frac{d q_{C l}}{d t}=\frac{Q_{C l, 0}-Q_{C l, e}}{M_{A}+\varepsilon V \frac{d C_{C l, e}}{d q_{C l}}} \\
& \frac{d q_{\mathrm{OH}}}{d t}=\frac{\mathrm{QC}_{\mathrm{OH}, 0}-\mathrm{QC}_{\mathrm{OH}_{\mathrm{e}}}}{\mathrm{M}_{\mathrm{A}}+\varepsilon \mathrm{\varepsilon} \frac{\mathrm{d}_{\mathrm{O}_{\mathrm{e}} \mathrm{e}}}{\mathrm{dq}_{\mathrm{OH}}}}
\end{aligned}
$$


In order to solve Equations III-19 and III-20, it is necessary to have values for the expressions $\frac{\mathrm{dC}_{\mathrm{Cl}, \mathrm{e}}}{\mathrm{dq}_{\mathrm{Cl}}}$ and $\frac{\mathrm{dC}_{\mathrm{OH}, \mathrm{e}}}{\mathrm{dq}_{\mathrm{OH}}}$. These expressions are obtained from the equilibrium expressions that relate concentration in the liquid phase to concentration in the resin phase for each ion. These equilibrium expressions are:

$$
\begin{aligned}
& C_{\mathrm{Cl}}=\frac{C_{T, A} q_{C l}}{q_{C l}+\alpha_{O H}^{C l} q_{O H}} \\
& C_{O H}=\frac{C_{T, A} q_{O H}}{q_{O H}+\alpha_{C l}^{O H} q_{C l}}
\end{aligned}
$$

Taking the partial derivative $\frac{\mathrm{dC}_{\mathrm{Cl}, \mathrm{e}}}{\mathrm{dq}_{\mathrm{Cl}}}$ from Equation III-21 results in the following:

$$
\frac{d C_{C l, e}}{d q_{C l}}=\frac{C_{T, A} \alpha_{O H}^{C l} q_{O H}}{\left(q_{C l}+\alpha_{O H}^{C l} q_{O H}\right)^{2}}
$$

Taking the partial derivative $\frac{\mathrm{dC}_{\mathrm{OH}, \mathrm{e}}}{\mathrm{dq}_{\mathrm{OH}}}$ from Equation III-22 results in the following:

$$
\frac{\mathrm{dC}_{\mathrm{OH}, \mathrm{e}}}{d \mathrm{q}_{\mathrm{OH}}}=\frac{\mathrm{C}_{\mathrm{T}, \mathrm{A}} \alpha_{\mathrm{Cl}}^{\mathrm{OH}} \mathrm{q}_{\mathrm{Cl}}}{\left(\mathrm{q}_{\mathrm{OH}}+\alpha_{\mathrm{Cl}}^{\mathrm{OH}} \mathrm{q}_{\mathrm{Cl}}\right)^{2}}
$$

Substituting Equation III-23 into Equation III-19 results in the following:

$$
\frac{d q_{C l}}{d t}=\frac{Q_{C l, 0}-Q_{C l, e}}{M_{A}+\varepsilon V\left[\frac{C_{T, A} \alpha_{O H}^{C l} q_{O H}}{\left(q_{C l}+\alpha_{O H}^{C l} q_{O H}\right)^{2}}\right]}
$$

Substituting Equation III-24 into Equation III-20 results in the following:

$$
\frac{d q_{\mathrm{OH}}}{d t}=\frac{Q C_{\mathrm{OH}, 0}-Q_{C_{\mathrm{OH}, \mathrm{e}}}}{M_{\mathrm{A}}+\varepsilon V\left[\frac{\mathrm{C}_{\mathrm{T}, \mathrm{A}} \alpha_{\mathrm{Cl}}^{\mathrm{OH}} \mathrm{q}_{\mathrm{Cl}}}{\left(\mathrm{q}_{\mathrm{OH}}+\alpha_{\mathrm{Cl}}^{\mathrm{OH}} \mathrm{q}_{\mathrm{Cl}}\right)^{2}}\right]}
$$

The term $\mathrm{C}_{\mathrm{Cl}, 0}$ in Equation III-25 and the term $\mathrm{C}_{\mathrm{OH}, 0}$ in Equation III-26 refer to the liquid phase influent concentrations of chloride and hydroxide ions, respectively. These values are known. In contrast, the term $\mathrm{C}_{\mathrm{Cl}, \mathrm{e}}$ in Equation III-25 and the 
term $\mathrm{C}_{\mathrm{OH}, \mathrm{e}}$ in Equation III-26 refer to the liquid phase effluent concentrations of chloride and hydroxide ions, respectively. These values are unknown. In order to solve Equation III-25 and Equation III-26, it is necessary to replace the terms $\mathrm{C}_{\mathrm{Cl}, \mathrm{e}}$ and $\mathrm{C}_{\mathrm{OH}, \mathrm{e}}$ using the equilibrium expressions given by Equations III-21 and III-22, respectively. The resulting equations are given below:

$$
\begin{gathered}
\frac{d q_{C l}}{d t}=\frac{Q C_{C l, 0}-Q\left[\frac{C_{T, A} q_{C l}}{q_{C l}+\alpha_{O H}^{C l} q_{O H}}\right]}{M_{A}+\varepsilon V\left[\frac{C_{T, A} \alpha_{O H}^{C l} q_{O H}}{\left(q_{C l}+\alpha_{O H}^{C l} q_{O H}\right)^{2}}\right]} \\
\frac{d q_{O H}}{d t}=\frac{Q C_{O H, 0}-Q\left[\frac{C_{T, A} q_{O H}}{q_{O H}+\alpha_{C l}^{O H} q_{C l}}\right]}{M_{A}+\varepsilon V\left[\frac{C_{T, A} \alpha_{C l}^{O H} q_{C l}}{\left(q_{O H}+\alpha_{C l}^{O H} q_{C l}\right)^{2}}\right]}
\end{gathered}
$$

Because in this case it is known that the total resin phase ion concentration is the sum of the resin phase sodium ion concentration and the resin phase hydrogen ion concentration, solution of Equations III-27 and III-28 simultaneously will result in an overspecification of the problem. Therefore the following relationship will be used in conjunction with either of the ODE's given by Equations III-27 and III-28 for this ion exchange model:

$$
\mathrm{q}_{\mathrm{T}, \mathrm{A}}=\mathrm{q}_{\mathrm{Cl}}+\mathrm{q}_{\mathrm{OH}}
$$

For this model, the ODE with respect to sodium will be programmed in order to solve for the effluent profiles of $\mathrm{Cl}^{-}$and $\mathrm{OH}^{-}$. Therefore, the equations programmed to solve the model will be Equation III-27 and Equation III-29. Equation III-29 will be rearranged to represent a solution for the $\mathrm{OH}^{-}$ concentration anywhere that it appears in Equation III-27. The rearrangement of Equation III-29 is shown:

$$
\mathrm{q}_{\mathrm{OH}}=\mathrm{q}_{\mathrm{T}, \mathrm{A}}-\mathrm{q}_{\mathrm{Cl}}
$$

Substituting Equation III-30 into Equation III-27 results in the single ODE that is solved by GEAR in order to determine $\mathrm{q}_{\mathrm{Cl}}$. This equation is shown below: 


$$
\frac{d q_{C l}}{d t}=\frac{Q C_{C l, 0}-Q\left[\frac{C_{T, A} q_{C l}}{q_{C l}+\alpha_{O H}^{C l}\left(q_{T, A}-q_{C l}\right)}\right]}{M_{A}+\varepsilon V\left[\frac{C_{T, A} \alpha_{O H}^{C l}\left(q_{T, A}-q_{C l}\right)}{\left(q_{C l}+\alpha_{O H}^{C l}\left(q_{T, A}-q_{C l}\right)\right)^{2}}\right]}
$$

Once $\mathrm{q}_{\mathrm{Cl}}$ is known from Equation III-31, $\mathrm{q}_{\mathrm{OH}}$ can be found by substituting back into Equation III-30. The liquid phase effluent concentrations $\left(\mathrm{C}_{\mathrm{Cl}, \mathrm{e}}\right.$ and $\left.\mathrm{C}_{\mathrm{OH}, \mathrm{e}}\right)$ can be found by substituting the resin phase concentrations $\left(\mathrm{q}_{\mathrm{Cl}}\right.$ and $\left.\mathrm{q}_{\mathrm{OH}}\right)$ into Equations III-21 and III-22, respectively.

\section{Converting the Single CSTR Model into Dimensionless Form for Sodium Exchanging onto IRN-77 (SAC) Exchange Resin in the Hydrogen Form and Chloride Exchanging onto IRN-78 (SBA) Exchange Resin in the Hydroxide Form}

After making some definitions, it is possible to convert Equations III-17, III-18, III-30, and III-31 into dimensionless form. The dimensionless resin phase concentrations of $\mathrm{Na}^{+}$and $\mathrm{H}^{+}\left(\overline{\mathrm{q}}_{\mathrm{Na}}\right.$ and $\overline{\mathrm{q}}_{\mathrm{H}}$, respectively) are defined in the following relationships:

$$
\begin{gathered}
\bar{q}_{\mathrm{Na}}=\frac{\mathrm{q}_{\mathrm{Na}}}{\mathrm{q}_{\mathrm{T}, \mathrm{C}}} \\
\overline{\mathrm{q}}_{\mathrm{H}}=\frac{\mathrm{q}_{\mathrm{H}}}{\mathrm{q}_{\mathrm{T}, \mathrm{C}}}
\end{gathered}
$$

Defining the equivalent time-averaged influent liquid phase concentration of ion $\mathrm{i}$ $\left(\overline{\mathrm{C}_{0, \mathrm{i}}}\right)$ and the total equivalent time-averaged influent liquid phase concentration of all cations $\left(\overline{\mathrm{C}_{\mathrm{T}, \text { avg, C }}}\right)$ in Equations III-34 and III-35 allows for the definition of $\overline{\mathrm{C}_{\mathrm{Na}, 0}}$ in Equation III-36.

$$
\begin{gathered}
\overline{\mathrm{C}_{0, \mathrm{i}}}=\frac{1}{\mathrm{t}} \int_{0}^{\mathrm{t}} \mathrm{C}_{0, \mathrm{i}}(\mathrm{t}) \mathrm{dt} \\
\overline{\mathrm{C}_{\mathrm{T}, \mathrm{avg}, \mathrm{C}}}=\sum_{\mathrm{j}=1}^{\mathrm{m}} \overline{\mathrm{C}_{0, \mathrm{j}}} \quad \text { where } \mathrm{m}=\text { number of cations } \\
\overline{\mathrm{C}_{\mathrm{Na}, 0}}=\frac{\mathrm{C}_{\mathrm{Na}, 0}}{\overline{\mathrm{C}_{0, \mathrm{Na}}}}
\end{gathered}
$$




$$
\begin{gathered}
\overline{\mathrm{C}_{\mathrm{H}, 0}}=\frac{\mathrm{C}_{\mathrm{Na}, 0}}{\overline{\mathrm{C}_{0, \mathrm{H}}}} \\
\left(\overline{\mathrm{C}_{\mathrm{T}, \mathrm{C}}}\right)_{\mathrm{Na}}=\overline{\mathrm{C}_{\mathrm{Na}, 0}}+\overline{\mathrm{C}_{\mathrm{H}, 0}} \times \frac{\mathrm{C}_{\mathrm{F}, \mathrm{Na}}}{\mathrm{C}_{\mathrm{F}, \mathrm{H}}}
\end{gathered}
$$

The dimensionless resin phase concentrations of $\mathrm{Cl}^{-}$and $\mathrm{OH}^{-}\left(\bar{q}_{\mathrm{Cl}}\right.$ and $\overline{\mathrm{q}}_{\mathrm{OH}}$, respectively) are defined in the following relationships:

$$
\begin{array}{r}
\overline{\mathrm{q}}_{\mathrm{Cl}}=\frac{\mathrm{q}_{\mathrm{Cl}}}{\mathrm{q}_{\mathrm{T}, \mathrm{A}}} \\
\overline{\mathrm{q}}_{\mathrm{OH}}=\frac{\mathrm{q}_{\mathrm{OH}}}{\mathrm{q}_{\mathrm{T}, \mathrm{A}}} \\
\overline{\mathrm{C}_{\mathrm{T}, \text { avg }, \mathrm{A}}}=\sum_{\mathrm{j}=1}^{\mathrm{k}} \overline{\mathrm{C}_{0, \mathrm{j}}} \quad \text { where } \mathrm{k}=\text { number of anions } \\
\overline{\mathrm{C}_{\mathrm{Cl}, 0}}=\frac{\mathrm{C}_{\mathrm{Cl}, 0}}{\overline{\mathrm{C}_{0, \mathrm{Cl}}}} \\
\left(\overline{\mathrm{C}_{\mathrm{T}, \mathrm{A}}}\right)_{\mathrm{Cl}}=\overline{\mathrm{C}_{\mathrm{Cl}, 0}}+\overline{\mathrm{C}_{\mathrm{OH}, 0}} \times \frac{\mathrm{C}_{\mathrm{F}, \mathrm{Cl}}}{\mathrm{C}_{\mathrm{F}, \mathrm{OH}}}
\end{array}
$$

Dimensionless time $(T)$ will be defined in terms of a capacity factor $\left(C_{F}\right)$ and the packed bed contact time $(\tau)$ from the following equation:

$$
\mathrm{T}=\frac{\mathrm{t}}{\mathrm{C}_{\mathrm{F}} \tau}
$$

where:

$$
\begin{aligned}
C_{F} & =C_{F, C}+C_{F, A} \\
C_{F, C} & =\frac{M_{C} q_{T, C}}{V \overline{C_{T, a v g, C}} \varepsilon} \\
C_{F, A} & =\frac{M_{A} q_{T, A}}{V \overline{C_{T, a v g, A}} \varepsilon} \\
C_{F, N a} & =\frac{M_{C} q_{T, C}}{V \overline{C_{0, N a}} \varepsilon}
\end{aligned}
$$




$$
\begin{aligned}
C_{F, H} & =\frac{M_{C} q_{T, C}}{V \overline{C_{0, H}} \varepsilon} \\
C_{F, C l} & =\frac{M_{C} q_{T, C}}{V \overline{C_{0, C l}} \varepsilon} \\
C_{F, O H} & =\frac{M_{C} q_{T, C}}{V \overline{C_{0, O H}} \varepsilon} \\
\tau & =\frac{V \varepsilon}{Q}
\end{aligned}
$$

Based on Equation III-44, an expression for $\frac{d}{d t}$ is given as follows:

$$
\frac{\mathrm{d}}{\mathrm{dt}}=\frac{1}{\mathrm{C}_{\mathrm{F}} \tau} \frac{\mathrm{d}}{\mathrm{dT}}
$$

Applying Equations III-32 through III-53 to Equations III-17, III-18, III-30, and III-31 results in the dimensionless form of the equations that need to be solved for the single CSTR model for the case of $\mathrm{Na}^{+}$exchanging onto the $\mathrm{H}^{+}$form of IRN-77 resin and $\mathrm{Cl}^{-}$exchanging onto the $\mathrm{OH}^{-}$form of IRN-78 resin. The dimensionless equations are given below:

$$
\frac{\overline{\mathrm{q}}_{\mathrm{H}}=1-\overline{\mathrm{q}}_{\mathrm{Na}}}{\mathrm{d} \overline{\mathrm{q}}_{\mathrm{Na}}=\frac{\overline{\mathrm{C}_{\mathrm{Na}, 0}}-\left[\frac{\left(\overline{\mathrm{C}_{\mathrm{T}, \mathrm{C}}}\right)_{\mathrm{Na}} \overline{\mathrm{q}}_{\mathrm{Na}}}{\left.\overline{\overline{\mathrm{q}}_{\mathrm{Na}}+\alpha_{\mathrm{H}}^{\mathrm{Na}}\left(1-\overline{\mathrm{q}}_{\mathrm{Na}}\right)}\right]}\right.}{\left(\frac{\mathrm{C}_{\mathrm{F}, \mathrm{Na}}}{\mathrm{C}_{\mathrm{F}}}\right)+\left(\frac{1}{\mathrm{C}_{\mathrm{F}}}\right)\left\{\frac{\left(\overline{\mathrm{C}_{\mathrm{T}, \mathrm{C}}}\right)_{\mathrm{Na}} \alpha_{\mathrm{H}}^{\mathrm{Na}}\left(1-\overline{\mathrm{q}}_{\mathrm{Na}}\right)}{\left[\overline{\mathrm{q}}_{\mathrm{Na}}+\alpha_{\mathrm{H}}^{\mathrm{Na}}\left(1-\overline{\mathrm{q}}_{\mathrm{Na}}\right)\right]^{2}}\right\}}}
$$

For a more detailed decription of converting the cation case to dimensionless form, see Appendix III.B.

$$
\overline{\mathrm{q}}_{\mathrm{OH}}=1-\overline{\mathrm{q}}_{\mathrm{Cl}}
$$




$$
\frac{d \overline{\mathrm{q}}_{\mathrm{Cl}}}{\mathrm{dT}}=\frac{\overline{\mathrm{C}_{\mathrm{Cl}, 0}}-\left[\frac{\left(\overline{\mathrm{C}_{\mathrm{T}, \mathrm{A}}}\right)_{\mathrm{Cl}} \overline{\mathrm{q}}_{\mathrm{Cl}}}{\left.\overline{\overline{\mathrm{q}}_{\mathrm{Cl}}+\alpha_{\mathrm{OH}}^{\mathrm{Cl}}\left(1-\overline{\mathrm{q}}_{\mathrm{Cl}}\right)}\right]}\right.}{\left(\frac{\mathrm{C}_{\mathrm{F}, \mathrm{Cl}}}{\mathrm{C}_{\mathrm{F}}}\right)+\left(\frac{1}{\mathrm{C}_{\mathrm{F}}}\right)\left\{\frac{\left(\overline{\mathrm{C}_{\mathrm{T}, \mathrm{A}}}\right)_{\mathrm{Cl}} \alpha_{\mathrm{OH}}^{\mathrm{Cl}}\left(1-\overline{\mathrm{q}}_{\mathrm{Cl}}\right)}{\left[\overline{\mathrm{q}}_{\mathrm{Cl}}+\alpha_{\mathrm{OH}}^{\mathrm{Cl}}\left(1-\overline{\mathrm{q}}_{\mathrm{Cl}}\right)\right]^{2}}\right\}}
$$

Converting the anion equations to dimensionless form is completely analogous to the cation case shown in Appendix III.B.

\section{Model Development for a Single CSTR for the General Case of NCATION Cations and NANION Anions}

The dimensioned form of the general case for NCOMP ( = NCATION + NANION) components is derived similarly to the dimensioned form of the previous case of $\mathrm{Na}^{+}$exchanging onto the $\mathrm{H}^{+}$form of IRN-77 resin and $\mathrm{Cl}^{-}$ exchanging onto the $\mathrm{OH}^{-}$form of IRN-78 resin. The equations presented below are for each component, i, in an NCOMP component simulation. The equations for both cations and anions will be shown below. In this development, the cations and anions are not coupled together in any way. Equation III-5 can be rewritten as:

$$
\frac{d q_{i}}{d t}=\frac{Q C_{i, 0}-Q C_{i, e}}{M_{C}+\varepsilon V \frac{d C_{i, e}}{d q_{i}}}
$$

In order to solve Equation III-58, it is necessary to evaluate the expression,

$\frac{d C_{i, e}}{d q_{i}}$, for each component $i$. The value of this term is obtained from the equilibrium expression that relates concentration in the liquid phase to concentration in the resin phase for each ion.

\section{Cations}

The general form of the equilibrium expression for each cation, $\mathrm{i}$, is given below (note this expression is analogous to the equilibrium expressions shown in Equations III-8 and III-9). 


$$
C_{i, e}=\frac{C_{T, C} q_{i}}{\sum_{j=1}^{\text {NCATION }} \alpha_{j}^{i} q_{j}}
$$

Taking the partial derivative, $\frac{d C_{i, e}}{d q_{i}}$, from Equation III-58 results in the following (see Equations III-10 and III-11 for similar equations relevant to two-component case):

$$
\frac{\mathrm{dC}_{\mathrm{i}, \mathrm{e}}}{\mathrm{dq} \mathrm{q}_{\mathrm{i}}}=\frac{\mathrm{C}_{\mathrm{T}, \mathrm{C}}\left(\sum_{\substack{\mathrm{j}=1 \\ \neq i \mathrm{i}}}^{\text {NCATION }} \alpha_{\mathrm{j}}^{\mathrm{i}} \mathrm{q}_{\mathrm{j}}\right)}{\left(\sum_{\mathrm{j}=1}^{\text {NCATION }} \alpha_{j}^{i} \mathrm{q}_{\mathrm{j}}\right)^{2}}
$$

Substituting Equation III-60 into Equation III-58 produces the following:

$$
\frac{d q_{i}}{d t}=\frac{Q_{i, 0}-Q C_{i, e}}{M_{c}+\varepsilon V\left[\frac{C_{T, C}\left(\sum_{\substack{j=1 \\ j \neq i}}^{N C A T I O N} \alpha_{j}^{i} q_{j}\right)}{\left(\sum_{j=1}^{N C A T I O N} \alpha_{j}^{i} q_{j}\right)^{2}}\right]}
$$

The term $C_{i, 0}$ in Equation III-61 refers to the liquid phase influent concentration of cation $i$ This value is known for each cation, $i$. In contrast, the term $C_{i, e}$ in Equation III-61 refers to the liquid phase effluent concentration of each cation, i. This value is unknown for each cation, i. In order to solve Equation III-61, it is necessary to replace the term $C_{i, e}$ using the equilibrium expression given by Equation III-59. The resulting expression is given below: 


$$
\frac{d q_{i}}{d t}=\frac{Q_{i, 0}-Q\left[\frac{C_{T, C} q_{i}}{\sum_{j=1}^{N C A T I O N} \alpha_{j}^{i} q_{j}}\right]}{M_{C}+\varepsilon V\left[\frac{C_{T, C}\left(\sum_{\substack{j=1 \\ j \neq i}}^{N C A T I O N} \alpha_{j}^{i} q_{j}\right)}{\left(\sum_{j=1}^{N C A T I O N} \alpha_{j}^{i} q_{j}\right)^{2}}\right]}
$$

In this case, the total resin phase concentration, $\mathrm{q}_{\mathrm{T}, \mathrm{C}}$, is a known quantity. It can be represented by the following expression.

$$
\mathrm{q}_{\mathrm{T}, \mathrm{C}}=\sum_{\mathrm{i}=1}^{\text {NCATION }} \mathrm{q}_{\mathrm{i}}
$$

The relationship given by Equation III-63 will be used to solve for one of the ion's concentrations. Therefore it will only be necessary to solve (NCATION - 1) ODE's simultaneously in Equation III-62. Otherwise the problem will be overspecified. The presaturant ion concentration will be determined using Equation III-63. The equation for the resin phase concentration of the presaturant ion can be written as:

$$
\mathrm{q}_{\text {presaturant }, \mathrm{C}}=\mathrm{q}_{\mathrm{T}, \mathrm{C}}-\sum_{\substack{\mathrm{i}=1 \\ \mathrm{i} \neq \text { presaturant }}}^{\text {NCATION-1 }} \mathrm{q}_{\mathrm{i}}
$$

The equations for the resin phase concentrations of the other (NCATION - 1) ions will be solved simultaneously using ODE's given by Equation III-65, which is reprinted below excluding the presaturant ion: Note that when the presaturant concentration appears in the counter loops that iterate from 1 to NCATION in the equation below, it is replaced by Equation III-64. 


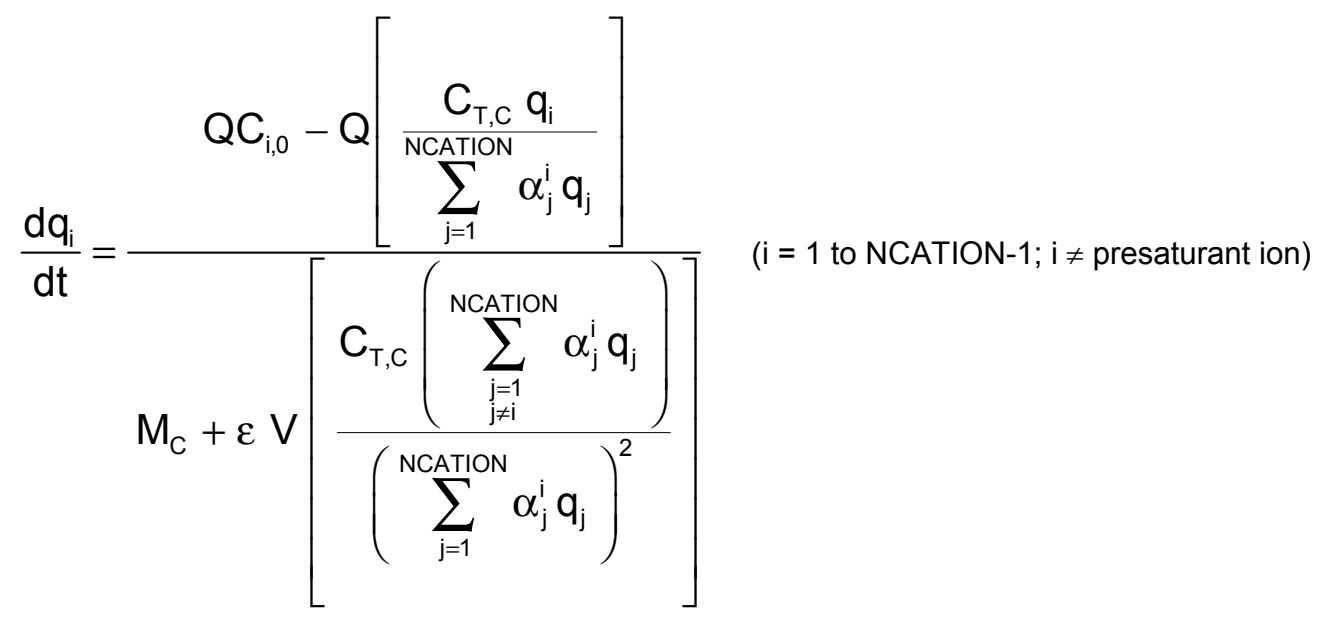

Anions

The general form of the equilibrium expression for each anion, $\mathrm{i}$, is given below (note this expression is analogous to the equilibrium expressions shown in Equations III-21 and III-22).

$$
C_{i, e}=\frac{C_{T, A} q_{i}}{\sum_{j=1}^{\text {NANION }} \alpha_{j}^{i} q_{j}}
$$

Taking the partial derivative, $\frac{d C_{i, e}}{d q_{i}}$, from Equation III-58 results in the following (see Equations III-23 and III-24 for similar equations relevant to two-component case):

$$
\frac{d C_{i, e}}{d q_{i}}=\frac{C_{T, A}\left(\sum_{\substack{j=1 \\ j \neq i}}^{\text {NANION }} \alpha_{j}^{i} q_{j}\right)}{\left(\sum_{j=1}^{\text {NANION }} \alpha_{j}^{i} q_{j}\right)^{2}}
$$

Substituting Equation III-67 into Equation III-58 produces the following: 


$$
\frac{d q_{i}}{d t}=\frac{Q C_{i, 0}-Q C_{i, e}}{M_{A}+\varepsilon V\left[\frac{C_{T, A}\left(\sum_{\substack{j=1 \\ j \neq i}}^{\text {NANION }} \alpha_{j}^{i} q_{j}\right)}{\left(\sum_{j=1}^{\text {NANION }} \alpha_{j}^{i} q_{j}\right)^{2}}\right]}
$$

The term $\mathrm{C}_{\mathrm{i}, 0}$ in Equation III-68 refers to the liquid phase influent concentration of anion $\mathrm{i}$ This value is known for each anion, i. In contrast, the term $\mathrm{C}_{\mathrm{i}, \mathrm{e}}$ in Equation III-68 refers to the liquid phase effluent concentration of each anion, i. This value is unknown for each anion, i. In order to solve Equation III-68, it is necessary to replace the term $\mathrm{C}_{\mathrm{i}, \mathrm{e}}$ using the equilibrium expression given by Equation III-66. The resulting expression is given below:

$$
\frac{d q_{i}}{d t}=\frac{{Q C_{i, 0}}-Q\left[\frac{C_{T, A} q_{i}}{\left.\sum_{j=1}^{\text {NANION } \alpha_{j}^{i} q_{j}}\right]}\right.}{M_{A}+\varepsilon V\left[\frac{C_{T, A}\left(\sum_{\substack{j=1 \\ j \neq i}}^{\text {NANION } \left.\alpha_{j}^{i} q_{j}\right)}\right.}{\left(\sum_{j=1}^{\text {NANION }} \alpha_{j}^{i} q_{j}\right)^{2}}\right]}
$$

In this case, the total resin phase concentration, $\mathrm{q}_{\mathrm{T}, \mathrm{A}}$, is a known quantity. It can be represented by the following expression.

$$
q_{T, A}=\sum_{i=1}^{\text {NANION }} q_{i}
$$

The relationship given by Equation III-70 will be used to solve for one of the ion's concentrations. Therefore it will only be necessary to solve (NANION - 1) ODE's simultaneously in Equation III-69. Otherwise the problem will be overspecified. The presaturant ion concentration will be determined using Equation III-70. The 
equation for the resin phase concentration of the presaturant ion can be written as:

$$
\mathrm{q}_{\text {presaturant } \mathrm{A}}=\mathrm{q}_{\mathrm{T}, \mathrm{A}}-\sum_{\substack{\mathrm{i}=1 \\ \mathrm{i} \neq \text { presaturant }}}^{\text {NANION-1 }} \mathrm{q}_{\mathrm{i}}
$$

The equations for the resin phase concentrations of the other (NANION - 1) anions will be solved simultaneously using ODE's given by Equation III-72, which is reprinted below excluding the presaturant ion: Note that when the presaturant concentration appears in the counter loops that iterate from 1 to NANION in the equation below, it is replaced by Equation III-71.

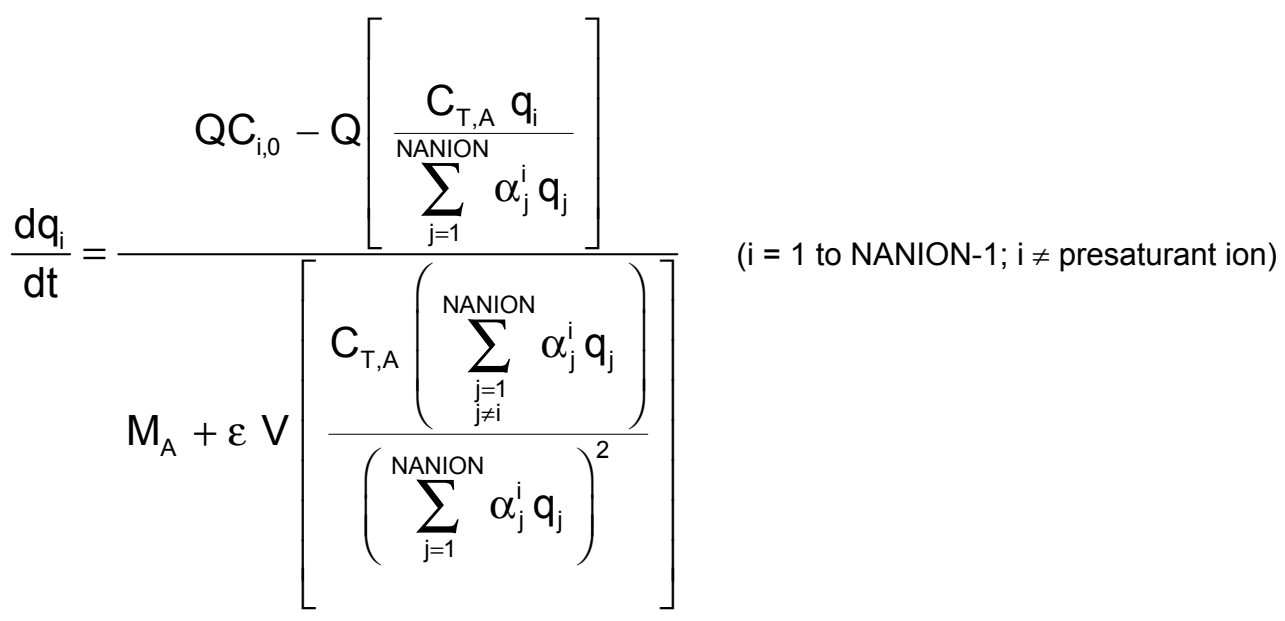

\section{Converting the Single CSTR Model into Dimensionless Form for the General Case of NCATION Cations and NANION Anions}

The process of converting the dimensioned equations for the single CSTR model with NCOMP (=NCATION+NANION) components is very similar to the case of $\mathrm{Na}^{+}$exchanging onto the $\mathrm{H}^{+}$form of IRN-77 resin and $\mathrm{Cl}^{-}$exchanging onto the $\mathrm{OH}^{-}$form of IRN-78 resin. The definition of dimensionless variables (analogous to Equations III-32 through III-53 above) is given below. The dimensionless resin phase concentrations of the cations are defined as:

$$
\overline{\mathrm{q}}_{\mathrm{i}}=\frac{\mathrm{q}_{\mathrm{i}}}{\mathrm{q}_{\mathrm{T}, \mathrm{C}}} \text { (for } \mathrm{i}=1 \text { to NCATION) }
$$

Defining the equivalent time-averaged influent liquid phase concentration of ion $\mathrm{i}$ $\left(\overline{\mathrm{C}_{0, \mathrm{i}}}\right)$ and the total equivalent time-averaged influent liquid phase concentration 
of all cations $\left(\overline{\mathrm{C}_{\mathrm{T}, \text { avg, } \mathrm{C}}}\right)$ in Equations III-74 and III-75, respectively, allows for the definition of $\overline{\mathrm{C}_{\mathrm{i}, 0}}$ in Equation III-76.

$$
\begin{array}{r}
\overline{\mathrm{C}_{0, \mathrm{i}}}=\frac{1}{\mathrm{t}} \int_{0}^{\mathrm{t}} \mathrm{C}_{0, \mathrm{i}}(\mathrm{t}) \mathrm{dt} \quad \text { (for } \mathrm{i}=1 \text { to NCOMP) } \\
\overline{\mathrm{C}_{\mathrm{T}, \mathrm{avg}, \mathrm{C}}}=\sum_{\mathrm{j}=1}^{\mathrm{m}} \overline{\mathrm{C}_{0, \mathrm{j}}} \quad \text { (for } \mathrm{m}=\text { NCATION) } \\
\overline{\mathrm{C}_{\mathrm{i}, 0}}=\frac{\mathrm{C}_{\mathrm{i}, 0}}{\overline{\mathrm{C}_{0, i}}} \\
\left(\overline{\mathrm{C}_{\mathrm{T}, \mathrm{C}}}\right)_{\mathrm{i}}=\left[\sum_{\mathrm{j}=1}^{\text {NCATION }}\left(\overline{\mathrm{C}_{\mathrm{j}, 0}} \times \frac{\mathrm{C}_{\mathrm{F}, \mathrm{i}}}{\mathrm{C}_{\mathrm{F}, \mathrm{j}}}\right)\right]
\end{array}
$$

The dimensionless resin phase concentrations of the anions are defined as:

$$
\begin{aligned}
& \overline{\mathrm{q}}_{\mathrm{i}}=\frac{\mathrm{q}_{\mathrm{i}}}{\mathrm{q}_{\mathrm{T}, \mathrm{A}}} \quad \text { (for } \mathrm{i}=1 \text { to NANION) } \\
& \left.\overline{\mathrm{C}_{\mathrm{T}, \text { avg }, \mathrm{A}}}=\sum_{\mathrm{j}=1}^{\mathrm{m}} \overline{\mathrm{C}_{0, \mathrm{j}}} \quad \text { (for } \mathrm{m}=\mathrm{NANION}\right) \\
& \overline{\mathrm{C}_{\mathrm{i}, 0}}=\frac{\mathrm{C}_{\mathrm{i}, 0}}{\overline{\mathrm{C}_{0, \mathrm{i}}}} \\
& \left(\overline{\mathrm{C}_{\mathrm{T}, \mathrm{A}}}\right)_{\mathrm{i}}=\left[\sum_{\mathrm{j}=1}^{\mathrm{NANION}}\left(\overline{\mathrm{C}_{j, 0}} \times \frac{\mathrm{C}_{\mathrm{F}, \mathrm{i}}}{\mathrm{C}_{\mathrm{F}, \mathrm{j}}}\right)\right]
\end{aligned}
$$

Dimensionless time $(T)$ will be defined based on a capacity factor $\left(C_{F}\right)$ and the packed bed contact time $(\tau)$ from the following equation:

$$
\mathrm{T}=\frac{\mathrm{t}}{\mathrm{C}_{\mathrm{F}} \tau}
$$

where:

$$
\begin{aligned}
C_{F} & =C_{F, C}+C_{F, A} \\
C_{F, C} & =\frac{M_{C} q_{T, C}}{V \overline{C_{T, a v g, C}} \varepsilon} \\
C_{F, A} & =\frac{M_{A} q_{T, A}}{V \overline{C_{T, a v g, A}} \varepsilon}
\end{aligned}
$$




$$
\begin{gathered}
\mathrm{C}_{\mathrm{F}, \mathrm{i}}=\frac{\mathrm{M}_{\mathrm{A}} \mathrm{q}_{\mathrm{T}, \mathrm{A}}}{\mathrm{V} \overline{\mathrm{C}_{0, \mathrm{i}}} \varepsilon} \\
\tau=\frac{\mathrm{V} \varepsilon}{\mathrm{Q}}
\end{gathered}
$$

Based on Equation III-82, an expression for $\frac{\mathrm{d}}{\mathrm{dt}}$ is given as follows:

$$
\frac{\mathrm{d}}{\mathrm{dt}}=\frac{1}{\mathrm{C}_{\mathrm{F}} \tau} \frac{\mathrm{d}}{\mathrm{dT}}
$$

Applying Equations III-73 through III-88 to Equations III-64, III-65, III-71, and III-72 results in the dimensionless form of the equations that need to be solved for the single CSTR model for the general case of NCOMP components. The dimensionless equations are shown below:

$$
\begin{aligned}
& \overline{\mathrm{q}}_{\text {presaturant }, \mathrm{C}}=1-\sum_{\substack{\mathrm{i}=1 \\
\mathrm{i} \neq \text { presaturant }}}^{\text {NCATION-1 }} \overline{\mathrm{q}}_{\mathrm{i}} \\
& \frac{d \bar{q}_{i}}{d T}=\frac{\overline{C_{i, 0}}-\left\{\frac{\left(\overline{C_{T, C}}\right)_{i} \bar{q}_{i}}{\sum_{j=1}^{\text {NCATION }} \alpha_{j}^{i} \bar{q}_{j}}\right\}}{\left(\frac{C_{F, i}}{C_{F}}\right)+\frac{1}{C_{F}}\left\{\frac{\left(\overline{C_{T, C}}\right)_{i}\left[\sum_{\substack{j=1 \\
j \neq i}}^{N C A T I O N} \alpha_{j}^{i} \bar{q}_{j}\right]}{\left(\sum_{j=1}^{N C A T I O N} \alpha_{j}^{i} \bar{q}_{j}\right)^{2}}\right\}}
\end{aligned}
$$

Note that anytime $\mathrm{j}=$ presaturant ion in Equation III-90, the equation for dimensionless resin phase concentration is provided by Equation III-89.

$$
\overline{\mathrm{q}}_{\text {presaturant,A }}=1-\sum_{\substack{\mathrm{i}=1 \\ \mathrm{i} \neq \text { presaturant }}}^{\mathrm{NANION}-1} \overline{\mathrm{q}}_{\mathrm{i}}
$$




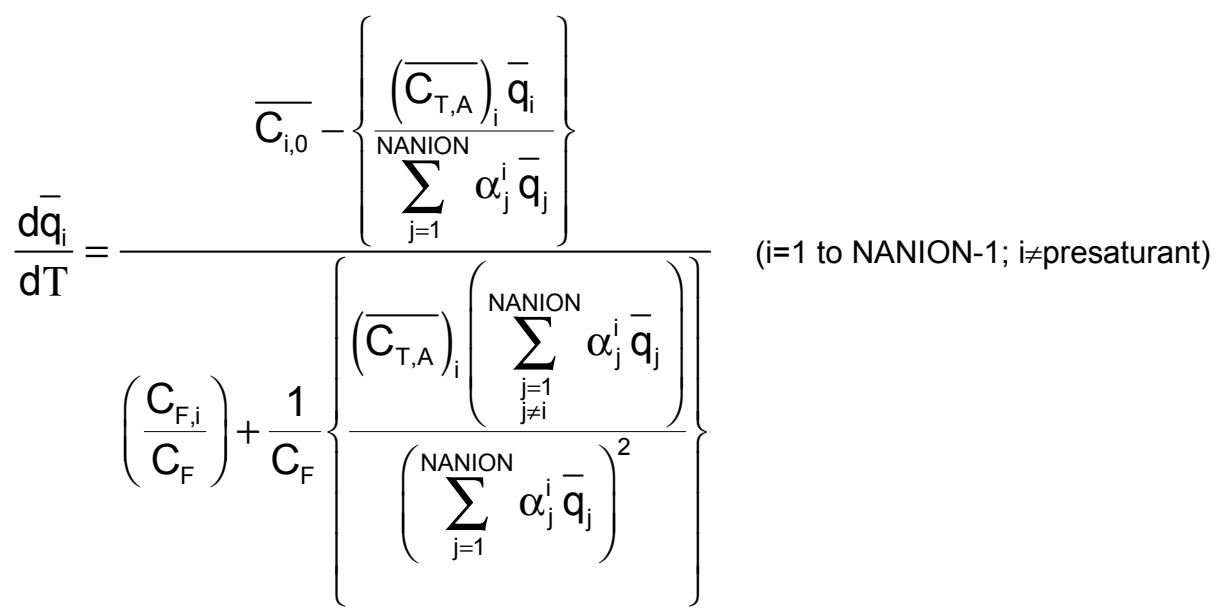

Note that anytime $\mathrm{j}=$ presaturant ion in Equation III-92, the equation for dimensionless resin phase concentration is provided by Equation III-91.

Extension of the Single CSTR Model to Accommodate Tanks in Series for Sodium Exchanging onto IRN-77 (SAC) Exchange Resin in the Hydrogen Form and Chloride Exchanging onto IRN-78 (SBA) Exchange Resin in the Hydroxide Form

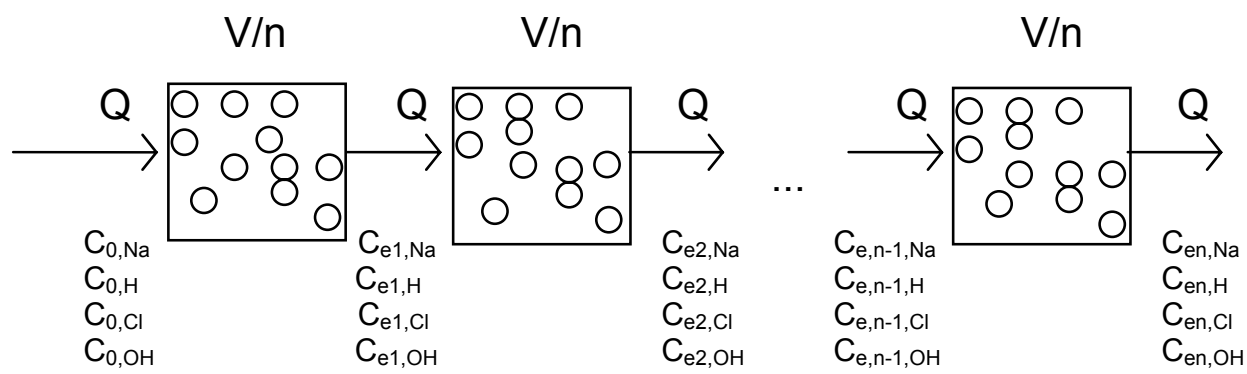

$\begin{array}{llll}\text { Tank No.: } & 1 & 2 & n\end{array}$

The equations that need to be solved for the tanks in series model arise from performing mass balances on each of the tanks in the system. What results is a system of $\mathrm{n}$ differential equations that need to be solved simultaneously, where $\mathrm{n}$ is the number of tanks. The development of the equations is similar to the development for the single CSTR. The differential equations that need to be solved are given below. 
Tank 1

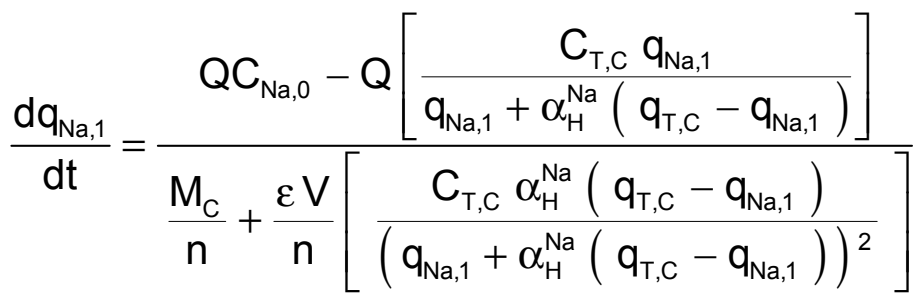

$$
\begin{aligned}
& \frac{d_{\mathrm{Cl}, 1}}{d t}=\frac{\mathrm{QC}_{\mathrm{Cl}, 0}-Q\left[\frac{\mathrm{C}_{\mathrm{T}, \mathrm{A}} \mathrm{q}_{\mathrm{Cl}, 1}}{\mathrm{q}_{\mathrm{Cl}, 1}+\alpha_{\mathrm{OH}}^{\mathrm{Cl}}\left(\mathrm{q}_{\mathrm{T}, \mathrm{A}}-\mathrm{q}_{\mathrm{Cl}, 1}\right)}\right]}{\frac{\mathrm{M}_{\mathrm{A}}}{\mathrm{n}}+\frac{\varepsilon \mathrm{V}}{\mathrm{n}}\left[\frac{\mathrm{C}_{\mathrm{T}, \mathrm{A}} \alpha_{\mathrm{OH}}^{\mathrm{Cl}}\left(\mathrm{q}_{\mathrm{T}, \mathrm{A}}-\mathrm{q}_{\mathrm{Cl}, 1}\right)}{\left(\mathrm{q}_{\mathrm{Cl}, 1}+\alpha_{\mathrm{OH}}^{\mathrm{Cl}}\left(\mathrm{q}_{\mathrm{T}, \mathrm{A}}-\mathrm{q}_{\mathrm{Cl}, 1}\right)\right)^{2}}\right]}
\end{aligned}
$$

Tanks 2 - $\mathbf{n}$

$$
\begin{aligned}
& \frac{\mathrm{dq}_{\mathrm{Na}, \mathrm{m}}}{\mathrm{dt}}=\frac{\mathrm{Q}\left[\frac{\mathrm{C}_{\mathrm{T}, \mathrm{C}} \mathrm{q}_{\mathrm{Na}, \mathrm{m}-1}}{\mathrm{q}_{\mathrm{Na}, \mathrm{m}-1}+\alpha_{H}^{N a}\left(\mathrm{q}_{\mathrm{T}, \mathrm{C}}-\mathrm{q}_{\mathrm{Na}, \mathrm{m}-1}\right)}\right]-\mathrm{Q}\left[\frac{\mathrm{C}_{\mathrm{T}, \mathrm{C}} \mathrm{q}_{\mathrm{Na}, \mathrm{m}}}{\mathrm{q}_{\mathrm{Na}, \mathrm{m}}+\alpha_{\mathrm{H}}^{\mathrm{Na}}\left(\mathrm{q}_{\mathrm{T}, \mathrm{C}}-\mathrm{q}_{\mathrm{Na}, \mathrm{m}}\right)}\right]}{\frac{\mathrm{M}_{\mathrm{C}}}{\mathrm{n}}+\frac{\varepsilon \mathrm{V}}{\mathrm{n}}\left[\frac{\mathrm{C}_{\mathrm{T}, \mathrm{C}} \alpha_{H}^{\mathrm{Na}}\left(\mathrm{q}_{\mathrm{T}, \mathrm{C}}-\mathrm{q}_{\mathrm{Na}, \mathrm{m}}\right)}{\left(\mathrm{q}_{\mathrm{Na}, \mathrm{m}}+\alpha_{H}^{\mathrm{Na}}\left(\mathrm{q}_{\mathrm{T}, \mathrm{C}}-\mathrm{q}_{\mathrm{Na}, \mathrm{m}}\right)\right)^{2}}\right]} \\
& \frac{d_{\mathrm{Cl}_{1, m}}}{d t}=\frac{Q\left[\frac{\mathrm{C}_{\mathrm{T}, \mathrm{A}} \mathrm{q}_{\mathrm{Cl}, \mathrm{m}-1}}{\mathrm{q}_{\mathrm{Cl}, \mathrm{m}-1}+\alpha_{\mathrm{OH}}^{\mathrm{Cl}}\left(\mathrm{q}_{\mathrm{T}, \mathrm{A}}-\mathrm{q}_{\mathrm{Cl}, \mathrm{m}-1}\right)}\right]-\mathrm{Q}\left[\frac{\mathrm{C}_{\mathrm{T}, \mathrm{A}} \mathrm{q}_{\mathrm{Cl}, \mathrm{m}}}{\mathrm{q}_{\mathrm{Cl}, \mathrm{m}}+\alpha_{\mathrm{OH}}^{\mathrm{Cl}}\left(\mathrm{q}_{\mathrm{T}, \mathrm{A}}-\mathrm{q}_{\mathrm{Cl}, \mathrm{m}}\right)}\right]}{\frac{\mathrm{M}_{\mathrm{A}}}{\mathrm{n}}+\frac{\varepsilon \mathrm{V}}{\mathrm{n}}\left[\frac{\mathrm{C}_{\mathrm{T}, \mathrm{A}} \alpha_{\mathrm{OH}}^{\mathrm{Cl}}\left(\mathrm{q}_{\mathrm{T}, \mathrm{A}}-\mathrm{q}_{\mathrm{Cl}, \mathrm{m}}\right)}{\left(\mathrm{q}_{\mathrm{Cl}, \mathrm{m}}+\alpha_{\mathrm{OH}}^{\mathrm{Cl}}\left(\mathrm{q}_{\mathrm{T}, \mathrm{A}}-\mathrm{q}_{\mathrm{Cl}, \mathrm{m}}\right)\right)^{2}}\right]}
\end{aligned}
$$

where: $m=$ the number of the tank $(2-n)$

Once $\mathrm{q}_{\mathrm{Na}, \mathrm{k}}$ and $\mathrm{q}_{\mathrm{Cl}, \mathrm{k}}$ (where $\mathrm{k}=$ the number of the tank (1-n)) are known from Equations III-93 through III-96, it is possible to solve for $\mathrm{q}_{\mathrm{H}, \mathrm{k}}$ and $\mathrm{q}_{\mathrm{OH}, \mathrm{k}}$, respectively, from the following relationships:

$$
\begin{aligned}
q_{H, k} & =q_{T, C}-q_{N a, k} \\
q_{O H, k} & =q_{T, A}-q_{C l, k}
\end{aligned}
$$


Once $\mathrm{q}_{\mathrm{Na}, \mathrm{k}}, \mathrm{q}_{\mathrm{H}, \mathrm{k}}, \mathrm{q}_{\mathrm{Cl}, \mathrm{k}}$, and $\mathrm{q}_{\mathrm{OH}, \mathrm{k}}$ are known, it is possible to make use of the equilibrium expressions and solve for the effluent liquid phase concentrations out of each tank.

$$
\begin{gathered}
C_{\mathrm{Na}, \mathrm{k}}=\frac{\mathrm{C}_{\mathrm{T}, \mathrm{C}} \mathrm{q}_{\mathrm{Na}, \mathrm{k}}}{\mathrm{q}_{\mathrm{Na}, \mathrm{k}}+\alpha_{\mathrm{H}}^{\mathrm{Na}} \mathrm{q}_{\mathrm{H}, \mathrm{k}}} \\
\mathrm{C}_{\mathrm{H}, \mathrm{k}}=\frac{\mathrm{C}_{\mathrm{T}, \mathrm{C}} \mathrm{q}_{\mathrm{H}, \mathrm{k}}}{\mathrm{q}_{\mathrm{H}, \mathrm{k}}+\alpha_{\mathrm{Na}}^{\mathrm{H}} \mathrm{q}_{\mathrm{Na}, \mathrm{k}}} \\
\mathrm{C}_{\mathrm{Cl}, \mathrm{k}}=\frac{\mathrm{C}_{\mathrm{T}, \mathrm{A}} \mathrm{q}_{\mathrm{Cl}, \mathrm{k}}}{\mathrm{q}_{\mathrm{Cl}, \mathrm{k}}+\alpha_{\mathrm{OH}}^{\mathrm{Cl}} \mathrm{q}_{\mathrm{OH}, \mathrm{k}}} \\
\mathrm{C}_{\mathrm{OH}, \mathrm{k}}=\frac{\mathrm{C}_{\mathrm{T}, \mathrm{A}} \mathrm{q}_{\mathrm{OH}, \mathrm{k}}}{\mathrm{q}_{\mathrm{OH}, \mathrm{k}}+\alpha_{\mathrm{Cl}}^{\mathrm{OH}} \mathrm{q}_{\mathrm{Cl}, \mathrm{k}}}
\end{gathered}
$$

Conversion of the Tanks in Series Model into Dimensionless Form for Sodium Exchanging onto IRN-77 (SAC) Exchange Resin in the Hydrogen Form and Chloride Exchanging onto IRN-78 (SBA) Exchange Resin in the Hydroxide Form

The procedure to convert the tanks in series model into dimensionless form is analogous to the procedure followed for the single CSTR model:

\section{Tank 1}

Conversion of Equation III-93 into dimensionless form results in the following:

$$
\frac{\mathrm{d}_{\mathrm{Na}, 1}}{\mathrm{dT}}=\frac{\overline{\mathrm{C}_{\mathrm{Na}, 0}}-\left[\frac{\left(\overline{\mathrm{C}_{\mathrm{T}, \mathrm{C}}}\right)_{\mathrm{Na}} \overline{\mathrm{q}}_{\mathrm{Na}, 1}}{\overline{\mathrm{q}}_{\mathrm{Na}, 1}+\alpha_{\mathrm{H}}\left(1-\overline{\mathrm{q}}_{\mathrm{Na}, 1}\right)}\right]}{\frac{\mathrm{C}_{\mathrm{F}, \mathrm{Na}}}{\mathrm{n} \mathrm{C}_{\mathrm{F}}}+\frac{1}{\mathrm{n} \mathrm{C}_{\mathrm{F}}}\left[\frac{\left(\overline{\mathrm{C}_{\mathrm{T}, \mathrm{C}}}\right)_{\mathrm{Na}} \alpha_{\mathrm{H}}^{\mathrm{Na}}\left(1-\overline{\mathrm{q}}_{\mathrm{Na}, 1}\right)}{\left(\overline{\mathrm{q}}_{\mathrm{Na}, 1}+\alpha_{\mathrm{H}}^{\mathrm{Na}}\left(1-\overline{\mathrm{q}}_{\mathrm{Na}, 1}\right)\right)^{2}}\right]}
$$

Conversion of Equation III-94 into dimensionless form results in the following: 


$$
\frac{d \overline{\mathrm{q}}_{\mathrm{Cl}, 1}}{\mathrm{dT}}=\frac{\overline{\mathrm{C}_{\mathrm{Cl}, 0}}-\left[\frac{\left(\overline{\mathrm{C}_{\mathrm{T}, \mathrm{A}}}\right)_{\mathrm{Cl}} \overline{\mathrm{q}}_{\mathrm{Cl}, 1}}{\overline{\mathrm{q}}_{\mathrm{Cl}, 1}+\alpha_{\mathrm{OH}}^{\mathrm{Cl}}\left(1-\overline{\mathrm{q}}_{\mathrm{Cl}, 1}\right)}\right]}{\frac{\mathrm{C}_{\mathrm{F}, \mathrm{Cl}}}{\mathrm{nC_{ \textrm {F } }}}+\frac{1}{\mathrm{nC}}\left\{\frac{\left(\overline{\mathrm{C}_{\mathrm{T}, \mathrm{A}}}\right)_{\mathrm{Cl}} \alpha_{\mathrm{OH}}^{\mathrm{Cl}}\left(1-\overline{\mathrm{q}}_{\mathrm{Cl}, 1}\right)}{\left[\overline{\mathrm{q}}_{\mathrm{Cl}, 1}+\alpha_{\mathrm{OH}}^{\mathrm{Cl}}\left(1-\overline{\mathrm{q}}_{\mathrm{Cl}, 1}\right)\right]^{2}}\right\}}
$$

\section{Tanks 2 - $\mathbf{n}$}

Conversion of Equation III-95 into dimensionless form results in the following:

$$
\frac{d \overline{\mathrm{q}}_{\mathrm{Na}, \mathrm{m}}}{\mathrm{dT}}=\frac{\left[\frac{\left(\overline{\mathrm{C}_{\mathrm{T}, \mathrm{C}}}\right)_{\mathrm{Na}} \overline{\mathrm{q}}_{\mathrm{Na}, \mathrm{m}-1}}{\overline{\mathrm{q}}_{\mathrm{Na}, \mathrm{m}-1}+\alpha_{\mathrm{H}}^{\mathrm{Na}}\left(1-\overline{\mathrm{q}}_{\mathrm{Na}, \mathrm{m}-1}\right)}\right]-\left[\frac{\left(\overline{\mathrm{C}_{\mathrm{T}, \mathrm{C}}}\right)_{\mathrm{Na}} \overline{\mathrm{q}}_{\mathrm{Na}, \mathrm{m}}}{\overline{\mathrm{q}}_{\mathrm{Na}, \mathrm{m}}+\alpha_{\mathrm{H}}^{\mathrm{Na}}\left(1-\overline{\mathrm{q}}_{\mathrm{Na}, \mathrm{m}}\right)}\right]}{\frac{\mathrm{C}_{\mathrm{F}, \mathrm{Na}}}{\mathrm{n} \mathrm{C}_{\mathrm{F}}}+\frac{1}{\mathrm{nC}}\left[\frac{\left(\overline{\mathrm{C}_{\mathrm{T}, \mathrm{C}}}\right)_{\mathrm{Na}} \alpha_{\mathrm{H}}^{\mathrm{Na}}\left(1-\overline{\mathrm{q}}_{\mathrm{Na}, \mathrm{m}}\right)}{\left\{\overline{\mathrm{q}}_{\mathrm{Na}, \mathrm{m}}+\alpha_{\mathrm{H}}^{\mathrm{Na}}\left(1-\overline{\mathrm{q}}_{\mathrm{Na}, \mathrm{m}}\right)\right\}^{2}}\right]}
$$

where: $m=$ the number of the tank $(2-n)$

Conversion of Equation III-96 into dimensionless form results in the following:

$$
\frac{d \overline{\mathrm{q}}_{\mathrm{Cl}, \mathrm{m}}}{\mathrm{dT}}=\frac{\left[\frac{\left(\overline{\mathrm{C}_{\mathrm{T}, \mathrm{A}}}\right)_{\mathrm{Cl}} \overline{\mathrm{q}}_{\mathrm{Cl}, \mathrm{m}-1}}{\overline{\mathrm{q}}_{\mathrm{Cl}, \mathrm{m}-1}+\alpha_{\mathrm{OH}}^{\mathrm{Cl}}\left(1-\overline{\mathrm{q}}_{\mathrm{Cl}, \mathrm{m}-1}\right)}\right]-\left[\frac{\left(\overline{\mathrm{C}_{\mathrm{T}, \mathrm{A}}}\right)_{\mathrm{Cl}} \overline{\mathrm{q}}_{\mathrm{Cl}, \mathrm{m}}}{\overline{\mathrm{q}}_{\mathrm{Cl}, \mathrm{m}}+\alpha_{\mathrm{OH}}^{\mathrm{Cl}}\left(1-\overline{\mathrm{q}}_{\mathrm{Cl}, \mathrm{m}}\right)}\right]}{\frac{\mathrm{C}_{\mathrm{F}, \mathrm{Cl}}}{\mathrm{n} \mathrm{C}_{\mathrm{F}}}+\frac{1}{\mathrm{n} \mathrm{C}_{\mathrm{F}}}\left\{\frac{\left(\overline{\mathrm{C}_{\mathrm{T}, \mathrm{A}}}\right)_{\mathrm{Cl}} \alpha_{\mathrm{OH}}^{\mathrm{Cl}}\left(1-\overline{\mathrm{q}}_{\mathrm{Cl}, \mathrm{m}}\right)}{\left[\overline{\mathrm{q}}_{\mathrm{Cl}, \mathrm{m}}+\alpha_{\mathrm{OH}}^{\mathrm{Cl}}\left(1-\overline{\mathrm{q}}_{\mathrm{Cl}, \mathrm{m}}\right)\right]^{2}}\right\}}
$$

Once $\overline{\mathrm{q}}_{\mathrm{Na}, \mathrm{k}}$ and $\overline{\mathrm{q}}_{\mathrm{Cl}, \mathrm{k}}$ (where $\mathrm{k}=$ the number of the tank (1-n)) are known from Equations III-103 through III-106, it is possible to solve for $\overline{\mathrm{q}}_{\mathrm{H}, \mathrm{k}}$ and $\overline{\mathrm{q}}_{\mathrm{OH}, \mathrm{k}}$ from the following:

$$
\begin{aligned}
& \overline{\mathrm{q}}_{\mathrm{H}, \mathrm{k}}=1-\overline{\mathrm{q}}_{\mathrm{Na}, \mathrm{k}} \\
& \overline{\mathrm{q}}_{\mathrm{OH}, \mathrm{k}}=1-\overline{\mathrm{q}}_{\mathrm{Cl}, \mathrm{k}}
\end{aligned}
$$

Once $\overline{\mathrm{q}}_{\mathrm{Na}, \mathrm{k}}, \overline{\mathrm{q}}_{\mathrm{H}, \mathrm{k}}, \overline{\mathrm{q}}_{\mathrm{Cl}, \mathrm{k}}$, and $\overline{\mathrm{q}}_{\mathrm{OH}, \mathrm{k}}$ are known, it is possible to make use of the equilibrium expressions and solve for the effluent liquid phase concentrations out of each tank. 


$$
\begin{gathered}
\overline{\mathrm{C}}_{\mathrm{Na}, \mathrm{k}}=\frac{\left(\overline{\mathrm{C}_{\mathrm{T}, \mathrm{C}}}\right)_{\mathrm{Na}} \overline{\mathrm{q}}_{\mathrm{Na}, \mathrm{k}}}{\overline{\mathrm{q}}_{\mathrm{Na}, \mathrm{k}}+\alpha_{\mathrm{H}}^{\mathrm{Na}} \overline{\mathrm{q}}_{\mathrm{H}, \mathrm{k}}} \\
\overline{\mathrm{C}}_{\mathrm{H}, \mathrm{k}}=\frac{\left(\overline{\mathrm{C}_{\mathrm{T}, \mathrm{C}}}\right)_{\mathrm{H}} \overline{\mathrm{q}}_{\mathrm{H}, \mathrm{k}}}{\overline{\mathrm{q}}_{\mathrm{H}, \mathrm{k}}+\alpha_{\mathrm{Na}}^{\mathrm{H}} \overline{\mathrm{q}}_{\mathrm{Na}, \mathrm{k}}} \\
\overline{\mathrm{C}}_{\mathrm{Cl}, \mathrm{k}}=\frac{\left(\overline{\mathrm{C}_{\mathrm{T}, \mathrm{A}}}\right)_{\mathrm{Cl}} \overline{\mathrm{q}}_{\mathrm{Cl}, \mathrm{k}}}{\overline{\mathrm{q}}_{\mathrm{Cl}, \mathrm{k}}+\alpha_{\mathrm{OH}}^{\mathrm{C}} \overline{\mathrm{q}}_{\mathrm{OH}, \mathrm{k}}} \\
\overline{\mathrm{C}}_{\mathrm{OH}, \mathrm{k}}=\frac{\left(\overline{\mathrm{C}_{\mathrm{T}, \mathrm{A}}}\right)_{\mathrm{OH}} \overline{\mathrm{q}}_{\mathrm{OH}, \mathrm{k}}}{\overline{\mathrm{q}}_{\mathrm{OH}, \mathrm{k}}+\alpha_{\mathrm{Cl}}^{\mathrm{OH}} \overline{\mathrm{q}}_{\mathrm{Cl}, \mathrm{k}}}
\end{gathered}
$$

\section{Extension of the Single CSTR Model to Accommodate Tanks in Series for the General Case of NCATION Cations and NANION Anions}

The equations that arise for the dimensioned form of the tanks in series model for the general case of NCOMP (=NCATION+NANION) components bear great similarity to the following two previous derivations of dimensioned equations: (1) Single CSTR Model for the General Case of NCATION Cations and NANION Anions and (2) Tanks in Series Model for the Case of $\mathrm{Na}^{+}$ Exchanging the $\mathrm{H}^{+}$form of IRN-77 Resin / $\mathrm{Cl}^{-}$Exchanging the $\mathrm{OH}^{-}$form of IRN-78 Resin . The resulting dimensioned equations for the tanks in series model with NCOMP components are given below:

\section{Tank 1}

$$
\frac{d q_{i, 1}}{d t}=\frac{{Q C_{i, 0}}-Q\left[\sum_{j=1}^{\frac{C_{T, C} q_{i, 1}}{\text { NCATION }} \alpha_{j}^{i} q_{j, 1}}\right]}{\frac{M_{C}}{n}+\frac{\varepsilon V}{n}\left[\frac{C_{T, C}\left(\sum_{\substack{j=1 \\ j \neq i}}^{\text {NCATION }} \alpha_{j}^{i} q_{j, 1}\right)}{\left(\sum_{j=1}^{\text {NCATION }} \alpha_{j}^{i} q_{j, 1}\right)^{2}}\right]}
$$




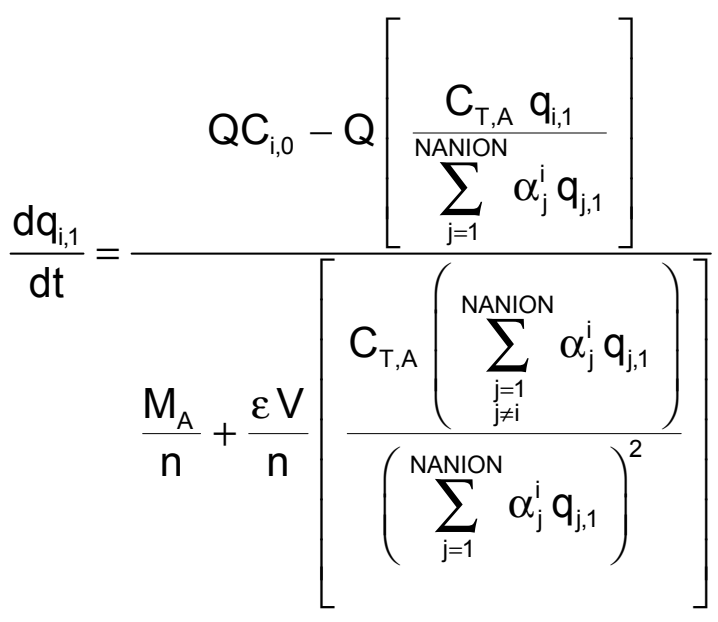

(i=1 to NANIION-1, i $\neq$ presaturant ion) $\quad(\mathrm{III}-114)$

Tanks $2-n(m=$ Number of the tank (2 through $n))$

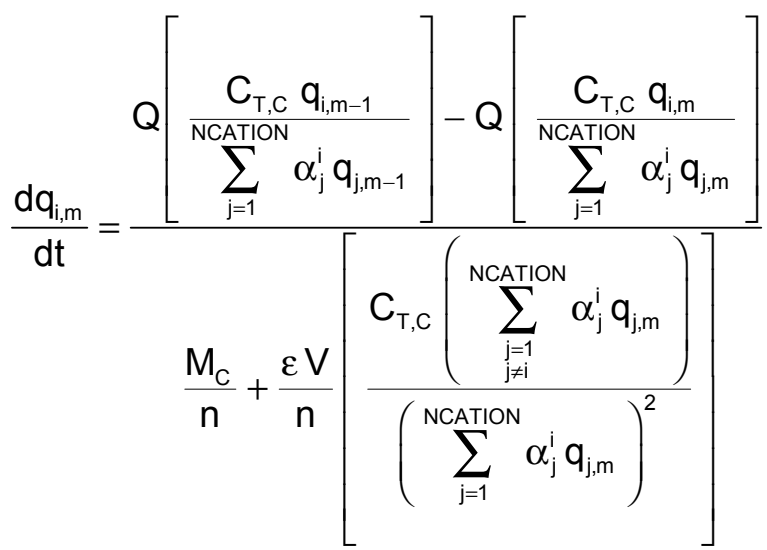

(i=1 to NCATION-1, i $\neq$ presaturant ion)(III-115)

$$
\frac{\mathrm{dq}_{\mathrm{i}, \mathrm{m}}}{\mathrm{dt}}=\frac{\mathrm{Q}\left[\frac{\mathrm{C}_{\mathrm{T}, \mathrm{A}} \mathrm{q}_{\mathrm{i}, \mathrm{m}-1}}{\sum_{\mathrm{j}=1}^{\text {NANION }} \alpha_{j}^{i} \mathrm{q}_{\mathrm{j}, \mathrm{m}-1}}\right]-\mathrm{Q}\left[\frac{\mathrm{C}_{\mathrm{T}, \mathrm{A}} \mathrm{q}_{\mathrm{i}, \mathrm{m}}}{\sum_{\mathrm{j}=1}^{\text {NANION }} \alpha_{j}^{i} \mathrm{q}_{\mathrm{j}, \mathrm{m}}}\right]}{\frac{\mathrm{M}_{\mathrm{A}}}{\mathrm{n}}+\frac{\varepsilon \mathrm{V}}{\mathrm{n}}\left[\frac{\mathrm{C}_{\mathrm{T}, \mathrm{A}}\left(\sum_{\substack{j=1 \\ j \neq i}}^{\text {NANION }} \alpha_{j}^{\mathrm{i}} \mathrm{q}_{\mathrm{j}, \mathrm{m}}\right)}{\left.\left(\sum_{\mathrm{j}=1}^{\text {NANION }} \alpha_{j}^{\mathrm{i}} \mathrm{q}_{\mathrm{j}, \mathrm{m}}\right)^{2}\right]}\right]}
$$

(i=1 to NANION-1, $\mathrm{i} \neq$ presaturant ion) (III-116)

Once the resin phase concentrations of all ions except the presaturant are known from tank $k(k=1-n)$, it is possible to calculate the resin phase concentration of the presaturant from tank $k$ as: 


$$
\begin{aligned}
& q_{\text {presaturant,C,k }}=q_{T, C}-\sum_{j \neq \text { presaturant,C }}^{\text {NCATION-1 }} q_{j, k} \\
& q_{\text {presaturant }, A, k}=q_{T, A}-\sum_{j \neq \text { presaturant, } A}^{\text {NANION-1 }} q_{j, k}
\end{aligned}
$$

Note that Equation III-117 is substituted into Equations III-113 and III-115 whenever the term $\mathrm{q}_{\text {presaturant,c }}$ is called for in those equations (in the summations from $\mathrm{j}=1$ to $\mathrm{j}=$ NCATION). Note also that Equation III-118 is substituted into Equations III-114 and III-116 whenever the term $\mathrm{q}_{\text {presaturant,A }}$ is called for in those equations (in the summations from $\mathrm{j}=1$ to $\mathrm{j}=\mathrm{NANION}$ ).

Once the resin phase concentrations are known in each tank, it is possible to make use of the equilibrium expressions and solve for the liquid phase effluent concentrations out of each tank:

$$
\begin{aligned}
& C_{i, k}=\frac{C_{T, C} q_{i, k}}{\text { NCATION }} \quad \text { (for } i=1 \text { to NCATION-1, i } \neq \text { presaturant ion) } \\
& \sum_{j=1} \alpha_{j}^{i} q_{j, k} \\
& C_{i, k}=\frac{C_{T, A} q_{i, k}}{\sum_{j=1}^{\text {NANION }} \alpha_{j}^{i} q_{j, k}} \quad \text { (for } i=1 \text { to NANION-1, i } \neq \text { presaturant ion) }
\end{aligned}
$$

For the presaturant ion , the liquid phase effluent concentration can be calculated as:

$$
\begin{aligned}
& \mathrm{C}_{\text {presaturant }, \mathrm{C}, \mathrm{k}}=\mathrm{C}_{\mathrm{T}, \mathrm{C}}-\sum_{\substack{\mathrm{j}=1 \\
\mathrm{j} \neq \text { presaturant, } \mathrm{C}}}^{\mathrm{NCATION}-1} \mathrm{C}_{\mathrm{j}, \mathrm{k}} \quad \text { (for } \mathrm{k}=1 \text { to Number of Tanks) } \\
& \mathrm{C}_{\text {presaturant,A,k}}=\mathrm{C}_{\mathrm{T}, \mathrm{A}}-\sum_{\substack{j=1 \\
j \neq \text { presaturant, } \mathrm{A}}}^{\mathrm{NANION-1}} \mathrm{C}_{\mathrm{j}, \mathrm{k}} \quad \text { (for } \mathrm{k}=1 \text { to Number of Tanks) }
\end{aligned}
$$




\section{Conversion of the Tanks in Series Model into Dimensionless Form for the General Case of NCATION Cations and NANION Anions}

Conversion of the dimensioned tanks in series equations for NCOMP components into dimensionless form is quite similar to the case of $\mathrm{Na}^{+}$ exchanging onto the $\mathrm{H}^{+}$form of IRN-77 resin / $\mathrm{Cl}^{-}$exchanging onto the $\mathrm{OH}^{-}$form of IRN-78 resin. The resultant dimensionless equations are provided below:

\section{Tank 1}

$\frac{d \overline{\mathrm{q}}_{\mathrm{i}, 1}}{\mathrm{dT}}=\frac{\overline{\mathrm{C}_{\mathrm{i}, 0}}-\left[\frac{\left(\overline{\mathrm{C}_{\mathrm{T}, \mathrm{C}}}\right)_{\mathrm{i}} \overline{\mathrm{q}}_{\mathrm{i}, 1}}{\left.\sum_{\mathrm{j}=1}^{\mathrm{NCATON}} \alpha_{j}^{i} \overline{\mathrm{q}}_{\mathrm{j}, 1}\right]}\right.}{\frac{\mathrm{C}_{\mathrm{F}, \mathrm{i}}}{\mathrm{nC_{F }}}+\frac{1}{\mathrm{nC} \mathrm{C}_{\mathrm{F}}}\left[\frac{\left(\overline{\mathrm{C}_{\mathrm{T}, \mathrm{C}}}\right)_{\mathrm{i}}\left(\sum_{\substack{j=1 \\ j \neq i}}^{\mathrm{NCATION}} \alpha_{j}^{i} \overline{\mathrm{q}}_{\mathrm{j}, 1}\right)}{\left(\sum_{\mathrm{j}=1}^{\mathrm{NCATION}} \alpha_{j}^{i} \overline{\mathrm{q}}_{\mathrm{j}, 1}\right)^{2}}\right]}$

( $\mathrm{i}=1$ to NCATION-1, $\mathrm{i} \neq$ presaturant ion) $\quad(\mathrm{III}-123)$

$$
\frac{d \bar{q}_{i, 1}}{d T}=\frac{\overline{C_{i, 0}}-\left[\frac{\left(\overline{C_{T, A}}\right)_{i} \bar{q}_{i, 1}}{\sum_{j=1}^{\text {NANIN }} \alpha_{j}^{i} \bar{q}_{j, 1}}\right]}{\frac{C_{F, i}}{n C_{F}}+\frac{1}{n C_{F}}\left[\frac{\left(\overline{C_{T, A}}\right)_{i}\left(\sum_{\substack{j=1 \\ j \neq i}}^{\text {NANION } \left.\alpha_{j}^{i} \bar{q}_{j, 1}\right)}\right.}{\left(\sum_{j=1}^{\text {NANION }} \alpha_{j}^{i} \bar{q}_{j, 1}\right)^{2}}\right]}
$$




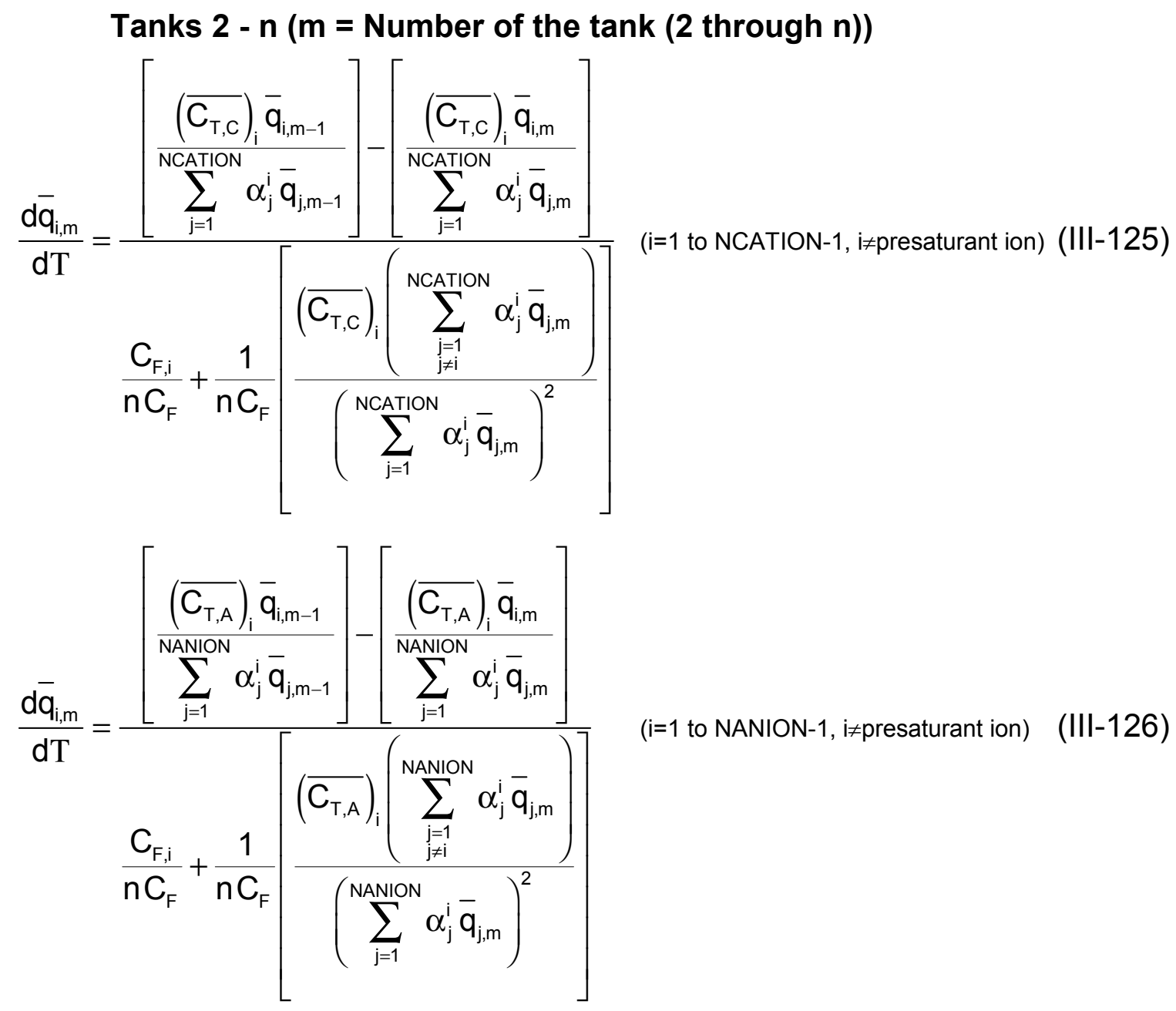

Once the dimensionless resin phase concentrations of all ions except the presaturant are known from tank $k(k=1-n)$, it is possible to calculate the dimensionless resin phase concentration of the presaturant from tank $k$ as:

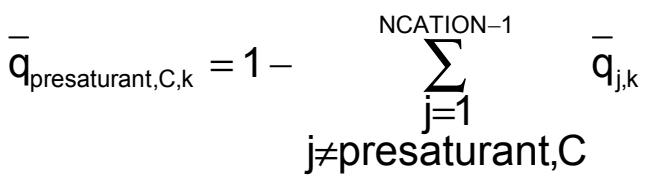

$$
\begin{aligned}
& \overline{\mathrm{q}}_{\text {presaturant,A,k}}=1-\sum_{j \neq \text { presaturant,A }}^{\substack{\mathrm{j}=1 \\
\text { NANION-1 }}} \overline{\mathrm{q}}_{\mathrm{j}, \mathrm{k}}
\end{aligned}
$$

Note that Equation III-127 is substituted into Equations III-123 and III-125 whenever the term $\overline{\mathrm{q}}_{\text {presaturant,c }}$ is called for in those equations (in the summations from $\mathrm{j}=1$ to NCATION). Note also that Equation III-128 is substituted into 
Equations III-124 and III-126 whenever the term $\overline{\mathrm{q}}_{\text {presaturant,A }}$ is called for in those equations (in the summations from $\mathrm{j}=1$ to NANION).

Once the dimensionless resin phase concentrations are known in each tank, it is possible to make use of the equilibrium expression and solve for the dimensionless liquid phase effluent concentration out of each tank:

$$
\begin{aligned}
& \overline{C_{i, k}}=\frac{\left(\overline{C_{T, C}}\right)_{i} \bar{q}_{i, k}}{\sum_{j=1}^{\text {NCAAIIN }} \alpha_{j}^{i} \bar{q}_{j, k}} \quad \text { (for } i=1 \text { to NCATION-1, i } i \neq \text { presaturant ion) }
\end{aligned}
$$

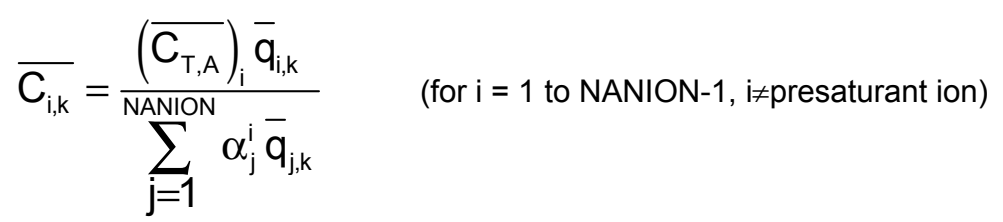

For the presaturant ion, the dimensionless liquid phase effluent concentration out of tank $\mathrm{k}$ can be calculated as:

$$
\begin{aligned}
& \overline{\mathrm{C}}_{\text {presaturant, } \mathrm{C}, \mathrm{k}}=\left(\overline{\mathrm{C}_{\mathrm{T}, \mathrm{C}}}\right)_{\text {presaturant }}-\sum_{\substack{\mathrm{j}=1 \\
\mathrm{j} \neq \text { presaturant, } \mathrm{C}}}^{\mathrm{NCATION-1}}\left[\left(\overline{\mathrm{C}_{\mathrm{j}, \mathrm{k}}}\right) \times\left(\frac{\mathrm{C}_{\mathrm{F}, \text { rersaturant }}}{\mathrm{C}_{\mathrm{F}, \mathrm{j}}}\right)\right] \quad(\mathrm{k}=1 \text { to Num. of Tanks) (III-131) }
\end{aligned}
$$

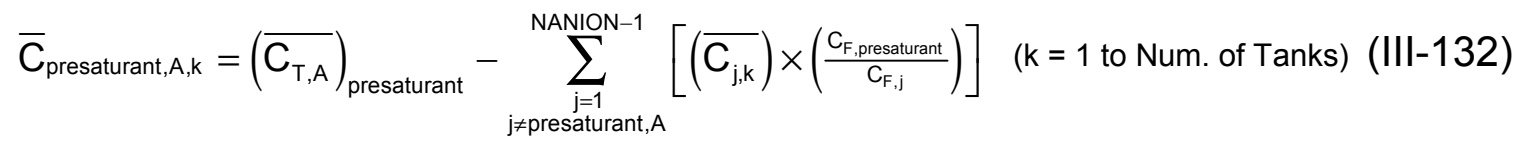

\section{Appendix III.A - Nomenclature}

$\mathrm{C}_{0} \quad$ Influent liquid phase concentration $\left(\right.$ eq $\left.^{-3}\right)$

$\overline{\mathrm{C}_{0, \mathrm{i}}} \quad$ Equivalent time-averaged influent liquid phase concentration of ion $\mathrm{i}$ $\left(\right.$ eq $\left.\mathrm{L}^{-3}\right)$

$\mathrm{C}_{\mathrm{Cl}} \quad$ Same as $\mathrm{C}_{\mathrm{Cl}, \mathrm{e}}$

$\mathrm{C}_{\mathrm{Cl}, 0} \quad$ Influent liquid phase concentration of $\mathrm{Cl}^{-}\left(\mathrm{eq} \mathrm{L}^{-3}\right)$

$\overline{\mathrm{C}_{\mathrm{Cl}, 0}} \quad$ Dimensionless influent liquid phase concentration of $\mathrm{Cl}^{-}$ (dimensionless)

$\mathrm{C}_{\mathrm{Cl}, \mathrm{e}} \quad$ Effluent liquid phase concentration of $\mathrm{Cl}^{-}\left(\mathrm{eq} \mathrm{L}^{-3}\right)$ 
$\mathrm{C}_{\mathrm{Cl}, \mathrm{k}} \quad$ Effluent liquid phase concentration of $\mathrm{Cl}^{-}$from tank number $\mathrm{k}$ (where $\mathrm{k}$ is a number between 1 and $n)\left(\right.$ eq $\left.^{-3}\right)$

$\overline{\mathrm{C}}_{\mathrm{Cl}, \mathrm{k}} \quad$ Dimensionless effluent liquid phase concentration of $\mathrm{Cl}^{-}$from tank number $\mathrm{k}$ (where $\mathrm{k}$ is a number between 1 and $\mathrm{n}$ ) (dimensionless)

$\mathrm{C}_{\mathrm{e}} \quad$ Effluent liquid phase concentration (eq $\mathrm{L}^{-3}$ )

$\mathrm{C}_{\mathrm{F}} \quad$ Capacity factor (dimensionless)

$\mathrm{C}_{\mathrm{F}, \mathrm{A}} \quad$ Capacity factor for anions (dimensionless)

$\mathrm{C}_{\mathrm{F}, \mathrm{C}} \quad$ Capacity factor for cations (dimensionless)

$\mathrm{C}_{\mathrm{F}, \mathrm{i}} \quad$ Capacity factor for ion $\mathrm{i}$ ( dimensionless)

$\mathrm{C}_{\mathrm{H}} \quad$ Same as $\mathrm{C}_{\mathrm{H}, \mathrm{e}}$

$\mathrm{C}_{\mathrm{H}, 0} \quad$ Influent liquid phase concentration of $\mathrm{H}^{+}\left(\mathrm{eq} \mathrm{L}^{-3}\right)$

$\mathrm{C}_{\mathrm{H}, \mathrm{e}} \quad$ Effluent liquid phase concentration of $\mathrm{H}^{+}\left(\mathrm{eq} \mathrm{L}^{-3}\right)$

$\mathrm{C}_{\mathrm{H}, \mathrm{k}} \quad$ Effluent liquid phase concentration of $\mathrm{H}^{+}$from tank number $\mathrm{k}$ (where $k$ is a number between 1 and $n$ ) $\left(\right.$ eq $\left.\mathrm{L}^{-3}\right)$

$\overline{\mathrm{C}}_{\mathrm{H}, \mathrm{k}} \quad$ Dimensionless effluent liquid phase concentration of $\mathrm{H}^{+}$from tank number $\mathrm{k}$ (where $\mathrm{k}$ is a number between 1 and $\mathrm{n}$ ) (dimensionless)

$\mathrm{C}_{\mathrm{i}, 0} \quad$ Influent liquid phase concentration of ion $\mathrm{i}\left(\mathrm{eq} \mathrm{L}^{-3}\right)$

$\overline{\mathrm{C}_{i, 0}} \quad$ Dimensionless influent liquid phase concentration of ion $\mathrm{i}$ (dimensionless)

$\mathrm{C}_{\mathrm{i}, \mathrm{e}} \quad$ Effluent liquid phase concentration of ion $\mathrm{i}\left(\mathrm{eq} \mathrm{L} \mathrm{L}^{-3}\right)$

$\mathrm{C}_{\mathrm{i}, \mathrm{k}} \quad$ Effluent liquid phase concentration of ion i from tank number $\mathrm{k}$ (eq $\mathrm{L}^{-3}$ )

$\overline{\mathrm{C}}_{\mathrm{i}, \mathrm{k}} \quad$ Dimensionless effluent liquid phase concentration of ion $\mathrm{i}$ from tank number $\mathrm{k}$ (dimensionless)

$\mathrm{C}_{\mathrm{Na}} \quad$ Same as $\mathrm{C}_{\mathrm{Na}, \mathrm{e}}$

$\mathrm{C}_{\mathrm{Na}, 0} \quad$ Influent liquid phase concentration of $\mathrm{Na}^{+}\left(\mathrm{eq} \mathrm{L}^{-3}\right)$ 


\begin{tabular}{|c|c|}
\hline$\overline{\mathrm{C}_{\mathrm{Na}, 0}}$ & $\begin{array}{l}\text { Dimensionless influent liquid phase concentration of } \mathrm{Na}^{+} \\
\text {(dimensionless) }\end{array}$ \\
\hline $\mathrm{C}_{\mathrm{Na}, \mathrm{e}}$ & Effluent liquid phase concentration of $\mathrm{Na}^{+}\left(\mathrm{eq} \mathrm{L}^{-3}\right)$ \\
\hline $\mathrm{C}_{\mathrm{Na}, \mathrm{k}}$ & $\begin{array}{l}\text { Effluent liquid phase concentration of } \mathrm{Na}^{+} \text {from tank number } \mathrm{k} \\
\text { (where } \mathrm{k} \text { is a number between } 1 \text { and } \mathrm{n} \text { ) }\left(\mathrm{eq} \mathrm{L}^{-3}\right)\end{array}$ \\
\hline$\overline{\mathrm{C}}_{\mathrm{Na}, \mathrm{k}}$ & $\begin{array}{l}\text { Dimensionless effluent liquid phase concentration of } \mathrm{Na}^{+} \text {from tank } \\
\text { number } k \text { (where } k \text { is a number between } 1 \text { and } n \text { ) (dimensionless) }\end{array}$ \\
\hline $\mathrm{C}_{\mathrm{OH}}$ & Same as $\mathrm{C}_{\mathrm{OH}, \mathrm{e}}$ \\
\hline $\mathrm{C}_{\mathrm{OH}, 0}$ & Influent liquid phase concentration of $\mathrm{OH}^{-}\left(\mathrm{eq} \mathrm{L}^{-3}\right)$ \\
\hline $\mathrm{C}_{\mathrm{OH}, \mathrm{e}}$ & Effluent liquid phase concentration of $\mathrm{OH}^{-}\left(\right.$eq L $\left.^{-3}\right)$ \\
\hline $\mathrm{C}_{\mathrm{OH}, \mathrm{k}}$ & $\begin{array}{l}\text { Effluent liquid phase concentration of } \mathrm{OH}^{-} \text {from tank number } \mathrm{k} \\
\text { (where } \mathrm{k} \text { is a number between } 1 \text { and } n \text { ) }\left(\mathrm{eq} \mathrm{L}^{-3}\right)\end{array}$ \\
\hline$\overline{\mathrm{C}}_{\mathrm{OH}, \mathrm{k}}$ & $\begin{array}{l}\text { Dimensionless effluent liquid phase concentration of } \mathrm{OH}^{-} \text {from tank } \\
\text { number } \mathrm{k} \text { (where } \mathrm{k} \text { is a number between } 1 \text { and } \mathrm{n} \text { ) (dimensionless) }\end{array}$ \\
\hline $\mathrm{C}_{\text {presaturant } \mathrm{A}, \mathrm{k}}$ & $\begin{array}{l}\text { Liquid phase concentration of the presaturant ion for the anionic } \\
\text { exchange resin in tank number } k \text { (where } k \text { is a number between } 1 \\
\text { and } n \text { ) }\left(\text { eq L }^{-3}\right)\end{array}$ \\
\hline$\overline{\mathrm{C}}_{\text {presaturant, } \mathrm{A}, \mathrm{k}}$ & $\begin{array}{l}\text { Dimensionless liquid phase concentration of the presaturant ion for } \\
\text { the anionic exchange resin in tank number } k \text { (where } k \text { is a number } \\
\text { between } 1 \text { and } n \text { ) (dimensionless) }\end{array}$ \\
\hline $\mathrm{C}_{\text {presaturant }, \mathrm{C}, \mathrm{k}}$ & $\begin{array}{l}\text { Liquid phase concentration of the presaturant ion for the cationic } \\
\text { exchange resin in tank number } k \text { (where } k \text { is a number between } 1 \\
\text { and } n \text { ) }\left(\text { eq L }^{-3}\right)\end{array}$ \\
\hline$\overline{\mathrm{C}}_{\text {presaturant,C,k}}$ & $\begin{array}{l}\text { Dimensionless liquid phase concentration of the presaturant ion for } \\
\text { the cationic exchange resin in tank number } k \text { (where } k \text { is a number } \\
\text { between } 1 \text { and } n \text { ) (dimensionless) }\end{array}$ \\
\hline
\end{tabular}


$\overline{\mathrm{C}_{\mathrm{T}, \text { avg } \mathrm{A}}} \quad$ Total equivalent time-averaged influent liquid phase concentration of all anions $\left(\right.$ eq $\left.^{-3}\right)$

$\overline{\mathrm{C}_{\mathrm{T}, \text { avg, }}} \quad$ Total equivalent time-averaged influent liquid phase concentration of all cations $\left(\right.$ eq L $\left.^{-3}\right)$

$\mathrm{C}_{\mathrm{T}, \mathrm{A}} \quad$ Total liquid phase concentration of all anions at time $\mathrm{t}\left(\right.$ eq $\left.\mathrm{L}^{-3}\right)$

$\left(\overline{\mathrm{C}_{\mathrm{T}, \mathrm{A}}}\right)_{i} \quad$ Dimensionless term representing the total liquid phase concentration of all anions at time $t$, equal to $\sum_{j=1}^{\text {NANION }}\left(\overline{C_{j, 0}} \times \frac{C_{F, i}}{C_{F, j}}\right)$ (dimensionless)

$\mathrm{C}_{\mathrm{T}, \mathrm{C}} \quad$ Total liquid phase concentration of all cations at time $\mathrm{t}\left(\mathrm{eq} \mathrm{\textrm {L } ^ { - 3 }}\right)$

$\left(\overline{\mathrm{C}_{\mathrm{T}, \mathrm{C}}}\right)_{\mathrm{i}} \quad$ Dimensionless term representing the total liquid phase concentration of all cations at time $t$, equal to $\sum_{j=1}^{\text {NCATION }}\left(\overline{C_{j, 0}} \times \frac{C_{F, j}}{C_{F, j}}\right)$ (dimensionless)

M Mass of resin ( $M$ )

$M_{A} \quad$ Mass of anionic exchange resin (M)

$M_{C} \quad$ Mass of cationic exchange resin (M)

$\mathrm{n} \quad$ Number of tanks (dimensionless)

NANION Number of anions (dimensionless)

NCATION Number of cations (dimensionless)

q Resin phase concentration $\left(\mathrm{eq} \mathrm{M}^{-1}\right)$

$\mathrm{q}_{\mathrm{Cl}} \quad$ Resin phase concentration of $\mathrm{Cl}^{-}\left(\right.$eq M$\left.^{-1}\right)$

$\overline{\mathrm{q}}_{\mathrm{Cl}} \quad$ Dimensionless resin phase concentration of $\mathrm{Cl}^{-}$(dimensionless)

$\mathrm{q}_{\mathrm{Cl}, 1} \quad$ Resin phase concentration of $\mathrm{Cl}^{-}$in tank number $1\left(\right.$ eq M$\left.^{-1}\right)$

$\overline{\mathrm{q}}_{\mathrm{Cl}, 1} \quad$ Dimensionless resin phase concentration of $\mathrm{Cl}^{-}$in tank number 1 (dimensionless) 


\begin{tabular}{|c|c|}
\hline $\mathrm{q}_{\mathrm{cl,m}, \mathrm{m}}$ & $\begin{array}{l}\text { Resin phase concentration of } \mathrm{Cl}^{-} \text {in tank number } \mathrm{m} \text { (where } \mathrm{m} \text { is a } \\
\left.\text { number between } 2 \text { and } \mathrm{n} \text { ) (eq } \mathrm{M}^{-1}\right)\end{array}$ \\
\hline$\overline{\mathrm{q}}_{\mathrm{cl}, \mathrm{m}}$ & $\begin{array}{l}\text { Dimensionless resin phase concentration of } \mathrm{Cl}^{-} \text {in tank number } \mathrm{m} \\
\text { (where } \mathrm{m} \text { is a number between } 2 \text { and } \mathrm{n} \text { ) (dimensionless) }\end{array}$ \\
\hline & $\begin{array}{l}\text { Resin phase concentration of } \mathrm{Cl}^{-} \text {in tank number } \mathrm{k} \text { (where } \mathrm{k} \text { is a } \\
\text { number between } 1 \text { and } \mathrm{n})\left(\mathrm{eq} \mathrm{M}^{-1}\right)\end{array}$ \\
\hline$\overline{\mathrm{q}}_{\mathrm{Cl}, \mathrm{k}}$ & $\begin{array}{l}\text { Dimensionless resin phase concentration of } \mathrm{Cl}^{-} \text {in tank number } \mathrm{k} \\
\text { (where } \mathrm{k} \text { is a number between } 1 \text { and } \mathrm{n} \text { ) (dimensionless) }\end{array}$ \\
\hline$q_{H}$ & Resin phase concentration of $\mathrm{H}^{+}\left(\mathrm{eq} \mathrm{M}^{-1}\right)$ \\
\hline$\overline{\mathrm{q}}_{\mathrm{H}}$ & Dimensionless resin phase concentration of $\mathrm{H}^{+}$(dimensionless) \\
\hline $\mathrm{q}_{\mathrm{H}, 1}$ & Resin phase concentration of $\mathrm{H}^{+}$in tank number $1\left(\mathrm{eq} \mathrm{M}^{-1}\right)$ \\
\hline$q_{H, m}$ & $\begin{array}{l}\text { Resin phase concentration of } \mathrm{H}^{+} \text {in tank number } \mathrm{m} \text { (where } \mathrm{m} \text { is a } \\
\text { number between } 2 \text { and } n)\left(\text { eq } \mathrm{M}^{-1}\right)\end{array}$ \\
\hline $\mathrm{q}_{\mathrm{H}, \mathrm{k}}$ & $\begin{array}{l}\text { Resin phase concentration of } \mathrm{H}^{+} \text {in tank number } \mathrm{k} \text { (where } \mathrm{k} \text { is a } \\
\text { number between } 1 \text { and } n)\left(\mathrm{eq} \mathrm{M}^{-1}\right)\end{array}$ \\
\hline$\overline{\mathrm{q}}_{\mathrm{H}, \mathrm{k}}$ & $\begin{array}{l}\text { Dimensionless resin phase concentration of } \mathrm{H}^{+} \text {in tank number } \mathrm{k} \\
\text { (where } \mathrm{k} \text { is a number between } 1 \text { and } \mathrm{n} \text { ) (dimensionless) }\end{array}$ \\
\hline & Resin phase concentration of ion $\mathrm{i}\left(\mathrm{eq} \mathrm{M}^{-1}\right)$ \\
\hline & Dimensionless resin phase concentration of ion i (dimensionless) \\
\hline$q_{i, 1}$ & Resin phase concentration of ion $\mathrm{i}$ in tank number $1\left(\mathrm{eq} \mathrm{M}^{-1}\right)$ \\
\hline$\overline{\mathrm{q}}_{\mathrm{i}, 1}$ & $\begin{array}{l}\text { Dimensionless resin phase concentration of ion } \mathrm{i} \text { in tank number } 1 \\
\text { (dimensionless) }\end{array}$ \\
\hline$q_{i, m}$ & $\begin{array}{l}\text { Resin phase concentration of ion } i \text { in tank number } m \text { (where } m \text { is a } \\
\text { number between } 2 \text { and } n)\left(\text { eq }^{-1}\right)\end{array}$ \\
\hline $\bar{a}$ & $\begin{array}{l}\text { Dimensionless resin phase concentration of ion } \mathrm{i} \text { in tank number } \mathrm{m} \\
\text { (where } \mathrm{m} \text { is a number between } 2 \text { and } \mathrm{n} \text { ) (dimensionless) }\end{array}$ \\
\hline
\end{tabular}


$\mathrm{q}_{\mathrm{i}, \mathrm{k}} \quad$ Resin phase concentration of ion $\mathrm{i}$ in tank number $\mathrm{k}$ (where $\mathrm{k}$ is a number between 1 and $n)\left(\right.$ eq $\left.\mathrm{M}^{-1}\right)$

$\overline{\mathrm{q}}_{\mathrm{i}, \mathrm{k}} \quad$ Dimensionless resin phase concentration of ion $\mathrm{i}$ in tank number $\mathrm{k}$ (where $\mathrm{k}$ is a number between 1 and $\mathrm{n}$ ) (dimensionless)

$\mathrm{q}_{\mathrm{Na}} \quad$ Resin phase concentration of $\mathrm{Na}^{+}\left(\right.$eq M$\left.^{-1}\right)$

$\overline{\mathrm{q}}_{\mathrm{Na}}$

Dimensionless resin phase concentration of $\mathrm{Na}^{+}$(dimensionless)

$\mathrm{q}_{\mathrm{Na}, 1}$ Resin phase concentration of $\mathrm{Na}^{+}$in tank number $1\left(\mathrm{eq} \mathrm{M}^{-1}\right)$

$\overline{\mathrm{q}}_{\mathrm{N}, 1}$ Dimensionless resin phase concentration of $\mathrm{Na}^{+}$in tank number 1 (dimensionless )

$\mathrm{q}_{\mathrm{Na}, \mathrm{m}}$ Resin phase concentration of $\mathrm{Na}^{+}$in tank number $\mathrm{m}$ (where $\mathrm{m}$ is a number between 2 and $n)\left(\right.$ eq M$\left.^{-1}\right)$

Dimensionless resin phase concentration of $\mathrm{Na}^{+}$in tank number $\mathrm{m}$ (where $\mathrm{m}$ is a number between 2 and $\mathrm{n}$ ) (dimensionless)

$\mathrm{q}_{\mathrm{Na}, \mathrm{k}}$ Resin phase concentration of $\mathrm{Na}^{+}$in tank number $\mathrm{k}$ (where $\mathrm{k}$ is a number between 1 and $n)\left(\right.$ eq M $\left.^{-1}\right)$

Dimensionless resin phase concentration of $\mathrm{Na}^{+}$in tank number $\mathrm{k}$ (where $\mathrm{k}$ is a number between 1 and $\mathrm{n}$ ) (dimensionless) Resin phase concentration of $\mathrm{OH}^{-}\left(\right.$eq M$\left.^{-1}\right)$ Dimensionless resin phase concentration of $\mathrm{OH}^{-}$(dimensionless) Resin phase concentration of $\mathrm{OH}^{-}$in tank number $1\left(\mathrm{eq} \mathrm{M}^{-1}\right)$ Resin phase concentration of $\mathrm{OH}^{-}$in tank number $\mathrm{m}$ (where $\mathrm{m}$ is a number between 2 and $n)\left(\right.$ eq $\left.^{-1}\right)$

$\mathrm{q}_{\mathrm{OH}, \mathrm{k}} \quad$ Resin phase concentration of $\mathrm{OH}^{-}$in tank number $\mathrm{k}$ (where $\mathrm{k}$ is a number between 1 and $n)\left(\right.$ eq $\left.^{-1}\right)$

$\overline{\mathrm{q}}_{\mathrm{OH}, \mathrm{k}} \quad$ Dimensionless resin phase concentration of $\mathrm{OH}^{-}$in tank number $\mathrm{k}$ (where $\mathrm{k}$ is a number between 1 and $\mathrm{n}$ ) (dimensionless) 
$\mathrm{q}_{\text {presaturant,A }} \quad$ Resin phase concentration of the presaturant ion on the anionic exchange resin $\left(\right.$ eq $\left.^{-1}\right)$

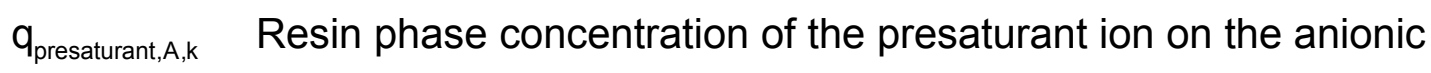
exchange resin in tank number $\mathrm{k}\left(\right.$ eq M$\left.^{-1}\right)$

$\overline{\mathrm{q}}_{\text {presaturant,A,k}}$ Dimensionless resin phase concentration of the presaturant ion on the anionic exchange resin in tank number $\mathrm{k}$ (dimensionless)

$q_{\text {presaturant, },} \quad$ Resin phase concentration of the presaturant ion on the cationic exchange resin $\left(\right.$ eq $\left.^{-1}\right)$

$\mathrm{q}_{\text {presaturant, }, \mathrm{k}, \mathrm{R}}$ Resin phase concentration of the presaturant ion on the cationic exchange resin in tank number $\left.\mathrm{k}_{(\text {eq }}{ }^{-1}\right)$

$\overline{\mathrm{q}}_{\text {presaturant,C,k}}$ Dimensionless resin phase concentration of the presaturant ion on the cationic exchange resin in tank number $\mathrm{k}$ (dimensionless)

$\mathrm{q}_{\mathrm{T}} \quad$ Total resin capacity (eq $\mathrm{M}^{-1}$ )

$\mathrm{q}_{\mathrm{T}, \mathrm{A}} \quad$ Total resin capacity of anionic exchange resin $\left(\right.$ eq M$\left.^{-1}\right)$

$\mathrm{q}_{\mathrm{T}, \mathrm{C}} \quad$ Total resin capacity of cationic exchange resin $\left(\right.$ eq M$\left.^{-1}\right)$

Q Water flow rate $\left(\mathrm{L}^{3} \mathrm{~T}^{-1}\right)$

$\mathrm{t} \quad$ Elapsed time $(\mathrm{T})$

$\mathrm{T} \quad$ Elapsed time (dimensionless)

V Total system volume for all tanks $\left(\mathrm{L}^{3}\right)$

$\alpha_{\mathrm{OH}}^{\mathrm{Cl}} \quad$ Separation factor (dimensionless)

$\alpha_{\mathrm{Cl}}^{\mathrm{OH}} \quad$ Separation factor (dimensionless)

$\alpha_{H}^{\mathrm{Na}} \quad$ Separation factor (dimensionless)

$\alpha_{\mathrm{Na}}^{\mathrm{H}} \quad$ Separation factor (dimensionless)

$\alpha_{j}^{i} \quad$ Separation factors (dimensionless)

$\varepsilon \quad$ Bed porosity (dimensionless)

$\tau \quad$ Packed bed contact time $(T)$ 
Appendix III.B - Detailed Description of Transferring Single CSTR Model Equations into Dimensionless Form for Cations

Equation Section 2The dimensionless variables were defined above:

$$
\begin{gathered}
\overline{\mathrm{q}}_{\mathrm{Na}}=\frac{\mathrm{q}_{\mathrm{Na}}}{\mathrm{q}_{\mathrm{T}, \mathrm{C}}} \\
\overline{\mathrm{q}}_{\mathrm{H}}=\frac{\mathrm{q}_{\mathrm{H}}}{\mathrm{q}_{\mathrm{T}, \mathrm{C}}} \\
\overline{\mathrm{C}_{0, \mathrm{i}}}=\frac{1}{\mathrm{t}} \int_{0}^{\mathrm{t}} \mathrm{C}_{0, \mathrm{i}}(\mathrm{t}) \mathrm{dt} \\
\overline{\mathrm{C}_{\mathrm{T}, \text { avg }, \mathrm{C}}}=\sum_{\mathrm{j}=1}^{\mathrm{m}} \overline{\mathrm{C}_{0, \mathrm{j}}} \quad \text { where } \mathrm{m}=\text { number of cations } \\
\overline{\mathrm{C}_{\mathrm{Na}, 0}}=\frac{\mathrm{C}_{\mathrm{Na}, 0}}{\overline{\mathrm{C}_{0, \mathrm{Na}}}} \\
\overline{\mathrm{C}_{\mathrm{T}, \mathrm{C}}}=\overline{\mathrm{C}_{\mathrm{Na}, 0}}+\overline{\mathrm{C}_{\mathrm{H}, 0}} \times \frac{\mathrm{C}_{\mathrm{F}, \mathrm{Na}}}{\mathrm{C}_{\mathrm{F}, \mathrm{H}}} \\
\mathrm{T}=\frac{\mathrm{t}}{\mathrm{C}_{\mathrm{F}} \tau}
\end{gathered}
$$

where:

$$
\begin{aligned}
C_{F} & =C_{F, C}+C_{F, A} \\
C_{F, C} & =\frac{M_{C} q_{T, C}}{V \overline{C_{T, a v g, C}} \varepsilon} \\
C_{F, A} & =\frac{M_{A} q_{T, A}}{V \overline{C_{T, a v g, A}} \varepsilon} \\
C_{F, N a} & =\frac{M_{C} q_{T, C}}{V \overline{C_{0, N a}} \varepsilon} \\
C_{F, H} & =\frac{M_{C} q_{T, C}}{V \overline{C_{0, H}} \varepsilon} \\
\tau & =\frac{V \varepsilon}{Q}
\end{aligned}
$$




$$
\frac{d}{d t}=\frac{1}{C_{F} \tau} \frac{d}{d T}
$$

The final form of the dimensioned equations for the single CSTR model (see Equations III-17 and III-18) were given by:

$$
\begin{aligned}
& q_{H}=q_{T, C}-q_{N a} \\
& \frac{d_{\mathrm{Na}}}{d t}=\frac{Q C_{N a, 0}-Q\left[\frac{C_{T, C} q_{N a}}{q_{N a}+\alpha_{H}^{N a}\left(q_{T, C}-q_{N a}\right)}\right]}{M+\varepsilon V\left[\frac{C_{T, C} \alpha_{H}^{N a}\left(q_{T, C}-q_{N a}\right)}{\left(q_{N a}+\alpha_{H}^{N a}\left(q_{T, C}-q_{N a}\right)\right)^{2}}\right]}
\end{aligned}
$$

The dimensionless form of Equation III-17 that results from dividing both sides of the equation by $\mathrm{q}_{\mathrm{T}, \mathrm{C}}$ :

$$
\overline{\mathrm{q}}_{\mathrm{H}}=1-\overline{\mathrm{q}}_{\mathrm{Na}}
$$

Conversion of Equation III-18 into dimensionless form is more complicated. A step by step conversion is presented below.

$$
\begin{aligned}
& \frac{q_{T, C}}{C_{F} \tau} \frac{d\left(\frac{q_{N a}}{q_{T, C}}\right)}{d\left(\frac{t}{C_{F} \tau}\right)}=
\end{aligned}
$$

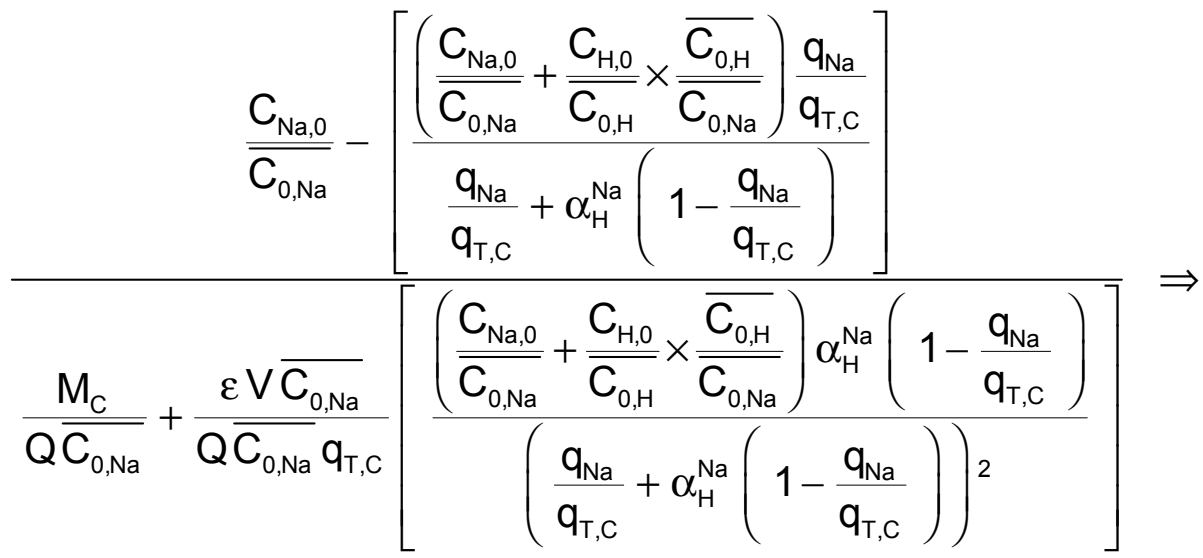




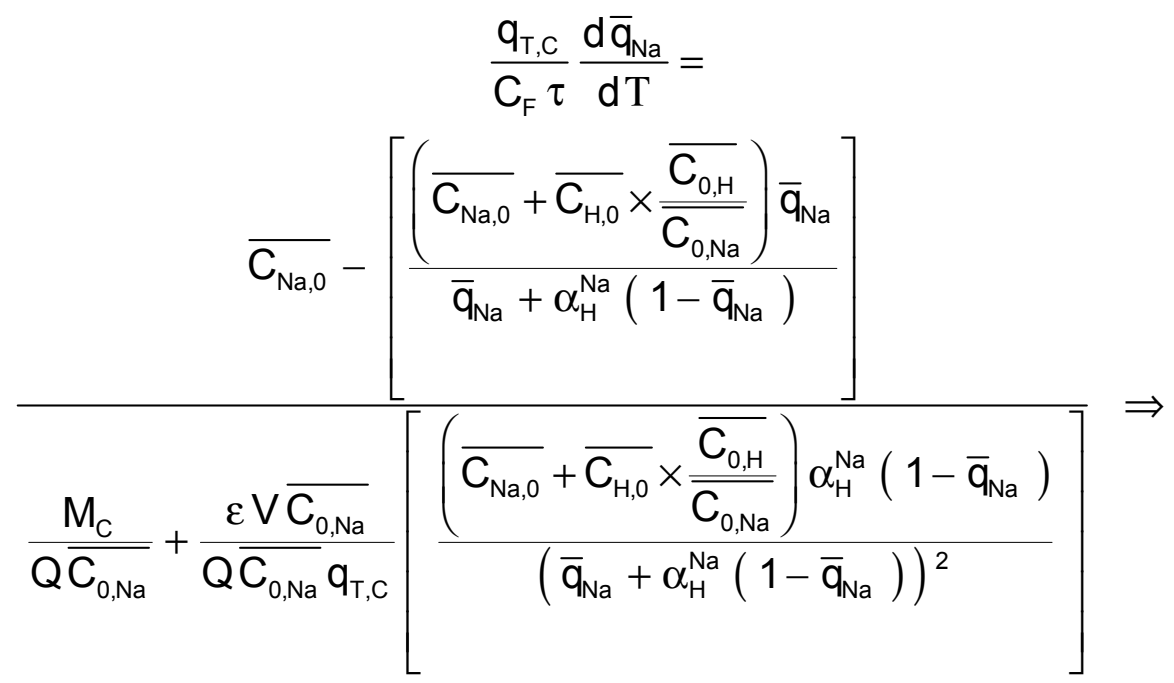

(III.B-2)

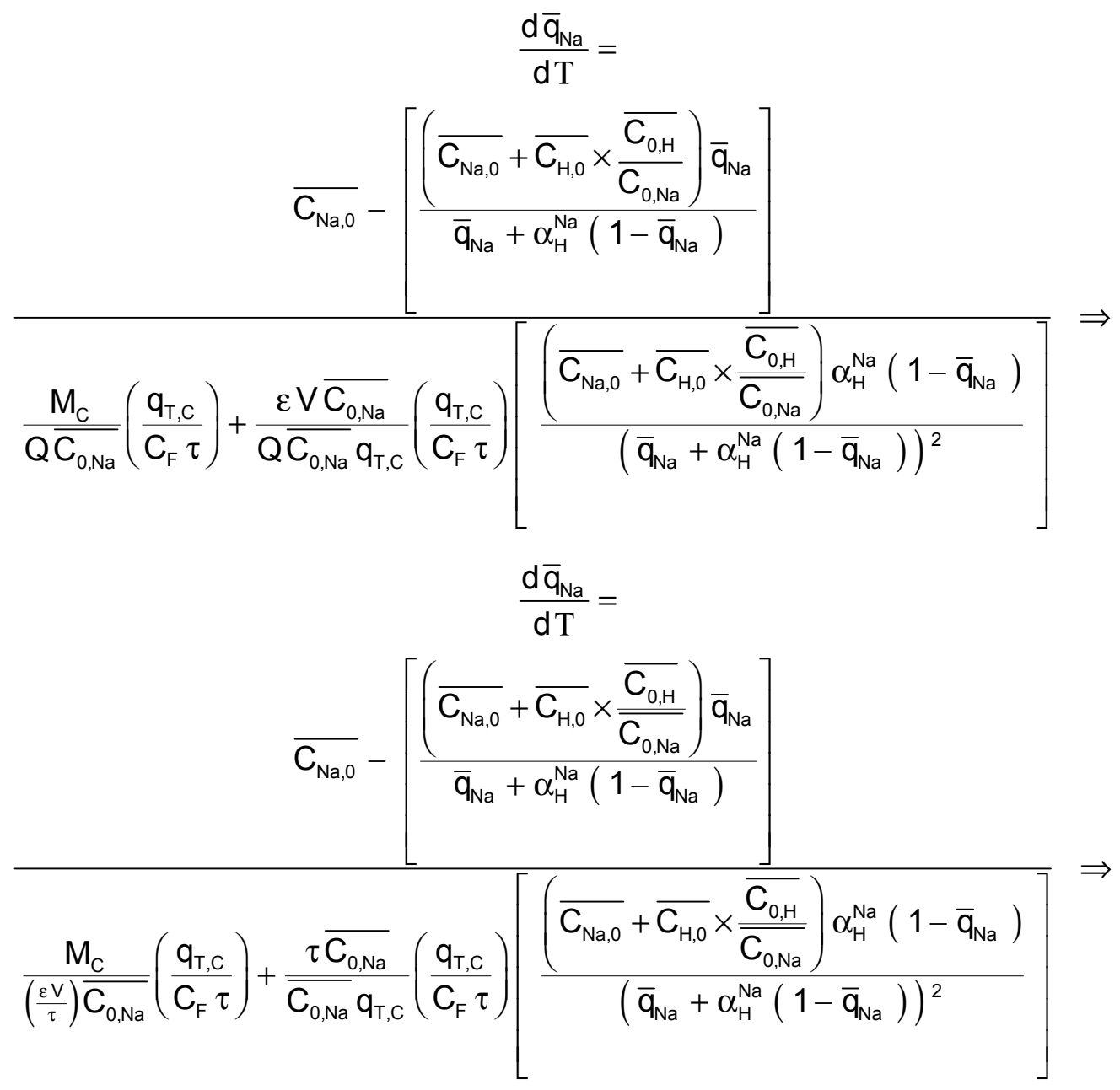

(III.B-3)

(III.B-4) 


$$
\begin{aligned}
& \frac{\mathrm{d} \overline{\mathrm{q}}_{\mathrm{Na}}}{\mathrm{dT}}=
\end{aligned}
$$

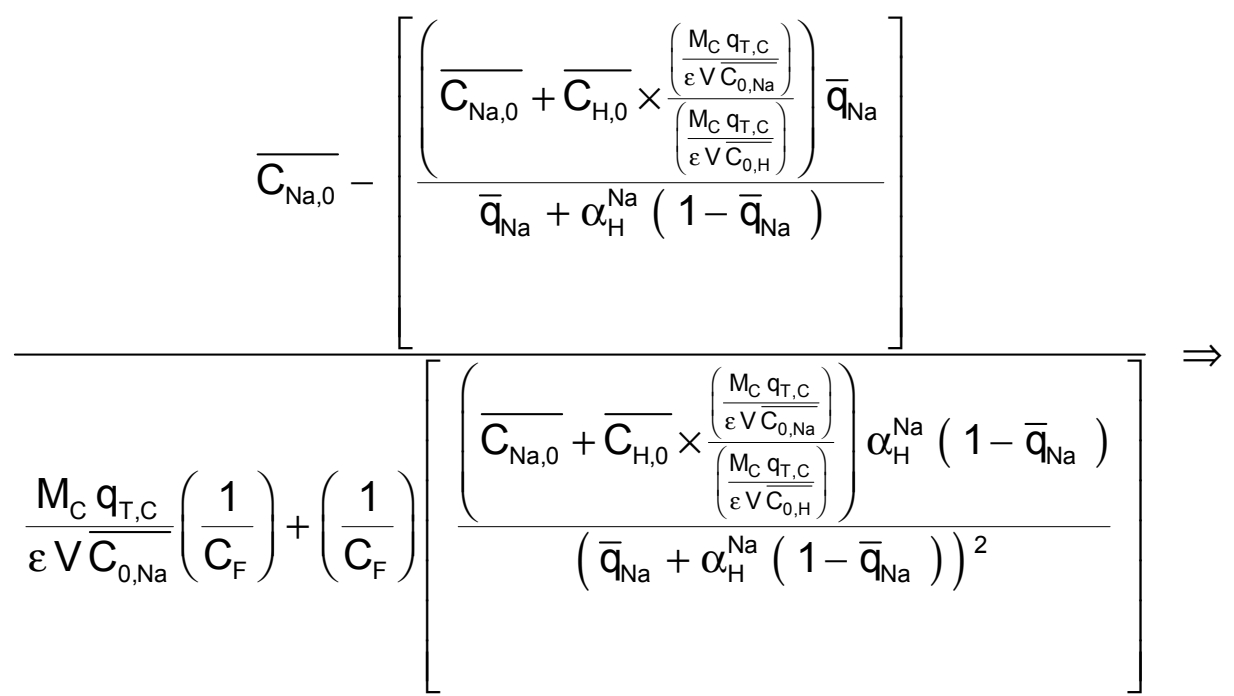

$$
\begin{aligned}
& \frac{d \overline{\mathrm{q}}_{\mathrm{Na}}}{\mathrm{dT}}=\frac{\overline{\mathrm{C}_{\mathrm{Na}, 0}}-\left[\frac{\left(\overline{\mathrm{C}_{\mathrm{Na}, 0}}+\overline{\mathrm{C}_{\mathrm{H}, 0}}+\overline{\mathrm{C}_{\mathrm{H}}} \times \frac{\mathrm{C}_{\mathrm{F}, \mathrm{Na}}}{\mathrm{C}_{\mathrm{F}, \mathrm{H}}}\right) \overline{\mathrm{q}}_{\mathrm{Na}}}{\overline{\mathrm{q}}_{\mathrm{Na}}+\alpha_{\mathrm{H}}^{\mathrm{Na}}\left(1-\overline{\mathrm{q}}_{\mathrm{Na}}\right)}\right]}{\left(\frac{\mathrm{C}_{\mathrm{F}, \mathrm{Na}}}{\mathrm{C}_{\mathrm{F}}}\right)+\left(\frac{1}{\mathrm{C}_{\mathrm{F}}}\right)\left[\frac{\left.\left(\overline{\mathrm{C}_{\mathrm{Na}, 0}}+\overline{\mathrm{C}_{\mathrm{H}, 0}} \times \frac{\mathrm{C}_{\mathrm{F}, \mathrm{Na}}}{\mathrm{C}_{\mathrm{F}, \mathrm{H}}}\right) \alpha_{\mathrm{H}}^{\mathrm{Na}}\left(1-\overline{\mathrm{q}}_{\mathrm{Na}}\right)\right]}{\left(\overline{\mathrm{q}}_{\mathrm{Na}}+\alpha_{\mathrm{H}}^{\mathrm{Na}}\left(1-\overline{\mathrm{q}}_{\mathrm{Na}}\right)\right)^{2}}\right]} \Rightarrow \\
& \frac{d \overline{\mathrm{q}}_{\mathrm{Na}}}{\mathrm{dT}}=\frac{\overline{\mathrm{C}_{\mathrm{Na}, 0}}-\left[\frac{\left(\overline{\mathrm{C}_{\mathrm{T}, \mathrm{C}}}\right) \overline{\mathrm{q}}_{\mathrm{Na}}}{\overline{\mathrm{q}}_{\mathrm{Na}}+\alpha_{\mathrm{H}}^{\mathrm{Na}}\left(1-\overline{\mathrm{q}}_{\mathrm{Na}}\right)}\right]}{\left(\frac{\mathrm{C}_{\mathrm{F}, \mathrm{Na}}}{\mathrm{C}_{\mathrm{F}}}\right)+\left(\frac{1}{\mathrm{C}_{\mathrm{F}}}\right)\left\{\frac{\left(\overline{\mathrm{C}_{\mathrm{T}, \mathrm{C}}}\right) \alpha_{\mathrm{H}}^{\mathrm{Na}}\left(1-\overline{\mathrm{q}}_{\mathrm{Na}}\right)}{\left[\overline{\mathrm{q}}_{\mathrm{Na}}+\alpha_{\mathrm{H}}^{\mathrm{Na}}\left(1-\overline{\mathrm{q}}_{\mathrm{Na}}\right)\right]^{2}}\right\}} \Rightarrow
\end{aligned}
$$




\section{Appendix IV - Equilbrium Approach Accounting for Water Formation Reaction, Charge Balance, and Degree of lonization Adopted for Mixed Bed Ion Exchange, Strong Acid Cation Exchange, Strong Base Anion Exchange, and Weak Base Anion Exchange}

\section{Description:}

This appendix explains the approach that is used for equilibrium in the ion exchange models: Strong Acid Cation (SAC) Exchange, Strong Base Anion (SBA) Exchange, Mixed Bed lon Exchange, and Weak Base Anion (WBA) Exchange. The equilibrium description accounts for charge balance, water formation reaction, and degree of ionization.

It is a simplified approach in that it is applied only after the complete solution of ODE's in IMSL algorithm DGEAR/DIFFUN after the last output point/time step. It is neither solved at each time step in DIFFUN nor solved after each output point prior to each new call to DGEAR. It is only solved at the very end. A description of how each segment of the algorithm is applied in the code will also be provided. Appendix IV.B provides some derivations related to the ionization of: (1) anionic species; and (2) cationic species.

\section{Equilibrium Expression for Mixed Bed Resin}

\section{Example Case: MTU Ersatz (4 cations, 7 anions)}

This example applies to the solution of Mixed Bed ion exchange equilibrium for the MTU Ersatz case, which includes 4 cations and 7 anions. The cations included are sodium $(\mathrm{Na})$, potassium $(\mathrm{K})$, calcium $(\mathrm{Ca})$ and hydrogen $(\mathrm{H})$. The anions included are acetate $(\mathrm{Ac})$, butyrate (But), chloride $(\mathrm{Cl})$, bicarbonate (HCO3, sulfate (SO4), N-methyl-N-“coconut oil acid" taurate (CMT), and hydroxide $(\mathrm{OH})$. This development assumes that acetate $(\mathrm{Ac})$ and butyrate (But) are the only species that ionize. The approach shown here for mixed bed ion exchange resin also applies to SAC and SBA ion exchange.

$$
\begin{gathered}
C_{N a}=\frac{C_{T, C} q_{N a}}{q_{N a}+\alpha_{K}^{N a} q_{K}+\alpha_{C a}^{N a} q_{C a}+\alpha_{H}^{N a} q_{H}} \\
C_{K}=\frac{C_{T, C} q_{K}}{\alpha_{N a}^{K} q_{N a}+q_{K}+\alpha_{C a}^{K} q_{C a}+\alpha_{H}^{K} q_{H}}
\end{gathered}
$$




$$
\begin{aligned}
& C_{C a}=\frac{C_{T, C} q_{C a}}{\alpha_{N a}^{C a} q_{N a}+\alpha_{K}^{C a} q_{K}+q_{C a}+\alpha_{H}^{C a} q_{H}} \\
& \mathrm{C}_{\mathrm{Na}}+\mathrm{C}_{\mathrm{K}}+\mathrm{C}_{\mathrm{Ca}}+\mathrm{C}_{\mathrm{H}}=\mathrm{C}_{\mathrm{Ac}}+\mathrm{C}_{\mathrm{But}}+\mathrm{C}_{\mathrm{Cl}}+\mathrm{C}_{\mathrm{HCO}_{3}}+\mathrm{C}_{\mathrm{SO}_{4}}+\mathrm{C}_{\mathrm{CMT}}+\mathrm{C}_{\mathrm{OH}} \\
& \mathrm{C}_{\mathrm{T}, \mathrm{Ac}}=\frac{\mathrm{C}_{\mathrm{T}, \mathrm{A}} \mathrm{q}_{\mathrm{Ac}}}{\mathrm{q}_{\mathrm{Ac}}+\alpha_{\mathrm{But}}^{\mathrm{Ac}} \mathrm{q}_{\mathrm{But}}+\alpha_{\mathrm{Cl}}^{\mathrm{Ac}} \mathrm{q}_{\mathrm{Cl}}+\alpha_{\mathrm{HCO}_{3}}^{\mathrm{Ac}} \mathrm{q}_{\mathrm{HCO}_{3}}+\alpha_{\mathrm{SO}_{4}}^{\mathrm{Ac}} \mathrm{q}_{\mathrm{SO}_{4}}+\alpha_{\mathrm{CMT}}^{\mathrm{Ac}} \mathrm{q}_{\mathrm{CMT}}+\alpha_{\mathrm{OH}}^{\mathrm{AC}} \mathrm{q}_{\mathrm{OH}}}+\mathrm{C}_{\mathrm{HAc}, 0} \\
& C_{\mathrm{T}, \mathrm{But}}=\frac{\mathrm{C}_{\mathrm{T}, \mathrm{A}} \mathrm{q}_{\mathrm{But}}}{\alpha_{\mathrm{Ac}}^{\text {But }} \mathrm{q}_{\mathrm{Ac}}+\mathrm{q}_{\mathrm{But}}+\alpha_{\mathrm{Cl}}^{\text {But }} \mathrm{q}_{\mathrm{Cl}}+\alpha_{\mathrm{HCO}_{3}}^{\text {But }} \mathrm{q}_{\mathrm{HCO}_{3}}+\alpha_{\mathrm{SO}_{4}}^{\text {But }} \mathrm{q}_{\mathrm{SO}_{4}}+\alpha_{\mathrm{CMT}}^{\text {But }} \mathrm{q}_{\mathrm{CMT}}+\alpha_{\mathrm{OH}}^{\text {But }} \mathrm{q}_{\mathrm{OH}}}+C_{\mathrm{HBut}, 0} \\
& \mathrm{C}_{\mathrm{Cl}}=\frac{\mathrm{C}_{\mathrm{T}, \mathrm{A}} \mathrm{q}_{\mathrm{Cl}}}{\alpha_{\mathrm{Ac}}^{\mathrm{Cl}} \mathrm{q}_{\mathrm{Ac}}+\alpha_{\mathrm{But}}^{\mathrm{Cl}} \mathrm{q}_{\mathrm{But}}+\mathrm{q}_{\mathrm{Cl}}+\alpha_{\mathrm{HCO}_{3}}^{\mathrm{Cl}} \mathrm{q}_{\mathrm{HCO}_{3}}+\alpha_{\mathrm{SO}_{4}}^{\mathrm{Cl}} \mathrm{q}_{\mathrm{SO}_{4}}+\alpha_{\mathrm{CMT}}^{\mathrm{Cl}} \mathrm{q}_{\mathrm{CMT}}+\alpha_{\mathrm{OH}}^{\mathrm{Cl}} q_{\mathrm{OH}}} \\
& \mathrm{C}_{\mathrm{HCO}_{3}}=\frac{\mathrm{C}_{\mathrm{T}, \mathrm{A}} \mathrm{q}_{\mathrm{HCO}_{3}}}{\alpha_{\mathrm{AC}}^{\mathrm{HCO}_{3}} \mathrm{q}_{\mathrm{Ac}}+\alpha_{\mathrm{But}}^{\mathrm{HCO}_{3}} \mathrm{q}_{\mathrm{But}}+\alpha_{\mathrm{Cl}}^{\mathrm{HCO}_{3}} \mathrm{q}_{\mathrm{Cl}}+\mathrm{q}_{\mathrm{HCO}_{3}}+\alpha_{\mathrm{SO}_{4}}^{\mathrm{HCO}_{3}} \mathrm{q}_{\mathrm{SO}_{4}}+\alpha_{\mathrm{CMT}}^{\mathrm{HCO}_{3}} \mathrm{q}_{\mathrm{CMT}}+\alpha_{\mathrm{OH}}^{\mathrm{HCO}_{3}} q_{\mathrm{OH}}}
\end{aligned}
$$

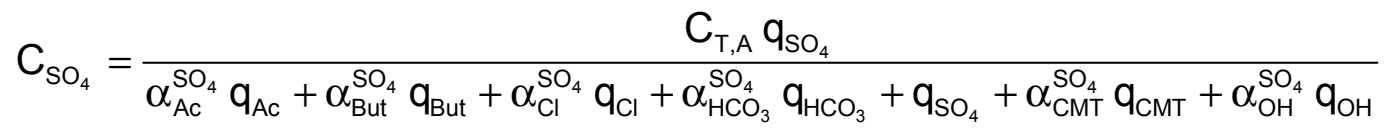

$$
\begin{aligned}
& \mathrm{C}_{\mathrm{CMT}}=\frac{\mathrm{C}_{\mathrm{T}, \mathrm{A}} \mathrm{q}_{\mathrm{CMT}}}{\alpha_{\mathrm{Ac}}^{\mathrm{CMT}} q_{\mathrm{Ac}}+\alpha_{\mathrm{But}}^{\mathrm{CMT}} q_{\mathrm{But}}+\alpha_{\mathrm{Cl}}^{\mathrm{CMT}} q_{\mathrm{Cl}}+\alpha_{\mathrm{HCO}_{3}}^{\mathrm{CMT}} q_{\mathrm{HCO}_{3}}+\alpha_{\mathrm{SO}_{4}}^{\mathrm{CMT}_{4}} q_{\mathrm{SO}_{4}}+q_{\mathrm{CMT}}+\alpha_{\mathrm{OH}}^{\mathrm{CMT}} q_{\mathrm{OH}}} \\
& \mathrm{C}_{\mathrm{H}} \times \mathrm{C}_{\mathrm{OH}}=10^{-8} \frac{\mathrm{meq}^{2}}{\mathrm{~L}^{2}} \\
& \mathrm{C}_{\mathrm{Ac}}=\frac{\mathrm{C}_{\mathrm{T}, \mathrm{Ac}}}{1+\left(\frac{\mathrm{C}_{\mathrm{H}} / 1000}{10^{-\mathrm{pK}_{\mathrm{a}, \mathrm{Ac}}}}\right)} \\
& \mathrm{C}_{\mathrm{But}}=\frac{\mathrm{C}_{\mathrm{T}, \mathrm{But}}}{1+\left(\frac{\mathrm{C}_{\mathrm{H}} / 1000}{10^{-\mathrm{pK}_{\mathrm{a}, \mathrm{But}}}}\right)}
\end{aligned}
$$

Unknowns: $\mathrm{C}_{\mathrm{Na}}, \mathrm{C}_{\mathrm{K}}, \mathrm{C}_{\mathrm{Ca}}, \mathrm{C}_{\mathrm{H}}, \mathrm{C}_{\mathrm{Ac}}, \mathrm{C}_{\mathrm{But}}, \mathrm{C}_{\mathrm{Cl}}, \mathrm{C}_{\mathrm{HCO}_{3}}, \mathrm{C}_{\mathrm{SO}_{4}}, \mathrm{C}_{\mathrm{CMT}}, \mathrm{C}_{\mathrm{OH}}, \mathrm{C}_{\mathrm{T}, \mathrm{Ac}}, \mathrm{C}_{\mathrm{T}, \mathrm{But}}$ Knowns: All q values and $\alpha$ values; $\mathrm{C}_{\mathrm{T}, \mathrm{C}}, \mathrm{C}_{\mathrm{T}, \mathrm{A}}$; all $\mathrm{pK}_{\mathrm{a}}$ values; $\mathrm{C}_{\mathrm{HAc}, 0}, \mathrm{C}_{\mathrm{HBut}, 0}$ 13 Equations, 13 Unknowns 


\section{Simplification of Equations}

It is possible to simplify the system of equations above to a system of 1 equation with 1 unknown as follows. Substitute Equation IV-5 into Equation IV-12 , which results in the following and eliminates the $C_{T, A C}$ unknown.

$$
C_{A C}=\frac{\left[\frac{C_{T, A} q_{A C}}{q_{A C}+\alpha_{B u t}^{A C} q_{B u t}+\alpha_{C l}^{A C} q_{C l}^{A C}+\alpha_{H C C_{3}}^{A C} q_{H C O_{3}}+\alpha_{S_{O_{4}}}^{A C} q_{S O_{4}}+\alpha_{C M T}^{A C} q_{C M T}+\alpha_{O H}^{A C} q_{O H}}\right]+C_{H A C, 0}}{1+\left(\frac{C_{H} / 1000}{10^{-p K_{a}, A C}}\right)}
$$

Substitute Equation IV-6 into Equation IV-13, which results in the following and eliminates the $\mathrm{C}_{\mathrm{T}, \mathrm{But}}$ unknown.

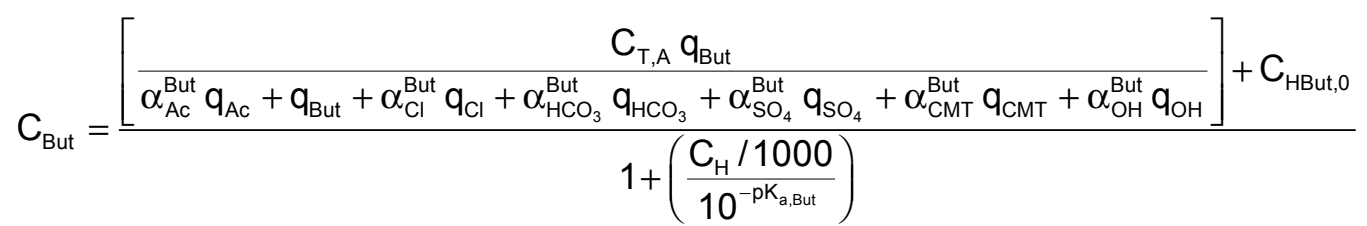

Solve Equation IV-11 for $\mathrm{C}_{\mathrm{OH}}$ :

$$
\mathrm{C}_{\mathrm{OH}}=\frac{10^{-8} \frac{\mathrm{meq}^{2}}{\mathrm{~L}^{2}}}{\mathrm{C}_{\mathrm{H}}}
$$


Substitute Equations IV-1, IV-2, IV-3, IV-14, IV-15, IV-7, IV-8, IV-9, IV-10, and IV-16 into Equation IV-4, which results in the following and eliminates the following 10 unknowns, respectively: $\mathrm{C}_{\mathrm{Na}}, \mathrm{C}_{\mathrm{K}}, \mathrm{C}_{\mathrm{Ca}}, \mathrm{C}_{\mathrm{Ac}}, \mathrm{C}_{\mathrm{But}}, \mathrm{C}_{\mathrm{Cl}}, \mathrm{C}_{\mathrm{HCO}_{3}}, \mathrm{C}_{\mathrm{SO}_{4}}$, $\mathrm{C}_{\mathrm{CMT}}$, and $\mathrm{C}_{\mathrm{OH}}$.

$$
\begin{aligned}
& \frac{C_{T, C} q_{N a}}{q_{N a}+\alpha_{K}^{N a} q_{K}+\alpha_{C a}^{N a} q_{C a}+\alpha_{H}^{N a} q_{H}}+\frac{C_{T, C} q_{K}}{\alpha_{N a}^{K} q_{N a}+q_{K}+\alpha_{C a}^{K} q_{C a}+\alpha_{H}^{K} q_{H}}+ \\
& \frac{\mathrm{C}_{\mathrm{T}, \mathrm{C}} \mathrm{q}_{\mathrm{Ca}}}{\alpha_{\mathrm{Na}}^{\mathrm{Ca}} \mathrm{q}_{\mathrm{Na}}+\alpha_{\mathrm{K}}^{\mathrm{Ca}} \mathrm{q}_{\mathrm{K}}+\mathrm{q}_{\mathrm{Ca}}+\alpha_{\mathrm{H}}^{\mathrm{Ca}} \mathrm{q}_{\mathrm{H}}}+\mathrm{C}_{\mathrm{H}} \\
& =
\end{aligned}
$$

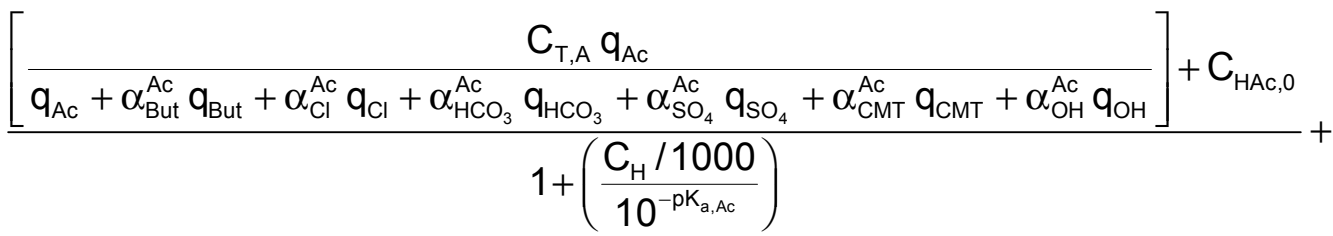

$$
\begin{aligned}
& \frac{\left[\frac{\mathrm{C}_{\mathrm{T}, \mathrm{A}} \mathrm{q}_{\mathrm{But}}}{\alpha_{\mathrm{Ac}}^{\text {But }} \mathrm{q}_{\mathrm{Ac}}+\mathrm{q}_{\mathrm{But}}+\alpha_{\mathrm{Cl}}^{\text {But }} \mathrm{q}_{\mathrm{CI}}+\alpha_{\mathrm{HCO}_{3}}^{\text {But }} \mathrm{q}_{\mathrm{HCO}}+\alpha_{\mathrm{SO}_{4}} \mathrm{q}_{\mathrm{SO}_{4}}+\alpha_{\mathrm{CMT}}^{\text {But }} \mathrm{q}_{\mathrm{CMT}}+\alpha_{\mathrm{OH}}^{\text {But }} \mathrm{q}_{\mathrm{OH}}}\right]+\mathrm{C}_{\mathrm{HBut}, \mathrm{O}}}{1+\left(\frac{\mathrm{C}_{\mathrm{H}} / 1000}{10^{-\mathrm{PK}_{\mathrm{a}, \mathrm{But}}}}\right)}+ \\
& \frac{\mathrm{C}_{\mathrm{T}, \mathrm{A}} \mathrm{q}_{\mathrm{Cl}}}{\alpha_{\mathrm{AC}}^{\mathrm{Cl}} q_{\mathrm{AC}}+\alpha_{\mathrm{But}}^{\mathrm{Cl}} q_{\mathrm{But}}+q_{\mathrm{Cl}}+\alpha_{\mathrm{HCO}_{3}}^{\mathrm{Cl}} q_{\mathrm{HCO}}+\alpha_{\mathrm{SO}_{4}} q_{\mathrm{SO}_{4}}+\alpha_{\mathrm{CMT}}^{\mathrm{Cl}} q_{\mathrm{CMT}}+\alpha_{\mathrm{OH}}^{\mathrm{Cl}} q_{\mathrm{OH}}}+ \\
& \frac{\mathrm{C}_{\mathrm{T}, \mathrm{A}} \mathrm{q}_{\mathrm{HCO}_{3}}}{\alpha_{\mathrm{AC}}^{\mathrm{HCO}_{3}} q_{\mathrm{AC}}+\alpha_{\mathrm{But}}^{\mathrm{HCO}_{3}} q_{\mathrm{But}}+\alpha_{\mathrm{Cl}}^{\mathrm{HCO}_{3}} q_{\mathrm{Cl}}+\mathrm{q}_{\mathrm{HCO}_{3}}+\alpha_{\mathrm{SO}_{4}}^{\mathrm{HCO}_{3}} \mathrm{q}_{\mathrm{SO}_{4}}+\alpha_{\mathrm{CMT}}^{\mathrm{HCO}_{3}} \mathrm{q}_{\mathrm{CMT}}+\alpha_{\mathrm{OH}}^{\mathrm{HCO}_{3}} q_{\mathrm{OH}}}+
\end{aligned}
$$

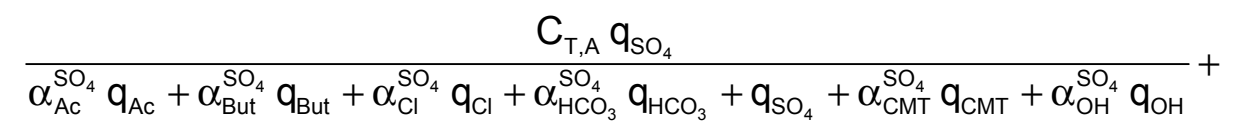

$$
\begin{aligned}
& \frac{\mathrm{C}_{\mathrm{T}, \mathrm{A}} \mathrm{q}_{\mathrm{CMT}}}{\alpha_{\mathrm{AC}}^{\mathrm{CMT}} \mathrm{q}_{\mathrm{Ac}}+\alpha_{\mathrm{But}}^{\mathrm{CMT}} \mathrm{q}_{\mathrm{But}}+\alpha_{\mathrm{Cl}}^{\mathrm{CMT}} \mathrm{q}_{\mathrm{Cl}}+\alpha_{\mathrm{HCO}_{3}}^{\mathrm{CMT}} \mathrm{q}_{\mathrm{HCO}_{3}}+\alpha_{\mathrm{SO}_{4}}^{\mathrm{CMT}} \mathrm{q}_{\mathrm{SO}_{4}}+\mathrm{q}_{\mathrm{CMT}}+\alpha_{\mathrm{OH}}^{\mathrm{CMT}} \mathrm{q}_{\mathrm{OH}}}+ \\
& \frac{10^{-8} \frac{\mathrm{meq}^{2}}{\mathrm{~L}^{2}}}{\mathrm{C}_{\mathrm{H}}}
\end{aligned}
$$

This is a single equation with a single unknown: $\mathrm{C}_{H}$.

\section{Solution Strategy}

The strategy to solve this problem will be to move all terms in Equation IV-17 to one side such that it will be a function equal to zero and then make use of a minimization bounded minimization algorithm to solve it. Rearranging Equation IV-17 in this manner results in the following: 


$$
\begin{aligned}
& \frac{\mathrm{C}_{\mathrm{T}, \mathrm{C}} \mathrm{q}_{\mathrm{Na}}}{\mathrm{q}_{\mathrm{Na}}+\alpha_{\mathrm{K}}^{\mathrm{Na}} \mathrm{q}_{\mathrm{K}}+\alpha_{\mathrm{Ca}}^{N a} \mathrm{q}_{\mathrm{Ca}}+\alpha_{H}^{N a} q_{H}}+\frac{\mathrm{C}_{\mathrm{T}, \mathrm{C}} \mathrm{q}_{\mathrm{K}}}{\alpha_{\mathrm{Na}}^{\mathrm{K}} \mathrm{q}_{\mathrm{Na}}+\mathrm{q}_{\mathrm{K}}+\alpha_{\mathrm{Ca}}^{\mathrm{K}} \mathrm{q}_{\mathrm{Ca}}+\alpha_{\mathrm{H}}^{\mathrm{K}} \mathrm{q}_{\mathrm{H}}}+ \\
& \frac{\mathrm{C}_{\mathrm{T}, \mathrm{C}} \mathrm{q}_{\mathrm{Ca}}}{\alpha_{\mathrm{Na}}^{\mathrm{Ca}} \mathrm{q}_{\mathrm{Na}}+\alpha_{\mathrm{K}}^{\mathrm{Ca}} \mathrm{q}_{\mathrm{K}}+\mathrm{q}_{\mathrm{Ca}}+\alpha_{\mathrm{H}}^{\mathrm{Ca}} \mathrm{q}_{\mathrm{H}}}+\mathrm{C}_{\mathrm{H}}- \\
& \frac{\left[\frac{\mathrm{C}_{\mathrm{T}, \mathrm{A}} \mathrm{q}_{\mathrm{Ac}}}{\mathrm{q}_{\mathrm{Ac}}+\alpha_{\mathrm{But}}^{\mathrm{AC}} \mathrm{q}_{\mathrm{But}}+\alpha_{\mathrm{Cl}}^{\mathrm{Ac}} \mathrm{q}_{\mathrm{Cl}}+\alpha_{\mathrm{HCO}_{3}}^{\mathrm{Ac}} \mathrm{q}_{\mathrm{HCO}_{3}}+\alpha_{\mathrm{SO}_{4}}^{\mathrm{AC}} \mathrm{q}_{\mathrm{SO}_{4}}+\alpha_{\mathrm{CMT}}^{\mathrm{AC}} \mathrm{q}_{\mathrm{CMT}}+\alpha_{\mathrm{OH}}^{\mathrm{Ac}} \mathrm{q}_{\mathrm{OH}}}\right]+\mathrm{C}_{\mathrm{HAc}, 0}}{1+\left(\frac{\mathrm{C}_{\mathrm{H}} / 1000}{10^{-\mathrm{pK}_{\mathrm{a}, \mathrm{Ac}}}}\right)}- \\
& \frac{\left[\frac{\mathrm{C}_{\mathrm{T}, \mathrm{A}} \mathrm{q}_{\mathrm{But}}}{\alpha_{\mathrm{Ac}}^{\text {But }} \mathrm{q}_{\mathrm{Ac}}+\mathrm{q}_{\mathrm{But}}+\alpha_{\mathrm{Cl}}^{\text {But }} \mathrm{q}_{\mathrm{Cl}}+\alpha_{\mathrm{HCO}_{3}}^{\text {But }} \mathrm{q}_{\mathrm{HCO}_{3}}+\alpha_{\mathrm{SO}_{4}}^{\text {But }} \mathrm{q}_{\mathrm{SO}_{4}}+\alpha_{\mathrm{CMT}}^{\text {But }} \mathrm{q}_{\mathrm{CMT}}+\alpha_{\mathrm{OH}}^{\text {But }} \mathrm{q}_{\mathrm{OH}}}\right]+\mathrm{C}_{\mathrm{HBut}, 0}}{1+\left(\frac{\mathrm{C}_{\mathrm{H}} / 1000}{10^{-\mathrm{pK}_{\mathrm{a}, \mathrm{But}}}}\right)}- \\
& \mathrm{C}_{\mathrm{T}, \mathrm{A}} \mathrm{q}_{\mathrm{Cl}} \\
& \overline{\alpha_{\mathrm{Ac}}^{\mathrm{Cl}} q_{\mathrm{AC}}+\alpha_{\mathrm{But}}^{\mathrm{Cl}} q_{\mathrm{But}}+q_{\mathrm{Cl}}+\alpha_{\mathrm{HCO}_{3}}^{\mathrm{Cl}} \mathrm{q}_{\mathrm{HCO}_{3}}+\alpha_{\mathrm{SO}_{4}}^{\mathrm{Cl}} q_{\mathrm{SO}_{4}}+\alpha_{\mathrm{CMT}}^{\mathrm{Cl}} q_{\mathrm{CMT}}+\alpha_{\mathrm{OH}}^{\mathrm{Cl}} q_{\mathrm{OH}}} \\
& \frac{\mathrm{C}_{\mathrm{T}, \mathrm{A}} \mathrm{q}_{\mathrm{HCO}_{3}}}{\alpha_{\mathrm{Ac}}^{\mathrm{HCO}_{3}} q_{\mathrm{Ac}}+\alpha_{\mathrm{But}}^{\mathrm{HCO}_{3}} q_{\mathrm{But}}+\alpha_{\mathrm{Cl}}^{\mathrm{HCO}_{3}} q_{\mathrm{Cl}}+\mathrm{q}_{\mathrm{HCO}_{3}}+\alpha_{\mathrm{SO}_{4}}^{\mathrm{HCO}_{3}} \mathrm{q}_{\mathrm{SO}_{4}}+\alpha_{\mathrm{CMT}}^{\mathrm{HCO}_{3}} q_{\mathrm{CMT}}+\alpha_{\mathrm{OH}}^{\mathrm{HCO}_{3}} q_{\mathrm{OH}}}- \\
& \mathrm{C}_{\mathrm{T}, \mathrm{A}} \mathrm{q}_{\mathrm{SO}_{4}}
\end{aligned}
$$

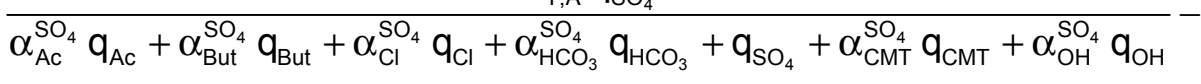

$$
\begin{aligned}
& \frac{\mathrm{C}_{\mathrm{T}, \mathrm{A}} \mathrm{q}_{\mathrm{CMT}}}{\alpha_{\mathrm{Ac}}^{\mathrm{CMT}} \mathrm{q}_{\mathrm{AC}}+\alpha_{\mathrm{But}}^{\mathrm{CMT}} \mathrm{q}_{\mathrm{But}}+\alpha_{\mathrm{Cl}}^{\mathrm{CMT}} \mathrm{q}_{\mathrm{Cl}}+\alpha_{\mathrm{HCO}_{3}}^{\mathrm{CMT}} \mathrm{q}_{\mathrm{HCO}_{3}}+\alpha_{\mathrm{SO}_{4}}^{\mathrm{CMT}} \mathrm{q}_{\mathrm{SO}_{4}}+\mathrm{q}_{\mathrm{CMT}}+\alpha_{\mathrm{OH}}^{\mathrm{CMT}} \mathrm{q}_{\mathrm{OH}}}- \\
& \frac{10^{-8} \frac{\mathrm{meq}^{2}}{\mathrm{~L}^{2}}}{\mathrm{C}_{\mathrm{H}}}=0
\end{aligned}
$$

The IMSL routine DBCLSF is used to solve this equation. The $\mathrm{pH}$ is bounded between 1 and 14. The description of DBCLSF from the manual is: "Solve a nonlinear least squares problem subject to bounds on the variables using a modified Levenberg-Marquardt algorithm and a finite-difference Jacobian."

\section{Initial Guess for $\mathrm{C}_{\mathrm{H}}$}

\section{First Time Step}

For the first time step, an initial guess for $\mathrm{C}_{\mathrm{H}}$ is taken by assuming that no species ionize. In this case, substitute Equation IV-16 into Equation IV-4:

$\mathrm{C}_{\mathrm{Na}}+\mathrm{C}_{\mathrm{K}}+\mathrm{C}_{\mathrm{Ca}}+\mathrm{C}_{\mathrm{H}}=\mathrm{C}_{\mathrm{Ac}}+\mathrm{C}_{\mathrm{But}}+\mathrm{C}_{\mathrm{Cl}}+\mathrm{C}_{\mathrm{HCO}_{3}}+\mathrm{C}_{\mathrm{SO}_{4}}+\mathrm{C}_{\mathrm{CMT}}+\frac{10^{-8} \frac{\mathrm{meq}^{2}}{\mathrm{~L}^{2}}}{\mathrm{C}_{\mathrm{H}}}$

Multiply both sides of Equation IV-19 by $\mathrm{C}_{\mathrm{H}}$ : 


$$
\left(\mathrm{C}_{\mathrm{Na}}+\mathrm{C}_{\mathrm{K}}+\mathrm{C}_{\mathrm{Ca}}\right) \mathrm{C}_{\mathrm{H}}+\mathrm{C}_{\mathrm{H}}^{2}=\left(\mathrm{C}_{\mathrm{AC}}+\mathrm{C}_{\mathrm{But}}+\mathrm{C}_{\mathrm{Cl}}+\mathrm{C}_{\mathrm{HCO}_{3}}+\mathrm{C}_{\mathrm{SO}_{4}}+\mathrm{C}_{\mathrm{CMT}}\right) \mathrm{C}_{\mathrm{H}}+10^{-8} \frac{\mathrm{meq}^{2}}{\mathrm{~L}^{2}}
$$

Rearranging produces an expression that can be solved by the quadratic formula for an initial guess on $\mathrm{C}_{\mathrm{H}}$ :

$$
\mathrm{C}_{\mathrm{H}}^{2}+\left[\left(\mathrm{C}_{\mathrm{Na}}+\mathrm{C}_{\mathrm{K}}+\mathrm{C}_{\mathrm{Ca}}\right)-\left(\mathrm{C}_{\mathrm{AC}}+\mathrm{C}_{\mathrm{But}}+\mathrm{C}_{\mathrm{Cl}}+\mathrm{C}_{\mathrm{HCO}_{3}}+\mathrm{C}_{\mathrm{SO}_{4}}+\mathrm{C}_{\mathrm{CMT}}\right)\right] \mathrm{C}_{\mathrm{H}}-10^{-8} \frac{\mathrm{meq}^{2}}{\mathrm{~L}^{2}}=0
$$

For species that do not ionize, liquid phase concentrations are determined as shown above:

$$
\begin{aligned}
& C_{\mathrm{Na}}=\frac{C_{\mathrm{T}, \mathrm{C}} q_{\mathrm{Na}}}{q_{\mathrm{Na}}+\alpha_{\mathrm{K}}^{\mathrm{Na}} q_{\mathrm{K}}+\alpha_{\mathrm{Ca}}^{\mathrm{Na}} q_{\mathrm{Ca}}+\alpha_{\mathrm{H}}^{\mathrm{Na}} q_{\mathrm{H}}} \\
& C_{K}=\frac{C_{T, C} q_{K}}{\alpha_{N a}^{K} q_{N a}+q_{K}+\alpha_{C a}^{K} q_{C a}+\alpha_{H}^{K} q_{H}} \\
& C_{C a}=\frac{C_{T, C} q_{C a}}{\alpha_{N a}^{C a} q_{N a}+\alpha_{K}^{C a} q_{K}+q_{C a}+\alpha_{H}^{C a} q_{H}} \\
& C_{C l}=\frac{C_{T, A} q_{C l}}{\alpha_{A C}^{C l} q_{A C}+\alpha_{B u t}^{C l} q_{B u t}+q_{C l}+\alpha_{\mathrm{HCO}_{3}}^{C l} q_{\mathrm{HCO}_{3}}+\alpha_{\mathrm{SO}_{4}}^{C l} q_{\mathrm{SO}_{4}}+\alpha_{C M T}^{C l} q_{C M T}+\alpha_{O H}^{C l} q_{\mathrm{OH}}} \\
& \mathrm{C}_{\mathrm{HCO}_{3}}=\frac{\mathrm{C}_{\mathrm{T}, \mathrm{A}} \mathrm{q}_{\mathrm{HCO}_{3}}}{\alpha_{\mathrm{AC}}^{\mathrm{HCO}_{3}} \mathrm{q}_{\mathrm{AC}}+\alpha_{\mathrm{But}}^{\mathrm{HCO}_{3}} q_{\mathrm{But}}+\alpha_{\mathrm{Cl}}^{\mathrm{HCO}_{3}} q_{\mathrm{Cl}}+\mathrm{q}_{\mathrm{HCO}_{3}}+\alpha_{\mathrm{SO}_{4}}^{\mathrm{HCO}_{3}} q_{\mathrm{SO}_{4}}+\alpha_{\mathrm{CMT}}^{\mathrm{HCO}_{3}} q_{\mathrm{CMT}}+\alpha_{\mathrm{OH}}^{\mathrm{HCO}_{3}} q_{\mathrm{OH}}}
\end{aligned}
$$

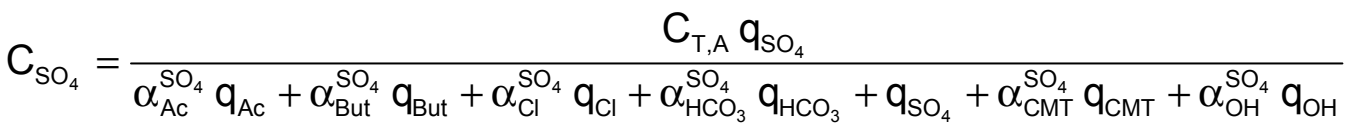

$$
\begin{aligned}
& C_{C M T}=\frac{C_{T, A} q_{C M T}}{\alpha_{A C}^{C M T} q_{A c}+\alpha_{B u t}^{C M T} q_{B u t}+\alpha_{C l}^{C M T} q_{C l}+\alpha_{\mathrm{HCO}_{3}}^{C M T} q_{\mathrm{HCO}_{3}}+\alpha_{\mathrm{SO}_{4}}^{C M T} q_{\mathrm{SO}_{4}}+q_{\mathrm{CMT}}+\alpha_{\mathrm{OH}}^{\mathrm{CMT}} \mathrm{q}_{\mathrm{OH}}}
\end{aligned}
$$

For species that ionize (Ac, But), liquid phase concentrations are determined by assuming that the species do not ionize and are completely present in the ionic form (e.g. $C_{A C}=C_{T, A C}, C_{B u t}=C_{T, B u t}$ ):

$\mathrm{C}_{\mathrm{AC}}=\mathrm{C}_{\mathrm{T}, \mathrm{Ac}}=$

$$
\begin{aligned}
& \frac{\mathrm{C}_{\mathrm{T}, \mathrm{A}} \mathrm{q}_{\mathrm{Ac}}}{\mathrm{q}_{\mathrm{Ac}}+\alpha_{\mathrm{But}}^{\mathrm{AC}} q_{\mathrm{But}}+\alpha_{\mathrm{Cl}}^{\mathrm{AC}} q_{\mathrm{Cl}}+\alpha_{\mathrm{HCO}_{3}}^{A C} q_{\mathrm{HCO}_{3}}+\alpha_{\mathrm{SO}_{4}}^{A c} q_{\mathrm{SO}_{4}}+\alpha_{\mathrm{CMT}}^{\mathrm{AC}} q_{\mathrm{CMT}}+\alpha_{\mathrm{OH}}^{A C} q_{\mathrm{OH}}}+C_{\mathrm{HAc}, 0} \\
& \mathrm{C}_{\text {But }}=\mathrm{C}_{\mathrm{T}, \mathrm{But}}= \\
& \frac{\mathrm{C}_{\mathrm{T}, \mathrm{A}} \mathrm{q}_{\mathrm{But}}}{\alpha_{\mathrm{Ac}}^{\text {But }} q_{\mathrm{Ac}}+q_{\mathrm{But}}+\alpha_{\mathrm{Cl}}^{\text {But }} q_{\mathrm{Cl}}+\alpha_{\mathrm{HCO}_{3}}^{\text {But }} q_{\mathrm{HCO}_{3}}+\alpha_{\mathrm{SO}_{4}}^{\text {But }} q_{\mathrm{SO}_{4}}+\alpha_{\mathrm{CMT}}^{\text {But }} \mathrm{q}_{\mathrm{CMT}}+\alpha_{\mathrm{OH}}^{\text {But }} q_{\mathrm{OH}}}+C_{\mathrm{HBut}, 0}
\end{aligned}
$$


Equations IV-22 through IV-30 are substituted into Equation IV-21 and Equation IV-21 is solved for $C_{H}$ via the quadratic formula. This $C_{H}$ value is used as an initial guess for the solution of Equation IV-18 at the first time step.

\section{Time Steps Subsequent to the Initial Time Step}

The $C_{H}$ value from the previous time step is used as an initial guess for the solution at the current time step.

\section{Generalized Case}

For each cation $i$ that does not ionize ( $\mathrm{pK}_{\mathrm{a}, \mathrm{i}}$ is very small) except the presaturant, $\mathrm{H}(\mathrm{i} \neq$ presaturant $)$ :

$$
C_{i}=\frac{C_{T, C} q_{i}}{\sum_{k=1}^{\text {NCATINN }} \alpha_{k}^{i} q_{k}}
$$

For each cation $i$ that ionizes $\left(\mathrm{pK}_{\mathrm{a}, \mathrm{i}}\right.$ is significant-Note that $i$ represents the unionized form of the species, which is not protonated):

$$
\begin{gathered}
C_{T, i}=\left[\frac{C_{T, C} q_{i H^{+}}}{\sum_{k=1}^{\text {NCATION }} \alpha_{k}^{i H} q_{k}}\right]+C_{i, 0} \\
C_{i H^{+}}=\frac{C_{T, i}}{1+\left(\frac{10^{-p K_{a, i}}}{C_{H} / 1000}\right)}
\end{gathered}
$$

Substituting Equation IV-32 into Equation IV-33:

$$
C_{i H^{+}}=\frac{\left[\frac{C_{T, C} q_{i H^{+}}}{\sum_{k=1}^{\text {NCATION }} \alpha_{k}^{i H} q_{k}}\right]+C_{i, 0}}{1+\left(\frac{10^{-p K_{a, i}}}{C_{H} / 1000}\right)}
$$

For each anion $\mathrm{j}$ that does not ionize $\left(\mathrm{pK}_{\mathrm{a}, \mathrm{j}}\right.$ is very small) except the presaturant, $\mathrm{OH}(\mathrm{j} \neq$ presaturant $)$ : 


$$
C_{j}=\frac{C_{T, A} q_{j}}{\sum_{k=1}^{\text {NANON }} \alpha_{k}^{j} q_{k}}
$$

For each anion $\mathrm{j}$ that ionizes $\left(\mathrm{pK}_{\mathrm{a}, \mathrm{j}}\right.$ is significant-Note that $\mathrm{j}$ represents the ionized form of the species, which is not protonated):

$$
\begin{gathered}
C_{T, j}=\left[\frac{C_{T, A} q_{j}}{\sum_{k=1}^{\text {NANION }} \alpha_{k}^{j} q_{k}}\right]+C_{H i, 0} \\
C_{j}=\frac{C_{T, j}}{1+\left(\frac{C_{H} / 1000}{10^{-p K_{a, j}}}\right)}
\end{gathered}
$$

Substituting Equation IV-36 into Equation IV-37:

$$
C_{j}=\frac{\left[\sum_{k=1}^{\frac{C_{T, A} q_{j}}{\text { NANION }} \alpha_{k}^{j} q_{k}}\right]+C_{H, j, 0}}{1+\left(\frac{C_{H} / 1000}{10^{-p K_{a, j}}}\right)}
$$

The charge balance for the generalized case is written as:

$$
\sum_{i=1}^{\text {NCATION }} C_{i}=\sum_{j=1}^{\text {NANION }} C_{j}
$$

For this equilibrium algorithm to function properly, hydrogen $(H)$ and hydroxide $(\mathrm{OH})$ must be present in the system. For this situation, Equation IV-39 can be rewritten as:

$$
\left(\sum_{\substack{i=1 \\ i \neq H}}^{\text {NCATION-1 }} C_{i}\right)+C_{H}=\left(\sum_{\substack{j=1 \\ j \neq O H}}^{N A N I O N-1} C_{j}\right)+C_{O H}
$$

The water formation is written as:

$$
\mathrm{C}_{\mathrm{H}} \times \mathrm{C}_{\mathrm{OH}}=10^{-8} \frac{\mathrm{meq}^{2}}{\mathrm{~L}^{2}}
$$

Solving Equation IV-41 for $\mathrm{C}_{\mathrm{OH}}$ results in: 


$$
\mathrm{C}_{\mathrm{OH}}=\frac{10^{-8} \frac{\mathrm{meq}^{2}}{L^{2}}}{\mathrm{C}_{\mathrm{H}}}
$$

The number of equations to be solved, NEQN, listed above for the generalized case, is:

$\mathrm{NEQN}=$

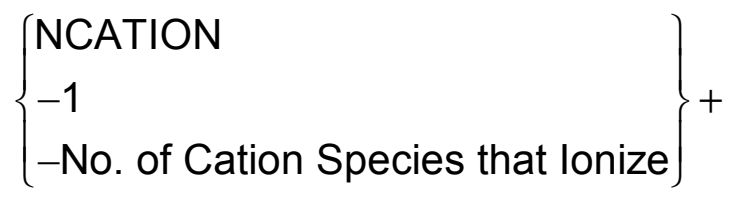

$\{$ No. of Cation Species that lonize $\times 2\}+$

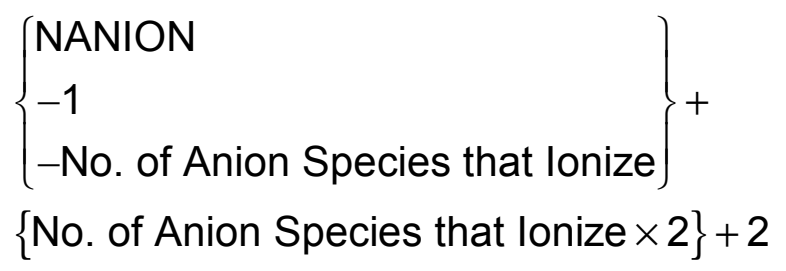

Unknowns: $\mathrm{C}_{\mathrm{Na}}, \mathrm{C}_{\mathrm{K}}, \mathrm{C}_{\mathrm{Ca}}, \mathrm{C}_{\mathrm{H}}, \mathrm{C}_{\mathrm{Ac}}, \mathrm{C}_{\mathrm{But}}, \mathrm{C}_{\mathrm{Cl}}, \mathrm{C}_{\mathrm{HCO}_{3}}, \mathrm{C}_{\mathrm{SO}_{4}}, \mathrm{C}_{\mathrm{CMT}}, \mathrm{C}_{\mathrm{OH}}, \mathrm{C}_{\mathrm{T}, \mathrm{Ac}}, \mathrm{C}_{\mathrm{T}, \mathrm{But}}$

For cation species that do not ionize other than hydrogen, $\mathrm{H}: \mathrm{C}_{\mathrm{i}}$

For cation species that ionize: $\mathrm{C}_{\mathrm{iH}}, \mathrm{C}_{\mathrm{T}, \mathrm{i}}$

$\mathrm{C}_{\mathrm{H}}$

For anion species that do not ionize other than hydroxide, $\mathrm{OH}: \mathrm{C}_{\mathrm{j}}$

For anion species that ionize: $C_{j}, C_{T, j}$

$\mathrm{C}_{\mathrm{OH}}$

Knowns: All q values and $\alpha$ values; $\mathrm{C}_{\mathrm{T}, \mathrm{C}}, \mathrm{C}_{\mathrm{T}, \mathrm{A}}$; all $\mathrm{pK}_{\mathrm{a}}$ values; $\mathrm{C}_{\mathrm{i}, 0}, \mathrm{C}_{\mathrm{H}, \mathrm{O}}$

NEQN Equations, NEQN Unknowns

\section{Simplification of Equations}

This can be reduced to one equation in one unknown $\left(\mathrm{C}_{H}\right)$ in an analogous fashion as for the MTU Ersatz example shown above by making several substitutions into the charge balance. For cations other than hydrogen, $\mathrm{H}$, substitute Equations IV-31 and IV-34 into the charge balance Equation IV-40: 


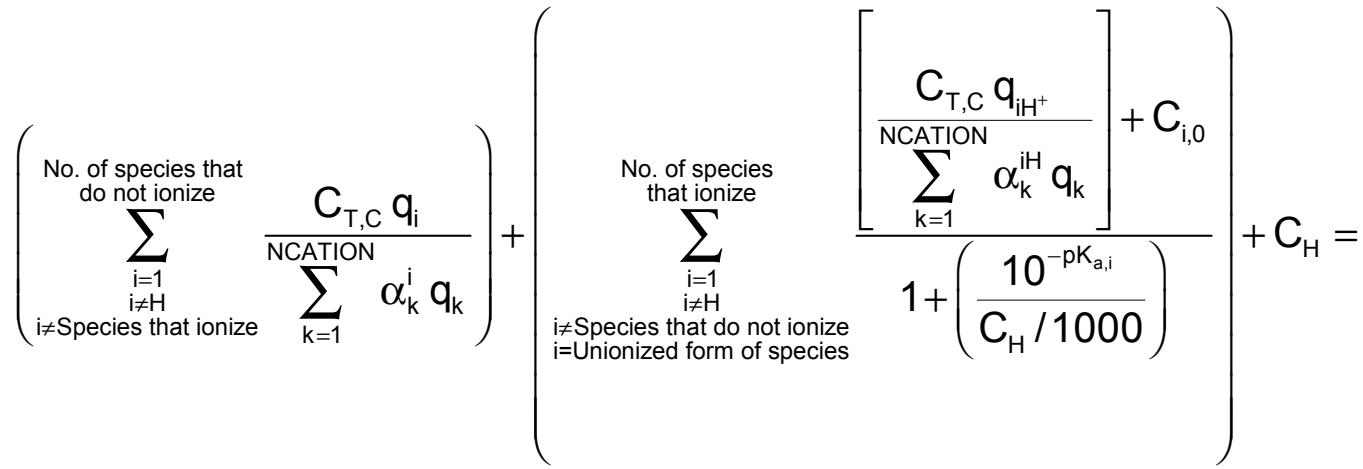

$$
\begin{aligned}
& \left(\sum_{\substack{j=1 \\
j \neq \mathrm{OH}}}^{\text {NANION-1 }} \mathrm{C}_{\mathrm{j}}\right)+\mathrm{C}_{\mathrm{OH}}
\end{aligned}
$$

For anions other than hydroxide, $\mathrm{OH}$, substitute Equations IV-35 and IV-38 into the charge balance Equation IV-44:

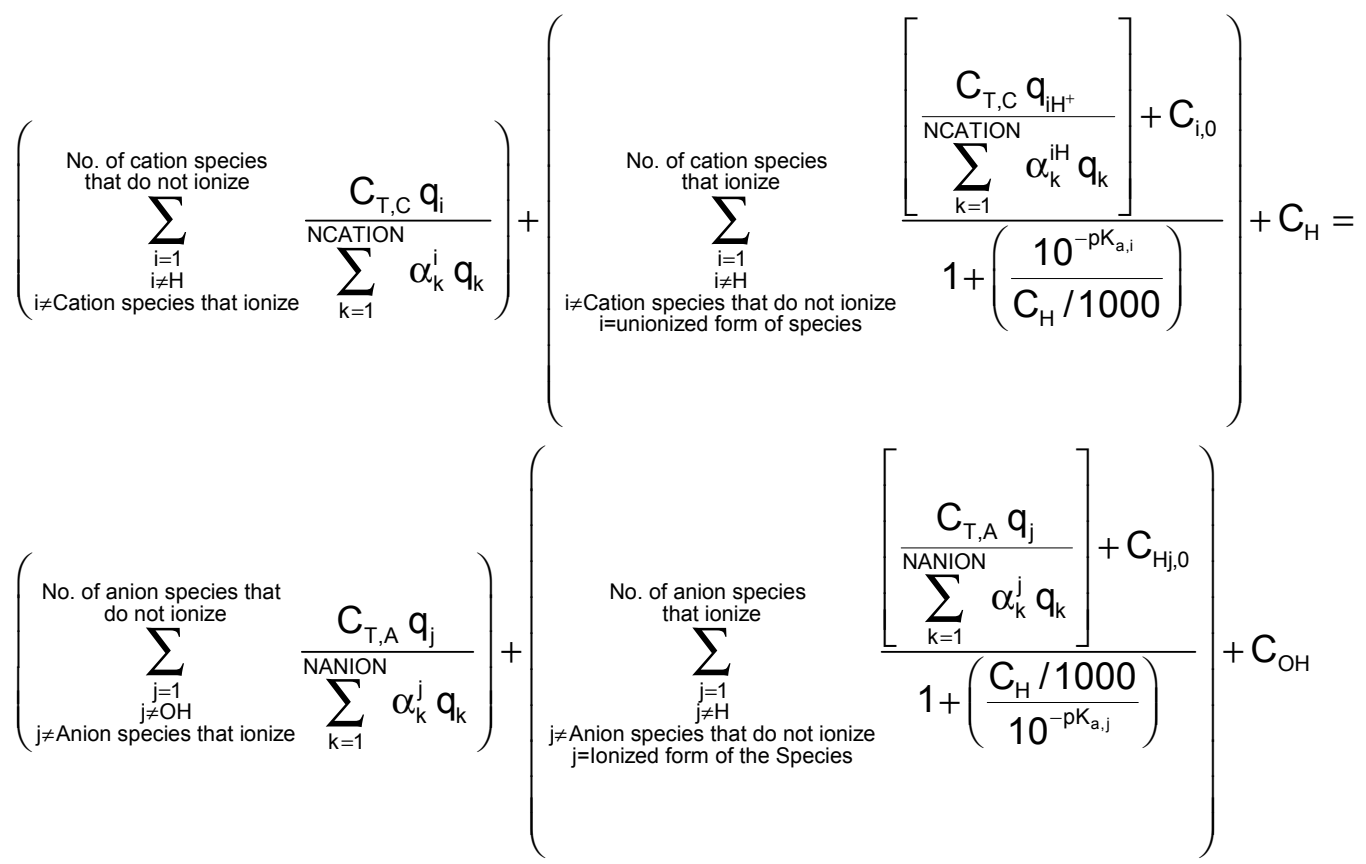


Substitute Equation IV-42 into Equation IV-45:

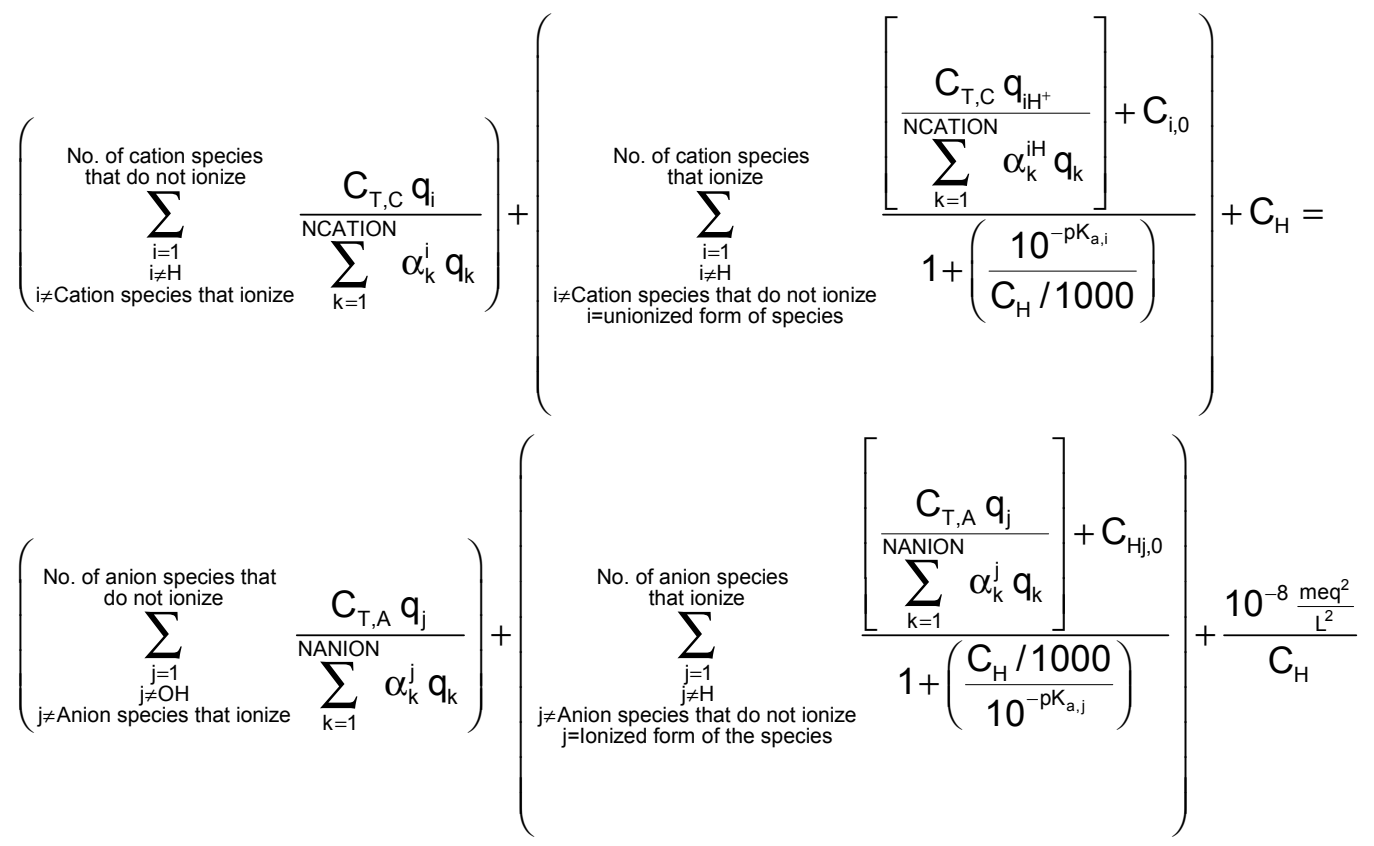

\section{Solution Strategy}

The strategy to solve this problem will be to move all terms in Equation IV-46 to one side such that it will be a function equal to zero and then make use of a minimization bounded minimization algorithm to solve it. Rearranging Equation IV-46 in this manner results in the following:

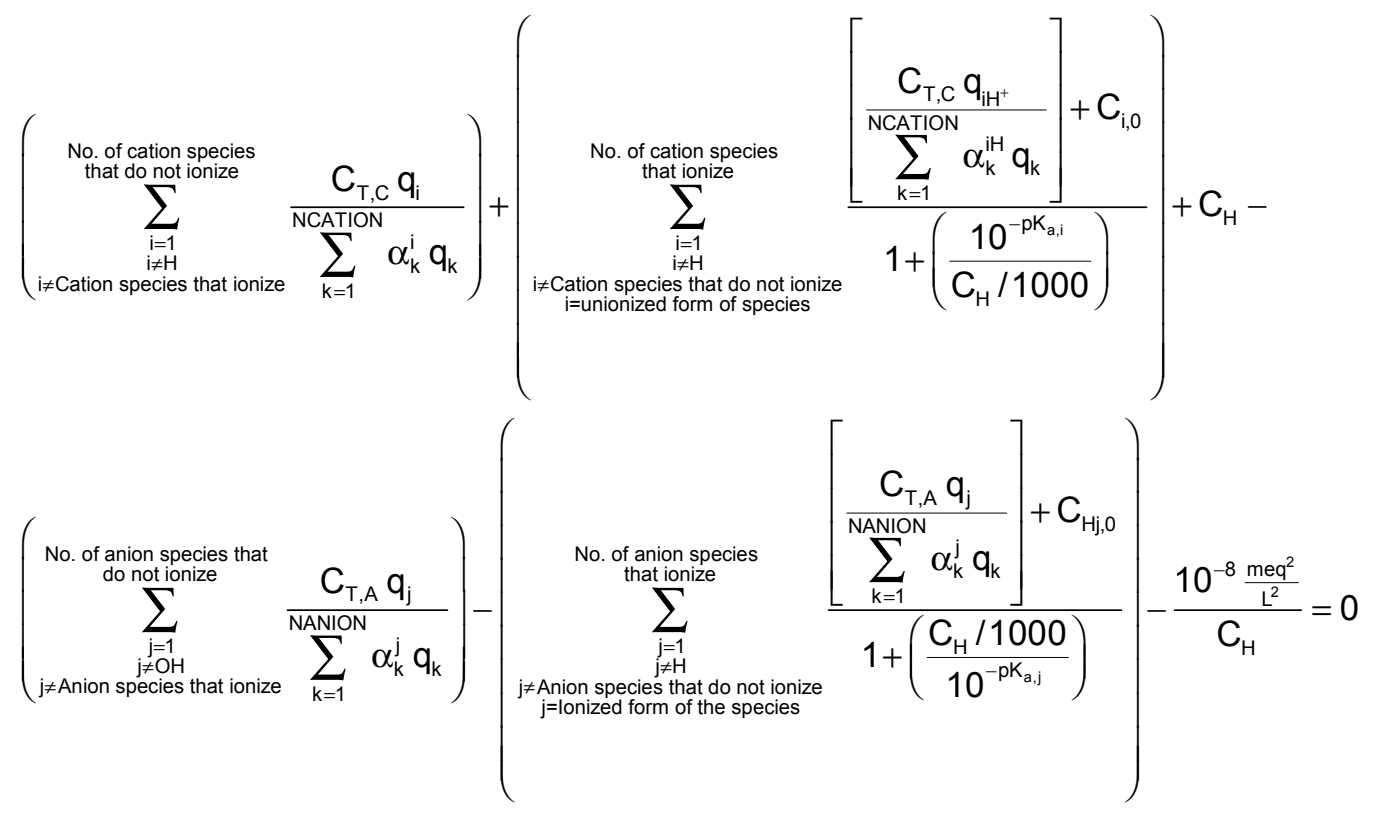

(IV-47) 
The IMSL routine DBCLSF is used to solve this equation. The $\mathrm{pH}$ is bounded between 1 and 14. The description of DBCLSF from the manual is: "Solve a nonlinear least squares problem subject to bounds on the variables using a modified Levenberg-Marquardt algorithm and a finite-difference Jacobian."

\section{Equilibrium Expression for Weak Base Anion (WBA) Exchange Resin Example Case: MTU Ersatz (4 cations, 7 anions)}

This example applies to the solution of Mixed Bed ion exchange equilibrium for the MTU Ersatz case, which includes 4 cations and 7 anions. The cations included are sodium $(\mathrm{Na})$, potassium $(\mathrm{K})$, calcium $(\mathrm{Ca})$ and hydrogen $(\mathrm{H})$. The anions included are acetate (Ac), butyrate (But), chloride $(\mathrm{Cl})$, bicarbonate (HCO3, sulfate (SO4), N-methyl-N-“coconut oil acid" taurate (CMT), and hydroxide $(\mathrm{OH})$. This development assumes that acetate (Ac) and butyrate (But) are the only species that ionize.

$$
\begin{aligned}
& \mathrm{C}_{\mathrm{Na}}+\mathrm{C}_{\mathrm{K}}+\mathrm{C}_{\mathrm{Ca}}+\mathrm{C}_{\mathrm{H}}=\mathrm{C}_{\mathrm{Ac}}+\mathrm{C}_{\mathrm{But}}+\mathrm{C}_{\mathrm{Cl}}+\mathrm{C}_{\mathrm{HCO}_{3}}+\mathrm{C}_{\mathrm{SO}_{4}}+\mathrm{C}_{\mathrm{CMT}}+\mathrm{C}_{\mathrm{OH}} \\
& \mathrm{C}_{\mathrm{T}, \mathrm{Ac}}=\mathrm{C}_{\mathrm{Ac}, \text { equil }}+\mathrm{C}_{\mathrm{HAc}, 0} \\
& \mathrm{C}_{\mathrm{T}, \mathrm{But}}=\mathrm{C}_{\text {But,equil }}+\mathrm{C}_{\mathrm{HBut}, 0} \\
& \mathrm{C}_{\mathrm{H}} \times \mathrm{C}_{\mathrm{OH}}=10^{-8} \frac{\mathrm{meq}^{2}}{\mathrm{~L}^{2}} \\
& C_{A c}=\frac{C_{T, A c}}{1+\left(\frac{C_{H} / 1000}{10^{-p K_{a, A c}}}\right)} \\
& C_{\text {But }}=\frac{C_{\mathrm{T}, \text { But }}}{1+\left(\frac{\mathrm{C}_{\mathrm{H}} / 1000}{10^{-\mathrm{pK}_{\mathrm{a} \text {, But }}}}\right)}
\end{aligned}
$$

in which $\mathrm{C}_{\mathrm{Ac} \text {,equil }}$ equals the liquid phase acetate concentration in equilibrium with the amount of acetate present in the resin phase and $\mathrm{C}_{\text {But,equil }}$ equals the liquid phase butyrate concentration in equilibrium with the amount of butyrate present in the resin phase.

Unknowns: $\mathrm{C}_{\mathrm{H}}, \mathrm{C}_{\mathrm{OH}}, \mathrm{C}_{\mathrm{Ac}}, \mathrm{C}_{\mathrm{But}}, \mathrm{C}_{\mathrm{T}, \mathrm{Ac}}, \mathrm{C}_{\mathrm{T}, \mathrm{But}}$ 
Knowns: $\mathrm{C}_{\mathrm{Na}}, \mathrm{C}_{\mathrm{K}}, \mathrm{C}_{\mathrm{Ca}}, \mathrm{C}_{\mathrm{Cl}_{1}}, \mathrm{C}_{\mathrm{HCO}_{3}}, \mathrm{C}_{\mathrm{SO}_{4}}, \mathrm{C}_{\mathrm{CMT}}$ All $\alpha$ values; $\mathrm{C}_{\mathrm{T}, \mathrm{C}}, \mathrm{C}_{\mathrm{T}, \mathrm{A}}$; all $\mathrm{pK} \mathrm{a}_{\mathrm{a}}$ values; $\mathrm{C}_{\mathrm{HAc}, 0}, \mathrm{C}_{\mathrm{HBut}, 0}, \mathrm{C}_{\mathrm{Ac}, \text { equil }}, \mathrm{C}_{\mathrm{But}, \text { equil }}$

6 Equations, 6 Unknowns

\section{Simplification of Equations}

It is possible to simplify the system of equations above to a system of 1 equation with 1 unknown as follows. Substitute Equation IV-49 into Equation IV-52, which results in the following and eliminates the $C_{T, A c}$ unknown.

$$
C_{A c}=\frac{C_{A c, e q u i}+C_{H A c, 0}}{1+\left(\frac{C_{H} / 1000}{10^{-p K_{a, A c}}}\right)}
$$

Substitute Equation IV-50 into Equation IV-53, which results in the following and eliminates the $\mathrm{C}_{\mathrm{T}, \mathrm{But}}$ unknown.

$$
C_{\text {But }}=\frac{C_{\text {But,equil }}+C_{\text {HBut }, 0}}{1+\left(\frac{C_{H} / 1000}{10^{-p K_{a, b u t}}}\right)}
$$

Solve Equation IV-51 for $\mathrm{C}_{\mathrm{OH}}$ :

$$
\mathrm{C}_{\mathrm{OH}}=\frac{10^{-8} \frac{\mathrm{meq}^{2}}{L^{2}}}{\mathrm{C}_{\mathrm{H}}}
$$

Substitute Equations IV-54, IV-55, and IV-56 into Equation IV-48, which results in the following and eliminates the following 3 unknowns, respectively: $C_{A c}, C_{B u t}$, and $\mathrm{C}_{\mathrm{OH}}$.

$$
\begin{aligned}
& \mathrm{C}_{\mathrm{Na}}+\mathrm{C}_{\mathrm{K}}+\mathrm{C}_{\mathrm{Ca}}+\mathrm{C}_{\mathrm{H}}= \\
& \frac{\mathrm{C}_{\mathrm{Ac}, \text { equil }}+\mathrm{C}_{\mathrm{HAc}, 0},}{1+\left(\frac{\mathrm{C}_{\mathrm{H}} / 1000}{10^{-\mathrm{pK}_{\mathrm{a}, \mathrm{Ac}}}}\right)}+\frac{\mathrm{C}_{\mathrm{But}, \text { equil }}+\mathrm{C}_{\mathrm{HBut}, 0}}{1+\left(\frac{\mathrm{C}_{\mathrm{H}} / 1000}{10^{-\mathrm{pK}_{\mathrm{a}, \mathrm{But}}}}\right)}+\mathrm{C}_{\mathrm{Cl}}+\mathrm{C}_{\mathrm{HCO}_{3}}+\mathrm{C}_{\mathrm{SO}_{4}}+\mathrm{C}_{\mathrm{CMT}}+\frac{10^{-8} \frac{\mathrm{meq}^{2}}{\mathrm{~L}^{2}}}{\mathrm{C}_{\mathrm{H}}}
\end{aligned}
$$

This is a single equation with a single unknown: $C_{H}$. 


\section{Solution Strategy}

The strategy to solve this problem will be to move all terms in Equation IV-57 to one side such that it will be a function equal to zero and then make use of a minimization bounded minimization algorithm to solve it. Rearranging Equation IV-57 in this manner results in the following:

$$
\begin{aligned}
& \mathrm{C}_{\mathrm{Na}}+\mathrm{C}_{\mathrm{K}}+\mathrm{C}_{\mathrm{Ca}}+\mathrm{C}_{\mathrm{H}}- \\
& \frac{\mathrm{C}_{\mathrm{Ac}, \text { equil }}+\mathrm{C}_{\mathrm{HAc}, 0}}{1+\left(\frac{\mathrm{C}_{\mathrm{H}} / 1000}{10^{-\mathrm{pK} \mathrm{K}_{\mathrm{a}, \mathrm{C}}}}\right)}-\frac{\mathrm{C}_{\text {But,equil }}+\mathrm{C}_{\mathrm{HBut}, 0}}{1+\left(\frac{\mathrm{C}_{\mathrm{H}} / 1000}{10^{-\mathrm{pK}_{\mathrm{a}, \mathrm{But}}}}\right)}-\mathrm{C}_{\mathrm{Cl}}-\mathrm{C}_{\mathrm{HCO}_{3}}-\mathrm{C}_{\mathrm{SO}_{4}}-\mathrm{C}_{\mathrm{CMT}}-\frac{10^{-8} \frac{\mathrm{meq}^{2}}{\mathrm{~L}^{2}}}{\mathrm{C}_{\mathrm{H}}}=0
\end{aligned}
$$

The IMSL routine DBCLSF is used to solve this equation. The $\mathrm{pH}$ is bounded between 1 and 14. The description of DBCLSF from the manual is: "Solve a nonlinear least squares problem subject to bounds on the variables using a modified Levenberg-Marquardt algorithm and a finite-difference Jacobian."

\section{Initial Guess for $\mathrm{C}_{\mathrm{H}}$}

First Time Step

For the first time step, an initial guess for $\mathrm{C}_{\mathrm{H}}$ is taken by assuming that no species ionize. In this case, substitute Equation IV-56 into Equation IV-48:

$$
\mathrm{C}_{\mathrm{Na}}+\mathrm{C}_{\mathrm{K}}+\mathrm{C}_{\mathrm{Ca}}+\mathrm{C}_{\mathrm{H}}=\mathrm{C}_{\mathrm{AC}}+\mathrm{C}_{\mathrm{But}}+\mathrm{C}_{\mathrm{Cl}}+\mathrm{C}_{\mathrm{HCO}_{3}}+\mathrm{C}_{\mathrm{SO}_{4}}+\mathrm{C}_{\mathrm{CMT}}+\frac{10^{-8} \frac{\mathrm{meq}^{2}}{\mathrm{~L}^{2}}}{\mathrm{C}_{\mathrm{H}}}
$$

Multiply both sides of Equation IV-59 by $\mathrm{C}_{\mathrm{H}}$ :

$$
\left(\mathrm{C}_{\mathrm{Na}}+\mathrm{C}_{\mathrm{K}}+\mathrm{C}_{\mathrm{Ca}}\right) \mathrm{C}_{\mathrm{H}}+\mathrm{C}_{\mathrm{H}}^{2}=\left(\mathrm{C}_{\mathrm{AC}}+\mathrm{C}_{\mathrm{But}}+\mathrm{C}_{\mathrm{Cl}}+\mathrm{C}_{\mathrm{HCO}_{3}}+\mathrm{C}_{\mathrm{SO}_{4}}+\mathrm{C}_{\mathrm{CMT}}\right) \mathrm{C}_{\mathrm{H}}+10^{-8} \frac{\mathrm{meq}^{2}}{\mathrm{~L}^{2}}
$$

Rearranging produces an expression that can be solved by the quadratic formula for an initial guess on $\mathrm{C}_{\mathrm{H}}$ :

$$
\mathrm{C}_{\mathrm{H}}^{2}+\left[\left(\mathrm{C}_{\mathrm{Na}}+\mathrm{C}_{\mathrm{K}}+\mathrm{C}_{\mathrm{Ca}}\right)-\left(\mathrm{C}_{\mathrm{Ac}}+\mathrm{C}_{\mathrm{But}}+\mathrm{C}_{\mathrm{Cl}}+\mathrm{C}_{\mathrm{HCO}_{3}}+\mathrm{C}_{\mathrm{SO}_{4}}+\mathrm{C}_{\mathrm{CMT}}\right)\right] \mathrm{C}_{\mathrm{H}}-10^{-8} \frac{\mathrm{meq}^{2}}{\mathrm{~L}^{2}}=0
$$

For species that do not ionize, liquid phase concentrations are known (equal to the liquid phase concentration of each ion in equilibrium with the amount of the ion present in the resin phase). For species that ionize (Ac, But), liquid phase concentrations are determined by assuming that the species do not ionize and are completely present in the ionic form (e.g. $C_{A C}=C_{T, A C}, C_{B u t}=C_{T, B u t}$ ):

$$
\mathrm{C}_{\mathrm{AC}}=\mathrm{C}_{\mathrm{T}, \mathrm{Ac}}=\mathrm{C}_{\mathrm{Ac}, \text { equil }}+\mathrm{C}_{\mathrm{HAc}, 0}
$$




$$
\mathrm{C}_{\text {But }}=\mathrm{C}_{\mathrm{T}, \text { But }}=\mathrm{C}_{\text {But,equil }}+\mathrm{C}_{\mathrm{HBut}, 0}
$$

Equations IV-62 and IV-63 are substituted into Equation IV-61 and Equation IV-61 is solved for $C_{H}$ via the quadratic formula. This $C_{H}$ value is used as an initial guess for the solution of Equation IV-58 at the first time step.

\section{Time Steps Subsequent to the Initial Time Step}

For time steps other than the initial time step, the $\mathrm{C}_{\mathrm{H}}$ value from the previous time step is used as an initial guess for the solution at the current time step.

\section{Appendix IV.A - Nomenclature}

$\mathrm{C}_{\mathrm{HAC}, 0}$

Amount of acetic acid present initially, equal to $\mathrm{C}_{\mathrm{H}, 0} \times \mathrm{C}_{\mathrm{Ac}, 0} / \mathrm{K}_{\mathrm{a}, \mathrm{Ac}}$

$\mathrm{C}_{\mathrm{HBut}, 0}$

Amount of butyric acid present initially, equal to $\mathrm{C}_{\mathrm{H}, 0} \times \mathrm{C}_{\mathrm{But}, 0} / \mathrm{K}_{\mathrm{a}, \mathrm{But}}$

\section{Appendix IV.B - Equilibrium Expression for Weak Organic Acids and} Bases (e.g. acetate, butyrate, triethanolamine, ammonium)

Equilibrium Expression for Anionic Species that lonize (e.g. Acetate and Butyrate)

In Clancey (1995), the following general equation is provided for anion

species that ionize:

$$
\left[\mathrm{A}^{-}\right]=\frac{\left[\mathrm{C}_{\mathrm{T}, \mathrm{A}}\right]}{1+\frac{\left[\mathrm{H}^{+}\right]}{\mathrm{K}_{\mathrm{a}}}}
$$

The derivation of Equation IV-64 is provided below.

$$
\begin{aligned}
& {\left[\mathrm{C}_{\mathrm{T}, \mathrm{A}}\right]=\left[\mathrm{A}^{-}\right]+[\mathrm{HA}]} \\
& \mathrm{HA} \stackrel{\mathrm{K}_{\mathrm{a}}}{\longleftrightarrow} \mathrm{H}^{+}+\mathrm{A}^{-} \\
& \mathrm{K}_{\mathrm{a}}=\frac{\left[\mathrm{H}^{+}\right]\left[\mathrm{A}^{-}\right]}{[\mathrm{HA}]}
\end{aligned}
$$

Solve Equation IV-65 for [HA]:

$$
[\mathrm{HA}]=\left[\mathrm{C}_{\mathrm{T}, \mathrm{A}}\right]-\left[\mathrm{A}^{-}\right]
$$


Substitute Equation IV-65 into Equation IV-67 and then solve for $\left[A^{-}\right]$and the derivation agrees with the result shown in Equation IV-64:

$$
\begin{gathered}
\mathrm{K}_{\mathrm{a}}=\frac{\left[\mathrm{H}^{+}\right]\left[\mathrm{A}^{-}\right]}{\left[\mathrm{C}_{\mathrm{T}, \mathrm{A}}\right]-\left[\mathrm{A}^{-}\right]} \\
{\left[\mathrm{A}^{-}\right]=\frac{\left[\mathrm{C}_{\mathrm{T}, \mathrm{A}}\right]}{1+\frac{\left[\mathrm{H}^{+}\right]}{\mathrm{K}_{\mathrm{a}}}}}
\end{gathered}
$$

\section{Equilibrium Expression for Cationic Species that lonize (e.g.} Ammonium and Triethanolamine)

Let $B$ refer to the species in the unionized form (e.g. ammonia). In this case, in contrast to above for weak organic acids, the acid is the ionized species $\left(\left[\mathrm{BH}^{+}\right]\right)$.

$$
\begin{gathered}
{\left[\mathrm{C}_{\mathrm{T}, \mathrm{B}}\right]=\left[\mathrm{BH}^{+}\right]+[\mathrm{B}]} \\
\mathrm{BH}^{+} \stackrel{\mathrm{K}_{\mathrm{a}}}{\longrightarrow \mathrm{B}+\mathrm{H}^{+}} \\
\mathrm{K}_{\mathrm{a}}=\frac{[\mathrm{B}]\left[\mathrm{H}^{+}\right]}{\left[\mathrm{BH}^{+}\right]}
\end{gathered}
$$

Solve Equation IV-71 for the unionized form, [B]:

$$
[\mathrm{B}]=\left[\mathrm{C}_{\mathrm{T}, \mathrm{B}}\right]-\left[\mathrm{BH}^{+}\right]
$$

Substitute Equation IV-74 into Equation IV-73 and then solve for $\left[\mathrm{BH}^{+}\right]$:

$$
\begin{gathered}
\mathrm{K}_{\mathrm{a}}=\frac{\left\{\left[\mathrm{C}_{\mathrm{T}, \mathrm{B}}\right]-\left[\mathrm{BH}^{+}\right]\right\}\left[\mathrm{H}^{+}\right]}{\left[\mathrm{BH}^{+}\right]} \\
{\left[\mathrm{BH}^{+}\right]=\frac{\left[\mathrm{C}_{\mathrm{T}, \mathrm{B}}\right]}{1+\frac{\mathrm{K}_{\mathrm{a}}}{\left[\mathrm{H}^{+}\right]}}}
\end{gathered}
$$

In this case B represents the non-ionized form of the species, such as ammonia, $\mathrm{NH}_{3}$. And $\left[\mathrm{BH}^{+}\right]$represents the acid form which is ionized, $\mathrm{NH}_{4}^{+}$. 


\section{Appendix V - Algorithm for Determining SAC and SBA properties within a Mixed Bed Ion Exchange Resin}

\section{Background Information: Physical Properties of a Mixed Bed Resin}

\begin{tabular}{|c|c|c|}
\hline $\begin{array}{c}\text { Cationic } \\
\text { Exchange } \\
\text { Resin }\end{array}$ & $\begin{array}{c}\text { Anionic } \\
\text { Exchange } \\
\text { Resin }\end{array}$ & $\begin{array}{c}\text { Void } \\
\text { Space }\end{array}$ \\
C & A & $\varepsilon$ \\
\hline
\end{tabular}

The volume of the bed is given as:

$$
\mathrm{V}_{\mathrm{B}}=\mathrm{V}_{\mathrm{C}}+\mathrm{V}_{\mathrm{A}}+\mathrm{V}_{\varepsilon}
$$

The volume of the resin within the bed is given as:

$$
\begin{gathered}
V_{r}=V_{C}+V_{A}=V_{B}-V_{\varepsilon}=V_{B}\left(1-\frac{V_{\varepsilon}}{V_{B}}\right)=V_{B}(1-\varepsilon) \\
\text { Note: } \varepsilon=\text { Porosity }=\frac{\text { Volume of Voids }}{\text { Volume of Bed }}=\frac{V_{\varepsilon}}{V_{B}}
\end{gathered}
$$

The bulk density of the cationic exchange resin can be calculated as:

$$
\begin{aligned}
\rho_{B, C} & =\frac{m_{C}}{V_{B}}=\frac{\frac{m_{C}}{V_{C}}}{\frac{V_{B}}{V_{C}}}=\rho_{A, C}\left(\frac{V_{C}}{V_{B}}\right)=\rho_{A, C}\left(\frac{V_{B}-V_{\varepsilon}-V_{A}}{V_{B}}\right)=\rho_{A, C}\left(1-\frac{V_{\varepsilon}}{V_{B}}-\frac{V_{A}}{V_{B}}\right)= \\
& =\rho_{A, C}\left(1-\varepsilon-\frac{V_{A}}{V_{B}}\right)=\rho_{A, C}\left(1-\varepsilon-\frac{V_{r}\left(\frac{V_{A}}{V_{r}}\right)}{V_{B}}\right)=\rho_{A, C}\left(1-\varepsilon-\frac{V_{B}(1-\varepsilon)\left(\frac{V_{A}}{V_{r}}\right)}{V_{B}}\right)= \\
& =\rho_{A, C}\left[(1-\varepsilon)-(1-\varepsilon)\left(\frac{V_{A}}{V_{r}}\right)\right]=\rho_{A, C}(1-\varepsilon)\left[1-\left(\frac{V_{A}}{V_{r}}\right)\right] \\
& =\rho_{A, C}(1-\varepsilon)\left(\frac{V_{C}}{V_{r}}\right)
\end{aligned}
$$

The bulk density of the anionic exchange resin can be calculated in the same fashion. The final result is presented below:

$$
\rho_{B, A}=\frac{m_{A}}{V_{B}}=\rho_{A, A}(1-\varepsilon)\left(\frac{V_{A}}{V_{r}}\right)
$$




\section{Algorithm for Adjusting Cations and Anions in Mixed Bed Resin}

User specifies:

Mass of IRN-150 resin (wet basis) $\left(m_{\text {mixed }}\right)$

Diameter of fixed bed (D)

Length of Fixed Bed ( $L$ )

Specified within Program (Assumed Constant):

Apparent Wet Density of IRN-150 ( $\left.\rho_{\text {A,mixed }}\right)$

Apparent Dry Density of IRN-150 $\left(\rho_{A \text {,mixed (dry) }}\right)$

Apparent Wet Density of IRN-77 $\left(\rho_{\mathrm{A}, \mathrm{C}}\right)$

Apparent Wet Density of IRN-78 $\left(\rho_{A, A}\right)$

Total capacity of IRN-77 (meq/g wet) $=\mathrm{q}_{\mathrm{T}, \mathrm{C}}$

Total capacity of IRN-78 (meq/g wet) $=\mathrm{q}_{\mathrm{T}, \mathrm{A}}$

Volumetric fraction of cationic exchange resin within mixed bed resin $\left(V_{C} / V_{r}\right)$

Volumetric fraction of anionic exchange resin within mixed bed resin $\left(V_{A} / V_{r}\right)$

Calculations for Mixed Bed Resin:

$$
\begin{aligned}
\mathrm{f}_{\text {solids,mixed }} & =\frac{\rho_{A, \text { mixed (dry) }}}{\rho_{A, \text { mixed }}} \\
\mathrm{m}_{\text {mixed (dry) }}= & \mathrm{m}_{\text {mixed }} \times \mathrm{f}_{\text {solids,mixed }} \\
\mathrm{V}_{\mathrm{r}}= & \frac{\mathrm{m}_{\text {mixed }}}{\rho_{A, \text { mixed }}}
\end{aligned}
$$

Calculations for Cationic Exchange Resin within Mixed Bed:

$$
\begin{gathered}
\mathrm{V}_{\mathrm{C}}=\left(\frac{\mathrm{V}_{\mathrm{C}}}{\mathrm{V}_{\mathrm{r}}}\right) \times \mathrm{V}_{\mathrm{r}} \\
\mathrm{m}_{\mathrm{C}}=\mathrm{V}_{\mathrm{C}} \times \rho_{\mathrm{A}, \mathrm{C}} \\
\mathrm{q}_{\mathrm{T}, \mathrm{C}}=\text { Given and assumed constant } \\
\text { Then Calculate } \mathrm{m}_{\mathrm{C}} \times \mathrm{q}_{\mathrm{T}, \mathrm{C}}
\end{gathered}
$$


Calculations for Anionic Exchange Resin within Mixed Bed:

$$
\begin{gathered}
\mathrm{V}_{\mathrm{A}}=\left(\frac{\mathrm{V}_{\mathrm{A}}}{\mathrm{V}_{\mathrm{r}}}\right) \times \mathrm{V}_{\mathrm{r}} \\
\mathrm{m}_{\mathrm{A}}=\mathrm{V}_{\mathrm{A}} \times \rho_{\mathrm{A}, \mathrm{A}} \\
\mathrm{q}_{\mathrm{T}, \mathrm{A}}=\text { Given and assumed constant } \\
\text { Then Calculate } \mathrm{m}_{\mathrm{A}} \times \mathrm{q}_{\mathrm{T}, \mathrm{A}}
\end{gathered}
$$

\section{Adjusting Values for Cations:}

Assume there are only cations in the mixed bed:

$$
\begin{gathered}
\left(\frac{\mathrm{V}_{\mathrm{C}}}{\mathrm{V}_{\mathrm{r}}}\right)_{\text {adjusted }}=1 \\
\left(\mathrm{~V}_{\mathrm{C}}\right)_{\text {adjusted }}=\left(\frac{\mathrm{V}_{\mathrm{C}}}{\mathrm{V}_{\mathrm{r}}}\right)_{\text {adjusted }} \times \mathrm{V}_{\mathrm{r}} \\
\left(\mathrm{m}_{\mathrm{C}}\right)_{\text {adjusted }}=\left(\mathrm{V}_{\mathrm{C}}\right)_{\text {adjusted }} \times \rho_{\mathrm{A}, \mathrm{C}}
\end{gathered}
$$

The value of $\mathrm{m}_{\mathrm{C}} \times \mathrm{q}_{\mathrm{T}, \mathrm{C}}$ from Equation $\mathrm{V}-7$ must remain the same both before and after the adjustment. Thus, the value of $\mathrm{q}_{\mathrm{T}, \mathrm{C}}$ must be adjusted such that this occurs:

$$
\left(\mathrm{q}_{\mathrm{T}, \mathrm{C}}\right)_{\text {adjusted }}=\frac{\mathrm{m}_{\mathrm{C}} \times \mathrm{q}_{\mathrm{T}, \mathrm{C}}}{\left(\mathrm{m}_{\mathrm{C}}\right)_{\text {adjusted }}}
$$

\section{Adjusting Values for Anions:}

Assume there are only anions in the mixed bed:

$$
\begin{gathered}
\left(\frac{\mathrm{V}_{\mathrm{A}}}{\mathrm{V}_{\mathrm{r}}}\right)_{\text {adjusted }}=1 \\
\left(\mathrm{~V}_{\mathrm{A}}\right)_{\text {adjusted }}=\left(\frac{\mathrm{V}_{\mathrm{A}}}{\mathrm{V}_{\mathrm{r}}}\right)_{\text {adjusted }} \times \mathrm{V}_{\mathrm{r}} \\
\left(\mathrm{m}_{\mathrm{A}}\right)_{\text {adjusted }}=\left(\mathrm{V}_{\mathrm{A}}\right)_{\text {adjusted }} \times \rho_{\mathrm{A}, \mathrm{C}}
\end{gathered}
$$


The value of $m_{A} \times q_{T, A}$ from Equation $V-11$ must remain the same both before and after the adjustment. Thus, the value of $\mathrm{q}_{\mathrm{T}, \mathrm{A}}$ must be adjusted such that this occurs:

$$
\left(q_{T, A}\right)_{\text {adjusted }}=\frac{m_{A} \times q_{T, A}}{\left(m_{A}\right)_{\text {adjusted }}}
$$

FORTRAN Variables for Adjustment

User Specified Parameters

\section{Variable Name}

M_MIXED

D

L

\section{Description}

Mass of IRN-150 resin (wet basis) $\left(\mathrm{m}_{\text {mixed }}\right)$

Diameter of fixed bed (D)

Length of Fixed Bed ( $L$ )

Parameters Known by Program (Assumed Constant between Runs)

\section{Variable Name}

RHOA_MIXED

RHOA_MIXED_DRY

RHOA_SAC

RHOA_SBA

QT_SAC

QT_SBA

F_MIXED_SAC

F_MIXED_SBA

\section{Description}

Apparent Wet Density of IRN-150 ( $\left.\rho_{\text {A,mixed }}\right)$

Apparent Dry Density of IRN-150 $\left(\rho_{A \text {,mixed (dry) }}\right)$

Apparent Wet Density of IRN-77 $\left(\rho_{\mathrm{A}, \mathrm{C}}\right)$

Apparent Wet Density of IRN-78 $\left(\rho_{A, A}\right)$

Total capacity of IRN-77 (meq/g wet) $=\mathrm{q}_{\mathrm{T}, \mathrm{C}}$

Total capacity of IRN-78 (meq/g wet) $=q_{T, A}$

Volumetric fraction of cationic exchange resin (IRN-

77) within mixed bed resin, IRN-150 $\left(V_{c} / V_{r}\right)$

Volumetric fraction of anionic exchange resin (IRN-

78) within mixed bed resin, IRN-150 $\left(V_{A} / V_{r}\right)$ 
Calculated Parameters

\section{Variable Name}

F_SOLIDS_MIXED

M_MIXED_DRY

V_MIXED

V_C

M_C

QT_C

V_A

M_A

QT_A

\section{Description}

Fraction of solids in the mixed bed resin (mass dry resin / mass wet resin) Mass of mixed bed (IRN-150) resin (dry basis)

$\left(\mathrm{m}_{\text {mixed (dry) }}\right)$

Volume of mixed bed (IRN-150) resin $\left(V_{r}\right)$

Volume of cationic exchange resin (IRN-77) within mixed bed (IRN-150) $=V_{C}$

Mass of cationic exchange resin within mixed bed (wet basis) $=\mathrm{m}_{\mathrm{C}}$

Total resin capacity of cationic exchange resin (wet basis $)=\mathrm{q}_{\mathrm{T}, \mathrm{C}}$

Volume of anionic exchange resin (IRN-78) within mixed bed $\left(\right.$ IRN-150) $=V_{A}$ Mass of anionic exchange resin within mixed bed (wet basis) $=m_{A}$

Total resin capacity of anionic exchange resin (wet basis $)=q_{T, A}$ 
Adjusted Parameters

Variable Name

ADJ_F_MIXED_SAC

ADJ_V_C

ADJ_M_C

ADJ_QT_C

ADJ_F_MIXED_SBA

ADJ_V_A

ADJ_M_A

ADJ_QT_A

\section{Description}

Adjusted volumetric fraction of cationic exchange resin (IRN-77) within mixed bed resin, IRN-150 = $\left(\mathrm{V}_{\mathrm{C}} / \mathrm{V}_{\mathrm{r}}\right)_{\text {adjusted }}$

Adjusted volume of cationic exchange resin (IRN-77) within mixed bed (IRN-150) $=\left(\mathrm{V}_{\mathrm{C}}\right)_{\text {adjusted }}$

Adjusted mass of cationic exchange resin within mixed bed (wet basis) $=\left(\mathrm{m}_{\mathrm{c}}\right)_{\text {adjusted }}$ Adjusted total resin capacity of cationic exchange resin (wet basis) $=\left(\mathrm{q}_{\mathrm{T}, \mathrm{C}}\right)_{\text {adjusted }}$

Adjusted volumetric fraction of anionic exchange resin (IRN-78) within mixed bed resin, IRN-150 = $\left(\mathrm{V}_{\mathrm{A}} / \mathrm{V}_{\mathrm{r}}\right)_{\text {adjusted }}$

Adjusted volume of anionic exchange resin (IRN-78) within mixed bed $(\mathrm{IRN}-150)=\left(\mathrm{V}_{\mathrm{A}}\right)_{\text {adjusted }}$

Adjusted mass of anionic exchange resin within mixed bed (wet basis) $=\left(\mathrm{m}_{\mathrm{A}}\right)_{\text {adjusted }}$

Adjusted total resin capacity of anionic exchange resin (wet basis) $=\left(\mathrm{q}_{\mathrm{T}, \mathrm{A}}\right)_{\text {adjusted }}$ 


\section{Appendix VI - Development of the Tanks in Series Equilibrium Model (TISEqM) for WBA Resins}

Model Development for Single CSTR for Chloride $\left(\mathrm{Cl}^{-}\right)$Exchanging onto IRA-68 (WBA) Exchange Resin in the Freebase ( $\mathrm{HOH}$ ) Form

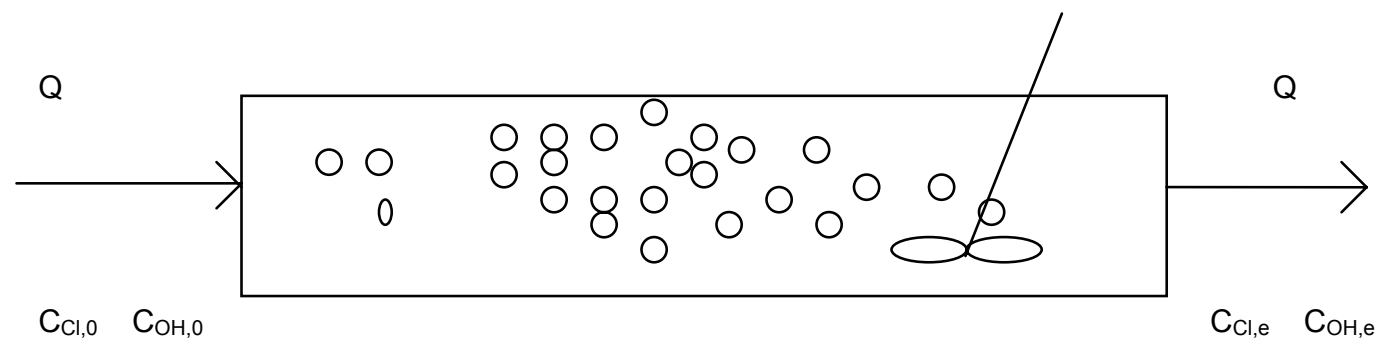

\section{General Mass Balance Equation:}

$$
\begin{gathered}
\text { in - out }+ \text { generation - loss }=\text { accumulation } \Rightarrow \\
\text { in - out }=\text { accumulation } \\
\mathrm{QC}_{0}-\mathrm{QC}_{\mathrm{e}}=\mathrm{M} \frac{\mathrm{dq}}{\mathrm{dt}}+\varepsilon \mathrm{V} \frac{\mathrm{dC_{e }}}{\mathrm{dt}}
\end{gathered}
$$

The term $\frac{\mathrm{dq}}{\mathrm{dt}}$ may be replaced by the following expression:

$$
\frac{\mathrm{dq}}{\mathrm{dt}}=\frac{\mathrm{dq}}{\mathrm{dC}_{\mathrm{e}}} \frac{\mathrm{dC}_{\mathrm{e}}}{\mathrm{dt}}
$$

Substituting Equation $\mathrm{VI}-3$ into Equation $\mathrm{VI}-2$ results in the following:

$$
\mathrm{QC}_{0}-\mathrm{QC}_{\mathrm{e}}=\mathrm{M} \frac{\mathrm{dq}}{\mathrm{dC}} \frac{\mathrm{dC} \mathrm{e}_{\mathrm{e}}}{\mathrm{dt}}+\varepsilon \mathrm{V} \frac{\mathrm{dC_{e }}}{\mathrm{dt}}
$$

Rearranging Equation VI-4 and solving for $\frac{d C_{e}}{d t}$ results in the following:

$$
\frac{\mathrm{dC}_{\mathrm{e}}}{\mathrm{dt}}=\frac{\mathrm{QC}_{0}-\mathrm{QC}_{\mathrm{e}}}{\mathrm{M} \frac{\mathrm{dq}}{\mathrm{dC}}+\varepsilon \mathrm{V}}
$$




\section{Chloride $\left(\mathrm{Cl}^{-}\right)$Exchanging the Freebase (HOH) Form of IRA-68 \\ (WBA) Exchange Resin}

For the case of $\mathrm{Cl}^{-}$exchanging on to the freebase form of IRA-68 resin, the mass balance on $\mathrm{Cl}^{-}$can be derived using the method shown above, resulting in an equation similar to Equation VI-5. These equations are shown below:

$$
\frac{\mathrm{dC}_{\mathrm{Cl}, \mathrm{e}}}{\mathrm{dt}}=\frac{\mathrm{QC}_{\mathrm{Cl}, 0}-\mathrm{QC}_{\mathrm{Cl}, \mathrm{e}}}{\mathrm{M}_{\mathrm{A}} \frac{\mathrm{dq}_{\mathrm{Cl}}}{\mathrm{dC}_{\mathrm{Cl}, \mathrm{e}}}+\varepsilon \mathrm{V}}
$$

In order to solve Equation VI-6, it is necessary to have a value for the expression $\frac{d q_{C l}}{d C_{C l, e}}$. This expression is obtained from the equilibrium expression that relates concentration in the liquid phase to concentration in the resin phase for each ion. This equilibrium expression is:

$$
q_{C l}=\frac{q_{T} b_{C l} C_{H} C_{C l}}{1+b_{C l} C_{H} C_{C l}}
$$

Taking the derivative $\frac{\mathrm{dq}_{\mathrm{Cl}}}{\mathrm{dC}_{\mathrm{Cl}, \mathrm{e}}}$ from Equation VI-7 results in the following:

$$
\begin{aligned}
\frac{d q_{C l}}{d C_{C l, e}} & =\frac{\left(1+b_{C l} C_{H} C_{C l}\right)\left(q_{T} b_{C l} C_{H}\right)-\left(q_{T} b_{C l} C_{H} C_{C l}\right)\left(b_{C l} C_{H}\right)}{\left(1+b_{C l} C_{H} C_{C l}\right)^{2}} \\
& =\frac{q_{T} b_{C l} C_{H}+b_{C l} C_{H} C_{C l} q_{T} b_{C l} C_{H}-q_{T} b_{C l} C_{H} C_{C l} b_{C l} C_{H}}{\left(1+b_{C l} C_{H} C_{C l}\right)^{2}} \\
& =\frac{q_{T} b_{C l} C_{H}}{\left(1+b_{C l} C_{H} C_{C l}\right)^{2}}
\end{aligned}
$$

Substituting Equation VI-8 into Equation VI-6 results in the following:

$$
\frac{\mathrm{dC}_{\mathrm{Cl}, \mathrm{e}}}{\mathrm{dt}}=\frac{\mathrm{QC}_{\mathrm{Cl}, 0}-\mathrm{QC}_{\mathrm{Cl}, \mathrm{e}}}{\mathrm{M}_{\mathrm{A}}\left[\frac{\mathrm{q}_{\mathrm{T}} \mathrm{b}_{\mathrm{Cl}} \mathrm{C}_{\mathrm{H}}}{\left(1+\mathrm{b}_{\mathrm{Cl}} \mathrm{C}_{\mathrm{H}} \mathrm{C}_{\mathrm{Cl}}\right)^{2}}\right]+\varepsilon \mathrm{V}}
$$


The term $\mathrm{C}_{\mathrm{Cl}, 0}$ in Equation VI-9 refers to the liquid phase influent concentration of chloride ions. This value is known. In contrast, the term $\mathrm{C}_{\mathrm{Cl}, \mathrm{e}}$ in Equation $\mathrm{VI}-9$ refers to the liquid phase effluent concentration of chloride ions. These values are unknown.

\section{Converting the Single CSTR Model into Dimensionless Form for Chloride $\left(\mathrm{Cl}^{-}\right)$Exchanging onto IRA-68 (WBA) Exchange Resin in the Freebase $(\mathrm{HOH})$ Form}

After defining dimensionless terms, it is possible to convert Equation VI-9 into dimensionless form. Defining the equivalent time-averaged influent liquid phase concentration of ion $\mathrm{i}\left(\overline{\mathrm{C}_{0, i}}\right)$ and the total equivalent time-averaged influent liquid phase concentration of all anions $\left(\overline{\mathrm{C}_{\mathrm{T}, \text { avg, } \mathrm{A}}}\right)$ in Equations $\mathrm{VI}-10$ and $\mathrm{VI}-11$ allows for the definition of $\overline{\mathrm{C}_{\mathrm{C}, 0}}$ in Equation $\mathrm{VI}-12$.

$$
\begin{gathered}
\overline{\mathrm{C}_{0, \mathrm{i}}}=\frac{1}{\mathrm{t}} \int_{0}^{\mathrm{t}} \mathrm{C}_{0, \mathrm{i}}(\mathrm{t}) \mathrm{dt} \\
\overline{\mathrm{C}_{\mathrm{T}, \mathrm{avg}, \mathrm{A}}}=\sum_{\mathrm{j}=1}^{\mathrm{m}} \overline{\mathrm{C}_{0, \mathrm{j}}} \quad \text { where } \mathrm{m}=\text { number of anions } \\
\overline{\mathrm{C}_{\mathrm{Cl}, 0}}=\frac{\mathrm{C}_{\mathrm{Cl}, 0}}{\overline{\mathrm{C}_{0, \mathrm{Cl}}}}
\end{gathered}
$$

A dimensionless Langmuir exchange constant $\left(\overline{b_{\mathrm{Cl}}}\right)$ will be defined as:

$$
\overline{\mathrm{b}_{\mathrm{Cl}}}=\mathrm{b}_{\mathrm{Cl}}\left(\overline{\mathrm{C}_{0, \mathrm{H}}}\right)\left(\overline{\mathrm{C}_{0, \mathrm{Cl}}}\right)
$$

Dimensionless time $(T)$ will be defined in terms of a capacity factor $\left(C_{F}\right)$ and the packed bed contact time $(\tau)$ from the following equation:

$$
\mathrm{T}=\frac{\mathrm{t}}{\mathrm{C}_{\mathrm{F}} \tau}
$$

where:

$$
\begin{aligned}
& C_{F}=\frac{M_{A} q_{T, A}}{V \overline{C_{T, a v g, A}} \varepsilon} \\
& C_{F, C l}=\frac{M_{A} q_{T}}{V \overline{C_{0, C l}} \varepsilon}
\end{aligned}
$$




$$
\tau=\frac{\mathrm{V} \varepsilon}{\mathrm{Q}}
$$

Based on Equation VI-14, an expression for $\frac{\mathrm{d}}{\mathrm{dt}}$ is given as follows:

$$
\frac{d}{d t}=\frac{1}{C_{F} \tau} \frac{d}{d T}
$$

Applying Equations VI-10 through VI-18 to Equation VI-9 results in the dimensionless form of the equation that need to be solved for the single CSTR model for the case of chloride $\left(\mathrm{Cl}^{-}\right)$exchanging onto the freebase $(\mathrm{HOH})$ form of IRA-68 (WBA) resin. The dimensionless equation is given below:

$$
\frac{d \overline{C_{C l}}}{d T}=\frac{\left(\overline{C_{C l, 0}}-\overline{C_{C l}}\right)}{\left.\left(\frac{C_{F, C l}}{C_{F}}\right)\left\{\frac{\bar{b}_{C l} \overline{C_{H}}}{\left[1+\bar{b}_{C l} \overline{C_{H}} \bar{C}_{C l}\right.}\right]^{2}\right\}+\frac{1}{C_{F}}}
$$

For a more detailed decription of the conversion to dimensionless form, see Appendix VI.B. Once the dimensionless liquid phase concentration of chloride is known, the dimensionless resin phase concentration can be determined from the dimensionless form of Equation VI-7:

$$
\overline{\mathrm{q}}_{\mathrm{Cl}}=\frac{\overline{\mathrm{b}}_{\mathrm{Cl}} \overline{\mathrm{C}}_{\mathrm{H}} \overline{\mathrm{C}}_{\mathrm{Cl}}}{1+\overline{\mathrm{b}}_{\mathrm{Cl}} \overline{\mathrm{C}}_{\mathrm{H}} \overline{\mathrm{C}}_{\mathrm{Cl}}}
$$

\section{Model Development for Single CSTR for General Case of NANION Anions}

The dimensioned form of the general case for NCOMP (= NANION) components is derived similarly to the dimensioned form of the previous case of chloride $\left(\mathrm{Cl}^{-}\right)$exchanging onto the freebase $(\mathrm{HOH})$ form of IRA-68 (WBA) exchange resin. The equations presented below are for each component, i, in an NCOMP component simulation. Equation VI-5 can be rewritten as:

$$
\frac{d C_{i, e}}{d t}=\frac{Q C_{i, 0}-Q C_{i, e}}{M \frac{d q_{i}}{d C_{i, e}}+\varepsilon V}
$$


In order to solve Equation VI-21, it is necessary to evaluate the expression, $\frac{d q_{i}}{d C_{i, e}}$, for each component $i$. The value of this term is obtained from the equilibrium expression that relates concentration in the resin phase to concentration in the liquid phase for each ion.

The general form of the equilibrium expression for each anion, $i$, is given below (note this expression is analogous to the equilibrium expressions shown in Equation VI-7).

$$
q_{i}=\frac{q_{T} b_{i} C_{H} C_{i}}{1+C_{H} \sum_{k=1}^{\text {NANION }} b_{k} C_{k}}
$$

Taking the partial derivative, $\frac{\mathrm{dq}_{\mathrm{i}}}{\mathrm{dC}_{\mathrm{i}, \mathrm{e}}}$, which is needed to solve Equation VI-21

results in the following (see Equation VI-8 for a similar equation relevant to twocomponent case):

$$
\begin{aligned}
\frac{d q_{i}}{d C_{i, e}} & =\frac{\left(1+C_{H} \sum_{k=1}^{\text {NANION }} b_{k} C_{k}\right)\left(q_{T} b_{i} C_{H}\right)-\left(q_{T} b_{i} C_{H} C_{i}\right)\left(b_{i} C_{H}\right)}{\left(1+C_{H} \sum_{k=1}^{\text {NANION }} b_{k} C_{k}\right)^{2}} \\
& =\frac{\left(1+C_{H} b_{i} C_{i}+C_{H} \sum_{\substack{j=1 \\
j \neq i}}^{\text {NANON }} b_{j} C_{j}\right)\left(q_{T} b_{i} C_{H}\right)-\left(q_{T} b_{i} C_{H} C_{i}\right)\left(b_{i} C_{H}\right)}{\left(1+C_{H} \sum_{k=1}^{\text {NANION }} b_{k} C_{k}\right)^{2}} \\
& =\frac{\left(1+C_{H} \sum_{\substack{j=1 \\
j \neq i}}^{\text {NANION }} b_{j} C_{j}\right)\left(q_{T} b_{i} C_{H}\right)+C_{H} b_{i} C_{i}\left(q_{T} b_{i} C_{H}\right)-\left(q_{T} b_{i} C_{H} C_{i}\right)\left(b_{i} C_{H}\right)}{\left(1+C_{H} \sum_{\substack{j=1 \\
j \neq i}}^{\text {NANION }} b_{j} C_{j}\right)\left(q_{T} b_{i} C_{H}\right)} \\
& =\frac{\left(1+C_{H} \sum_{k=1}^{\text {NANION }} b_{k} C_{k}\right)^{2}}{\left(1+C_{k}\right)^{2}}
\end{aligned}
$$


Substituting Equation VI-23 into Equation VI-21 produces the following:

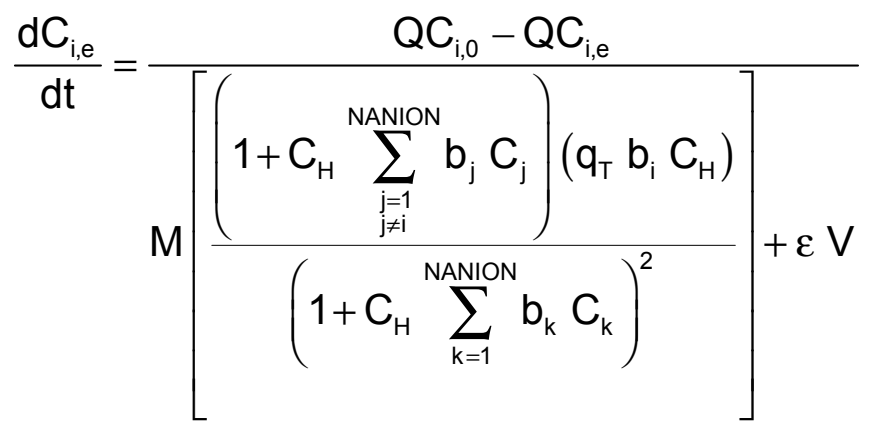

The term $\mathrm{C}_{i, 0}$ in Equation $\mathrm{VI}-24$ refers to the liquid phase influent concentration of anion $\mathrm{i}$ This value is known for each anion, i. In contrast, the term $\mathrm{C}_{\mathrm{i}, \mathrm{e}}$ in Equation VI-24 refers to the liquid phase effluent concentration of each anion, i. This value is unknown for each anion, i.

\section{Converting the Single CSTR Model into Dimensionless Form for the General Case of NANION Anions}

The process of converting the dimensioned equations for the single CSTR model with NCOMP (=NANION) components is very similar to the case of chloride $\left(\mathrm{Cl}^{-}\right)$exchanging onto the freebase $(\mathrm{HOH})$ form of IRA-68 (WBA) exchange resin. The definition of dimensionless variables (analogous to Equations $\mathrm{VI}-10$ through $\mathrm{VI}-18$ above) is given below.

Defining the equivalent time-averaged influent liquid phase concentration of ion $\mathrm{i}\left(\overline{\mathrm{C}_{0, \mathrm{i}}}\right)$ and the total equivalent time-averaged influent liquid phase concentration of all anions $\left(\overline{\mathrm{C}_{\mathrm{T}, \text { avg, } \mathrm{A}}}\right)$ in Equations $\mathrm{VI}-25$ and $\mathrm{VI}-26$, respectively, allows for the definition of $\overline{\mathrm{C}_{i, 0}}$ in Equation VI-27.

$$
\begin{aligned}
& \overline{\mathrm{C}_{0, \mathrm{i}}}=\frac{1}{\mathrm{t}} \int_{0}^{\mathrm{t}} \mathrm{C}_{0, \mathrm{i}}(\mathrm{t}) \mathrm{dt} \text { (for } \mathrm{i}=1 \text { to NCOMP) } \\
& \overline{\mathrm{C}_{\mathrm{T}, \text { avg, } \mathrm{A}}}= \\
&=\sum_{\mathrm{j}=1}^{\text {NANION } \overline{\mathrm{C}_{0, \mathrm{j}}}} \\
& \overline{\mathrm{C}_{\mathrm{i}, 0}}=\frac{\mathrm{C}_{\mathrm{i}, 0}}{\overline{\mathrm{C}_{0, \mathrm{i}}}}
\end{aligned}
$$


A dimensionless Langmuir exchange constant $\left(\overline{b_{i}}\right)$ will be defined as:

$$
\overline{b_{i}}=b_{i}\left(\overline{\mathrm{C}_{0, H}}\right)\left(\overline{\mathrm{C}_{0, \mathrm{i}}}\right)
$$

Dimensionless time $(T)$ will be defined based on a capacity factor $\left(C_{F}\right)$ and the packed bed contact time $(\tau)$ from the following equation:

$$
\mathrm{T}=\frac{\mathrm{t}}{\mathrm{C}_{\mathrm{F}} \tau}
$$

where:

$$
\begin{gathered}
C_{F}=\frac{M_{A} q_{T, A}}{V \overline{C_{T, a v g, A}} \varepsilon} \\
C_{F, i}=\frac{M_{A} q_{T}}{V \overline{C_{0, i}} \varepsilon} \\
\tau=\frac{V \varepsilon}{Q}
\end{gathered}
$$

Based on Equation VI-29, an expression for $\frac{d}{d t}$ is given as follows:

$$
\frac{d}{d t}=\frac{1}{C_{F} \tau} \frac{d}{d T}
$$

Applying Equations $\mathrm{VI}-25$ through $\mathrm{VI}-33$ to Equation $\mathrm{VI}-24$ results in the dimensionless form of the equation that needs to be solved for the single CSTR model for the general case of NCOMP components. The dimensionless equation is shown below:

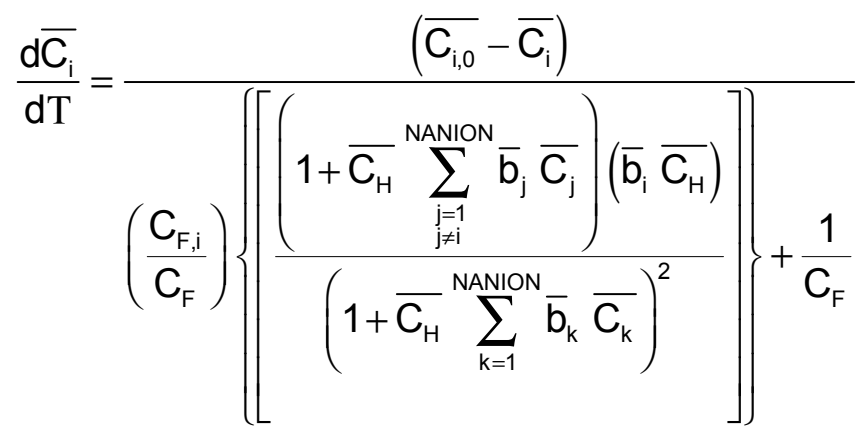


Once the dimensionless liquid phase concentration of anion $i$ is known, the dimensionless resin phase concentration can be determined from the dimensionless form of Equation VI-22:

$$
\overline{\mathrm{q}}_{\mathrm{i}}=\frac{\overline{\mathrm{b}}_{\mathrm{i}} \overline{\mathrm{C}}_{\mathrm{H}} \overline{\mathrm{C}}_{\mathrm{i}}}{1+\overline{\mathrm{C}}_{\mathrm{H}} \sum_{\mathrm{k}=1}^{\text {NANION }} \overline{\mathrm{b}}_{\mathrm{k}} \overline{\mathrm{C}}_{\mathrm{k}}}
$$

Extension of the Single CSTR Model to Accommodate Tanks in Series for Chloride $\left(\mathrm{Cl}^{-}\right)$Exchanging onto IRA-68 (WBA) Exchange Resin in the Freebase $(\mathrm{HOH})$ Form

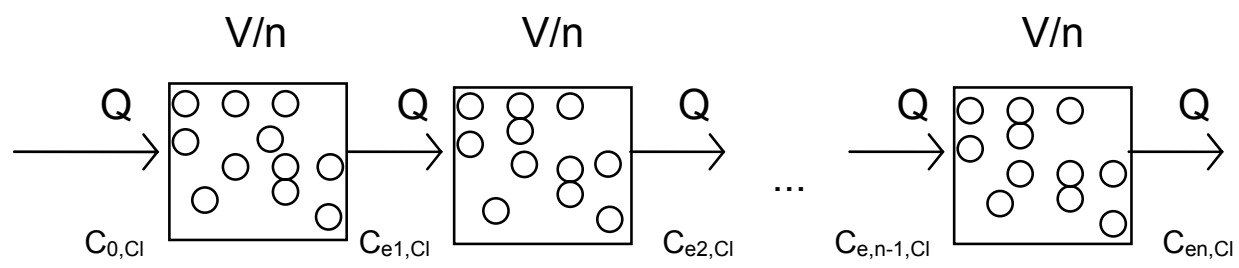

$\begin{array}{llll}\text { Tank No.: } & 1 & 2 & n\end{array}$

The equations that need to be solved for the tanks in series model arise from performing mass balances on each of the tanks in the system. What results is a system of $\mathrm{n}$ differential equations that need to be solved simultaneously, where $\mathrm{n}$ is the number of tanks. The development of the equations is similar to the development for the single CSTR. The differential equations that need to be solved are given below.

Tank 1

$$
\frac{\mathrm{dC}_{\mathrm{Cl}, 1}}{\mathrm{dt}}=\frac{\mathrm{QC}_{\mathrm{Cl}, 0}-\mathrm{QC}_{\mathrm{Cl}, 1}}{\frac{\mathrm{M}_{\mathrm{A}}}{\mathrm{n}}\left[\frac{\mathrm{q}_{\mathrm{T}} \mathrm{b}_{\mathrm{Cl}} \mathrm{C}_{\mathrm{H}, 1}}{\left(1+\mathrm{b}_{\mathrm{Cl}} \mathrm{C}_{\mathrm{H}, 1} \mathrm{C}_{\mathrm{Cl}, 1}\right)^{2}}\right]+\frac{\varepsilon \mathrm{V}}{\mathrm{n}}}
$$

Tanks 2 - $\mathbf{n}$

$$
\frac{d C_{\mathrm{Cl}, \mathrm{m}}}{\mathrm{dt}}=\frac{\mathrm{QC}_{\mathrm{Cl}, \mathrm{m}-1}-\mathrm{QC}_{\mathrm{Cl}, \mathrm{m}}}{\frac{\mathrm{M}_{\mathrm{A}}}{\mathrm{n}}\left[\frac{\mathrm{q}_{\mathrm{T}} \mathrm{b}_{\mathrm{Cl}} \mathrm{C}_{\mathrm{H}, \mathrm{m}}}{\left(1+\mathrm{b}_{\mathrm{Cl}} \mathrm{C}_{\mathrm{H}, \mathrm{m}} \mathrm{C}_{\mathrm{Cl}, \mathrm{m}}\right)^{2}}\right]+\frac{\varepsilon \mathrm{V}}{\mathrm{n}}}
$$

where: $m=$ the number of the tank $(2-n)$ 
Conversion of the Tanks in Series Model into Dimensionless Form for Chloride $\left(\mathrm{Cl}^{-}\right)$Exchanging onto IRA-68 (WBA) Exchange Resin in the Freebase $(\mathrm{HOH})$ Form

The procedure to convert the tanks in series model into dimensionless form is analogous to the procedure followed for the single CSTR model:

\section{Tank 1}

Conversion of Equation VI-36 into dimensionless form results in the following:

$$
\frac{\mathrm{d} \overline{\mathrm{C}_{\mathrm{C}, 1}}}{\mathrm{dT}}=\frac{\overline{\mathrm{C}_{\mathrm{Cl}, 0}}-\overline{\mathrm{C}_{\mathrm{Cl}, 1}}}{\frac{\mathrm{C}_{\mathrm{F}, \mathrm{Cl}}}{\mathrm{n} \mathrm{C}_{\mathrm{F}}}\left[\frac{\overline{\mathrm{b}}_{\mathrm{Cl}} \overline{\mathrm{C}_{\mathrm{H}, 1}}}{\left(1+\overline{\mathrm{b}}_{\mathrm{Cl}} \overline{\mathrm{C}_{\mathrm{H}, 1}} \overline{\mathrm{C}_{\mathrm{Cl}, 1}}\right)^{2}}\right]+\frac{1}{\mathrm{n} \mathrm{C}_{\mathrm{F}}}}
$$

\section{Tanks 2 - $\mathbf{n}$}

Conversion of Equation VI-37 into dimensionless form results in the following:

$$
\frac{\mathrm{d} \overline{\mathrm{C}_{\mathrm{Cl}, \mathrm{m}}}}{\mathrm{dT}}=\frac{\overline{\mathrm{C}_{\mathrm{Cl}, \mathrm{m}-1}}-\overline{\mathrm{C}_{\mathrm{Cl}, \mathrm{m}}}}{\frac{\mathrm{C}_{\mathrm{F}, \mathrm{Cl}}}{\mathrm{n} \mathrm{C}_{\mathrm{F}}}\left[\frac{\overline{\mathrm{b}}_{\mathrm{Cl}} \overline{\mathrm{C}_{\mathrm{H}, \mathrm{m}}}}{\left(1+\overline{\mathrm{b}}_{\mathrm{Cl}} \overline{\mathrm{C}_{\mathrm{H}, \mathrm{m}}} \overline{\mathrm{C}_{\mathrm{Cl}, \mathrm{m}}}\right)^{2}}\right]+\frac{1}{\mathrm{n} \mathrm{C}_{\mathrm{F}}}}
$$

where: $m=$ the number of the tank $(2-n)$

Once the dimensionless liquid phase concentration of chloride is known in tank $m$, the dimensionless resin phase concentration can be determined from the dimensionless form of Equation VI-7, solved separately for each tank, $m$ :

$$
\overline{\mathrm{q}}_{\mathrm{cl}, \mathrm{m}}=\frac{\overline{\mathrm{b}}_{\mathrm{Cl}} \overline{\mathrm{C}}_{\mathrm{H}, \mathrm{m}} \overline{\mathrm{C}}_{\mathrm{Cl}, \mathrm{m}}}{1+\overline{\mathrm{b}}_{\mathrm{cl}} \overline{\mathrm{C}}_{\mathrm{H}, \mathrm{m}} \overline{\mathrm{C}}_{\mathrm{Cl}, \mathrm{m}}}
$$

\section{Extension of the Single CSTR Model to Accommodate Tanks in Series for the General Case of NANION Anions}

The equations that arise for the dimensioned form of the tanks in series model for the general case of NCOMP (=NANION) components bear great similarity to the following two previous derivations of dimensioned equations: Single CSTR Model for the General Case of NANION Anions and (2) Tanks in Series Model for the Case of Chloride $\left(\mathrm{Cl}^{-}\right)$Exchanging the Freebase $(\mathrm{HOH})$ 
form of IRA-68 (WBA) Exchange Resin . The resulting dimensioned equations for the tanks in series model with NCOMP components are given below:

Tank 1

$\frac{d C_{i, 1}}{d t}=\frac{{Q C_{i, 0}}-Q C_{i, 1}}{M\left[\frac{\left(1+C_{H, 1} \sum_{\substack{j=1 \\ j \neq i}}^{\text {NANION }} b_{j} C_{j, 1}\right)\left(q_{T} b_{i} C_{H, 1}\right)}{\left(1+C_{H, 1} \sum_{k=1}^{\text {NANION }} b_{k} C_{k, 1}\right)^{2}}\right]+\varepsilon V}$

(i=1 to NANION-1, i $\neq$ presaturant) $\quad(\mathrm{VI}-41)$

Tanks $\mathbf{2}-\mathbf{n}(\mathbf{m}=$ Number of the tank (2 through $n))$

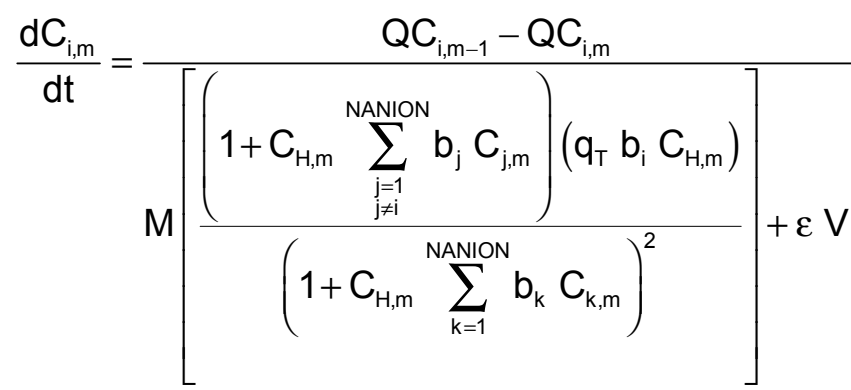

(i=1 to NANION-1, i $\neq$ presaturant) (VI-42)

Conversion of the Tanks in Series Model into Dimensionless Form for the General Case of NANION Anions

Conversion of the dimensioned tanks in series equations for NCOMP components into dimensionless form is quite similar to the case of chloride $\left(\mathrm{Cl}^{-}\right)$ exchanging onto the Freebase $(\mathrm{HOH})$ form of IRA-68 (WBA) exchange resin. The resultant dimensionless equations are provided below:

\section{Tank 1}

$\frac{\mathrm{d} \overline{\mathrm{C}_{i, 1}}}{\mathrm{dT}}=\frac{\overline{\mathrm{C}_{\mathrm{F}, \mathrm{i}}}}{\mathrm{n} \mathrm{C}_{\mathrm{F}}}\left[\frac{\left(1+\overline{\mathrm{C}_{\mathrm{H}, 1}} \sum_{\substack{\mathrm{j}=1 \\ j \neq i}}^{\text {NANION }} \overline{\mathrm{C}_{\mathrm{i}, 1}} \overline{\mathrm{C}_{\mathrm{j}, 1}}\right)\left(\overline{\mathrm{b}}_{\mathrm{i}} \overline{\mathrm{C}_{\mathrm{H}, 1}}\right)}{\left(1+\overline{\mathrm{C}_{\mathrm{H}, 1}} \sum_{\mathrm{k}=1}^{\text {NANION }} \overline{\mathrm{b}_{\mathrm{k}}} \overline{\mathrm{C}_{\mathrm{k}, 1}}\right)^{2}}\right]+\frac{1}{\mathrm{n} \mathrm{C}_{\mathrm{F}}}$

( $i=1$ to NANION-1, $i \neq$ presaturant) $(\mathrm{VI}-43)$ 


\section{Tanks $2-\mathbf{n}(m=$ Number of the tank (2 through $n))$}

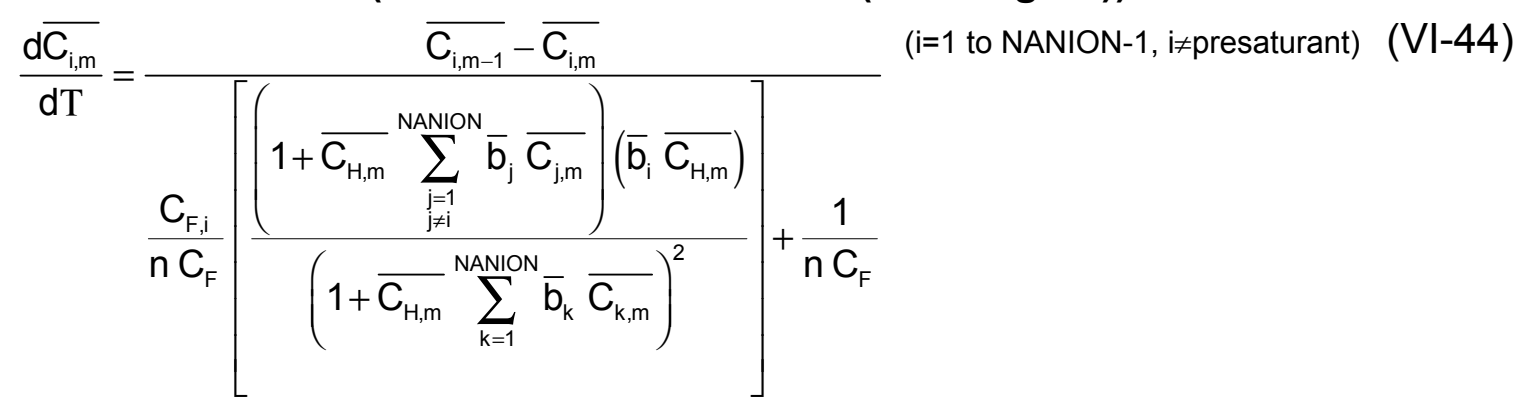

Once the dimensionless liquid phase concentration of anion $i$ is known in tank $m$, the dimensionless resin phase concentration can be determined from the dimensionless form of Equation $\mathrm{VI}-22$, solved separately for each tank, $m$ :

$$
\overline{\mathrm{q}}_{\mathrm{i}, \mathrm{m}}=\frac{\overline{\mathrm{b}}_{\mathrm{i}} \overline{\mathrm{C}}_{\mathrm{H}, \mathrm{m}} \overline{\mathrm{C}}_{\mathrm{i}, \mathrm{m}}}{1+\overline{\mathrm{C}}_{\mathrm{H}, \mathrm{m}} \sum_{\mathrm{k}=1}^{\text {NANION }} \overline{\mathrm{b}}_{\mathrm{k}} \overline{\mathrm{C}}_{\mathrm{k}, \mathrm{m}}}
$$

\section{Appendix VI.A - Nomenclature}

$\mathrm{C}_{0} \quad$ Influent liquid phase concentration $\left(\mathrm{eq} \mathrm{L}^{-3}\right)$

$\overline{\mathrm{C}_{0, \mathrm{i}}} \quad$ Equivalent time-averaged influent liquid phase concentration of ion $\mathrm{i}$ (eq $\mathrm{L}^{-3}$ )

$\mathrm{C}_{\mathrm{Cl}} \quad$ Same as $\mathrm{C}_{\mathrm{Cl}, \mathrm{e}}$

$\mathrm{C}_{\mathrm{Cl}, 0} \quad$ Influent liquid phase concentration of $\mathrm{Cl}^{-}\left(\right.$eq $\left.\mathrm{L}^{-3}\right)$

$\overline{\mathrm{C}_{\mathrm{Cl}, 0}} \quad$ Dimensionless influent liquid phase concentration of $\mathrm{Cl}^{-}$ (dimensionless)

$\mathrm{C}_{\mathrm{Cl}, \mathrm{e}} \quad$ Effluent liquid phase concentration of $\mathrm{Cl}^{-}\left(\mathrm{eq} \mathrm{L}^{-3}\right)$

$\mathrm{C}_{\mathrm{Cl}, \mathrm{k}} \quad$ Effluent liquid phase concentration of $\mathrm{Cl}^{-}$from tank number $\mathrm{k}$ (where $\mathrm{k}$ is a number between 1 and $n)\left(\mathrm{eq} \mathrm{L}^{-3}\right)$

$\overline{\mathrm{C}}_{\mathrm{Cl}, \mathrm{k}} \quad$ Dimensionless effluent liquid phase concentration of $\mathrm{Cl}^{-}$from tank number $k$ (where $k$ is a number between 1 and $n$ ) (dimensionless)

$\mathrm{C}_{\mathrm{e}} \quad$ Effluent liquid phase concentration (eq $\mathrm{L}^{-3}$ )

$\mathrm{C}_{\mathrm{F}} \quad$ Capacity factor (dimensionless) 

$\mathrm{C}_{\mathrm{F}, \mathrm{A}} \quad$ Capacity factor for anions (dimensionless)
$\mathrm{C}_{\mathrm{F}, \mathrm{C}} \quad$ Capacity factor for cations (dimensionless)
$\mathrm{C}_{\mathrm{H}} \quad$ Same as $\mathrm{C}_{\mathrm{H}, \mathrm{e}}$
$\mathrm{C}_{\mathrm{H}, 0} \quad$ Influent liquid phase concentration of $\mathrm{H}^{+}\left(\mathrm{eq} \mathrm{L}^{-3}\right)$
$\mathrm{C}_{\mathrm{H}, \mathrm{e}} \quad$ Effluent liquid phase concentration of $\mathrm{H}^{+}\left(\mathrm{eq} \mathrm{L}^{-3}\right)$
$\mathrm{C}_{\mathrm{H}, \mathrm{k}} \quad$ Effluent liquid phase concentration of $\mathrm{H}^{+}$from tank number $\mathrm{k}$ (where $k$ is a number between 1 and $n$ ) (eq $L^{-3}$ )
$\overline{\mathrm{C}}_{\mathrm{H}, \mathrm{k}} \quad$ Dimensionless effluent liquid phase concentration of $\mathrm{H}^{+}$from tank number $\mathrm{k}$ (where $\mathrm{k}$ is a number between 1 and $\mathrm{n}$ ) (dimensionless)
$\mathrm{C}_{\mathrm{i}, 0} \quad$ Influent liquid phase concentration of ion $\mathrm{i}\left(\right.$ eq $\left.\mathrm{L}^{-3}\right)$
$\overline{\mathrm{C}_{i, 0}} \quad$ Dimensionless influent liquid phase concentration of ion $\mathrm{i}$ (dimensionless)
$\mathrm{C}_{\mathrm{i}, \mathrm{e}} \quad$ Effluent liquid phase concentration of ion $\mathrm{i}\left(\mathrm{eq} \mathrm{L}^{-3}\right)$
$\mathrm{C}_{\mathrm{i}, \mathrm{k}} \quad$ Effluent liquid phase concentration of ion i from tank number $\mathrm{k}$ $\left(\right.$ eq $\left.\mathrm{L}^{-3}\right)$
$\overline{\mathrm{C}}_{\mathrm{i}, \mathrm{k}} \quad$ Dimensionless effluent liquid phase concentration of ion i from tank number $\mathrm{k}$ (dimensionless)
$\mathrm{C}_{\mathrm{Na}} \quad$ Same as $\mathrm{C}_{\mathrm{Na}, \mathrm{e}}$
$\mathrm{C}_{\mathrm{Na}, 0} \quad$ Influent liquid phase concentration of $\mathrm{Na}^{+}\left(\right.$eq $\left.\mathrm{L}^{-3}\right)$
$\overline{\mathrm{C}_{\mathrm{Na}, 0}} \quad$ Dimensionless influent liquid phase concentration of $\mathrm{Na}^{+}$ (dimensionless )
$\mathrm{C}_{\mathrm{Na}, \mathrm{e}} \quad$ Effluent liquid phase concentration of $\mathrm{Na}^{+}\left(\right.$eq L$\left.^{-3}\right)$
$\mathrm{C}_{\mathrm{Na}, \mathrm{k}} \quad$ Effluent liquid phase concentration of $\mathrm{Na}^{+}$from tank number $\mathrm{k}$ (where $k$ is a number between 1 and $n)\left(e q L^{-3}\right)$
$\overline{\mathrm{C}}_{\mathrm{Na}, \mathrm{k}} \quad$ Dimensionless effluent liquid phase concentration of $\mathrm{Na}^{+}$from tank number $k$ (where $k$ is a number between 1 and $n$ ) (dimensionless) 


\begin{tabular}{|c|c|}
\hline $\mathrm{OH}$ & Same as $\mathrm{C}_{\mathrm{OH}, \mathrm{e}}$ \\
\hline $\mathrm{O}_{\mathrm{OH}, \mathrm{O}}$ & Influent liquid phase concentration of $\mathrm{OH}^{-}\left(\mathrm{eq} \mathrm{L}^{-3}\right)$ \\
\hline $\mathrm{OH}, \mathrm{e}$ & Effluent liquid phase concentration of $\mathrm{OH}^{-}\left(\mathrm{eq} \mathrm{L}^{-3}\right)$ \\
\hline $\mathrm{OH}, \mathrm{k}$ & $\begin{array}{l}\text { Effluent liquid phase concentration of } \mathrm{OH}^{-} \text {from tank number } \mathrm{k} \\
\text { (where } \mathrm{k} \text { is a number between } 1 \text { and } \mathrm{n} \text { ) }\left(\mathrm{eq}^{-3}\right)\end{array}$ \\
\hline $\mathrm{OH,k}$ & $\begin{array}{l}\text { Dimensionless effluent liquid phase concentration of } \mathrm{OH}^{-} \text {from tank } \\
\text { number } k \text { (where } k \text { is a number between } 1 \text { and } n \text { ) (dimensionless) }\end{array}$ \\
\hline presaturant, $\mathrm{A}, \mathrm{k}$ & $\begin{array}{l}\text { Liquid phase concentration of the presaturant ion for the anionic } \\
\text { exchange resin in tank number } k \text { (where } k \text { is a number between } 1 \\
\text { and } n \text { ) }\left(\text { eq L }^{-3} \text { ) }\right.\end{array}$ \\
\hline presaturant,A,k & $\begin{array}{l}\text { Dimensionless liquid phase concentration of the presaturant ion for } \\
\text { the anionic exchange resin in tank number } k \text { (where } k \text { is a number } \\
\text { between } 1 \text { and } n \text { ) (dimensionless) }\end{array}$ \\
\hline $\mathrm{C}_{\text {presaturant }, \mathrm{C}, \mathrm{k}}$ & $\begin{array}{l}\text { Liquid phase concentration of the presaturant ion for the cationic } \\
\text { exchange resin in tank number } k \text { (where } k \text { is a number between } 1 \\
\text { and } n \text { ) }\left(\text { eq L }^{-3}\right)\end{array}$ \\
\hline$\overline{\mathrm{C}}_{\text {presaturant, }, \mathrm{C}, \mathrm{k}}$ & $\begin{array}{l}\text { Dimensionless liquid phase concentration of the presaturant ion for } \\
\text { the cationic exchange resin in tank number } k \text { (where } k \text { is a number } \\
\text { between } 1 \text { and } n \text { ) (dimensionless) }\end{array}$ \\
\hline$\overline{\mathrm{C}_{\mathrm{T}, \text { avg }, \mathrm{A}}}$ & $\begin{array}{l}\text { Total equivalent time-averaged influent liquid phase concentration } \\
\text { of all anions (eq } \mathrm{L}^{-3} \text { ) }\end{array}$ \\
\hline$\overline{\mathrm{C}_{\mathrm{T}, \mathrm{avg}, \mathrm{C}}}$ & $\begin{array}{l}\text { Total equivalent time-averaged influent liquid phase concentration } \\
\text { of all cations ( eq } \mathrm{L}^{-3} \text { ) }\end{array}$ \\
\hline $\mathrm{C}_{\mathrm{T}, \mathrm{A}}$ & Total liquid phase concentration of all anions at time $t\left(\right.$ eq $\left.\mathrm{L}^{-3}\right)$ \\
\hline & $\begin{array}{l}\text { Dimensionless total liquid phase concentration of all anions at time } \\
\mathrm{t} \text { (dimensionless) }\end{array}$ \\
\hline
\end{tabular}




\begin{tabular}{|c|c|}
\hline $\mathrm{C}_{\mathrm{T}, \mathrm{C}}$ & Total liquid phase concentration of all cations at time $\mathrm{t}\left(\mathrm{eq} \mathrm{L}^{-3}\right)$ \\
\hline \multirow[t]{2}{*}{$\overline{\mathrm{C}_{\mathrm{T}, \mathrm{C}}}$} & Dimensionless total liquid phase concentration of all cations at time \\
\hline & $\mathrm{t}$ (dimensionless) \\
\hline M & Mass of resin (M) \\
\hline $\mathrm{M}_{\mathrm{A}}$ & Mass of anionic exchange resin (M) \\
\hline$M_{c}$ & Mass of cationic exchange resin $(\mathrm{M})$ \\
\hline$n$ & Number of tanks (dimensionless) \\
\hline NANION & Number of anions (dimensionless) \\
\hline NCATION & Number of cations ( dimensionless) \\
\hline q & Resin phase concentration $\left(\right.$ eq $\left.^{-1}\right)$ \\
\hline$q_{\mathrm{Cl}}$ & Resin phase concentration of $\mathrm{Cl}^{-}\left(\mathrm{eq} \mathrm{M}^{-1}\right)$ \\
\hline$\overline{\mathrm{q}}_{\mathrm{Cl}}$ & Dimensionless resin phase concentration of $\mathrm{Cl}^{-}$(dimensionless ) \\
\hline $\mathrm{q}_{\mathrm{Cl}, 1}$ & Resin phase concentration of $\mathrm{Cl}^{-}$in tank number $1\left(\right.$ eq M$\left.^{-1}\right)$ \\
\hline$\overline{\mathrm{q}}_{\mathrm{Cl}, 1}$ & $\begin{array}{l}\text { Dimensionless resin phase concentration of } \mathrm{Cl}^{-} \text {in tank number } 1 \\
\text { (dimensionless) }\end{array}$ \\
\hline $\mathrm{q}_{\mathrm{Cl}, \mathrm{m}}$ & $\begin{array}{l}\text { Resin phase concentration of } \mathrm{Cl}^{-} \text {in tank number } \mathrm{m} \text { (where } \mathrm{m} \text { is a } \\
\left.\text { number between } 2 \text { and } \mathrm{n} \text { ) (eq } \mathrm{M}^{-1}\right)\end{array}$ \\
\hline$\overline{\mathrm{q}}_{\mathrm{Cl,m}}$ & $\begin{array}{l}\text { Dimensionless resin phase concentration of } \mathrm{Cl}^{-} \text {in tank number } \mathrm{m} \\
\text { (where } \mathrm{m} \text { is a number between } 2 \text { and } \mathrm{n} \text { ) (dimensionless) }\end{array}$ \\
\hline $\mathrm{q}_{\mathrm{Cl}, \mathrm{k}}$ & $\begin{array}{l}\text { Resin phase concentration of } \mathrm{Cl}^{-} \text {in tank number } \mathrm{k} \text { (where } \mathrm{k} \text { is a } \\
\text { number between } 1 \text { and } \mathrm{n})\left(\mathrm{eq} \mathrm{M}^{-1}\right)\end{array}$ \\
\hline$\overline{\mathrm{q}}_{\mathrm{cl}, \mathrm{k}}$ & $\begin{array}{l}\text { Dimensionless resin phase concentration of } \mathrm{Cl}^{-} \text {in tank number } \mathrm{k} \\
\text { (where } \mathrm{k} \text { is a number between } 1 \text { and } \mathrm{n} \text { ) (dimensionless) }\end{array}$ \\
\hline$q_{H}$ & Resin phase concentration of $\mathrm{H}^{+}\left(\mathrm{eq} \mathrm{M}^{-1}\right)$ \\
\hline$\overline{\mathrm{q}}_{\mathrm{H}}$ & Dimensionless resin phase concentration of $\mathrm{H}^{+}$(dimensionless) \\
\hline $\mathrm{q}_{\mathrm{H}, 1}$ & Resin phase concentration of $\mathrm{H}^{+}$in tank number $1\left(\right.$ eq $\left.^{-1}\right)$ \\
\hline
\end{tabular}




\begin{tabular}{|c|c|}
\hline $\mathrm{q}_{\mathrm{H}, \mathrm{m}}$ & $\begin{array}{l}\text { Resin phase concentration of } \mathrm{H}^{+} \text {in tank number } \mathrm{m} \text { (where } \mathrm{m} \text { is a } \\
\text { number between } 2 \text { and } \mathrm{n} \text { ) }\left(\mathrm{eq} \mathrm{M}^{-1}\right)\end{array}$ \\
\hline $\mathrm{q}_{\mathrm{H}, \mathrm{k}}$ & $\begin{array}{l}\text { Resin phase concentration of } \mathrm{H}^{+} \text {in tank number } \mathrm{k} \text { (where } \mathrm{k} \text { is a } \\
\text { number between } 1 \text { and } \mathrm{n})\left(\mathrm{eq} \mathrm{M}^{-1}\right)\end{array}$ \\
\hline$\overline{\mathrm{q}}_{\mathrm{H}, \mathrm{k}}$ & $\begin{array}{l}\text { Dimensionless resin phase concentration of } \mathrm{H}^{+} \text {in tank number } \mathrm{k} \\
\text { (where } \mathrm{k} \text { is a number between } 1 \text { and } \mathrm{n} \text { ) (dimensionless) }\end{array}$ \\
\hline$q_{i}$ & Resin phase concentration of ion $\mathrm{i}\left(\mathrm{eq} \mathrm{M}^{-1}\right)$ \\
\hline $\bar{q}_{i}$ & Dimensionless resin phase concentration of ion i (dimensionless) \\
\hline$q_{i, 1}$ & Resin phase concentration of ion i in tank number $1\left(\right.$ eq M$\left.^{-1}\right)$ \\
\hline$\overline{\mathrm{q}}_{\mathrm{i}, 1}$ & $\begin{array}{l}\text { Dimensionless resin phase concentration of ion } \mathrm{i} \text { in tank number } 1 \\
\text { (dimensionless) }\end{array}$ \\
\hline $\mathrm{q}_{\mathrm{i}, \mathrm{m}}$ & $\begin{array}{l}\text { Resin phase concentration of ion } \mathrm{i} \text { in tank number } \mathrm{m} \text { (where } \mathrm{m} \text { is a } \\
\left.\text { number between } 2 \text { and } \mathrm{n} \text { ) ( eq } \mathrm{M}^{-1}\right)\end{array}$ \\
\hline$\overline{\mathrm{q}}_{\mathrm{i}, \mathrm{m}}$ & $\begin{array}{l}\text { Dimensionless resin phase concentration of ion } \mathrm{i} \text { in tank number } \mathrm{m} \\
\text { (where } \mathrm{m} \text { is a number between } 2 \text { and } \mathrm{n} \text { ) (dimensionless) }\end{array}$ \\
\hline$q_{i, k}$ & $\begin{array}{l}\text { Resin phase concentration of ion } i \text { in tank number } k \text { (where } k \text { is a } \\
\text { number between } 1 \text { and } n)\left(\text { eq M}^{-1}\right)\end{array}$ \\
\hline$\overline{\mathrm{q}}_{\mathrm{i}, \mathrm{k}}$ & $\begin{array}{l}\text { Dimensionless resin phase concentration of ion } \mathrm{i} \text { in tank number } \mathrm{k} \\
\text { (where } \mathrm{k} \text { is a number between } 1 \text { and } \mathrm{n} \text { ) (dimensionless) }\end{array}$ \\
\hline $\mathrm{q}_{\mathrm{Na}}$ & Resin phase concentration of $\mathrm{Na}^{+}\left(\mathrm{eq} \mathrm{M}^{-1}\right)$ \\
\hline$\overline{\mathrm{q}}_{\mathrm{Na}}$ & Dimensionless resin phase concentration of $\mathrm{Na}^{+}$(dimensionless) \\
\hline $\mathrm{q}_{\mathrm{Na}, 1}$ & Resin phase concentration of $\mathrm{Na}^{+}$in tank number $1\left(\right.$ eq M$\left.^{-1}\right)$ \\
\hline$\overline{\mathrm{q}}_{\mathrm{Na}, 1}$ & $\begin{array}{l}\text { Dimensionless resin phase concentration of } \mathrm{Na}^{+} \text {in tank number } 1 \\
\text { (dimensionless) }\end{array}$ \\
\hline$q_{N a, m}$ & $\begin{array}{l}\text { Resin phase concentration of } \mathrm{Na}^{+} \text {in tank number } \mathrm{m} \text { (where } \mathrm{m} \text { is a } \\
\text { number between } 2 \text { and } \mathrm{n} \text { ) }\left(\mathrm{eq} \mathrm{M}^{-1}\right)\end{array}$ \\
\hline
\end{tabular}


$\overline{\mathrm{q}}_{\mathrm{Na}, \mathrm{m}}$

$q_{\mathrm{Na}, \mathrm{k}}$

$\overline{\mathrm{q}}_{\mathrm{Na}, \mathrm{k}}$

$\mathrm{q}_{\mathrm{OH}}$

$\overline{\mathrm{q}}_{\mathrm{OH}}$

$\mathrm{q}_{\mathrm{OH}, 1}$

$\mathrm{q}_{\mathrm{OH}, \mathrm{m}}$

$\mathrm{q}_{\mathrm{OH}, \mathrm{k}}$

$\overline{\mathrm{q}}_{\mathrm{OH}, \mathrm{k}}$

$\mathrm{q}_{\text {presaturant, } A}$

$\mathrm{q}_{\text {presaturant,A,k }}$

$\overline{\mathrm{q}}_{\text {presaturant,A,k }}$

$\mathrm{q}_{\text {presaturant, }, \mathrm{C}}$

$\mathrm{q}_{\text {presaturant, }, \mathrm{C}, \mathrm{k}}$

Dimensionless resin phase concentration of $\mathrm{Na}^{+}$in tank number $\mathrm{m}$ (where $\mathrm{m}$ is a number between 2 and $\mathrm{n}$ ) (dimensionless) Resin phase concentration of $\mathrm{Na}^{+}$in tank number $\mathrm{k}$ (where $\mathrm{k}$ is a number between 1 and $n)\left(\right.$ eq $\left.^{-1}\right)$

Dimensionless resin phase concentration of $\mathrm{Na}^{+}$in tank number $\mathrm{k}$ (where $\mathrm{k}$ is a number between 1 and $\mathrm{n}$ ) (dimensionless)

Resin phase concentration of $\mathrm{OH}^{-}\left(\right.$eq M $\left.^{-1}\right)$

Dimensionless resin phase concentration of $\mathrm{OH}^{-}$(dimensionless )

Resin phase concentration of $\mathrm{OH}^{-}$in tank number $1\left(\right.$ eq M$\left.^{-1}\right)$

Resin phase concentration of $\mathrm{OH}^{-}$in tank number $\mathrm{m}$ (where $\mathrm{m}$ is a number between 2 and $n)\left(\right.$ eq $\left.^{-1}\right)$

Resin phase concentration of $\mathrm{OH}^{-}$in tank number $\mathrm{k}$ (where $\mathrm{k}$ is a number between 1 and $n)\left(\right.$ eq M$\left.^{-1}\right)$

Dimensionless resin phase concentration of $\mathrm{OH}^{-}$in tank number $\mathrm{k}$ (where $\mathrm{k}$ is a number between 1 and $\mathrm{n}$ ) (dimensionless)

Resin phase concentration of the presaturant ion on the anionic exchange resin $\left(\right.$ eq $\left.^{-1}\right)$

Resin phase concentration of the presaturant ion on the anionic exchange resin in tank number $\mathrm{k}\left(\mathrm{eq} \mathrm{M}^{-1}\right)$

Dimensionless resin phase concentration of the presaturant ion on the anionic exchange resin in tank number $\mathrm{k}$ (dimensionless) Resin phase concentration of the presaturant ion on the cationic exchange resin $\left(\right.$ eq $\left.^{-1}\right)$

Resin phase concentration of the presaturant ion on the cationic exchange resin in tank number $\mathrm{k}_{\left(\mathrm{eq} \mathrm{M}^{-1}\right)}$ 
$\overline{\mathrm{q}}_{\text {presaturant,C,k }}$ Dimensionless resin phase concentration of the presaturant ion on the cationic exchange resin in tank number $\mathrm{k}$ (dimensionless)

\begin{tabular}{|c|c|}
\hline$q_{T}$ & Total resin capacity $\left(\right.$ eq $\left.\mathrm{M}^{-1}\right)$ \\
\hline$q_{T, A}$ & Total resin capacity of anionic exchange resin $\left(\right.$ eq $\left.^{-1}\right)$ \\
\hline$q_{T, C}$ & Total resin capacity of cationic exchange resin $\left(\right.$ eq M $\left.^{-1}\right)$ \\
\hline Q & Water flow rate $\left(\mathrm{L}^{3} \mathrm{~T}^{-1}\right)$ \\
\hline $\mathrm{t}$ & Elapsed time ( $\mathrm{T}$ ) \\
\hline $\mathrm{T}$ & Elapsed time (dimensionless) \\
\hline V & Total system volume for all tanks $\left(\mathrm{L}^{3}\right)$ \\
\hline$\alpha_{\mathrm{OH}}^{\mathrm{Cl}}$ & Separation factor (dimensionless) \\
\hline$\alpha_{\mathrm{Cl}}^{\mathrm{OH}}$ & Separation factor (dimensionless) \\
\hline$\alpha_{H}^{\mathrm{Na}}$ & Separation factor (dimensionless) \\
\hline$\alpha_{\mathrm{Na}}^{\mathrm{H}}$ & Separation factor (dimensionless) \\
\hline$\alpha_{j}^{i}$ & Separation factors ( dimensionless ) \\
\hline$\varepsilon$ & Bed porosity (dimensionless) \\
\hline$\tau$ & Packed bed contact time $(T)$ \\
\hline
\end{tabular}

Appendix VI.B - Detailed Description of Transferring Single CSTR Model Equations into Dimensionless Form

The dimensionless variables were defined above:

$$
\begin{gathered}
\overline{\mathrm{C}_{0, \mathrm{i}}}=\frac{1}{\mathrm{t}} \int_{0}^{\mathrm{t}} \mathrm{C}_{0, \mathrm{i}}(\mathrm{t}) \mathrm{dt} \\
\overline{\mathrm{C}_{\mathrm{T}, \text { avg }, \mathrm{A}}}=\sum_{\mathrm{j}=1}^{\mathrm{m}} \overline{\mathrm{C}_{0, \mathrm{j}}} \quad \text { where } \mathrm{m}=\text { number of anions } \\
\overline{\mathrm{C}_{\mathrm{Cl}, 0}}=\frac{\mathrm{C}_{\mathrm{Cl}, 0}}{\overline{\mathrm{C}_{0, \mathrm{Cl}}}} \\
\overline{\mathrm{b}_{\mathrm{Cl}}}=\mathrm{b}_{\mathrm{Cl}}\left(\overline{\mathrm{C}_{0, \mathrm{H}}}\right)\left(\overline{\mathrm{C}_{0, \mathrm{Cl}}}\right)
\end{gathered}
$$




$$
\mathrm{T}=\frac{\mathrm{t}}{\mathrm{C}_{\mathrm{F}} \tau}
$$

where:

$$
\begin{gathered}
C_{F}=\frac{M_{A} q_{T}}{V \overline{C_{T, a v g, A}} \varepsilon} \\
C_{F, C l}=\frac{M_{A} q_{T}}{V \overline{C_{0, C l}} \varepsilon} \\
\tau=\frac{V \varepsilon}{Q} \\
\frac{d}{d t}=\frac{1}{C_{F} \tau} \frac{d}{d T}
\end{gathered}
$$

The final form of the dimensioned equation for the single CSTR model was given by:

$$
\frac{d C_{C l}}{d t}=\frac{C_{C l, 0}-C_{C l}}{\frac{M_{A}}{Q}\left[\frac{q_{T} b_{C l} C_{H}}{\left(1+b_{C l} C_{H} C_{C l}\right)^{2}}\right]+\frac{\varepsilon V}{Q}}
$$

Conversion of Equation VI-9 into dimensionless form is more complicated. A step by step conversion is presented below.

$$
\begin{aligned}
& \frac{\overline{C_{0, C l}}}{C_{F} \tau} \frac{d\left(\frac{C_{C l}}{\overline{C_{0, C l}}}\right)}{d\left(\frac{t}{C_{F} \tau}\right)}=\frac{\overline{C_{0, C l}}\left(\frac{C_{C l, 0}}{\overline{C_{0, C l}}}-\frac{C_{C I}}{\overline{C_{0, C l}}}\right)}{\frac{M_{A}}{Q}\left[\frac{\mathrm{q}_{\mathrm{T}} b_{C l} C_{H}}{\left(1+b_{C l} C_{H} C_{C l}\right)^{2}}\right]+\frac{\varepsilon V}{Q}} \Rightarrow
\end{aligned}
$$

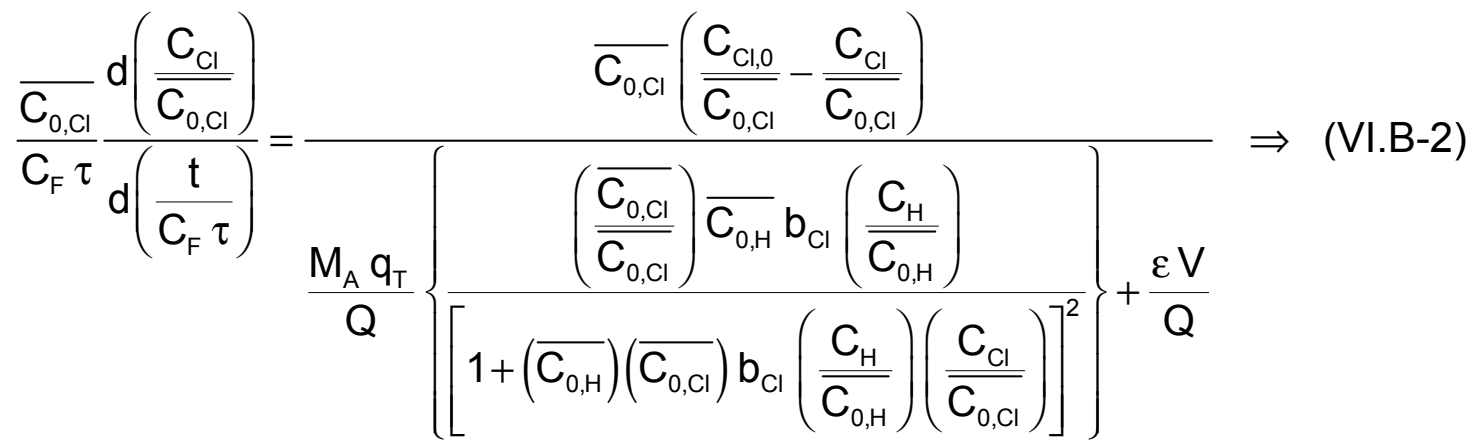




$$
\begin{aligned}
& \frac{d\left(\frac{C_{C l}}{\overline{C_{0, C l}}}\right)}{d\left(\frac{t}{C_{F} \tau}\right)}=\frac{\left(\overline{C_{C l, 0}}-\overline{C_{C l}}\right)}{\frac{M_{A} q_{T}}{Q \overline{C_{0, C l}} C_{F} \tau}\left\{\frac{\overline{b_{C l}} \overline{C_{H}}}{\left[1+\bar{b}_{C l} \overline{C_{H}} \overline{C_{C l}}\right]^{2}}\right\}+\frac{\varepsilon V}{Q_{C_{F}} \tau}} \Rightarrow \\
& \frac{d \overline{C_{C l}}}{d T}=\frac{\left(\overline{C_{C l, 0}}-\overline{C_{C l}}\right)}{\frac{M_{A} q_{T}}{Q \overline{C_{0, C l}} C_{F} \frac{\varepsilon V}{Q}}\left\{\frac{\bar{b}_{C l} \overline{C_{H}}}{\left[1+\bar{b}_{C l} \overline{C_{H}} \overline{C_{C l}}\right]^{2}}\right\}+\frac{\varepsilon V}{Q C_{F} \frac{\varepsilon V}{Q}}} \Rightarrow \\
& \frac{d \overline{C_{C l}}}{d T}=\frac{\left(\overline{C_{C l, 0}}-\overline{C_{C l}}\right)}{\left(\frac{M_{A} q_{T}}{\overline{C_{0, C l}} \varepsilon V}\right)\left(\frac{1}{C_{F}}\right)\left\{\frac{\bar{b}_{C l} \overline{C_{H}}}{\left[1+\bar{b}_{C l} \overline{C_{H}} \overline{C_{C l}}\right]^{2}}\right\}+\frac{1}{C_{F}}} \Rightarrow \\
& \frac{d \overline{\mathrm{C}_{\mathrm{Cl}}}}{\mathrm{dT}}=\frac{\left(\overline{\mathrm{C}_{\mathrm{Cl}, 0}}-\overline{\mathrm{C}_{\mathrm{Cl}}}\right)}{\left(\frac{\mathrm{C}_{\mathrm{F}, \mathrm{Cl}}}{\mathrm{C}_{\mathrm{F}}}\right)\left\{\frac{\overline{\mathrm{b}}_{\mathrm{Cl}} \overline{\mathrm{C}_{\mathrm{H}}}}{\left[1+\overline{\mathrm{b}}_{\mathrm{Cl}} \overline{\mathrm{C}_{\mathrm{H}}} \overline{\mathrm{C}_{\mathrm{Cl}}}\right]^{2}}\right\}+\frac{1}{\mathrm{C}_{\mathrm{F}}}}
\end{aligned}
$$


Appendix VII - Explanation of MFBMODEL Software Use

Quick Start: Getting Started with the MFBMODEL Software

Starting the MFBMODEL Program

Launch MFBMODEL from the program group where it is installed in windows. The title window shown in Figure VII - 1 will appear:

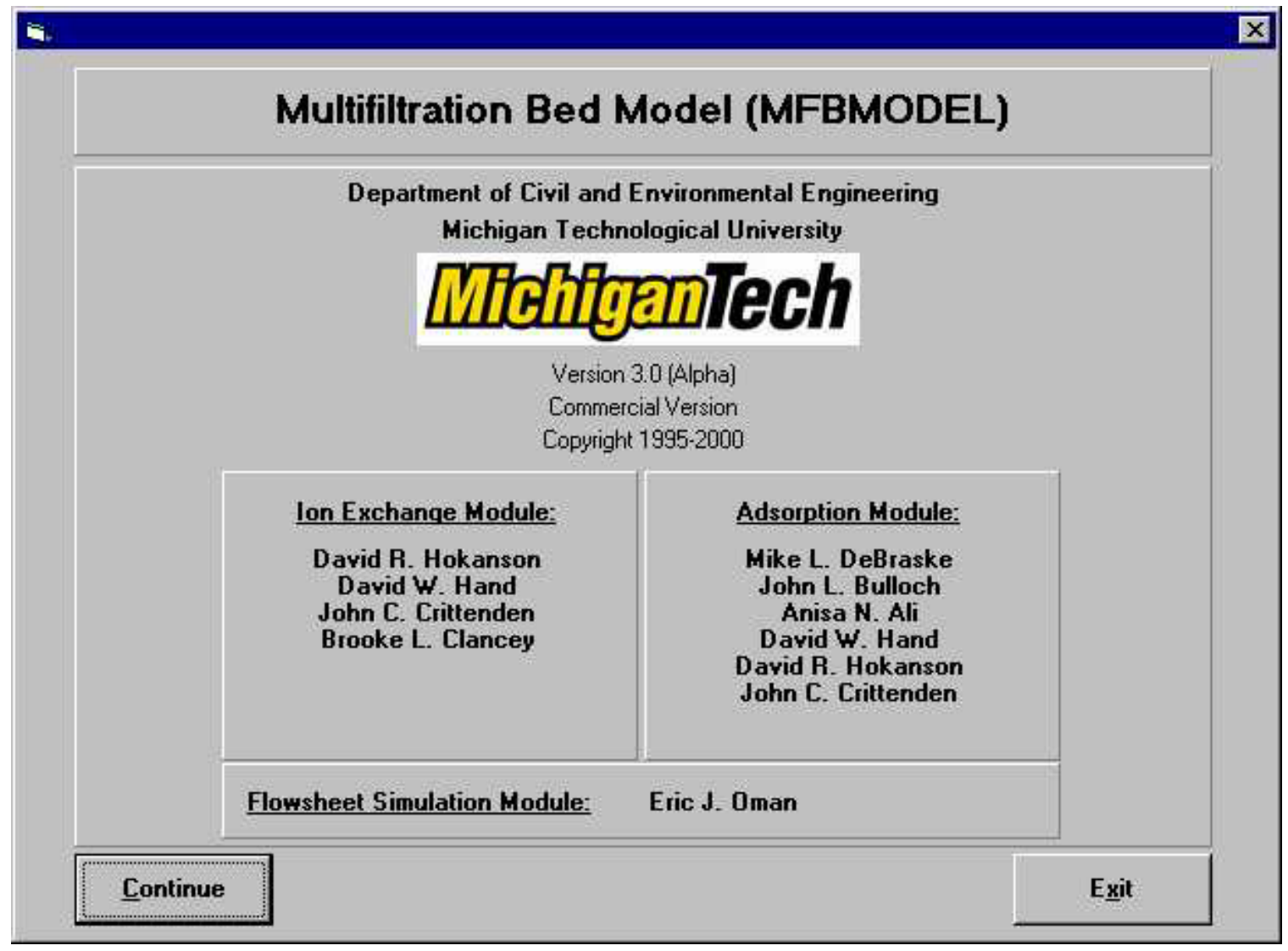

Figure VII - 1 - MFBMODEL Title Screen

Click on the Continue button shown in Figure VII - 1. The disclaimer window shown in Figure VII - 2 will appear. 


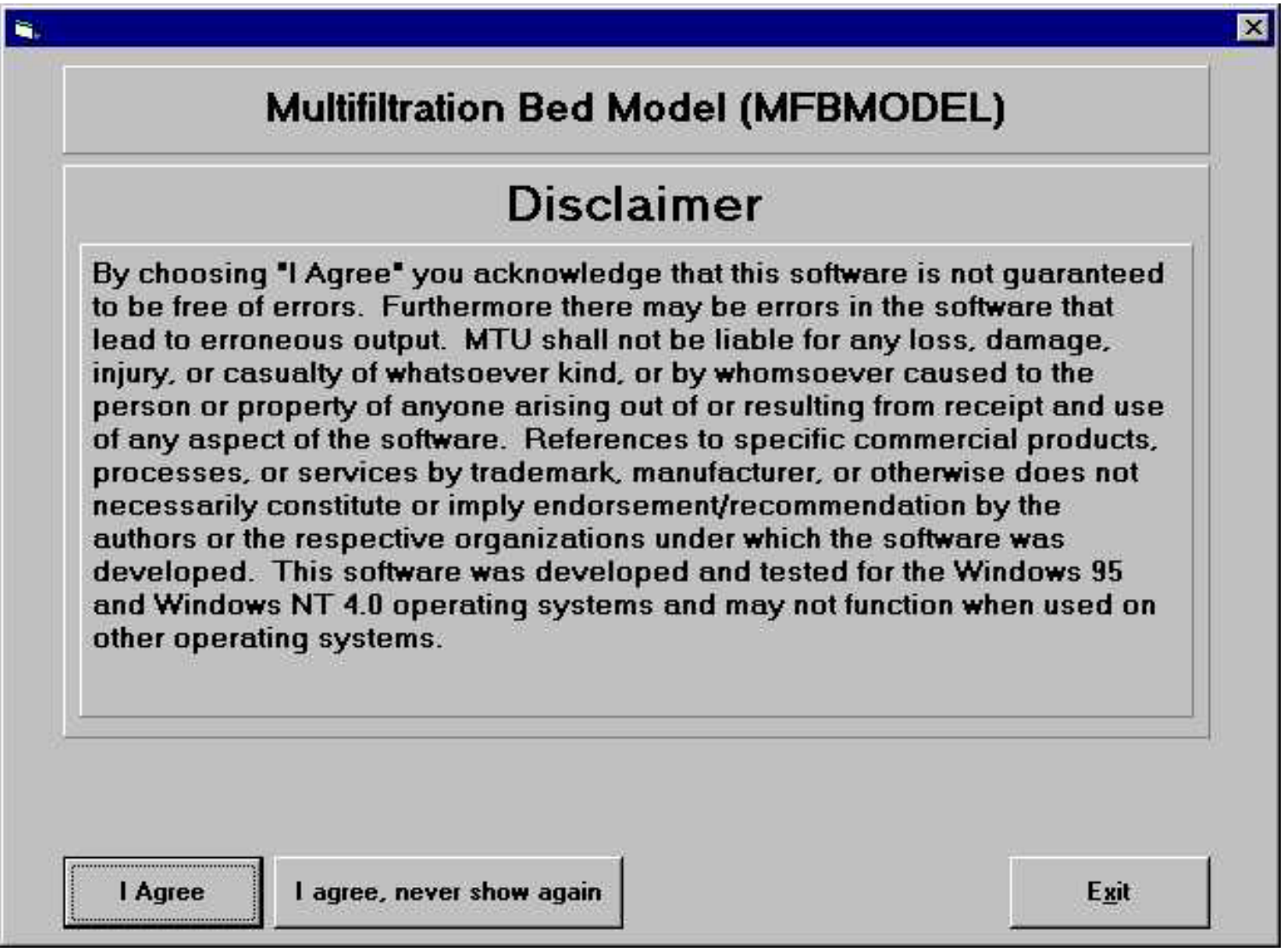

Figure VII - 2 - MFBMODEL Disclaimer Window

Click on the I Agree button or the I agree, never show again button shown in Figure VII - 2. Clicking either button will cause the window shown in to appear. Clicking the I agree, never show again button will result in the disclaimer window shown in Figure VII - 2 not appearing during startup of subsequent MFBMODEL sessions. The disclaimer window is available for viewing from the main MFBMODEL window in the Help menu ... View Disclaimer option. 
Opening an Existing MFBMODEL Simulation

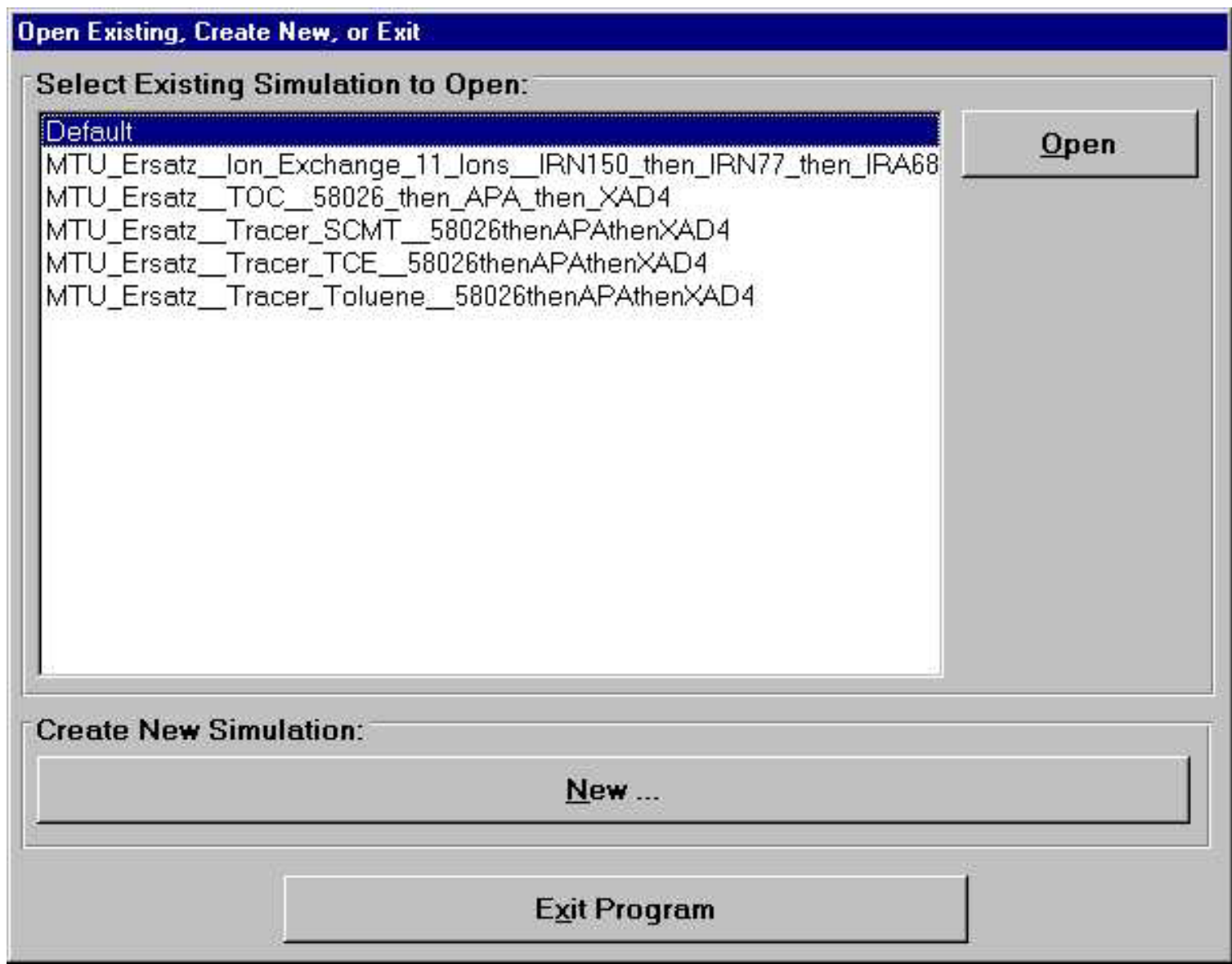

Figure VII - 3 - Open Existing or Create New Simulation Window

A default simulation, which is named Default in the list of existing simulations shown in Figure VII - 3, has been included with the MFBMODEL software package. Figure VII - 4 shows a schematic of the multifiltration bed configuration used in the default simulation, which consists of eight beds in series (three ion exchange resins followed by three adsorbents followed by two ion exchange resins).

Select the simulation Default in the Select Existing Simulation to Open list box shown in Figure VII - 3. Click on the Open button. The main MFBMODEL window will appear for the case of the default simulation, as shown in Figure VII - 5. 


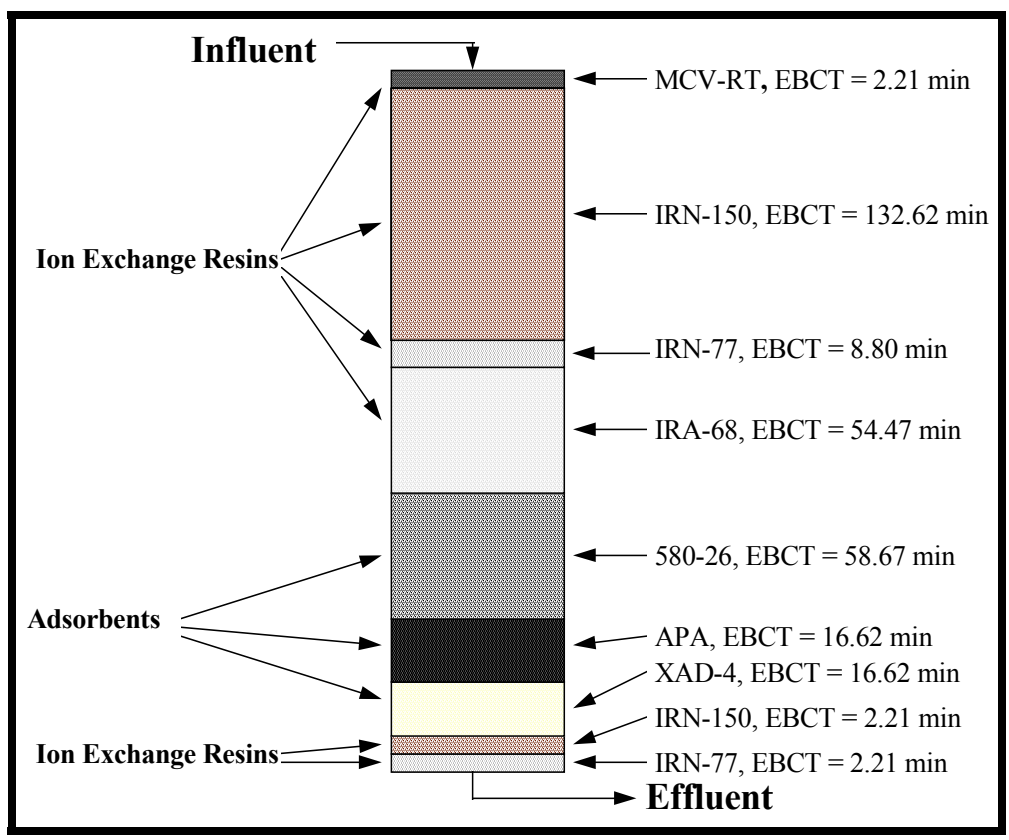

Figure VII - 4 - Schematic of the Multifiltration Bed Used in the Default Simulation

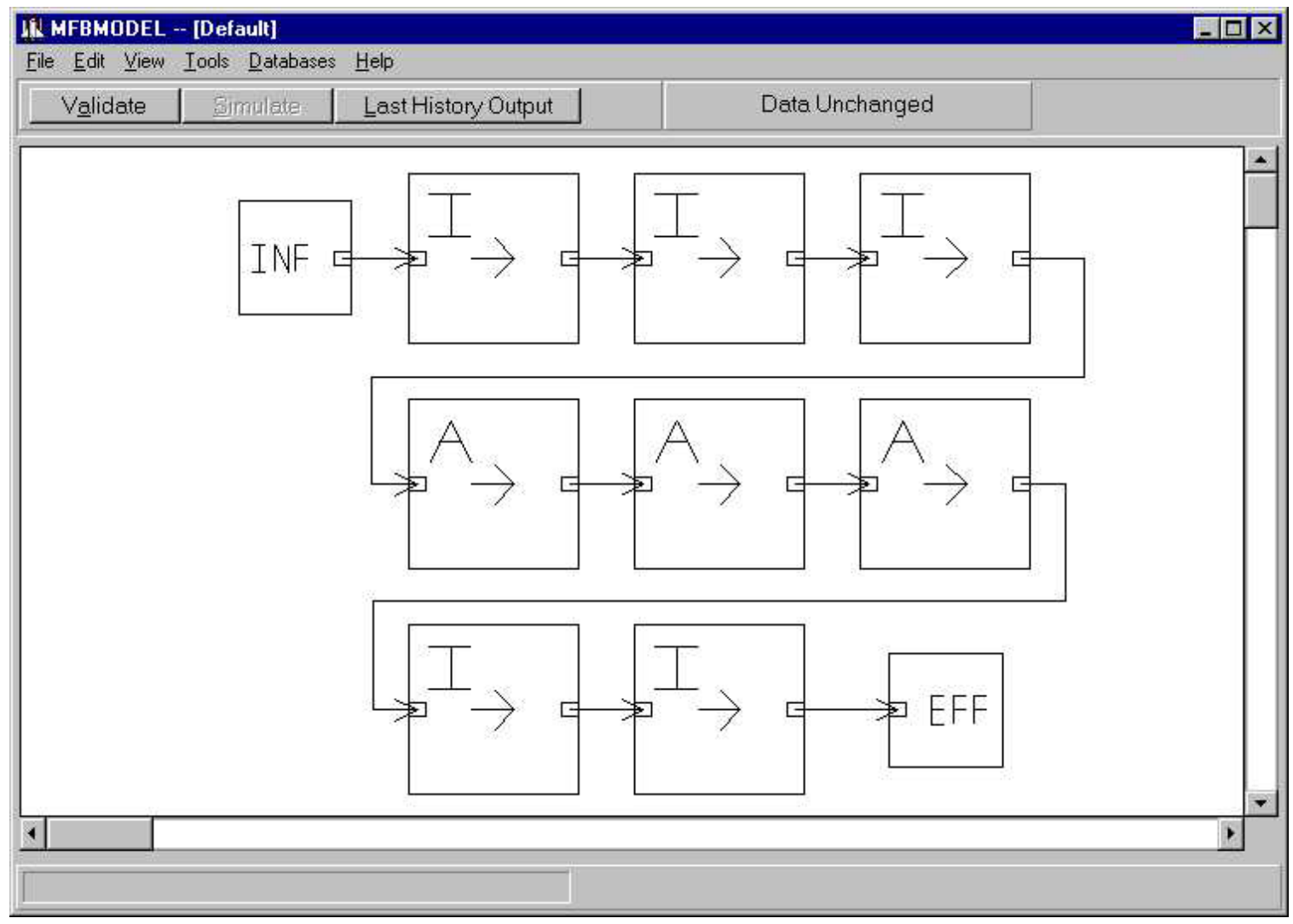

Figure VII - 5 - Main MFBMODEL Window for Default Simulation 


\section{Running an Existing MFBMODEL Simulation}

To run the Default simulation, it is first necessary to click on the Validate button in the upper left area of the main MFBMODEL window shown in Figure VII - 5. Before pressing the Validate button, the Simulate button shown in the upper left area of Figure VII - 5 is disabled. Provided there are no errors in the current simulation configuration, after pressing the Validate button, the Simulate button will become enabled, as shown in Figure VII - 6 .

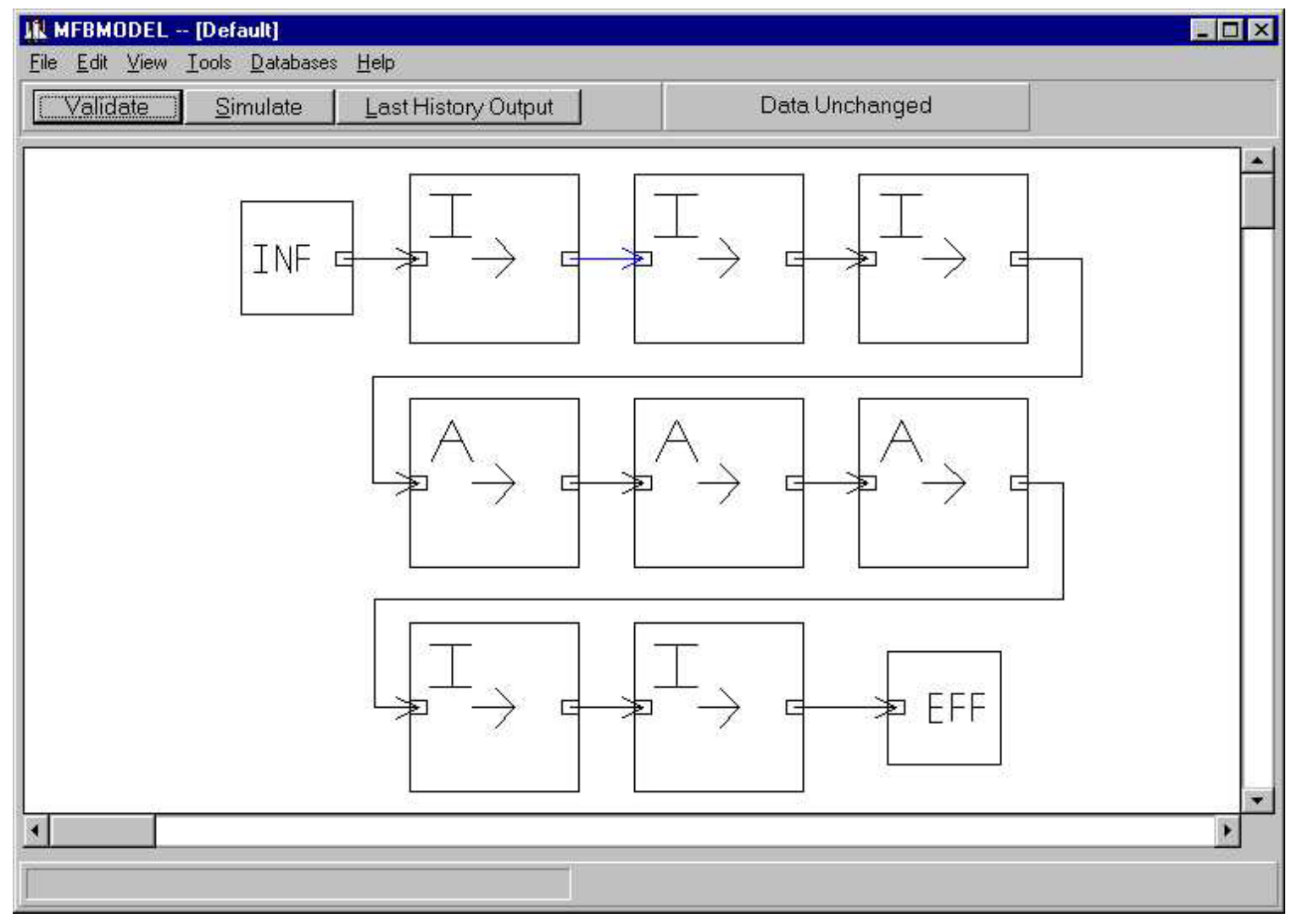

Figure VII - 6 - Main MFBMODEL Window after Validate Button Has Been Pressed

Once the Simulate button is enabled, pressing it will begin the MFBMODEL simulation. 
Click the Simulate button in Figure VII - 6. The simulation begins and will continue until each of eight beds in the Default simulation have been processed with either the TISEqM for ion exchange beds or the PSDM for adsorbent beds. During the run, for each bed, a window will pop up displaying progress of MFBMODEL toward completion of processing of a given bed. Figure VII - 7 shows the progress window displayed during processing of the first ion exchange bed (bed 1 of 8 in the default simulation). Figure VII - 8 shows the progress window shown during processing of the first adsorbent bed (bed 4 of 8 in the default simulation). For adsorbent simulations, progress is shown toward completion of each axial element, as shown in Figure VII - 8.

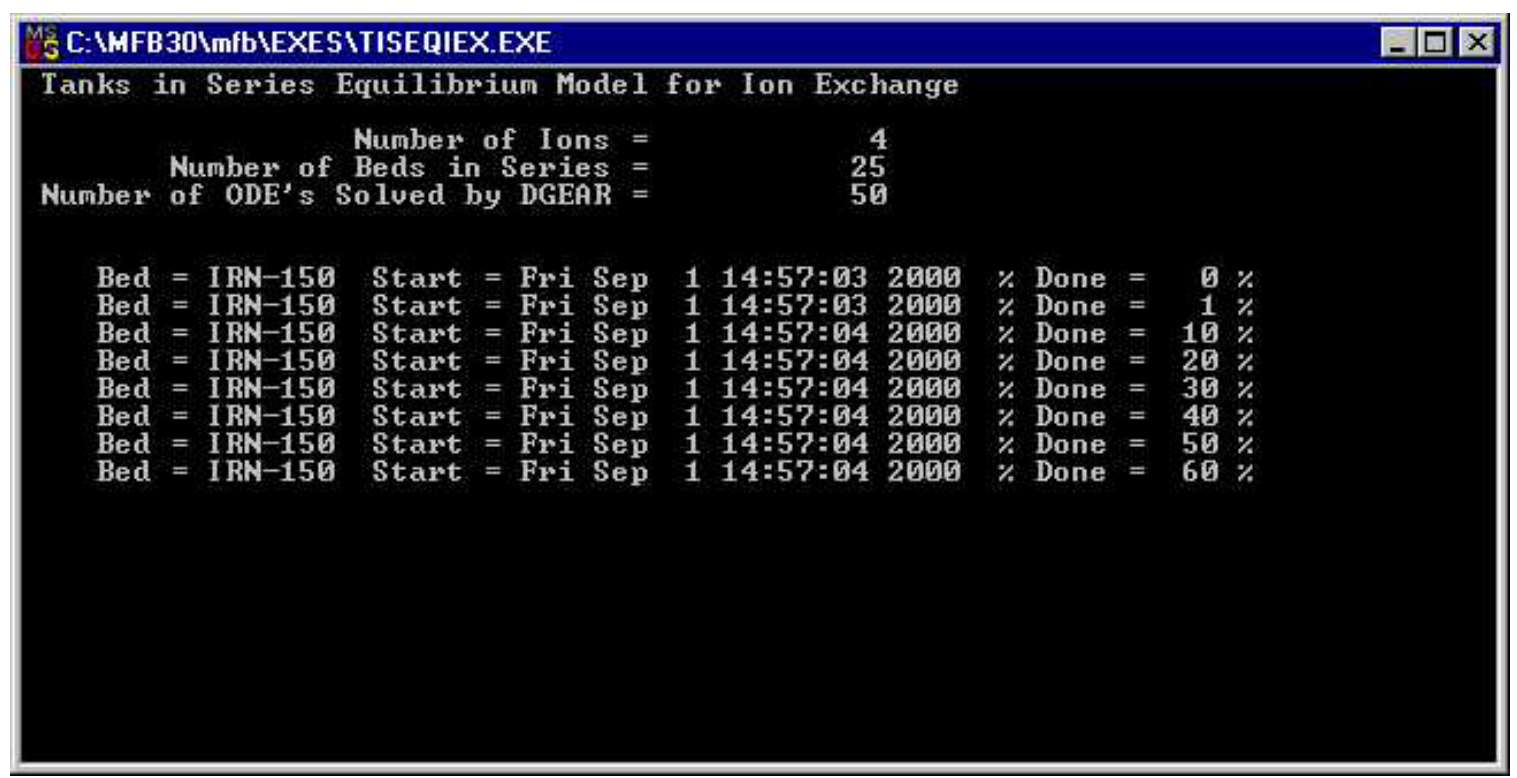

Figure VII - 7 - Progress Window for First lon Exchange Bed (Bed 1 of 8 ) in Default Simulation 


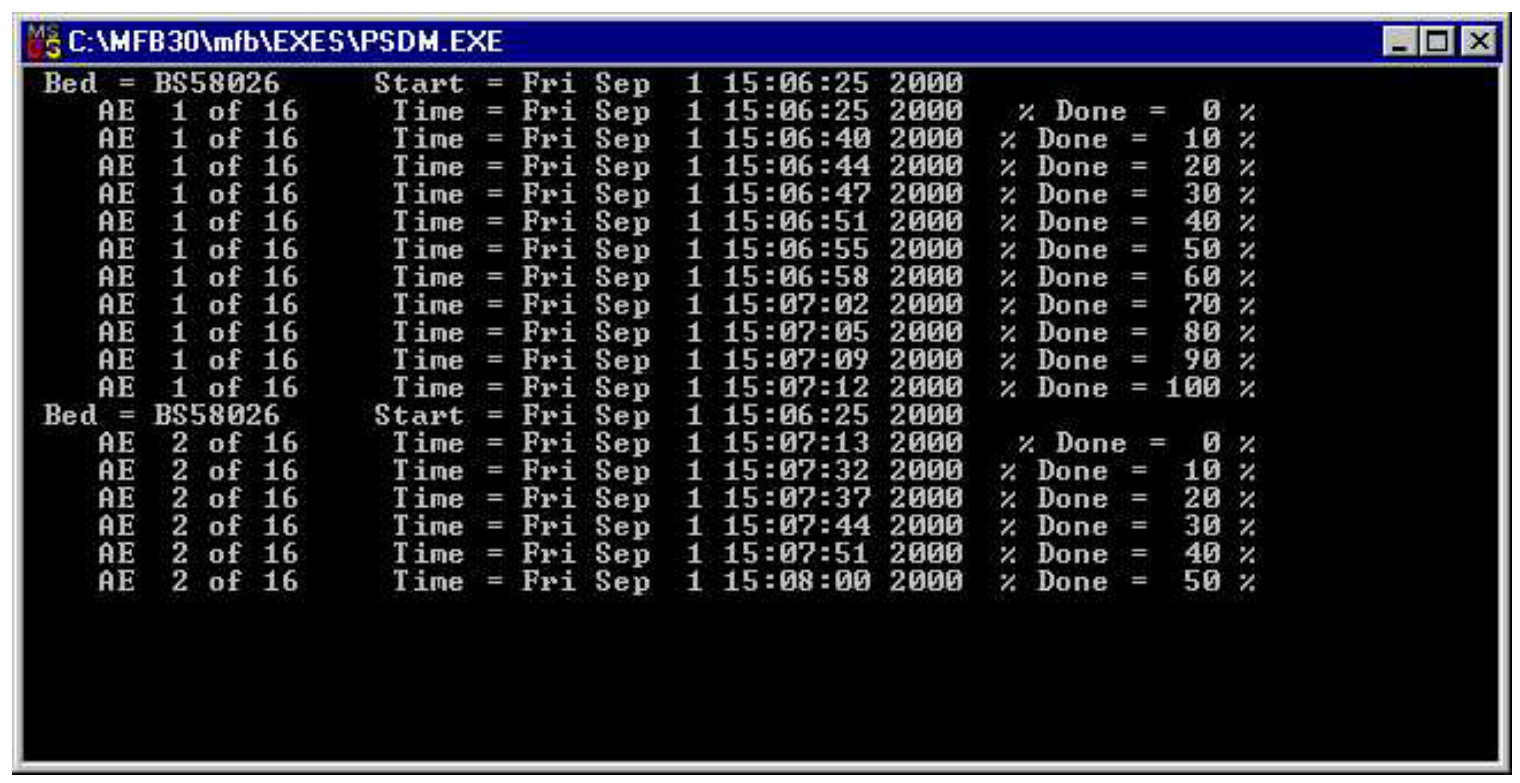

Figure VII - 8 - Progress Window for First Adsorbent Bed (Bed 4 of 8) in Default Simulation

When the MFBMODEL simulation is complete, the Simulation History window will be shown, indicating that the simulation has been completed and how long it took to process each bed. Figure VII - 9 shows the Simulation History window for the default simulation. Even though the total simulation time is not displayed in Figure VII - 9, it is available by scrolling further down the Simulation History window to the bottom. This simulation was performed on a Pentium III $500 \mathrm{MHz}$ computer with $384 \mathrm{MB}$ of SDRAM and the total simulation time was approximately 85 minutes. Click on the Close button shown in Figure VII - 9 to close the Simulation History window. After the Simulation History window has been closed, the most recent simulation history is available to the user by clicking the Last History Output button in the upper left area of the main MFBMODEL window shown in Figure VII - 6. 


\section{Close}

09/01/2000 10:57:18 AM : MFBMODEL Version 3.0.61 (Standard)

09/01/2000 10:57:18 AM : BEGAN SIMULATION

09/01/2000 10:57:18 AM : Began simulation of lon Exchange Bed 'lon Bed 1'

09/01/2000 10:57:27 AM: Spent 0.15 minutes on this bed.

09/01/2000 10:57:27 AM: Performing adjustment algorithm on this bed

09/01/2000 10:57:27 AM: Copied VCO file forward (no call to AD.JFCCMT needed)

09/01/2000 10:57:27 AM : Began simulation of lon Exchange Bed 'lon Bed 2'

09/01/2000 10:57:56 AM: Spent 0.48 minutes on this bed.

09/01/2000 10:57:56 AM: Performing adjustment algorithm on this bed

09/01/2000 10:57:56 AM: Copied VCO file forward (no call to AD.JFCCMT needed)

09/01/2000 10:57:56 AM : Began simulation of lon Exchange Bed 'lon Bed 3'

09/01/2000 10:58:32 AM: Spent 0.60 minutes on this bed.

09/01/2000 10:58:32 AM: Performing adjustment algorithm on this bed

09/01/2000 10:58:32 AM: Copied VCO file forward (no call to AD.JFCCMT needed)

09/01/2000 10:58:32 AM : Began simulation of Adsorption Bed '580-26 Adsorption Bed'

09/01/2000 11:34:11 AM: Spent 35.65 minutes on this bed.

09/01/2000 11:34:11 AM: Performing adjustment algorithm on this bed

Figure VII - 9 - Simulation History Window for the Default Simulation

Note: At any point during an MFBMODEL run, the simulation can be stopped using the command sequence: <control> C.

\section{Obtaining Output Information from an MFBMODEL Simulation}

To obtain effluent concentration profiles from the series of eight beds simulated, situate the mouse pointer over the last bed simulated (Ion Bed 5; Bed

8 of 8 ), which is the bed immediately preceding the box labeled "EFF" in the main MFBMODEL window (see Figure VII -6). With the mouse pointer over this last ion exchange bed, click the right mouse button and select the View Effluent option from the pop up menu that appears upon clicking the right mouse, as shown in Figure VII - 10. 


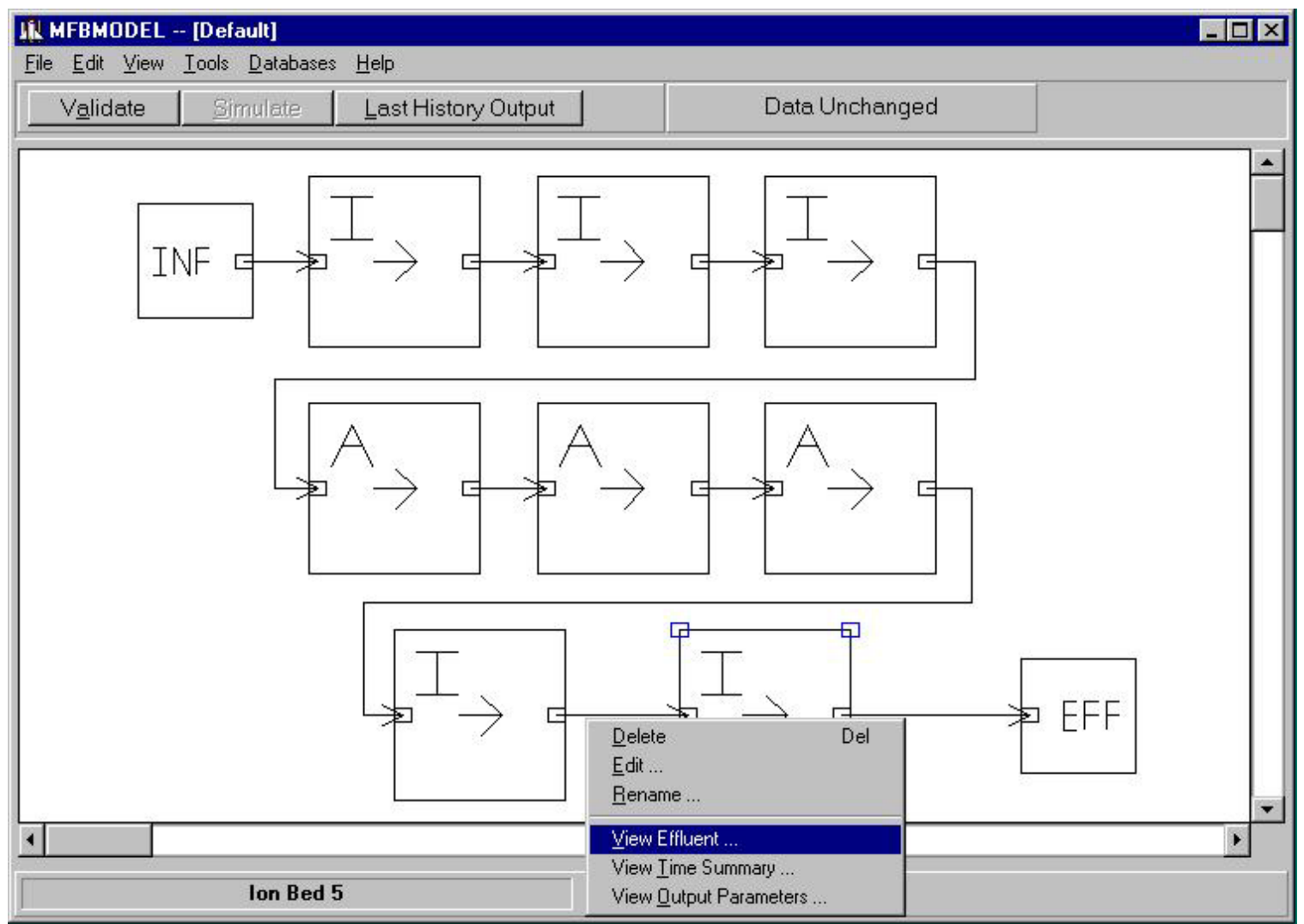

Figure VII - 10 - View Effluent Option for Displaying Simulation Output

The View Effluent command will generate a grid showing adsorption and ion exchange effluent profiles from the final bed in the series. A progress window will appear on the screen while the grid is being generated. Once grid generation is complete, the effluent concentration information will appear on the screen in the grid, as shown in Figure VII - 11. The grid that appears will contain seven tabs. The first tab, labeled "TOC", contains a Table of Contents (TOC) showing the information available in each of the tabs within the grid. This TOC tab is shown in Figure VII - 11. As shown in Figure VII - 11, the additional six tabs in the grid are labeled as follows:

Tab 2 - "timePOWTbvfFLOW_Results"; Tab 3 - "Adsorbate Conc. vs Time";

Tab 4 - "Adsorbate Conc. vs Pounds H2O"; Tab 5 - "Anion Conc. vs Time";

Tab 6 - "Cation Conc. vs Time"; and Tab 7 - "Notes".

Description of the information available on each tab is provided below. All of the output information is provided in tabular format; there is no graphical information provided. 


\begin{tabular}{|c|c|c|c|c|c|c|c|}
\hline \multicolumn{7}{|c|}{ A, lon Exchange Bed [lon Bed 5] } & 回区 \\
\hline \multicolumn{8}{|c|}{ File Édit } \\
\hline & A & B & C & D & $E$ & $F$ & $\Delta$ \\
\hline 1 & Workb & \multicolumn{2}{|c|}{ Table of Contents. } & & & & \\
\hline 2 & & & & & & & \\
\hline 3 & Tab & \multicolumn{2}{|c|}{ Description } & & & & \\
\hline 4 & & TOC & & & & & \\
\hline 5 & & \multicolumn{3}{|c|}{ timePOWTbvFLOW_Results } & & & \\
\hline 6 & & \multicolumn{3}{|c|}{ Adsorbate Conc. vs Time } & & & \\
\hline 7 & & \multicolumn{4}{|c|}{ Adsorbate Conc. vs Pounds $\mathrm{H} 2 \mathrm{O}$} & & \\
\hline 8 & & \multicolumn{2}{|c|}{ Anion Conc. vs Time } & & & & \\
\hline 9 & & \multicolumn{2}{|c|}{ Cation Conc. vs Time } & & & & \\
\hline 10 & & Notes & & & & & - \\
\hline \multicolumn{6}{|c|}{ 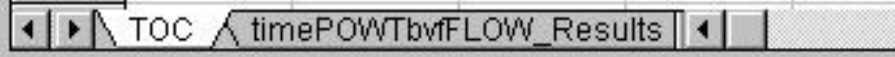 } & \multicolumn{2}{|c|}{ - } \\
\hline
\end{tabular}

\section{Figure VII - 11 - Results Grid from Effluent of the Default Simulation}

Figure VII - 12 shows the MFBMODEL results grid for tab 2:

"timePOWTbvfFLOW_Results". This tab contains information on the flowrate to MFBMODEL as a function of time, pounds of water treated (POWT) and bed volumes fed (BVF). It is particularly useful for a variable flow simulation, where the flow varies as a function of time, to verify that the variable flow scenario is set up as anticipated. The following information is available in this tab, as shown in Figure VII - 12 for the default simulation, which is a constant flow simulation at a flowrate of $10 \mathrm{lb} . \mathrm{H}_{2} \mathrm{O} / \mathrm{hr}$ ). Column "A" contains time in minutes. Column "B" contains Pounds of Water Treated (POWT). Column "C" contains Bed Volumes Fed (BVF). Column "D" contains Flowrate in $\mathrm{m}^{3} / \mathrm{s}$. Column "E" contains Flowrate in $\mathrm{lb} . / \mathrm{hr}$. 


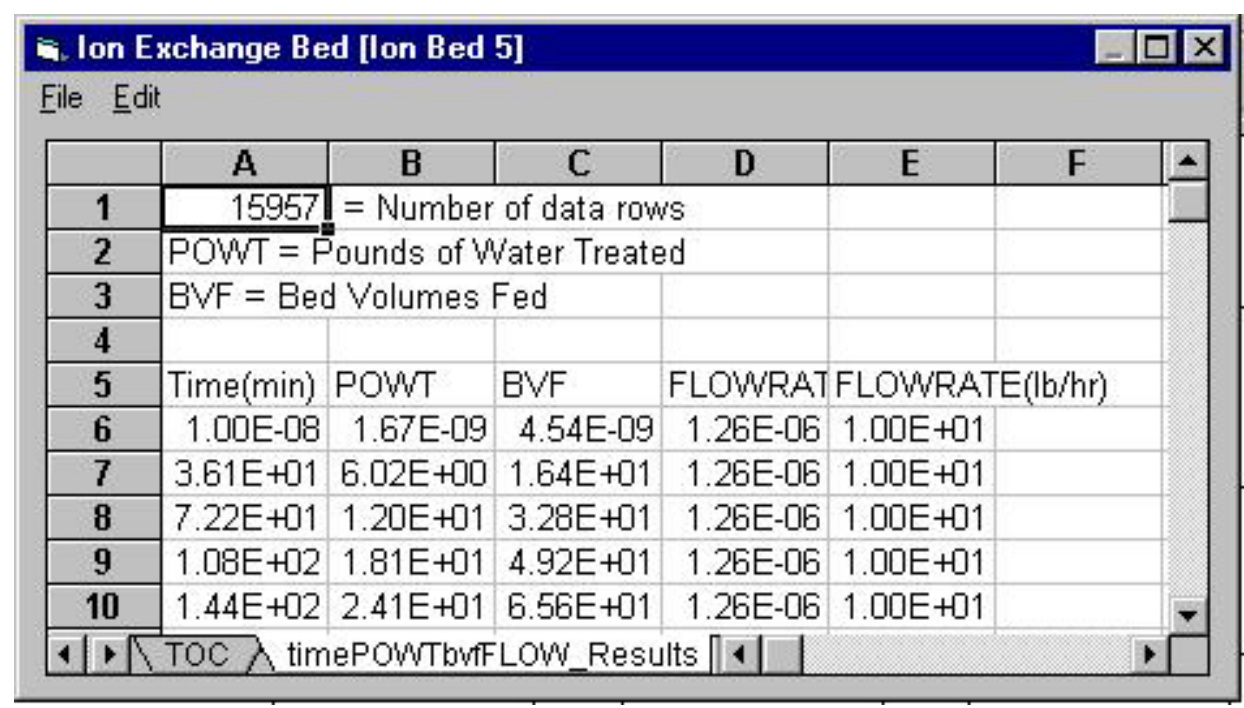

\section{Figure VII - 12 - MFBMODEL Results Grid for Tab 2: "timePOWTbvfFLOW_Results"}

Figure VII - 13 shows the MFBMODEL results grid for tab 3: "Adsorbate Conc. vs Time". This tab contains information on adsorbate concentration (adsorbate equals tracer toluene for the case of the default simulation) as a function of time. Column "A" contains time in minutes. Column "B" contains adsorbate concentration in units of $\mu \mathrm{g} / \mathrm{L}$.

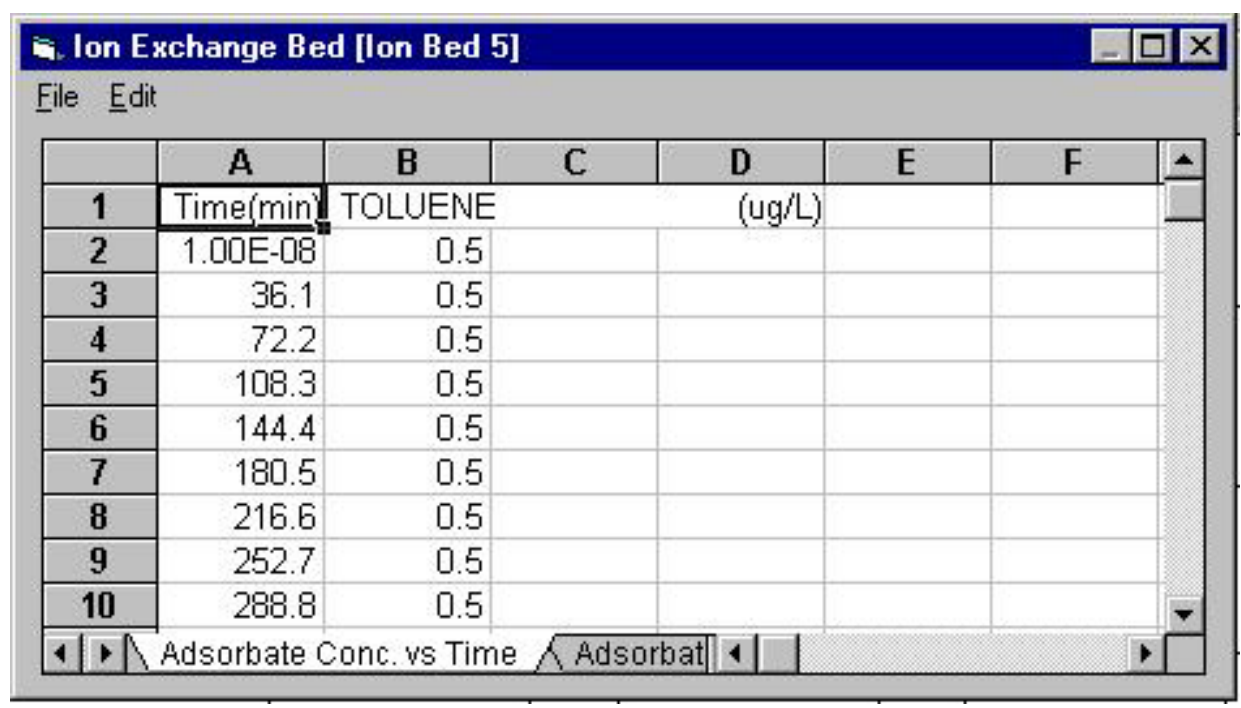

Figure VII - 13 - MFBMODEL Results Grid for Tab 3: "Adsorbate Conc. vs Time"

Figure VII - 14 shows the MFBMODEL results grid for tab 4: "Adsorbate Conc. vs Pounds H2O". This tab contains information on adsorbate 
concentration as a function of pounds of water treated. Column "A" contains pounds of water treated. Column "B" contains adsorbate concentration in units of $\mu \mathrm{g} / \mathrm{L}$.

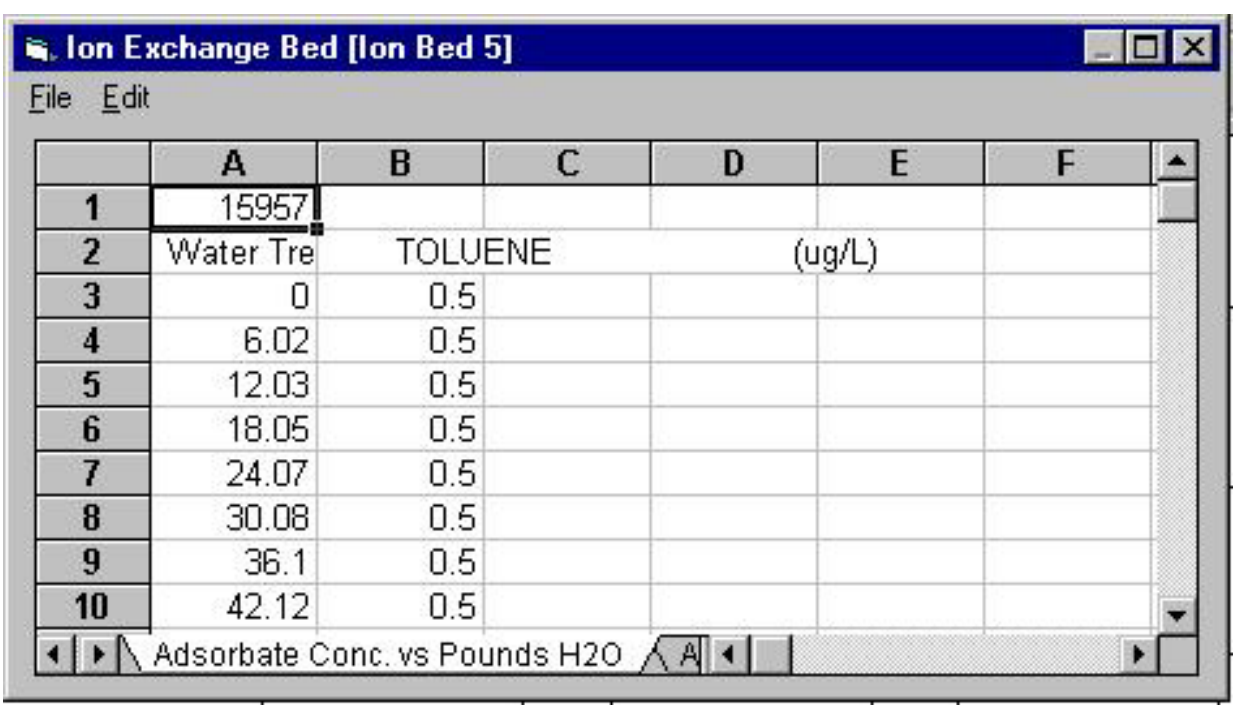

Figure VII - 14 - Results Grid for Tab 4: "Adsorbate Conc. vs Pounds H2O" Figure VII - 15 shows MFBMODEL results grid for tab 5: "Anion Conc. vs Time". This tab contains information on anion concentration profiles in various units (e.g., $\mathrm{mg} / \mathrm{L}$, meq/L and reduced concentration $\left[\mathrm{C} / \mathrm{C}_{0}\right]$ ) for each of the anions present in the default simulation (hydroxide, chloride) as a function of time (minutes and days), pounds of water treated (POWT) and bed volumes fed (BVF). Column "A" contains time in minutes. Column "B" contains time in days. Column "C" contains POWT. Column "D" contains BVF. Column "E" contains hydroxide concentration in $\mathrm{mg} / \mathrm{L}$. Column "F" contains chloride concentration in mg/L. Column "G" contains hydroxide concentration in meq/L. Column "H" contains chloride concentration in meq/L. Column "I" contains hydroxide concentration represented as reduced concentration $\left(C / \mathrm{C}_{0}\right)$. Column "J" contains chloride concentration represented as reduced concentration $\left(C / C_{0}\right)$. 


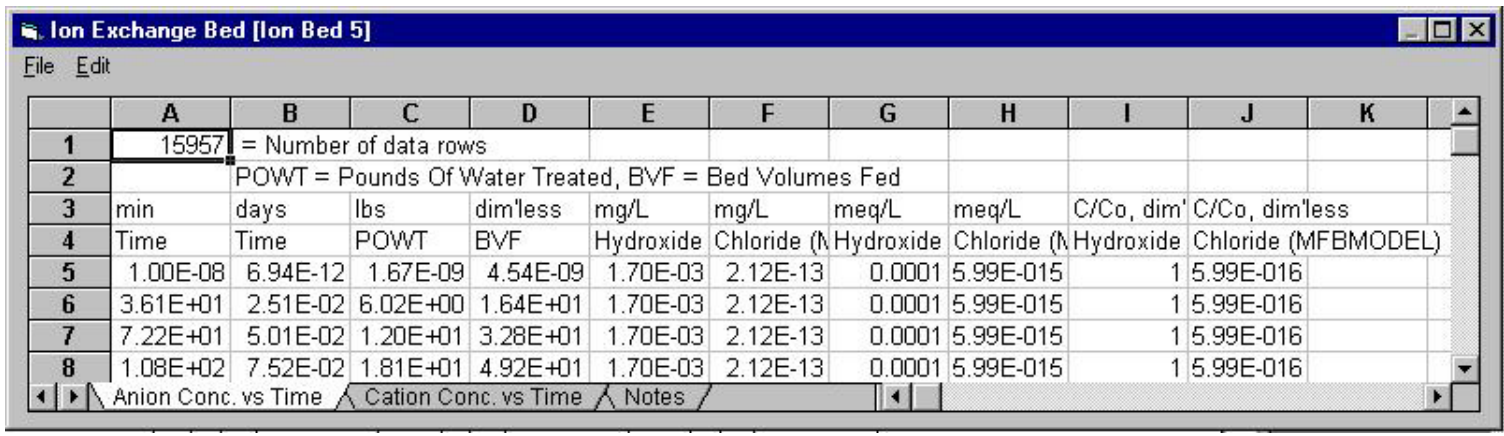

\section{Figure VII - 15 - Results Grid for Tab 5: "Anion Conc. vs Time"}

Figure VII - 16 shows the MFBMODEL results grid for tab 6: "Cation Conc. vs Time". This tab contains information on cation concentration profiles in various units (e.g., mg/L, meq/L and reduced concentration $\left[\mathrm{C} / \mathrm{C}_{0}\right]$ ) for each of the cations present in the default simulation (sodium, hydrogen) as a function of time (minutes and days), pounds of water treated (POWT) and bed volumes fed (BVF). Column "A" contains time in minutes. Column "B" contains time in days. Column "C" contains POWT. Column "D" contains BVF. Column "E" contains hydrogen concentration in $\mathrm{mg} / \mathrm{L}$. Column " $\mathrm{F}$ " contains sodium concentration in mg/L. Column "G" contains hydrogen concentration in meq/L. Column "H" contains sodium concentration in meq/L. Column "l" contains hydrogen concentration represented as reduced concentration $\left(C / \mathrm{C}_{0}\right)$. Column "J" shows sodium concentration represented as reduced concentration $\left(C / C_{0}\right)$.

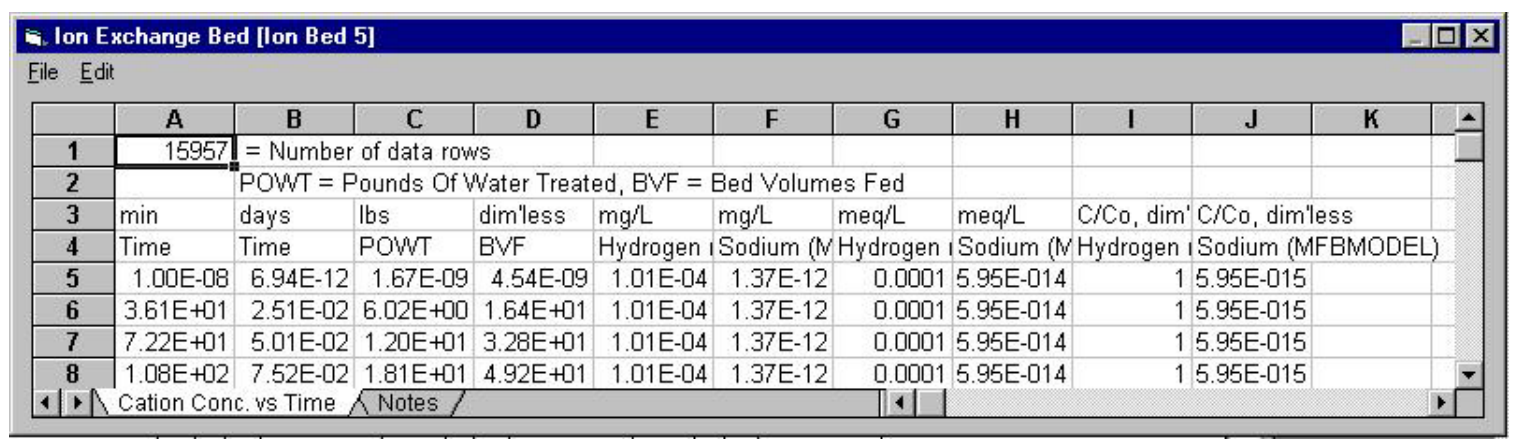

Figure VII - 16 - Results Grid for Tab 6: "Cation Conc. vs Time"

Tab 7 is a "Notes" tab where the user may place any notes about the simulation. It contains no output information. 
The MFBMODEL results grid is not generated in Microsoft Excel $₫$, but it may be saved in Excel format (MS Excel 5.0/95 format, which is readable with newer Excel versions). To save the MFBMODEL results in Excel format, choose Save As... from the File menu on the grid. Figure VII - 17 shows the Save As window, where the user may specify a file name and folder location for storing the MFBMODEL results. For this example case, the results file is given the name "effluent.xls" and stored in the ..Imfb folder.

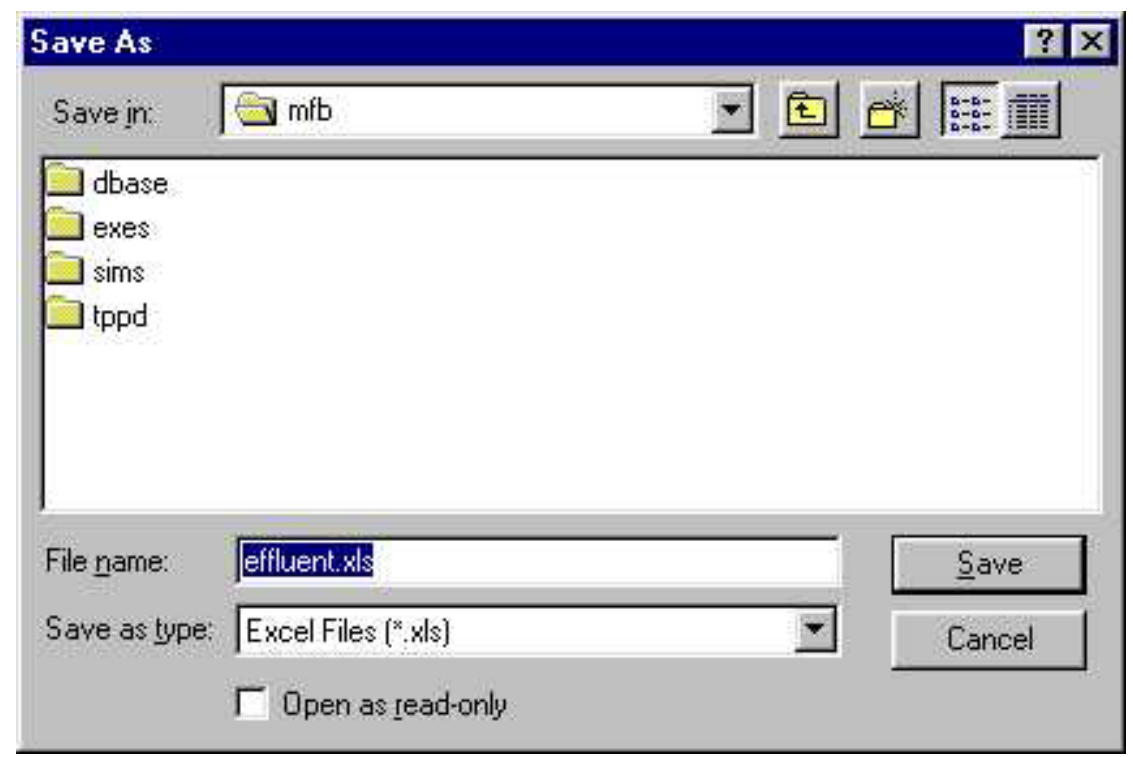

Figure VII - 17 - Save As Window for the MFBMODEL Results Grid

\section{Plotting MFBMODEL Results Using Microsoft Excel}

Once the MFBMODEL results information is saved in this manner, it is possible to plot the results using Microsoft Excel. Generating the results plots is the responsibility of the user, as they are not automatically created using the MFBMODEL software. Fortunately, it is straightforward to generate plots based on the information available in the results grid, which was saved in Excel format under the name "effluent.xls" in the MFBMODEL folder (..Imfb).

The following method represents the authors' method for generating results charts using Excel. The user is free to use this method or another method of their choosing to generate results charts based on the information in "effluent.xls". The results below will be created using Microsoft Excel 97. Open 
effluent.xls in Excel. If using a newer version of Excel than version 5.0/95, it is recommended to save effluent.xls in the current version of Excel format via the Save As... command in Excel. In the Save As Type dropdown list, change the selected item from "Microsoft Excel 5.0/95 Workbook (".xls) to "Microsoft Excel Workbook (".xls)". Figure VII - 18 shows the Excel Save As window after this change in Save As Type has been made. After clicking the Save button, choose to overwrite the existing version of effluent.xls.

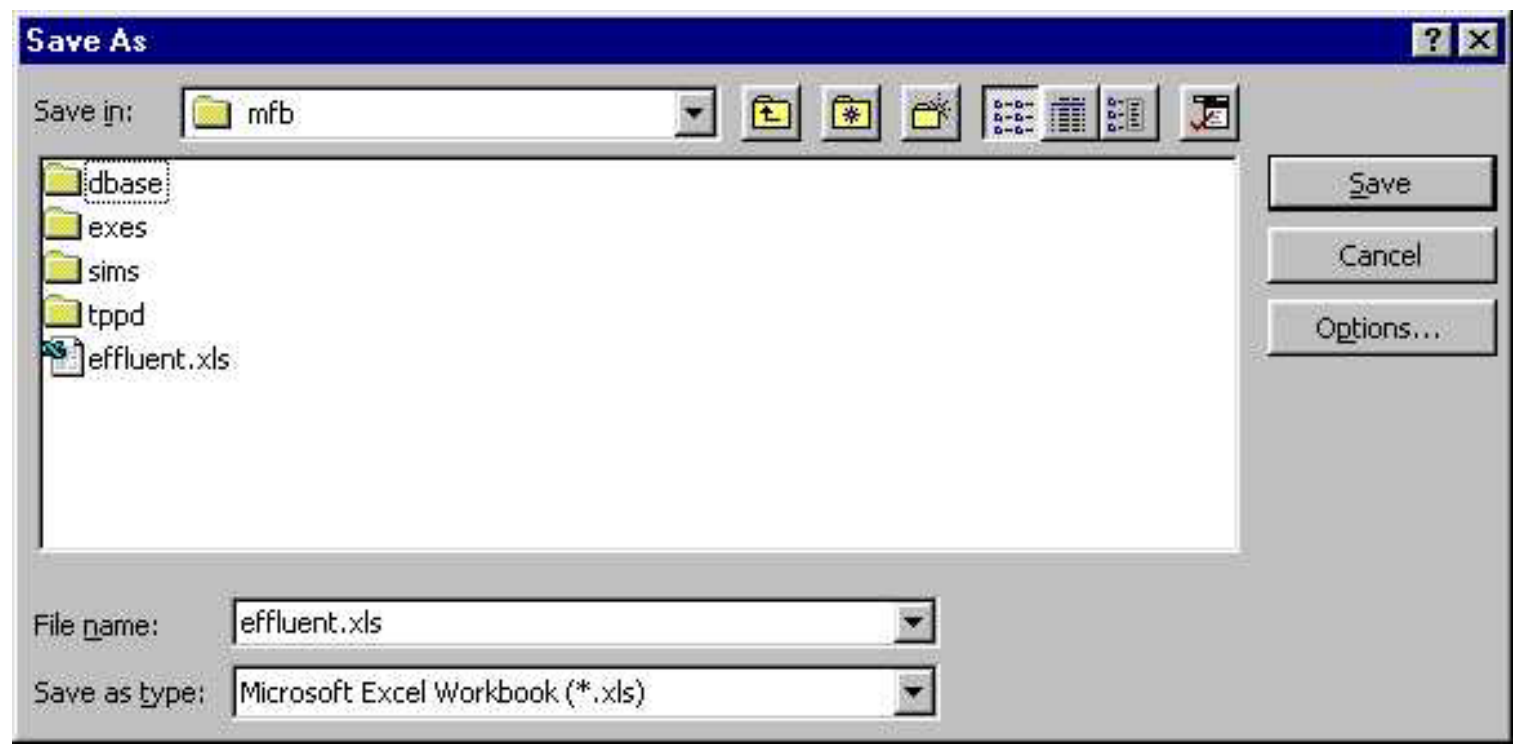

Figure VII - 18 - Save As Window in Microsoft Excel

Any of the information in effluent.xls may be plotted. To showcase the results, the following three charts will be created: Chart 1 - Toluene $(\mathrm{mg} / \mathrm{L})$ versus Pounds of Water Treated; Chart 2 - Sodium (mg/L) versus Pounds of Water Treated; and Chart 3 - Chloride $(\mathrm{mg} / \mathrm{L})$ versus Pounds of Water Treated. A new sheet, named "Chart1 Data" is created in effluent.xls and placed at the end of the workbook. This new sheet will contain the data to be plotted, including the Pounds of Water treated information from the sheet "Adsorbate Conc. vs Pounds H2O". This new sheet will also contain the toluene concentration information, but note that the toluene concentration values from sheet "Adsorbate Conc. vs Pounds H2O" are converted to units of mg/L for display on Chart1. Figure VII - 19 shows the formulas used on the Chart1 Data worksheet based on 
the information stored in effluent.xls from MFBMODEL. The data on the Chart1 Data sheet is plotted on a chart on a sheet named "Chart1".

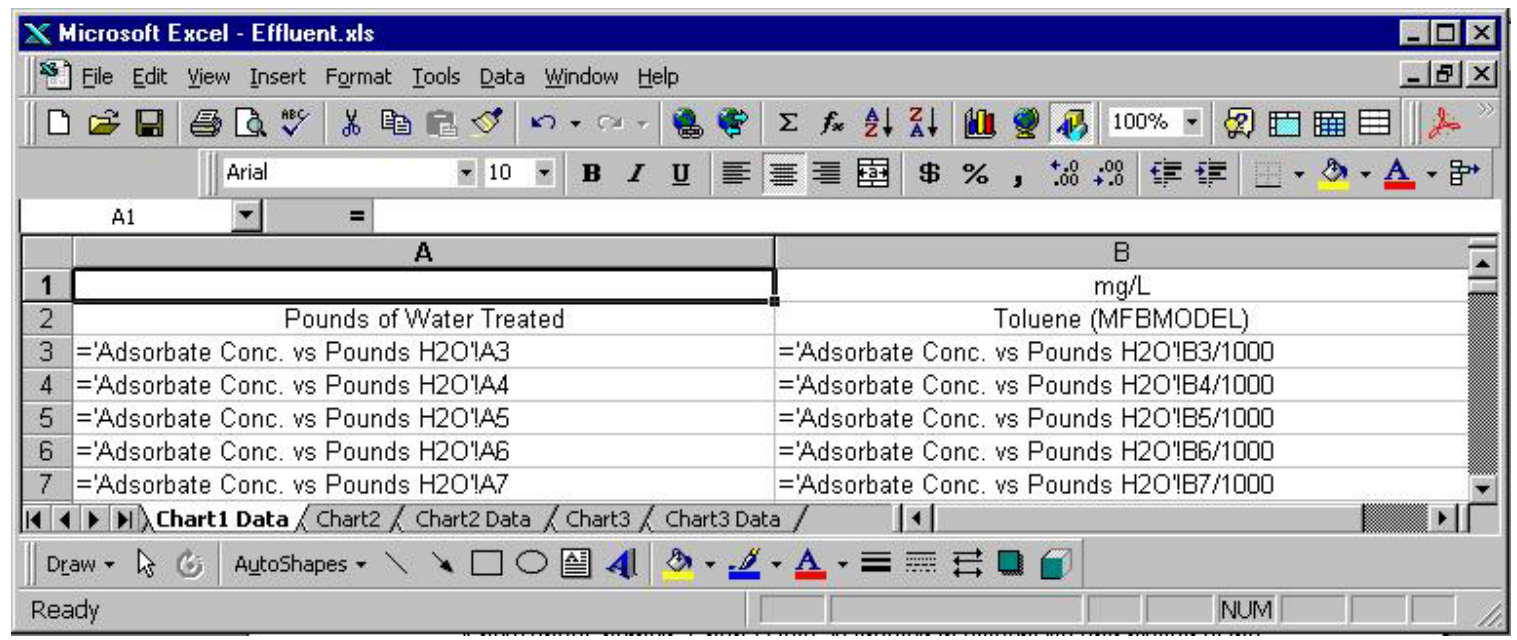

Figure VII - 19 - Excel Formulas on the Chart1 Data Worksheet

A new sheet, named "Chart2 Data" is created in effluent.xls and placed at the end of the workbook. This new sheet will contain the data to be plotted for sodium, including the Pounds of Water treated and sodium (mg/L) information from the sheet "Cation Conc. vs Time". Figure VII - 20 shows the formulas used on the Chart2 Data worksheet based on the information stored in effluent.xls from MFBMODEL. The data on the Chart2 Data sheet is plotted on a chart on a sheet named "Chart2".

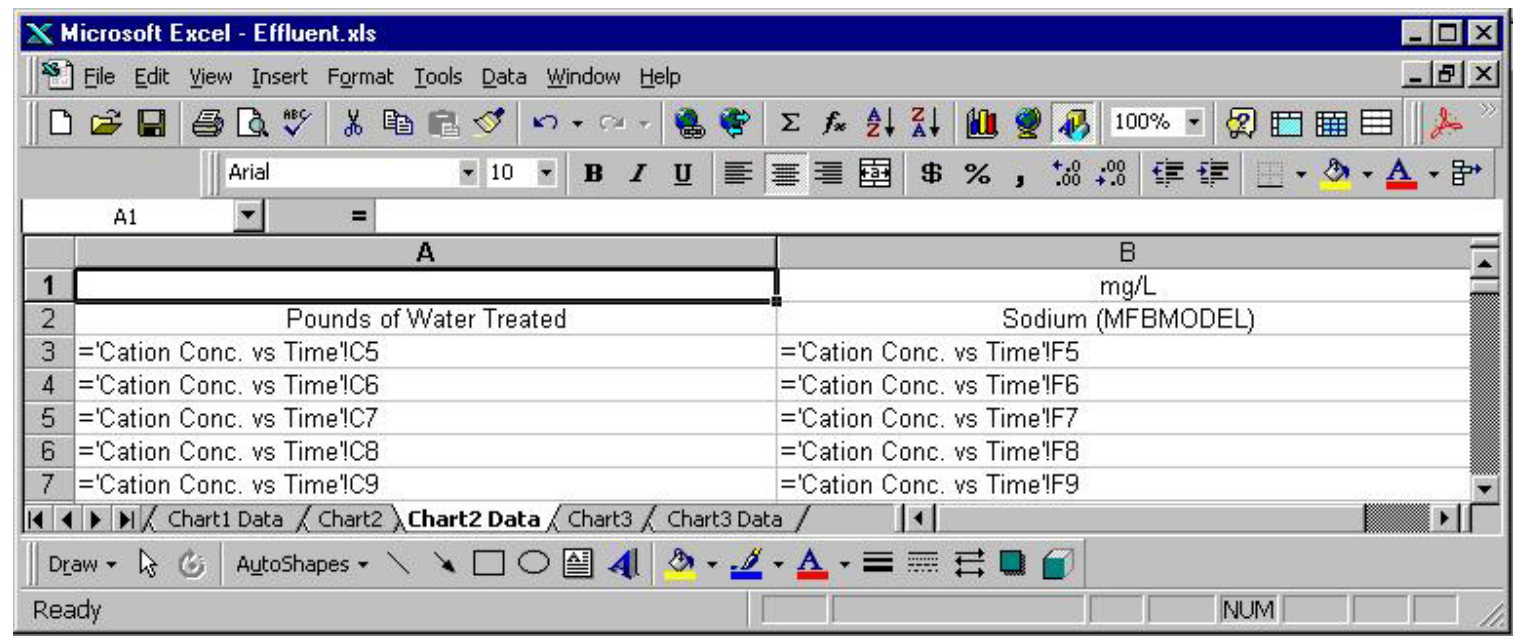

Figure VII - 20 - Excel Formulas on the Chart2 Data Worksheet 
A new sheet, named "Chart3 Data" is created in effluent.xls and placed at the end of the workbook. This new sheet will contain the data to be plotted for chloride, including the Pounds of Water treated and chloride $(\mathrm{mg} / \mathrm{L})$ information from the sheet "Anion Conc. vs Time". Figure VII - 21 shows the formulas used on the Chart3 Data worksheet based on the information stored in effluent.xls from MFBMODEL. The data on the Chart3 Data sheet is plotted on a chart on a sheet named "Chart3".

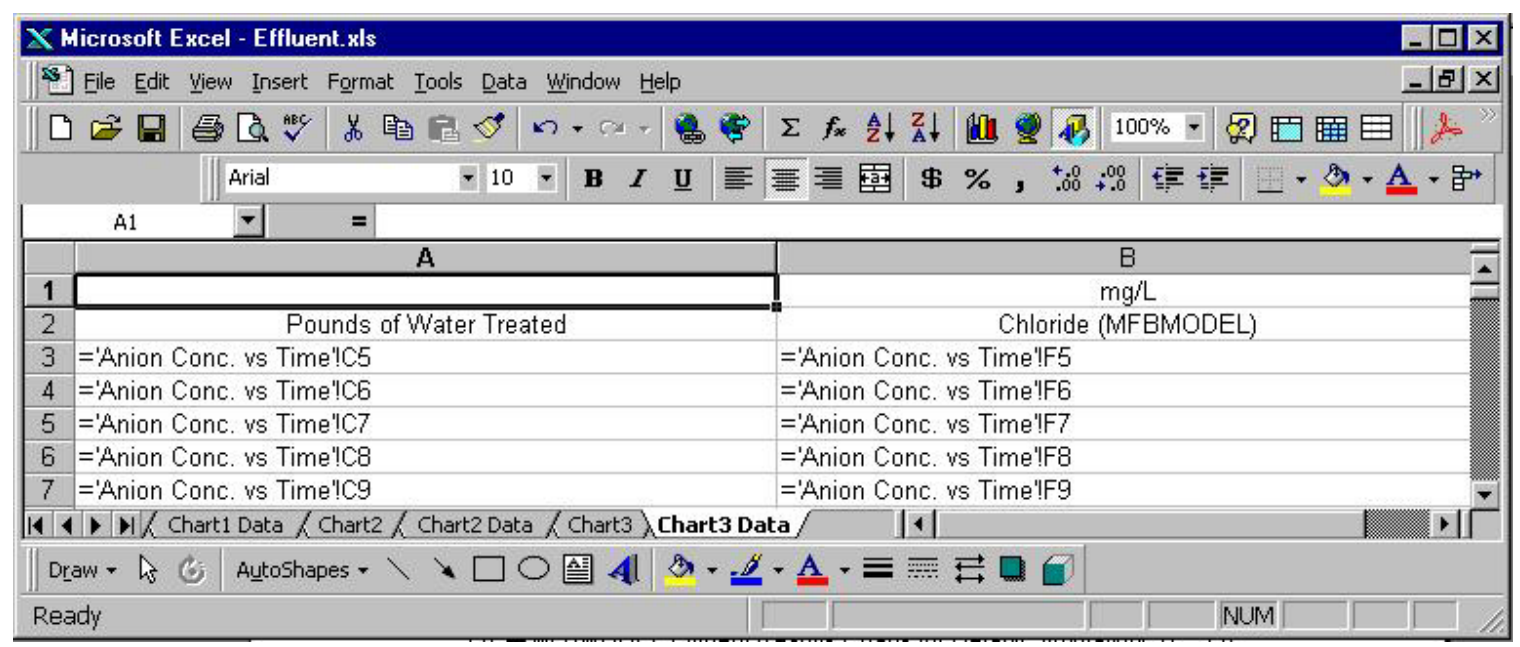

Figure VII - 21 - Excel Formulas on the Chart3 Data Worksheet MFBMODEL Effluent Results Charts for Default Simulation

Figure VII - 22 shows toluene $(\mathrm{mg} / \mathrm{L})$ as a function of pounds of water treated for the default simulation (Chart1). Figure VII - 23 shows sodium (mg/L) as a function of pounds of water treated for the default simulation (Chart2). Figure VII - 24 shows chloride $(\mathrm{mg} / \mathrm{L})$ as a function of pounds of water treated for the default simulation (Chart3). 


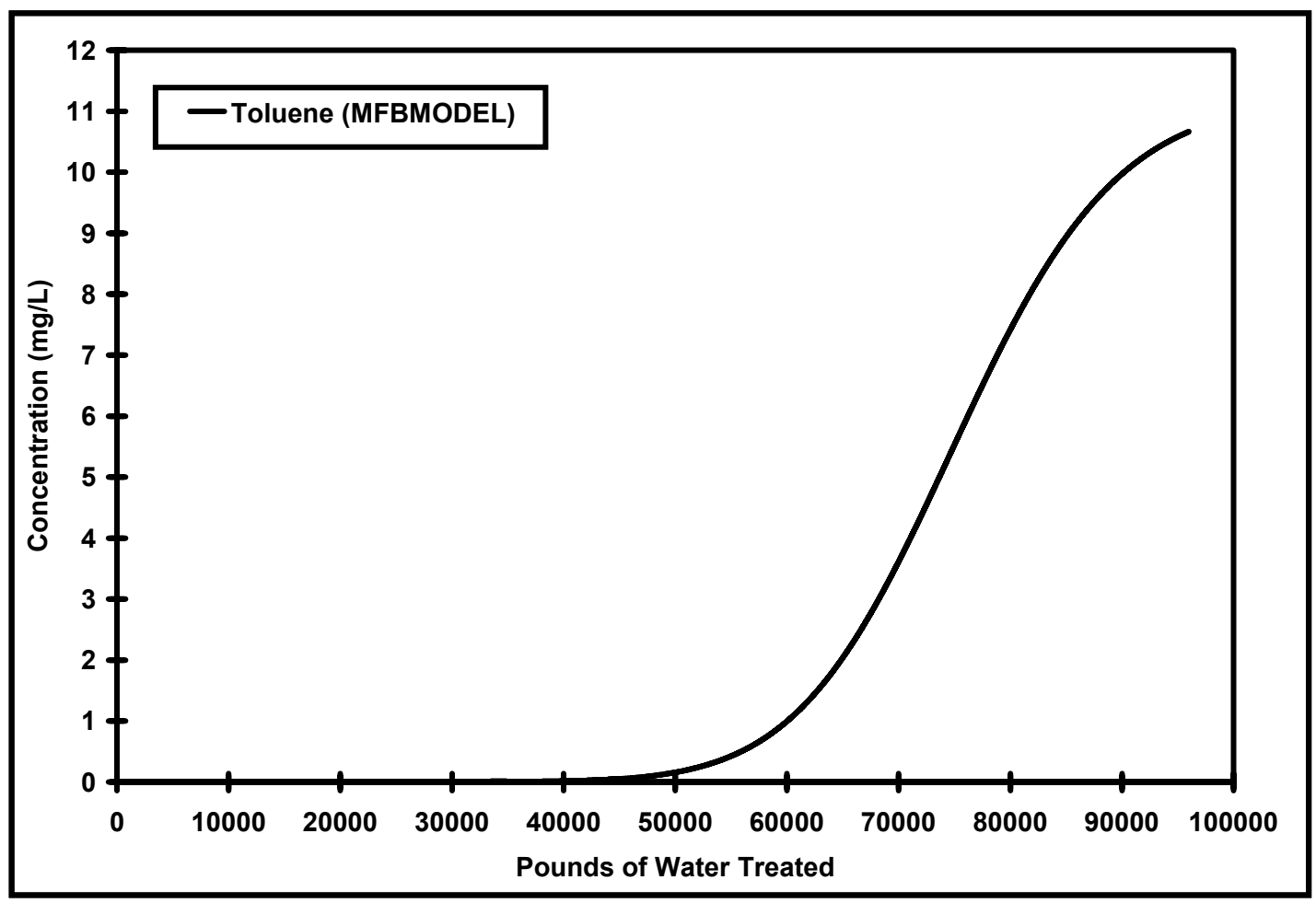

Figure VII - 22 - Tracer Toluene MFBMODEL Prediction for Default Simulation

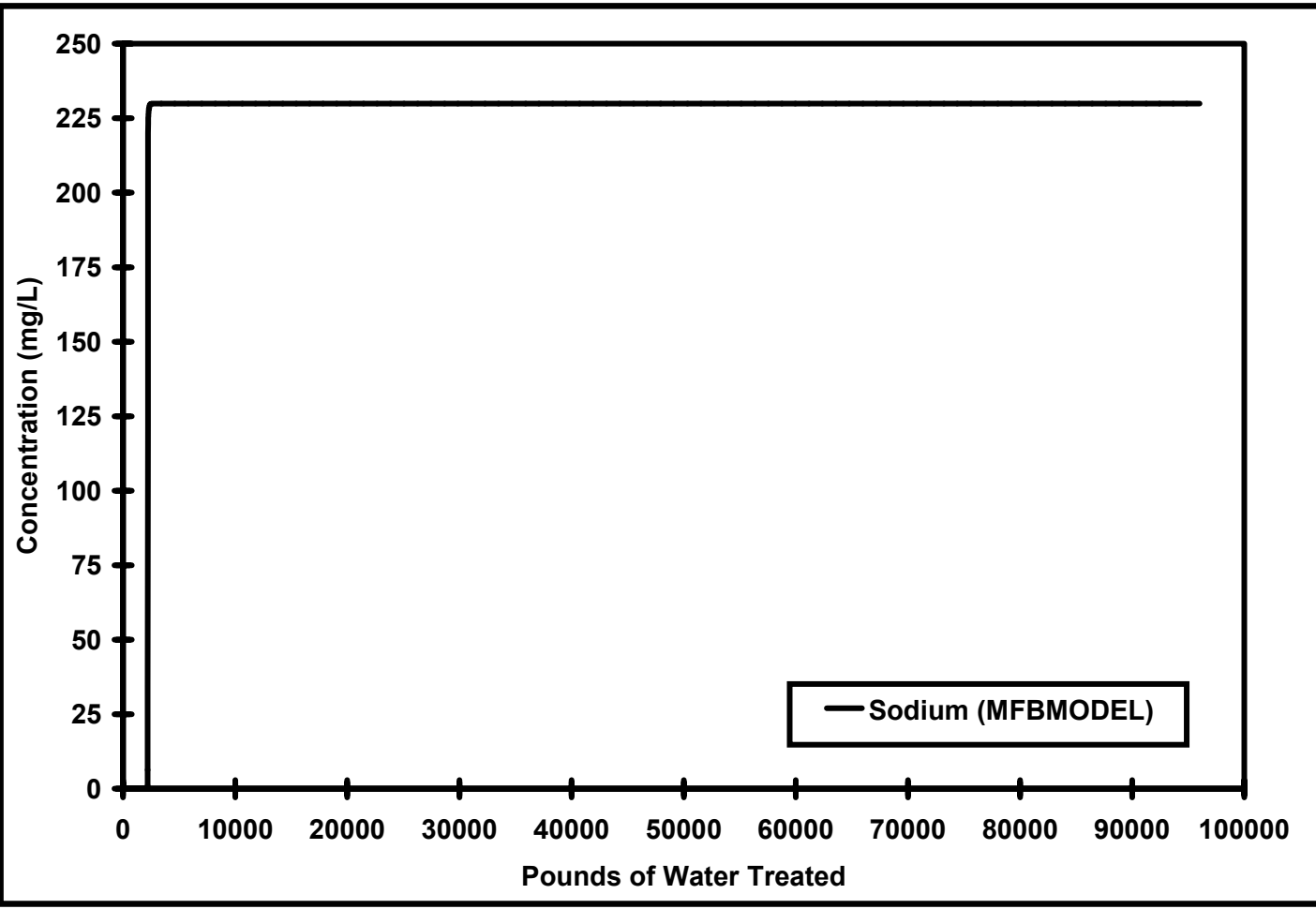

Figure VII - 23 - Sodium MFBMODEL Prediction for Default Simulation 


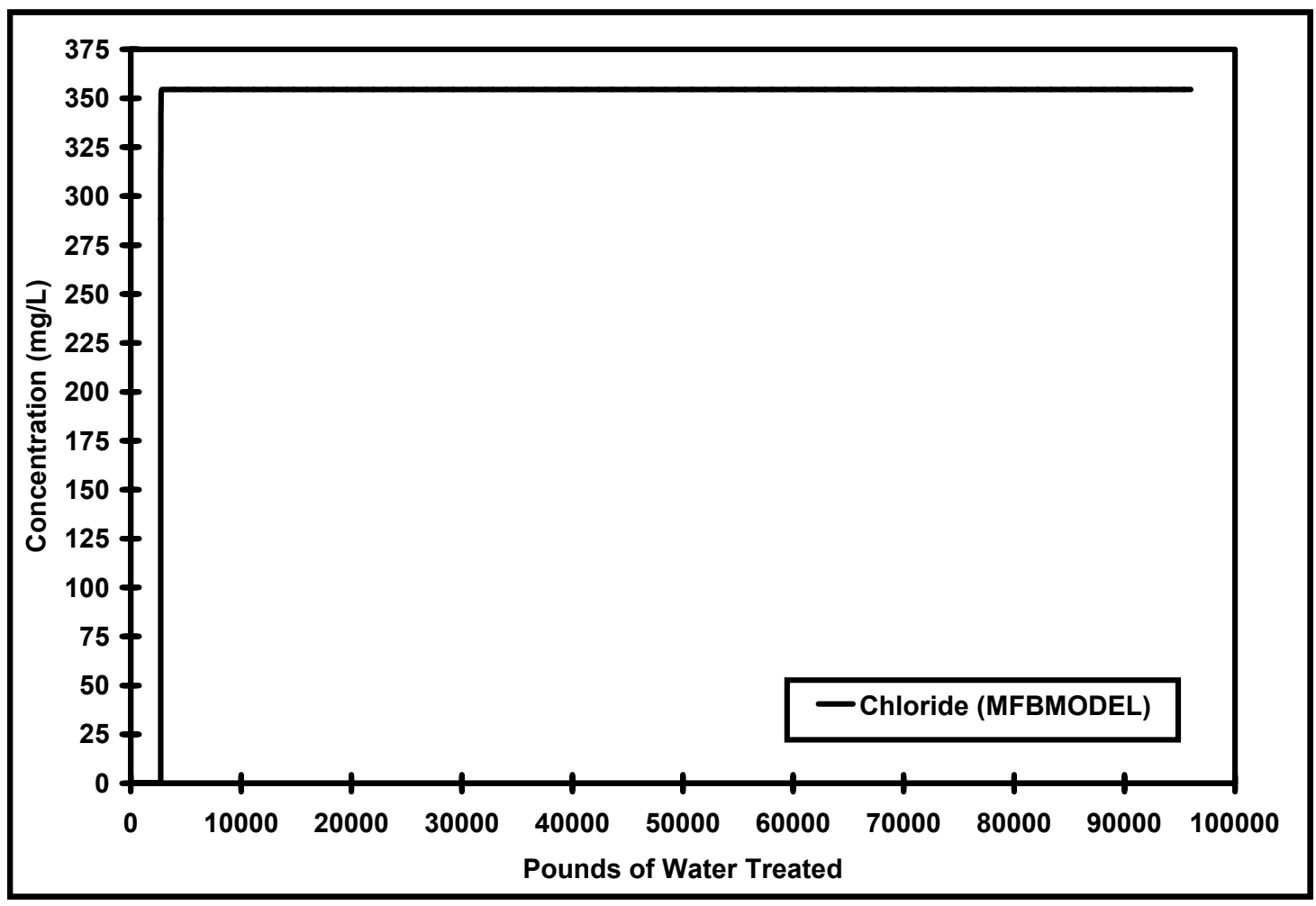

Figure VII - 24 - Chloride MFBMODEL Prediction for Default Simulation 


\section{Appendix VIII Column Procedure for Kinetic Studies}

The following procedures were used to conduct the column studies.

\section{0) Equipment cleaning procedure}

All equipment used in experiments was cleaned with the following procedure or that set forth by Sievers Co. for ultra low level TOC analysis.

A.) All equipment is washed with Micro, a phosphate free laboratory cleaner.

B.) The equipment is rinsed with Milli-Q water several times and then air dried.

The Milli-Q system consists of:

1.) Two activated adsorption cartridges to remove dissolved organics.

2.) Two ion exchange cartridges to remove cations, anions, and ionized organics.

3.) One 1 meter GAC packed column.

4.) A millipore membrane filter to remove microorganisms greater than 0.45 microns.

C.) The equipment is rinsed with ethanol and air dried.

D.) All glassware is baked in a $250^{\circ} \mathrm{C}$ forced air oven for one hour. All teflon and stainless steel apparatus was dried at $105^{\circ} \mathrm{C}$ in a forced air oven for one hour.

\section{0) Column set-up}

\section{1) lon exchange columns}

A.) Columns with an inner diameter of 2.5 or $5.0 \mathrm{~cm}$ were used in the column experiments. The columns had teflon endcaps seated with rubber o-rings to ensure a leakproof seal. The bottom of the bed was supported by USTM 150 mesh stainless steel screen and Teflon tubing was attached to the top of the column for pumping solution through the column.

B.) The desired amount ion exchange resin was slurried into the column with Milli-Q water. 
C.) The solutions were pumped downflow through the columns. The exact flow rate was determined gravimetrically.

D.) The height of the ion exchange bed was measured regularly to determine swelling and for calculation of EBCT.

\section{2) Adsorption columns}

A.) Columns with an inner diameter of $5.0 \mathrm{~cm}$ were capped with a Teflon end cap. The resin was retained with 150 mesh stainless steel screen at one end, and attached to a pump with Teflon tubing for solution introduction on the other end.

B.) The desired amount of adsorbent was slurried into the column with Milli$Q$ water.

C.) The adsorbents were degassed by applying a vacuum to the top of the column and agitating the adsorbent until no air bubbles were observed to be coming out of the adsorbent particles.

D.) The solutions were pumped downflow through the columns. The exact flow rate was determined gravimetrically.

E.) The height of the adsorbent bed was measured regularly to determine any change in bed size and for calculation of EBCT.

\section{0) Sampling}
A.) The column influent and effluent was collected at the desired intervals, $50 \mathrm{~mL}$ per sample. The exact time of sampling was recorded.
B.) The compounds of interest were monitored. 


\section{Appendix IX Ion Exchange Results for MFBMODEL Prediction of Experimental Data \\ MFBMODEL Setup}

The first three ion exchange beds in the MFBMODEL verification experiment were simulated in a single MFBMODEL run, consisting of three ion exchange beds in series. The three ion exchange beds included in this simulation were a mixed bed ion exchange resin (Rohm and Haas IRN-150), a strong acid cation (SAC) exchange resin (Rohm and Haas IRN-77) and a weak base anion (WBA) exchange resin (Rohm and Haas IRA-68). Figure IX - 1 shows the Open Existing, Create New or Exit window within MFBMODEL, in which the ersatz ion exchange simulation is highlighted. This simulation can be opened within MFBMODEL as described in Appendix VII for a different simulation. Upon opening the simulation entitled "MTU_Ersatz_lon_Exchange_11_Ions_IRN150_then_IRN77_then_IRA68", the main MFBMODEL window for this simulation will open, as shown in Figure IX $-2$. 


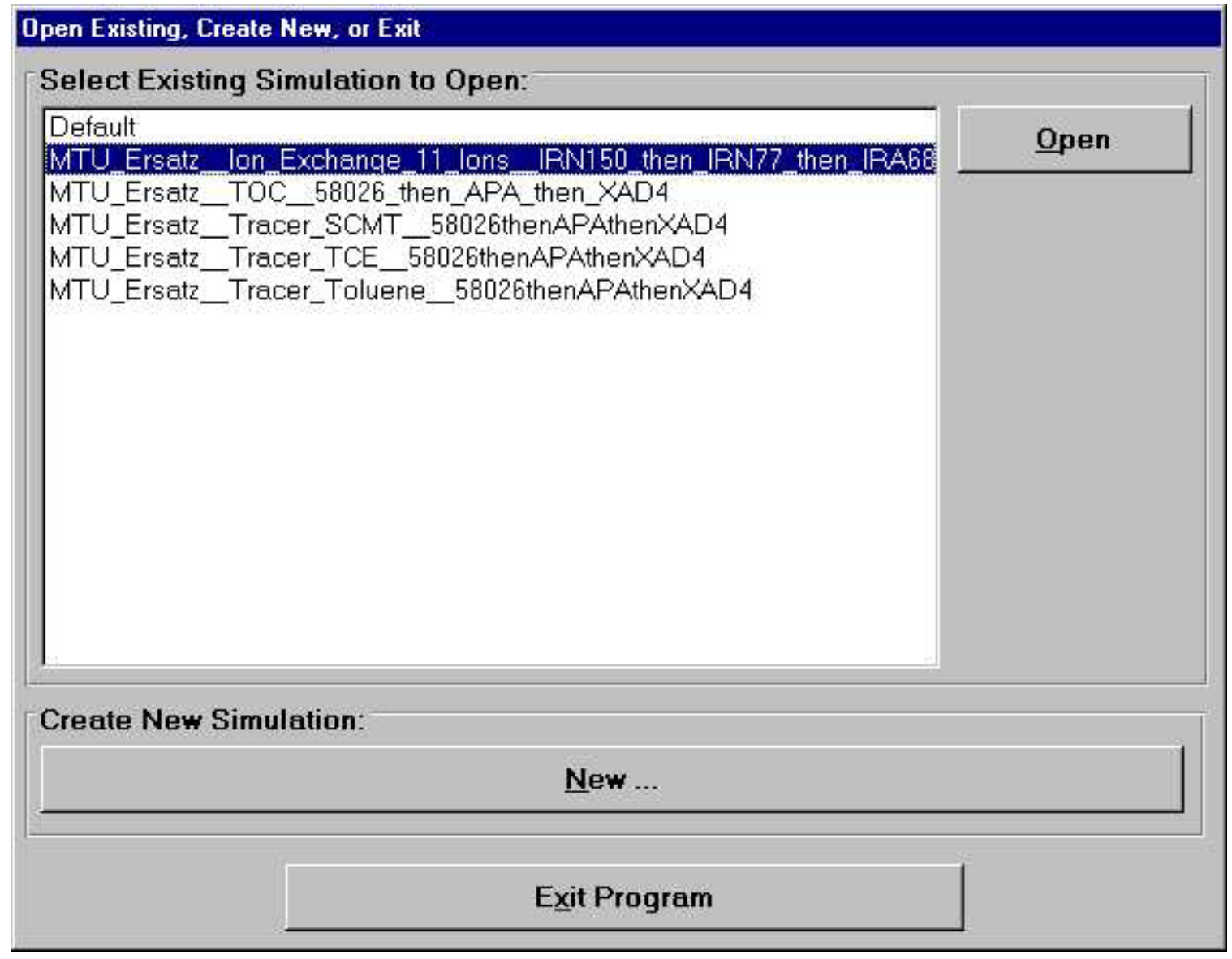

Figure IX - 1 - Open Existing, Create New or Exit Window in MFBMODEL Showing Ersatz MFBMODEL Verification Experiment lon Exchange Simulation 


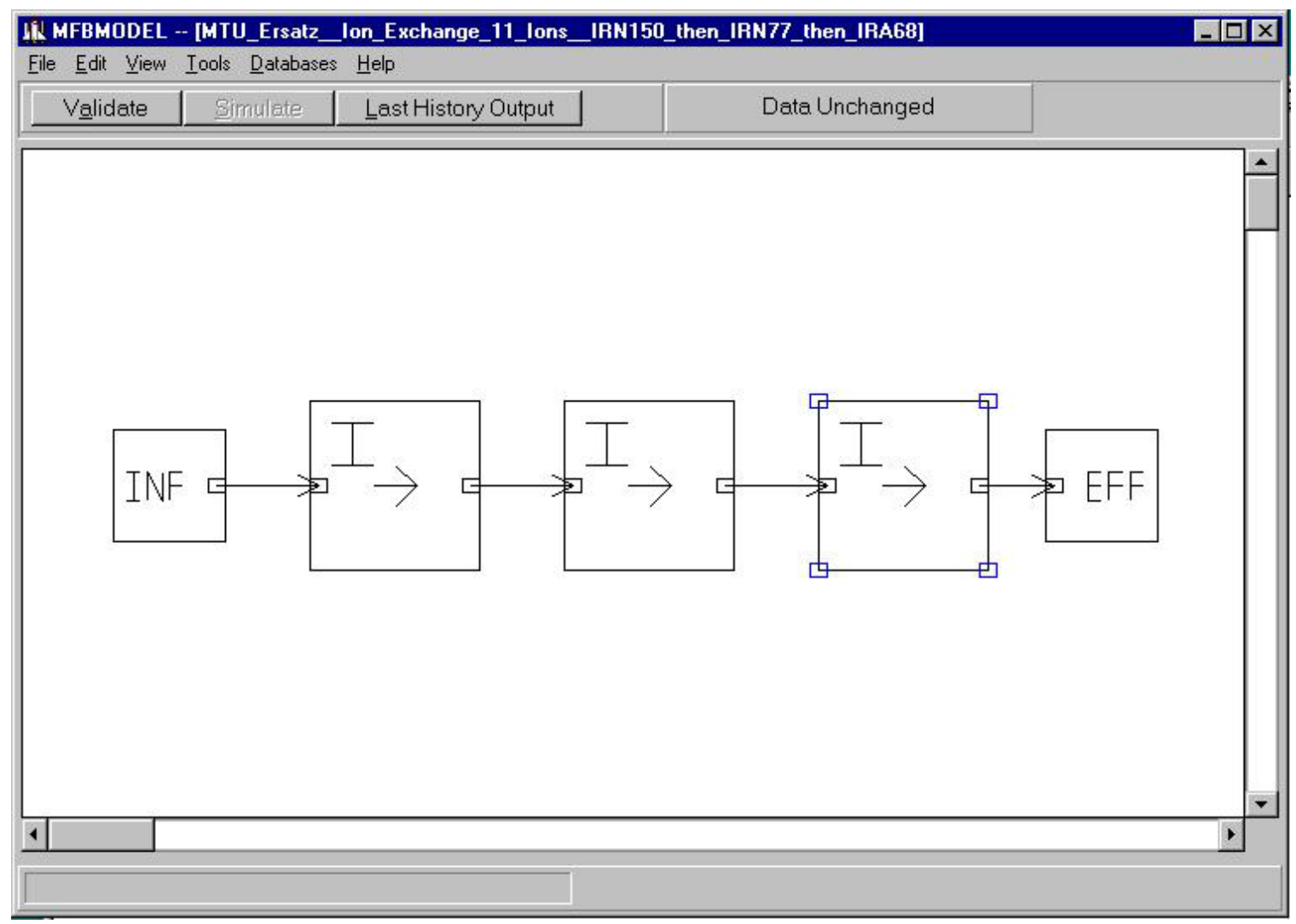

Figure IX - 2 - Main MFBMODEL Window for Michigan Tech Ersatz Column Experiment Simulation File:

"MTU_Ersatz_Ion_Exchange_11_Ions_IRN150_then_IRN77_then_IRA68"

Appendix VII explains how to obtain results from an MFBMODEL

simulation. An MFBMODEL manual has been written, which shows all the details for setting up an ion exchange simulation within MFBMODEL, but it is not presented in this proposal. This MFBMODEL simulation was performed for eleven ions in the ersatz shower and handwash wastewater:

Cations: Sodium, Potassium, Calcium, Hydrogen

Anions: Acetate, Butyrate, Chloride, Bicarbonate, Sulfate, CMT, Hydroxide Model results compared to experimental data for each ion on each resin are presented below in the following units: $\mathrm{mg} / \mathrm{L}$ versus Pounds of Water Treated (note that these are the units preferred by the project sponsors, ION Corporation and NASA Marshall Space Flight Center in Huntsville, Alabama). Appendix IX.A presents the same results in additional units that may be useful for interpretation: 
(1) $\mathrm{mg} / \mathrm{L}$ versus Time in Days; (2) meq/L versus Bed Volumes Treated; and (3) Reduced Concentration $\left(\mathrm{C} / \mathrm{C}_{0}\right)$ versus Bed Volumes Treated.

\section{Mixed Bed lon Exchange Resin: Rohm \& Haas IRN-150}

Table IX - 1 shows the properties of the first mixed bed ion exchange column in the multifiltration bed verification experiment.

Table IX - 1 - Properties of Mixed Bed Resin Column Used in MFBMODEL Verification Experiment

\begin{tabular}{l|c}
\hline Property & Value \\
\hline Mass of Resin, g (lb) & $4522(9.969)$ \\
\hline Diameter of Bed, cm (in.) & $5.1(2.01)$ \\
\hline Length of Bed, cm (in.) & $279.75(110.1)$ \\
\hline Flowrate, $\mathrm{mL} / \mathrm{min}(\mathrm{lb} / \mathrm{hr})$ & $47.88(6.33)$ \\
\hline Number of lons Simulated & $11(4$ cations, 7 anions $)$ \\
\hline EBCT, min & 120 \\
\hline
\end{tabular}




\section{Cation Results}

\section{Sodium}

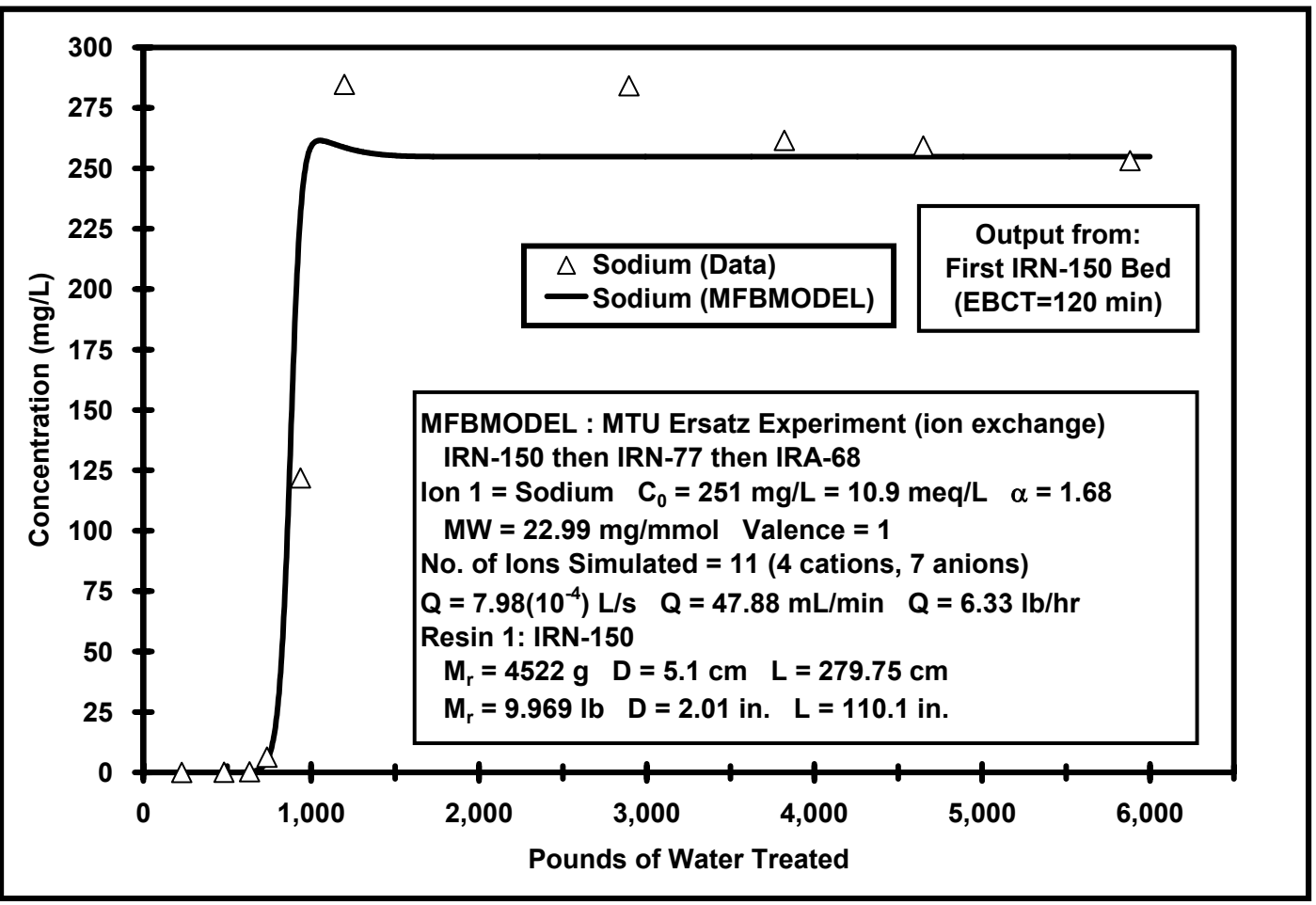

\section{Potassium}

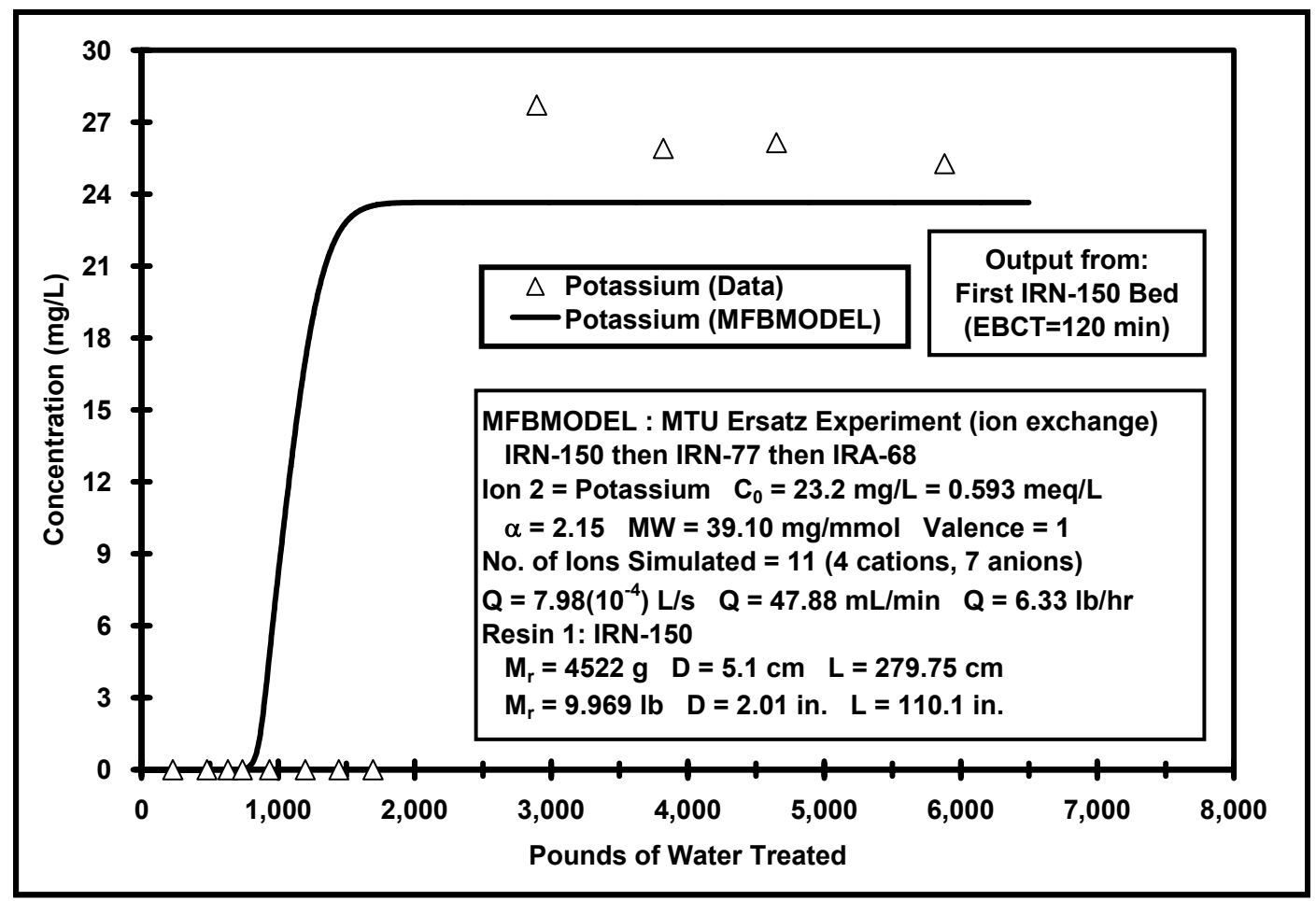




\section{Calcium}

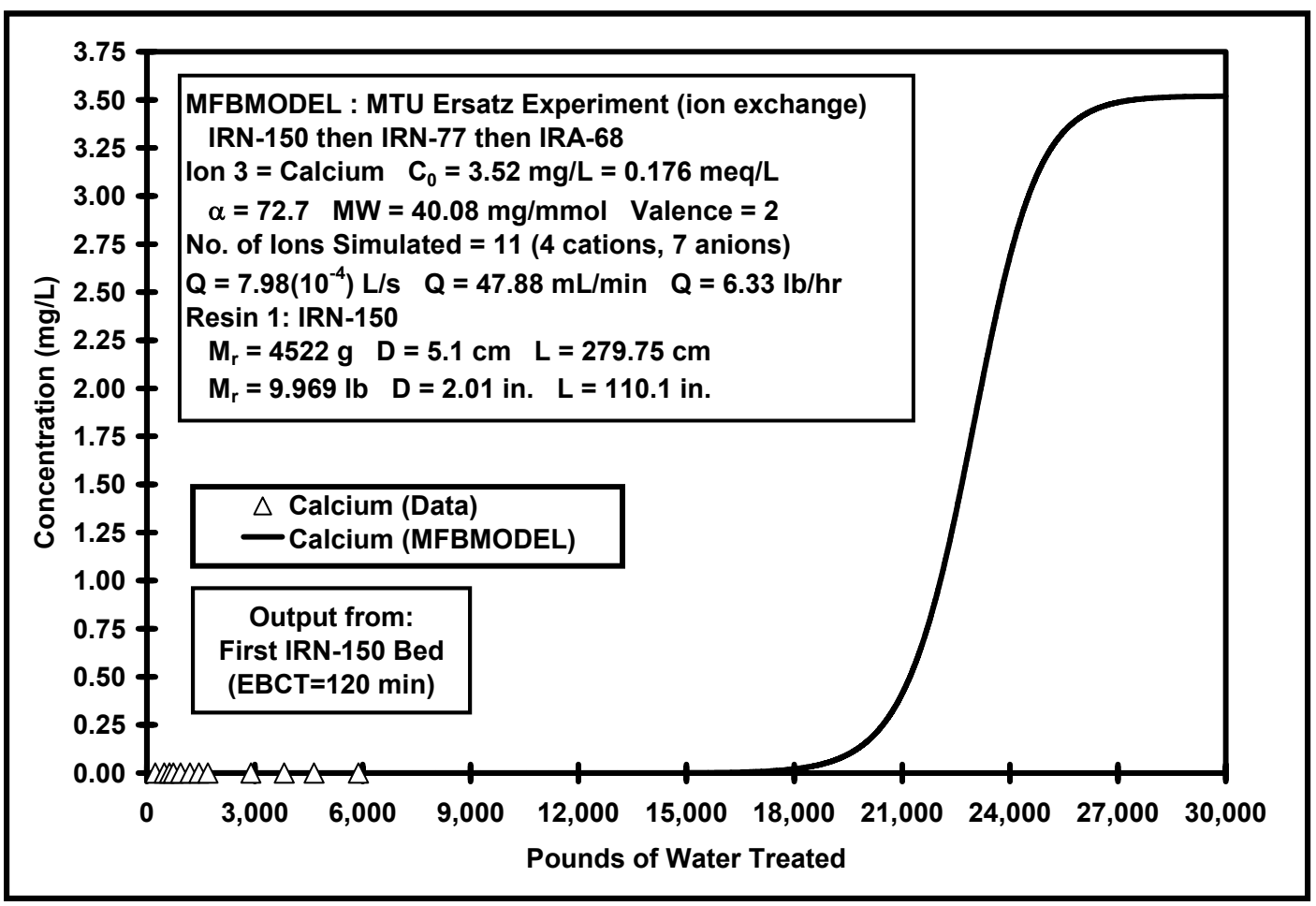

Hydrogen

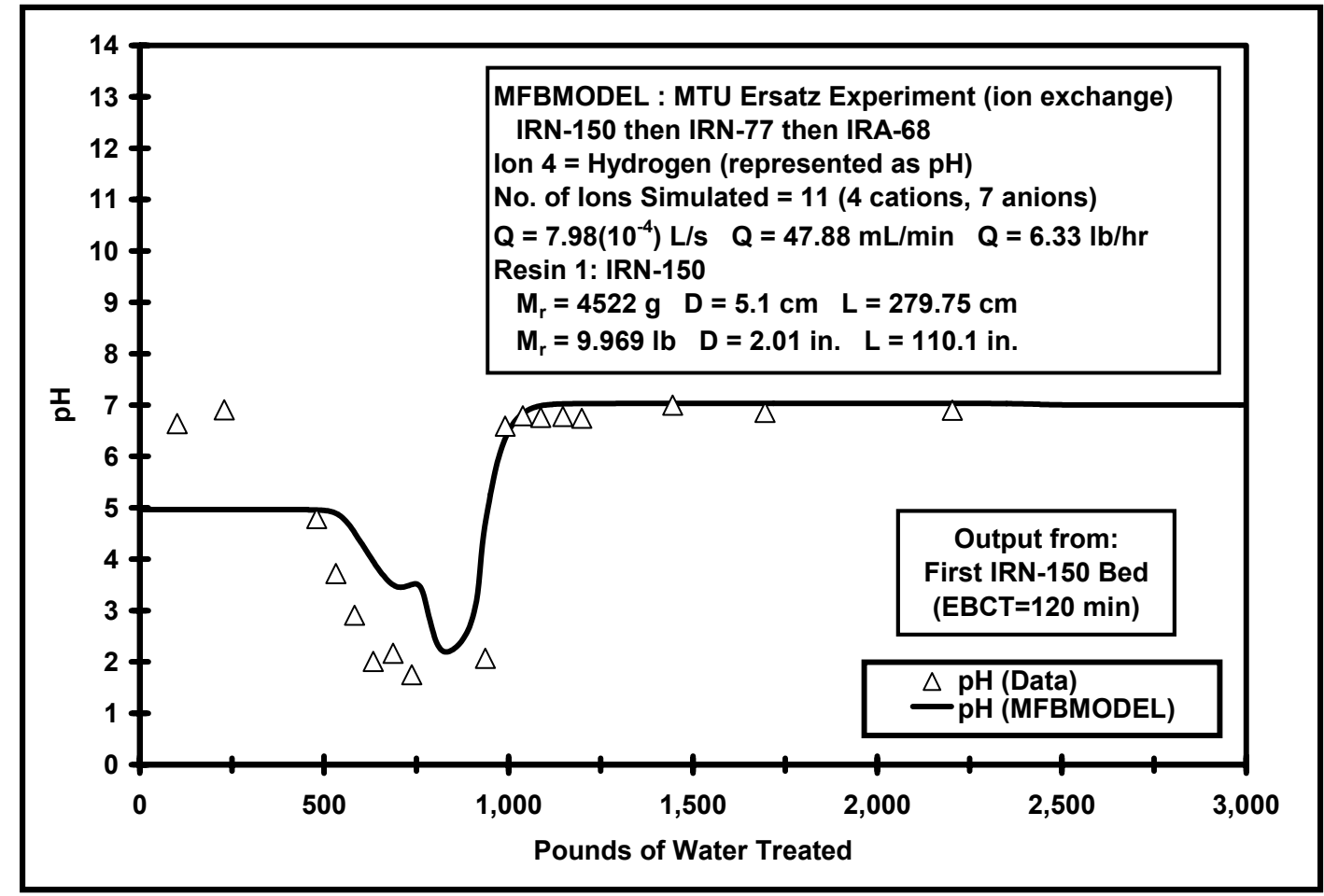




\section{Anion Results}

\section{Acetate}

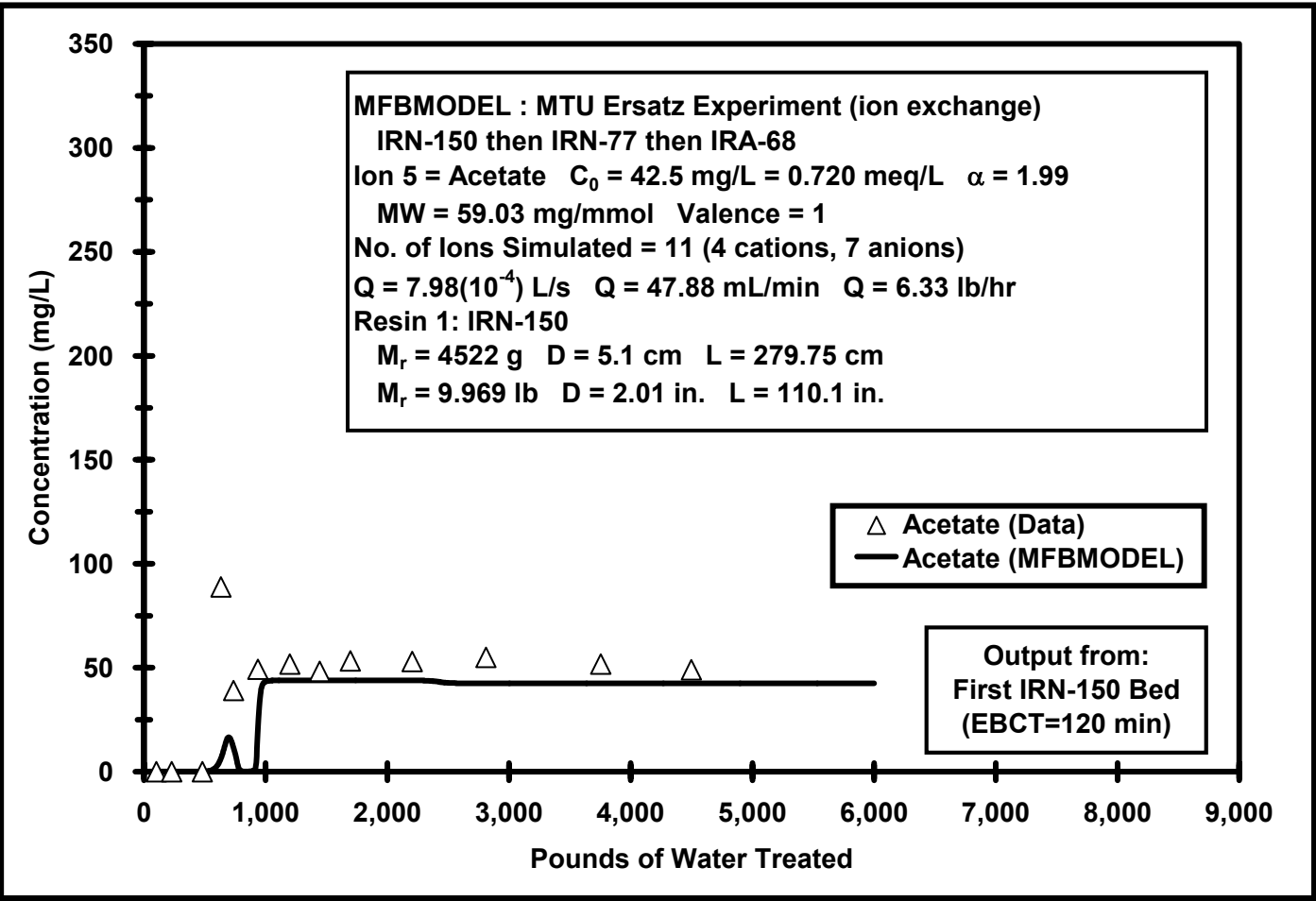

\section{Butyrate}

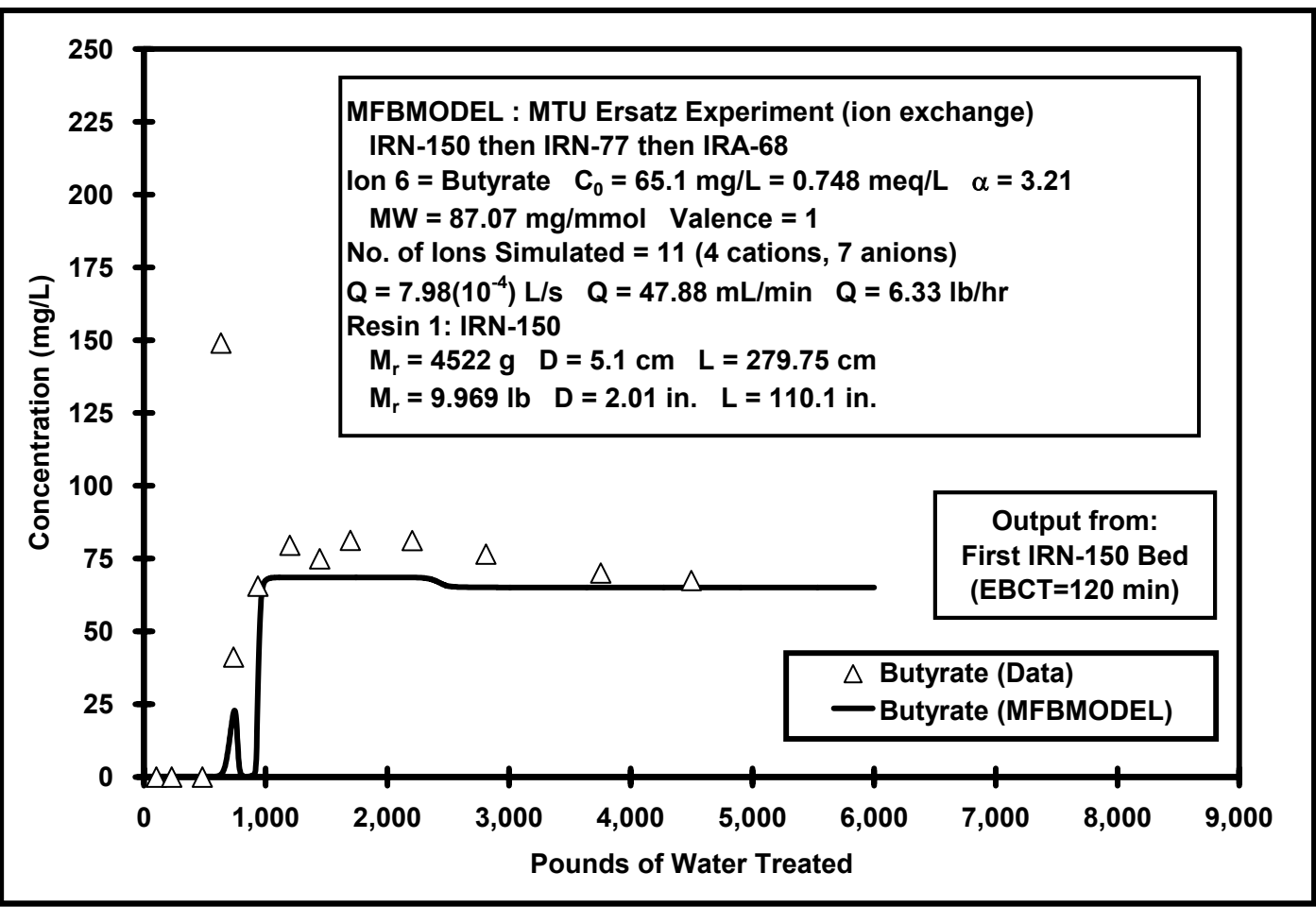




\section{Chloride}

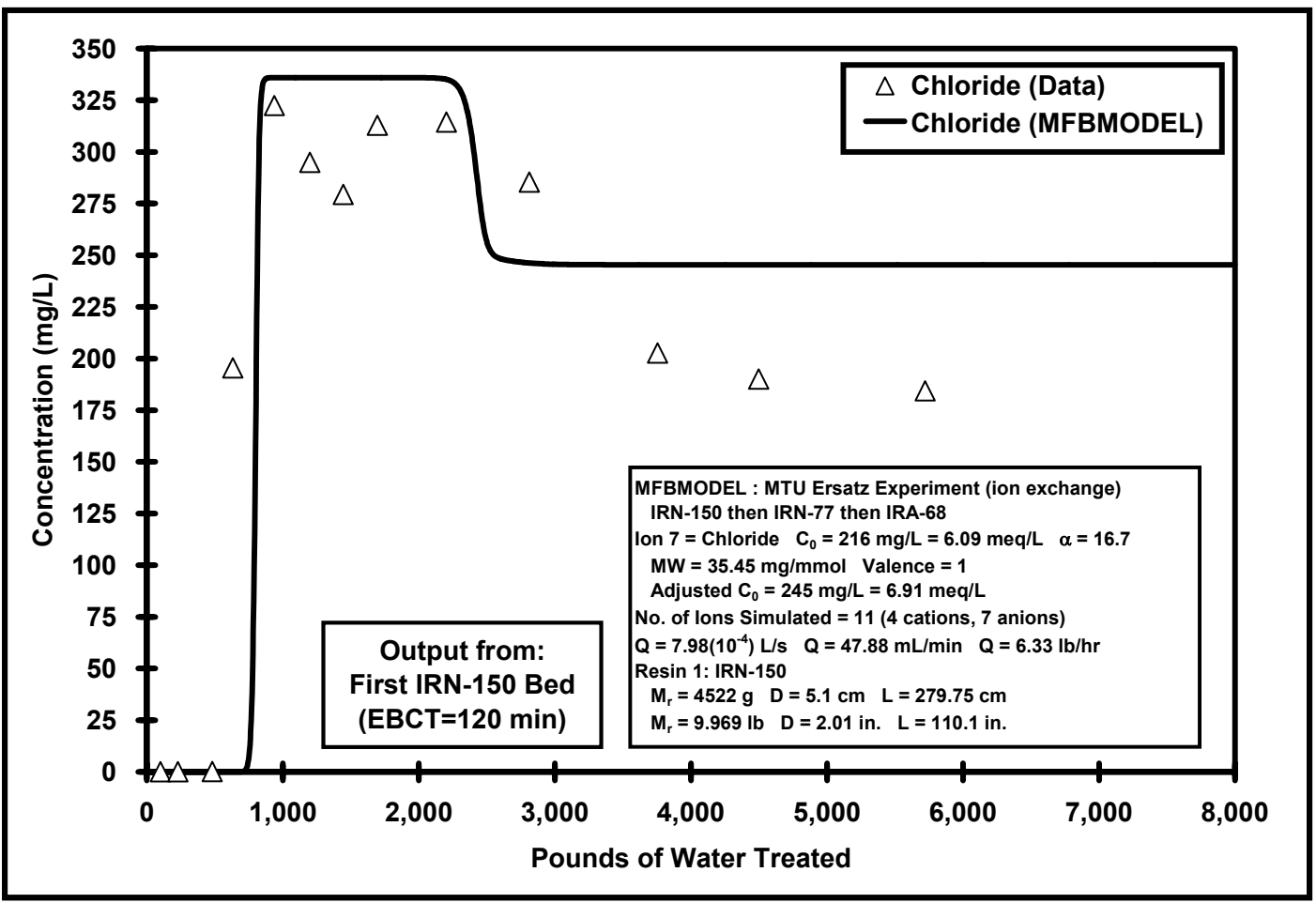

\section{Bicarbonate}

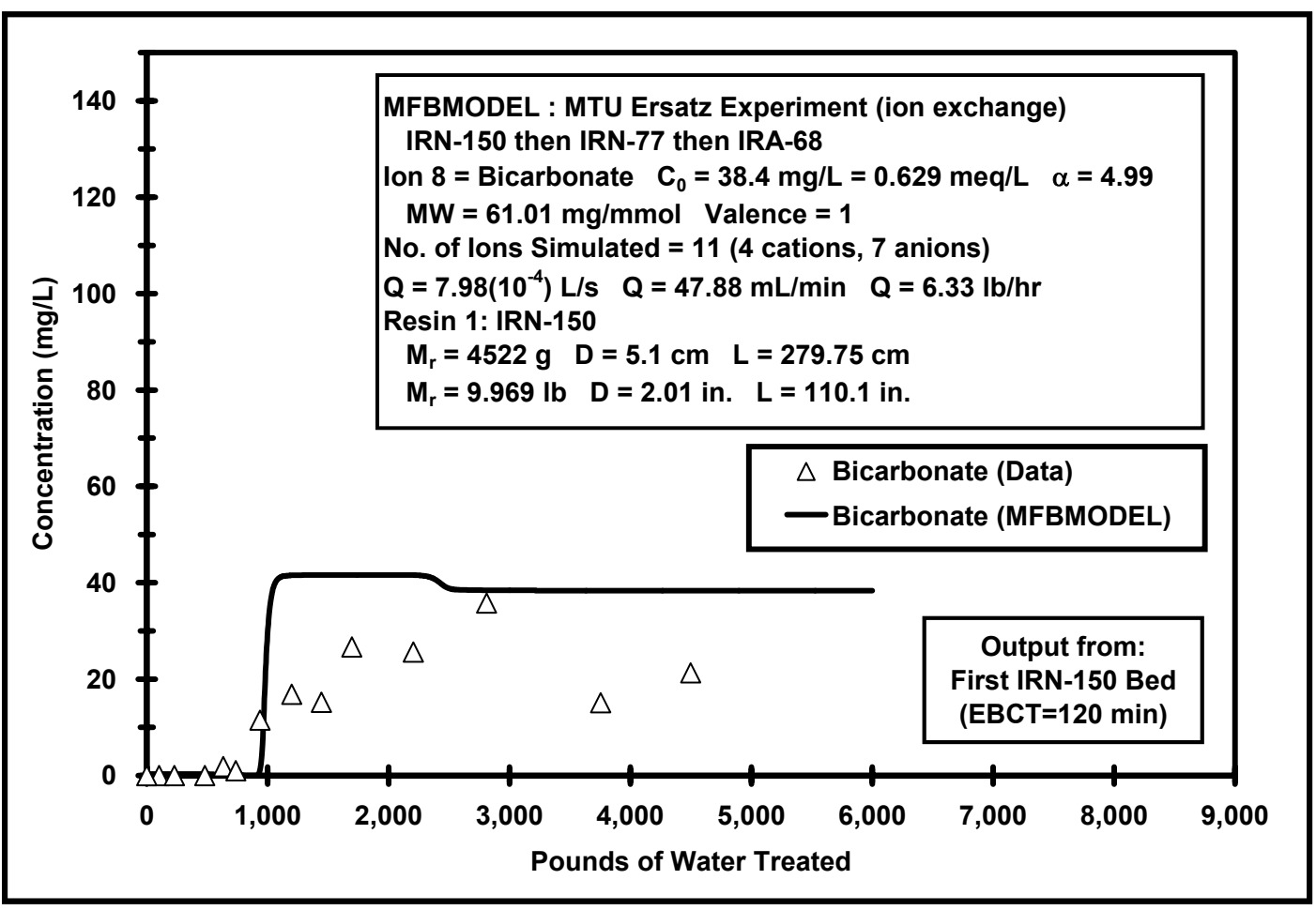




\section{Sulfate}

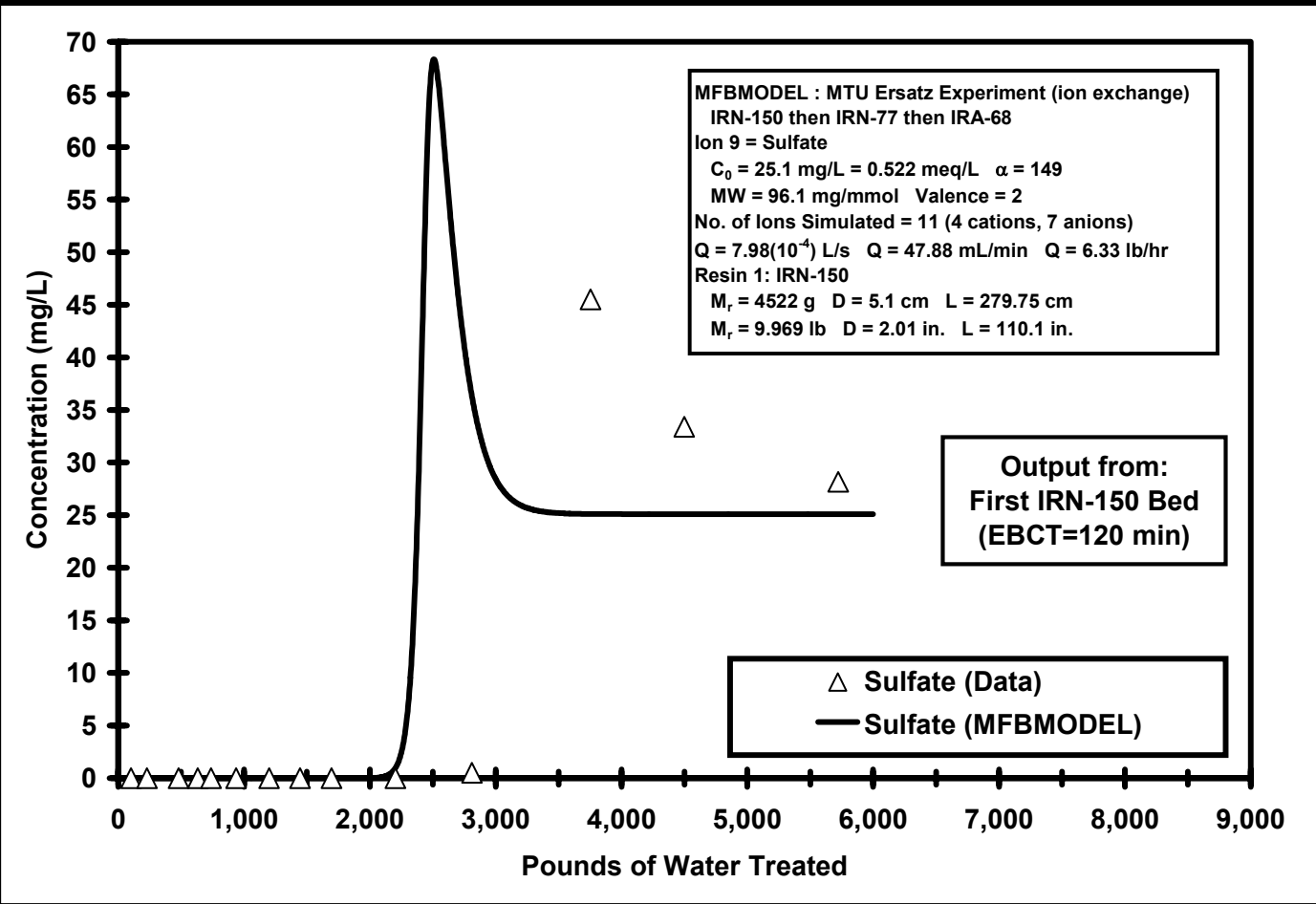

\section{CMT}

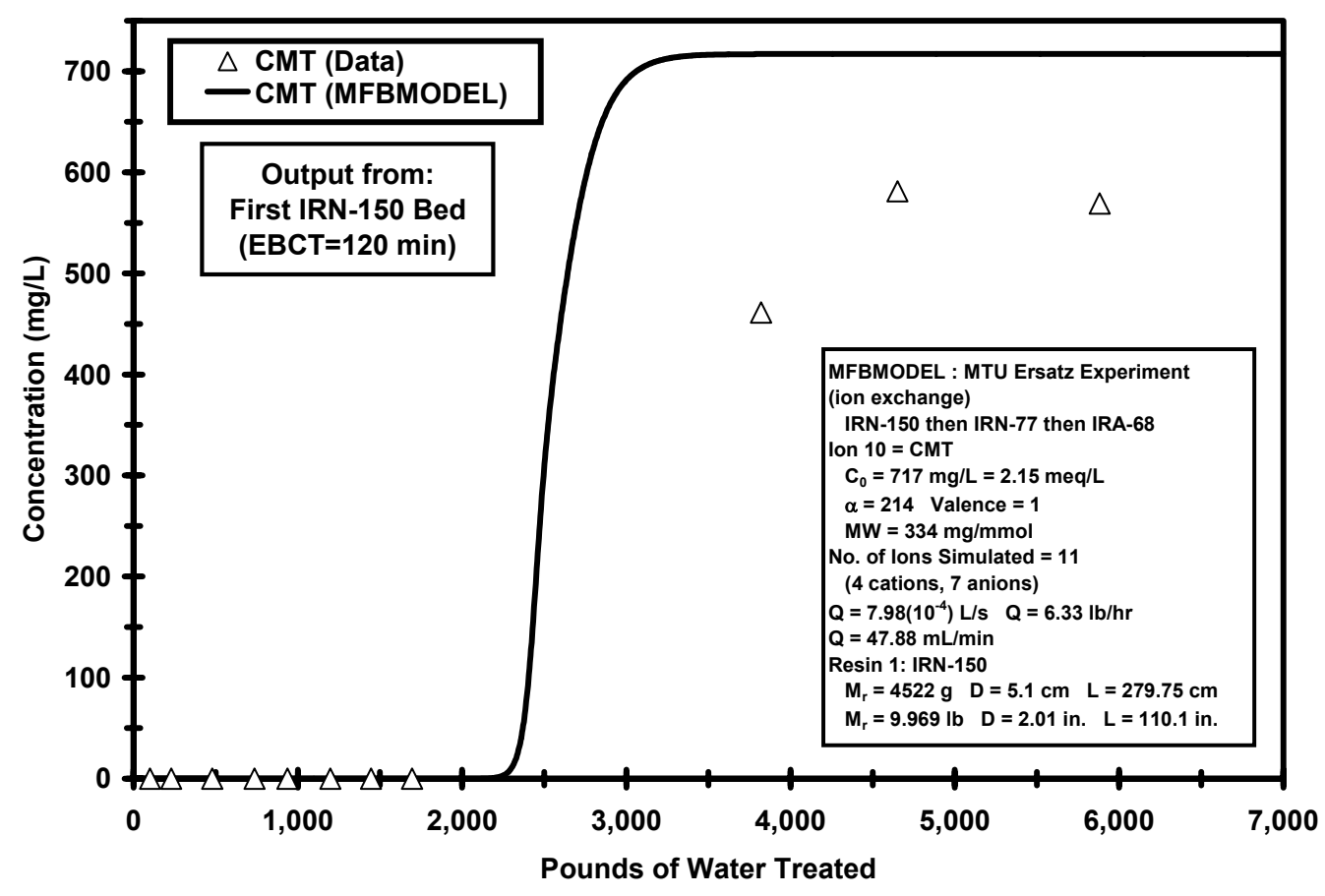




\section{Hydroxide}

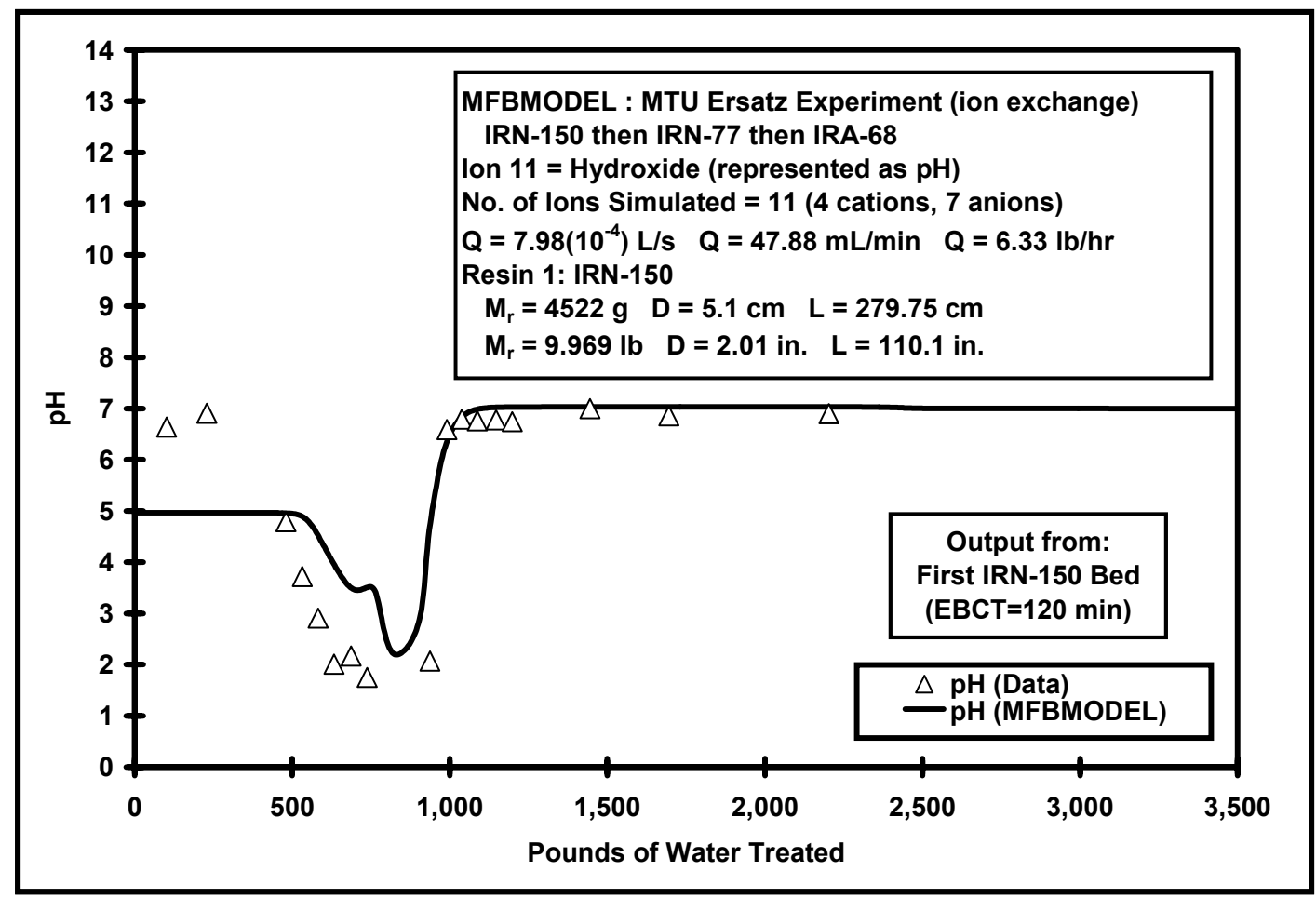

\section{Strong Acid Cation (SAC) Exchange Resin: Rohm \& Haas IRN-77}

Table IX - 2 shows the properties of the first strong acid cation (SAC) exchange column in the multifiltration bed verification experiment.

Table IX - 2 - Properties of First Strong Acid Cation Exchange Resin Column Used in MFBMODEL Verification Experiment

\begin{tabular}{l|c}
\hline Property & Value \\
\hline Mass of Resin, g (lb) & $374.6(0.826)$ \\
\hline Diameter of Bed, cm (in.) & $4.93(1.94)$ \\
\hline Length of Bed, cm (in.) & $22.1(8.7)$ \\
\hline Flowrate, $\mathrm{mL} / \mathrm{min}(\mathrm{lb} / \mathrm{hr})$ & $47.88(6.33)$ \\
\hline Number of lons Simulated & $11(4$ cations, 7 anions) \\
\hline EBCT, min & 8.8 \\
\hline
\end{tabular}




\section{Cation Results}

\section{Sodium}

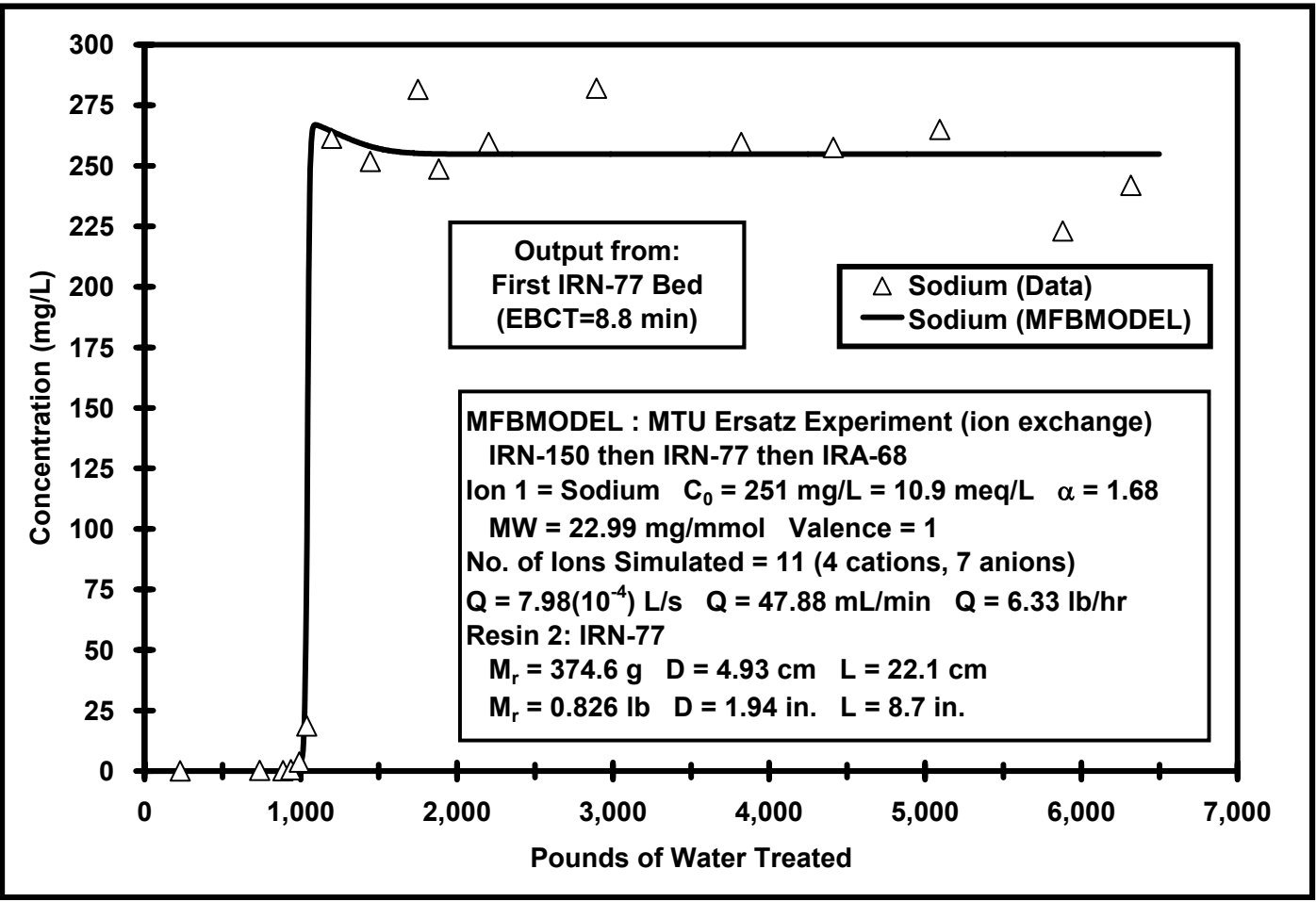

\section{Potassium}

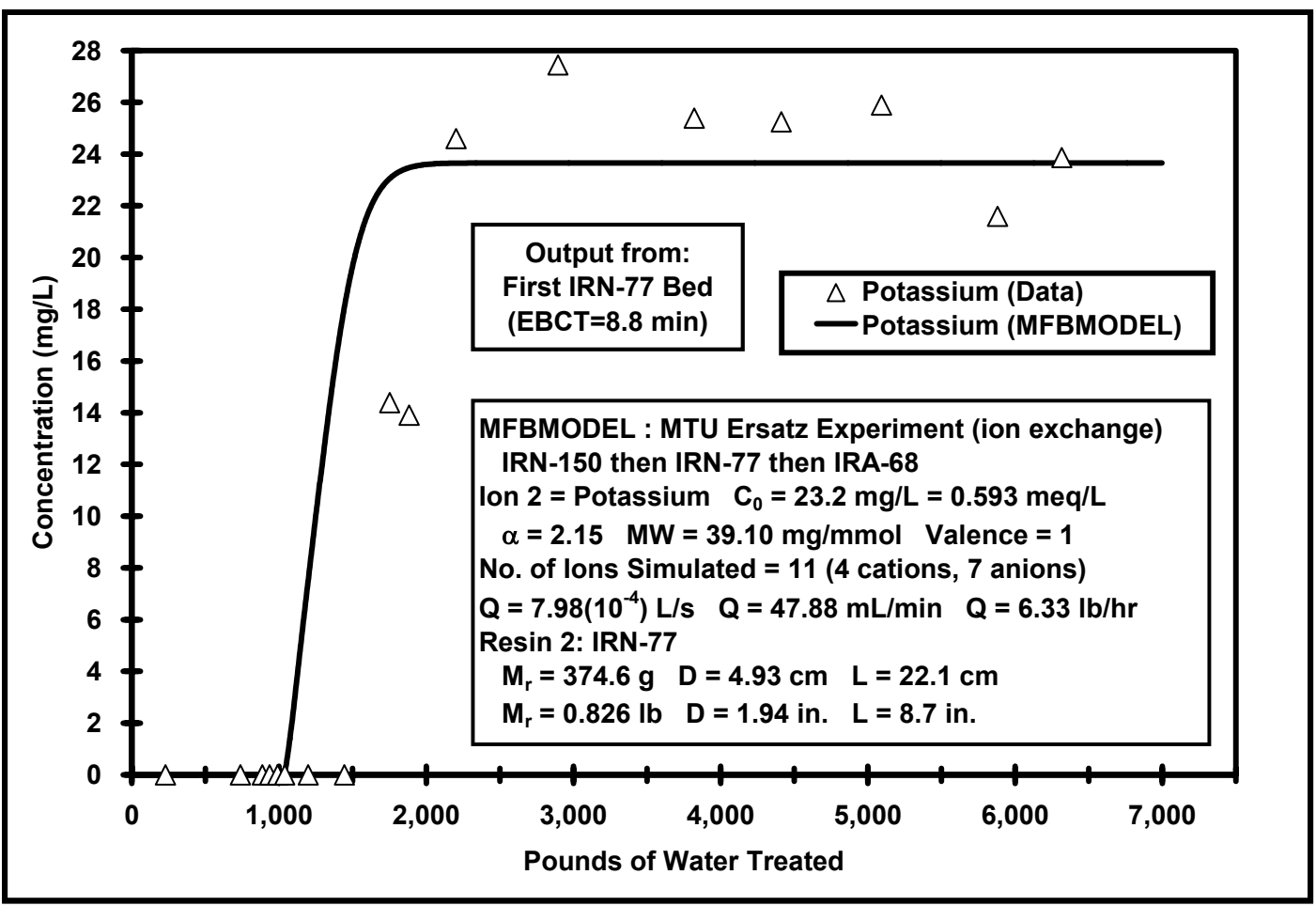




\section{Calcium}

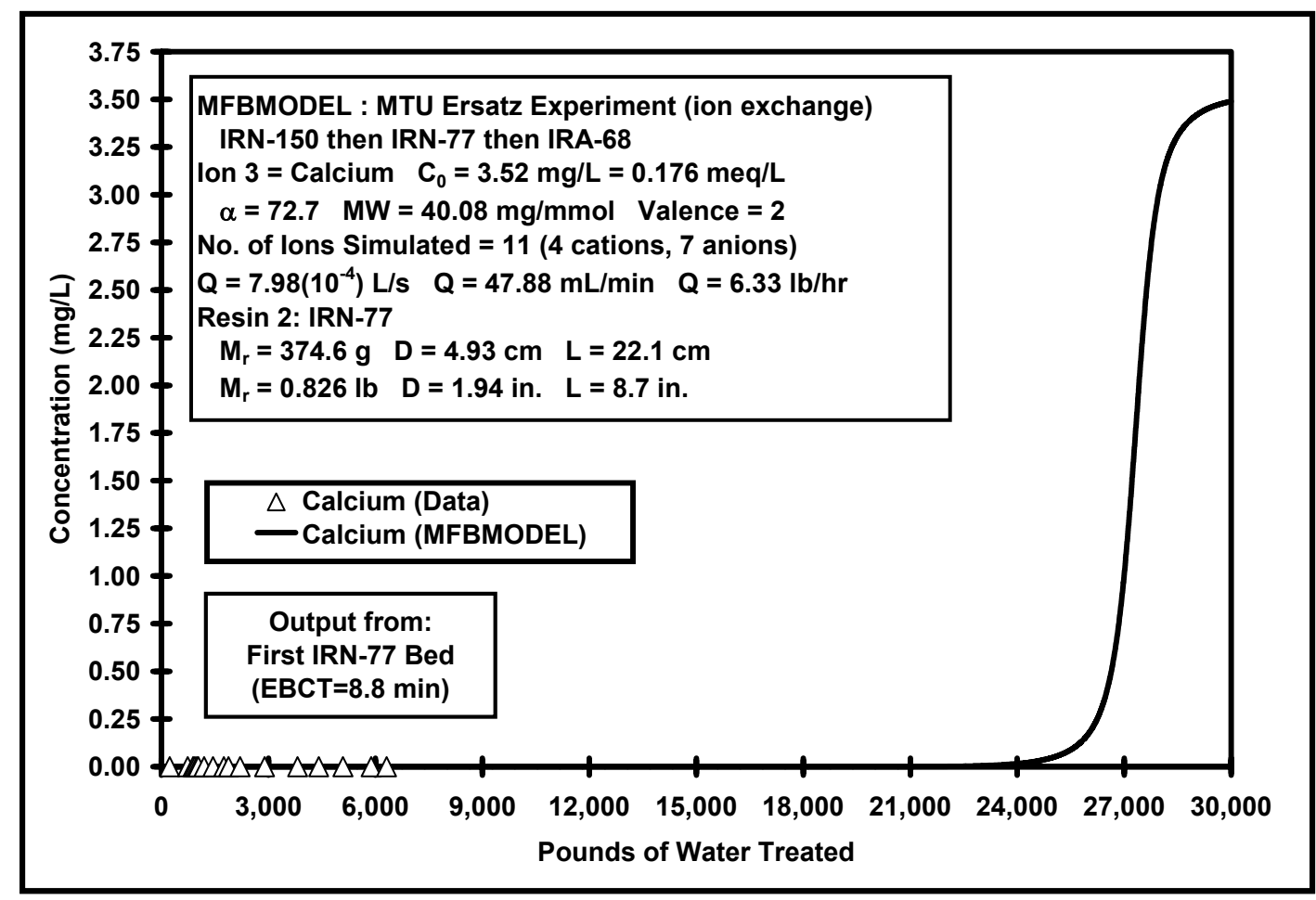

Hydrogen

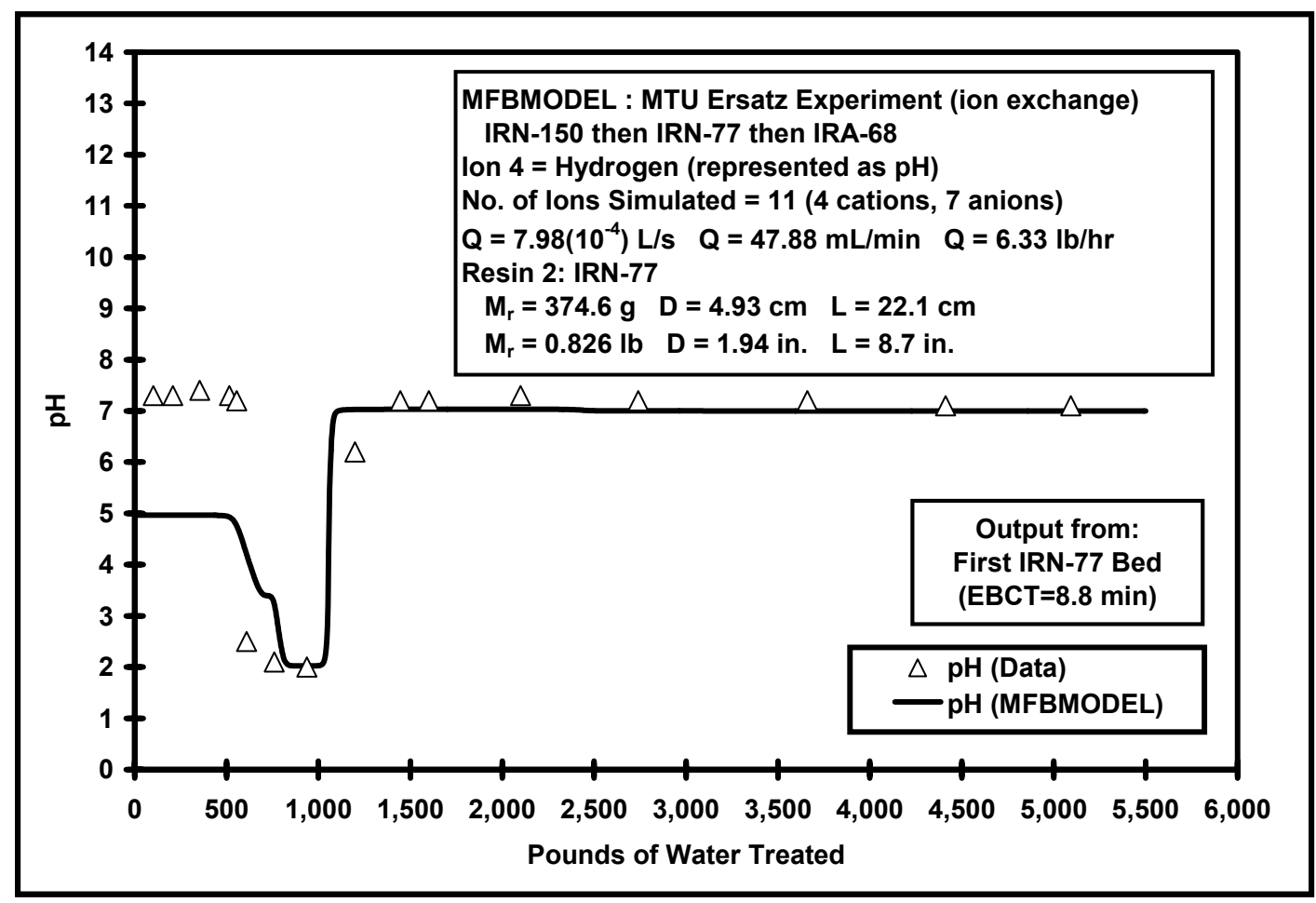


Weak Base Anion (WBA) Exchange Resin: Rohm \& Haas IRN-77

Table IX - 3 shows the properties of the first strong acid cation (SAC) exchange column in the multifiltration bed verification experiment.

Table IX - 3 - Properties of Weak Base Anion Exchange Resin Column Used in MFBMODEL Verification Experiment

\begin{tabular}{l|c}
\hline Property & Value \\
\hline Mass of Resin, g (lb) & $2042.1(4.50)$ \\
\hline Diameter of Bed, cm (in.) & $5.16(2.03)$ \\
\hline Length of Bed, cm (in.) & $135.8(53.5)$ \\
\hline Flowrate, $\mathrm{mL} / \mathrm{min}(\mathrm{lb} / \mathrm{hr})$ & $47.88(6.33)$ \\
\hline Number of lons Simulated & $11(4$ cations, 7 anions $)$ \\
\hline EBCT, min & 59 \\
\hline
\end{tabular}

\section{Anion Results}

Acetate

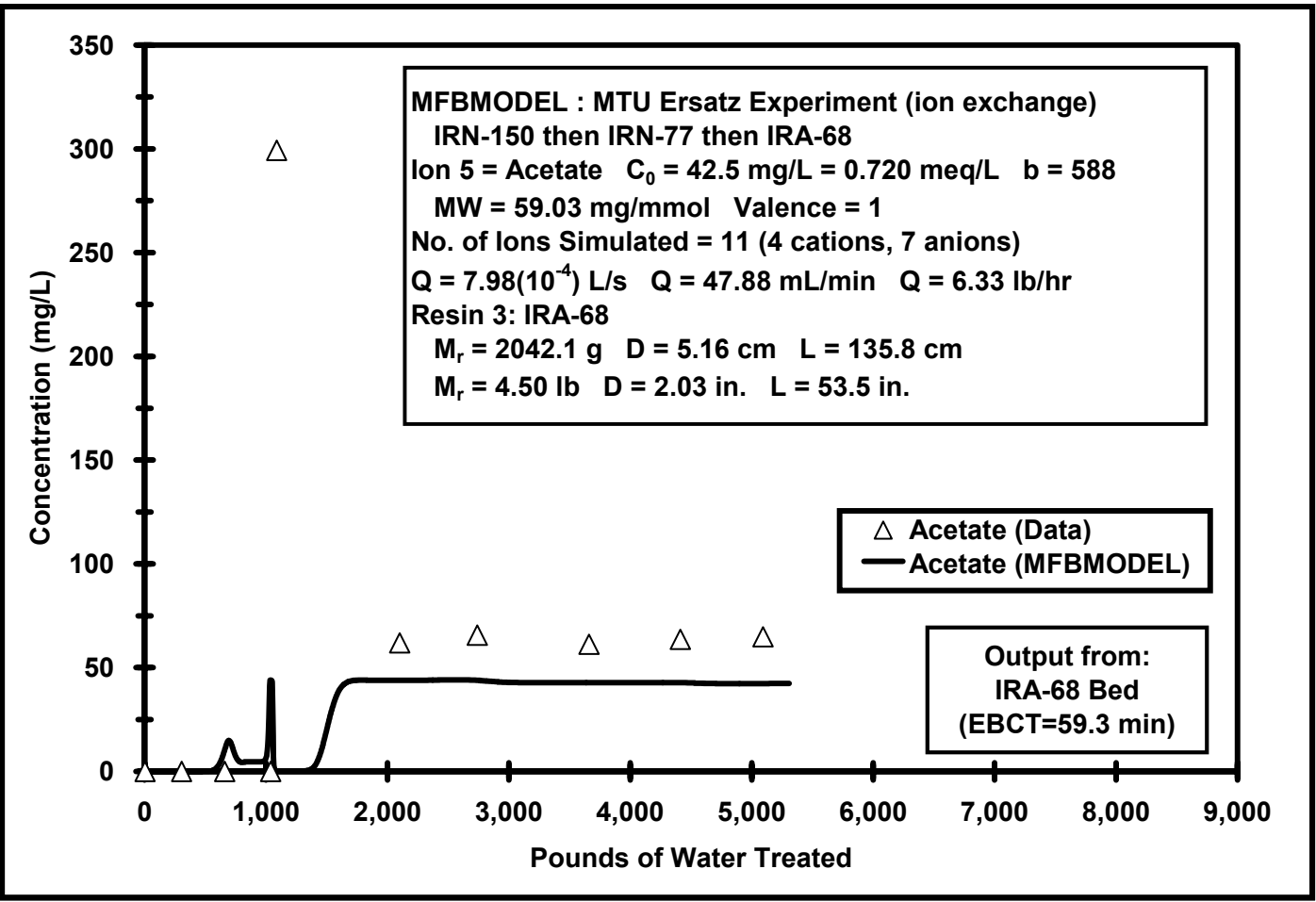




\section{Butyrate}

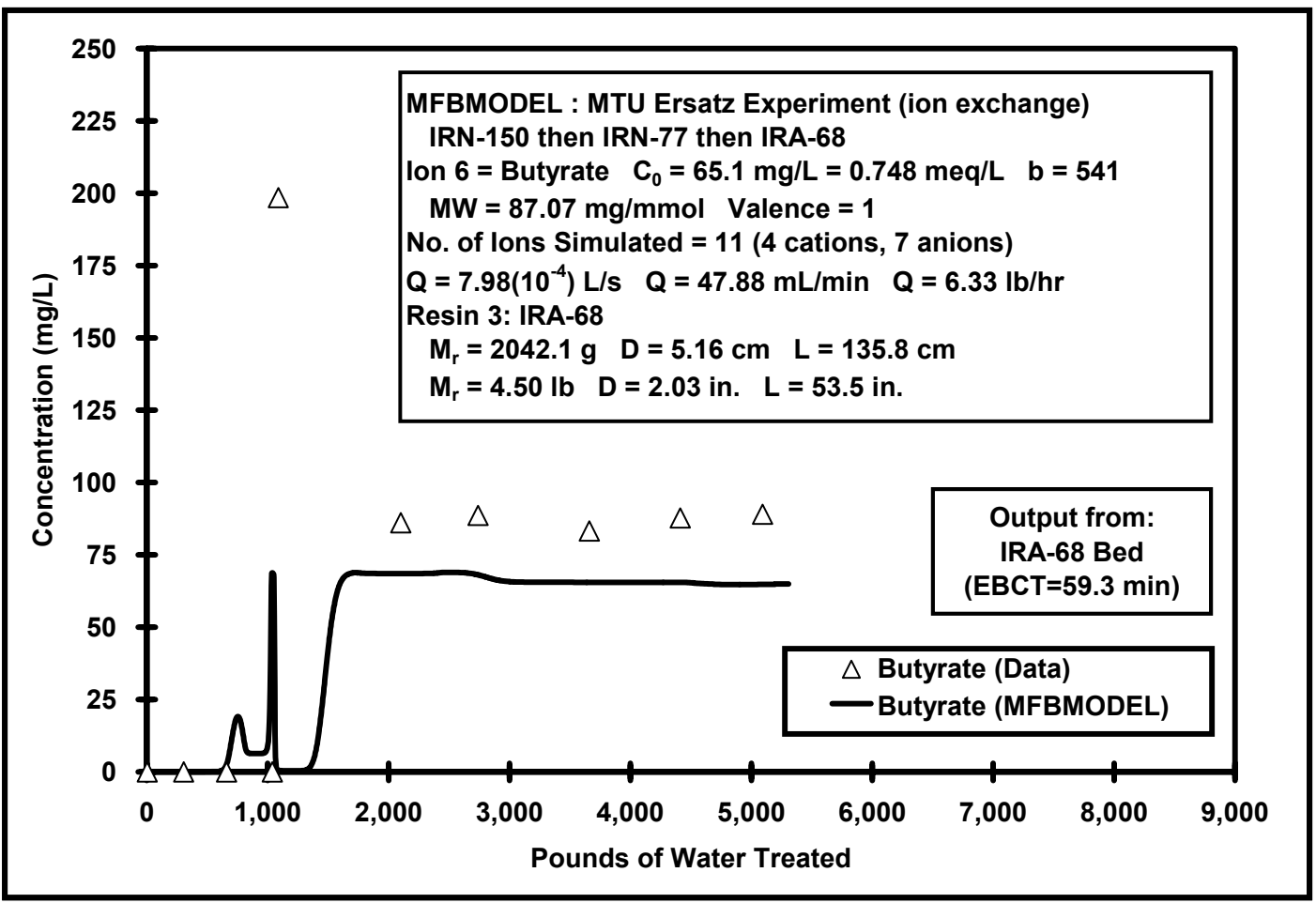

\section{Chloride}

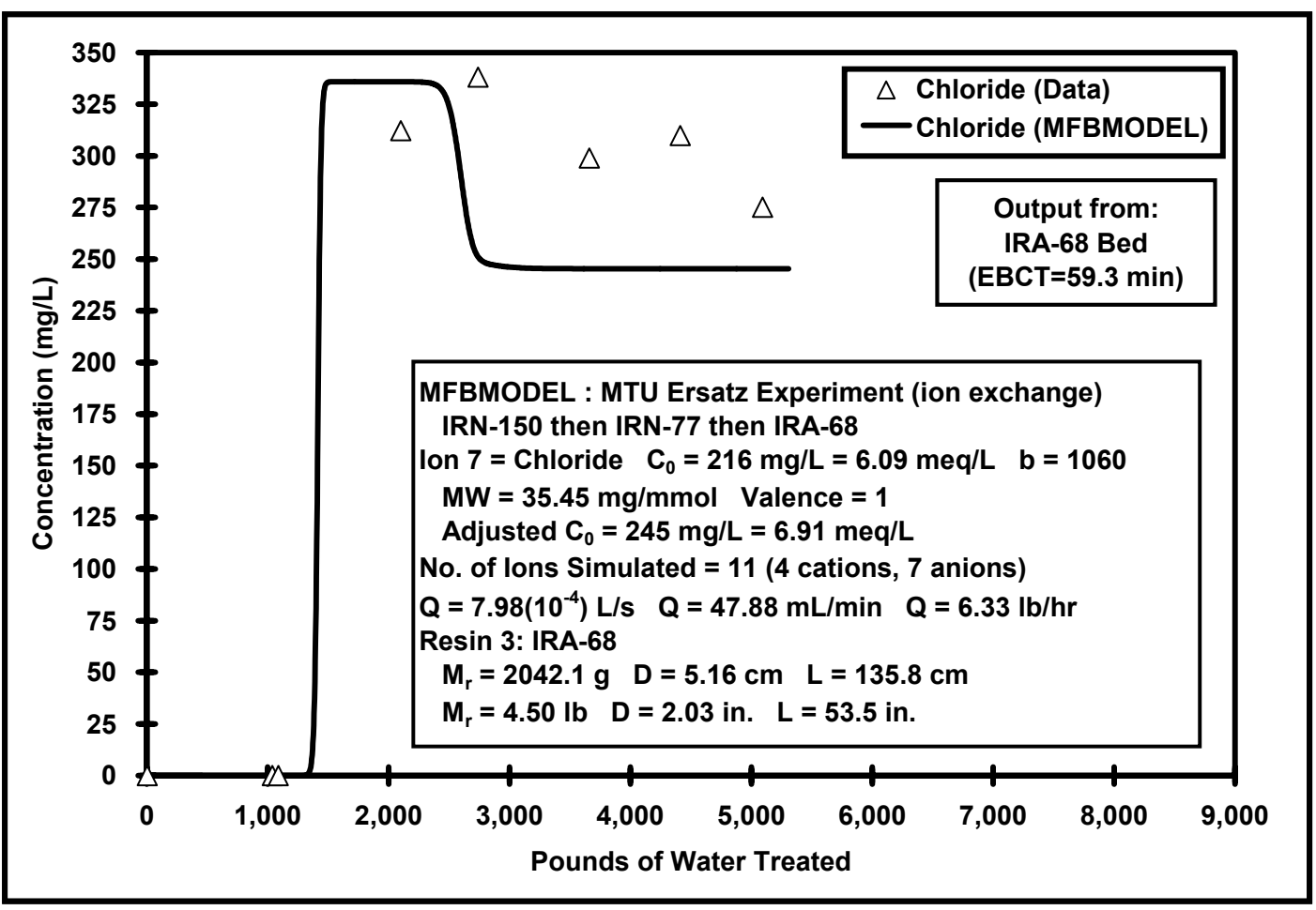




\section{Bicarbonate}

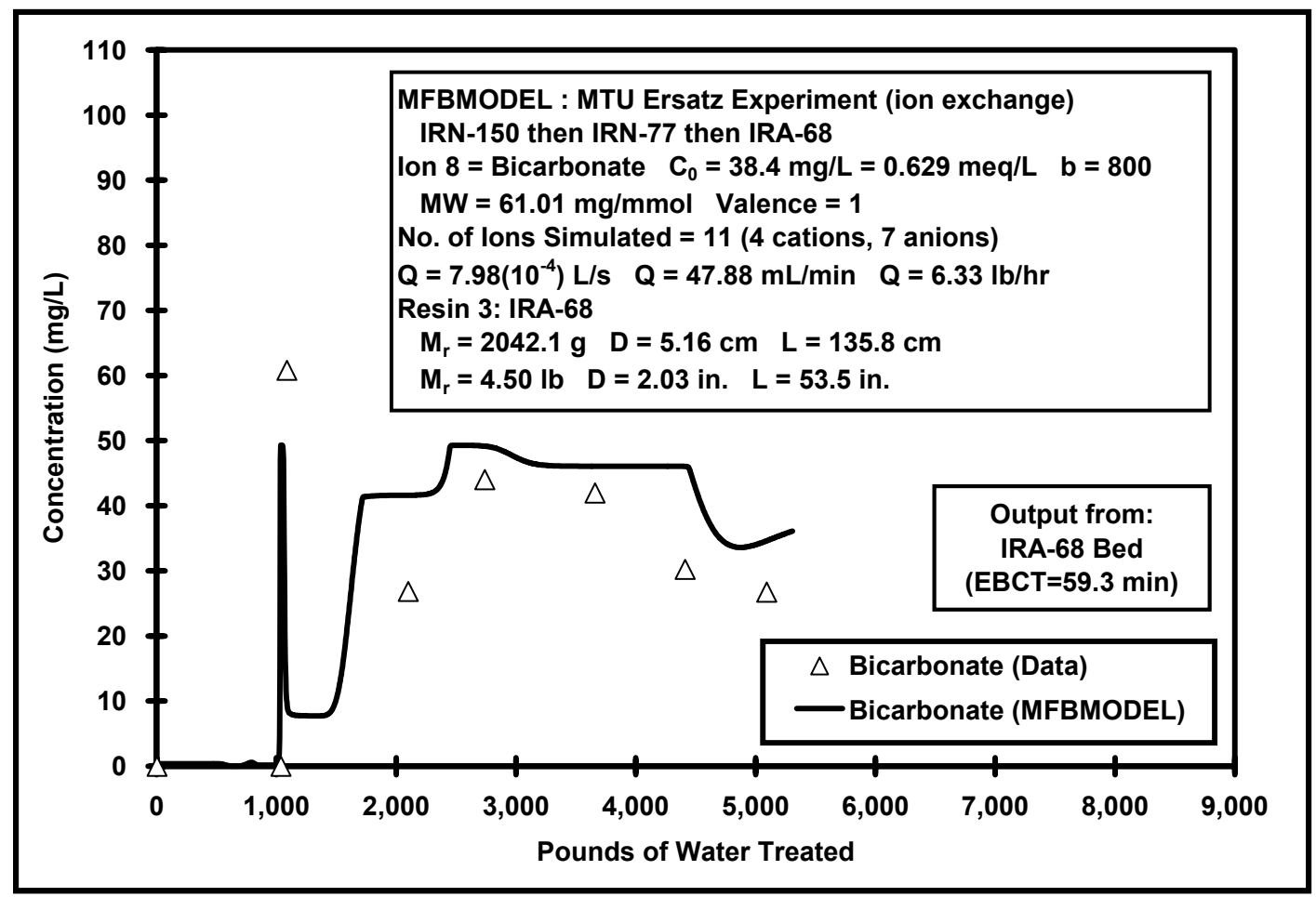

\section{Sulfate}

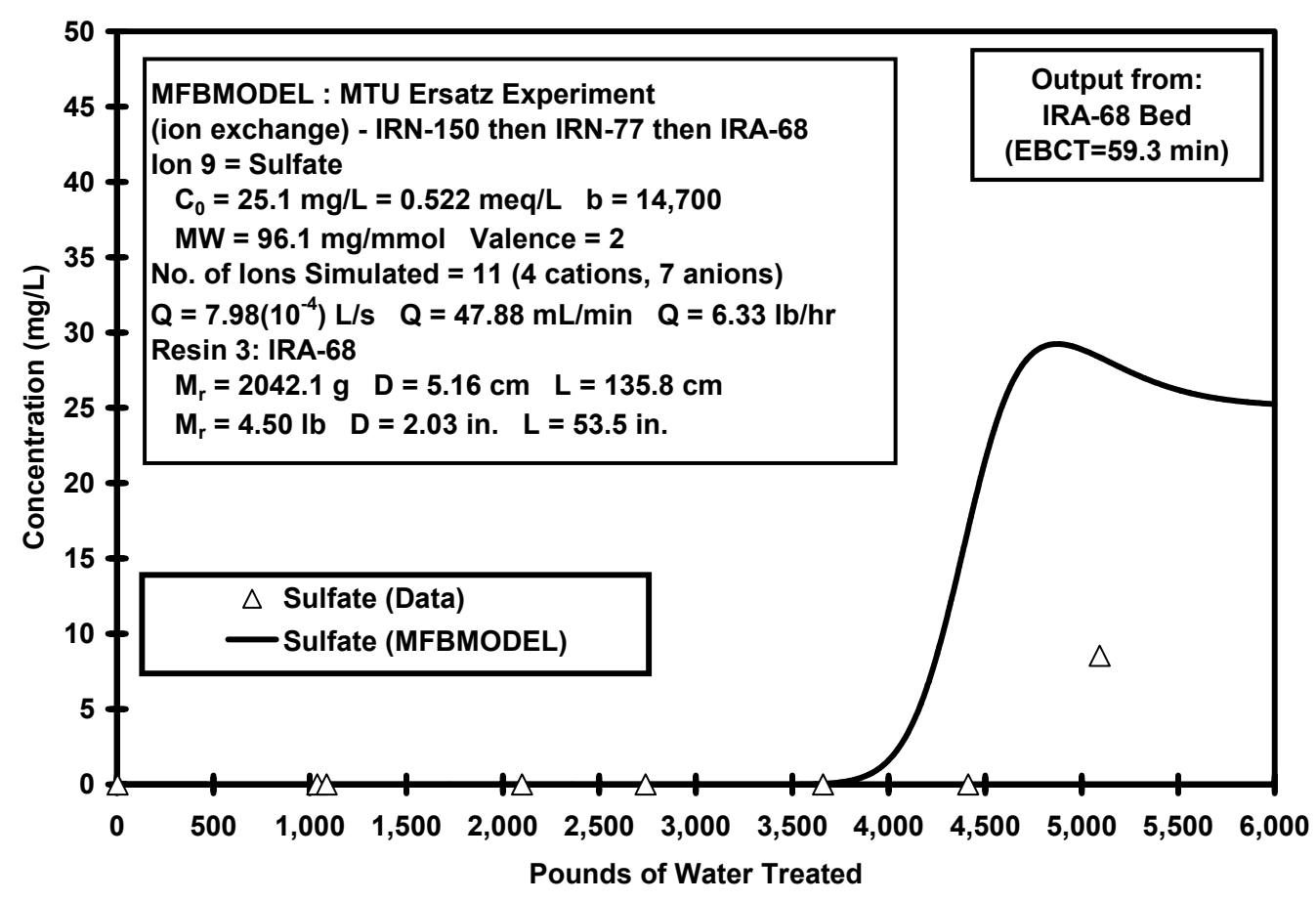


CMT

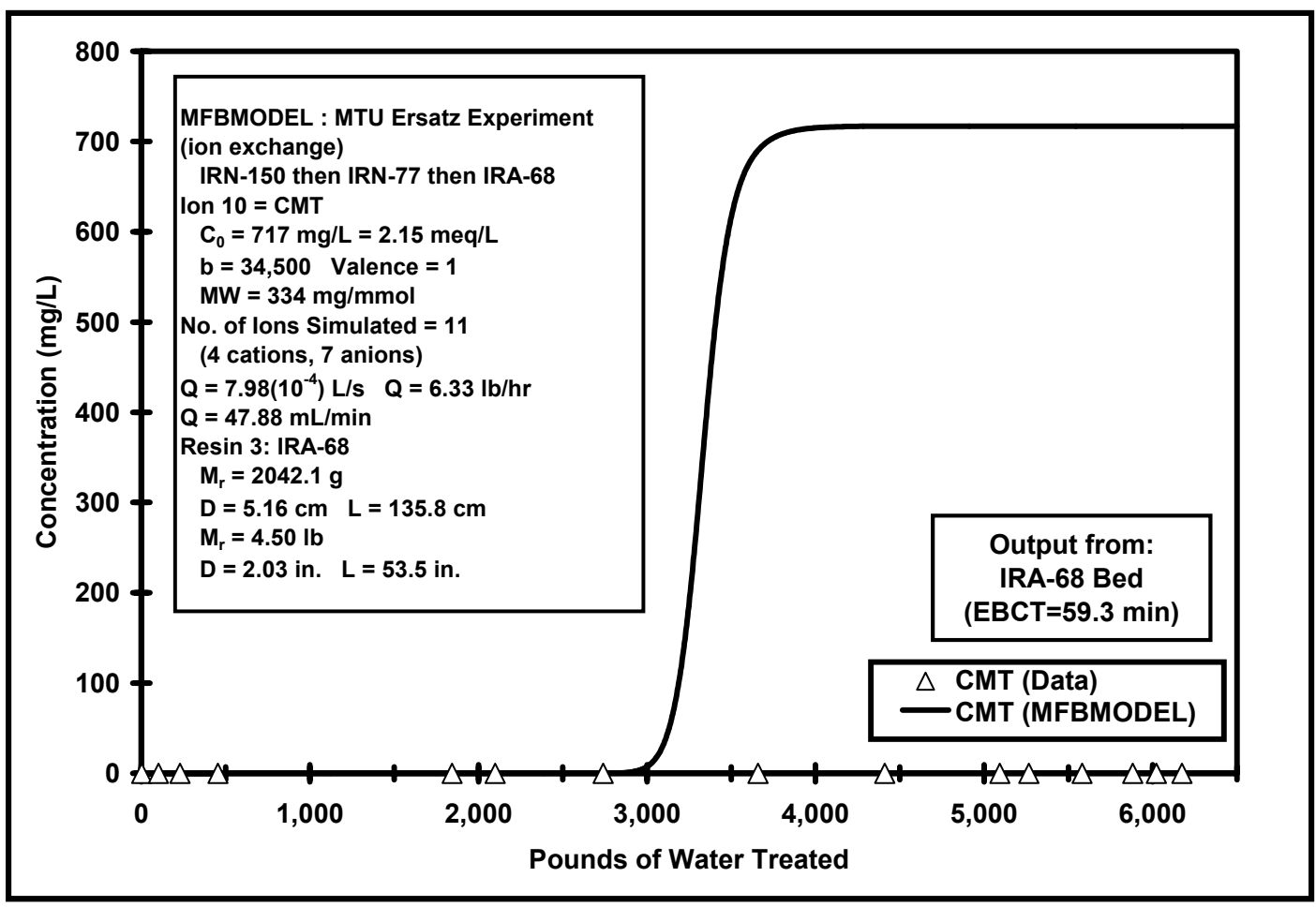

Hydroxide

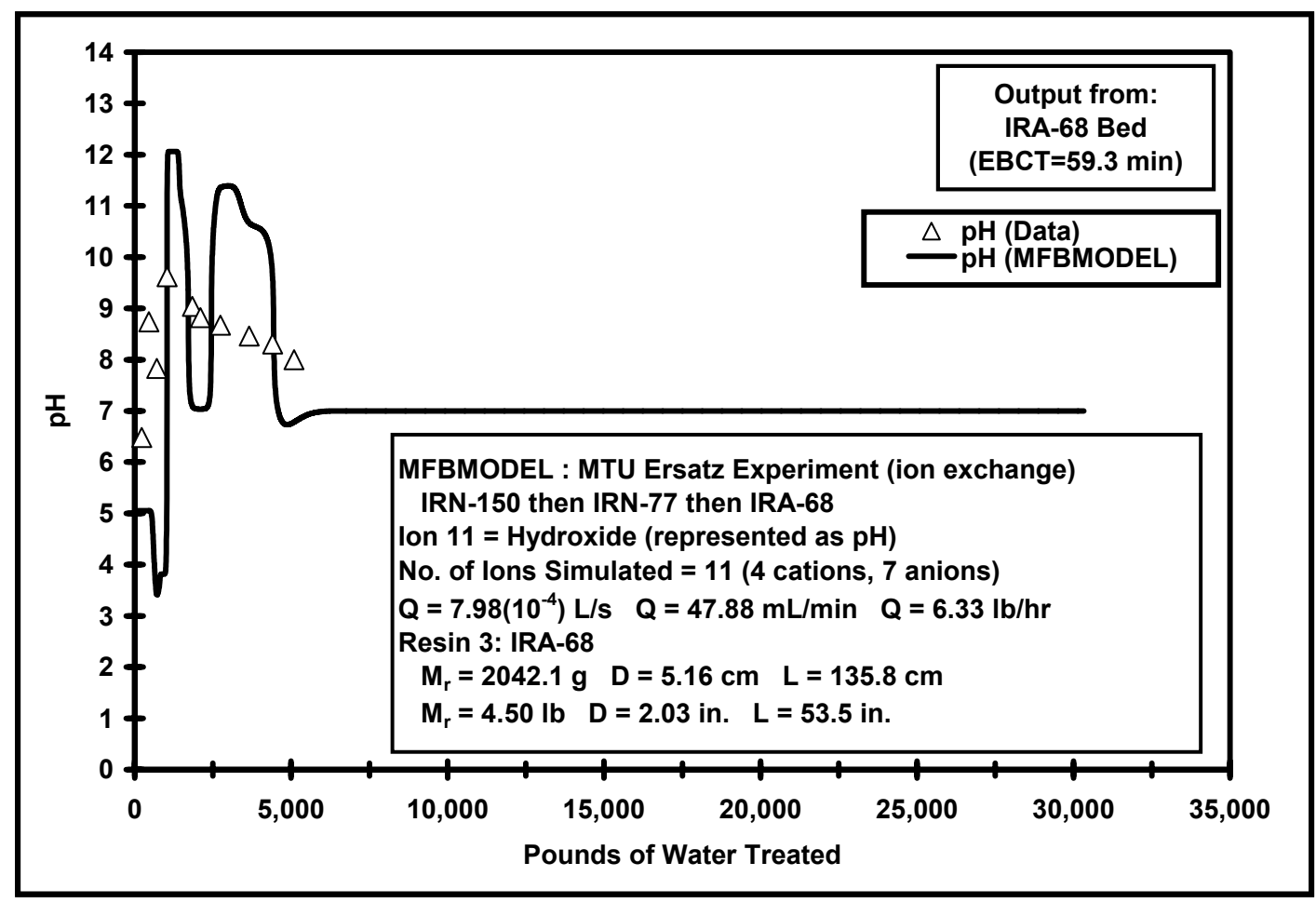


Appendix IX.A - Ion Exchange Results Presented in Additional Units

Units of $\mathrm{mg} / \mathrm{L}$ versus Time in Days

Mixed Bed Ion Exchange Resin: Rohm \& Haas IRN-150

Cation Results

Sodium

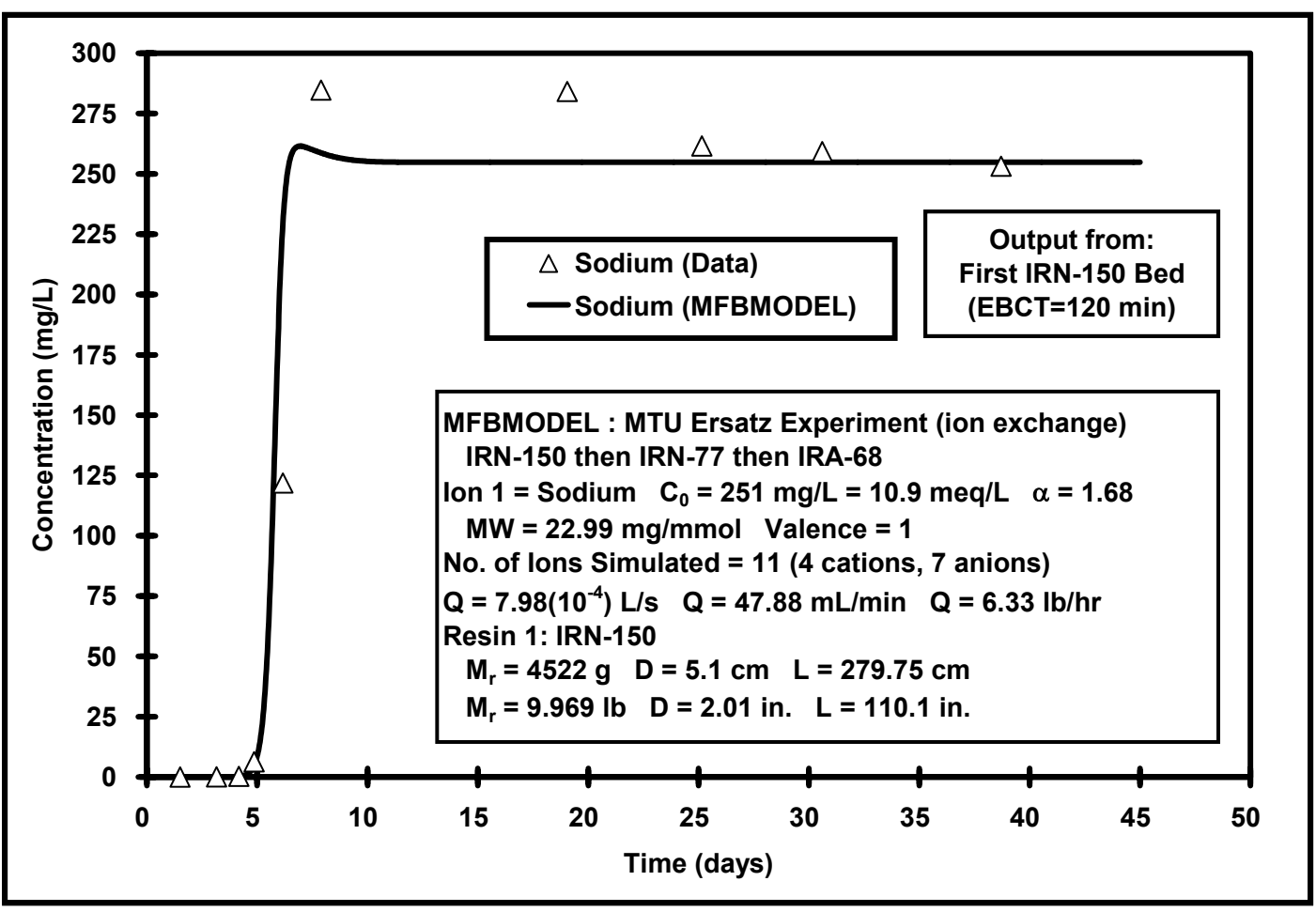




\section{Potassium}

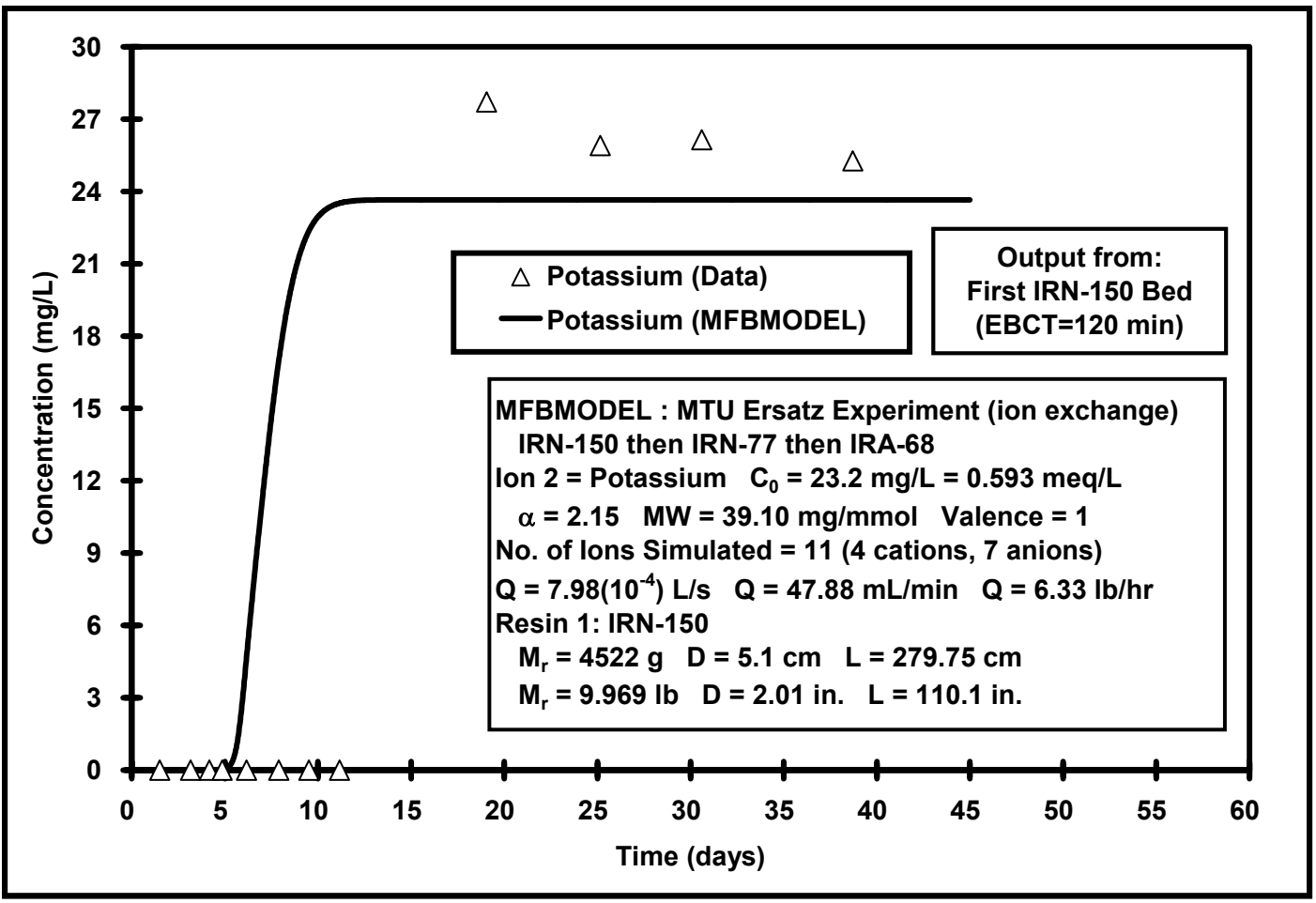

\section{Calcium}

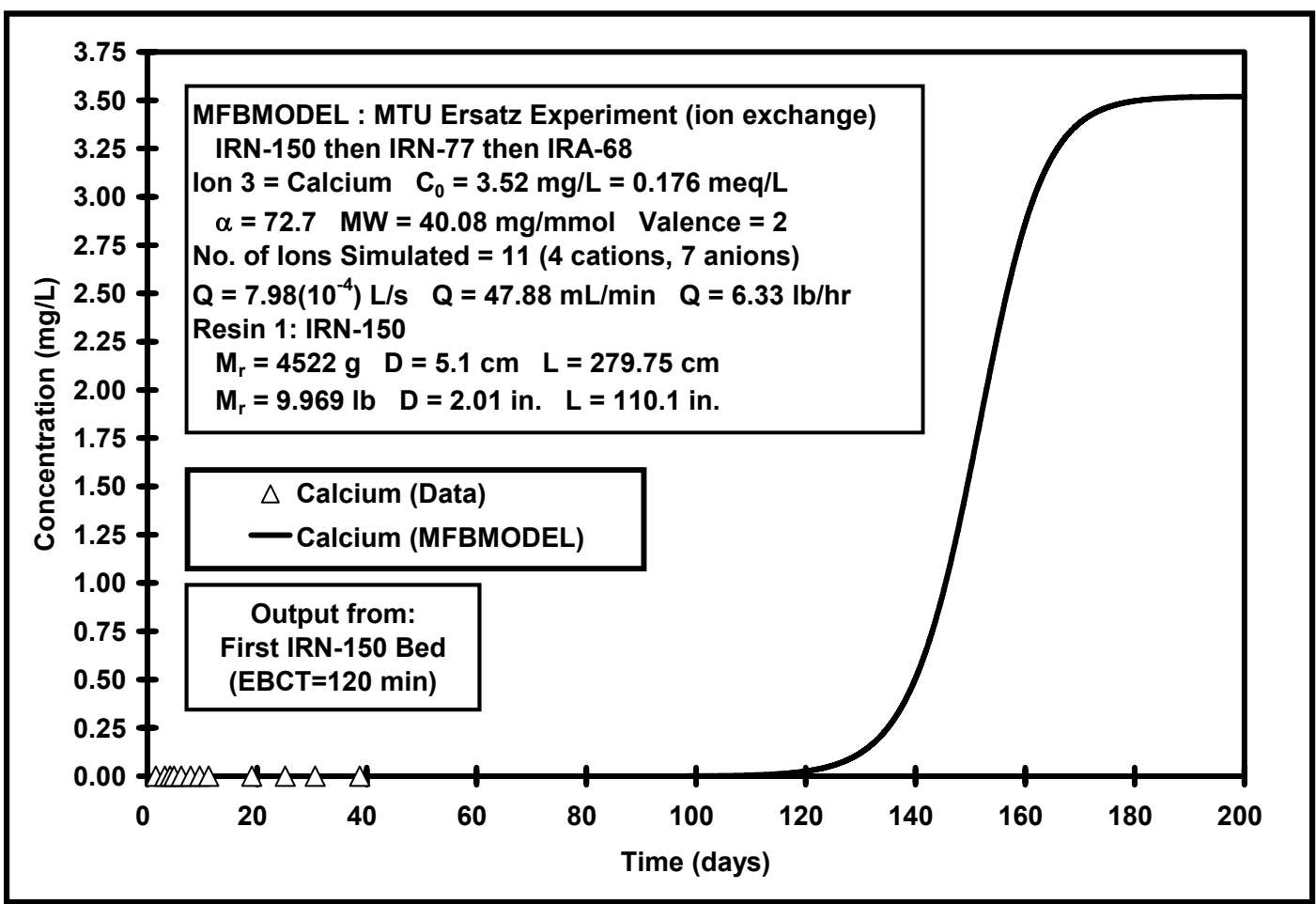




\section{Hydrogen}

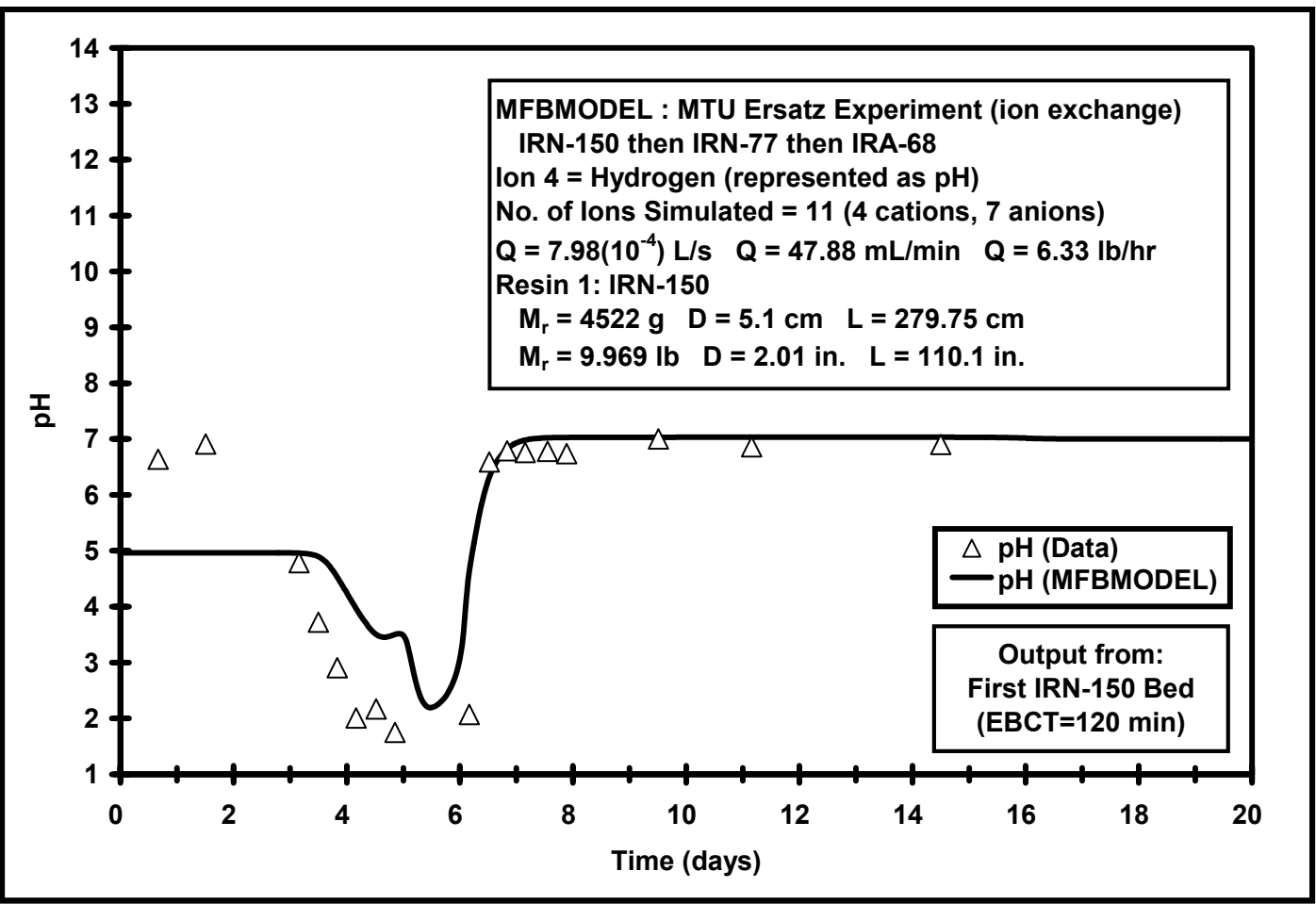

\section{Anion Results}

Acetate

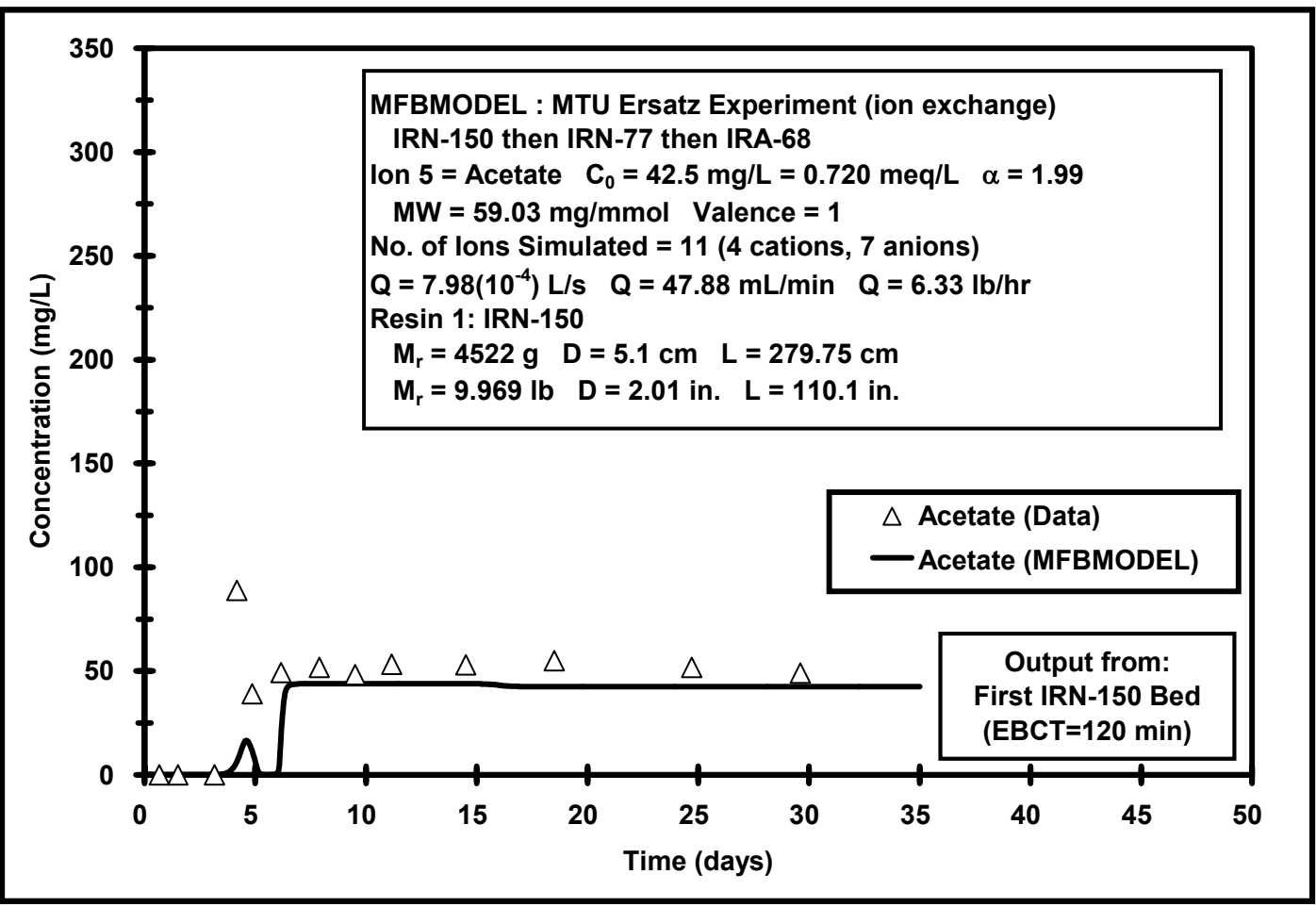




\section{Butyrate}

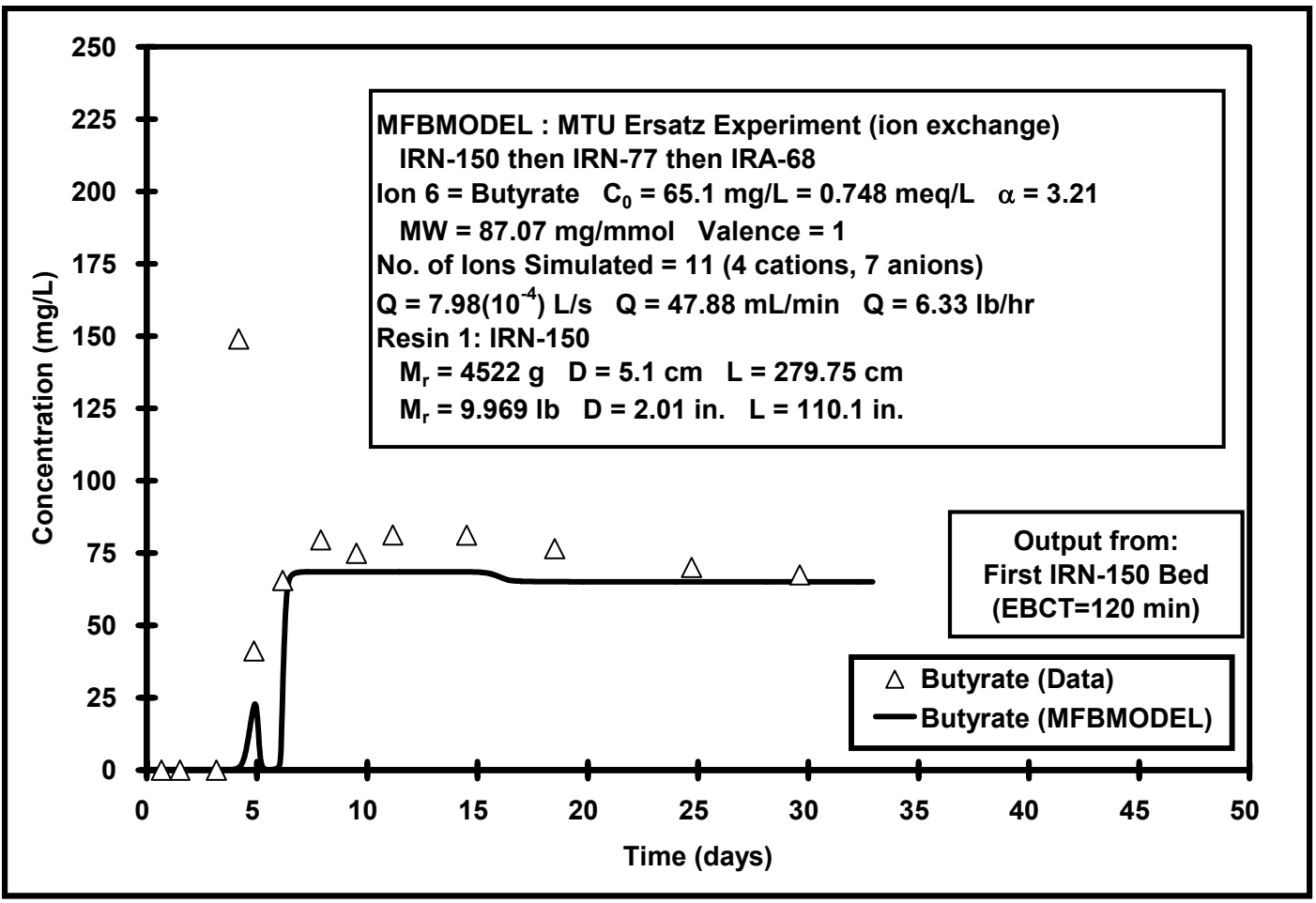

\section{Chloride}

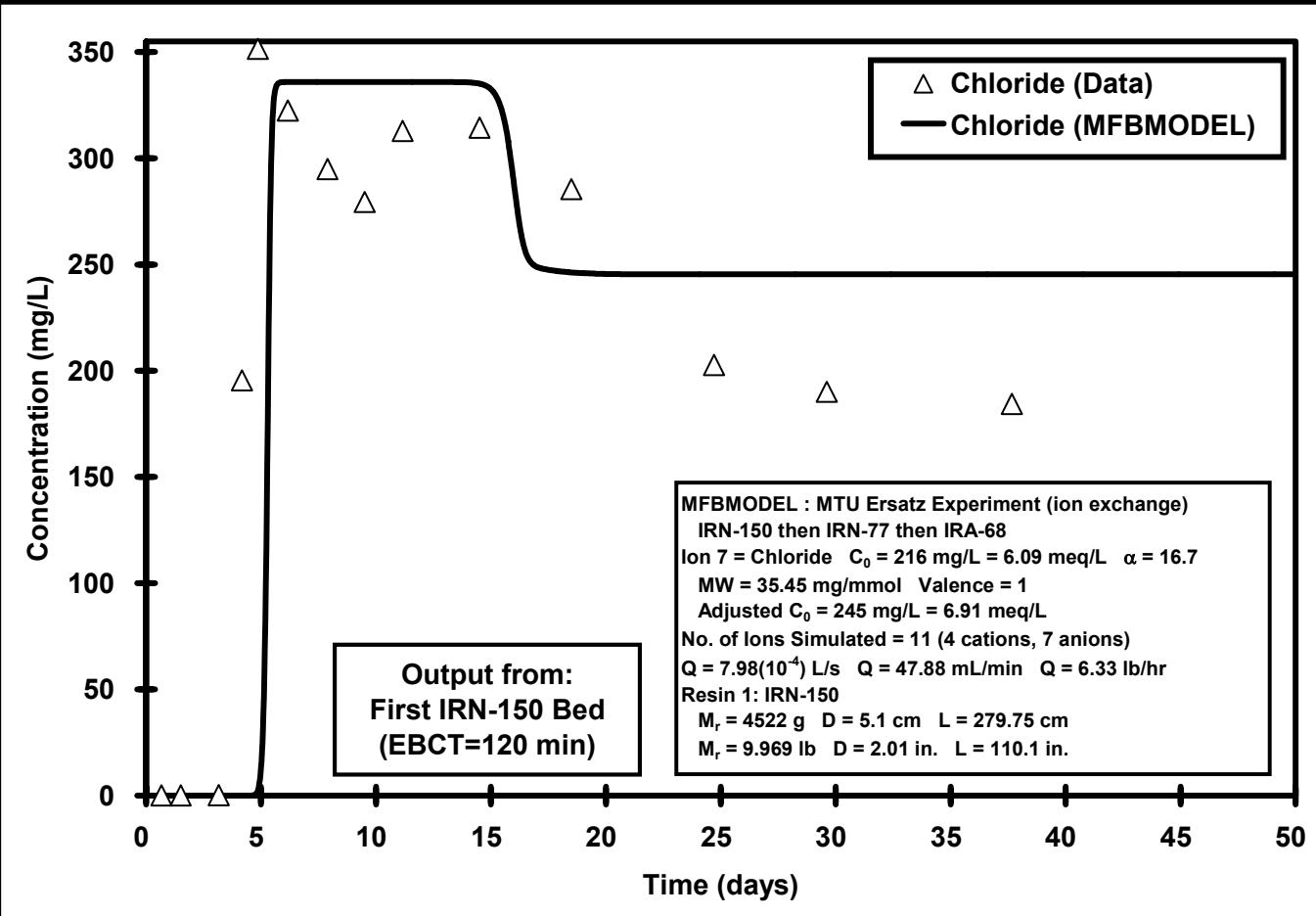




\section{Bicarbonate}

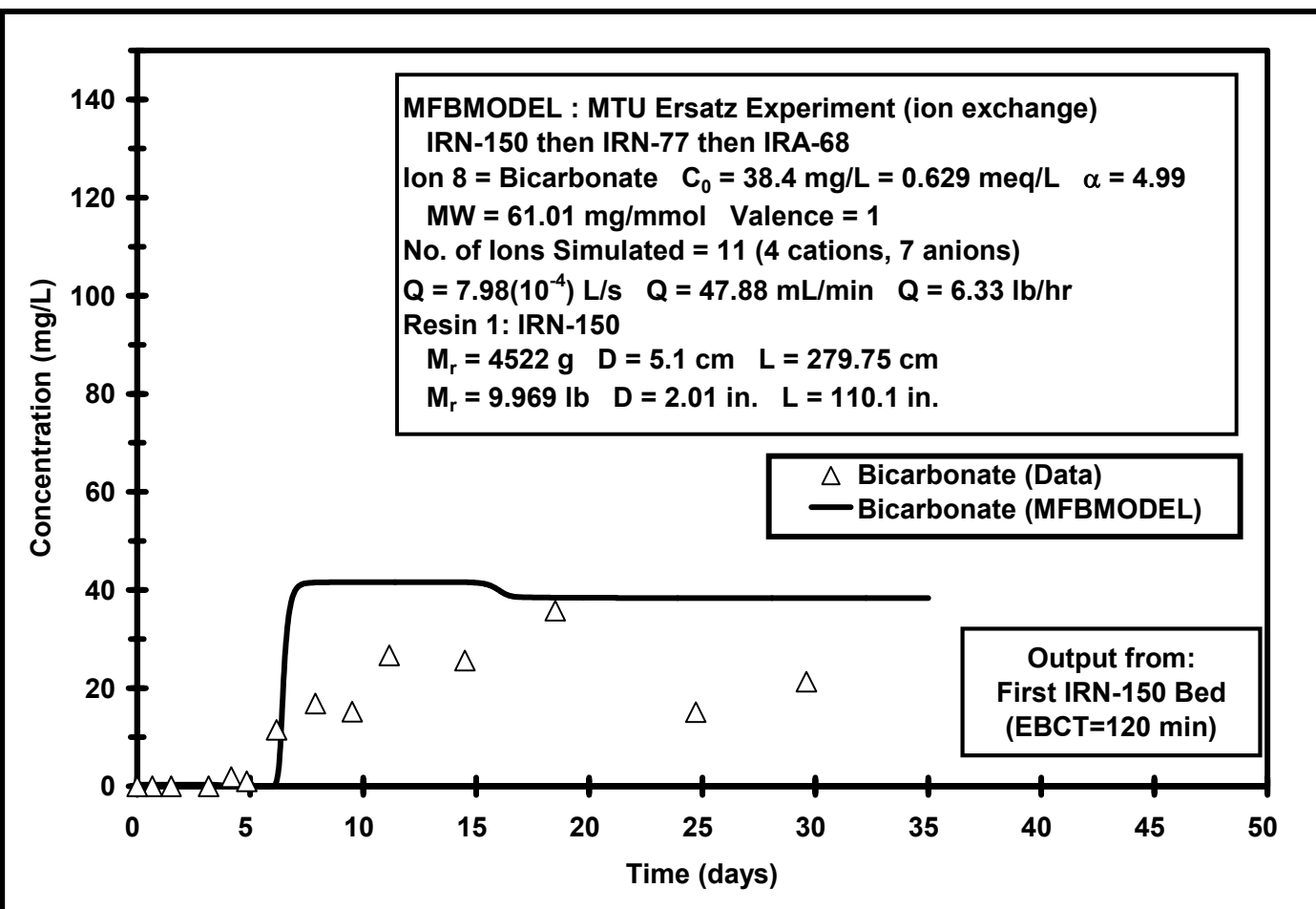

\section{Sulfate}

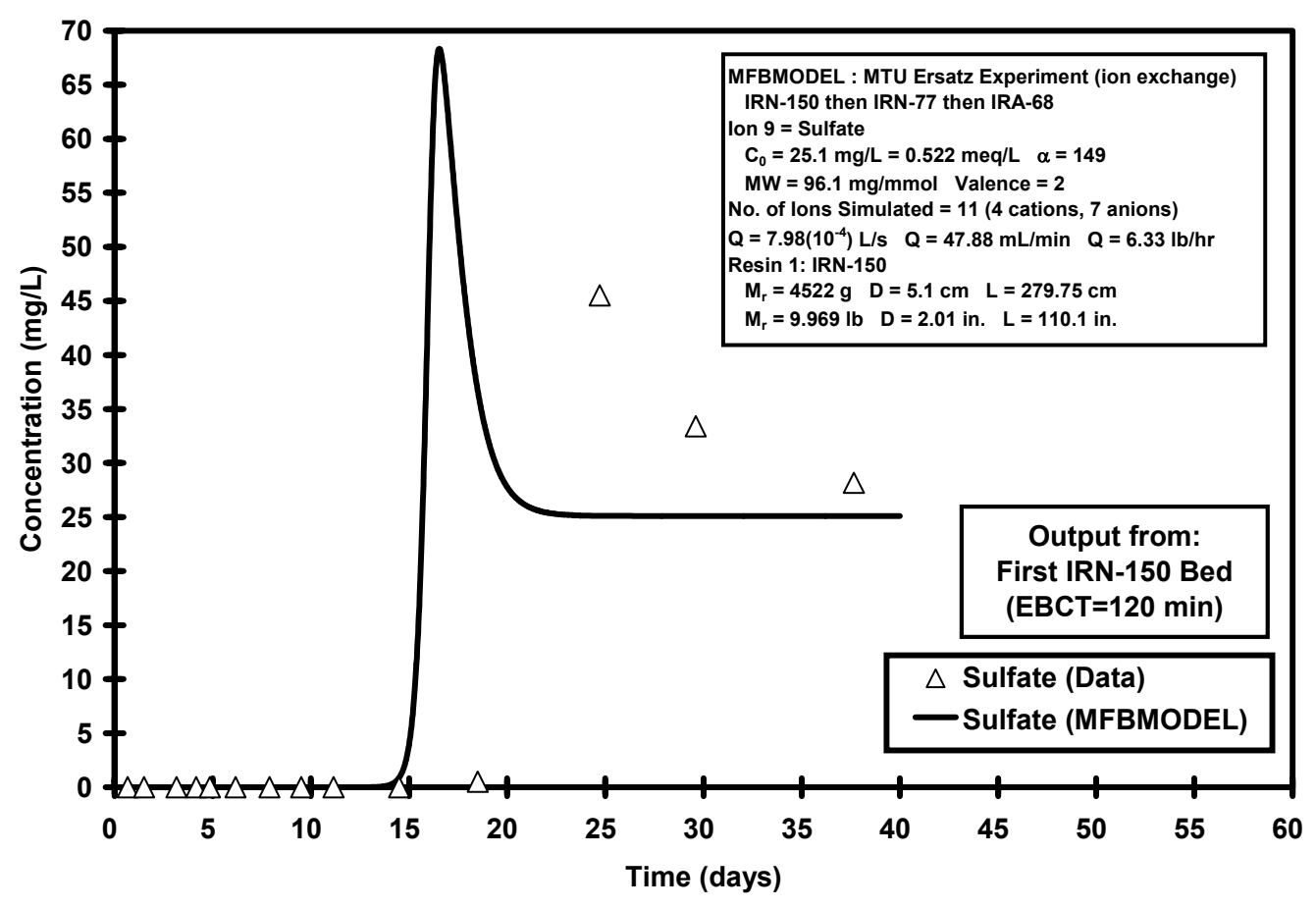




\section{CMT}

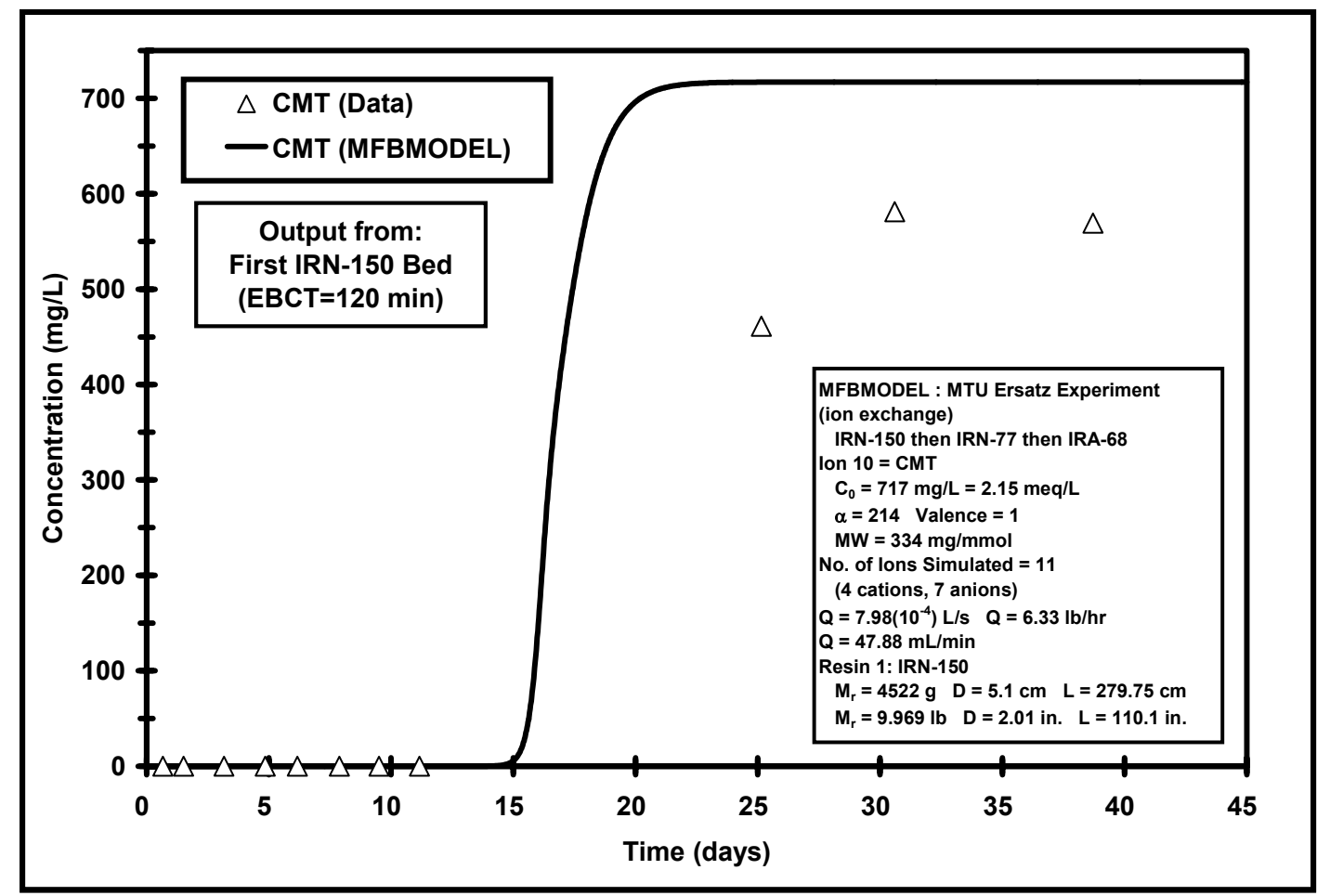

Hydroxide

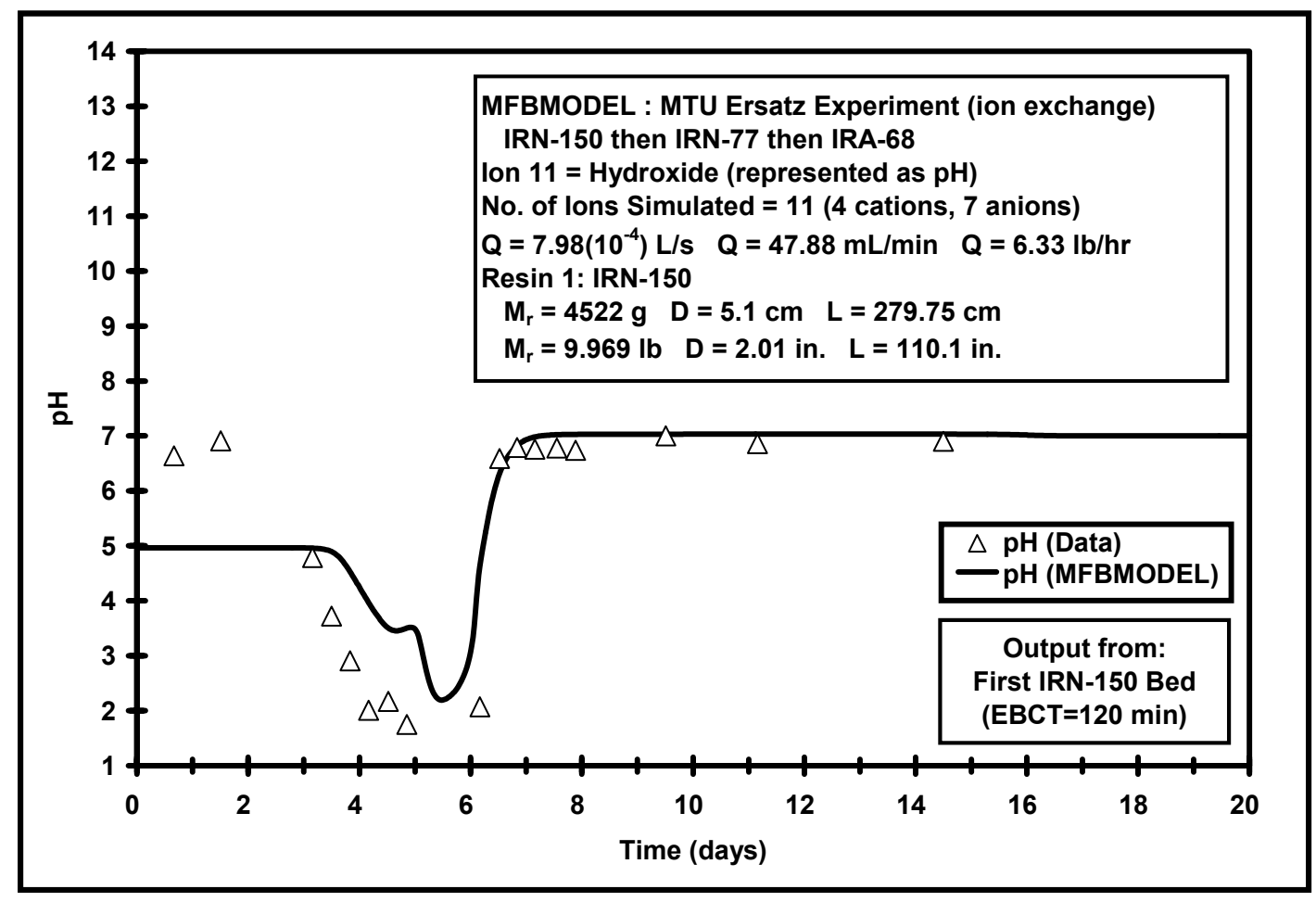




\section{Strong Acid Cation (SAC) Exchange Resin: Rohm \& Haas IRN-77 \\ Cation Results \\ Sodium}

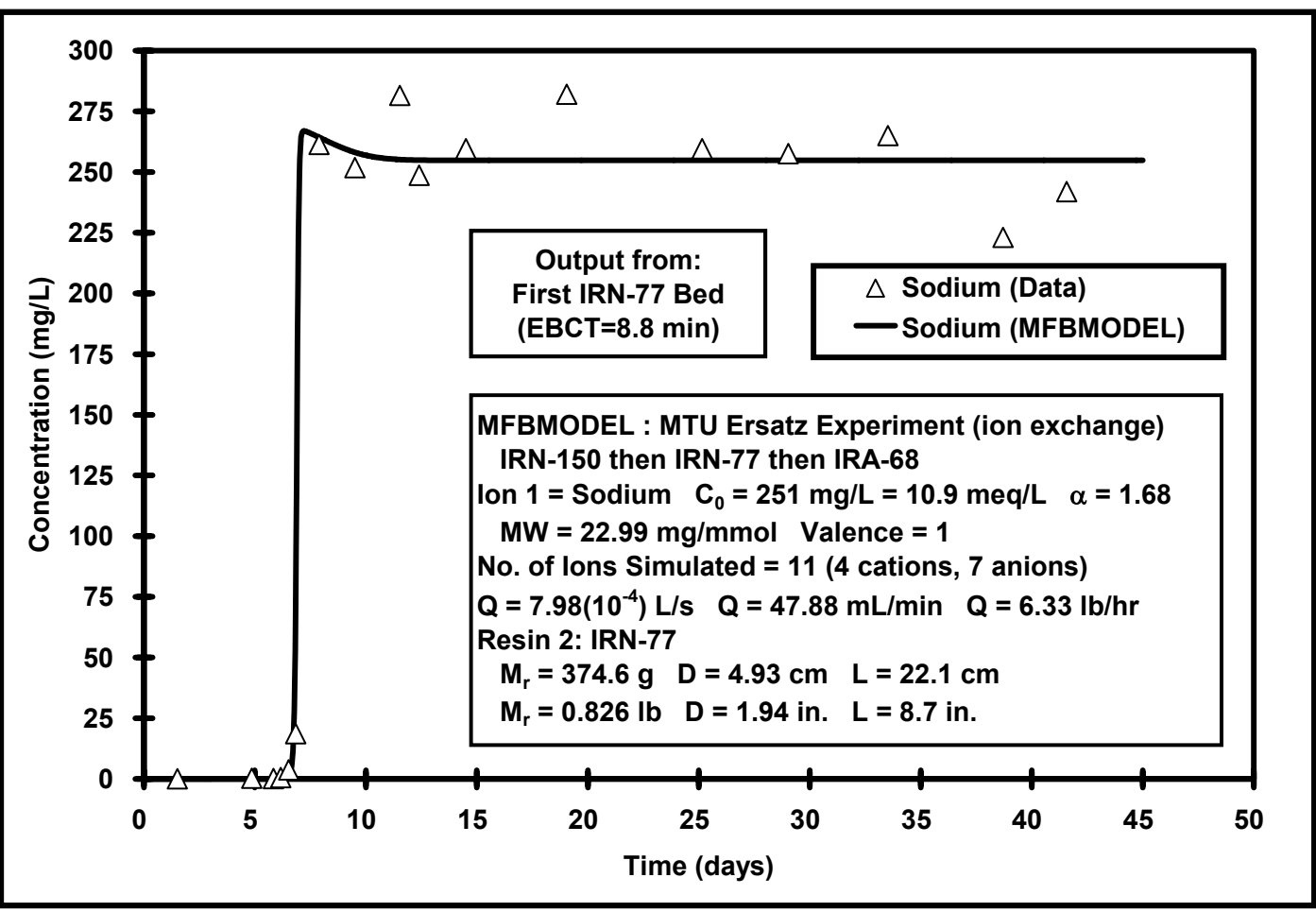

\section{Potassium}

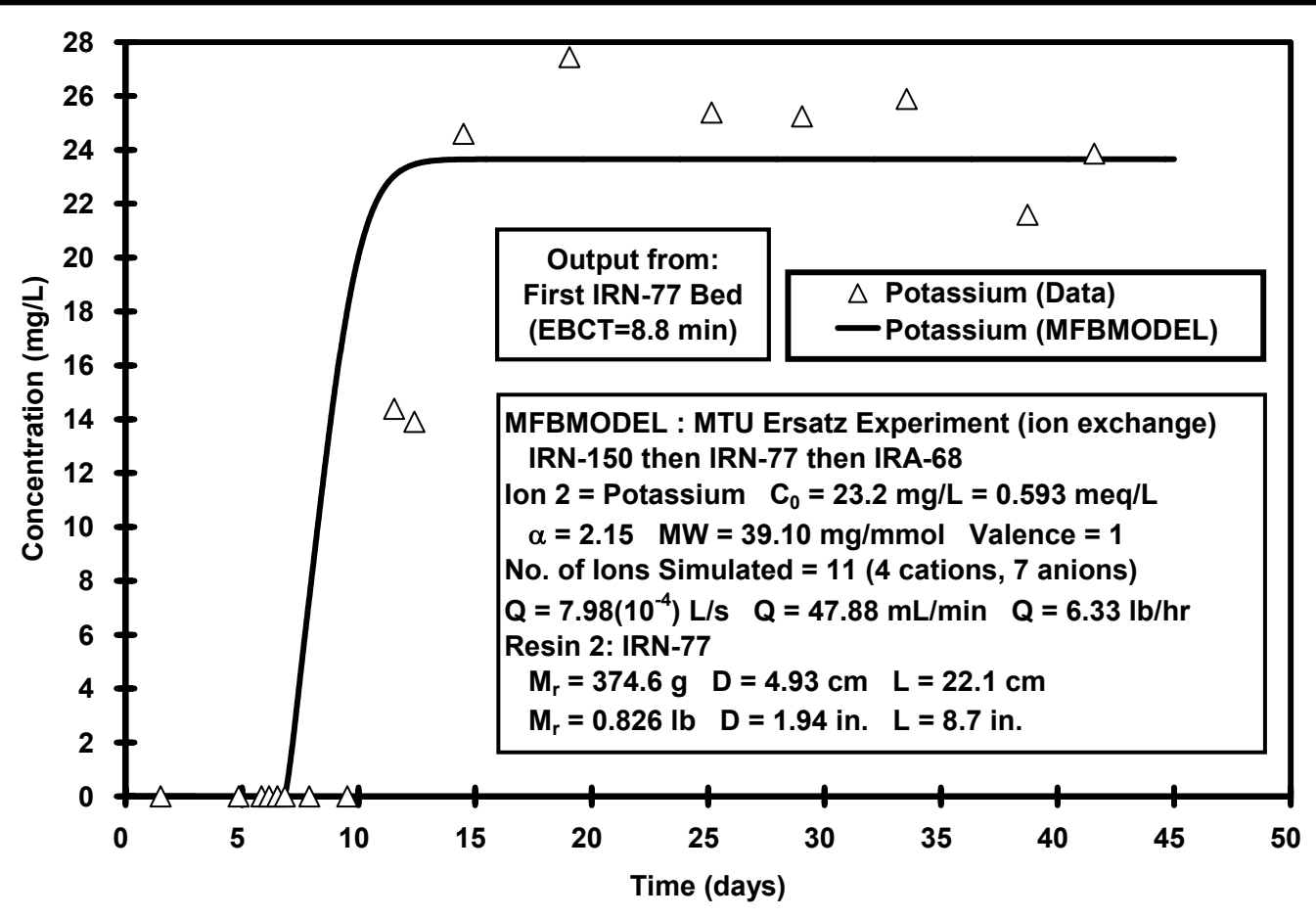




\section{Calcium}

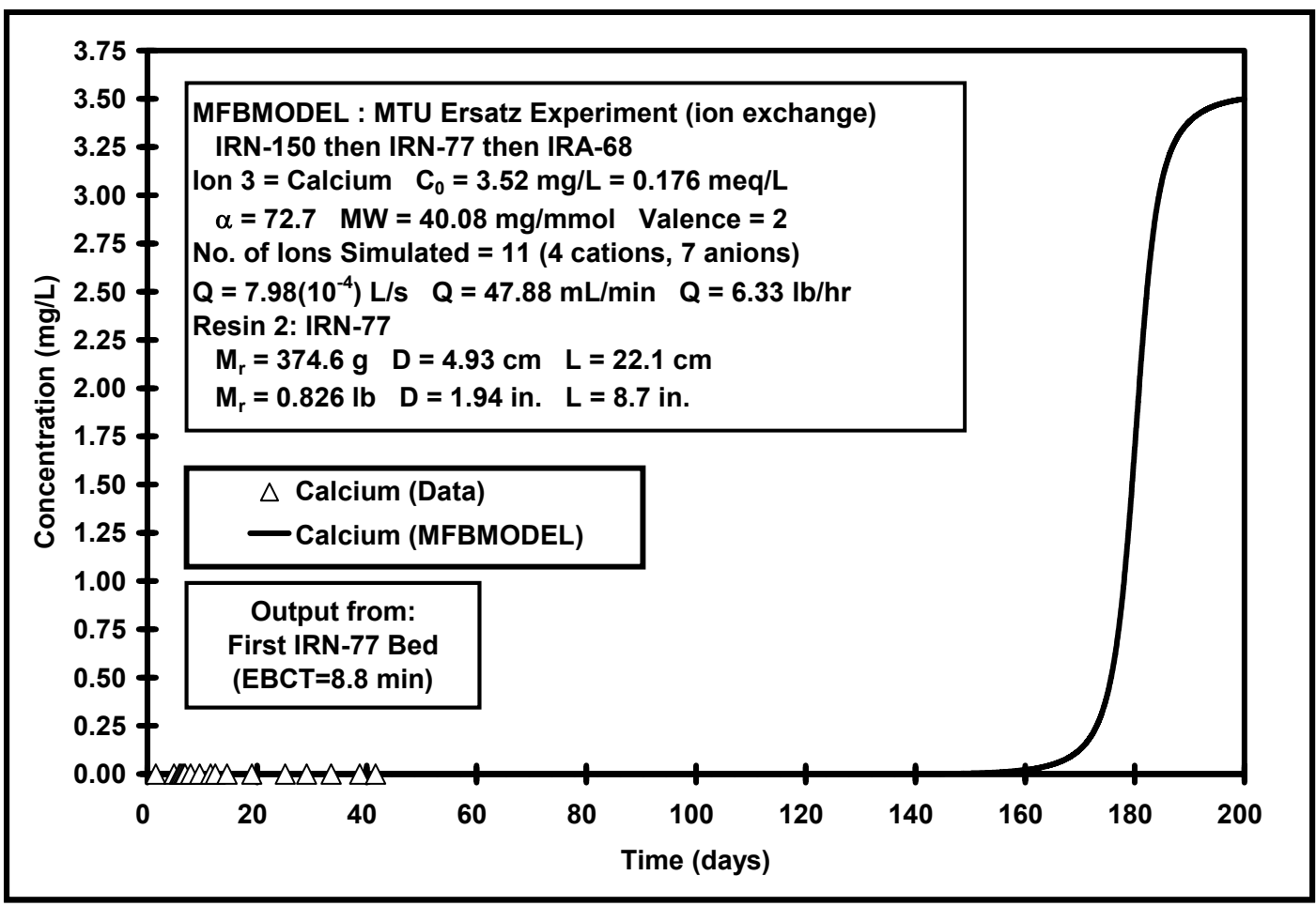

\section{Hydrogen}

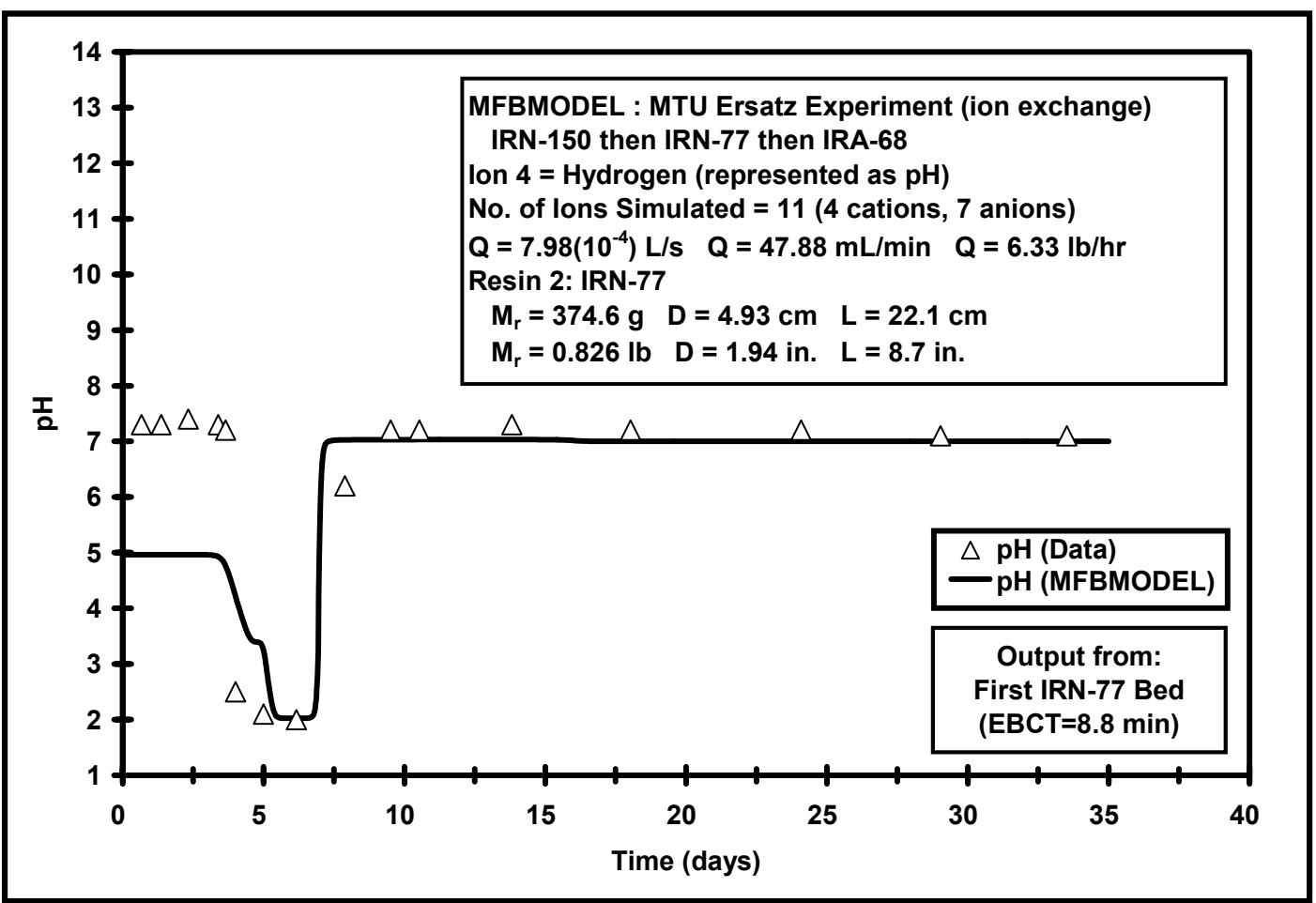


Weak Base Anion (WBA) Exchange Resin: Rohm \& Haas IRN-77

Anion Results

Acetate

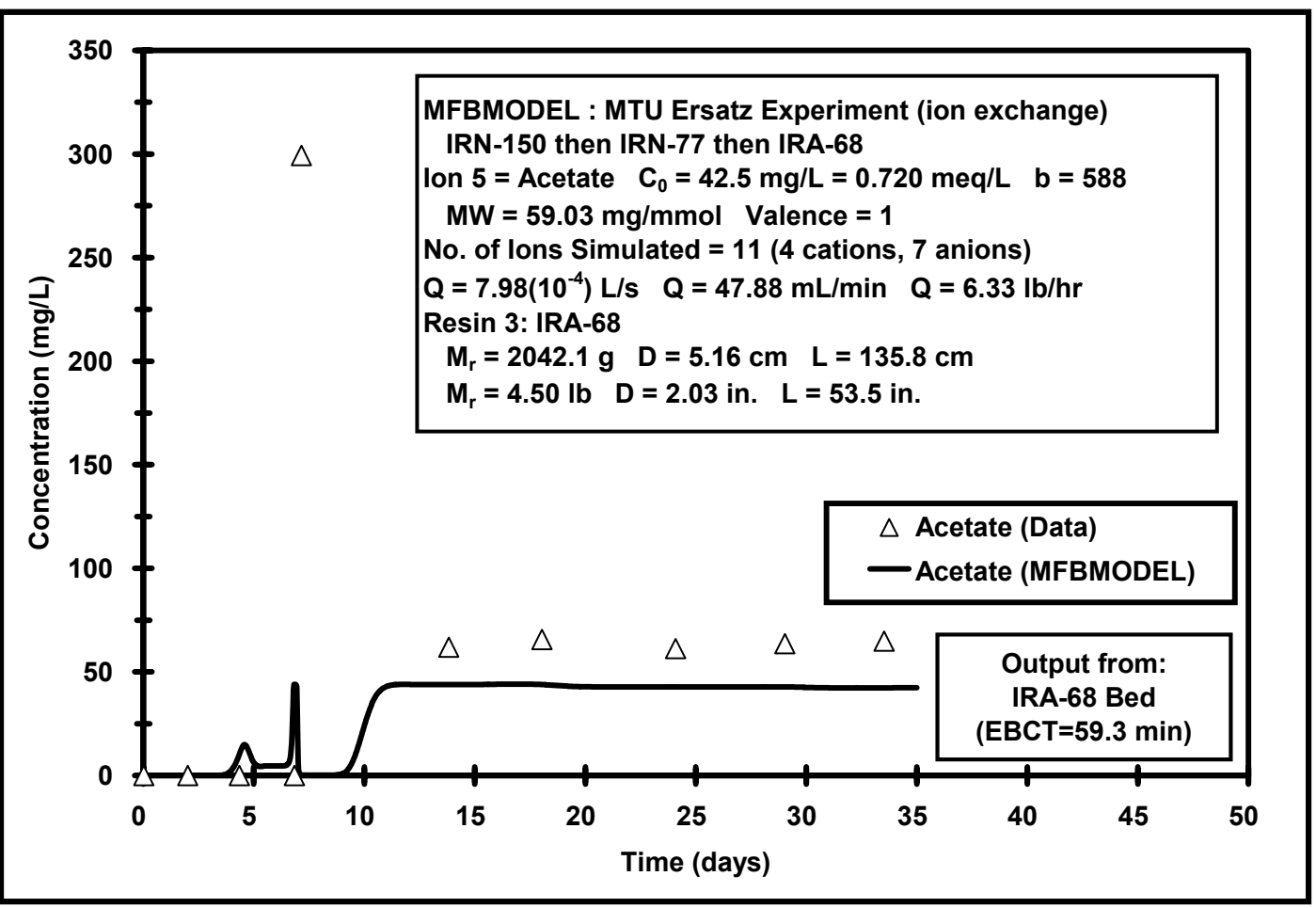

Butyrate

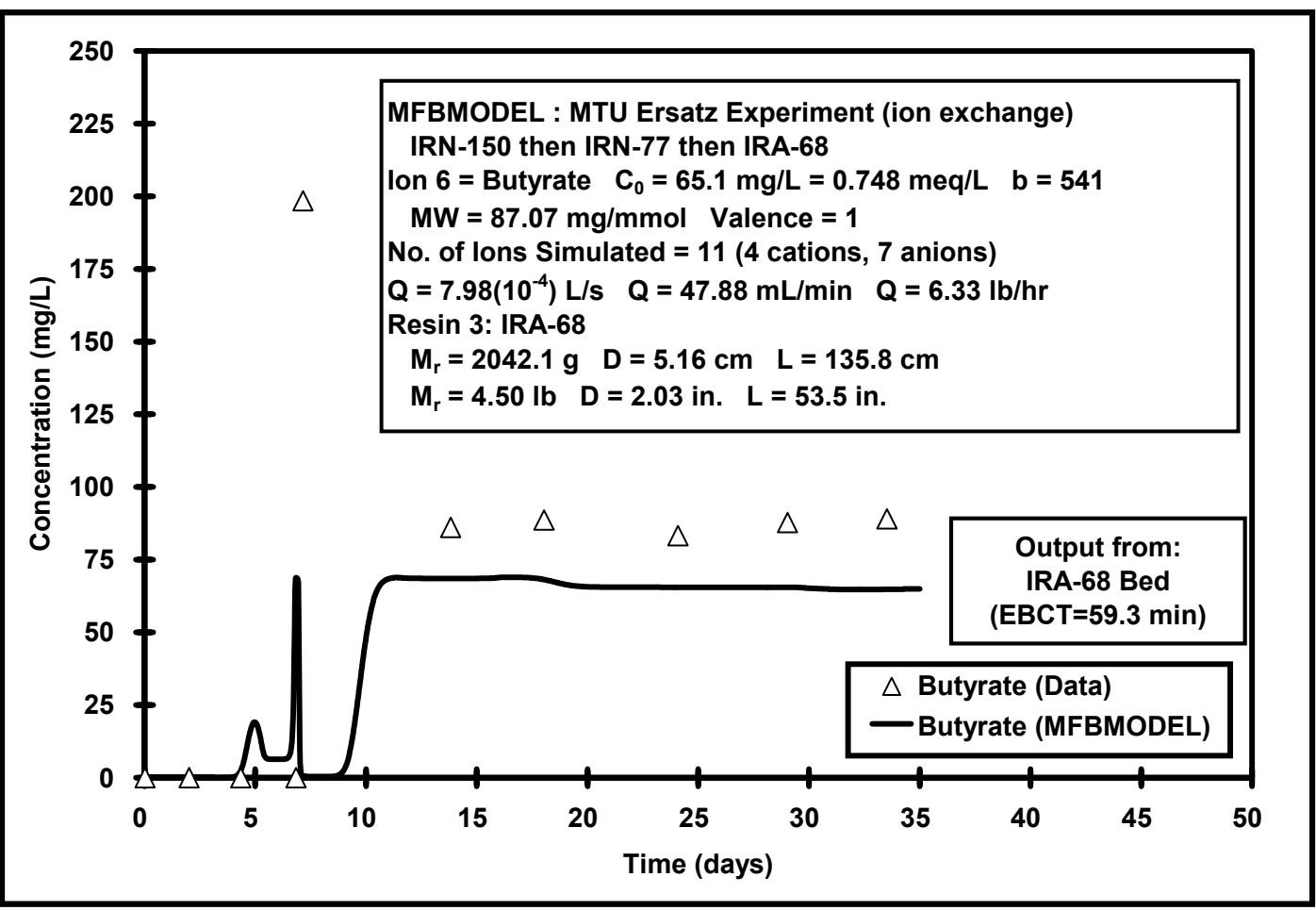




\section{Chloride}

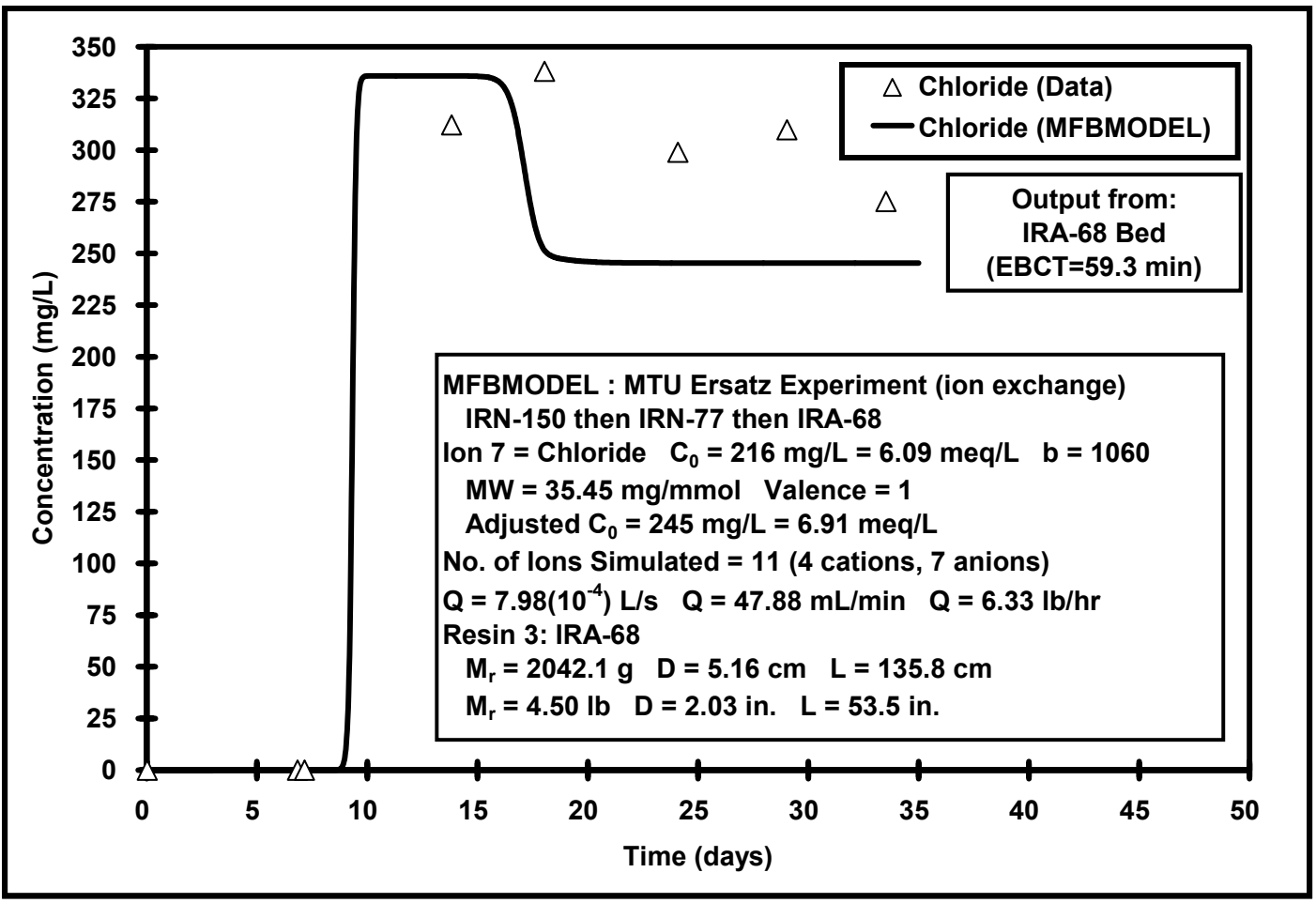

\section{Bicarbonate}

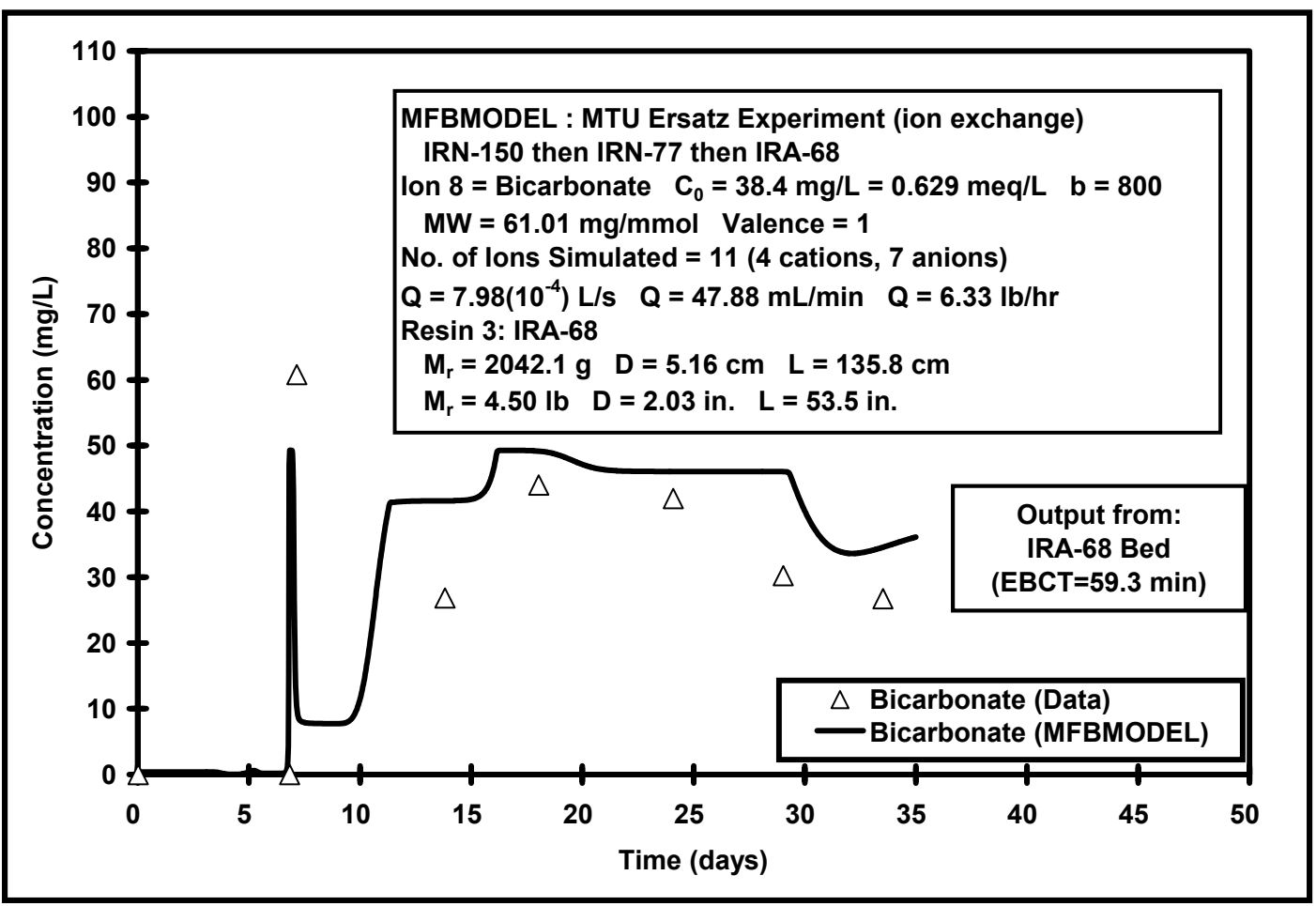




\section{Sulfate}

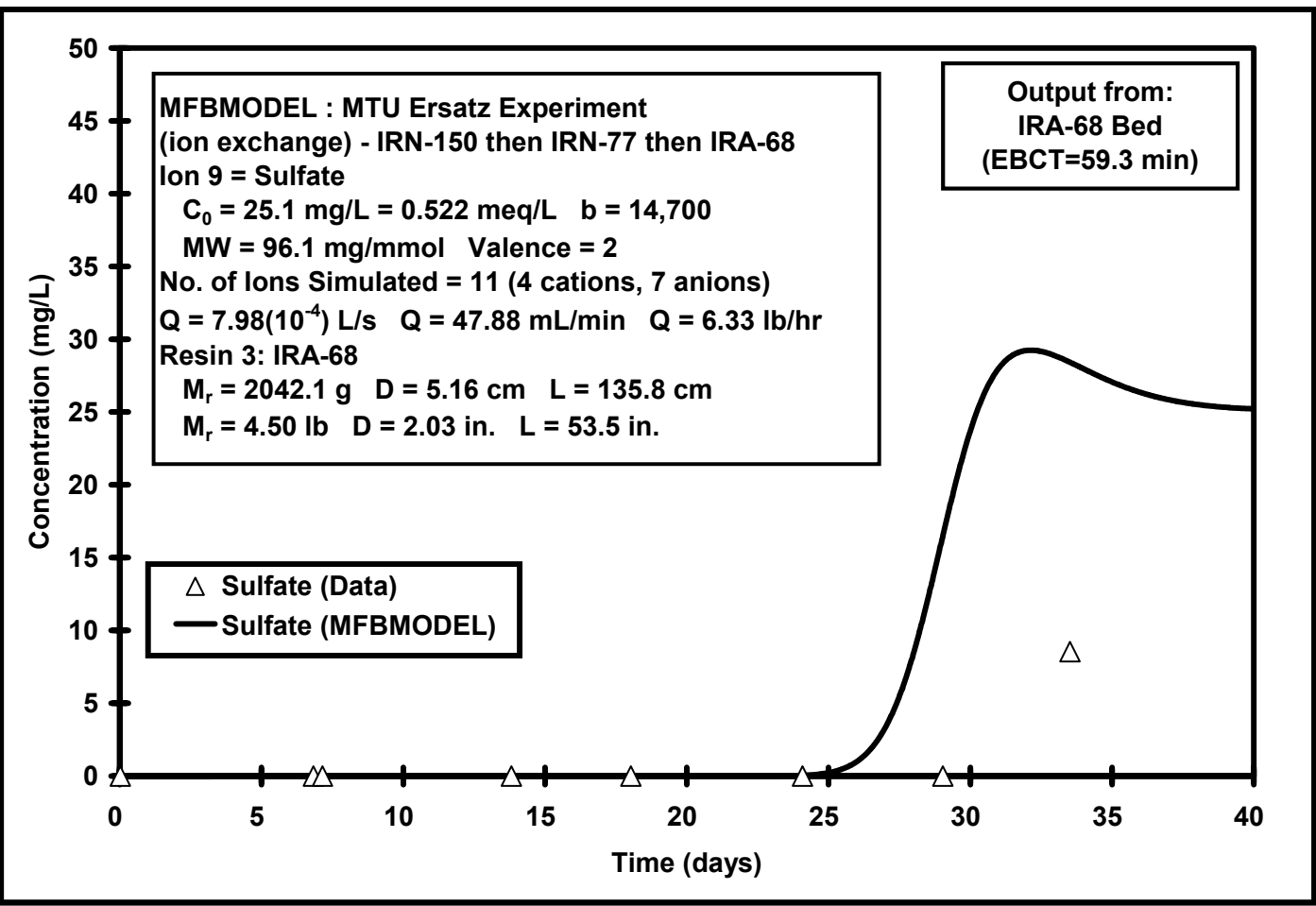

\section{CMT}

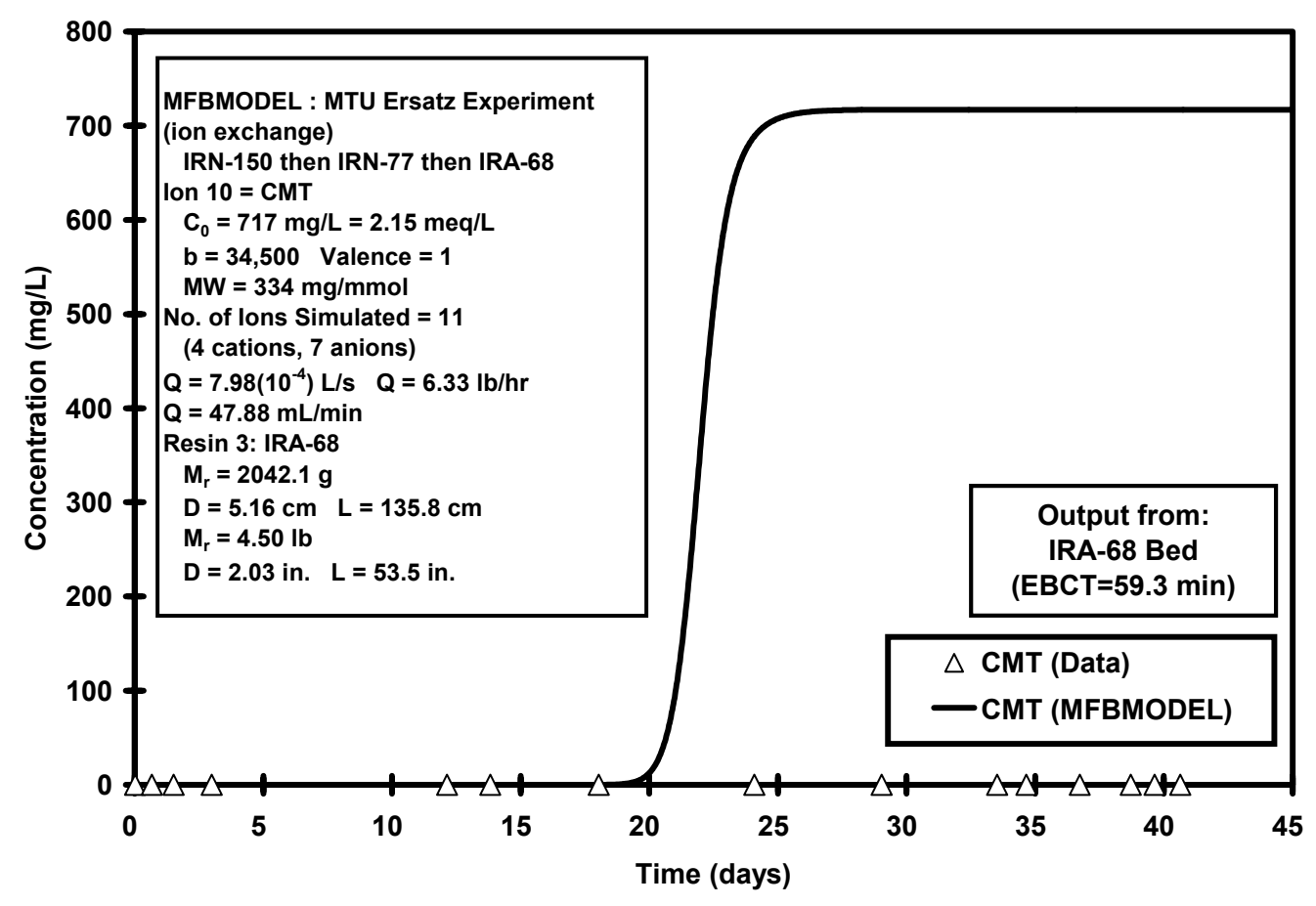




\section{Hydroxide}

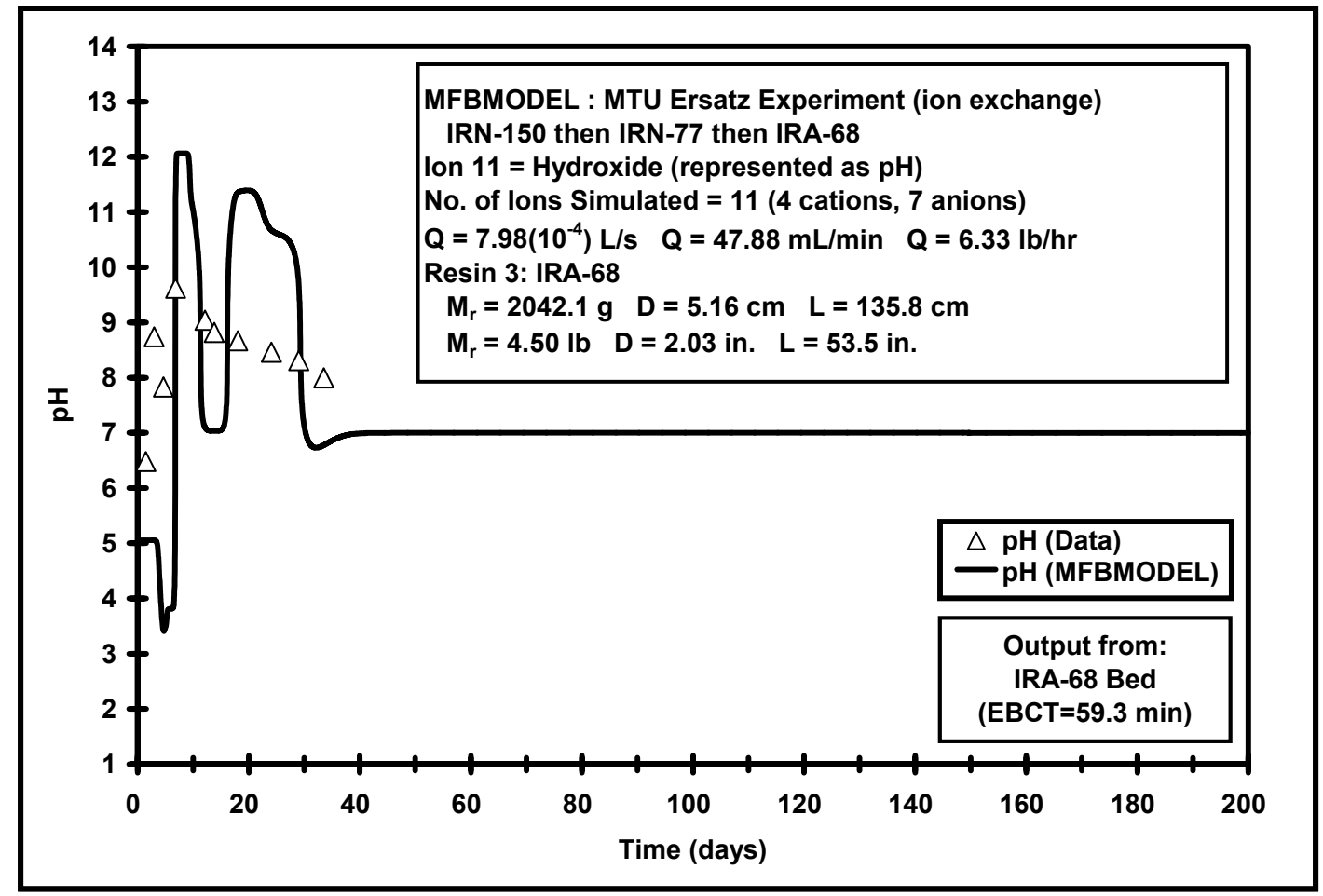




\section{Units of meq/L versus Bed Volumes Treated \\ Mixed Bed Ion Exchange Resin: Rohm \& Haas IRN-150 \\ Cation Results}

Sodium

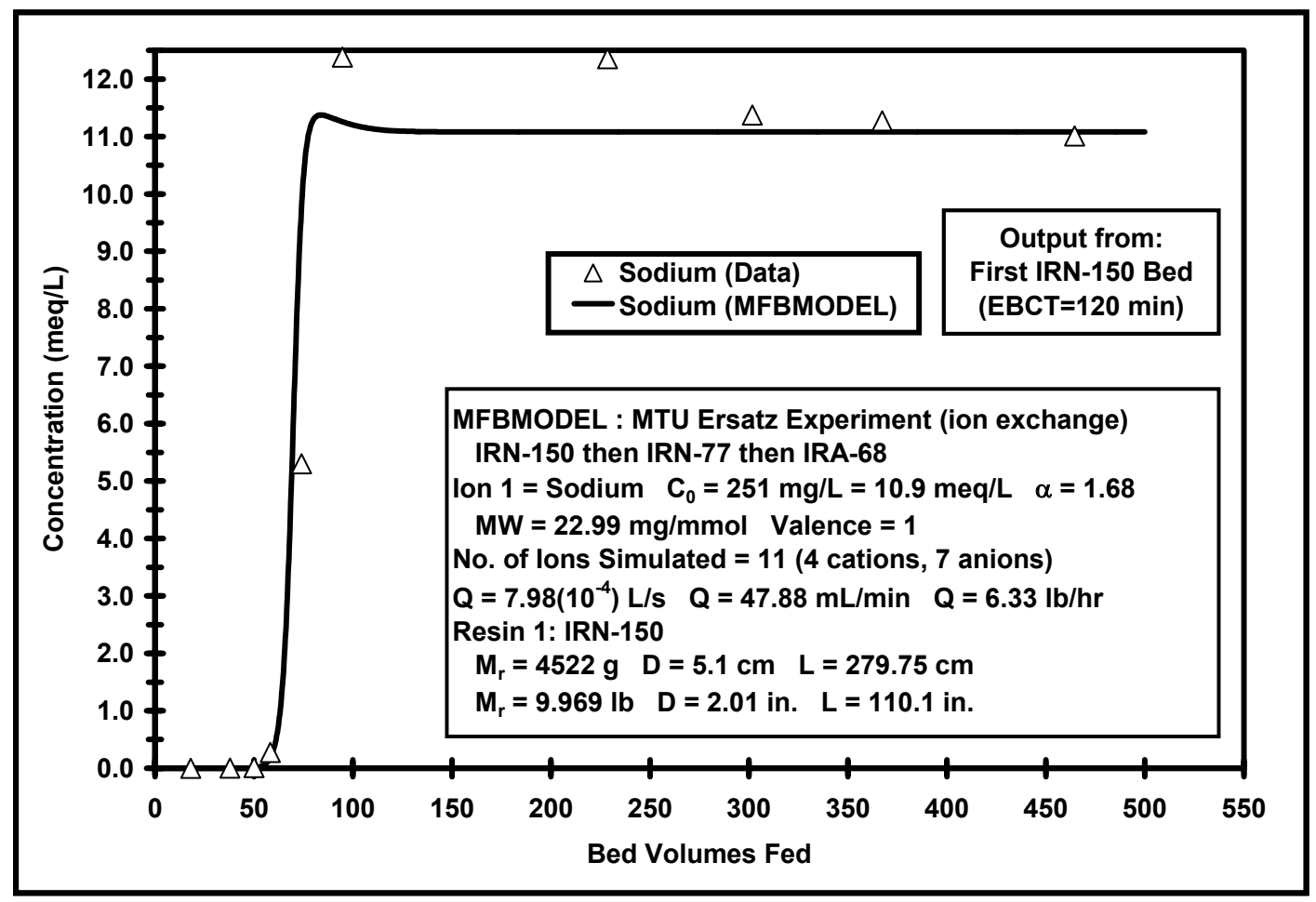




\section{Potassium}

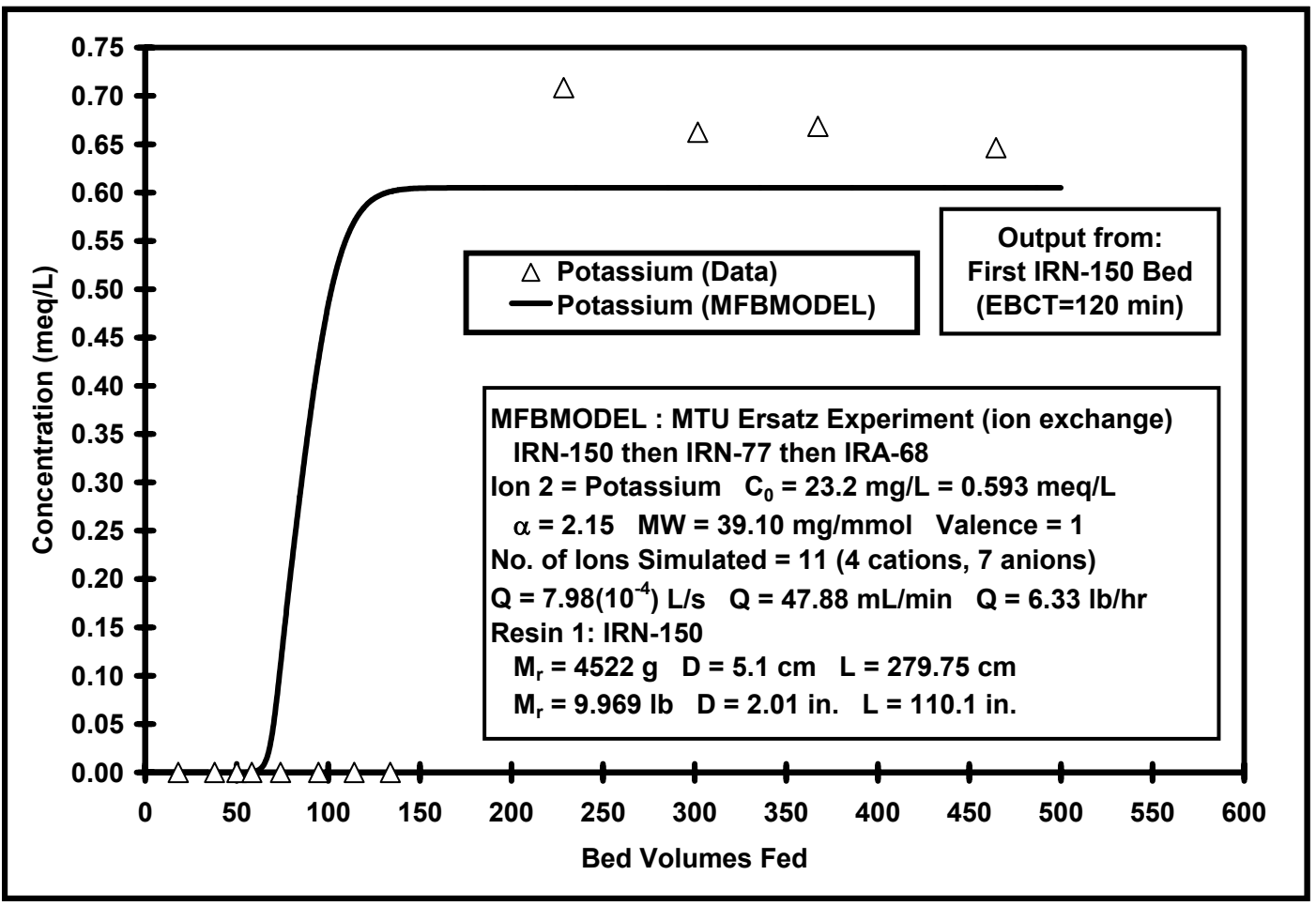

\section{Calcium}

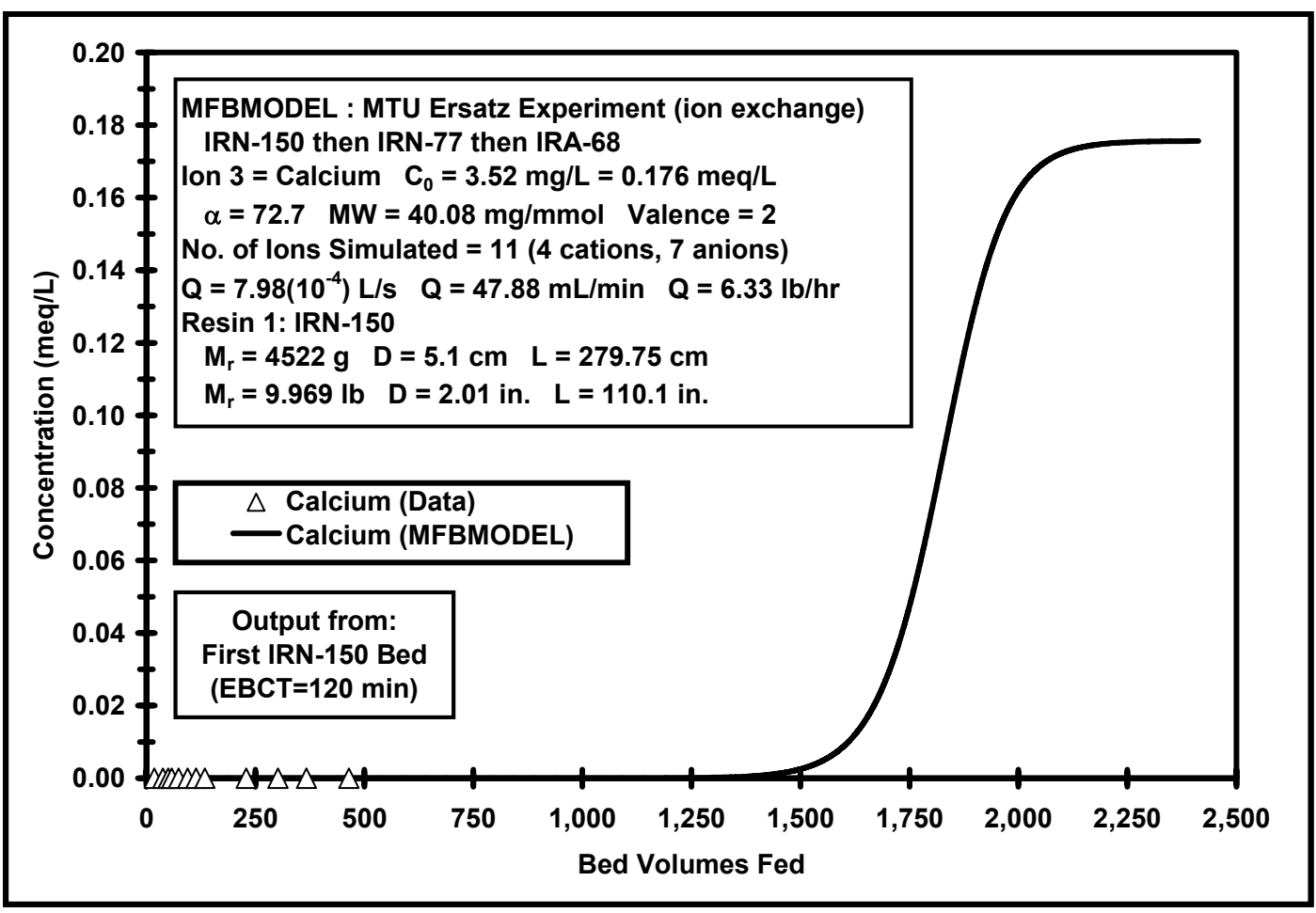




\section{Hydrogen}

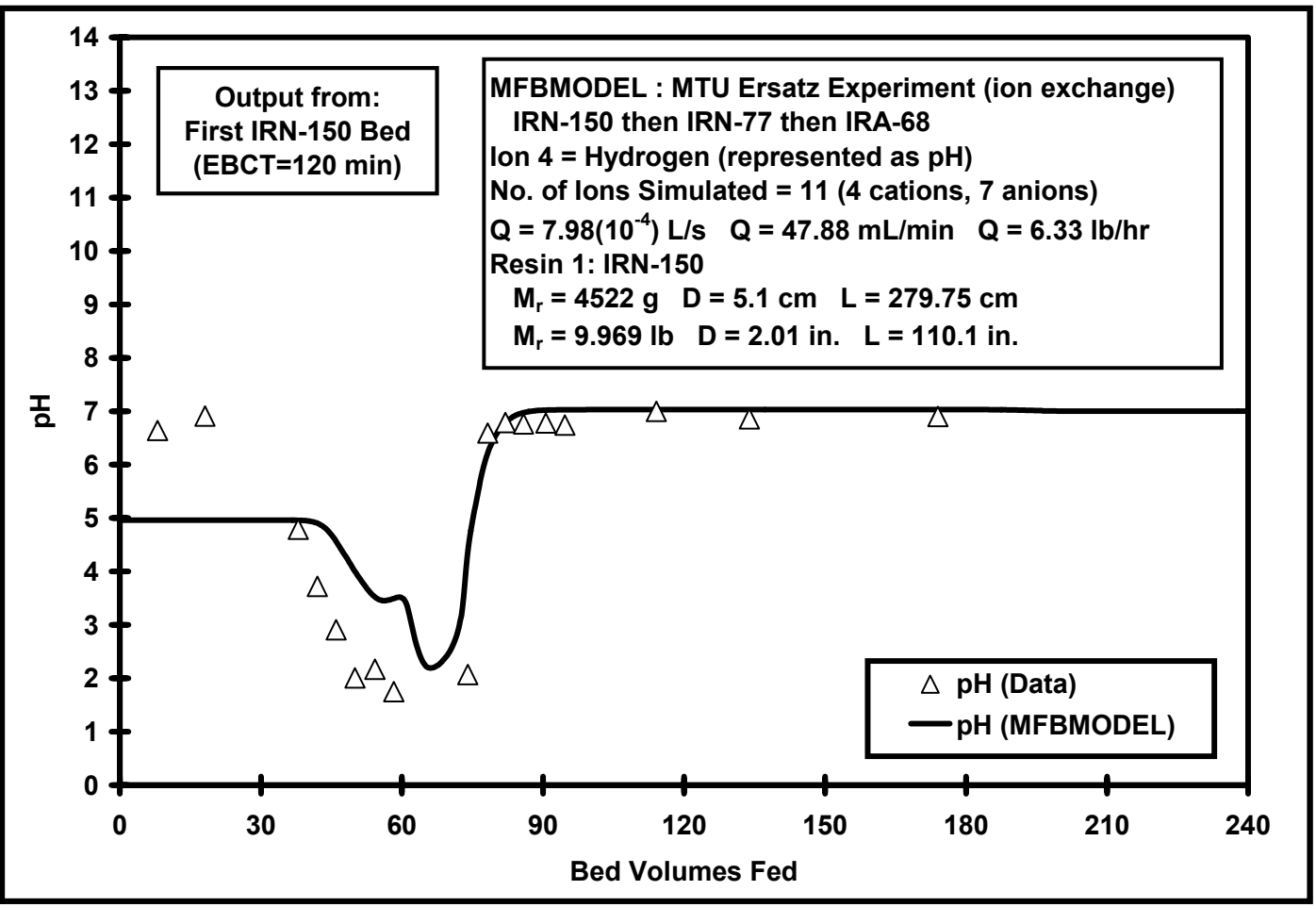

\section{Anion Results}

Acetate

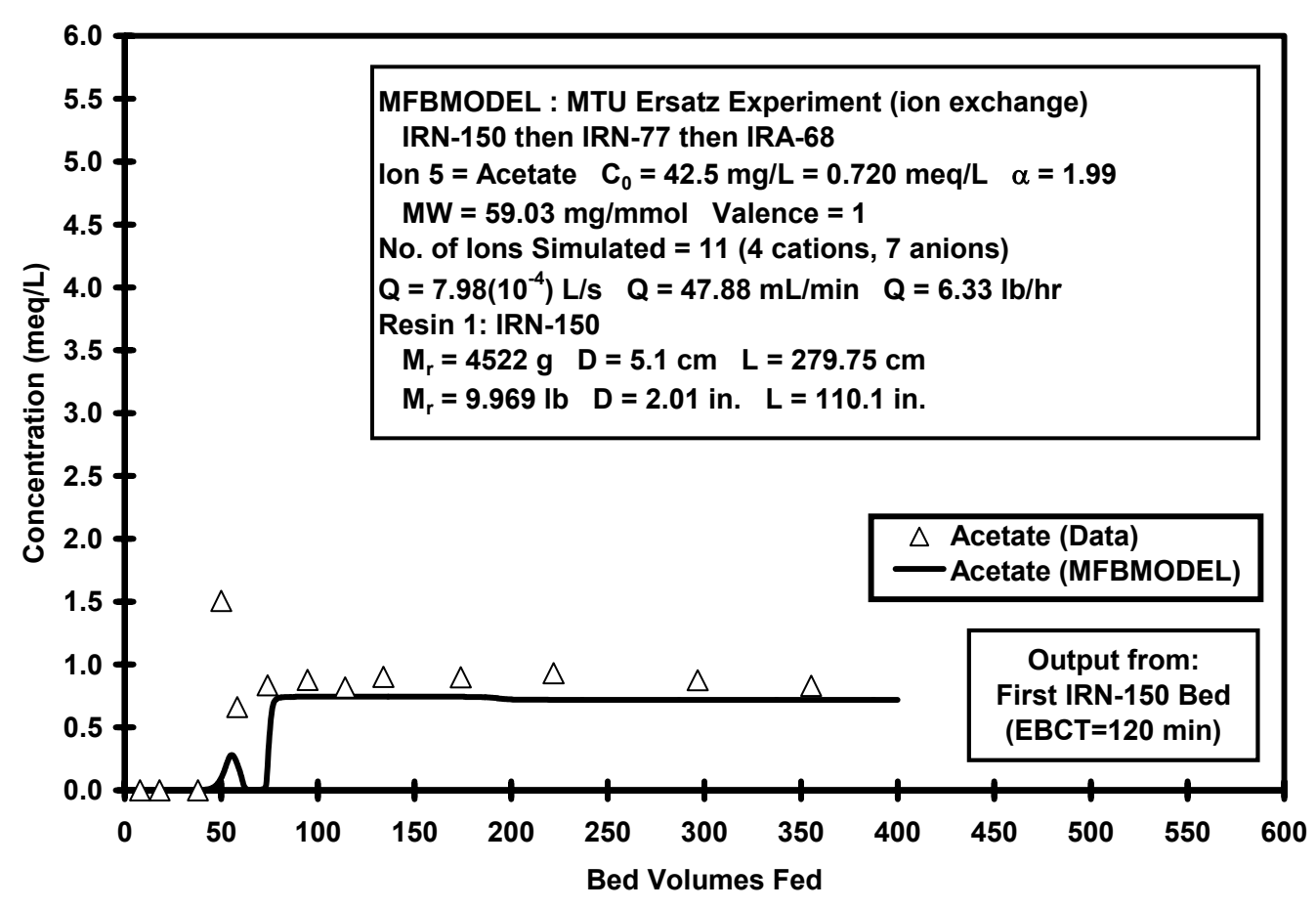




\section{Butyrate}

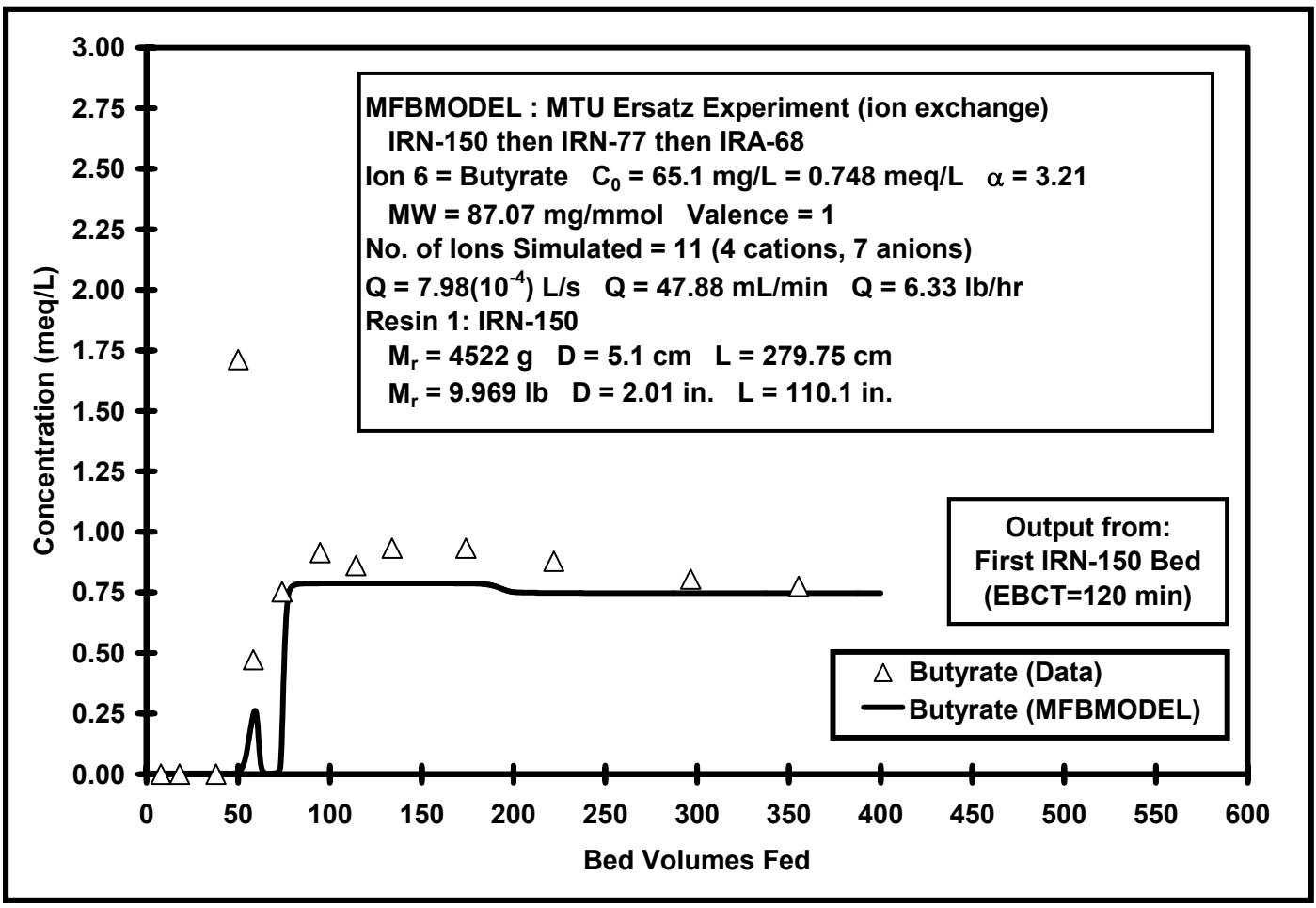

\section{Chloride}

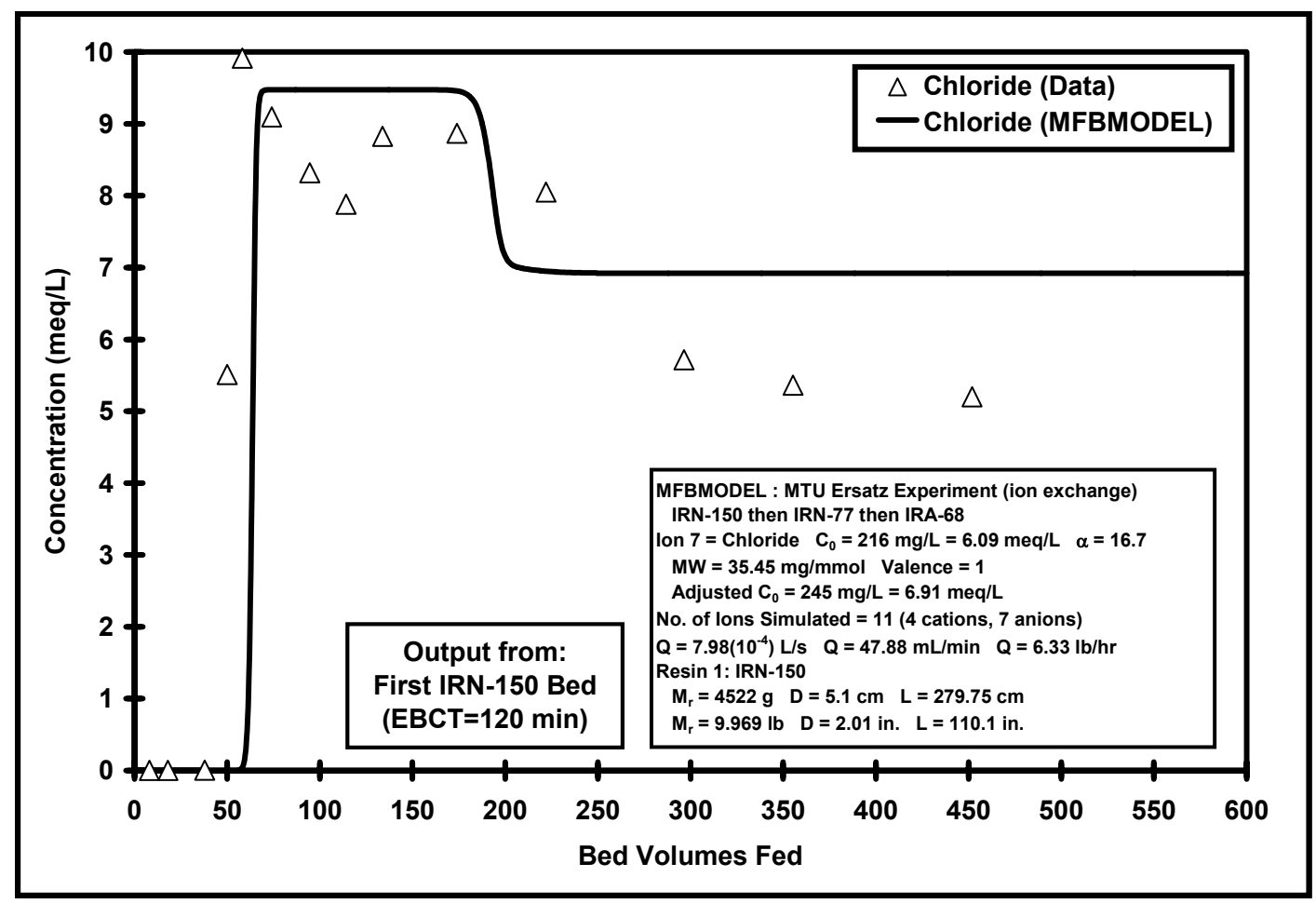




\section{Bicarbonate}

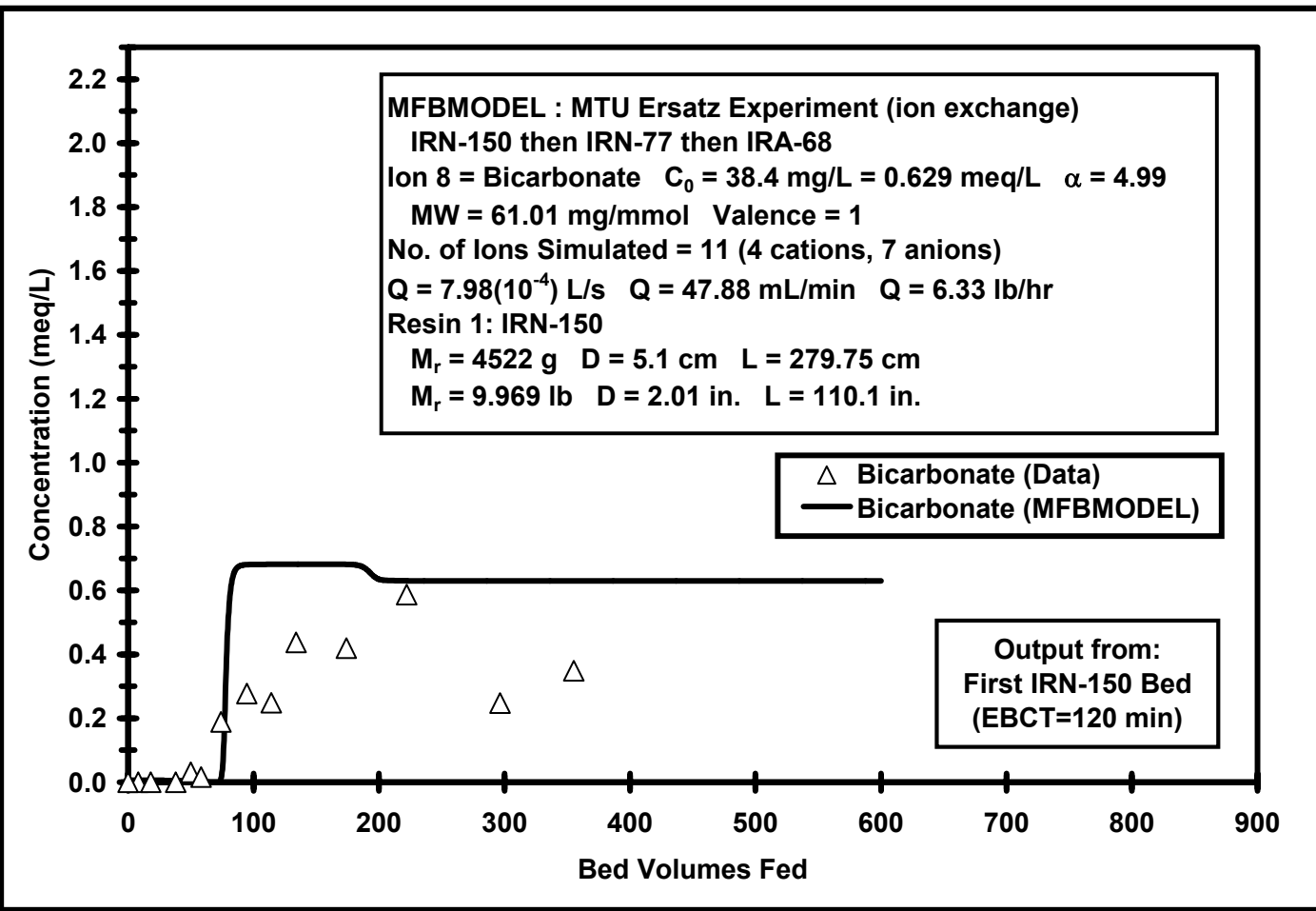

Sulfate

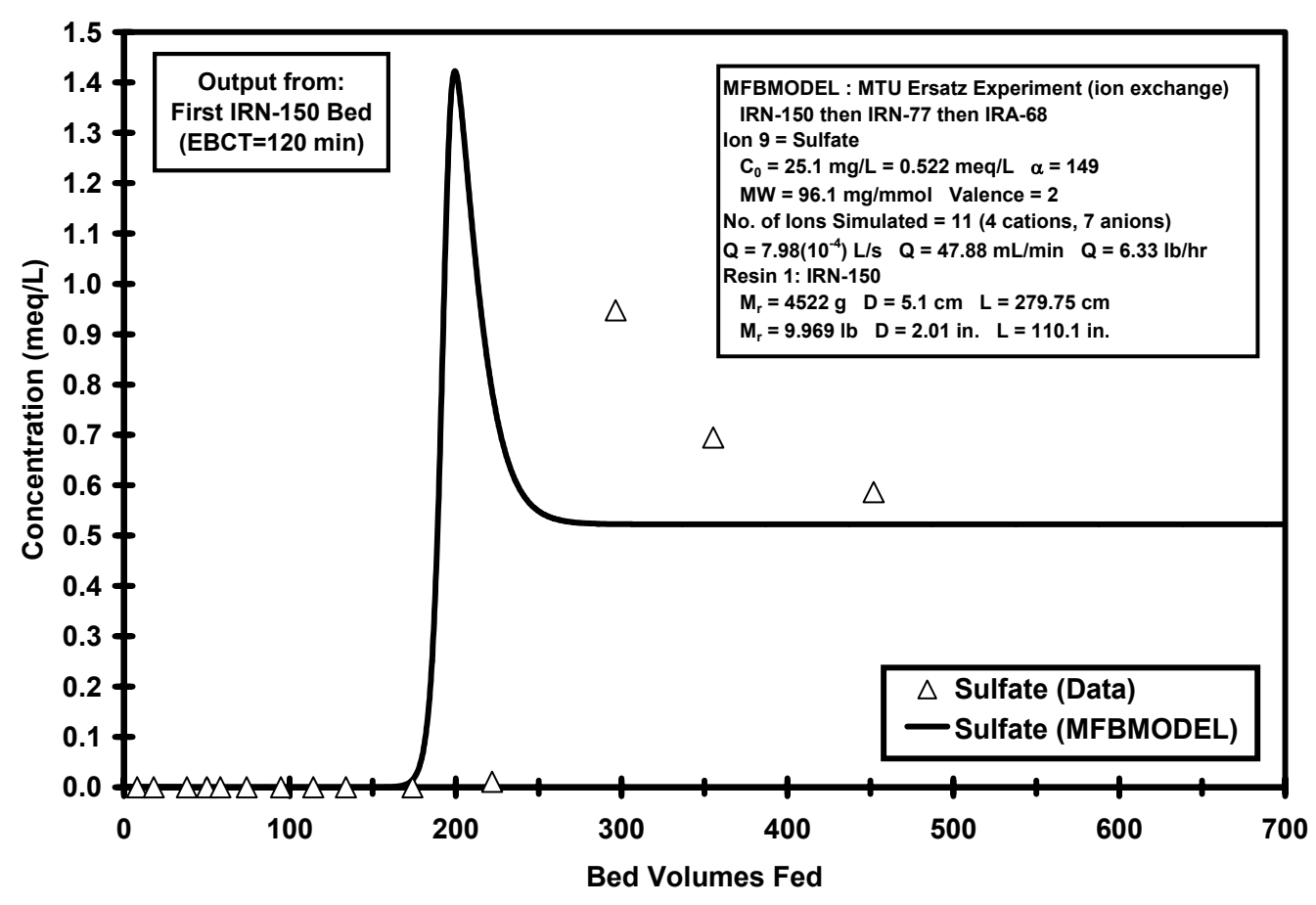




\section{CMT}

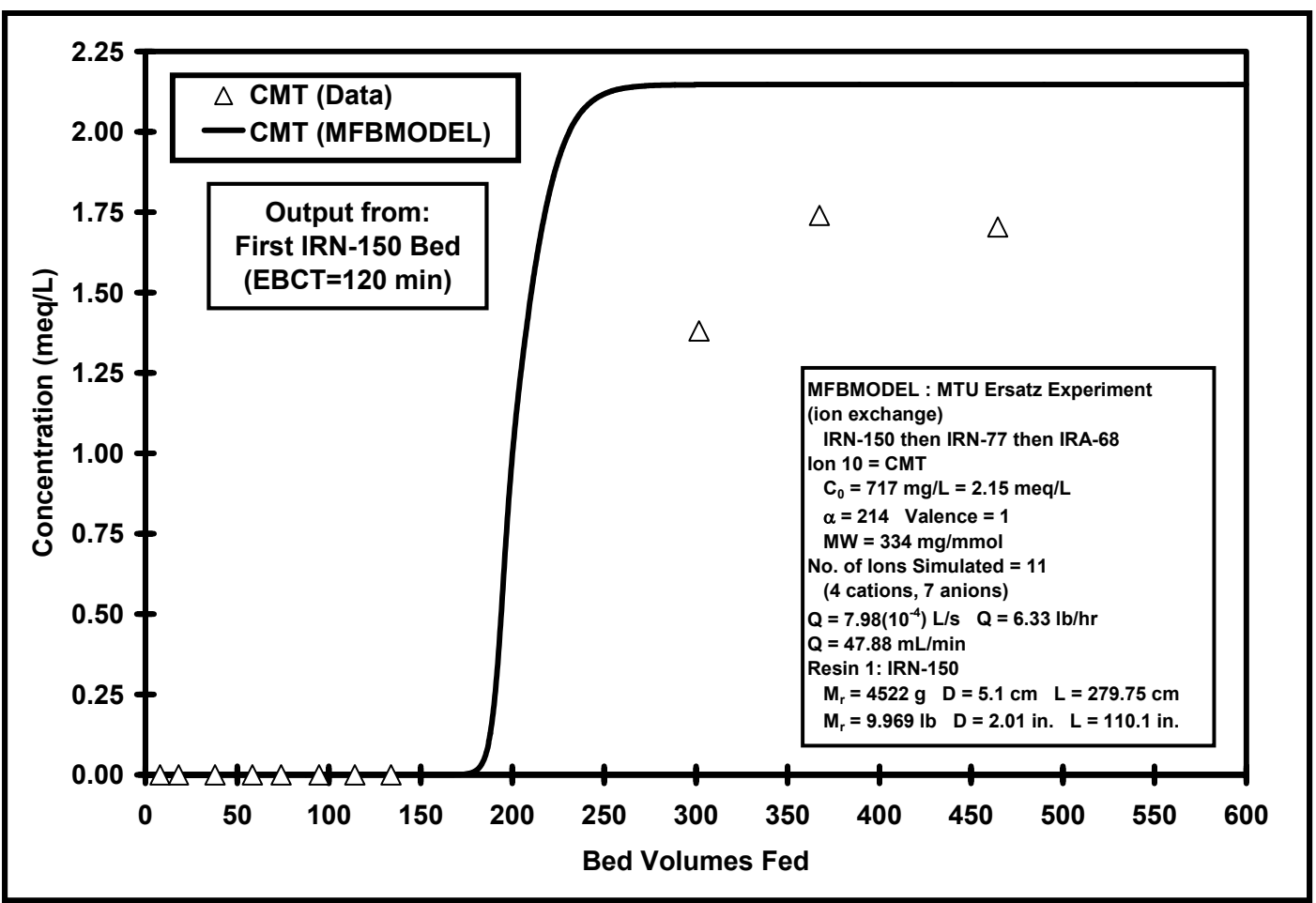

\section{Hydroxide}

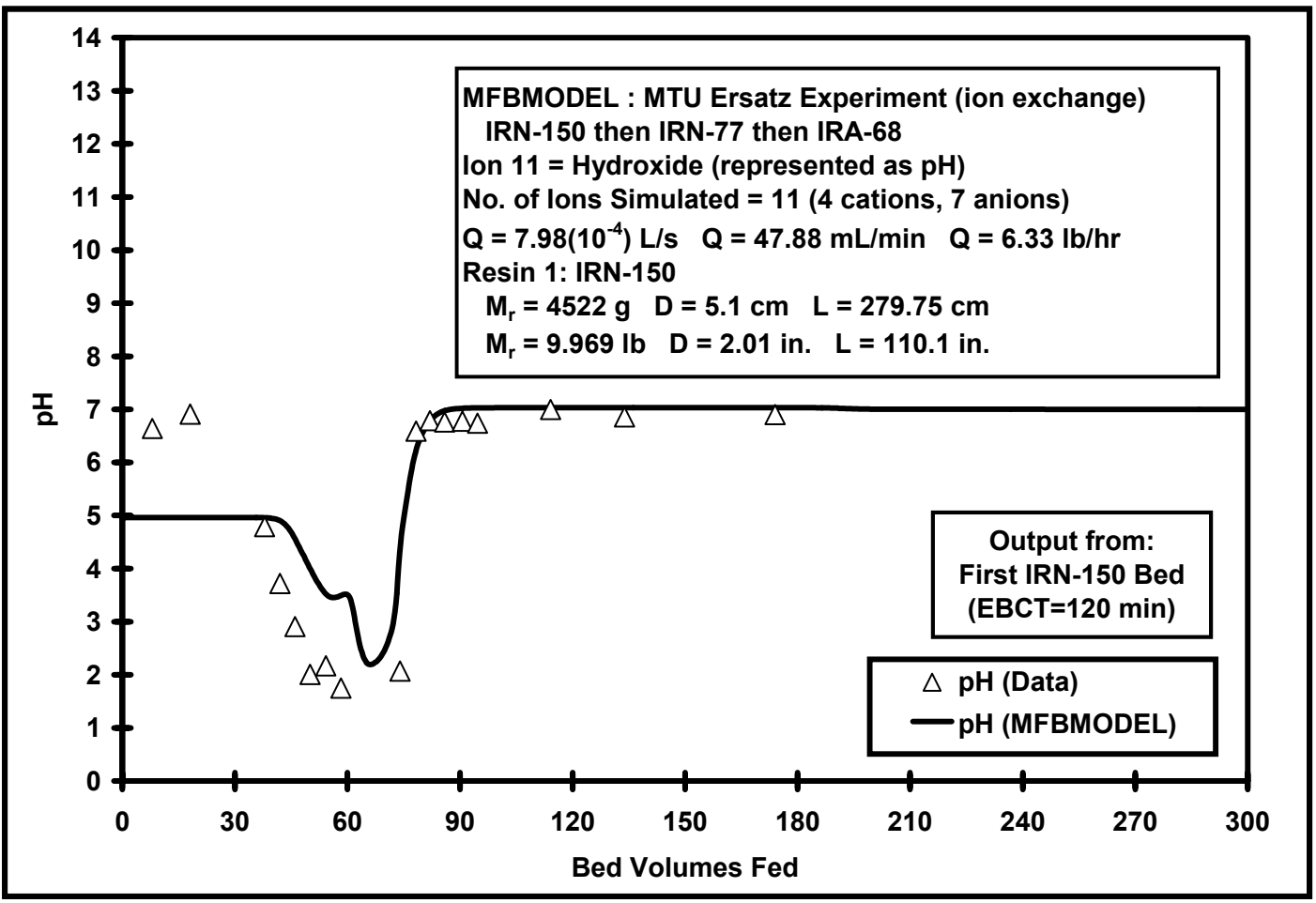




\section{Strong Acid Cation (SAC) Exchange Resin: Rohm \& Haas IRN-77 \\ Cation Results \\ Sodium}

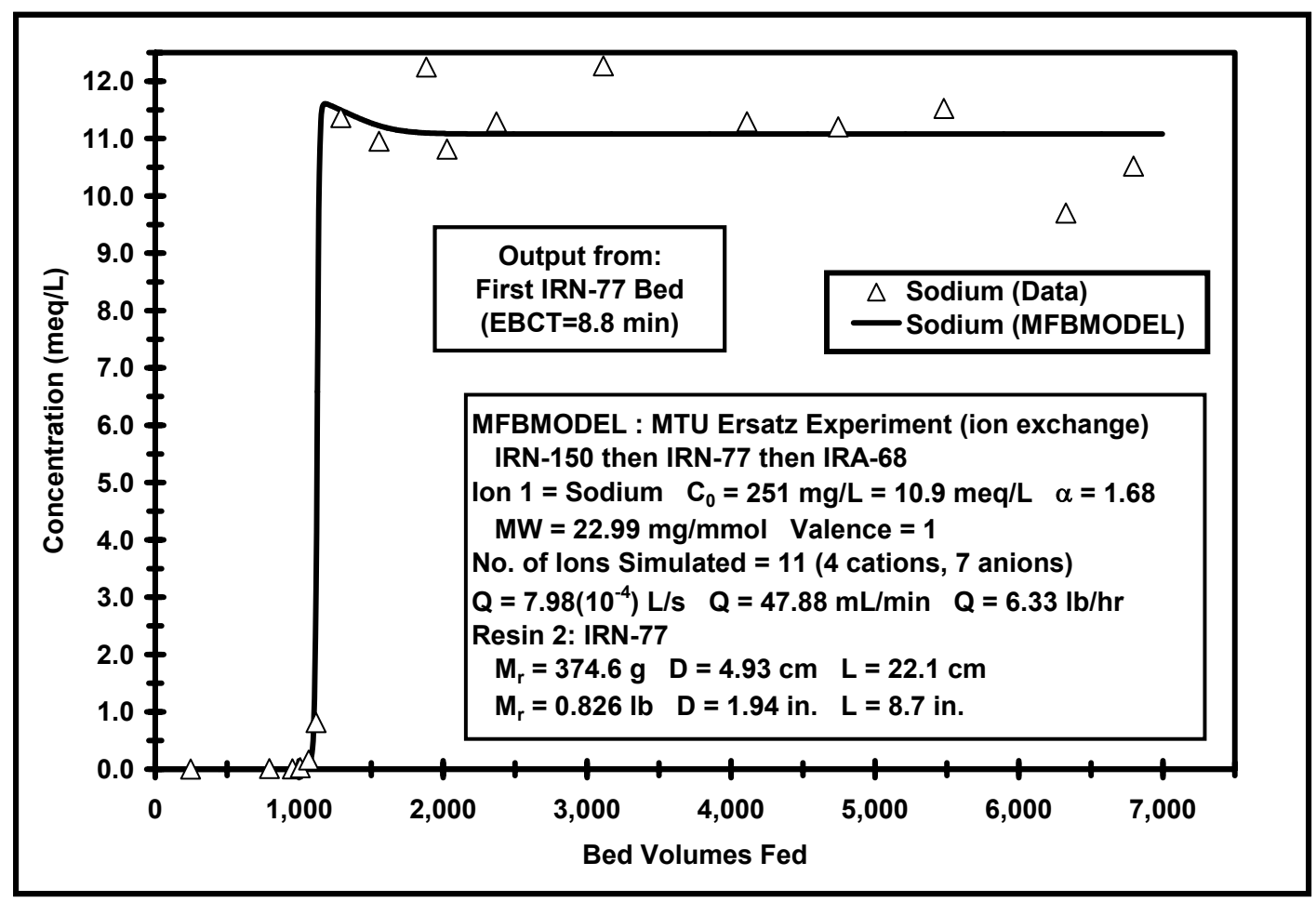

\section{Potassium}

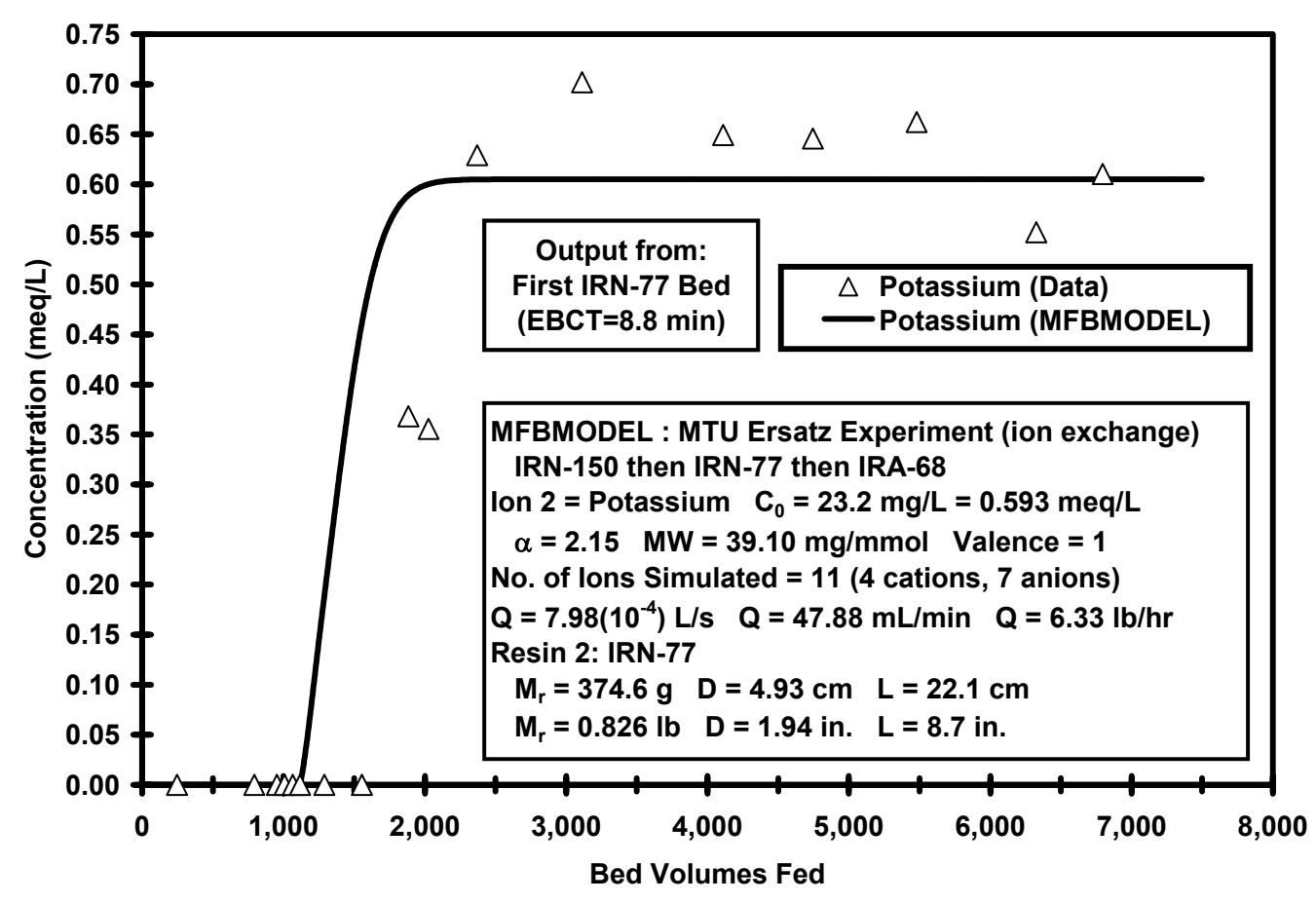




\section{Calcium}

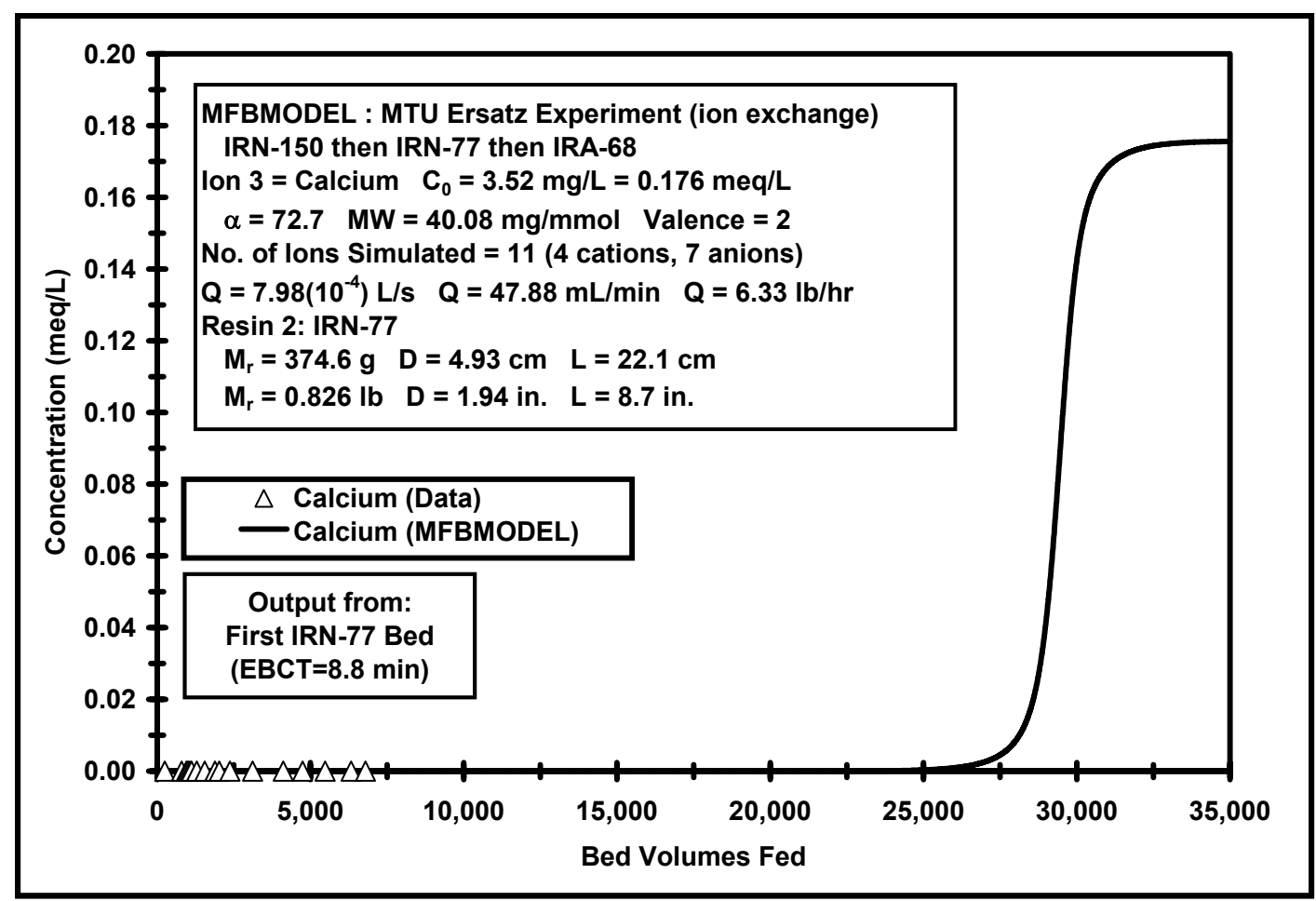

\section{Hydrogen}

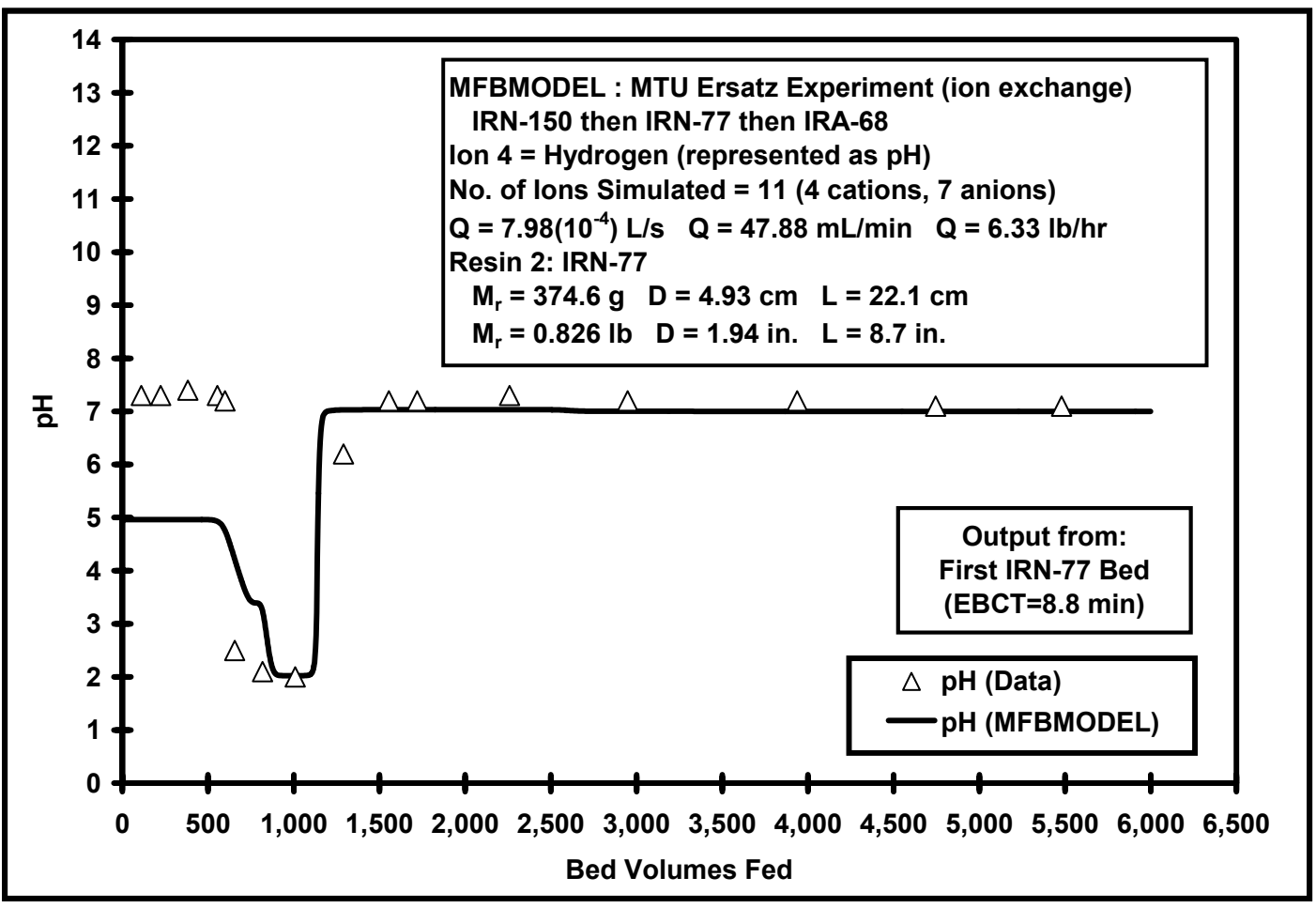


Weak Base Anion (WBA) Exchange Resin: Rohm \& Haas IRN-77

Anion Results

Acetate

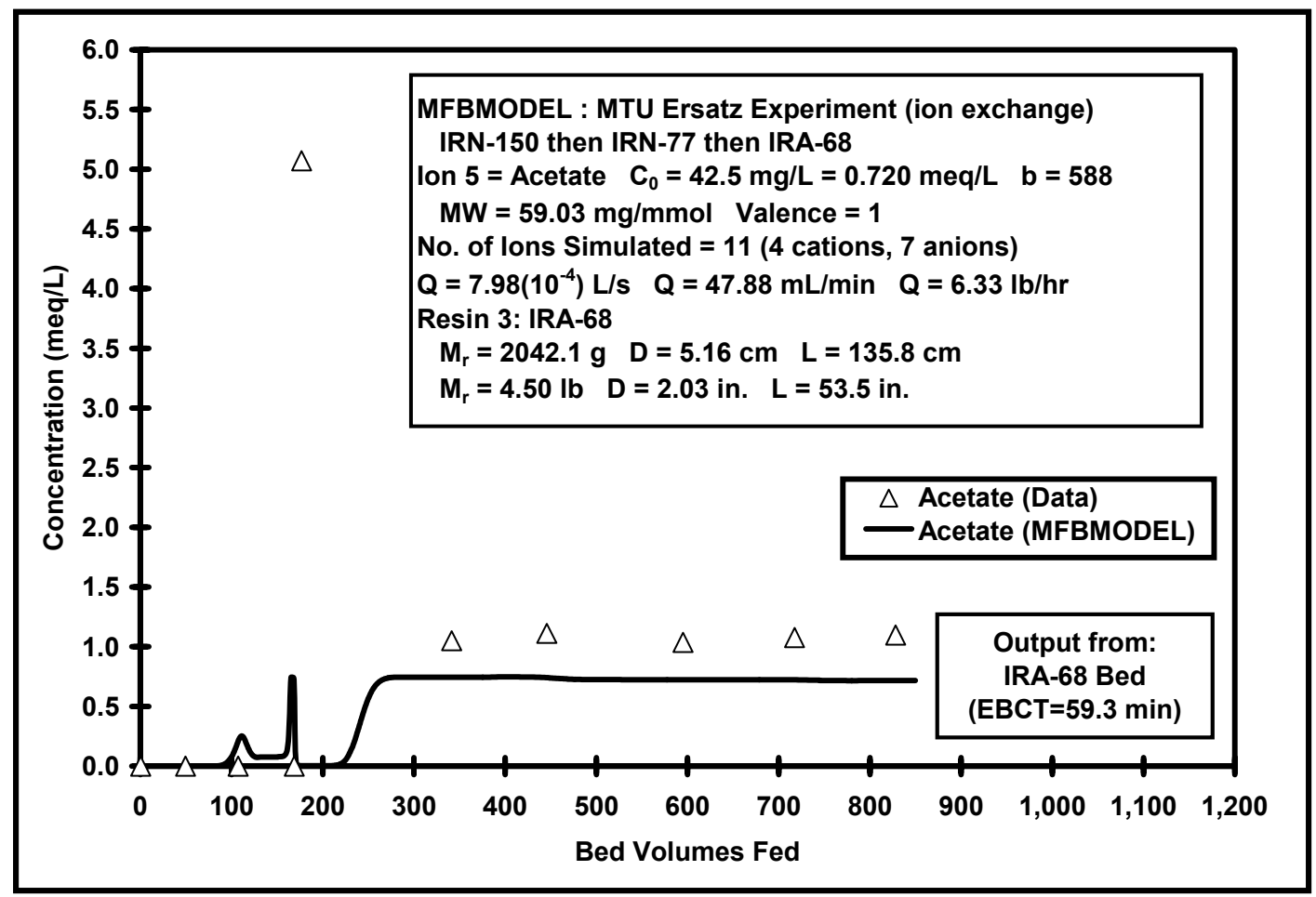

Butyrate

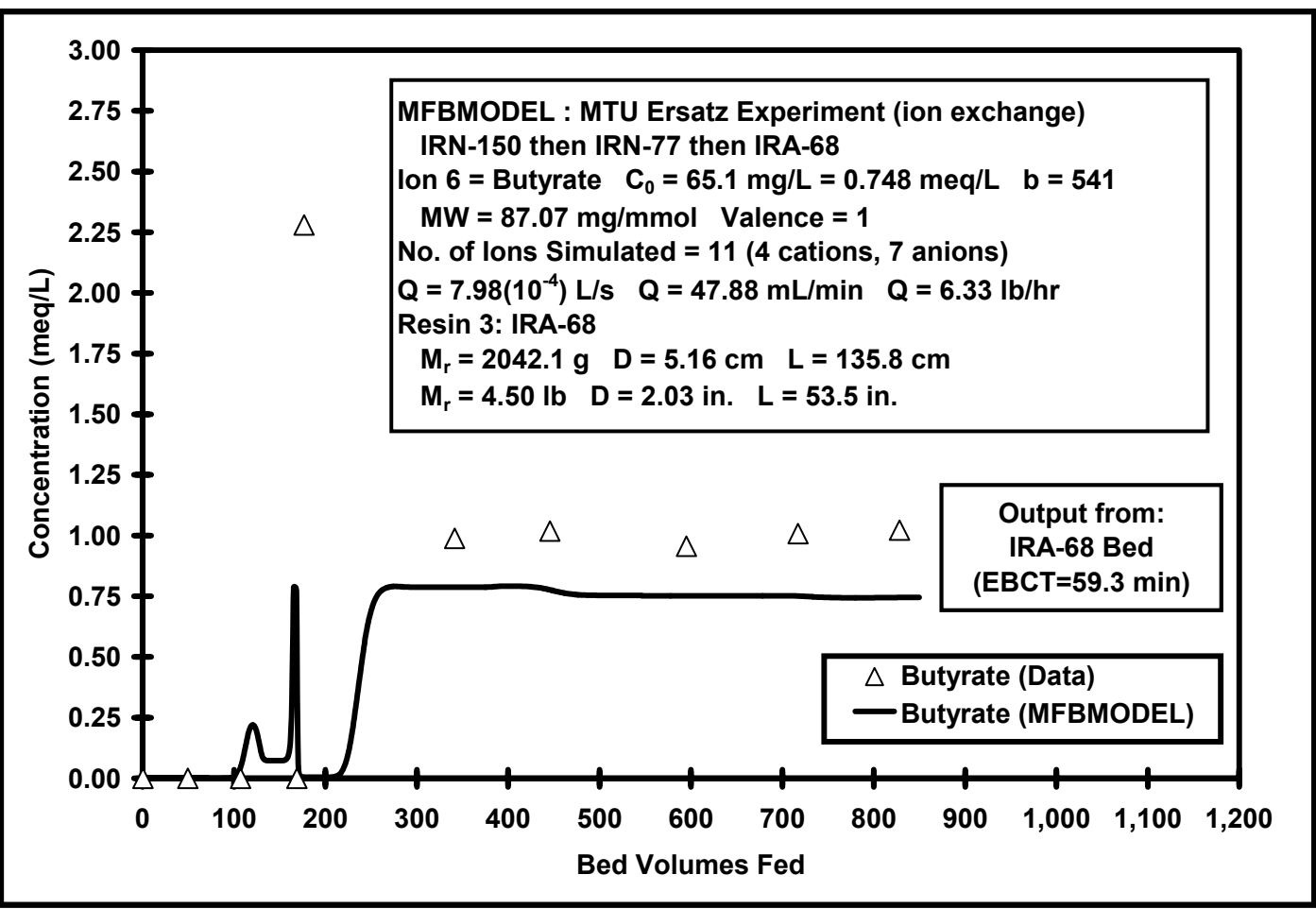




\section{Chloride}

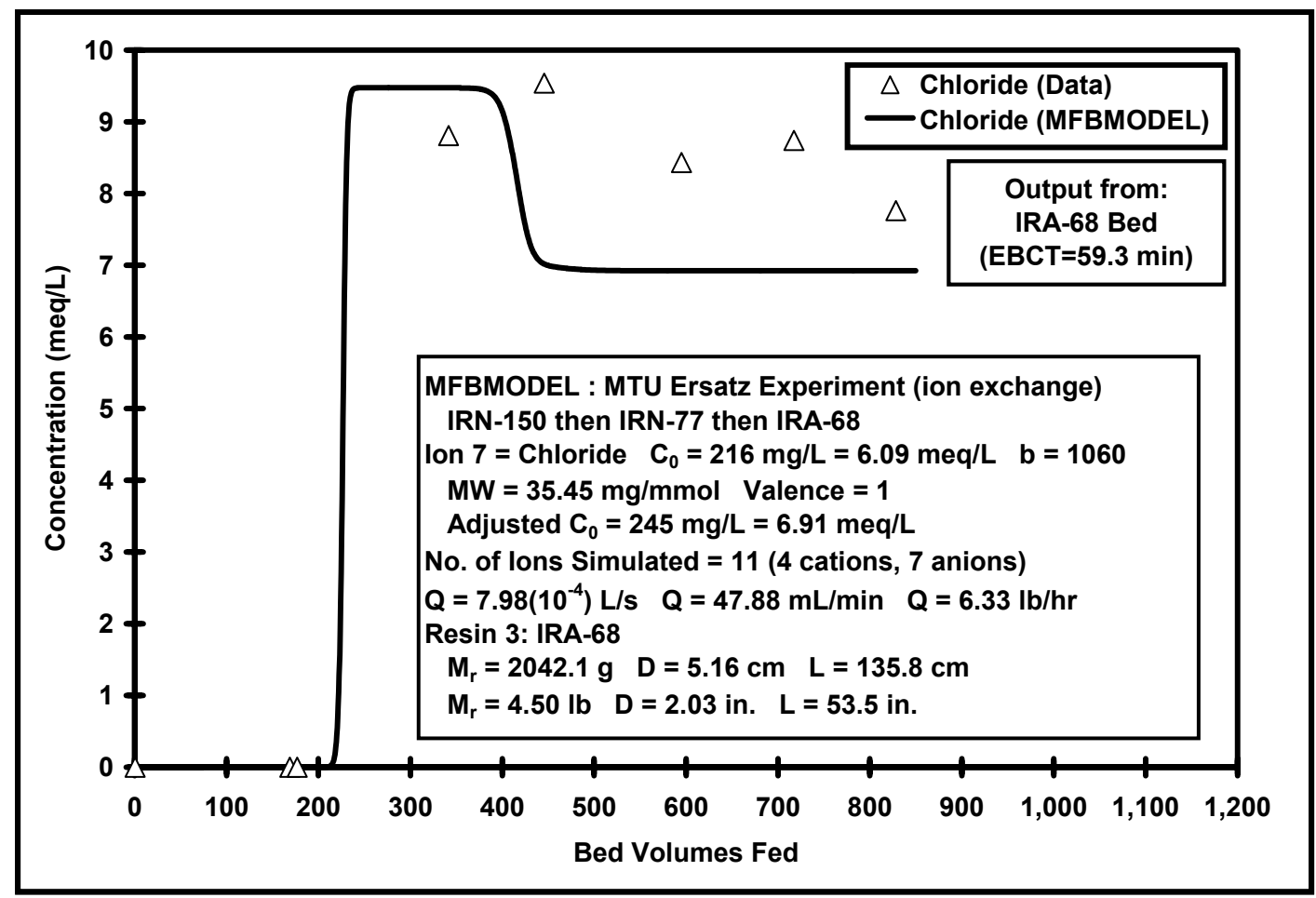

\section{Bicarbonate}

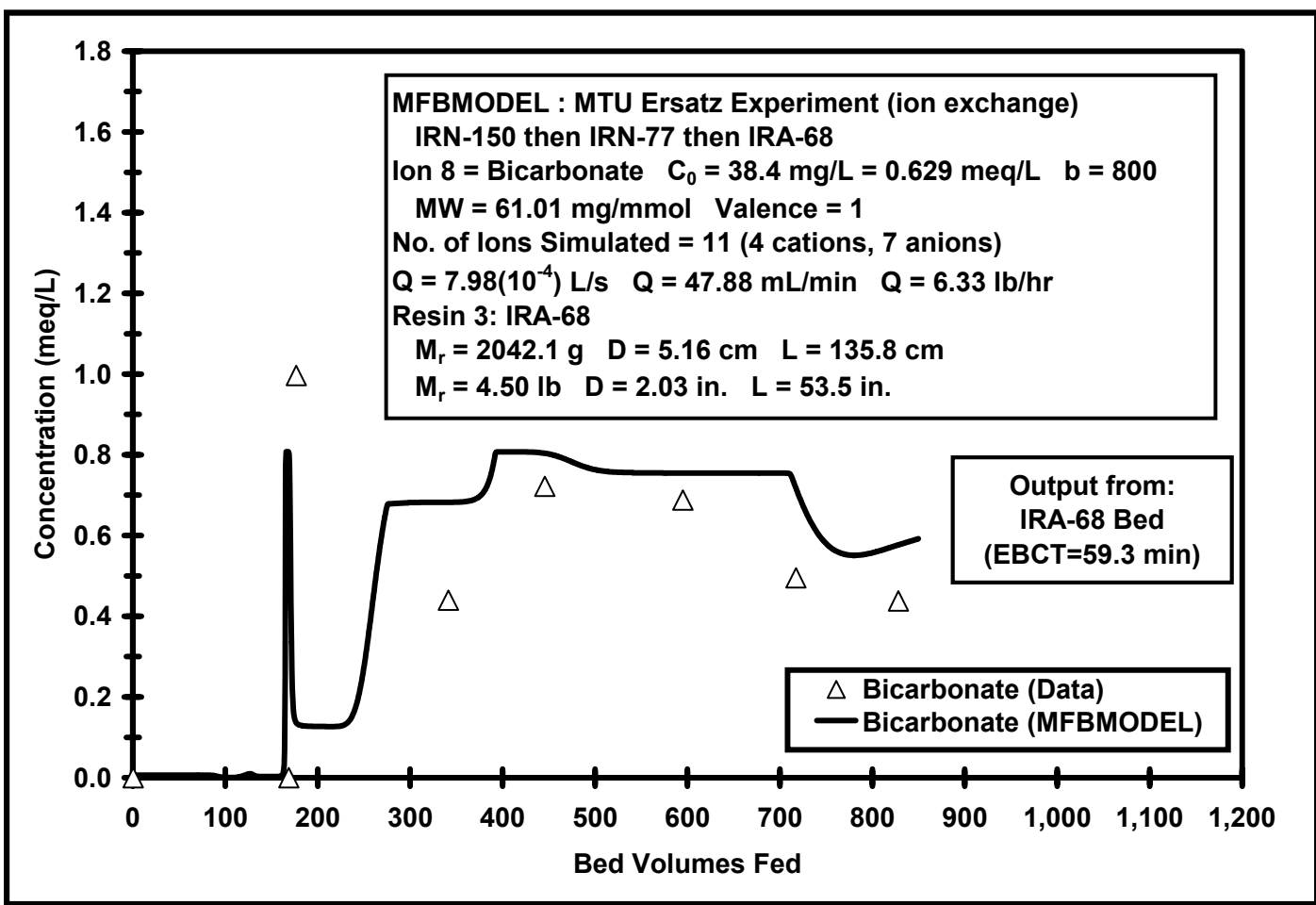




\section{Sulfate}

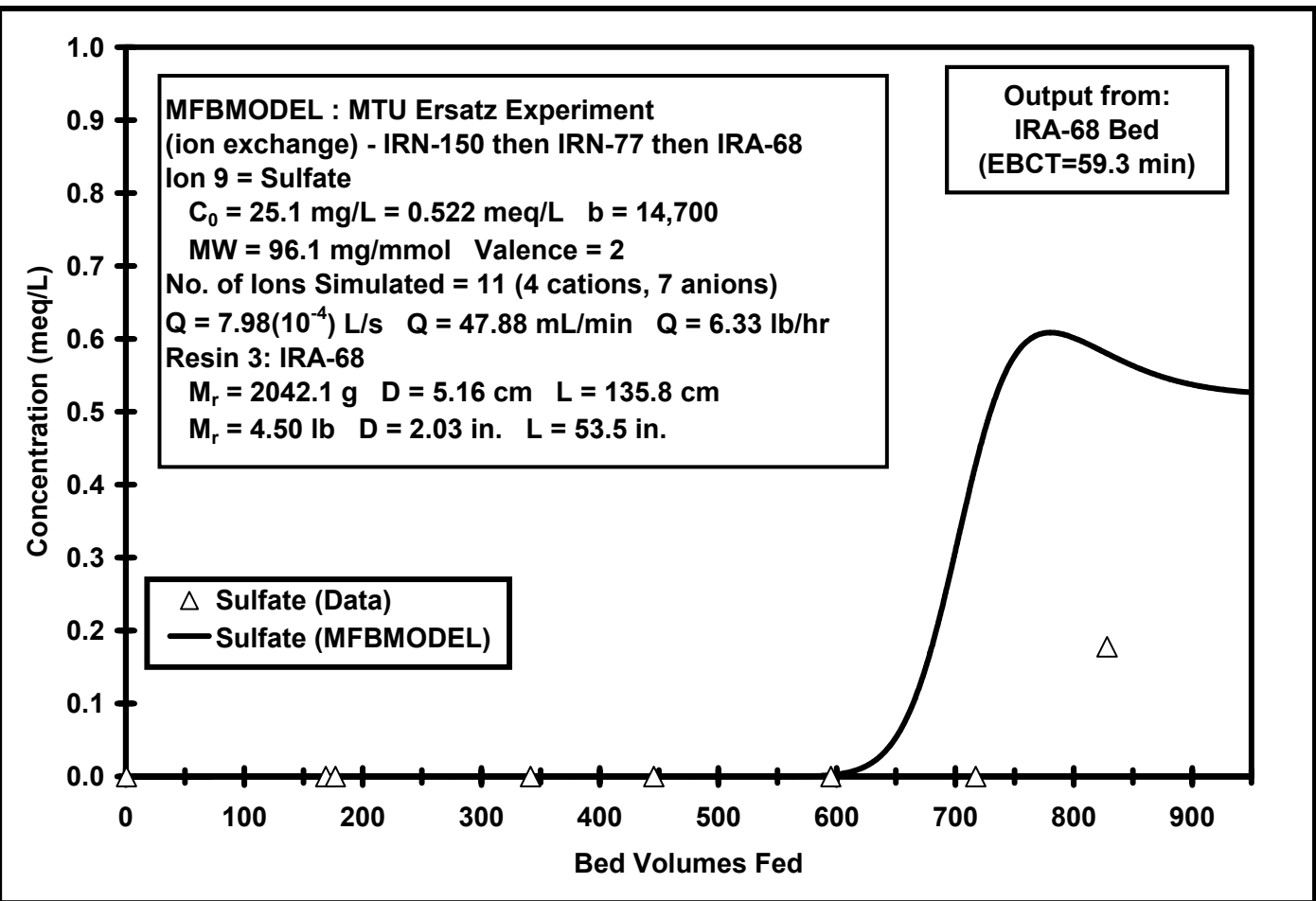

\section{CMT}

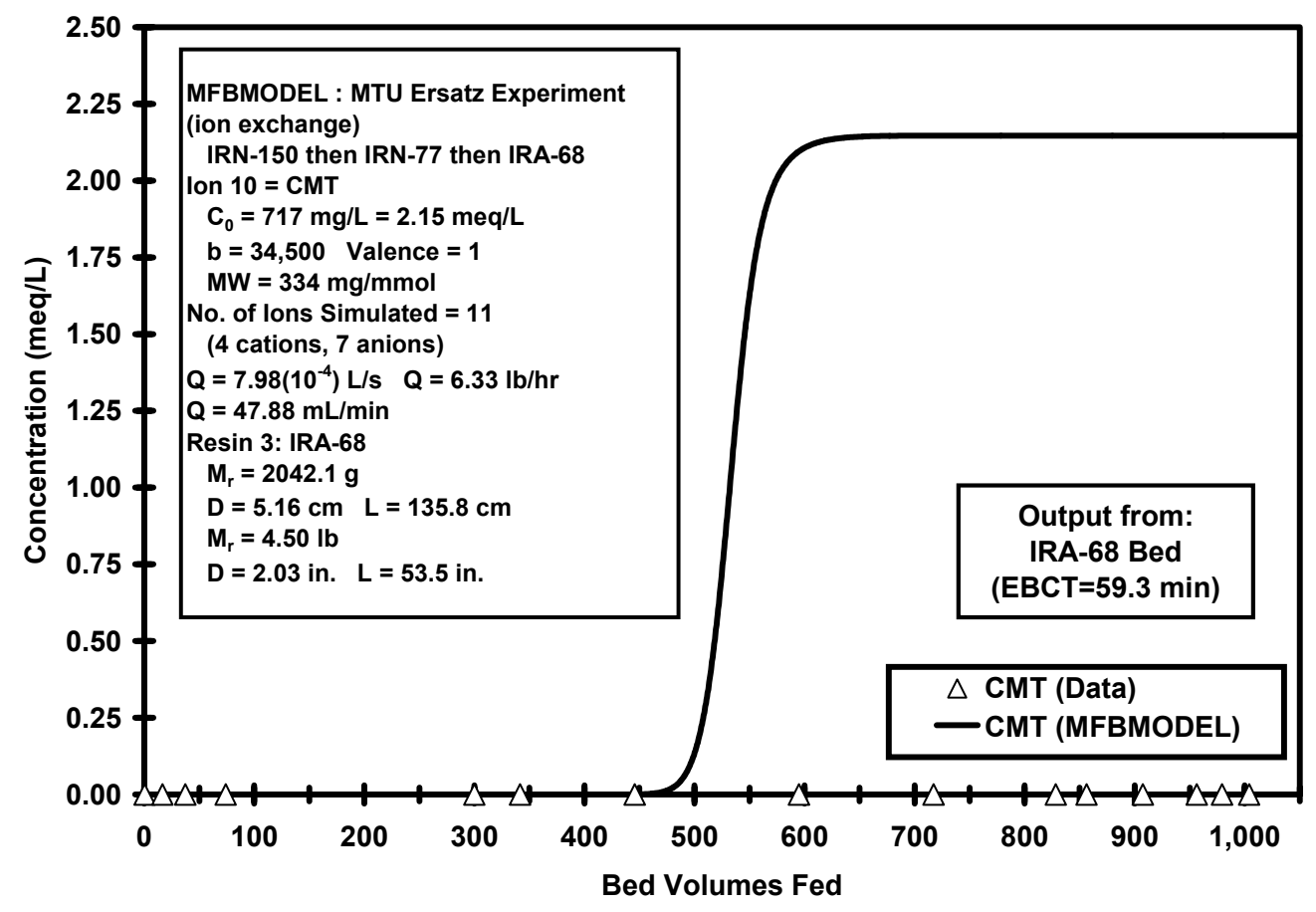




\section{Hydroxide}

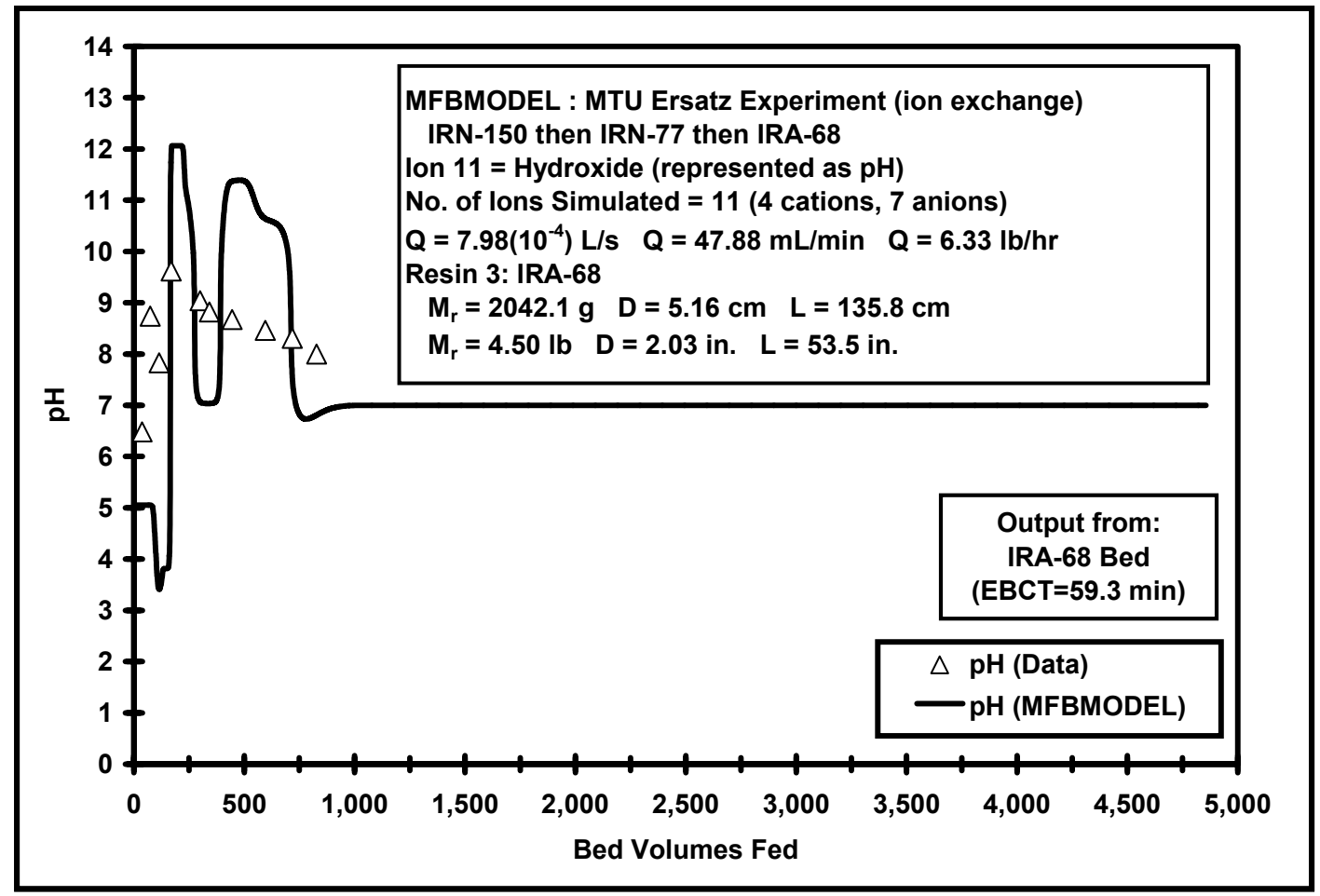




\section{Units of Reduced Concentration $\left(\mathrm{C} / \mathrm{C}_{0}\right)$ versus Bed Volumes Treated Mixed Bed Ion Exchange Resin: Rohm \& Haas IRN-150 \\ Cation Results \\ Sodium}

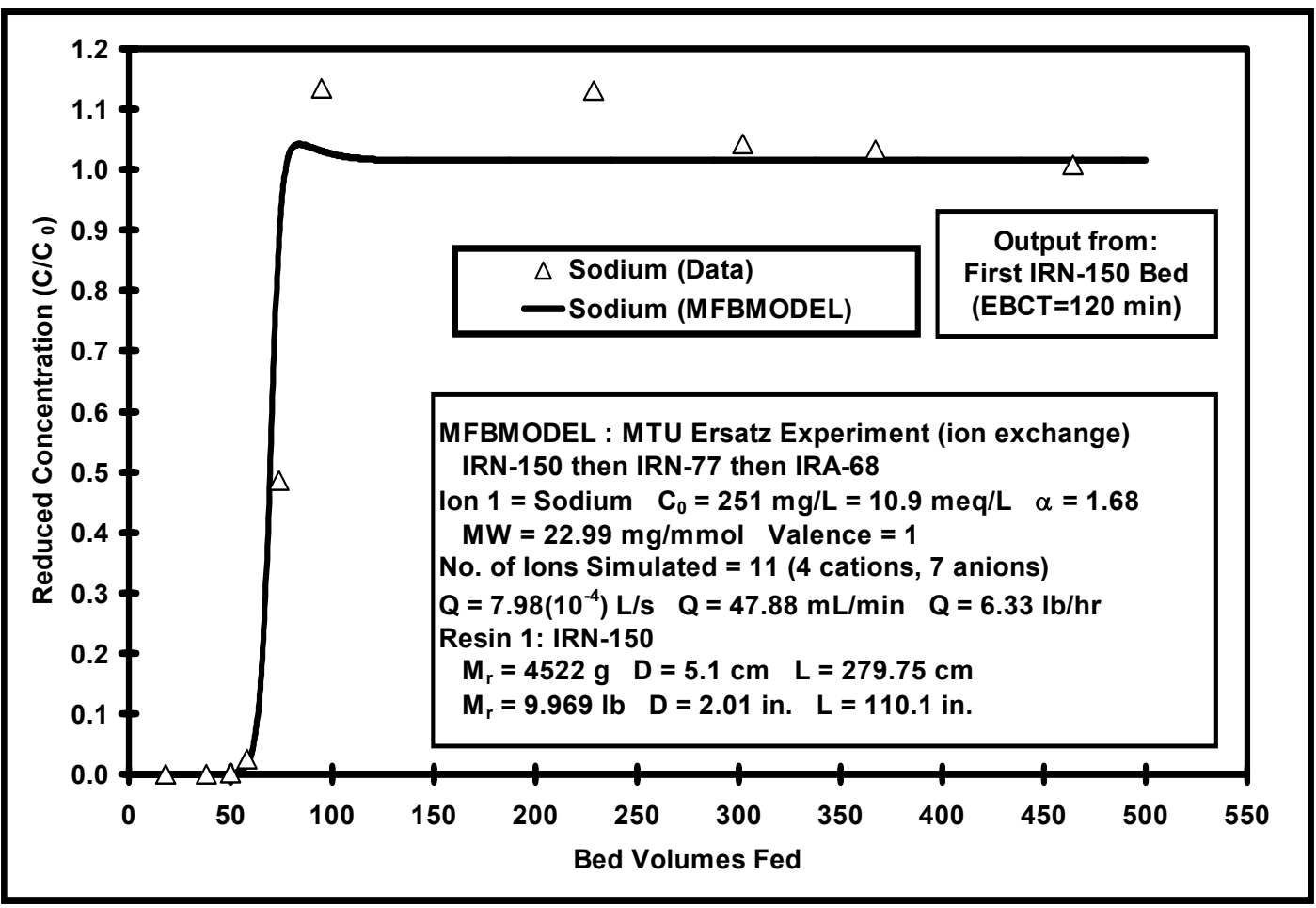




\section{Potassium}

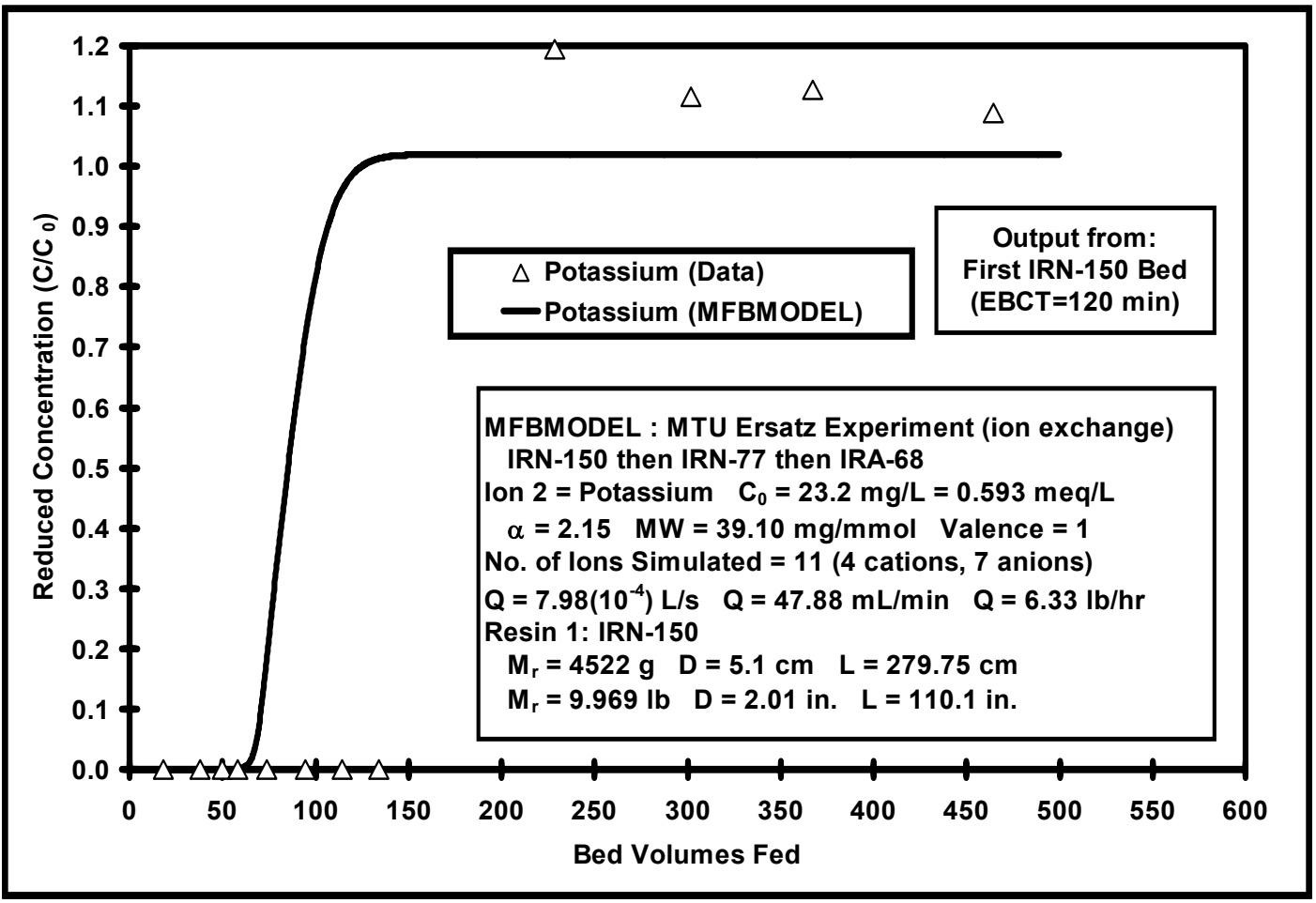

\section{Calcium}

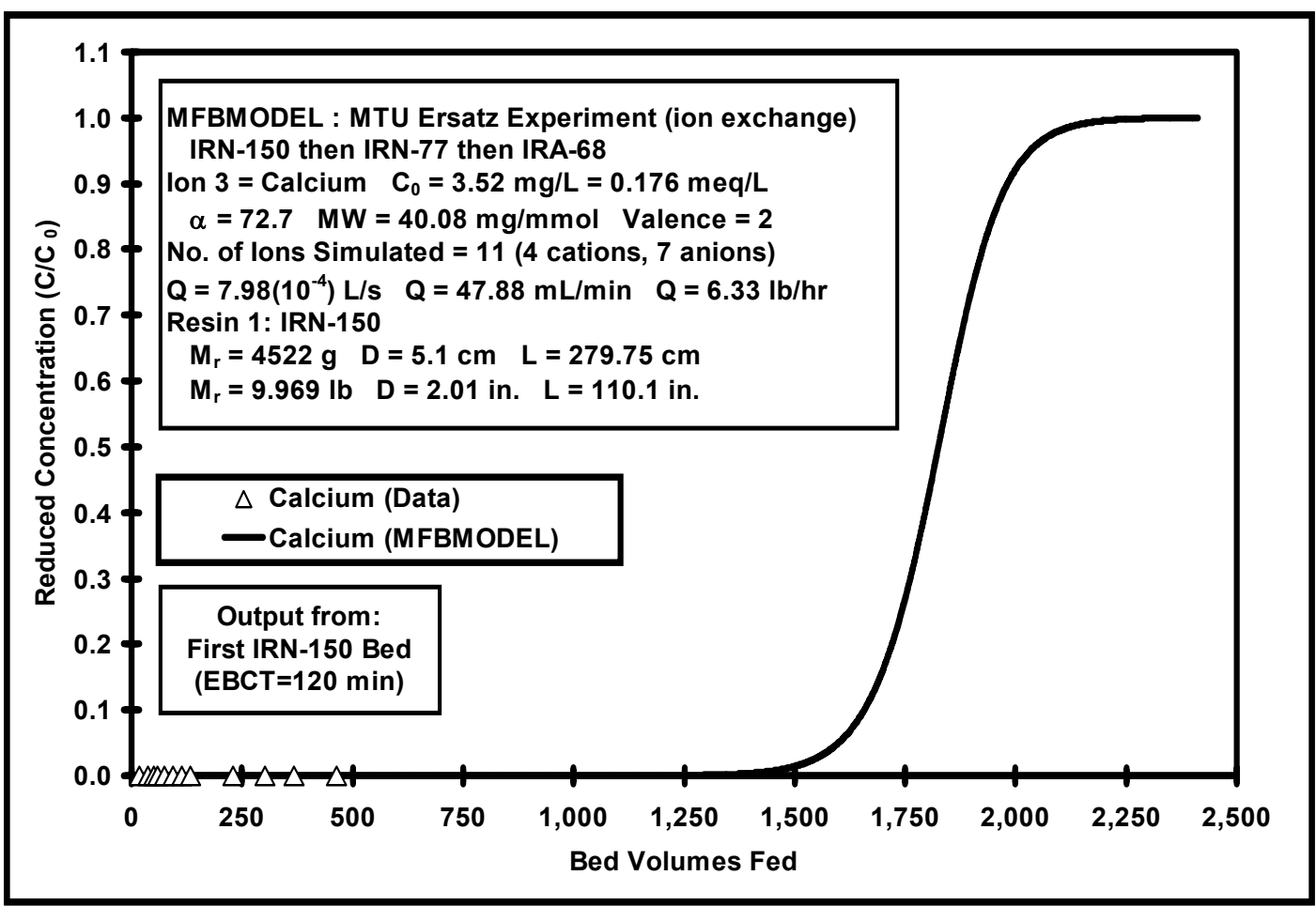




\section{Hydrogen}

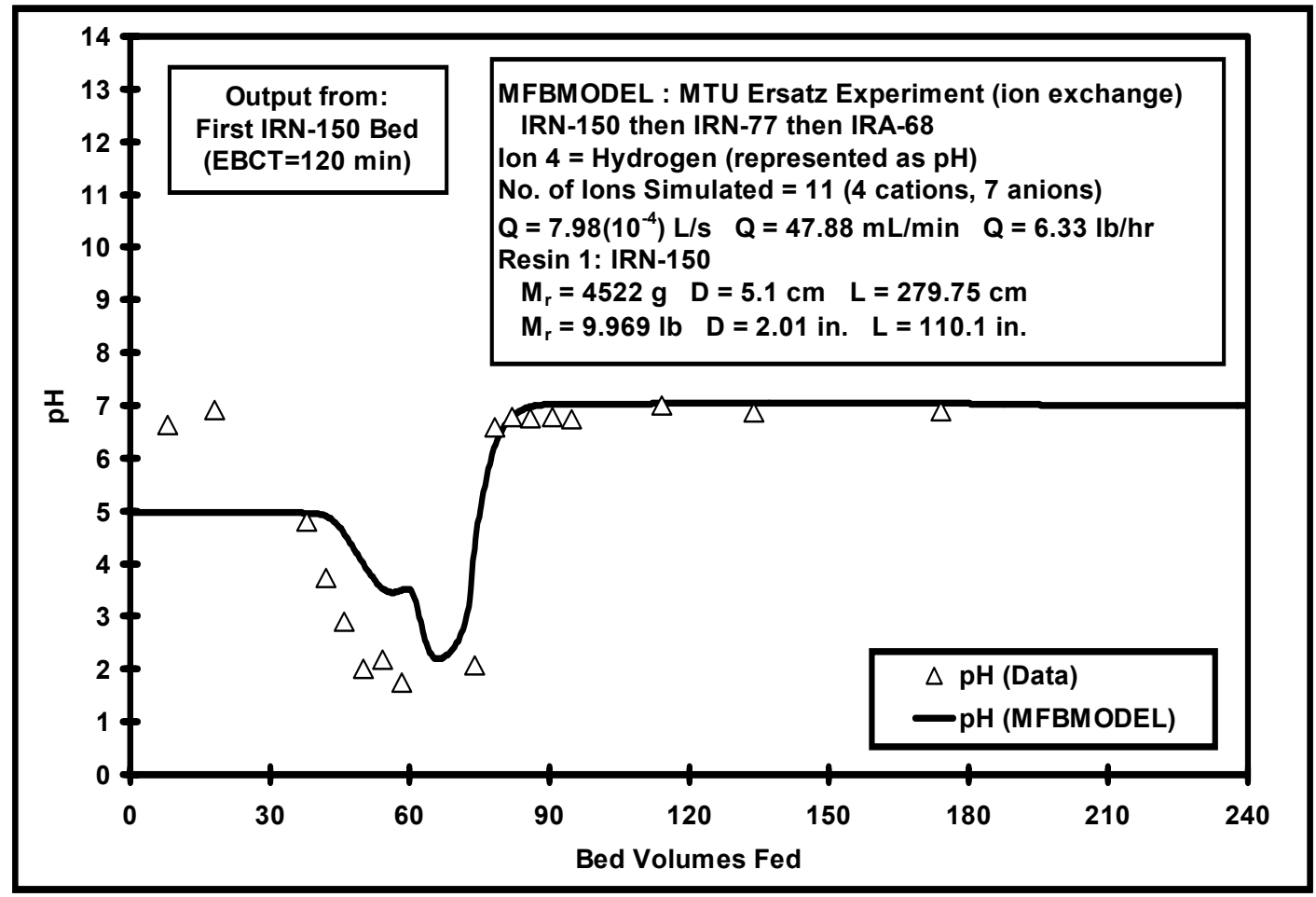

\section{Anion Results}

\section{Acetate}

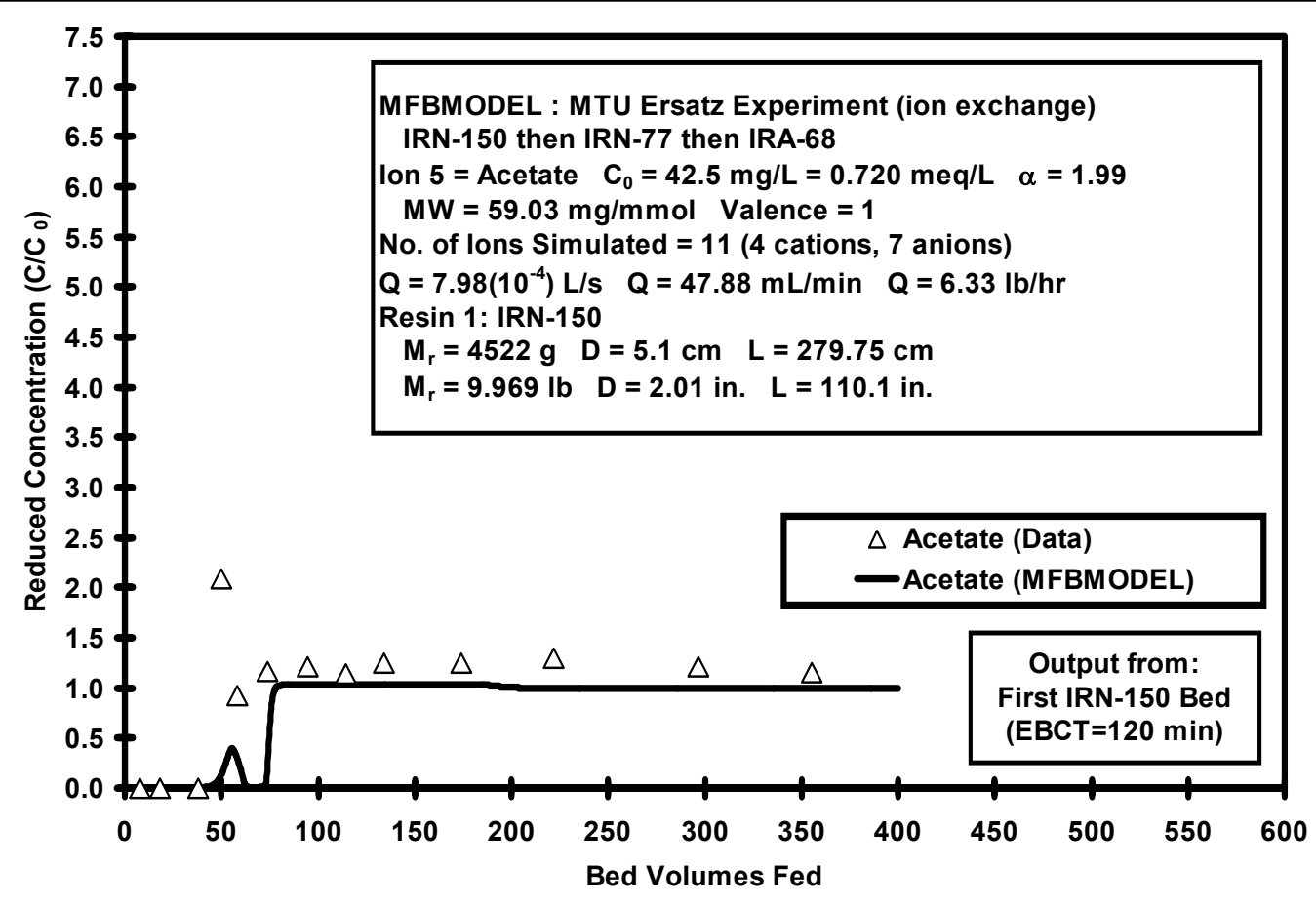




\section{Butyrate}

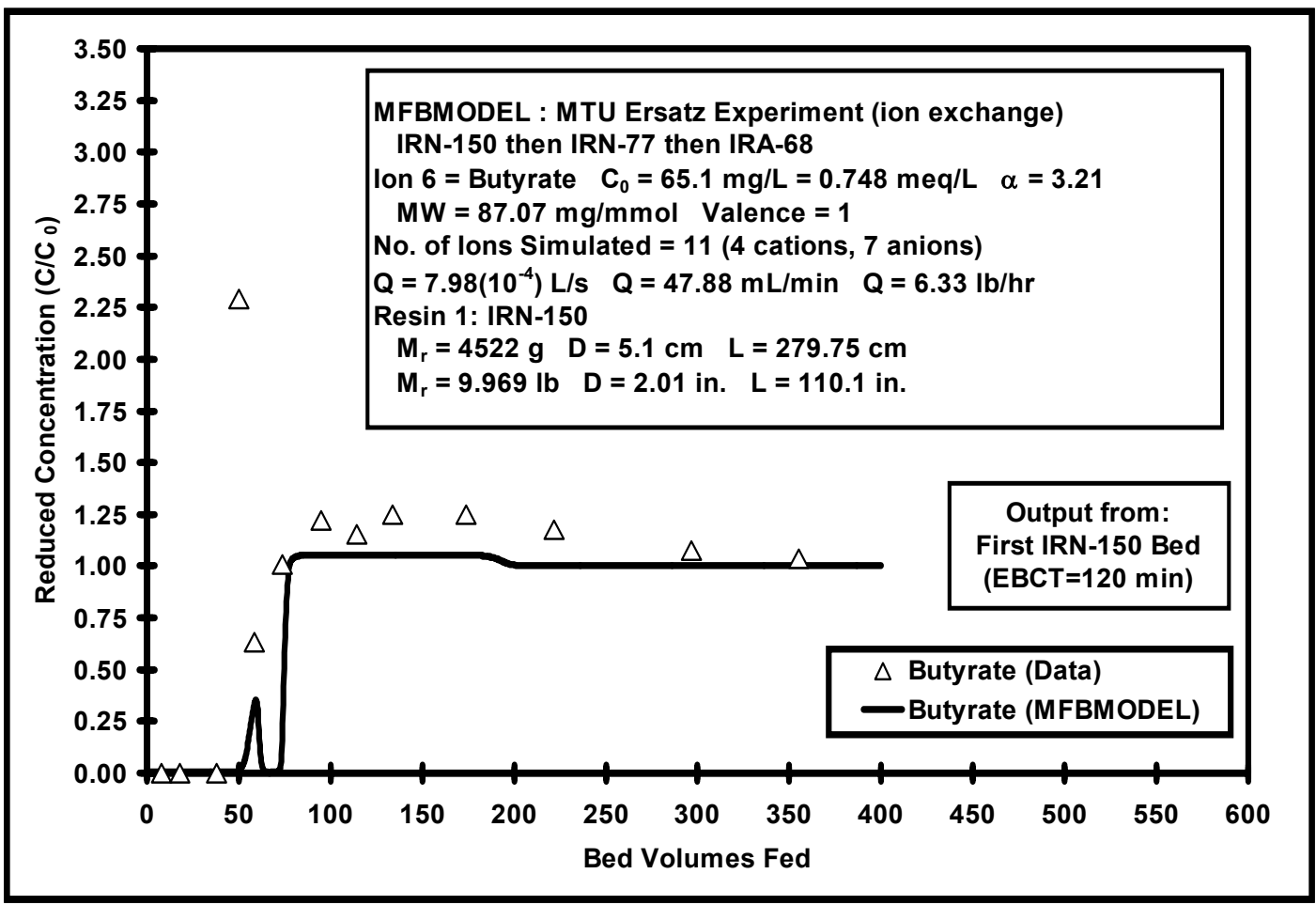

\section{Chloride}

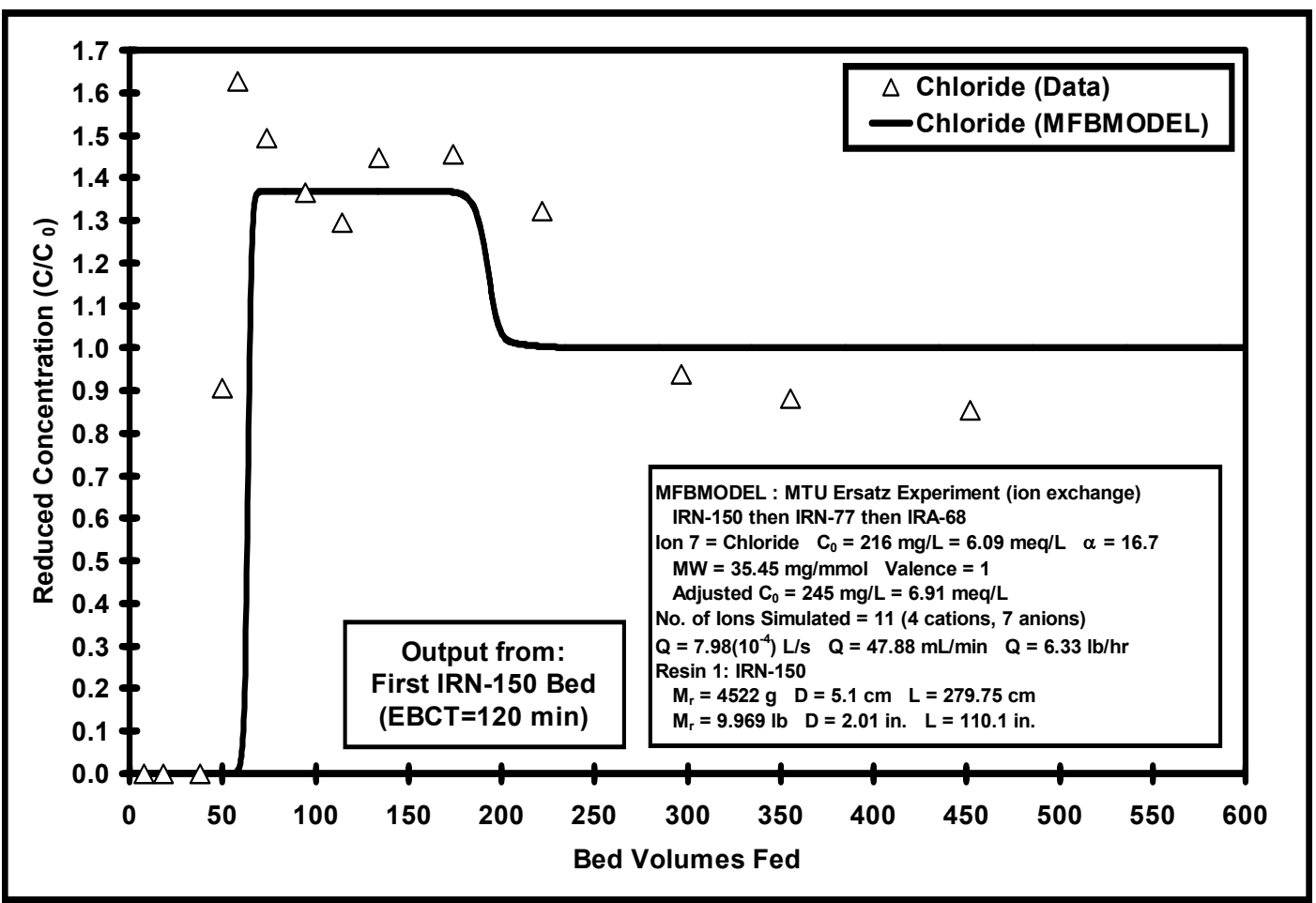




\section{Bicarbonate}

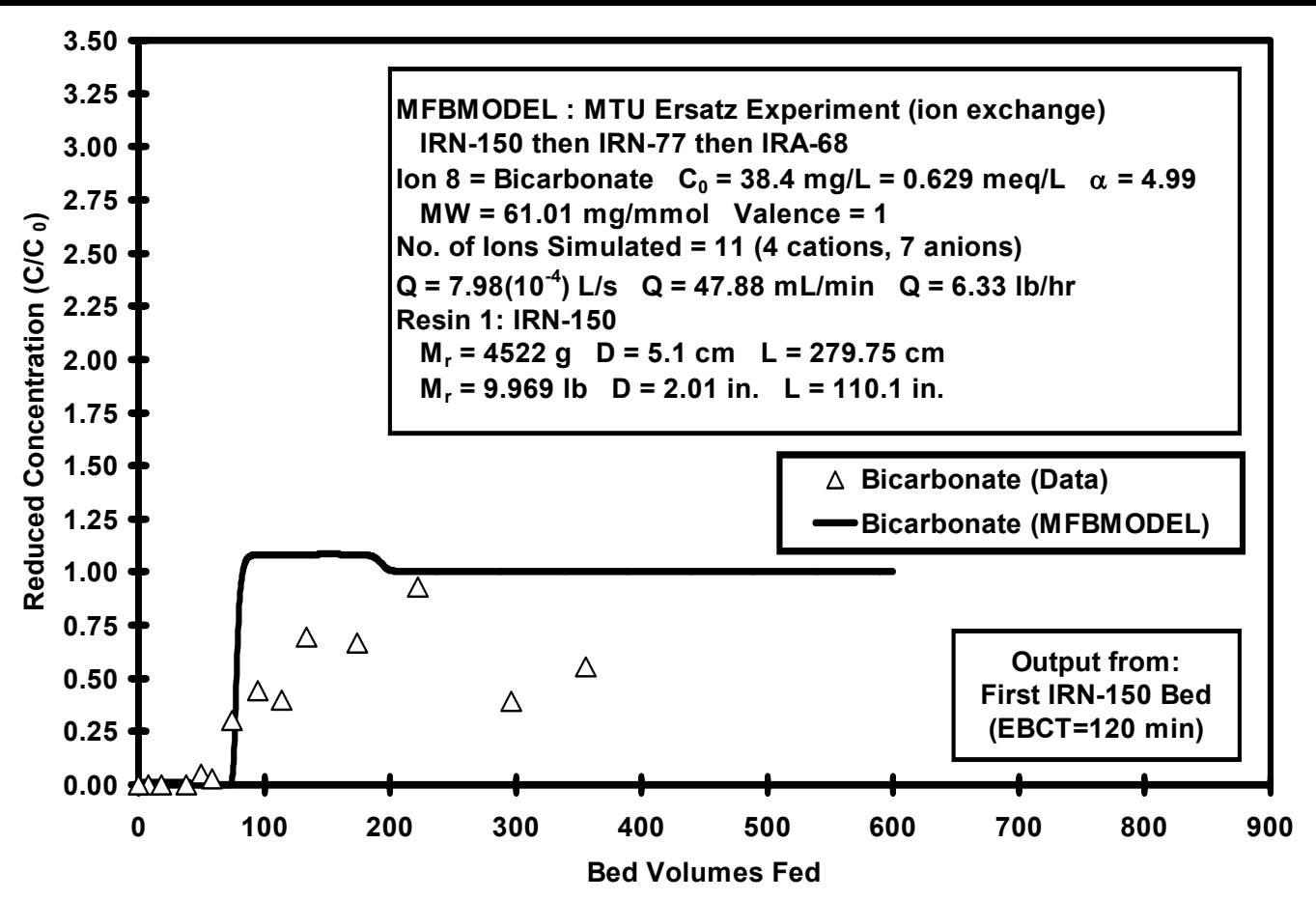

Sulfate

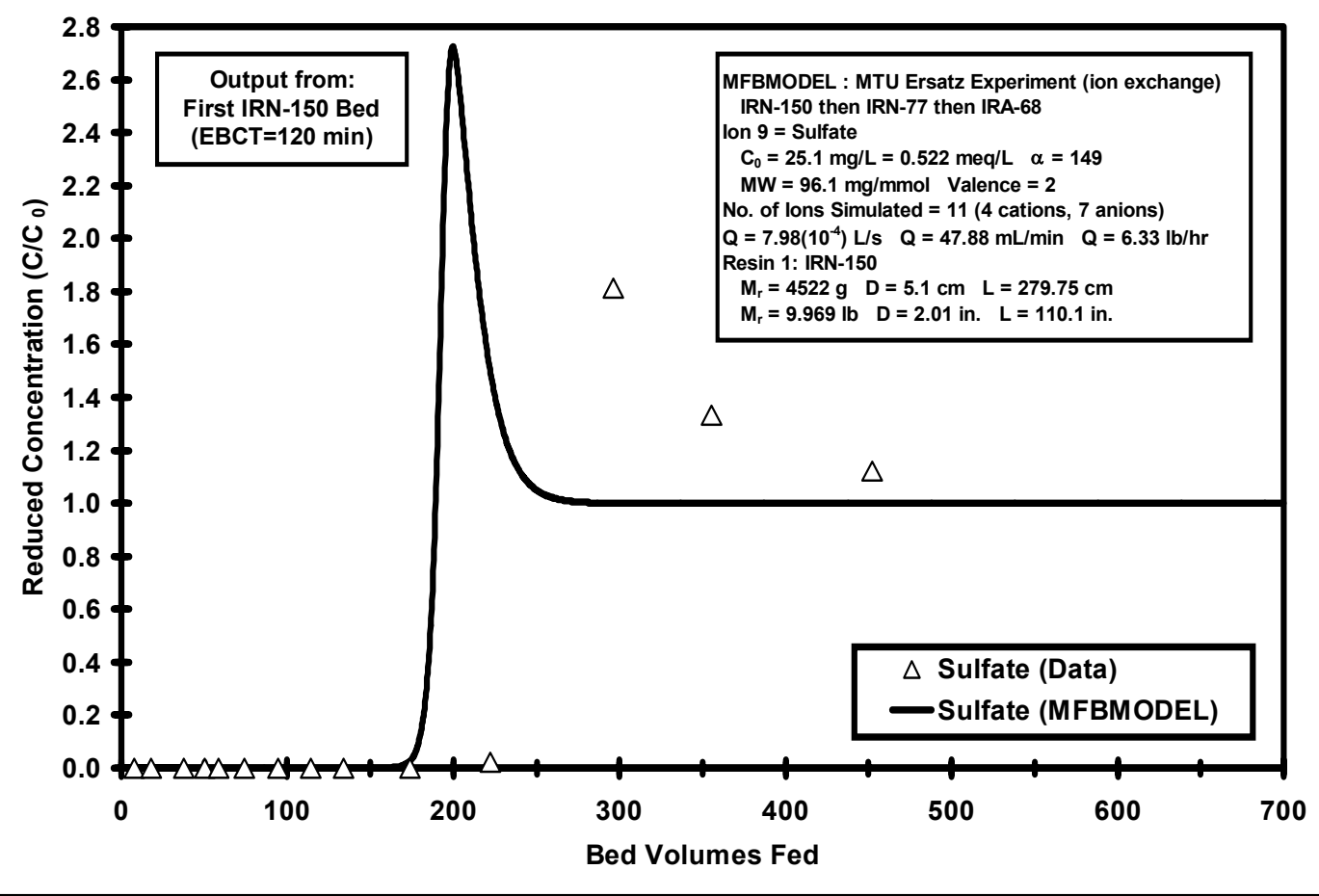




\section{CMT}

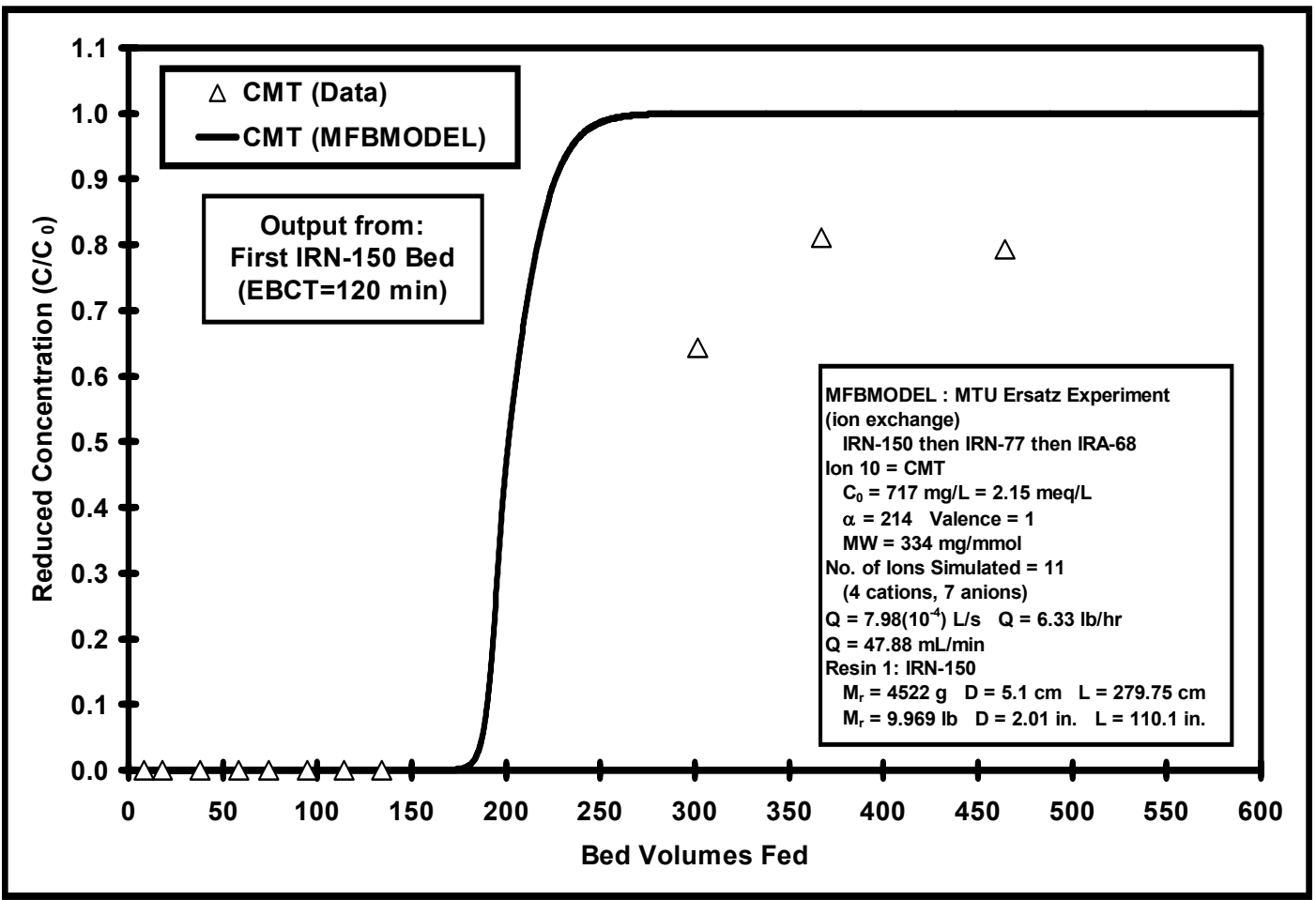

Hydroxide

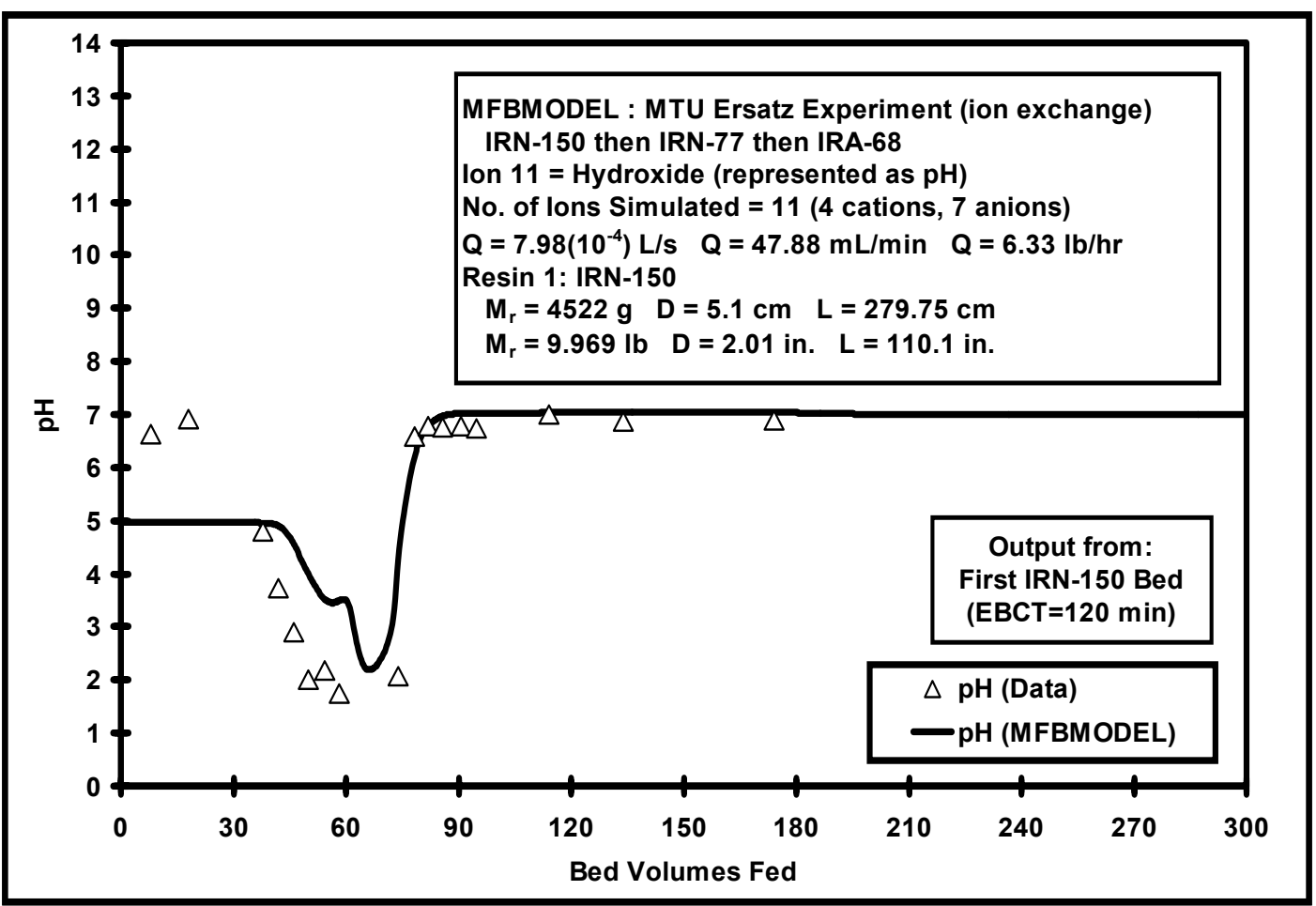




\section{Strong Acid Cation (SAC) Exchange Resin: Rohm \& Haas IRN-77 \\ Cation Results \\ Sodium}

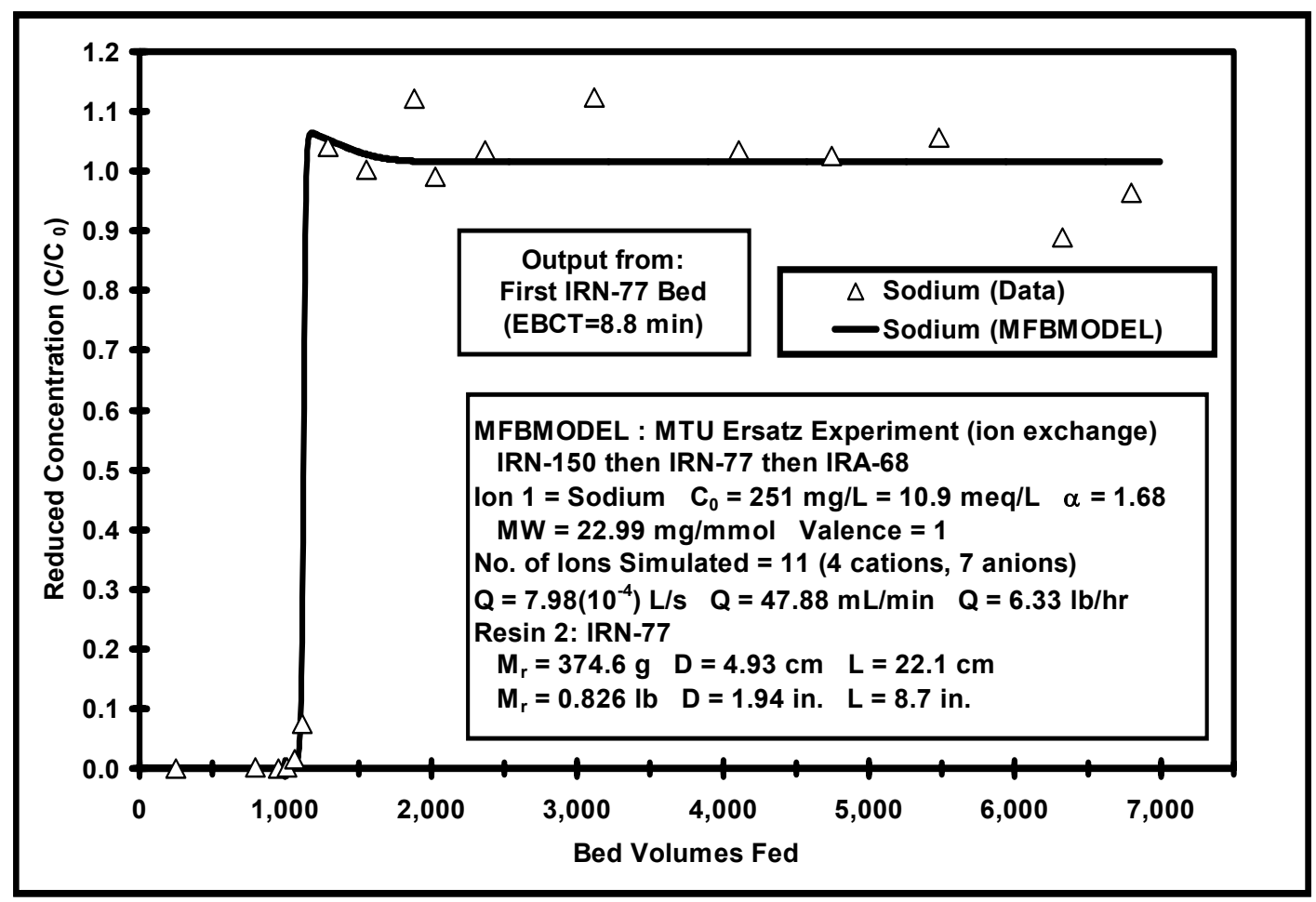

Potassium

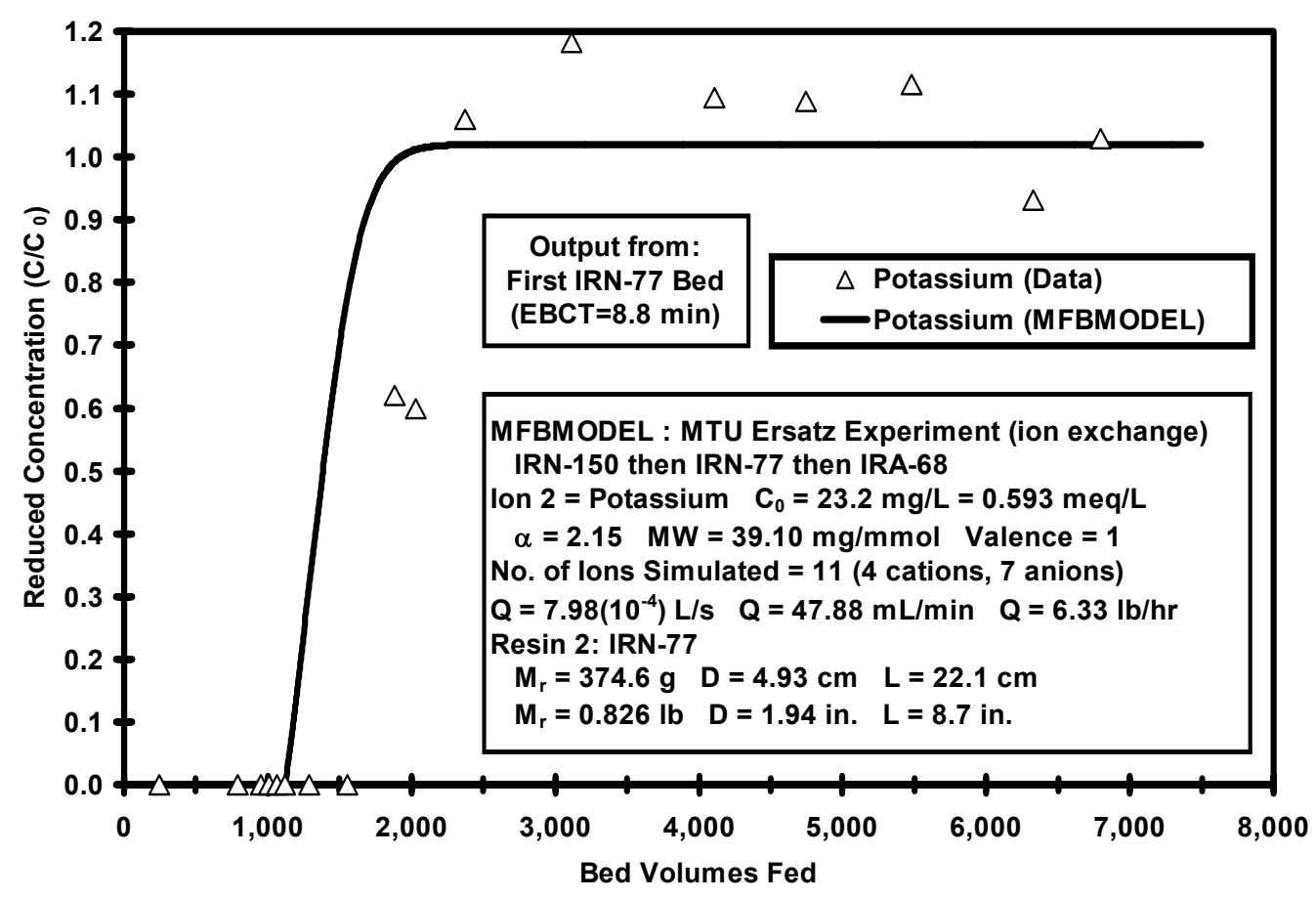




\section{Calcium}

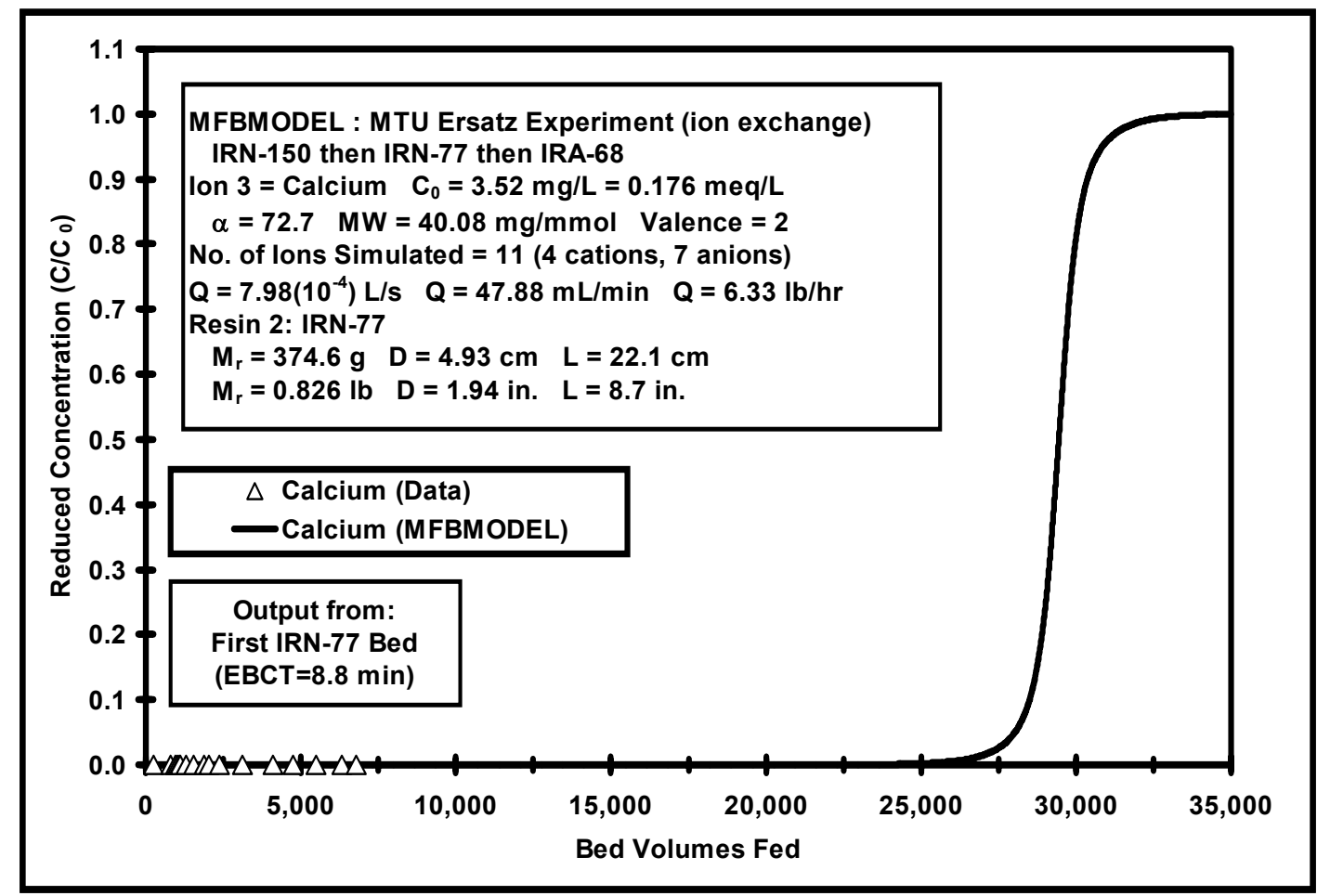

\section{Hydrogen}

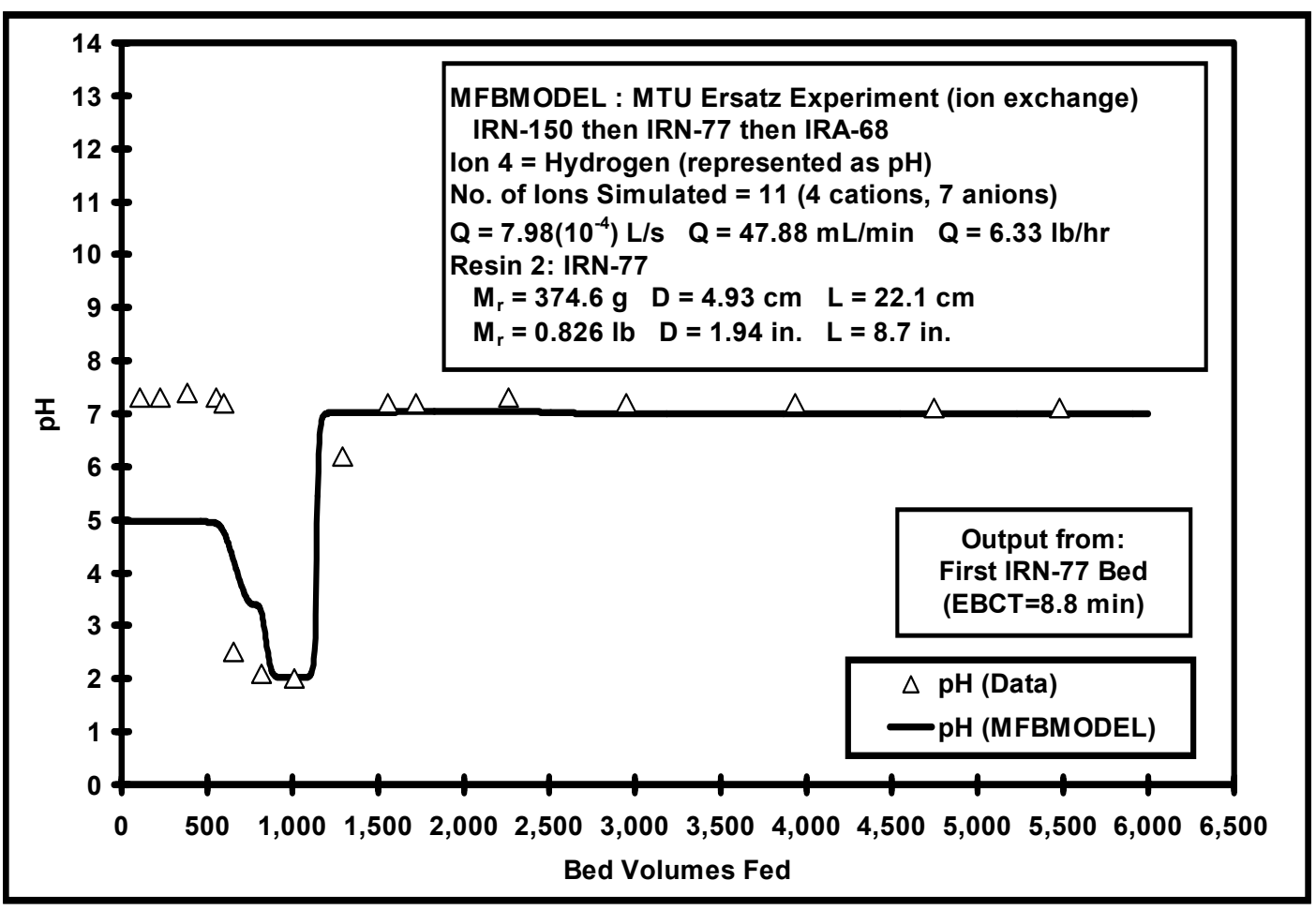


Weak Base Anion (WBA) Exchange Resin: Rohm \& Haas IRN-77

Anion Results

Acetate

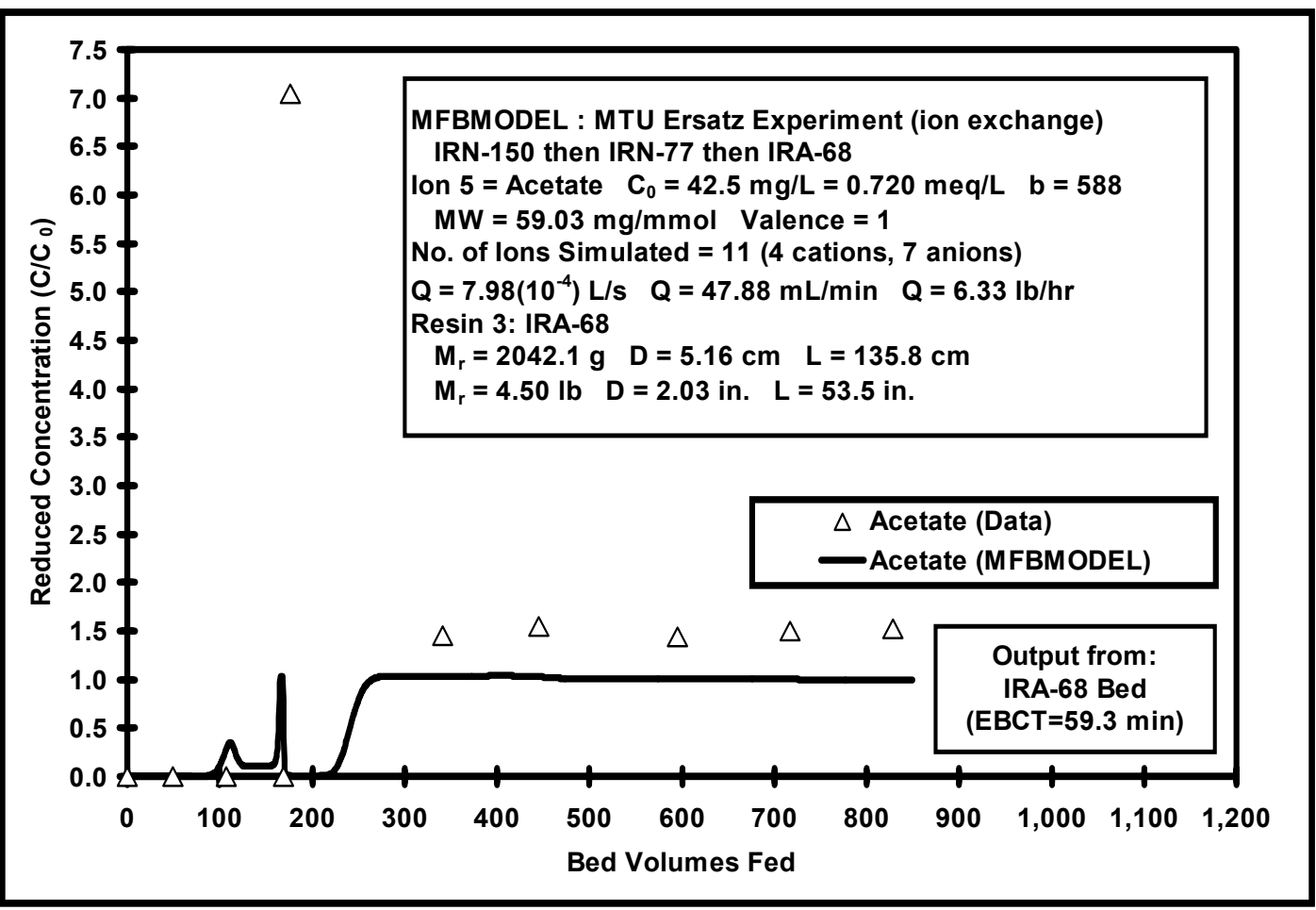

Butyrate

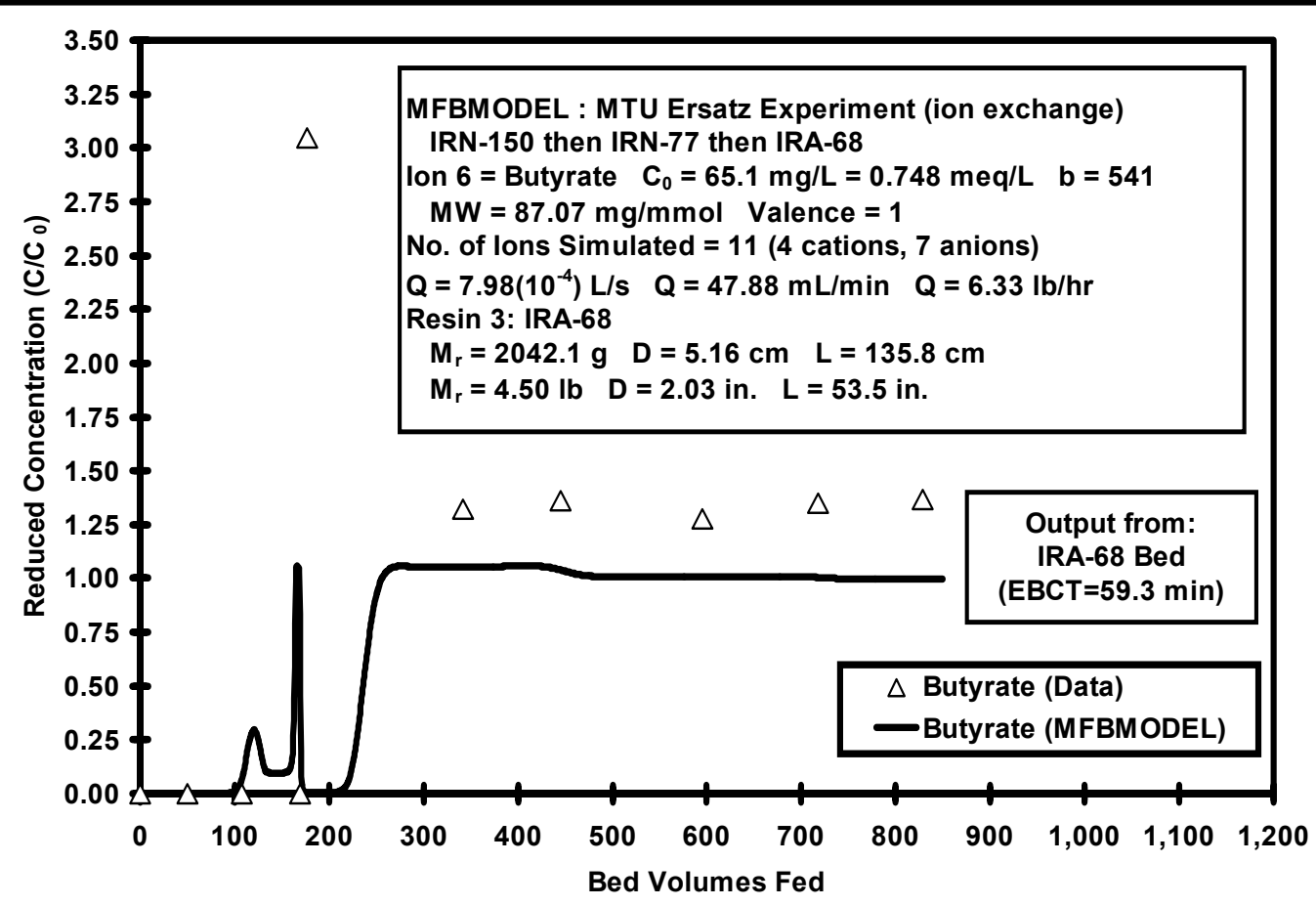




\section{Chloride}

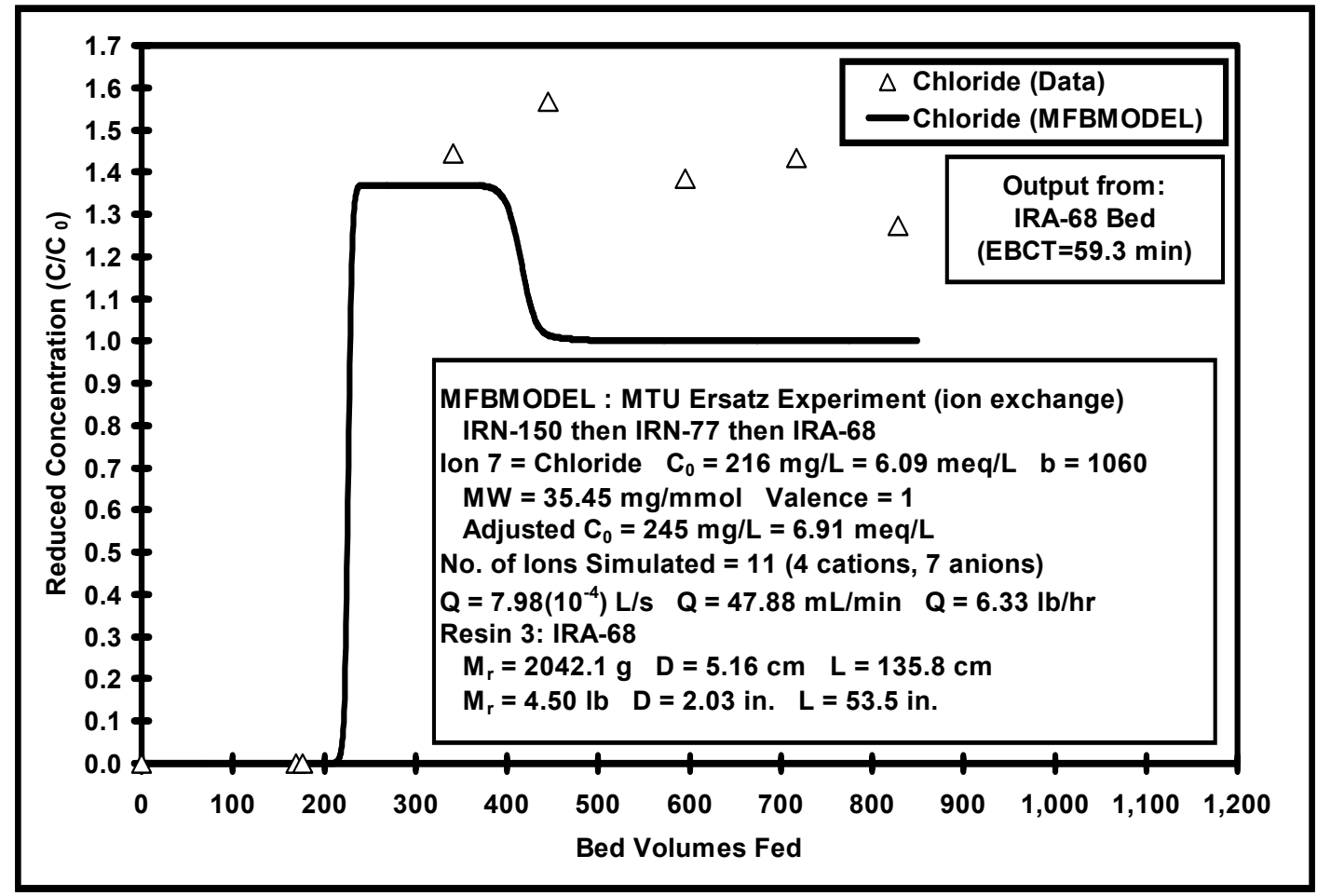

\section{Bicarbonate}

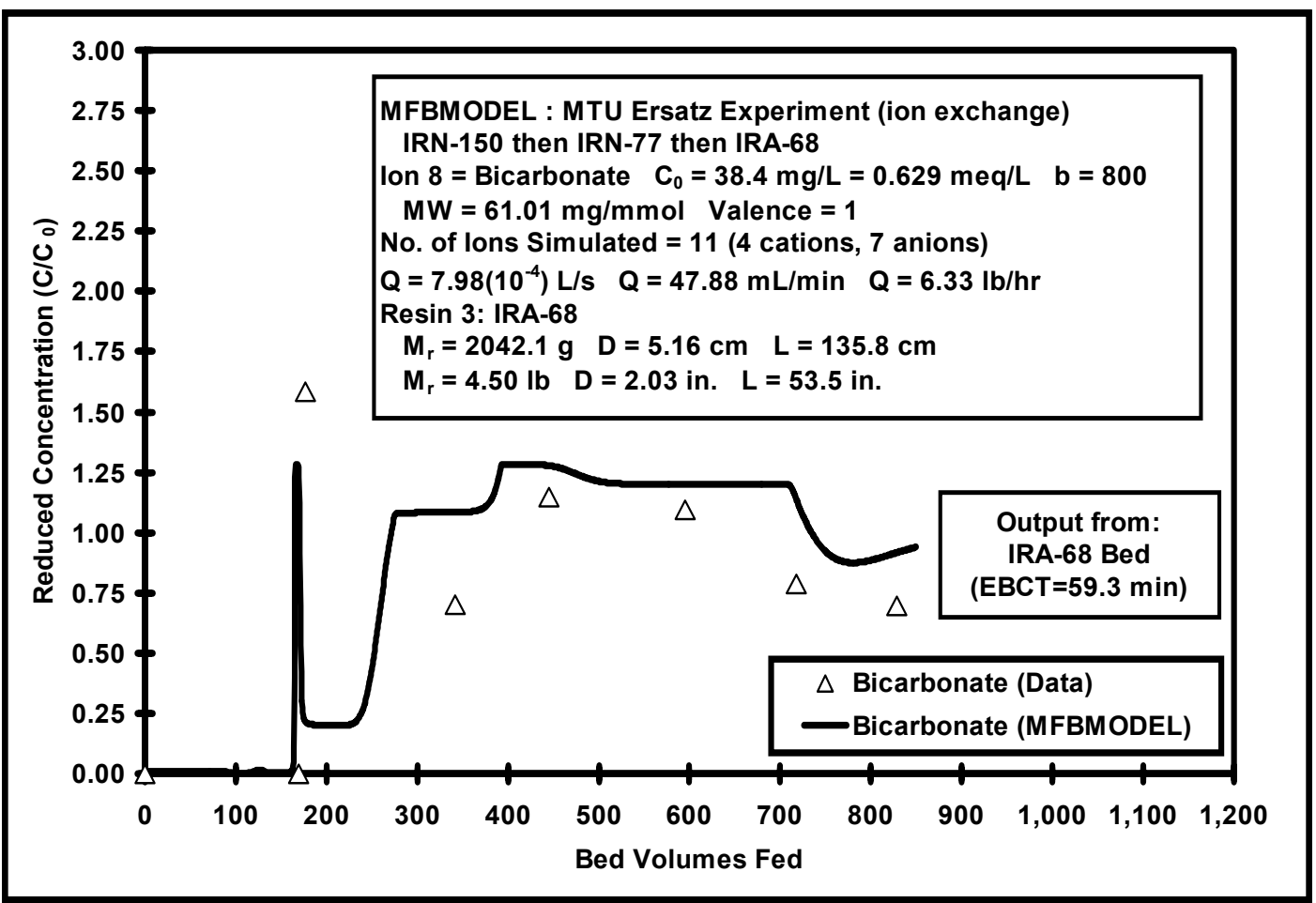




\section{Sulfate}

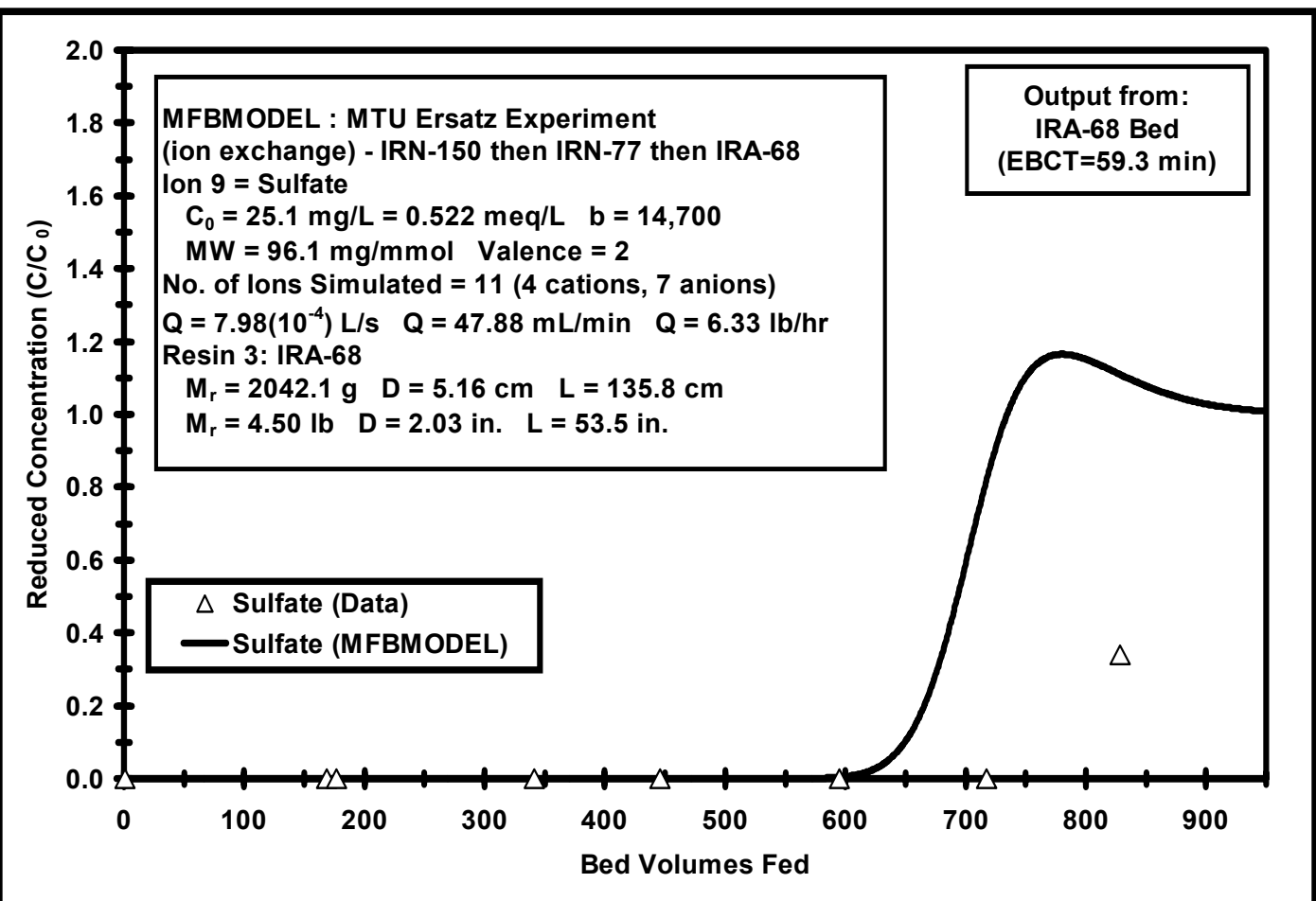

\section{CMT}

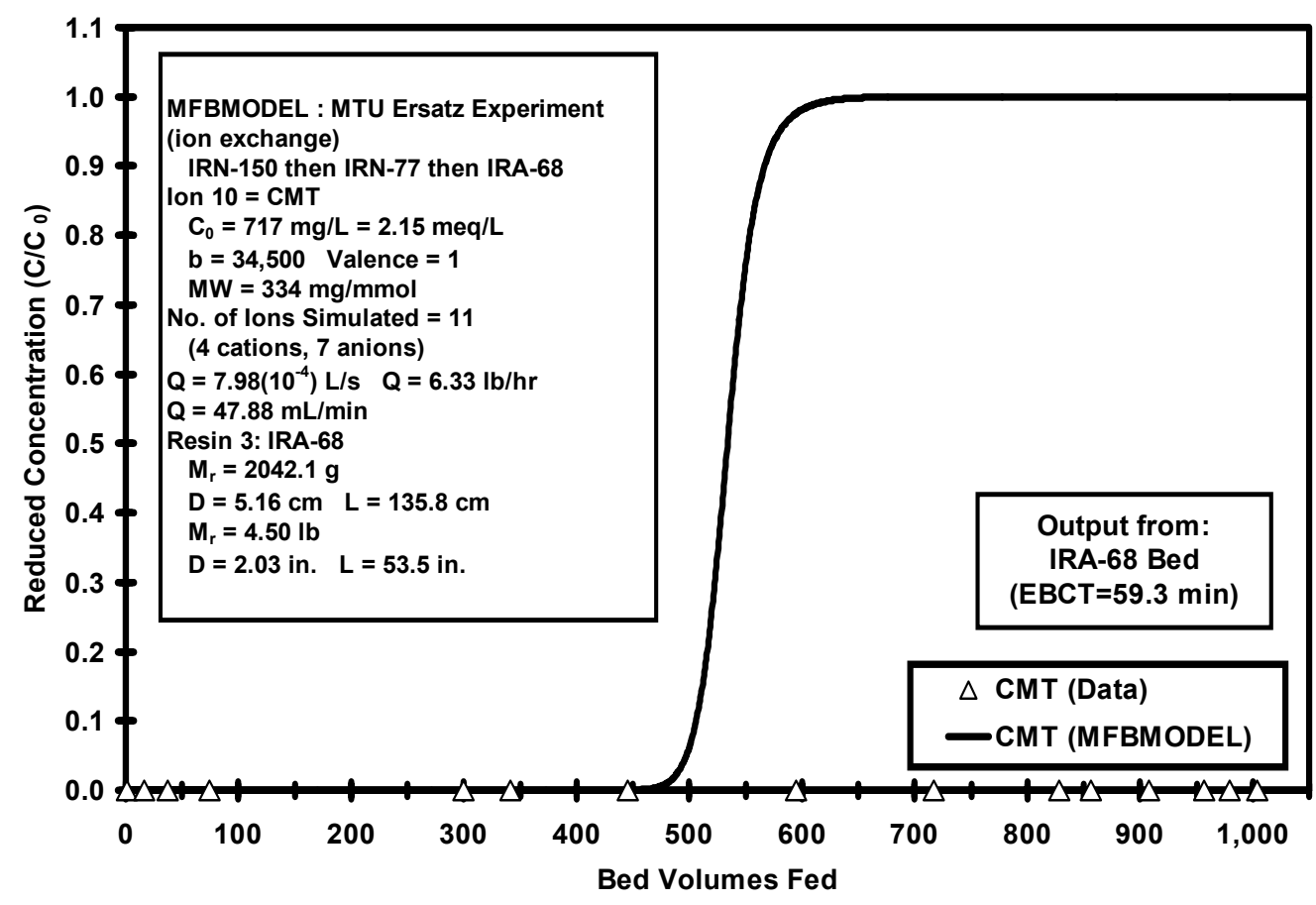




\section{Hydroxide}

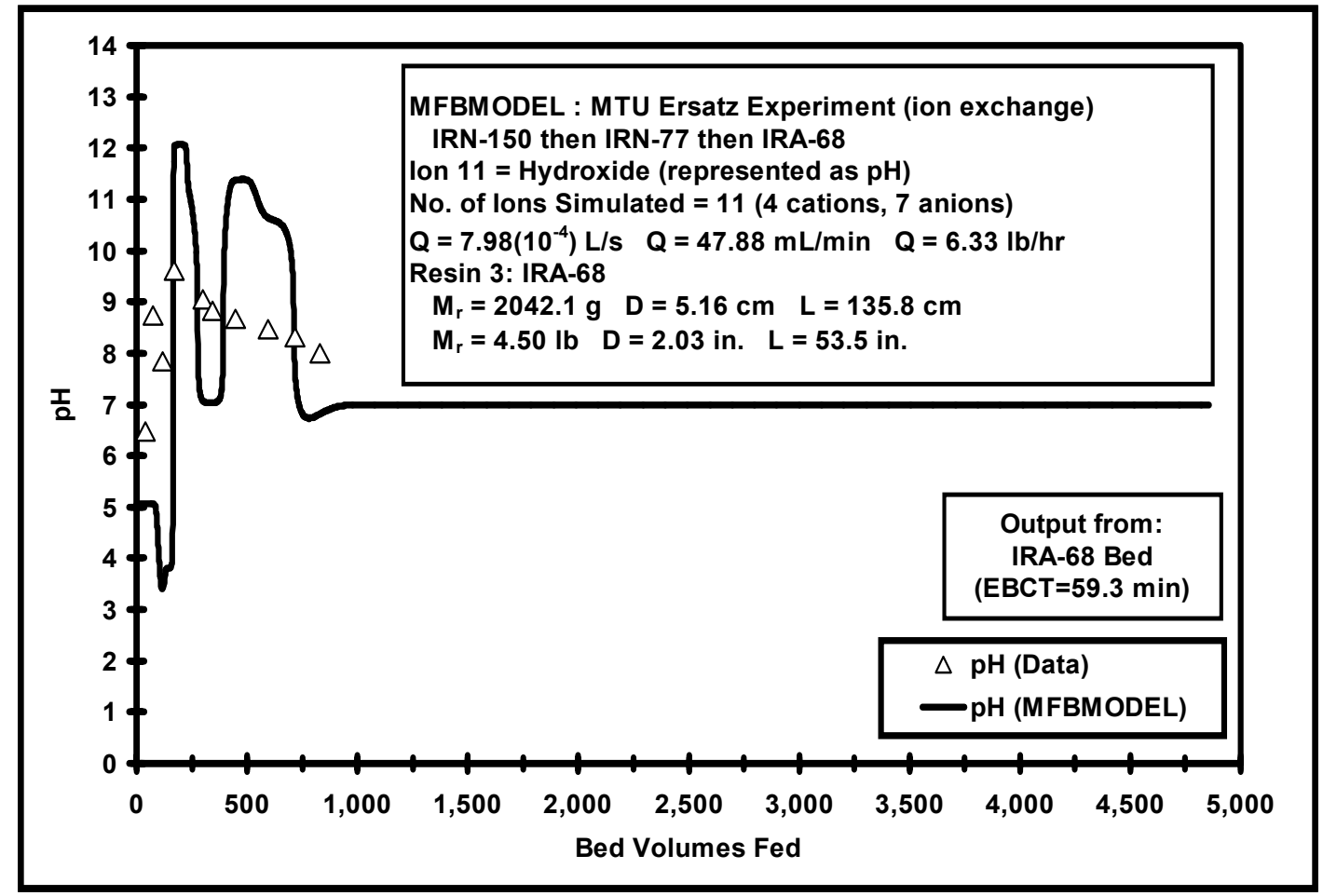




\section{Appendix X Adsorption Results for MFBMODEL Prediction of Experimental Data}

The adsorption results presented in Appendix X were originally simulated using a stand-alone adsorption model (PSDM) independent of the MFBMODEL GUI (Bulloch, 1995). Each compound and each adsorbent bed required a separate run of the PSDM. This required twelve runs of the PSDM (three adsorbents times four compounds). For the results presented in this project, the capability to simulate adsorbents in series within a graphical user interface was developed. Using MFBMODEL, four model runs are required to generate the adsorption results (one run for each compound). Model results are presented compared to experimental data in the following units: $\mathrm{mg} / \mathrm{L}$ versus Pounds of Water Treated (note that these are the units preferred by the project sponsors, ION Corporation and NASA Marshall Space Flight Center in Huntsville, Alabama). Appendix X.A presents the same results in additional units that may be useful for interpretation: (1) $\mathrm{mg} / \mathrm{L}$ versus Time in Days; (2) $\mathrm{mg} / \mathrm{L}$ versus Bed Volumes Treated.

\section{Total Organic Carbon (TOC)}

\section{MFBMODEL Setup}

The total organic carbon (TOC) for the MFBMODEL verification experiment was simulated in a single MFBMODEL run, consisting of three adsorbents in series: Barneby Sutcliffe 580-26 GAC, Calgon APA GAC, and Rohm and Haas XAD-4 Resin. Figure IX - 1 shows the Open Existing, Create New or Exit window within MFBMODEL. The TOC simulation can be opened within MFBMODEL as described in Appendix VII for a different simulation. Upon opening the simulation entitled "MTU_Ersatz_TOC_58026_then_APA_then_XAD4", the main MFBMODEL window for this simulation will open, as shown in Figure $X-1$. 


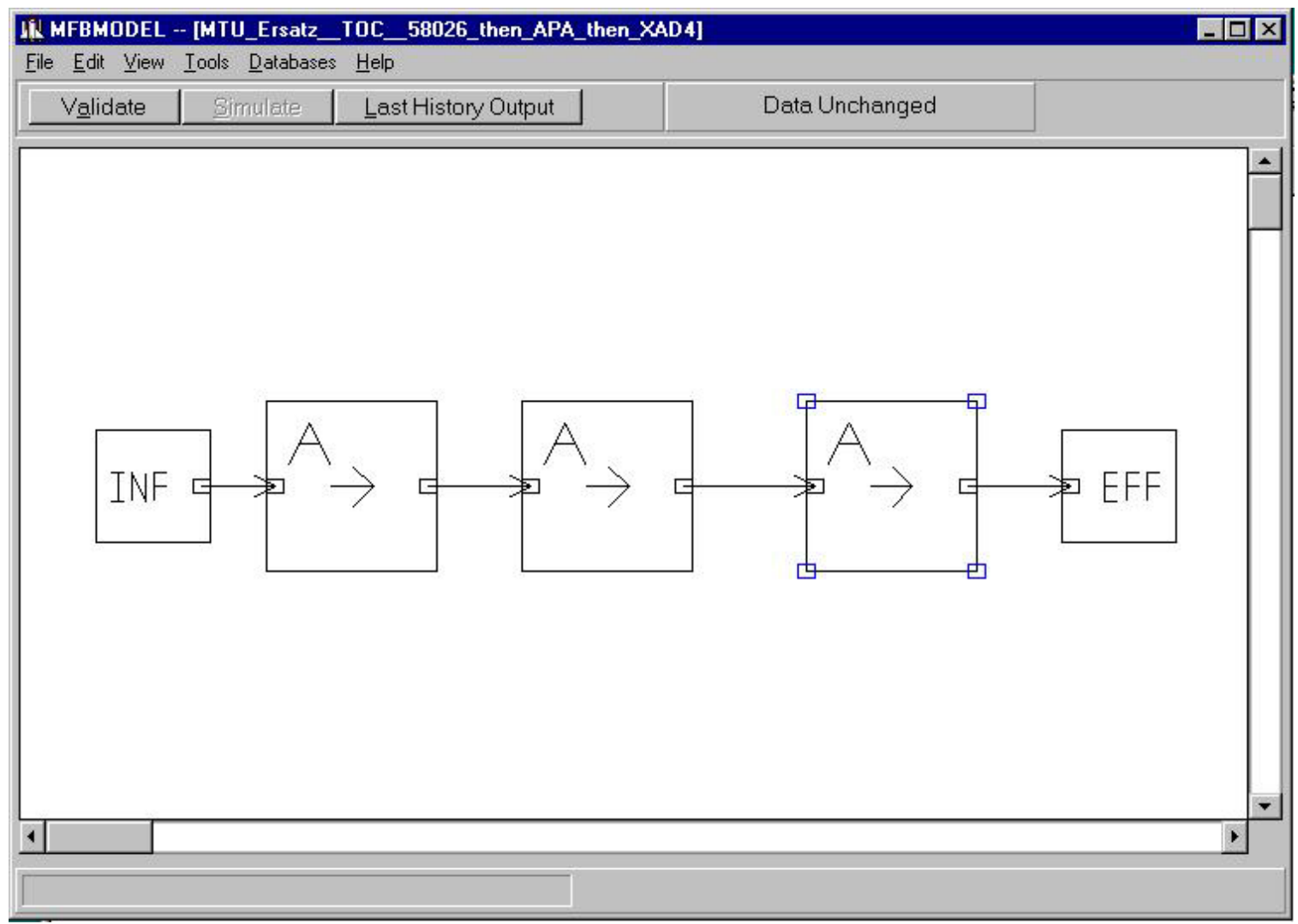

Figure X - 1 - Main MFBMODEL Window for Michigan Tech Ersatz Column Experiment Simulation File:

"MTU_Ersatz_TOC_58026_then_APA_then_XAD4"

Appendix VII explains how to obtain results from an MFBMODEL

simulation. An MFBMODEL manual has been written, which shows all the details for setting up an ion exchange simulation within MFBMODEL, but it is not presented in this proposal. Model results compared to experimental data for TOC through each adsorbent are presented below. 


\section{Granular Activated Carbon (GAC) Adsorbent: Barneby Sutcliffe 580-}

26

Table X - 1 shows the properties of the 580-26 GAC column in the multifiltration bed verification experiment.

\section{Table X - 1 - Properties of 580-26 GAC Column Used in MFBMODEL Verification Experiment}

\begin{tabular}{l|c}
\hline Property & Value \\
\hline Mass of Adsorbent, g (lb) & $1070(2.36)$ \\
\hline Diameter of Bed, cm (in.) & $5.12(2.02)$ \\
\hline Length of Bed, cm (in.) & $139.9(55.1)$ \\
\hline Flowrate, $\mathrm{mL} / \mathrm{min}(\mathrm{lb} / \mathrm{hr})$ & $47.88(6.33)$ \\
\hline Water Matrix & Ersatz \\
\hline EBCT, min & 60.2 \\
\hline
\end{tabular}

MFBMODEL results compared to experimental data for TOC through 580$26 \mathrm{GAC}$ are presented below.

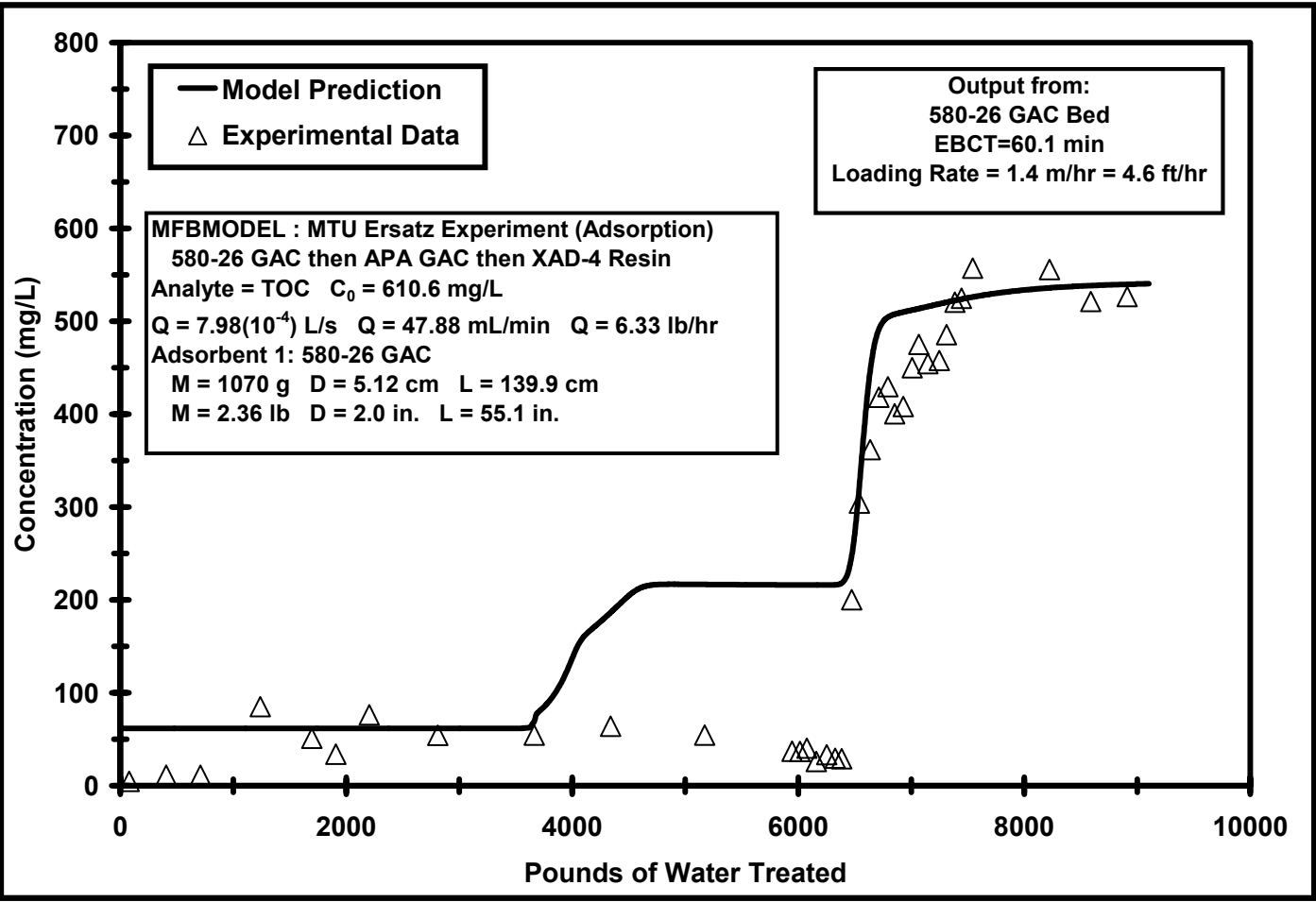




\section{Granular Activated Carbon (GAC) Adsorbent: Calgon APA}

Table $X$ - 2 shows the properties of the APA GAC column in the multifiltration bed verification experiment.

Table X - 2 - Properties of APA GAC Column Used in MFBMODEL Verification Experiment

\begin{tabular}{l|c}
\hline Property & Value \\
\hline Mass of Adsorbent, g (lb) & $300(0.661)$ \\
\hline Diameter of Bed, cm (in.) & $5.15(2.03)$ \\
\hline Length of Bed, cm (in.) & $40.7(16.0)$ \\
\hline Flowrate, $\mathrm{mL} / \mathrm{min}(\mathrm{lb} / \mathrm{hr})$ & $47.88(6.33)$ \\
\hline Water Matrix & Ersatz \\
\hline EBCT, min & 17.7 \\
\hline
\end{tabular}

MFBMODEL results compared to experimental data for TOC through APA GAC are presented below.

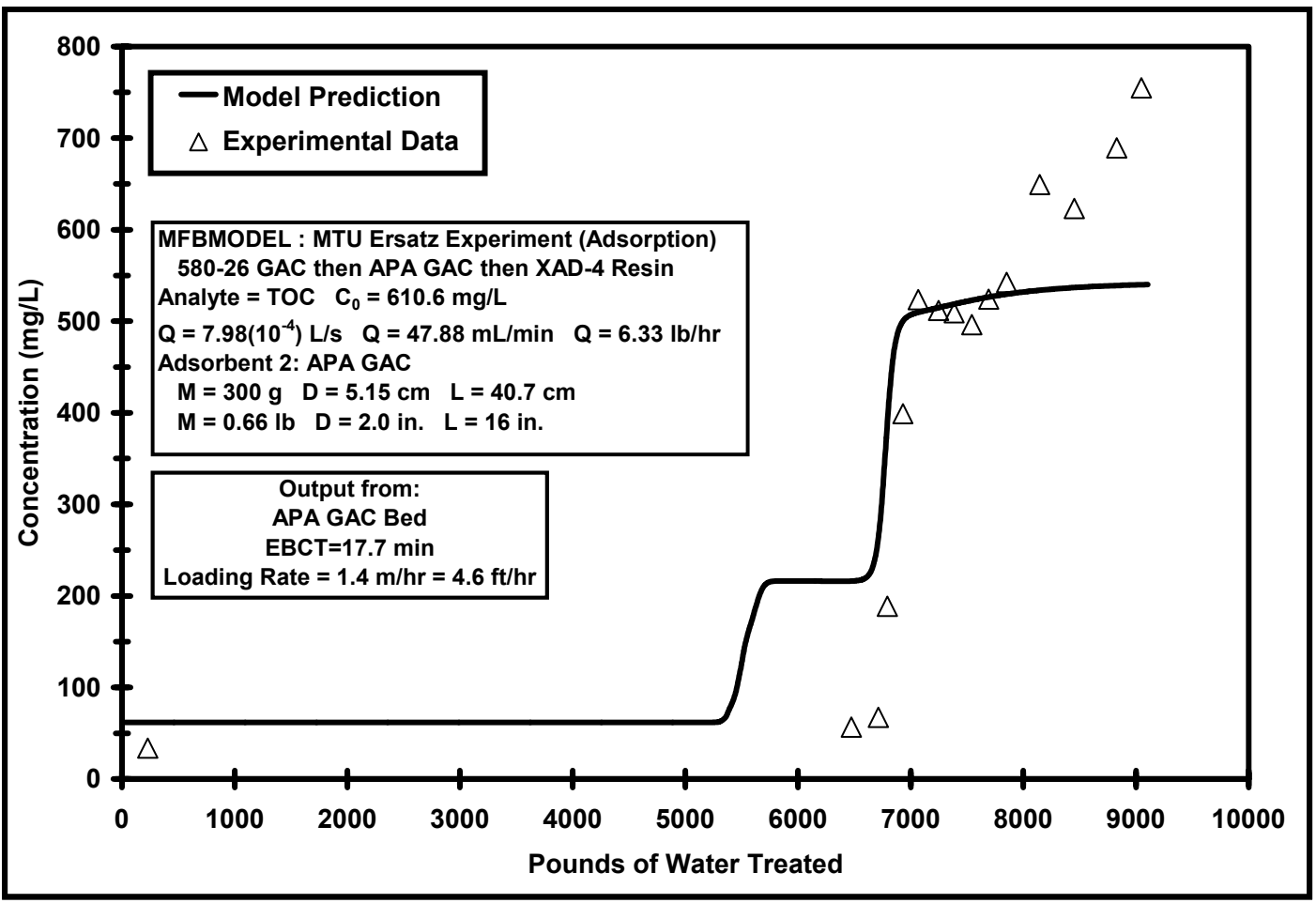




\section{Adsorbent: Rohm \& Haas XAD-4 Resin}

Table $X$ - 3 shows the properties of the XAD-4 resin column in the multifiltration bed verification experiment.

Table X - 3 - Properties of XAD-4 Resin Column Used in MFBMODEL Verification Experiment

\begin{tabular}{l|c}
\hline Property & Value \\
\hline Mass of Adsorbent, g (lb) & $273(0.602)$ \\
\hline Diameter of Bed, cm (in.) & $5.10(2.01)$ \\
\hline Length of Bed, cm (in.) & $39.1(15.4)$ \\
\hline Flowrate, $\mathrm{mL} / \mathrm{min}(\mathrm{lb} / \mathrm{hr})$ & $47.88(6.33)$ \\
\hline Water Matrix & Ersatz \\
\hline EBCT, min & 16.7 \\
\hline
\end{tabular}

MFBMODEL results compared to experimental data for TOC through XAD-4 resin are presented below.

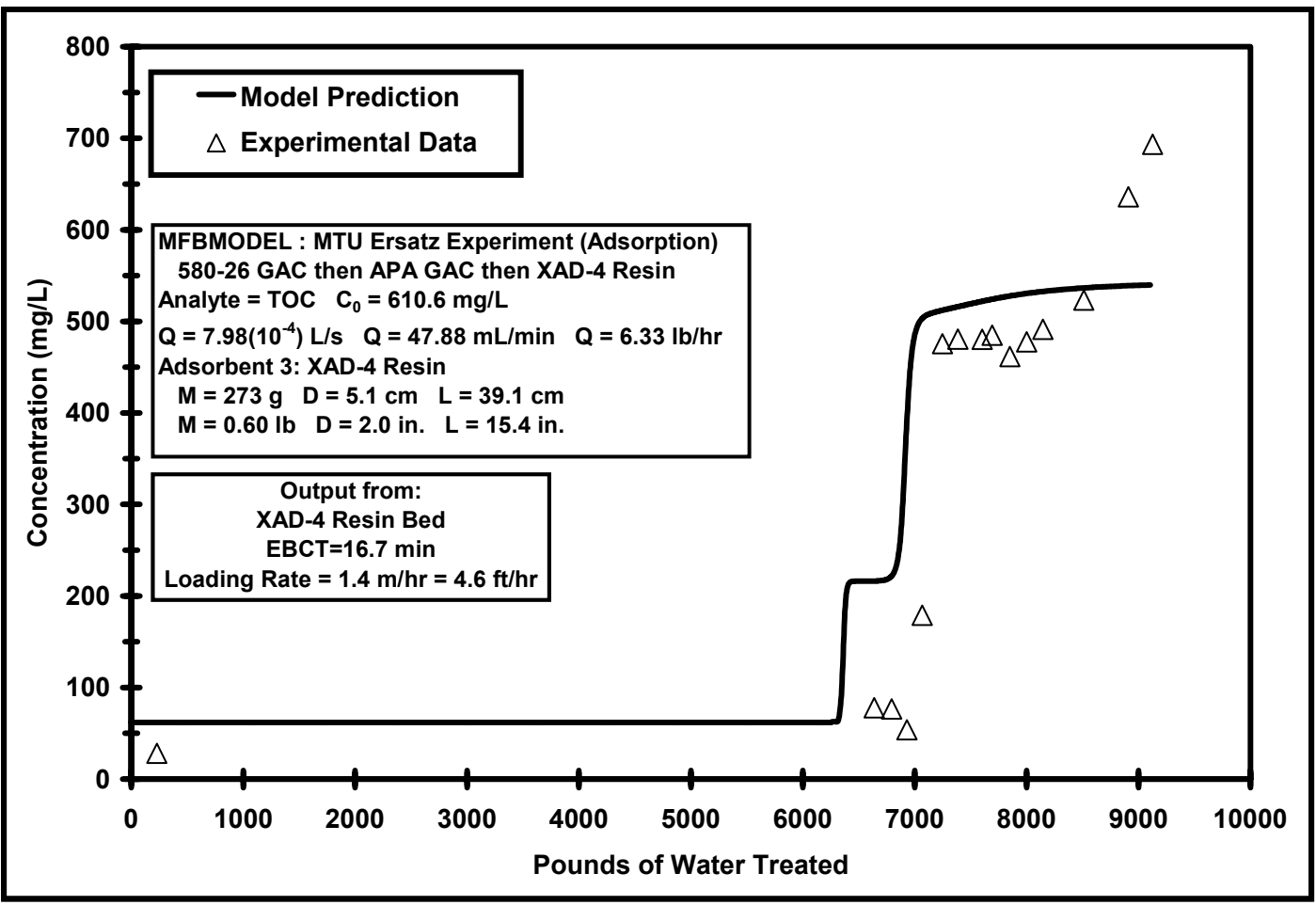




\section{Tracer Compound: SCMT}

\section{MFBMODEL Setup}

The SCMT for the MFBMODEL verification experiment was simulated in a single MFBMODEL run, consisting of three adsorbents in series: Barneby Sutcliffe 580-26 GAC, Calgon APA GAC, and Rohm and Haas XAD-4 Resin. Figure IX - 1 shows the Open Existing, Create New or Exit window within MFBMODEL. The TOC simulation can be opened within MFBMODEL as described in Appendix VII for a different simulation. Upon opening the simulation entitled "MTU_Ersatz_Tracer_SCMT_58026thenAPAthenXAD4", the main MFBMODEL window for this simulation will open, as shown in Figure $X-2$.

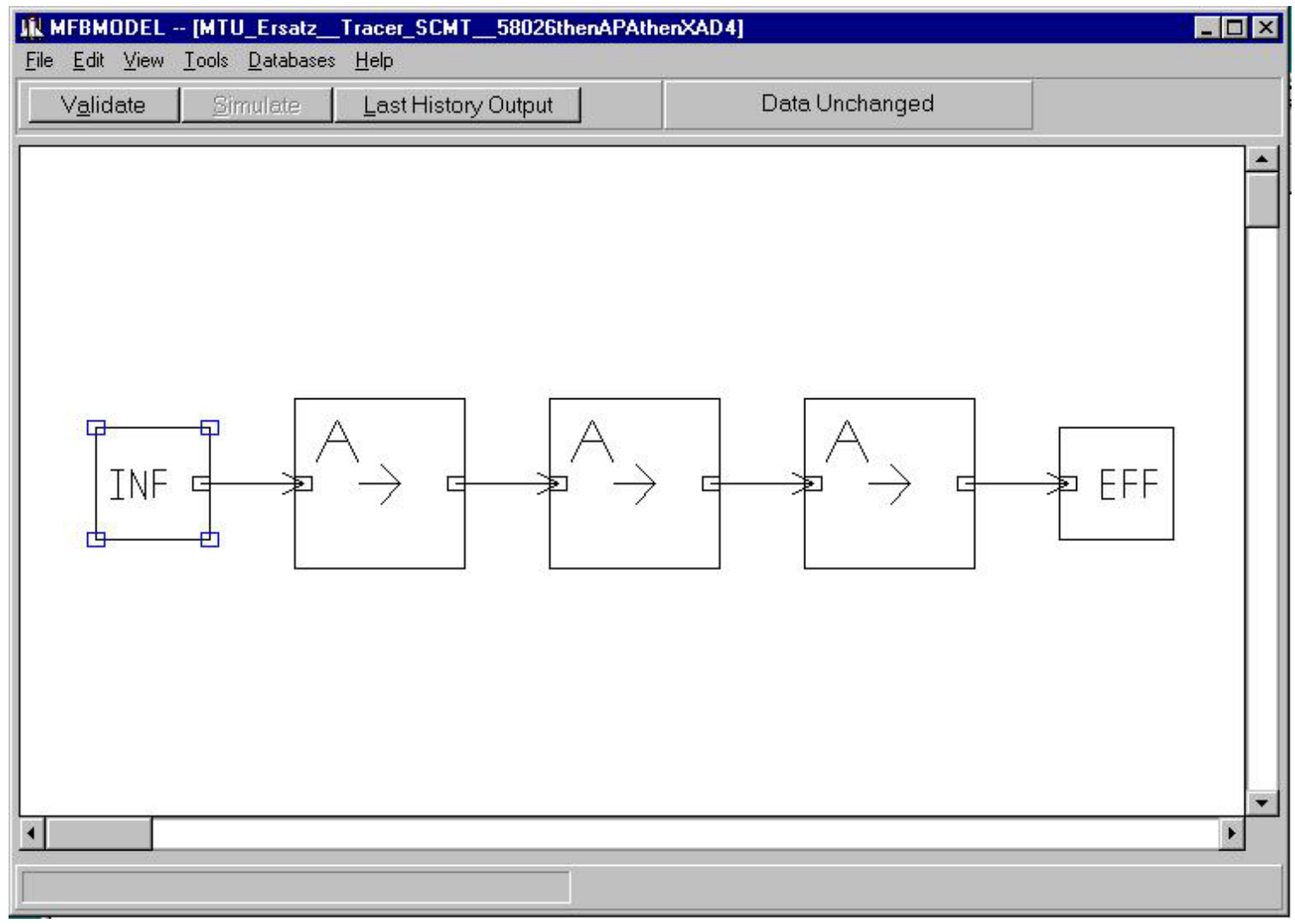

Figure X - 2 - Main MFBMODEL Window for Michigan Tech Ersatz Column Experiment Simulation File:

"MTU_Ersatz_Tracer_SCMT_58026thenAPAthenXAD4" 
Appendix VII explains how to obtain results from an MFBMODEL simulation. An MFBMODEL manual has been written, which shows all the details for setting up an ion exchange simulation within MFBMODEL, but it is not presented in this proposal. Model results compared to experimental data for SCMT through each adsorbent are presented below.

\section{Granular Activated Carbon (GAC) Adsorbent: Barneby Sutcliffe 580- 26}

Table X - 1 above shows the properties of the 580-26 GAC column in the multifiltration bed verification experiment. MFBMODEL results compared to experimental data for SCMT through 580-26 GAC are presented below.

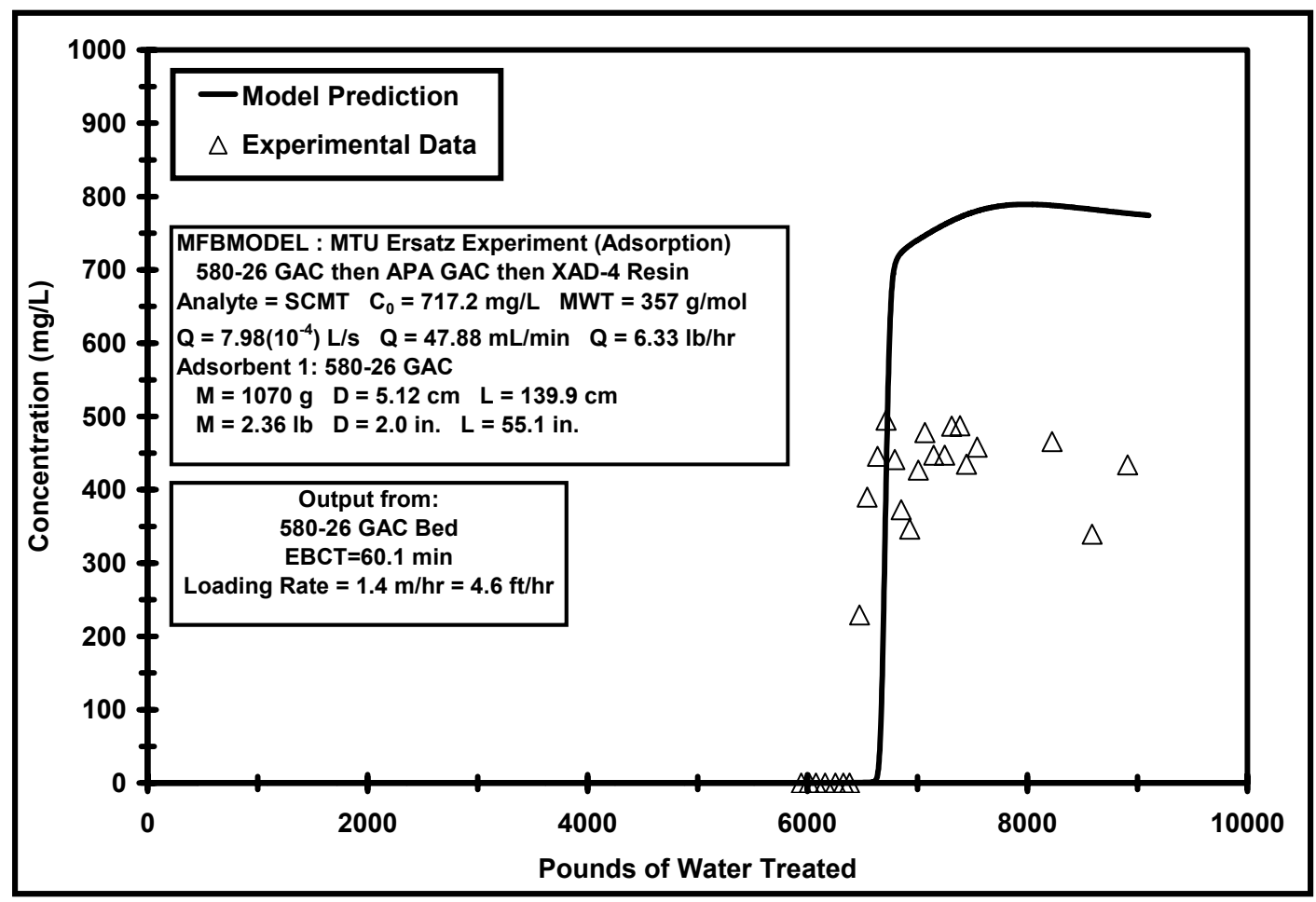

\section{Granular Activated Carbon (GAC) Adsorbent: Calgon APA}

Table X - 2 above shows the properties of the APA GAC column in the multifiltration bed verification experiment. MFBMODEL results compared to experimental data for SCMT through APA GAC are presented below. 


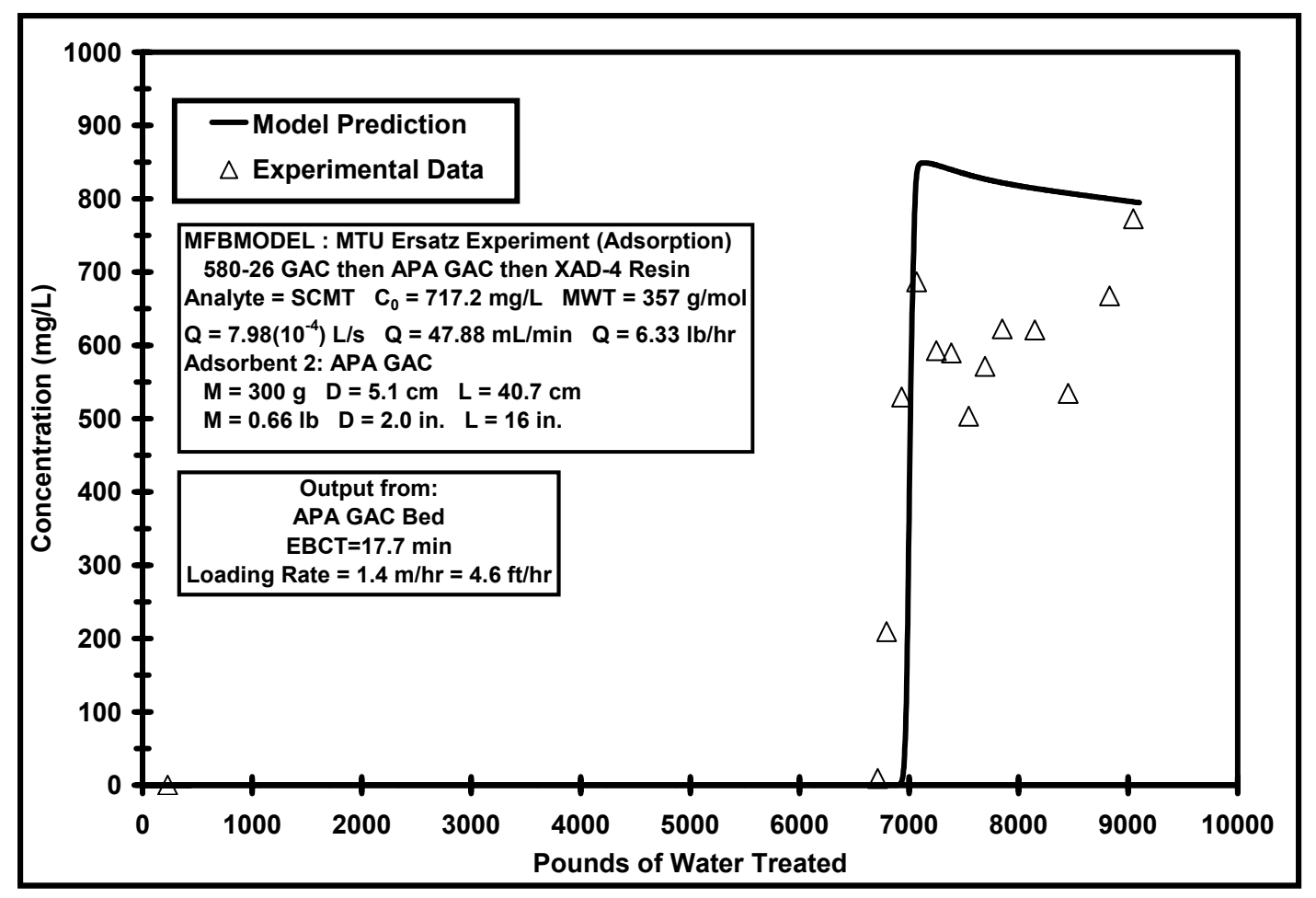

\section{Adsorbent: Rohm \& Haas XAD-4 Resin}

Table X - 3 above shows the properties of the XAD- 4 resin column in the multifiltration bed verification experiment. MFBMODEL results compared to experimental data for SCMT through XAD-4 resin are presented below.

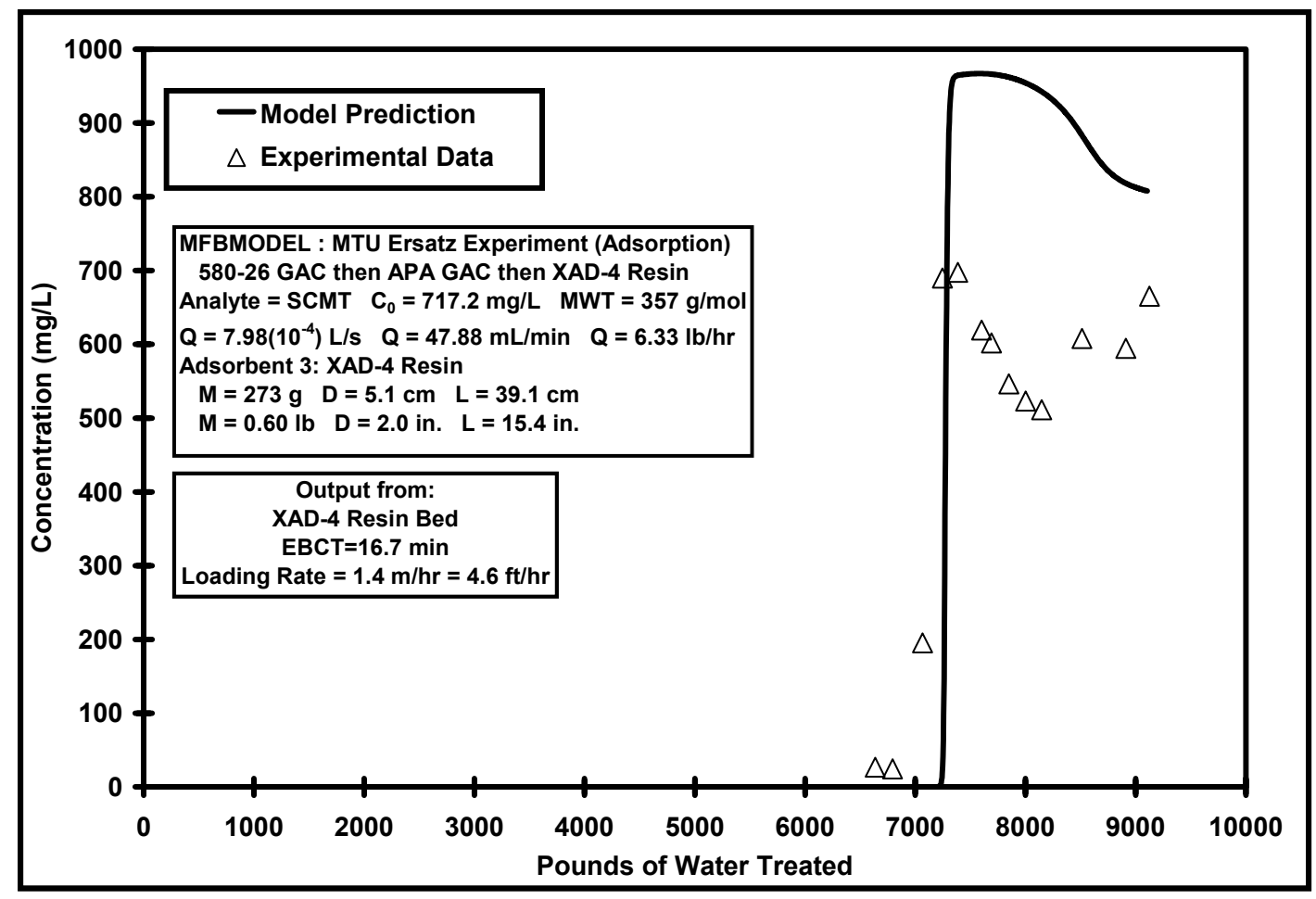




\section{Tracer Compound: Trichloroethylene (TCE)}

\section{MFBMODEL Setup}

The TCE for the MFBMODEL verification experiment was simulated in a single MFBMODEL run, consisting of three adsorbents in series: Barneby Sutcliffe 580-26 GAC, Calgon APA GAC, and Rohm and Haas XAD-4 Resin. Figure IX - 1 shows the Open Existing, Create New or Exit window within MFBMODEL. The TOC simulation can be opened within MFBMODEL as described in Appendix VII for a different simulation. Upon opening the simulation entitled "MTU_Ersatz_Tracer_TCE_58026thenAPAthenXAD4", the main MFBMODEL window for this simulation will open, as shown in Figure $\mathrm{X}-3$.

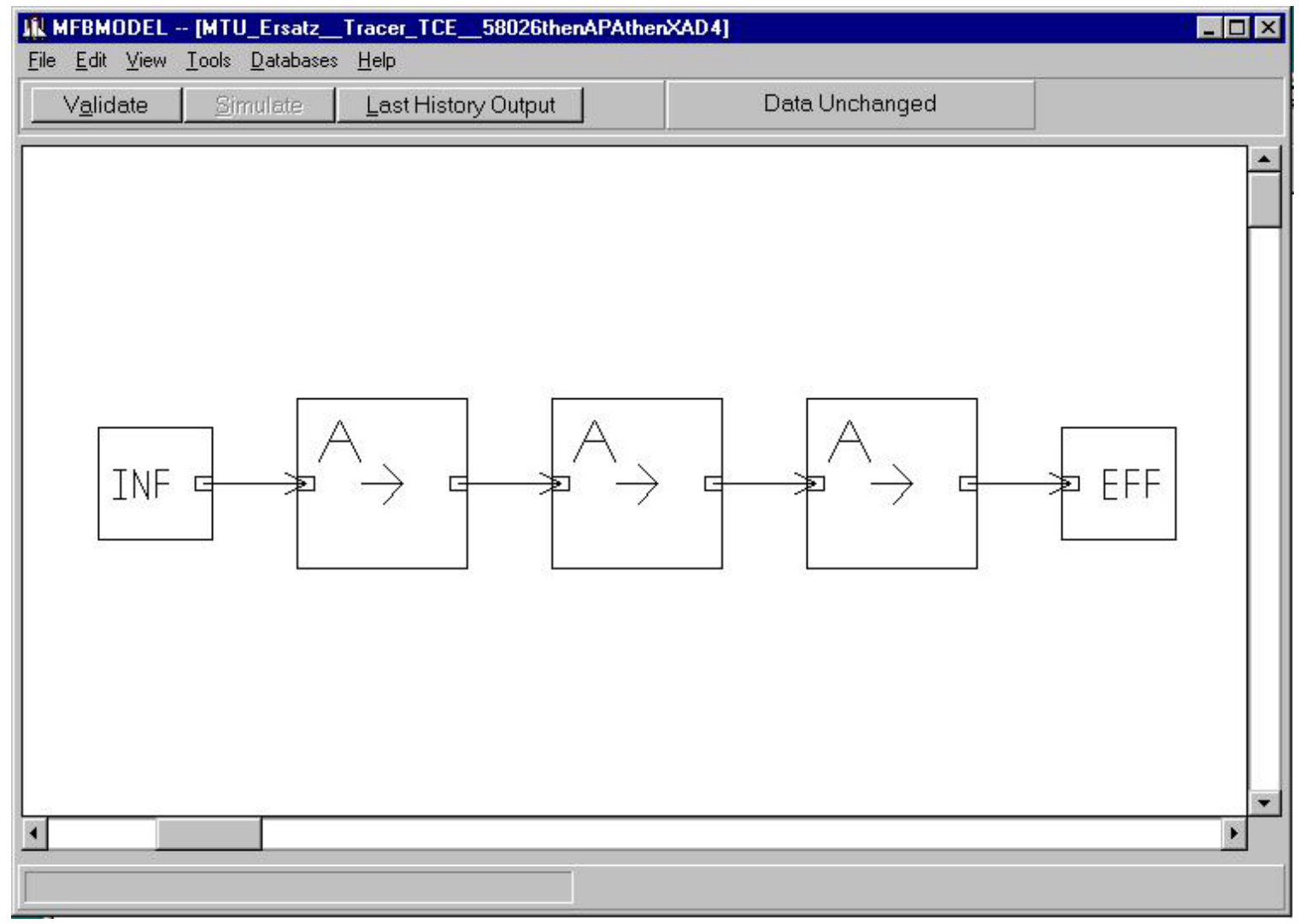

Figure X - 3 - Main MFBMODEL Window for Michigan Tech Ersatz Column Experiment Simulation File: "MTU_Ersatz_Tracer_TCE_58026thenAPAthenXAD4" 
Appendix VII explains how to obtain results from an MFBMODEL simulation. An MFBMODEL manual has been written, which shows all the details for setting up an ion exchange simulation within MFBMODEL, but it is not presented in this proposal. Model results compared to experimental data for TCE through each adsorbent are presented below.

\section{Granular Activated Carbon (GAC) Adsorbent: Barneby Sutcliffe 580- 26}

Table X - 1 above shows the properties of the 580-26 GAC column in the multifiltration bed verification experiment. MFBMODEL results compared to experimental data for TCE through 580-26 GAC are presented below.

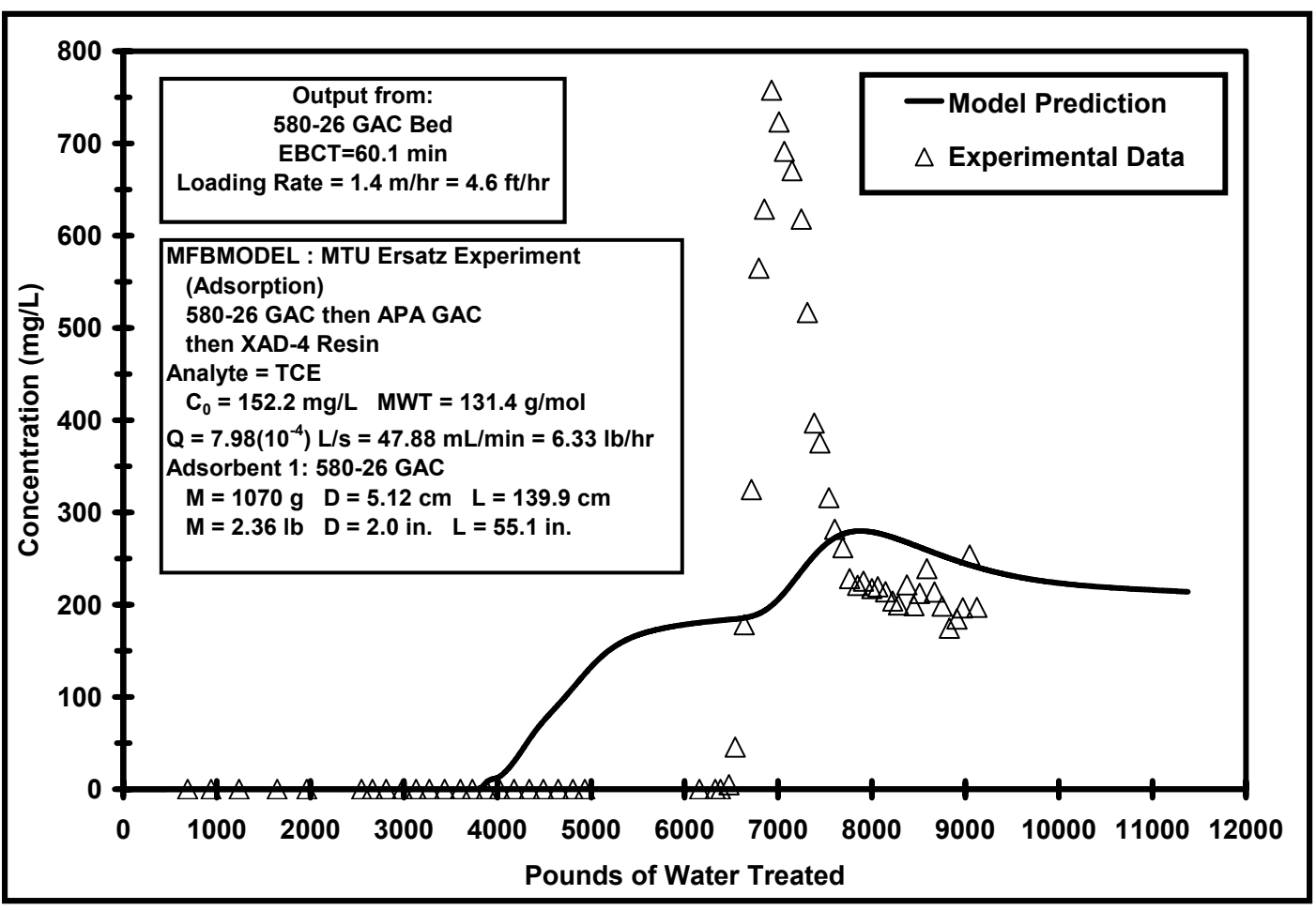

\section{Granular Activated Carbon (GAC) Adsorbent: Calgon APA}

Table X - 2 above shows the properties of the APA GAC column in the multifiltration bed verification experiment. MFBMODEL results compared to experimental data for TCE through APA GAC are presented below. 


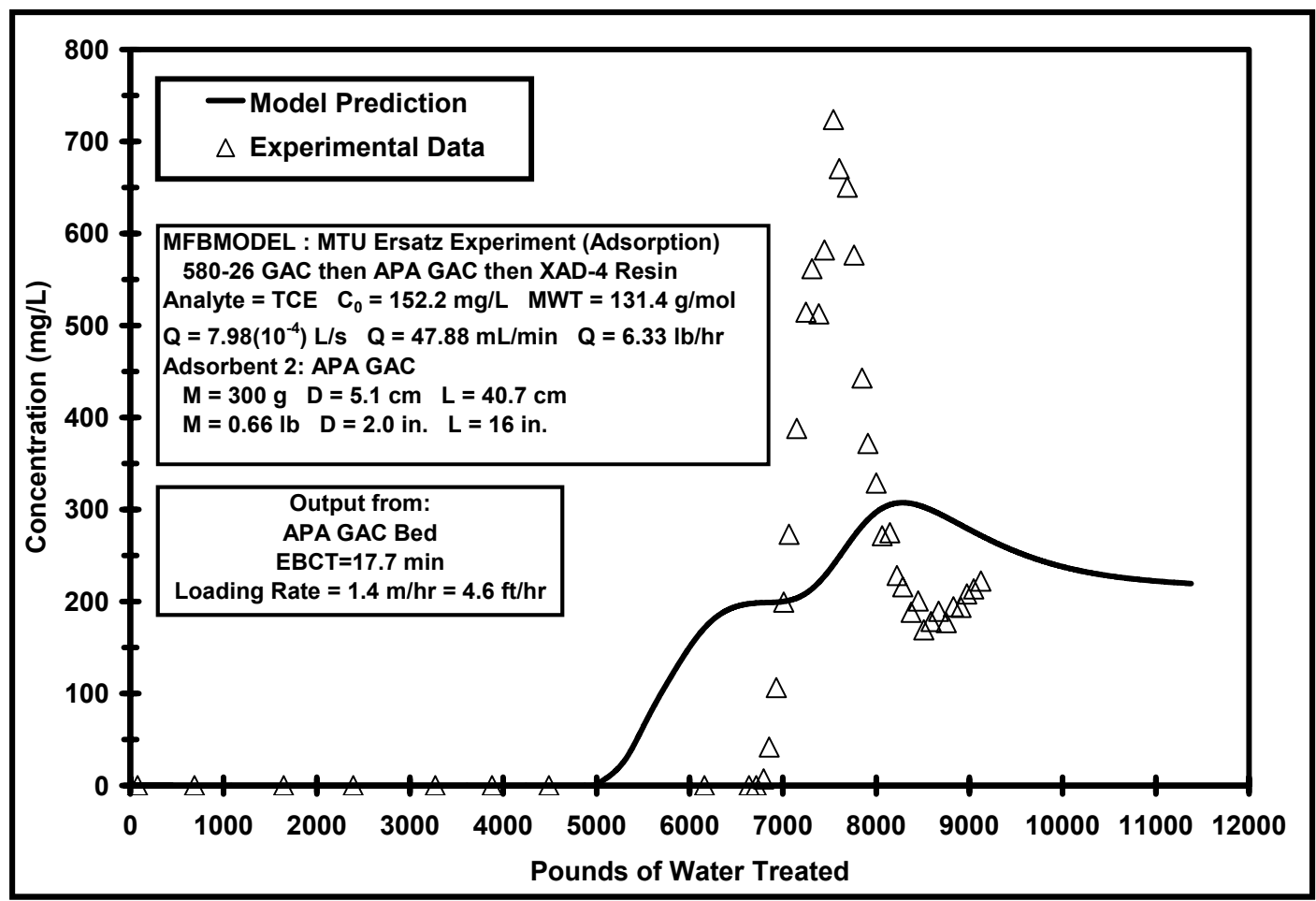

Adsorbent: Rohm \& Haas XAD-4 Resin

Table $X-3$ above shows the properties of the XAD-4 resin column in the multifiltration bed verification experiment. MFBMODEL results compared to experimental data for TCE through XAD-4 resin are presented below.

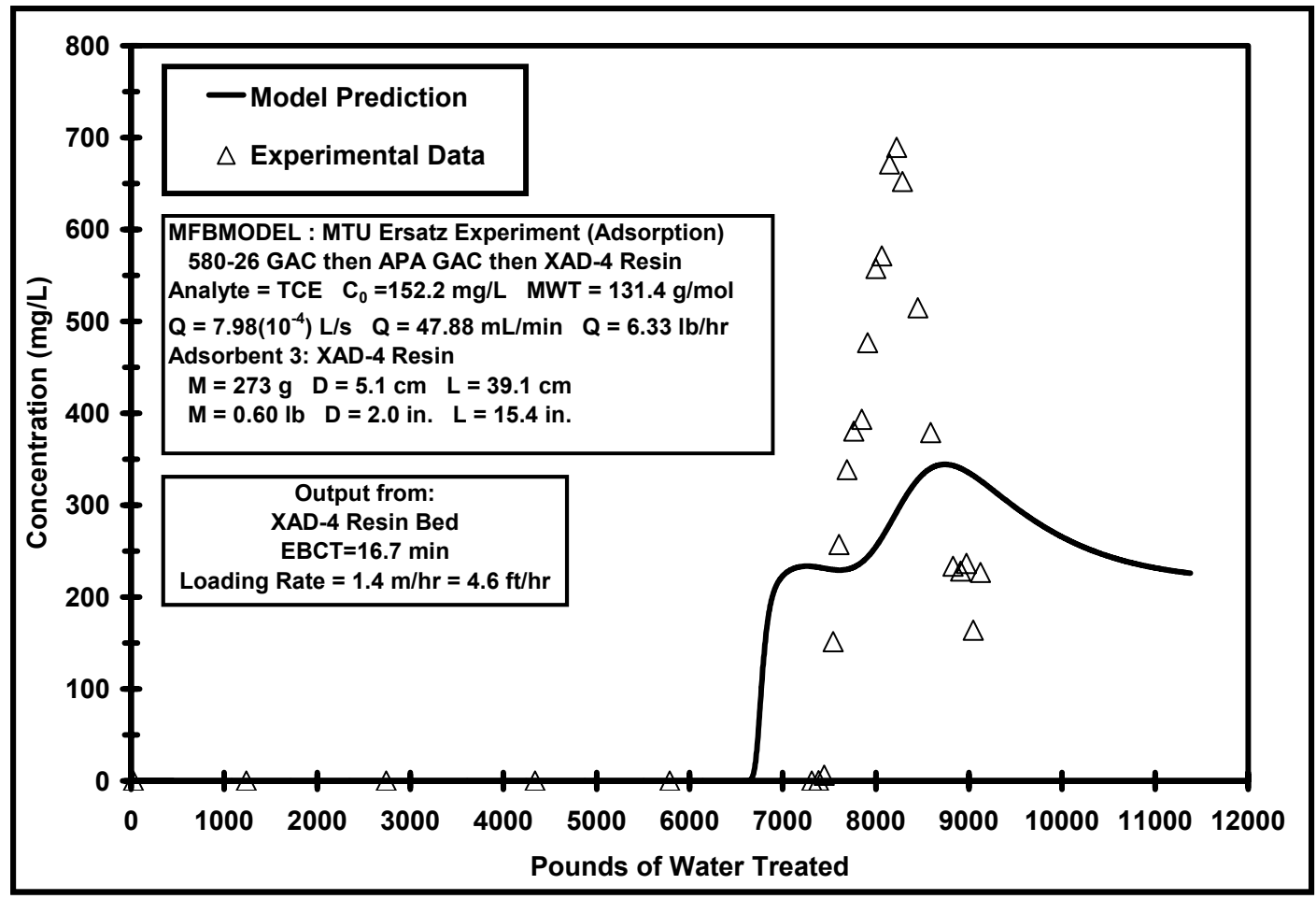




\section{Tracer Compound: Toluene}

\section{MFBMODEL Setup}

The toluene for the MFBMODEL verification experiment was simulated in a single MFBMODEL run, consisting of three adsorbents in series: Barneby Sutcliffe 580-26 GAC, Calgon APA GAC, and Rohm and Haas XAD-4 Resin. Figure IX - 1 shows the Open Existing, Create New or Exit window within MFBMODEL. The TOC simulation can be opened within MFBMODEL as described in Appendix VII for a different simulation. Upon opening the simulation entitled "MTU_Ersatz_Tracer_Toluene_58026thenAPAthenXAD4", the main MFBMODEL window for this simulation will open, as shown in Figure $\mathrm{X}-4$.

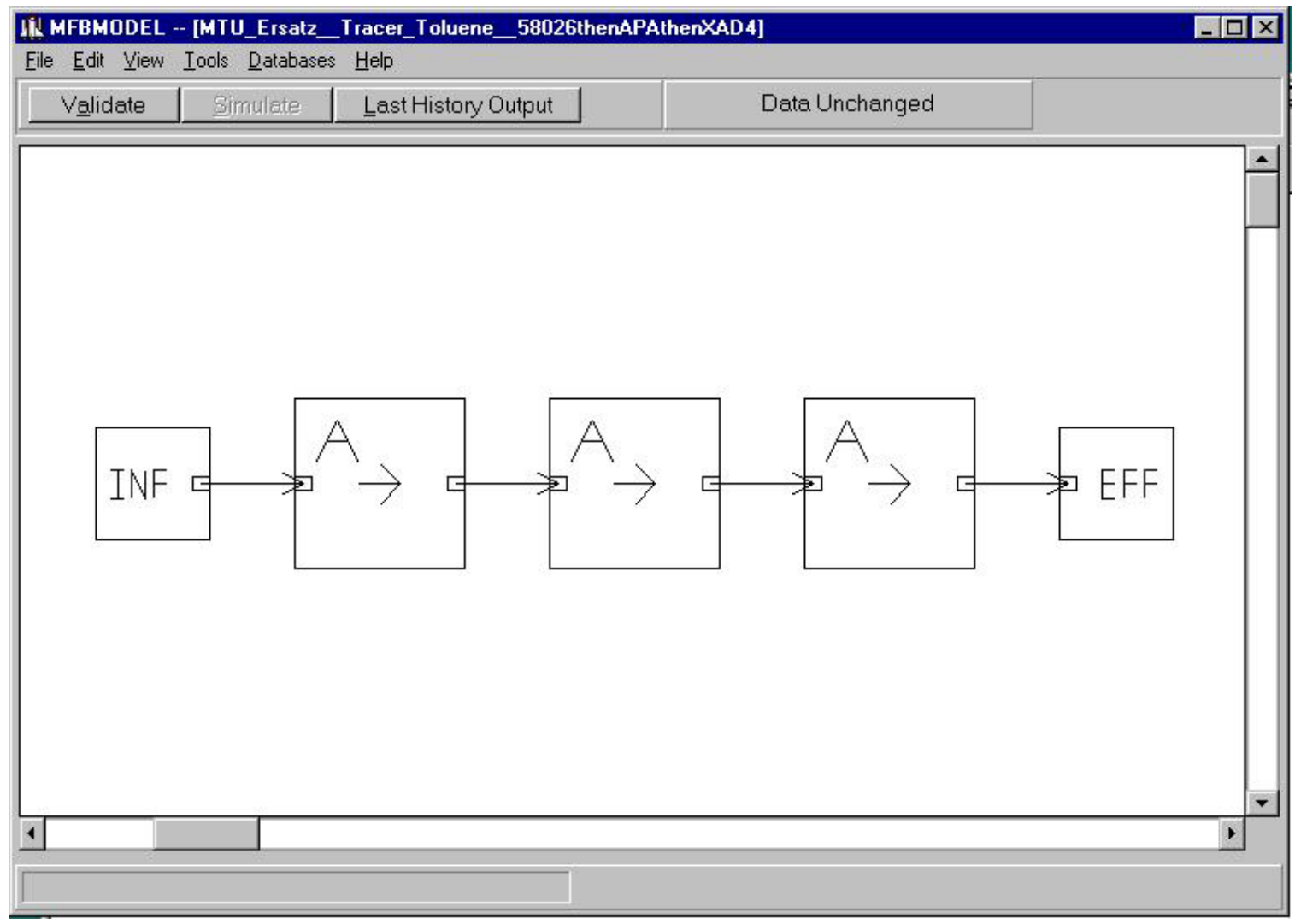

Figure X - 4 - Main MFBMODEL Window for Michigan Tech Ersatz Column Experiment Simulation File:

"MTU_Ersatz_Tracer_Toluene_58026thenAPAthenXAD4" 
Appendix VII explains how to obtain results from an MFBMODEL simulation. An MFBMODEL manual has been written, which shows all the details for setting up an ion exchange simulation within MFBMODEL, but it is not presented in this proposal. Model results compared to experimental data for toluene through each adsorbent are presented below.

\section{Granular Activated Carbon (GAC) Adsorbent: Barneby Sutcliffe 580- 26}

Table X - 1 above shows the properties of the 580-26 GAC column in the multifiltration bed verification experiment. MFBMODEL results compared to experimental data for toluene through 580-26 GAC are presented below.

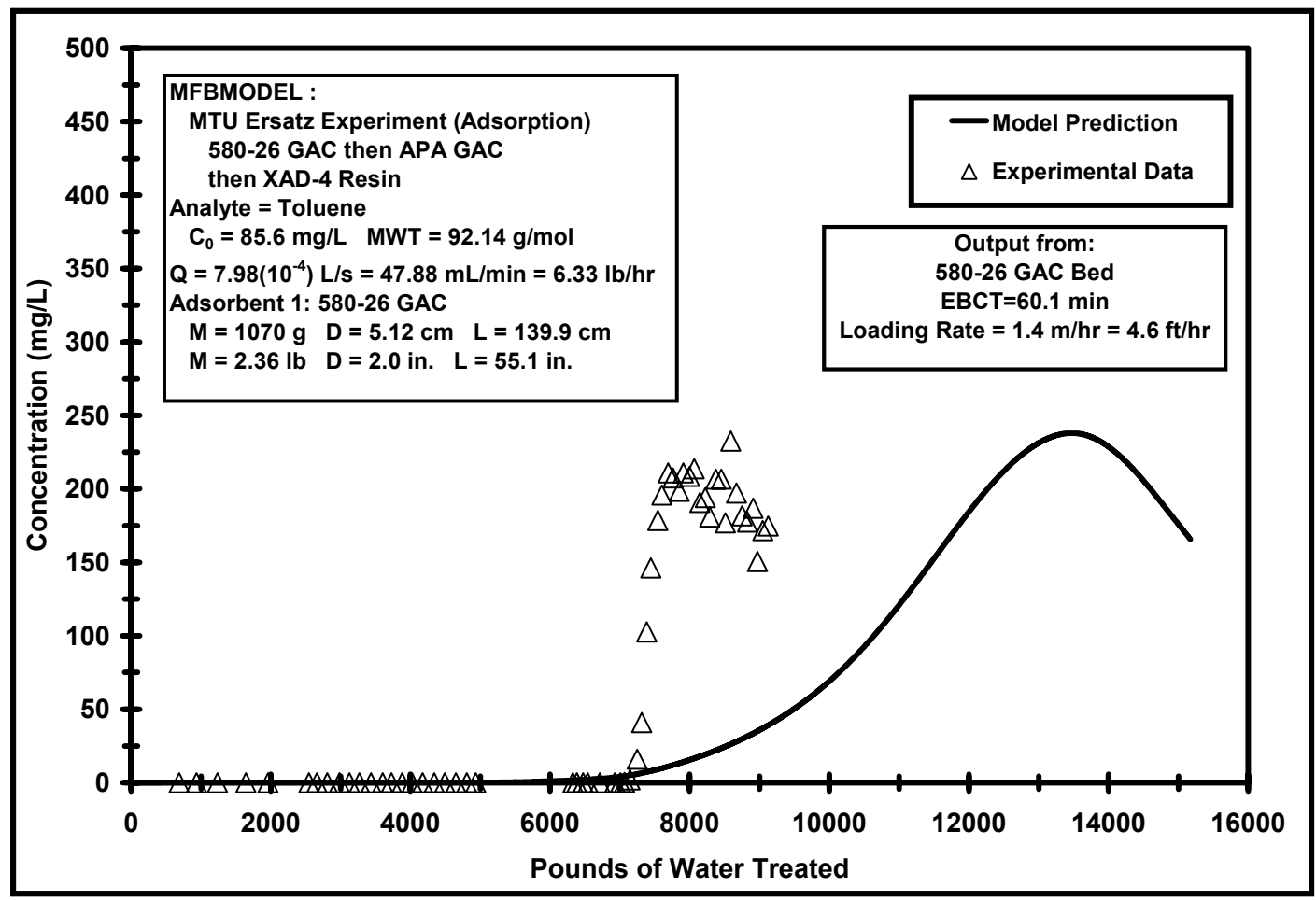

\section{Granular Activated Carbon (GAC) Adsorbent: Calgon APA}

Table X - 2 above shows the properties of the APA GAC column in the multifiltration bed verification experiment. MFBMODEL results compared to experimental data for toluene through APA GAC are presented below. 


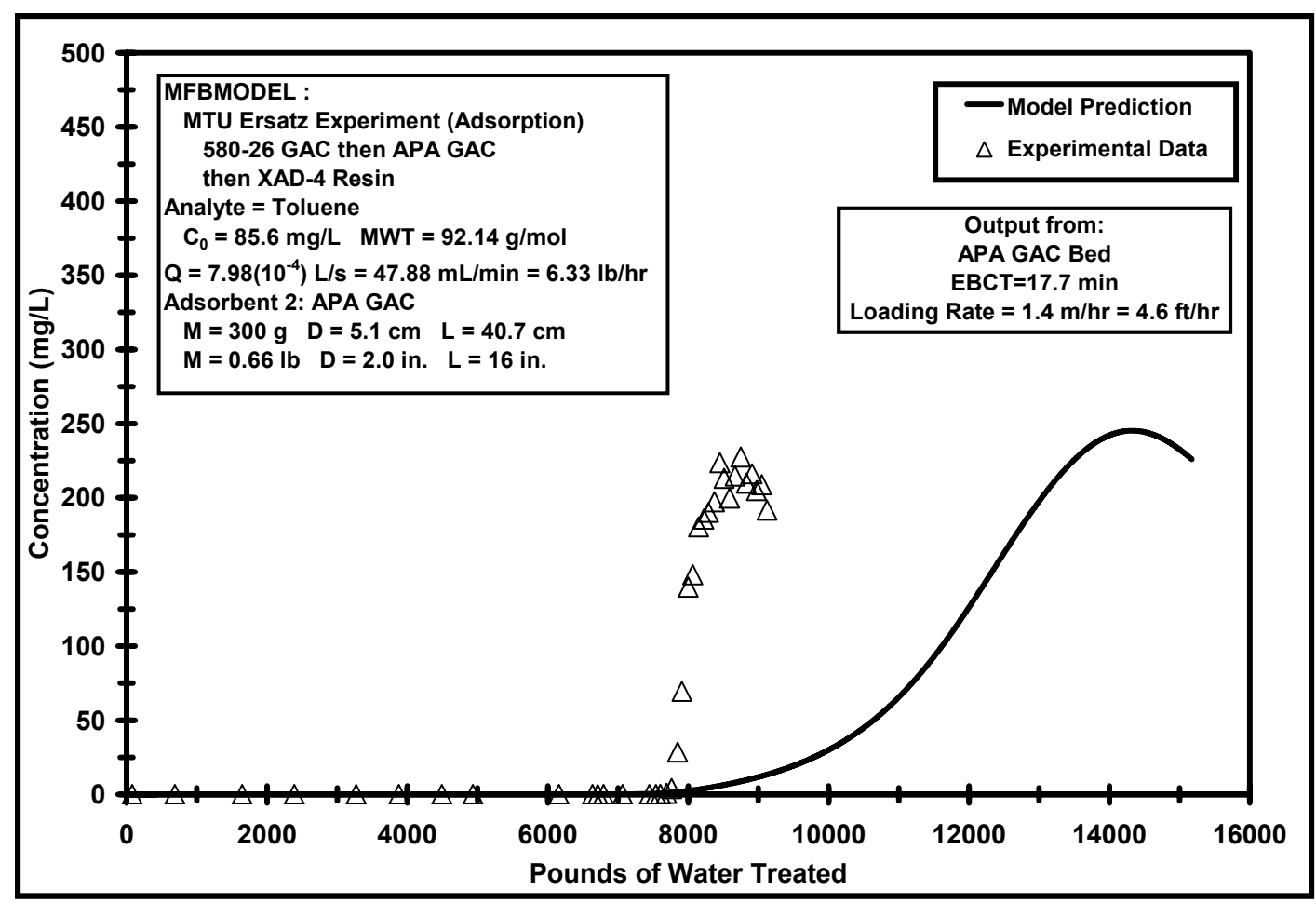

\section{Adsorbent: Rohm \& Haas XAD-4 Resin}

Table X - 3 above shows the properties of the XAD-4 resin column in the multifiltration bed verification experiment. MFBMODEL results compared to experimental data for toluene through XAD-4 resin are presented below.

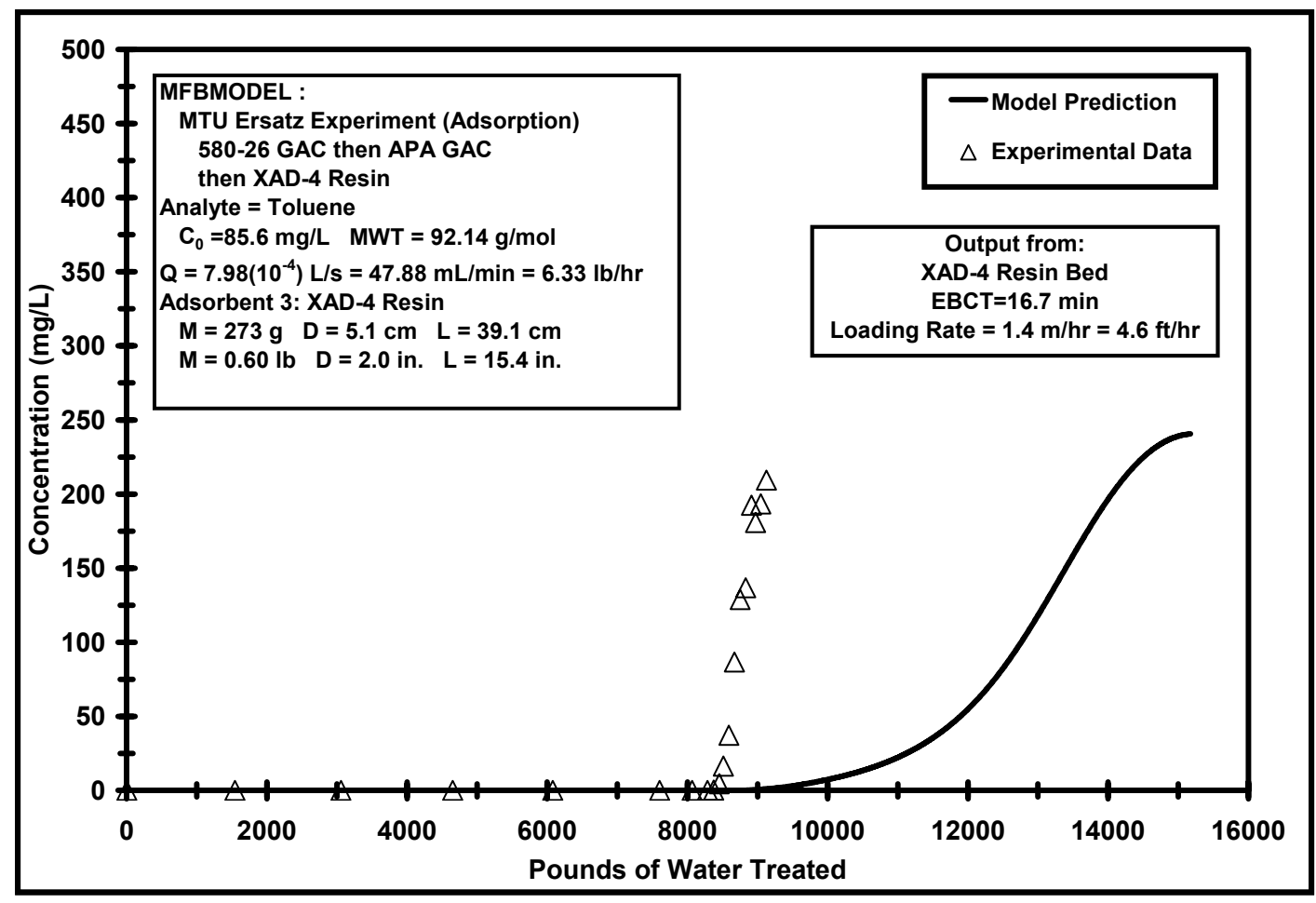




\section{Appendix X.A - Adsorption Results Presented in Additional Units Units of $\mathrm{mg} / \mathrm{L}$ versus Time in Days Total Organic Carbon (TOC)}

GAC Adsorbent: Barneby Sutcliffe 580-26

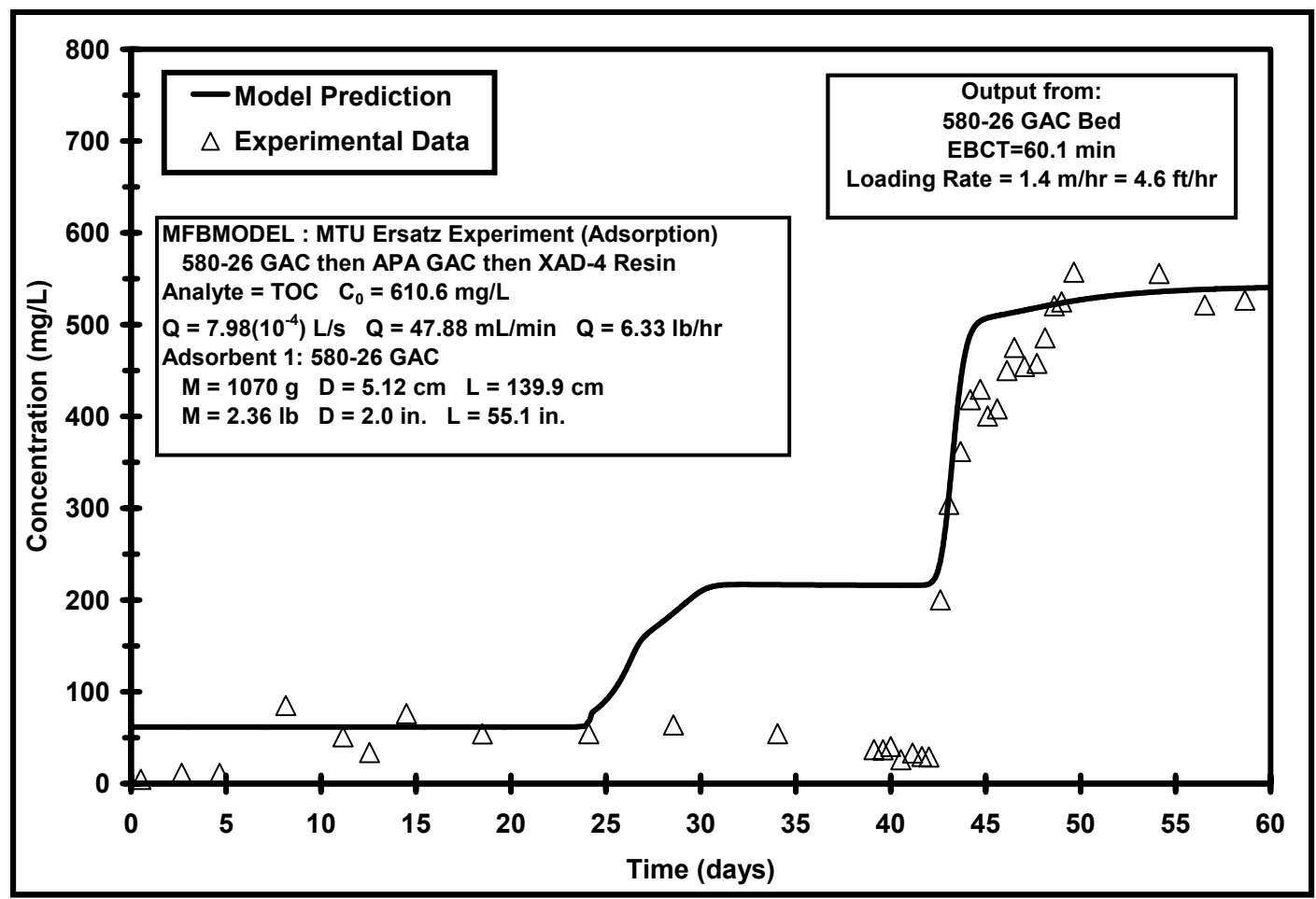




\section{GAC Adsorbent: Calgon APA}

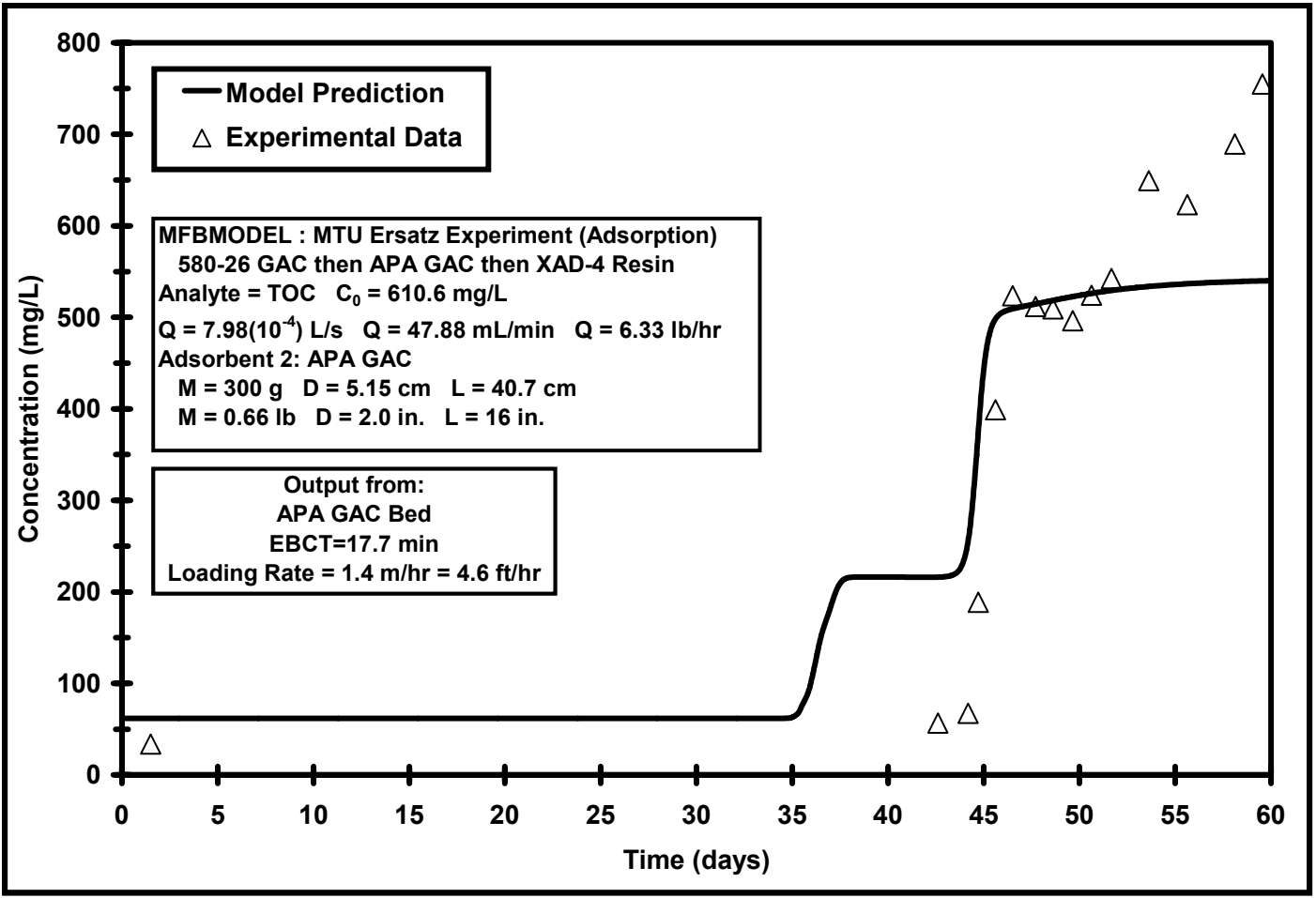

\section{Adsorbent: Rohm \& Haas XAD-4 Resin}

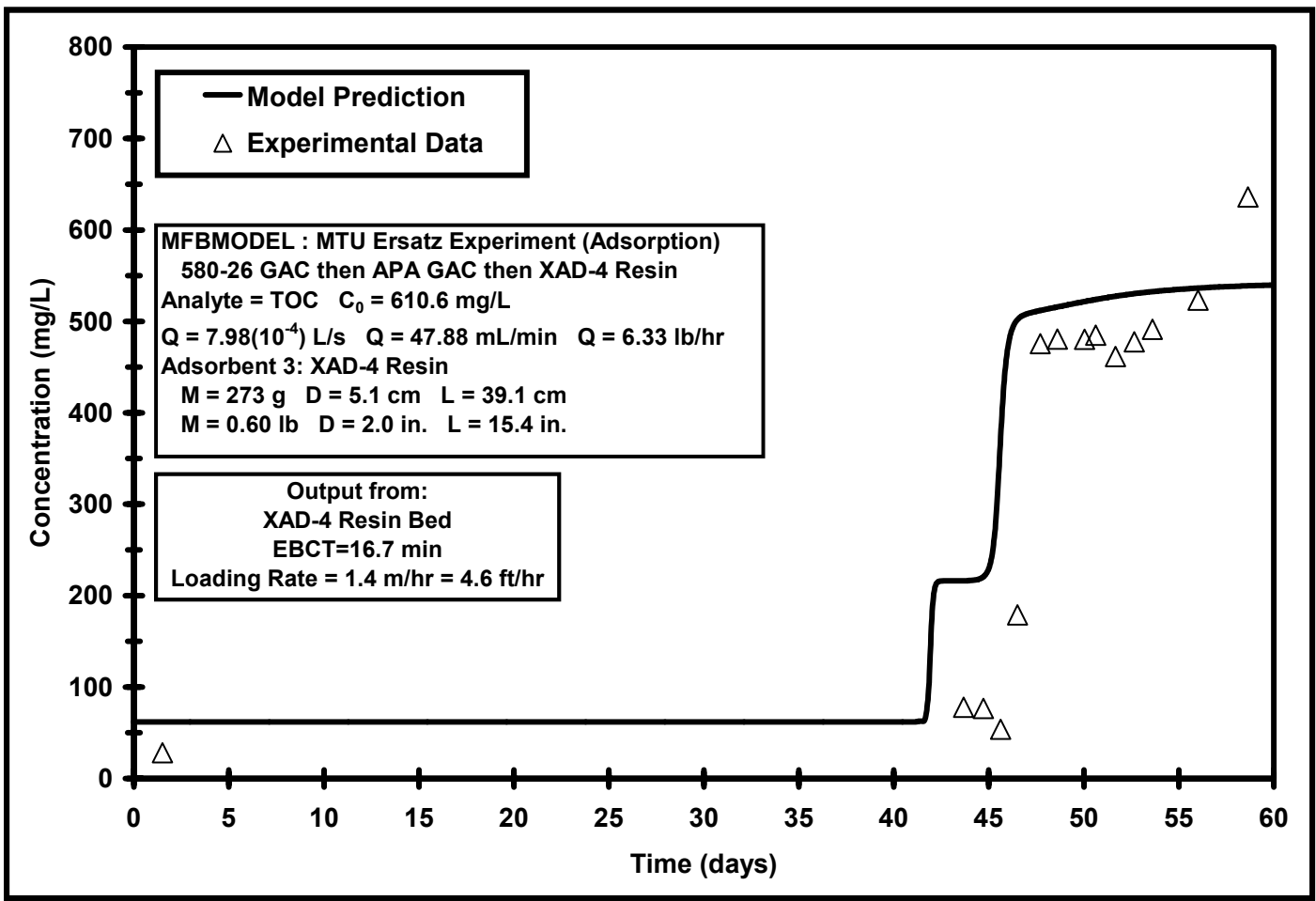




\section{Tracer Compound: SCMT}

GAC Adsorbent: Barneby Sutcliffe 580-26

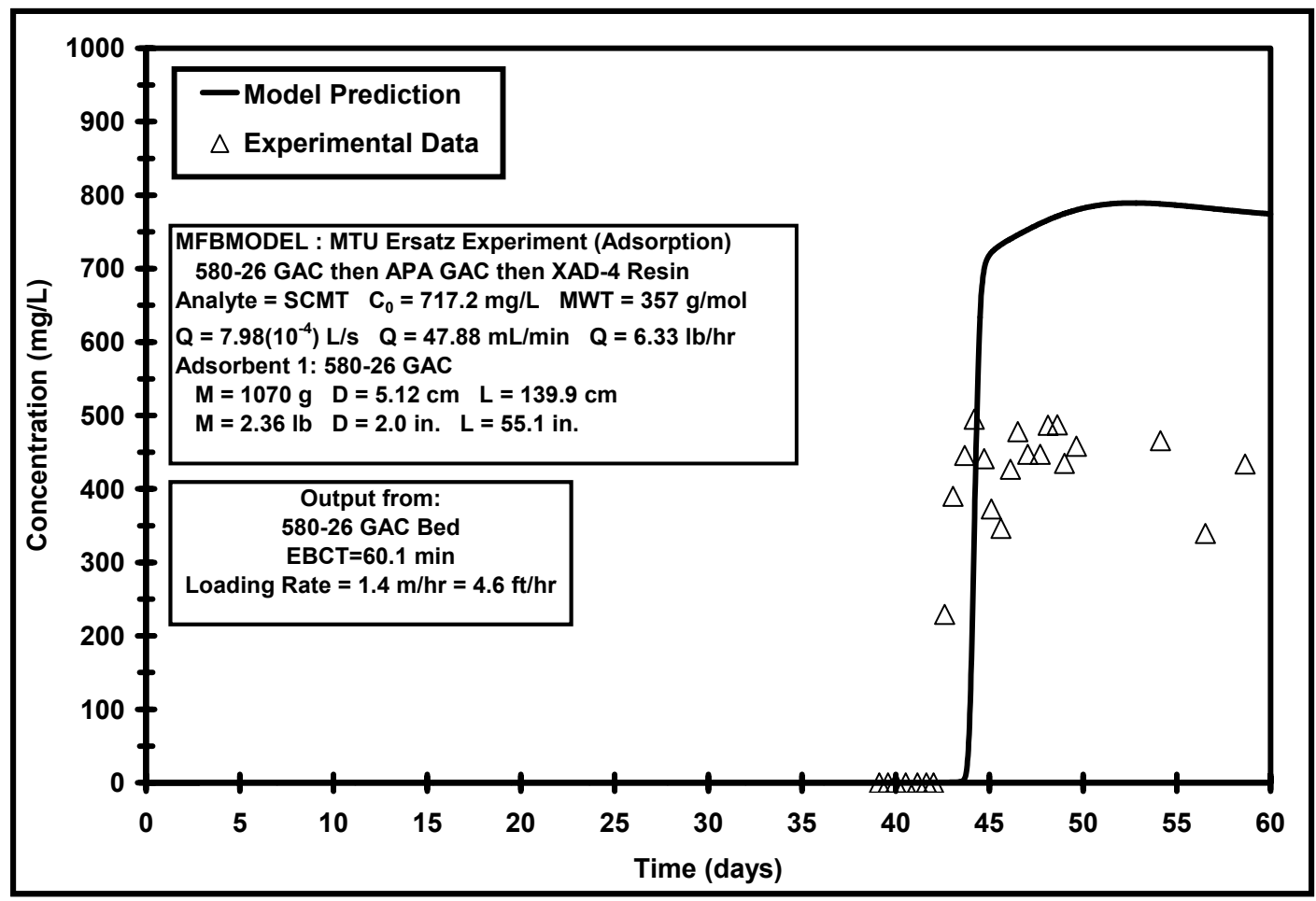

GAC Adsorbent: Calgon APA

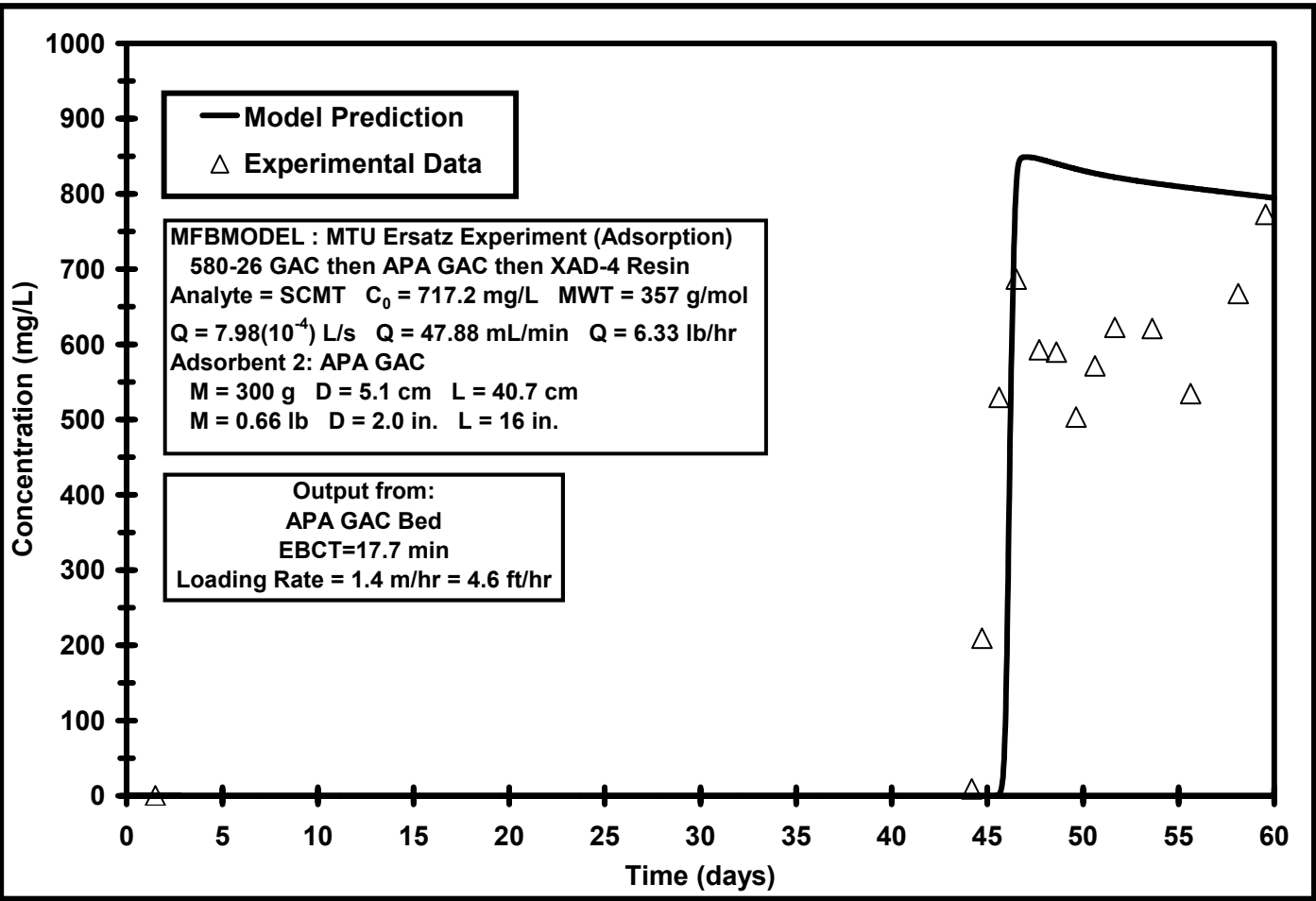




\section{Adsorbent: Rohm \& Haas XAD-4 Resin}

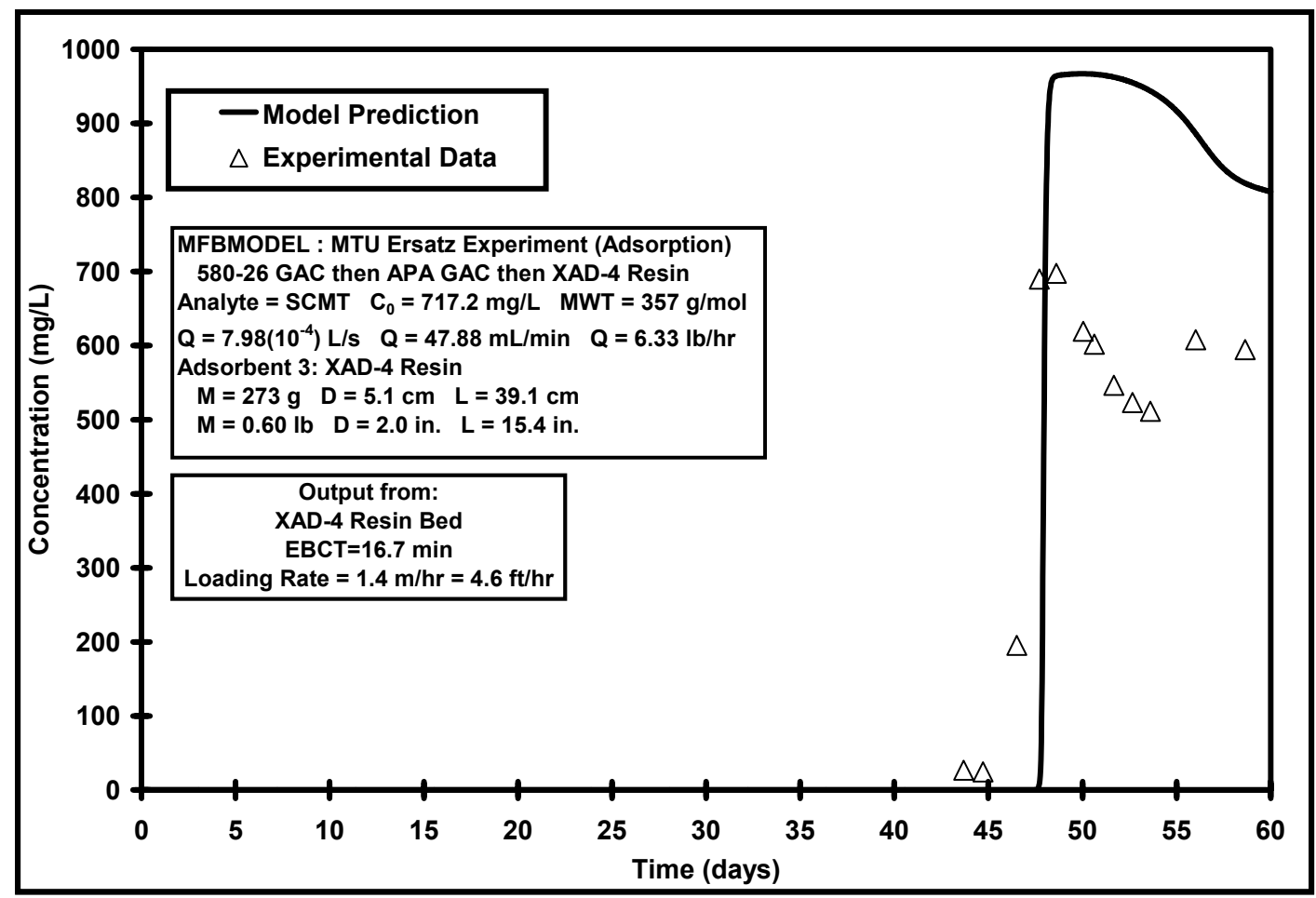

Tracer Compound: Trichloroethylene (TCE)

GAC Adsorbent: Barneby Sutcliffe 580-26

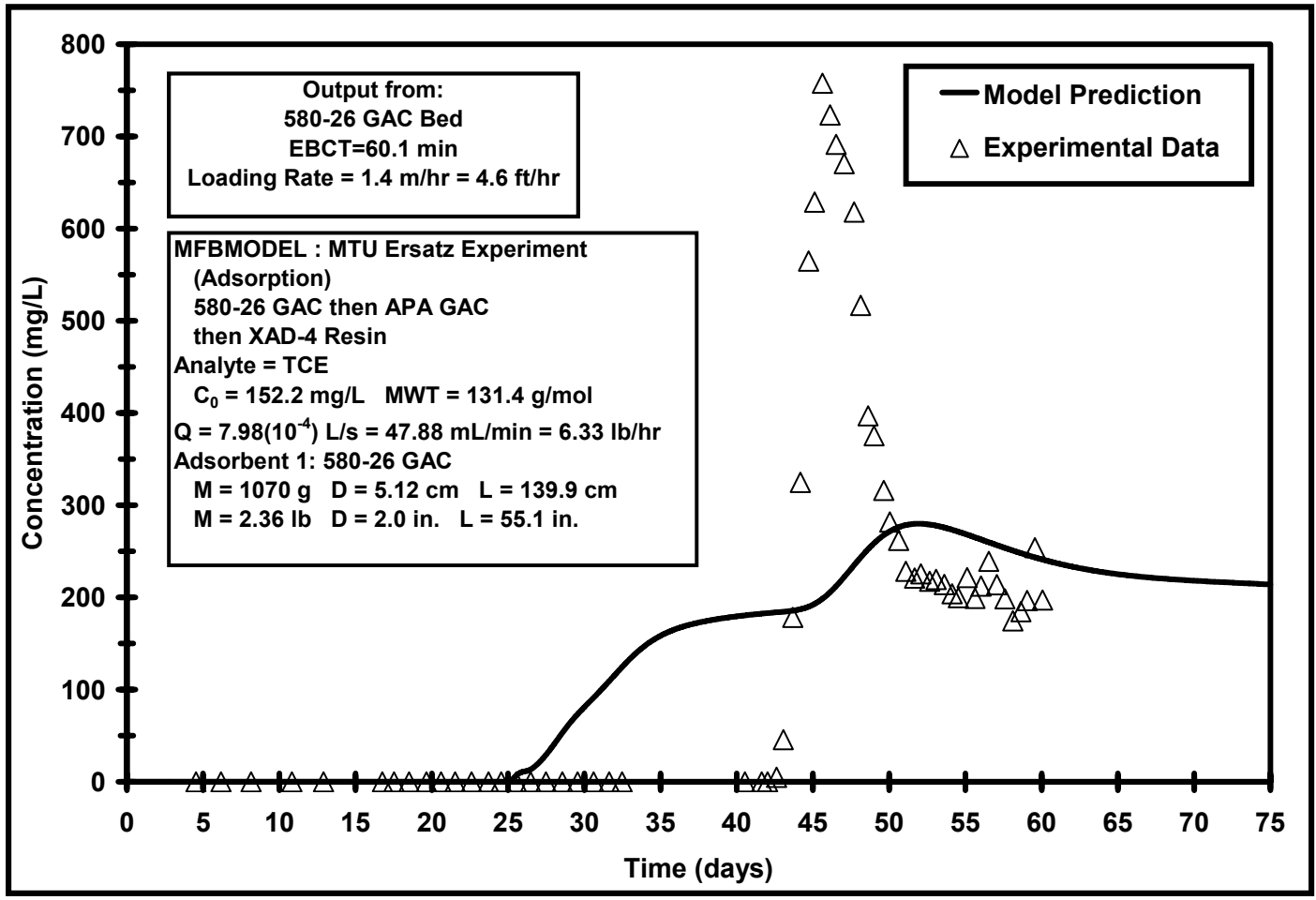




\section{GAC Adsorbent: Calgon APA}

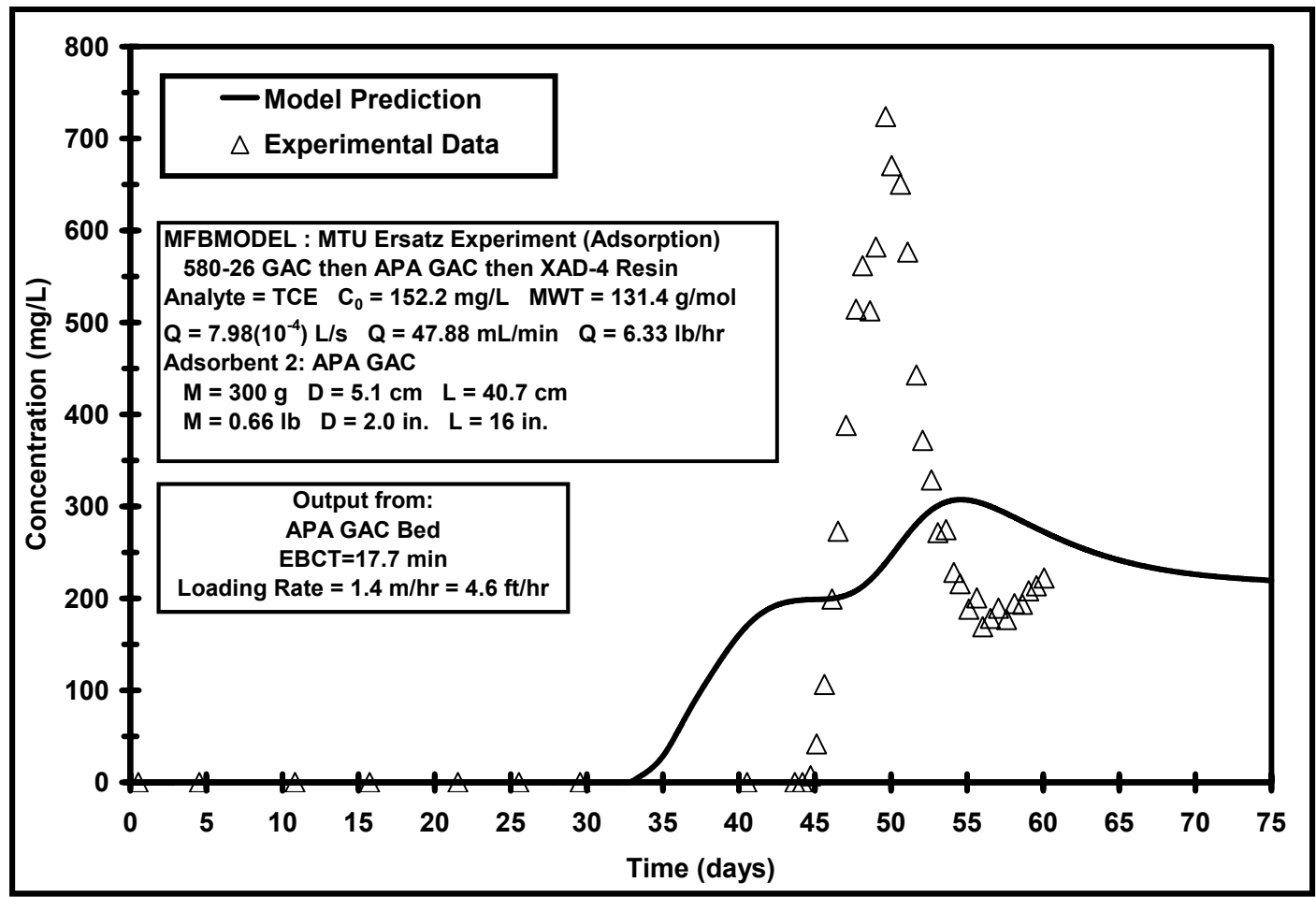

\section{Adsorbent: Rohm \& Haas XAD-4 Resin}

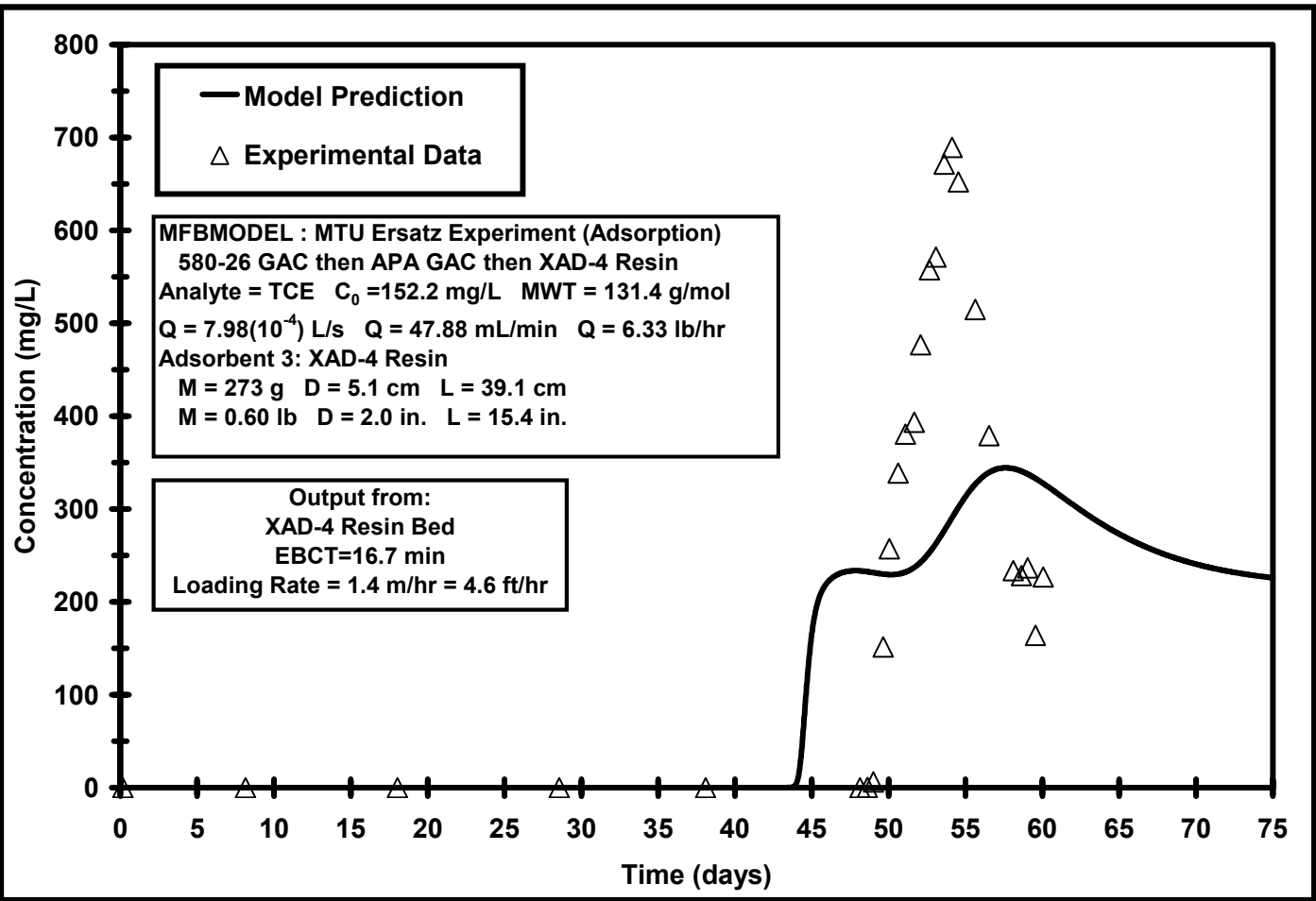




\section{Tracer Compound: Toluene}

GAC Adsorbent: Barneby Sutcliffe 580-26

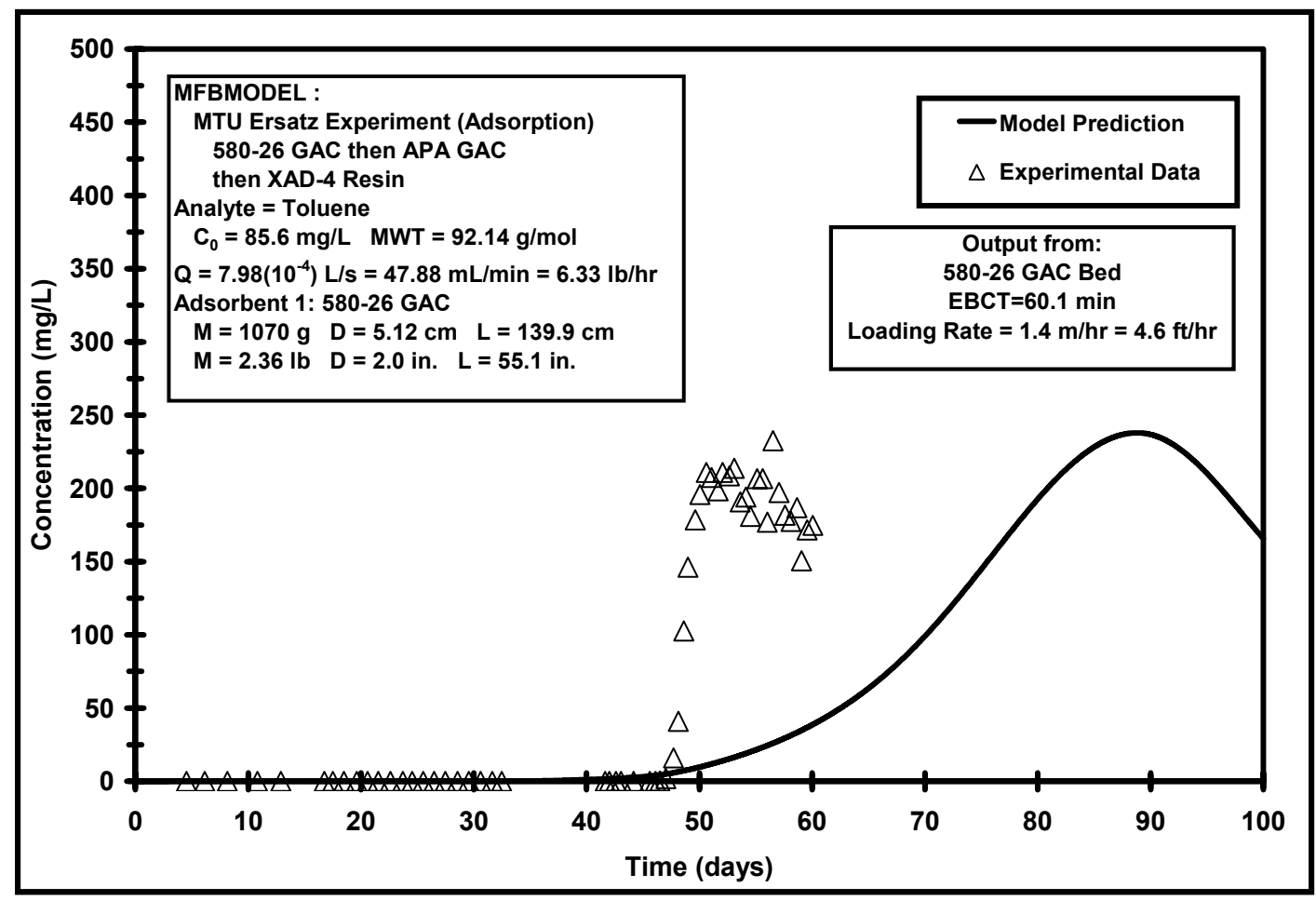

GAC Adsorbent: Calgon APA

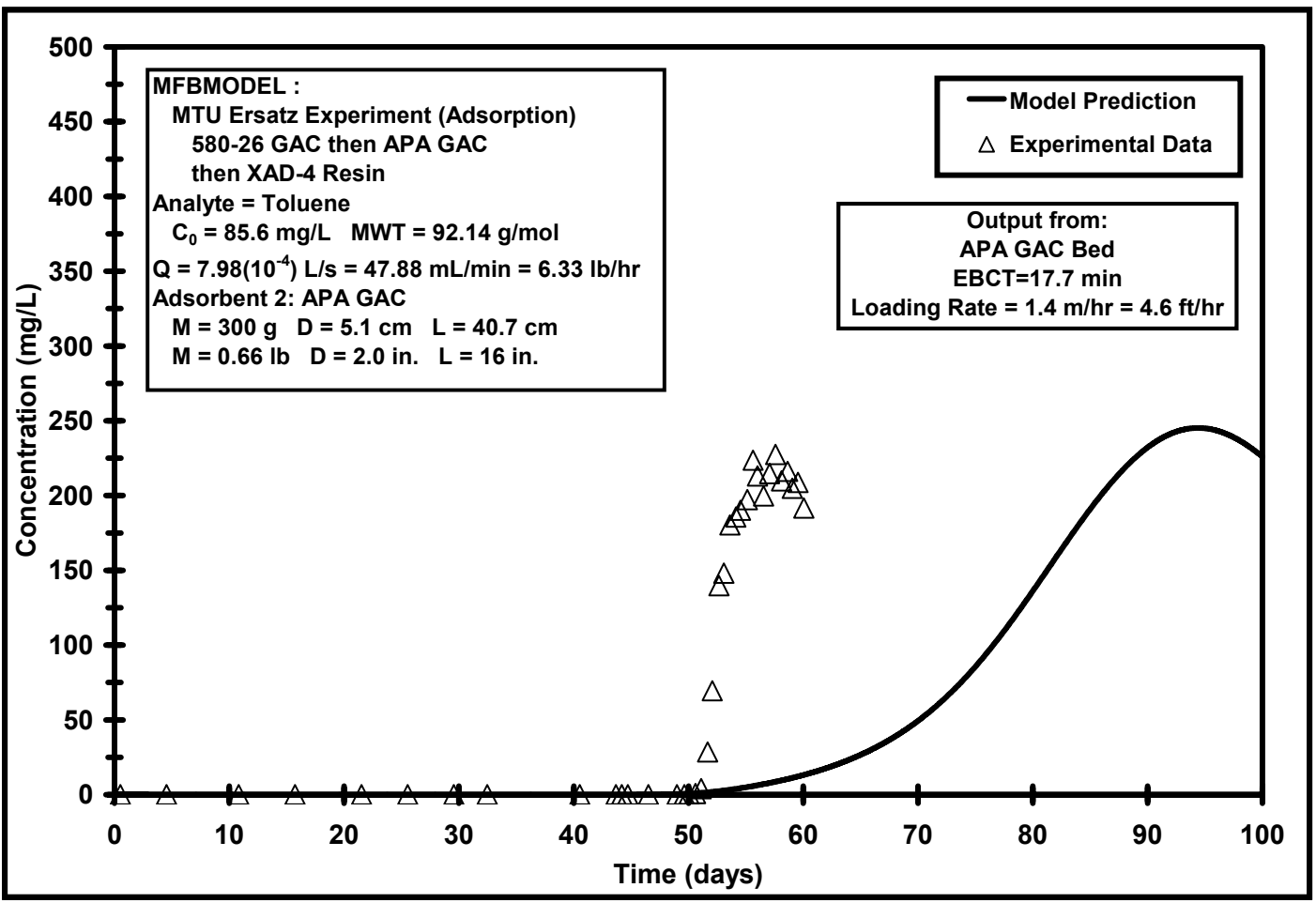




\section{Adsorbent: Rohm \& Haas XAD-4 Resin}

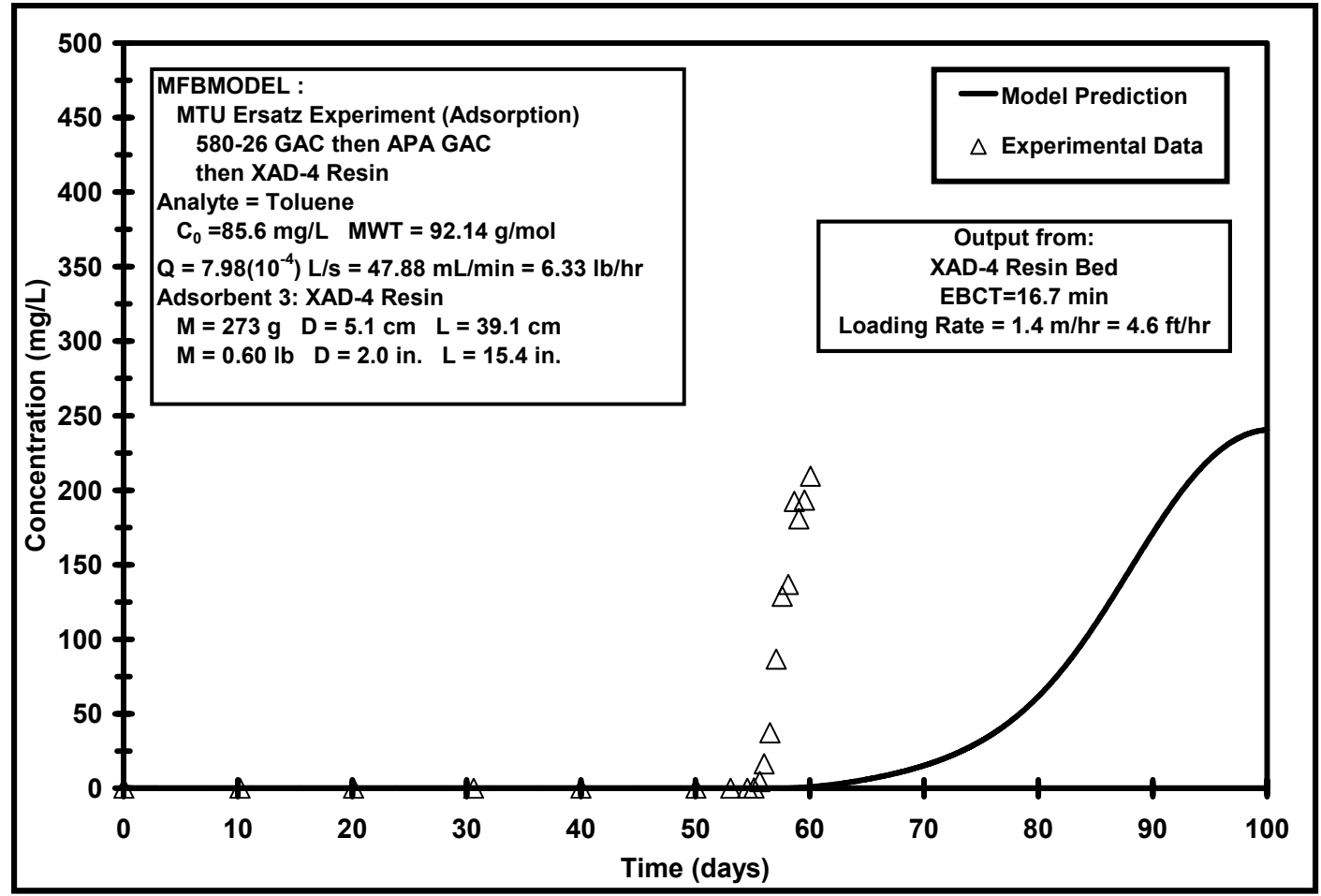

Units of $\mathrm{mg} / \mathrm{L}$ versus Reduced Concentration $\left(\mathrm{C} / \mathrm{C}_{0}\right)$

Total Organic Carbon (TOC)

GAC Adsorbent: Barneby Sutcliffe 580-26

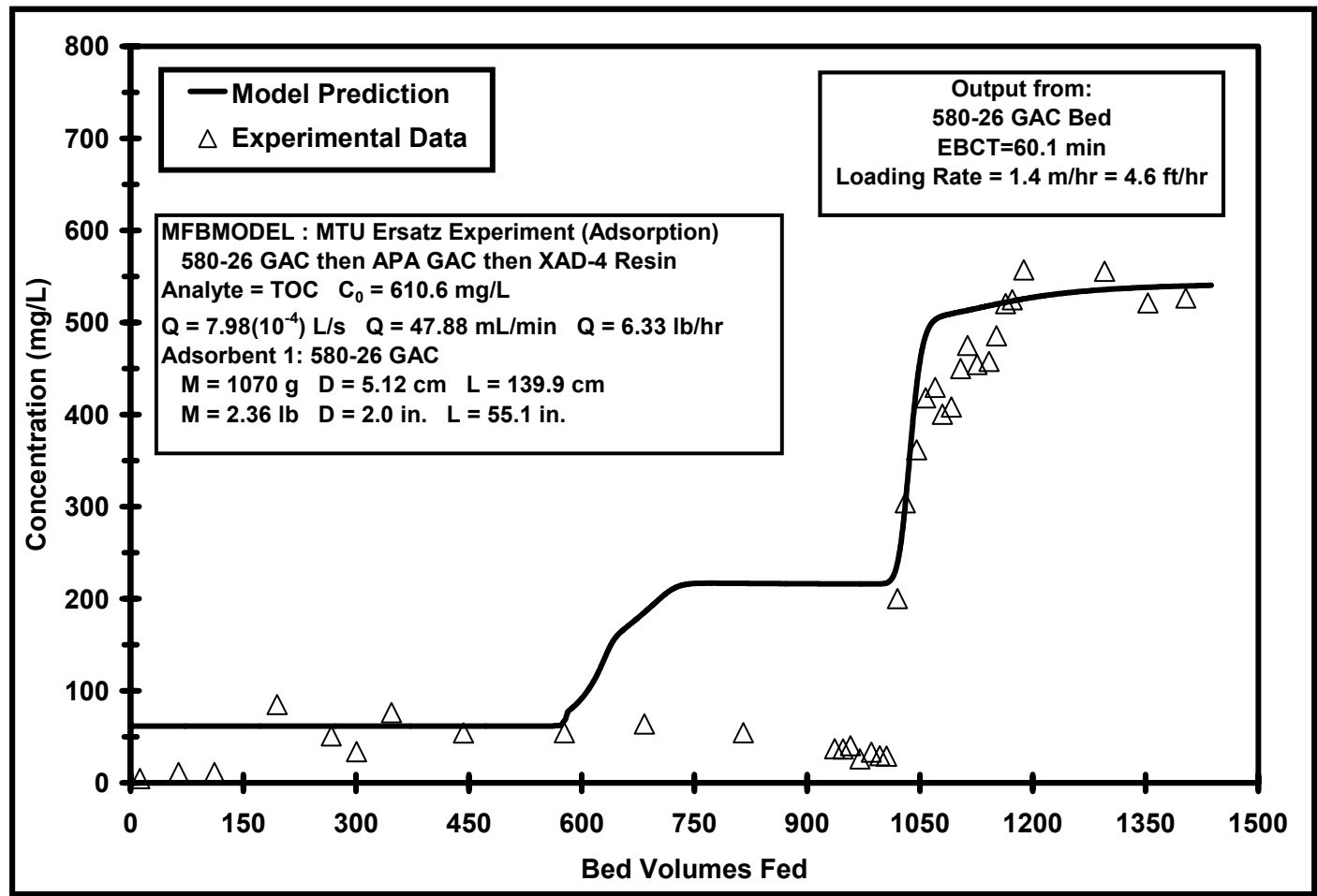




\section{GAC Adsorbent: Calgon APA}

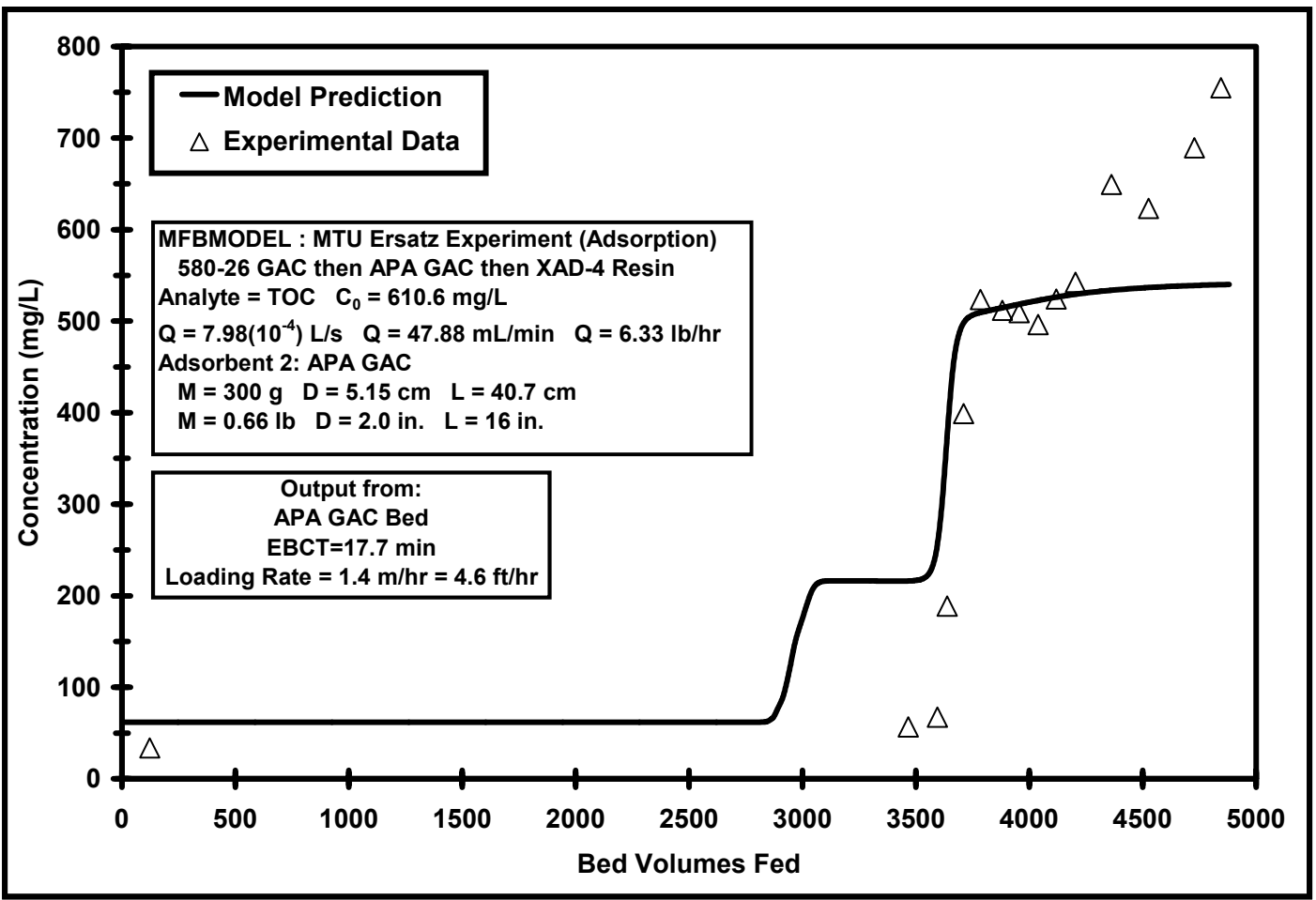

\section{Adsorbent: Rohm \& Haas XAD-4 Resin}

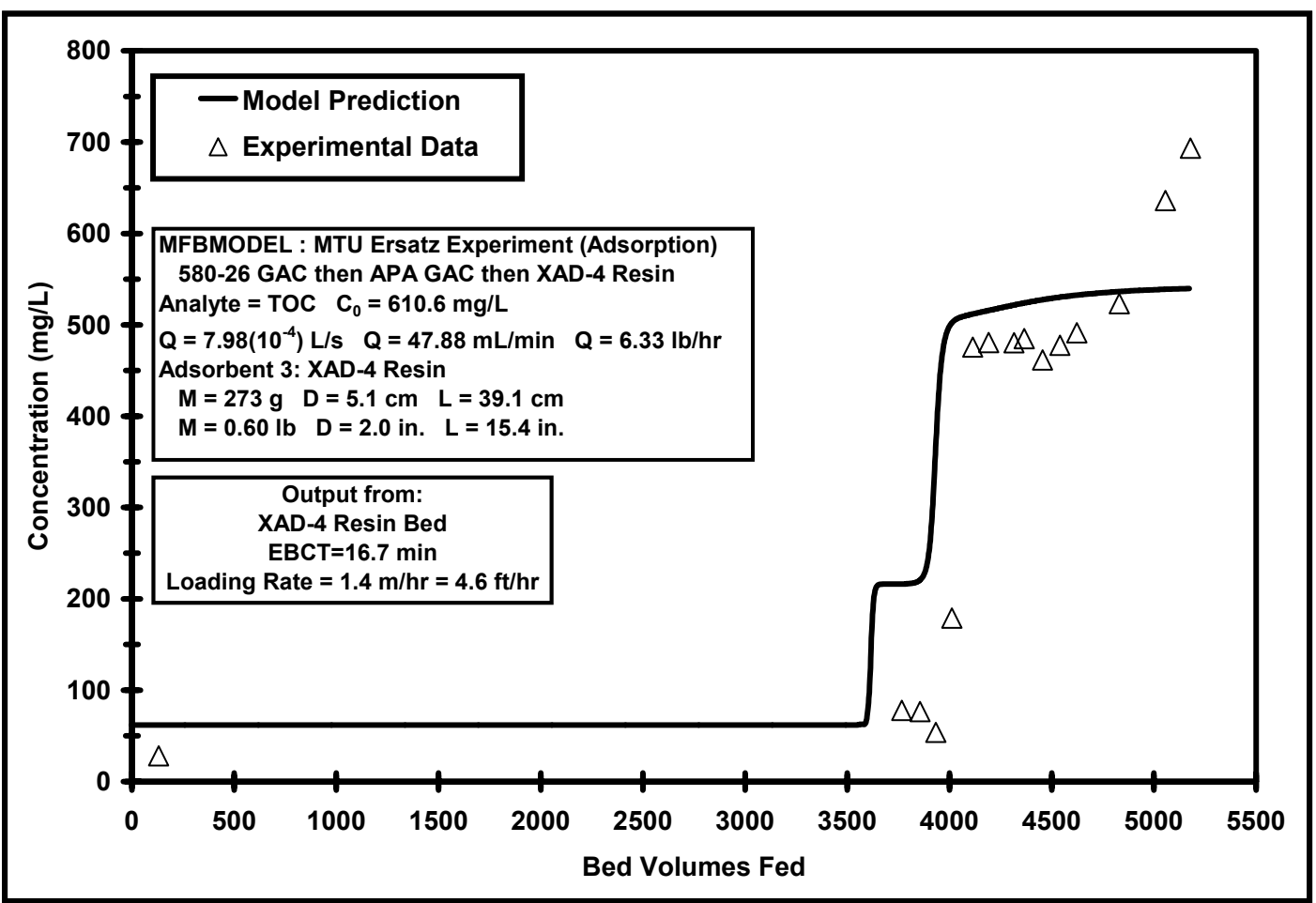


Tracer Compound: SCMT

GAC Adsorbent: Barneby Sutcliffe 580-26

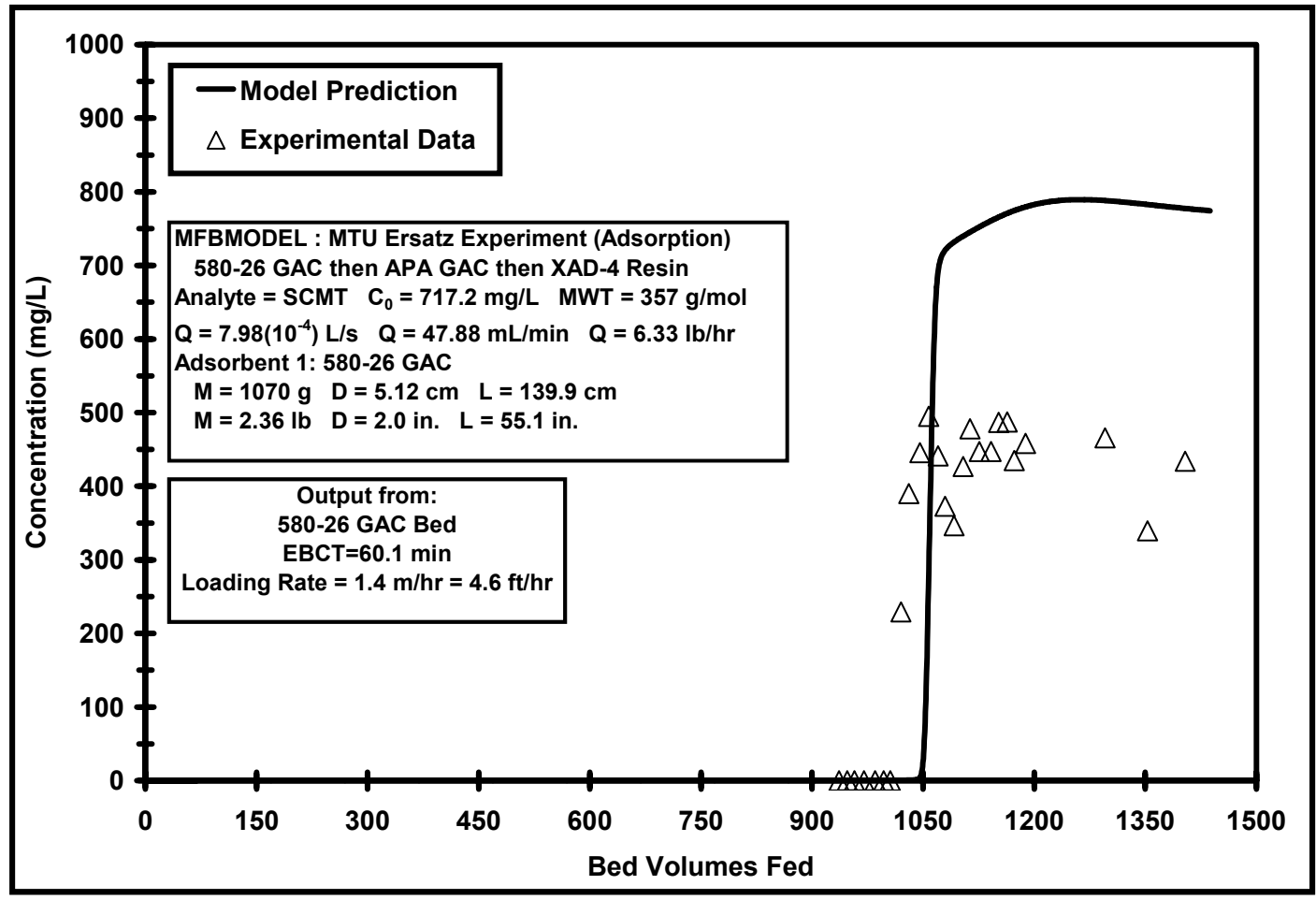

GAC Adsorbent: Calgon APA

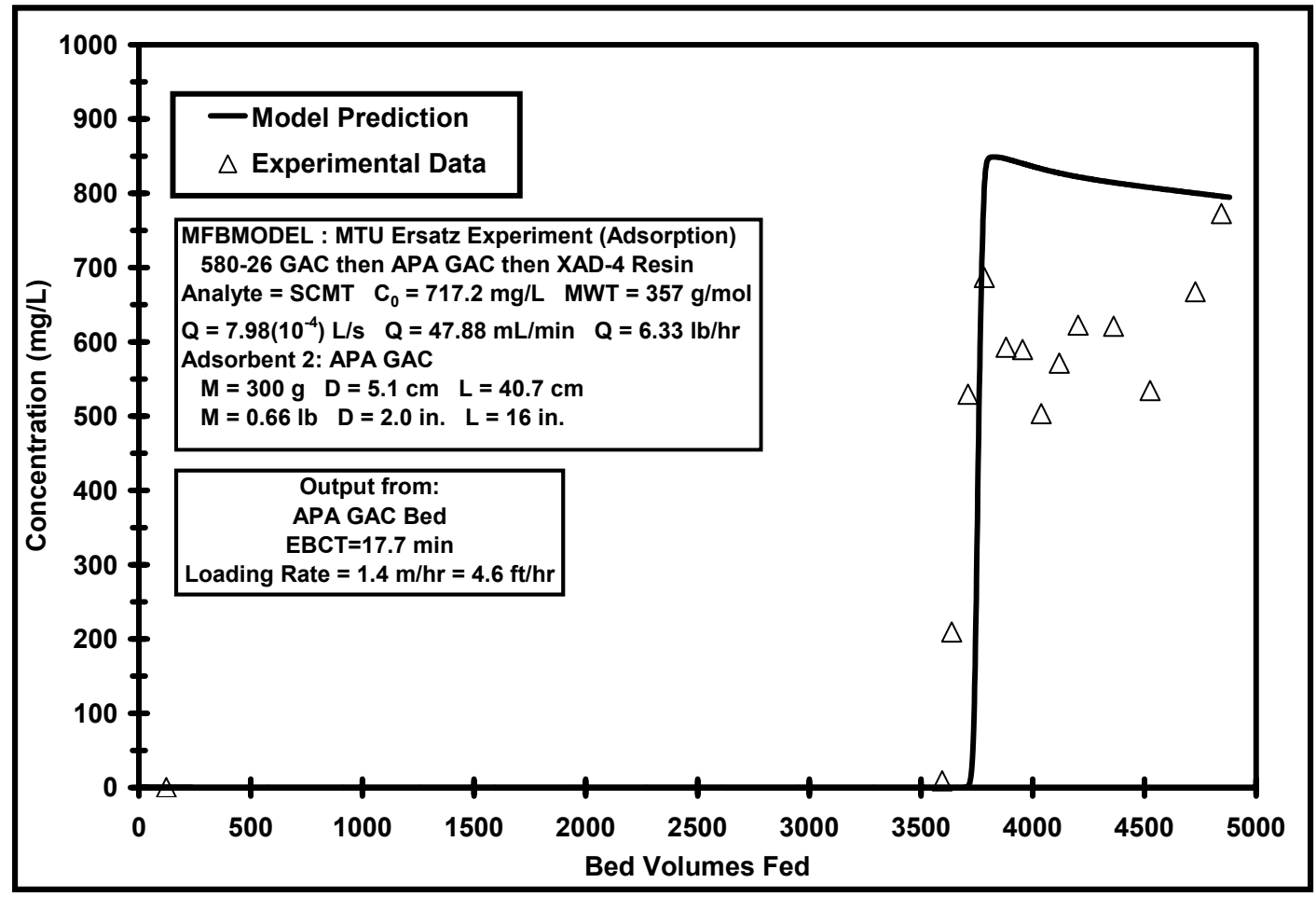




\section{Adsorbent: Rohm \& Haas XAD-4 Resin}

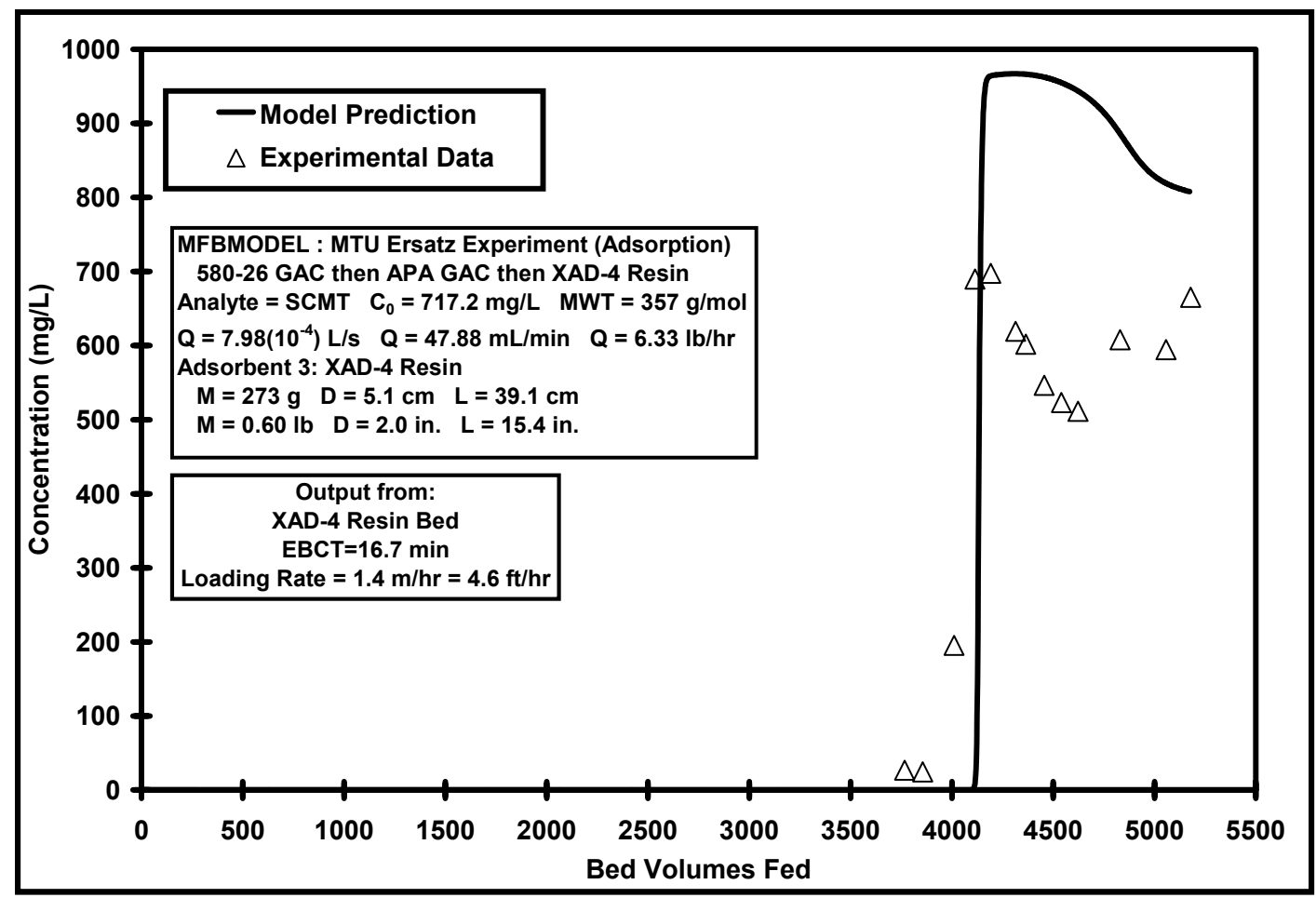

Tracer Compound: Trichloroethylene (TCE)

GAC Adsorbent: Barneby Sutcliffe 580-26

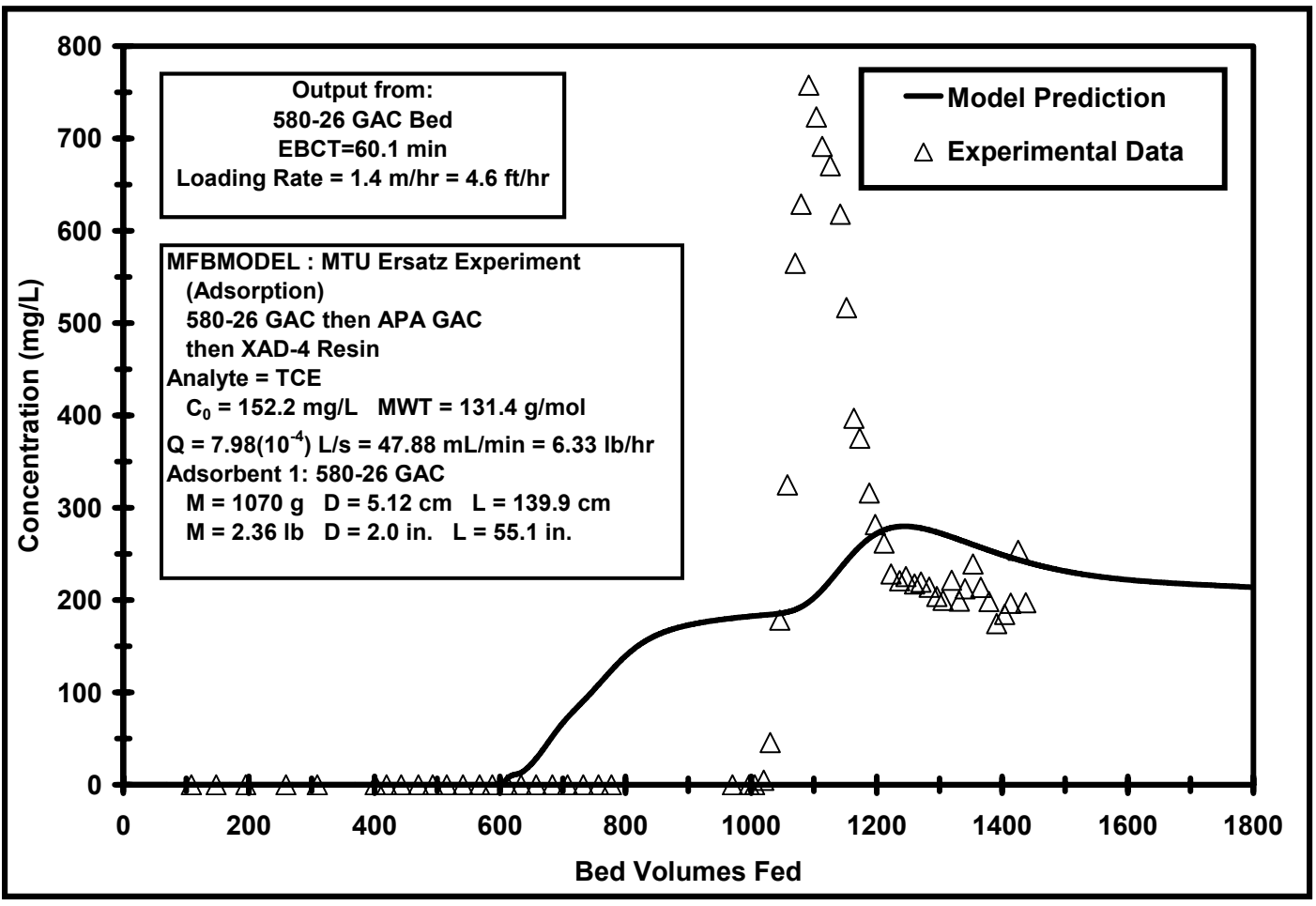




\section{GAC Adsorbent: Calgon APA}

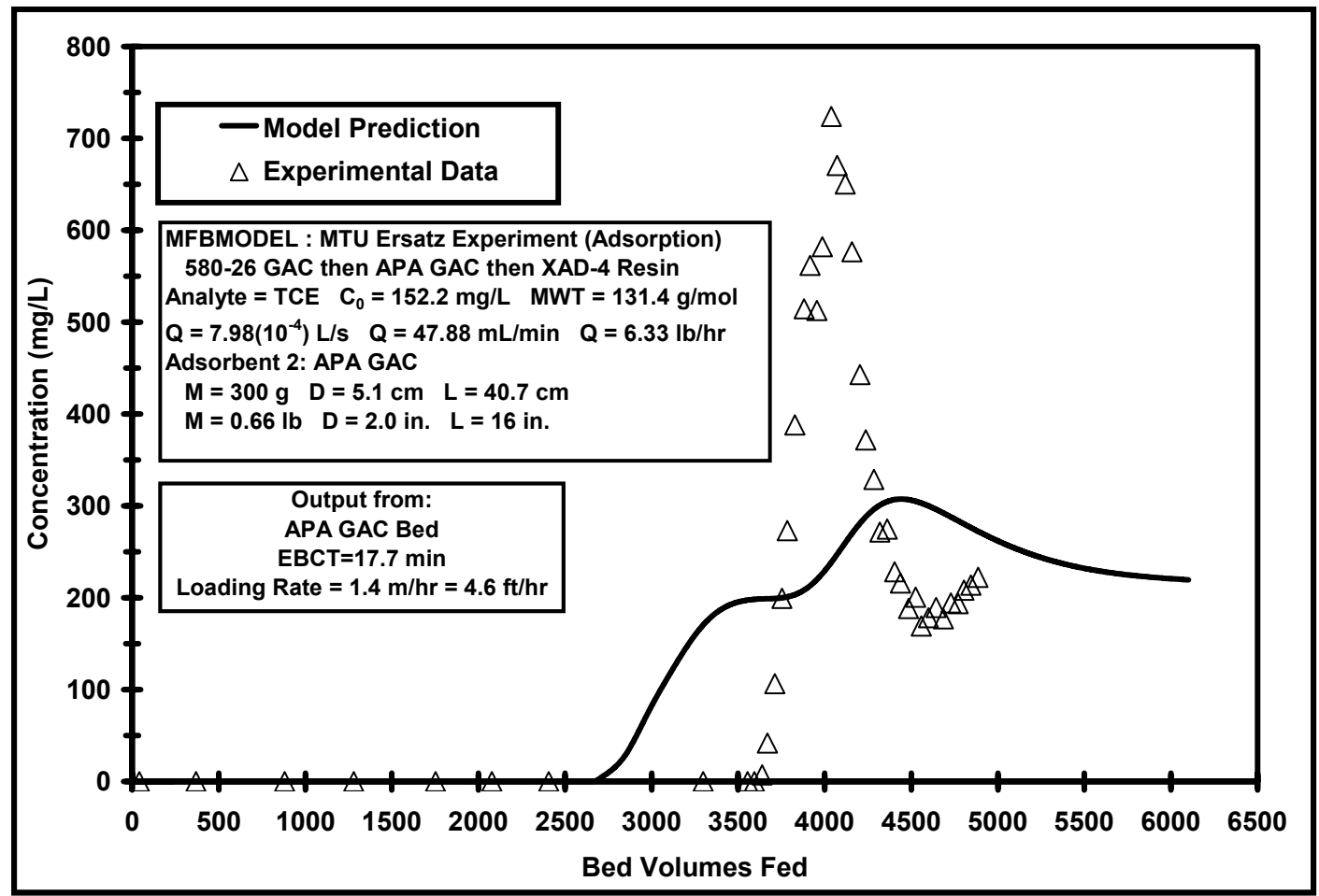

\section{Adsorbent: Rohm \& Haas XAD-4 Resin}

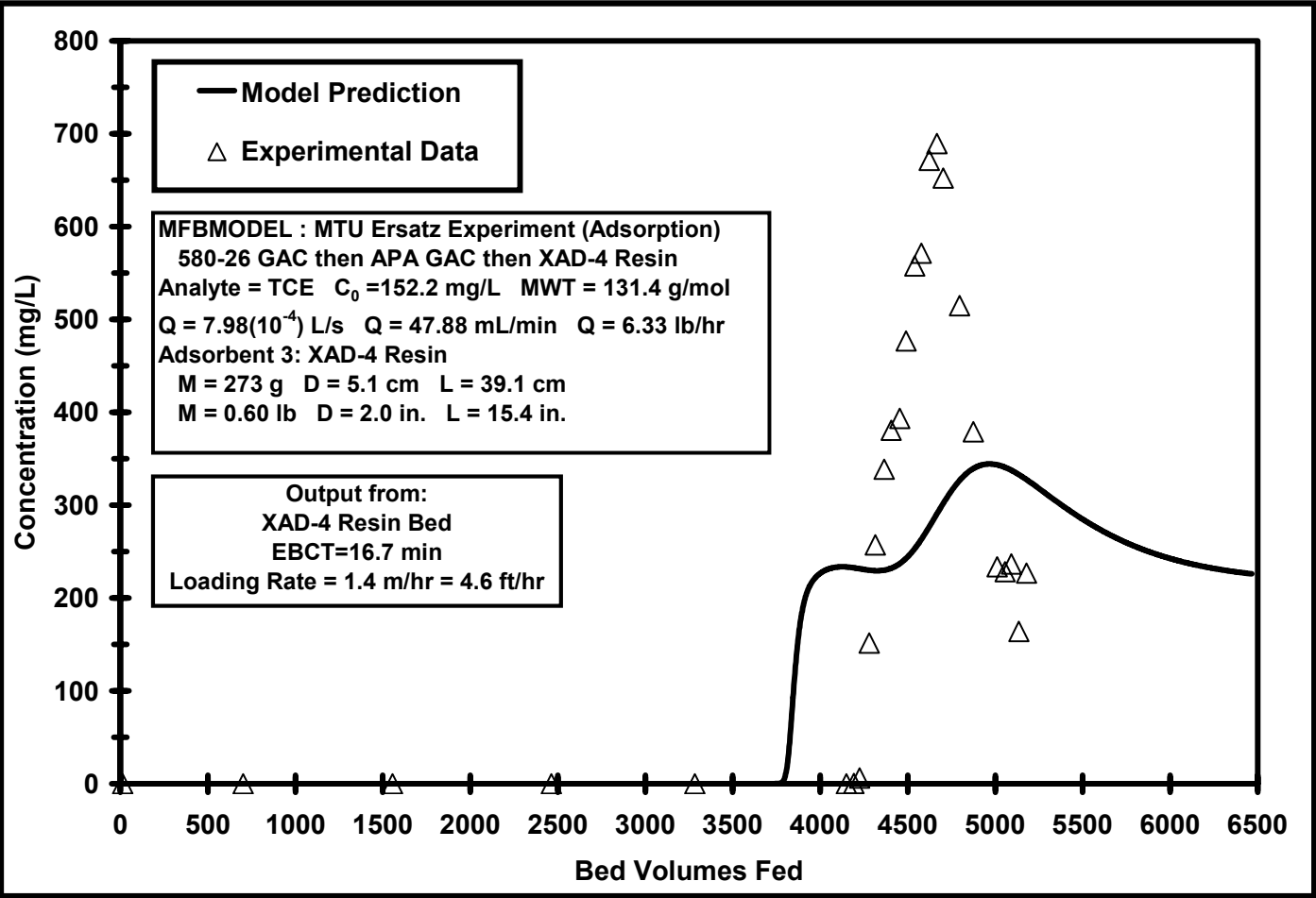




\section{Tracer Compound: Toluene}

GAC Adsorbent: Barneby Sutcliffe 580-26

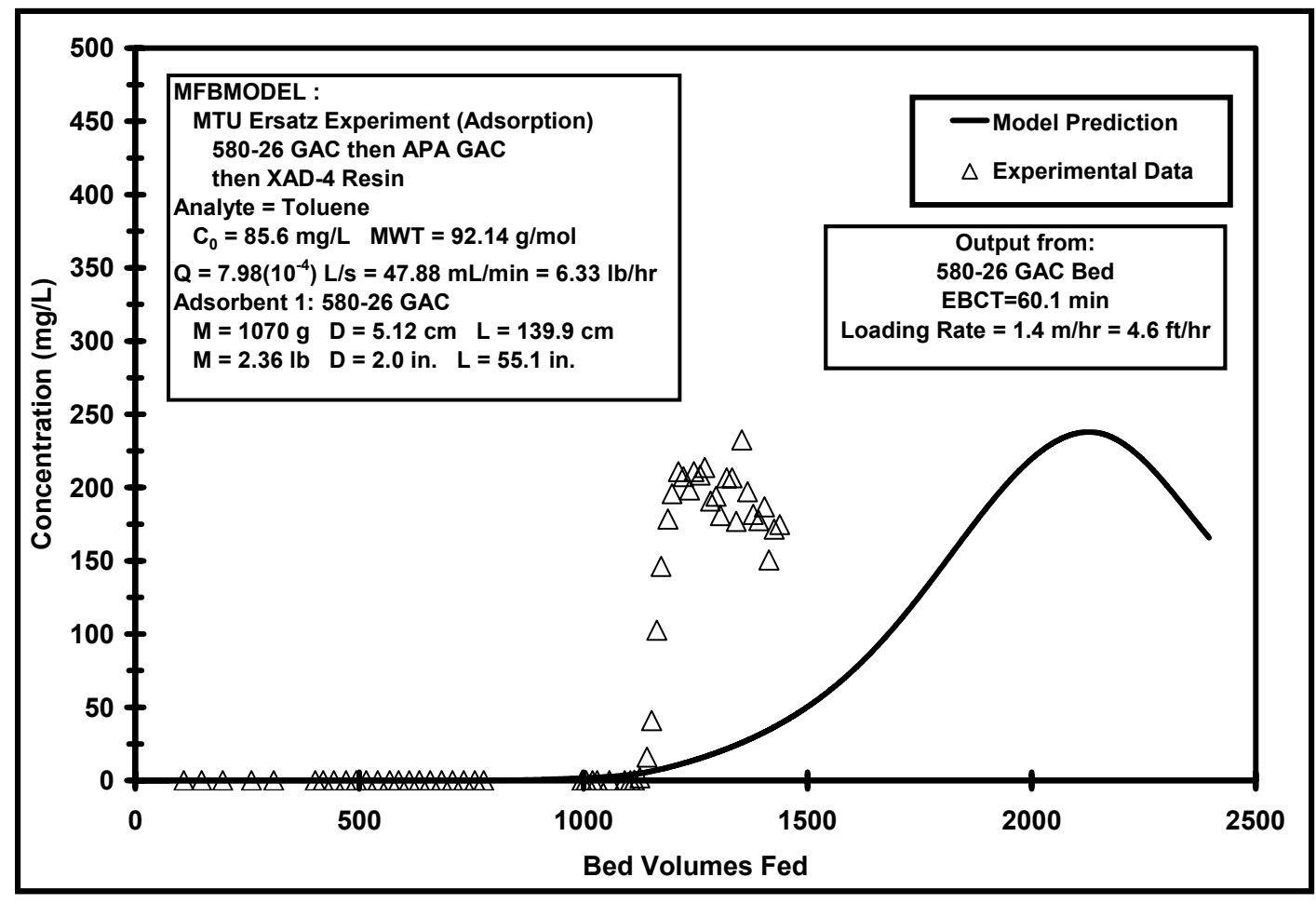

GAC Adsorbent: Calgon APA

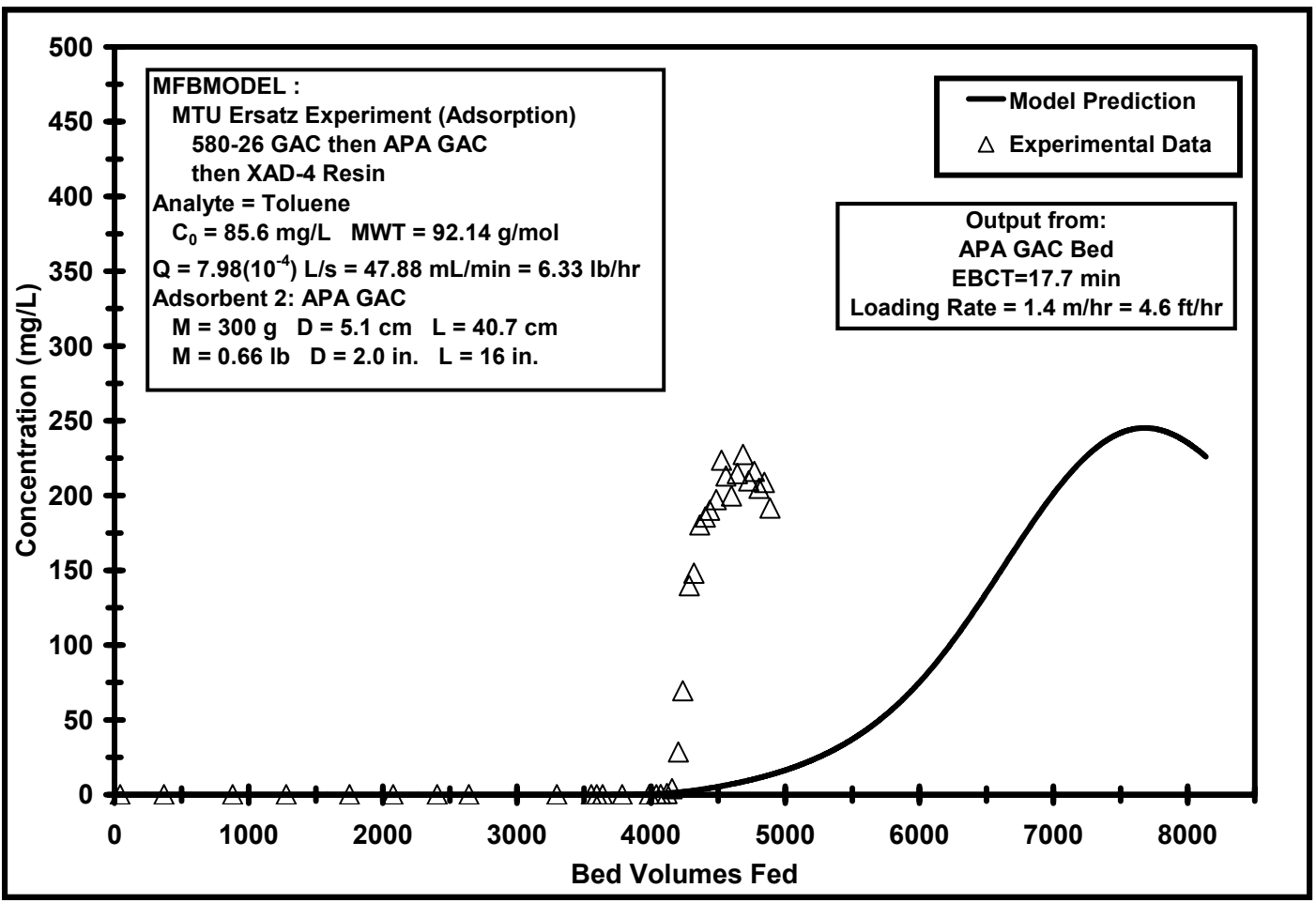




\section{Adsorbent: Rohm \& Haas XAD-4 Resin}

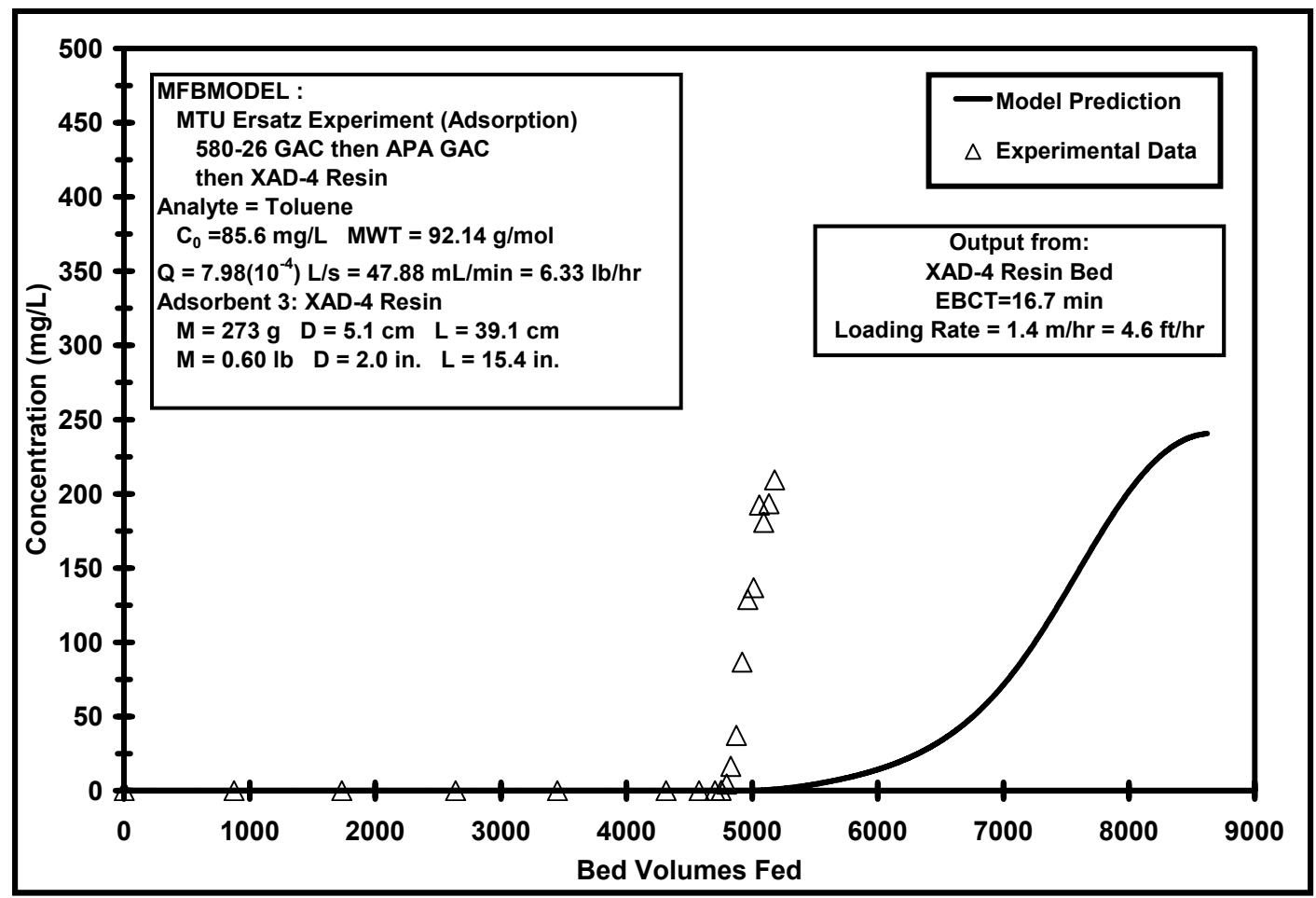




\section{Appendix XI - Development of the Pore Diffusion Model (PDM) for SAC and SBA Resins}

\section{Derivation of the Equivalent Balances in a Fixed-Bed Ion Exchange Column}

The equations describing the fate of $\mathrm{n}$ ions in a fixed-bed ion exchanger are presented herein. The assumptions and mechanisms incorporated into the model are given in the main report in the section called model framework. The nomenclature for the following development is given at the end of this appendix.

\section{Liquid-Phase Equivalent Balance}

The liquid-phase equivalent balance for ion, $i$, can be expressed in words as:

$$
\begin{gathered}
\left\{\begin{array}{c}
\text { Equivalents of ion } \mathrm{i} \\
\text { entering by advection }
\end{array}\right\}-\left\{\begin{array}{c}
\text { Equivalents of ion } \mathrm{i} \\
\text { leaving by advection }
\end{array}\right\}= \\
\left\{\begin{array}{c}
\text { Equivalents of ion } \mathrm{i} \\
\text { accumulated in the liquid phase }
\end{array}\right\}+\left\{\begin{array}{c}
\text { Equivalents of ion } \mathrm{i} \\
\text { accumulated in the resin phase }
\end{array}\right\}
\end{gathered}
$$

Expressing this in mathematical terms:

$$
\begin{gathered}
\varepsilon V A\left[C_{i}(z, t)-C_{i}(z+\Delta z, t)\right] \Delta t=\varepsilon A\left[C_{i}(z, t+\Delta t)-C_{i}(z, t)\right] \Delta z \\
+k_{f, i} A_{p}\left[C_{i}(z, t)-C_{p, i}(r=R, z, t)\right] \Delta t
\end{gathered}
$$

Dividing Equation $\mathrm{XI}-1$ by $\mathrm{A} \varepsilon \Delta \mathrm{z} \Delta \mathrm{t}$ and taking the limit as $z$ and $t$ approach zero gives:

$$
-V \frac{\partial C_{i}(z, t)}{\partial z}=\frac{\partial C_{i}(z, t)}{\partial t}+\frac{k_{f i} A_{p}}{A \varepsilon \Delta z}\left[C_{i}(z, t)-C_{p, i}(r=R, z, t)\right]
$$

Assuming the resin has the same external surface area as a sphere, the total external surface area of a resin particle $\left(A_{p}\right)$ equals the product of the number of resin particles and the surface area of a spherical resin particle. In mathematical terms:

$$
A_{P}=\left(\frac{3 M}{4 \pi R^{3} \rho_{a}}\right)\left(4 \pi R^{2}\right)
$$


To simplify Equation $\mathrm{XI}-2$, the resin dosage, $\mathrm{D}_{0}$, is given as:

$$
D_{0}=\frac{M}{A \Delta z}=\rho_{a}(1-\varepsilon)
$$

Combining Equations $\mathrm{XI}-1, \mathrm{XI}-2$, and $\mathrm{XI}-3$ yields the final form of the liquid-phase equivalent balance:

$$
-V \frac{\partial C_{i}(z, t)}{\partial z}=\frac{\partial C_{i}(z, t)}{\partial t}+\frac{3 k_{f, i}(1-\varepsilon)}{R \varepsilon}-\left[C_{i}(z, t)-C_{p, i}(r=R, z, t)\right]
$$

The initial condition for Equation XI-5 is:

$$
C_{i}(0 \leq z \leq L, t=0)=0
$$

The boundary condition for Equation $\mathrm{XI}-5$ is:

$$
C_{i}(z=0, t \geq 0)=C_{o, i}(t)
$$

\section{Intraparticle-Phase Equivalent Balance}

To derive the intraparticle equivalent phase balance for component $i$, an equivalent balance is written on a differential element of resin particle, $\Delta r$. The ionic mass flux, $J_{i}$ at any radial position will be the flux due to pore diffusion:

$$
\mathrm{J}_{\mathrm{i}}=-\mathrm{D}_{\mathrm{p}, \mathrm{i}} \varepsilon_{\mathrm{p}} \frac{\partial \mathrm{C}_{\mathrm{p}, \mathrm{i}}}{\partial \mathrm{r}}
$$

in which $D_{p, i}$ is the apparent pore diffusivity for component $i$. As discussed in the previous work, some researchers have found the pore diffusivities to depend upon the other exchanging ions. Consequently, the apparent $D_{p, i}$ includes this dependence. Writing an equivalent balance on a differential element of a resin particle for component $i$ in words yields:

$$
\left\{\begin{array}{c}
\text { Equivalents } \\
\text { of ion } \mathrm{i} \\
\text { entering at } r
\end{array}\right\}-\left\{\begin{array}{c}
\text { Equivalents } \\
\text { of ion } \mathrm{i} \\
\text { leaving at } \mathrm{r}+\Delta \mathrm{r}
\end{array}\right\}=\left\{\begin{array}{c}
\text { Equivalents } \\
\text { of ion i accumulated } \\
\text { in spherical shell }
\end{array}\right\}
$$

With the use of Equation XI-8, the intraparticle phase equivalent balance for component $i$ in mathematical terms becomes: 


$$
\begin{gathered}
{\left[-D_{p, i} \varepsilon_{p} \frac{\partial C_{p, i}(r, z, t)}{\partial r}\right] 4 \pi r^{2} \Delta t-\left[-D_{p, i} \varepsilon_{p} \frac{\partial C_{p, i}(r+\Delta r, z, t)}{\partial r}\right] 4 \pi(r+\Delta r)^{2} \Delta t} \\
=\left[\rho_{a} q_{i}(r, z, t+\Delta t)+\varepsilon_{p} C_{p, i}(r, z, t+\Delta t)\right] 4 \pi r^{2} \Delta r- \\
{\left[\rho_{a} q_{i}(r, z, t)+\varepsilon_{p} C_{p, i}(r, z, t)\right] 4 \pi r^{2} \Delta r}
\end{gathered}
$$

The left-hand side of Equation XI-9 accounts for the equivalents entering and leaving the differential element by pore diffusion. It is equal to the amount of equivalents that has exchanged within the resin pores in the differential element.

Note that the resin phase equivalent concentration gradients on the left hand side of Equation XI-9 represent a mean value evaluated at some time between $t$ and $t+\Delta t$ given by the mean value theorem. Accordingly, the concentrations on the right hand side are mean concentrations evaluated at some point in the interval $r$ and $r+\Delta r$.

The final form of the intraparticle phase equivalent balance for component $i$ is obtained by dividing Equation XI-9 by $\rho_{\mathrm{a}} 4 \pi \mathrm{r}^{2} \Delta \mathrm{r} \Delta \mathrm{t}$ and taking the limit as $\Delta \mathrm{r}$ and $\Delta \mathrm{t}$ approach zero.

$$
\frac{1}{r^{2}} \frac{\partial}{\partial r}\left[r^{2} \frac{D_{p, i} \varepsilon_{p}}{\rho_{a}} \frac{\partial C_{p, i}(r, z, t)}{\partial r}\right]=\frac{\partial}{\partial t}\left[q_{i}(r, z, t)+\frac{\varepsilon_{p}}{\rho_{a}} C_{p, i}(r, z, t)\right]
$$

To solve Equation $\mathrm{XI}-10$, one initial condition and two boundary conditions are needed. The initial condition is given by:

$$
\left[\mathrm{q}_{\mathrm{i}}(\mathrm{r}, \mathrm{z}, \mathrm{t})+\frac{\varepsilon_{\mathrm{p}}}{\rho_{\mathrm{a}}} \mathrm{C}_{\mathrm{p}, \mathrm{i}}(\mathrm{r}, \mathrm{z}, \mathrm{t})\right](0 \leq \mathrm{r} \leq \mathrm{R}, 0 \leq \mathrm{z} \leq \mathrm{L}, \mathrm{t}=0)=0
$$

Equation XI-11 is valid for all the exchanging ions except for the presaturant ion which is equal to the total resin capacity. Due to symmetry at the center of the resin particle, the first boundary condition is given by:

$$
\frac{\partial}{\partial r}\left[q_{i}(r, z, t)+\frac{\varepsilon_{p}}{\rho_{a}} C_{p, i}(r, z, t)\right](r=0,0 \leq z \leq L, t)=0
$$


The second boundary condition describes the situation at the exterior surface of the resin particle. Writing an equivalent balance at the resin boundary, the amount of equivalents leaving the liquid phase must equal the amount of equivalents transferred to the resin phase:

$$
\left\{\begin{array}{c}
\text { Equivalents of ion } \mathrm{i} \\
\text { Transferred through the } \\
\text { Liquid Phase Boundary Layer }
\end{array}\right\}=\left\{\begin{array}{c}
\text { Equivalents of ion } \mathrm{i} \\
\text { Accumulated within } \\
\text { the Resin Particle }
\end{array}\right\}
$$

In mathematical terms:

$$
\left\{\begin{array}{c}
\mathrm{k}_{\mathrm{f}, \mathrm{i}}\left[\mathrm{C}_{\mathrm{i}}(\mathrm{z}, \mathrm{t})-\mathrm{C}_{\mathrm{p}, \mathrm{i}}(\mathrm{r}=\mathrm{R}, \mathrm{z}, \mathrm{t})\right] 4 \pi \mathrm{R}^{2} \Delta \mathrm{t}= \\
\left\{\begin{array}{c}
{\left[\mathrm{q}_{\mathrm{ave}, \mathrm{i}}(\mathrm{z}, \mathrm{t}+\Delta \mathrm{t})+\frac{\varepsilon_{\mathrm{p}}}{\rho_{\mathrm{a}}} \mathrm{C}_{\mathrm{p}, \mathrm{ave}, \mathrm{i}}(\mathrm{z}, \mathrm{t}+\Delta \mathrm{t})\right]-} \\
{\left[\mathrm{q}_{\mathrm{ave}, \mathrm{i}}(\mathrm{z}, \mathrm{t})+\frac{\varepsilon_{\mathrm{p}}}{\rho_{\mathrm{a}}} \mathrm{C}_{\mathrm{p}, \mathrm{ave}, \mathrm{i}}(\mathrm{z}, \mathrm{t})\right]}
\end{array}\right\}
\end{array}\right\} \frac{4}{3} \pi \mathrm{R}^{3} \rho_{\mathrm{a}}
$$

Dividing Equation $\mathrm{XI}-13$ by $\Delta \mathrm{t}$ and taking the limit as $\Delta \mathrm{t}$ approaches zero results in:

$$
\frac{\partial}{\partial t}\left[\mathrm{q}_{\mathrm{ave}, \mathrm{i}}(\mathrm{z}, \mathrm{t})+\frac{\varepsilon_{\mathrm{p}}}{\rho_{\mathrm{a}}} \mathrm{C}_{\mathrm{p}, \mathrm{ave}, \mathrm{i}}(\mathrm{z}, \mathrm{t})\right]=\frac{3 \mathrm{k}_{\mathrm{f}, \mathrm{i}}}{\mathrm{R} \rho_{\mathrm{a}}}\left[\mathrm{C}_{\mathrm{i}}(\mathrm{z}, \mathrm{t})-\mathrm{C}_{\mathrm{p}, \mathrm{i}}(\mathrm{r}=\mathrm{R}, \mathrm{z}, \mathrm{t})\right]
$$

The average resin phase equivalent concentration is given by:

$$
\mathrm{q}_{\mathrm{ave}, \mathrm{i}}(\mathrm{z}, \mathrm{t})+\frac{\varepsilon_{\mathrm{p}}}{\rho_{\mathrm{a}}} \mathrm{C}_{\mathrm{p}, \text { ave }, \mathrm{i}}(\mathrm{z}, \mathrm{t})=\frac{3}{\mathrm{R}^{3}} \int_{0}^{\mathrm{R}}\left[\mathrm{q}_{\mathrm{i}}(\mathrm{r}, \mathrm{z}, \mathrm{t})+\frac{\varepsilon_{\mathrm{p}}}{\rho_{\mathrm{a}}} \mathrm{C}_{\mathrm{p}, \mathrm{i}}(\mathrm{r}, \mathrm{z}, \mathrm{t})\right] \mathrm{r}^{2} \mathrm{dr}
$$

Substituting Equation $\mathrm{XI}-15$ into Equation $\mathrm{XI}-14$ yields the final form of the second boundary condition for Equation $\mathrm{XI}-10$ :

$$
\frac{\partial}{\partial t}\left\{\int_{0}^{R}\left[q_{i}(r, z, t)+\frac{\varepsilon_{p}}{\rho_{a}} C_{p, i}(r, z, t)\right] r^{2} d r\right\}=\frac{k_{f, i} R^{2}}{\rho_{a}}\left[C_{i}(z, t)-C_{p, i}(r=R, z, t)\right]
$$




\section{Coupling Equation}

In order to solve the liquid-phase and intraparticle-phase equivalent

balances, the number of equivalents of ion $i$ in the resin pores, $C_{p, i}(r, z, t)$ must be expressed in terms of the number of equivalents in the resin phase for ion $i$, $q_{i}(r, z, t)$. This relationship is known as the coupling equation and is expressed as:

$$
C_{p, i}(r, z, t)=\frac{C_{T}(z, t)\left[q_{i}(r, z, t)\right]}{\sum_{j=1}^{m} \alpha_{j}^{i} q_{j}(r, z, t)}
$$

where:

$$
C_{T}(z, t)=\sum_{j=1}^{m} C_{0, j}\left(t-\frac{z}{V}\right)
$$

\section{Conversion of the Fixed-Bed Model Equations for lon Exchange into Dimensionless Form}

This section contains the conversion of the dimensioned equations into their dimensionless form using the following dimensionless variables and parameters. The reduced spatial coordinates are defined as:

$$
\begin{aligned}
& \bar{r}=\frac{r}{R} \\
& \bar{z}=\frac{z}{L}
\end{aligned}
$$

Dimensionless time is defined in terms of throughput:

$$
T=\frac{t}{\tau\left(D_{T}+1\right)}
$$


The following variables are defined to calculate dimensionless concentrations:

$$
\begin{gathered}
\overline{\mathrm{C}_{0, \mathrm{i}}}=\frac{1}{\mathrm{t}} \int_{0}^{\mathrm{t}} \mathrm{C}_{0, \mathrm{i}}(\mathrm{t}) \mathrm{dt} \\
\overline{\mathrm{C}_{\mathrm{T}, \text { avg }}}=\sum_{\mathrm{j}=1}^{\mathrm{m}} \overline{\mathrm{C}_{0, \mathrm{j}}} \\
\mathrm{Y}_{\mathrm{T}}=\mathrm{q}_{\mathrm{T}}+\frac{\varepsilon_{\mathrm{P}}}{\rho_{\mathrm{a}}} \overline{\mathrm{C}_{\mathrm{T}, \text { avg }}}
\end{gathered}
$$

Dimensionless concentrations are defined as:

$$
\begin{gathered}
\overline{\mathrm{X}}_{\mathrm{i}}(\overline{\mathrm{z}}, \mathrm{T})=\frac{\mathrm{C}_{\mathrm{i}}(\mathrm{z}, \mathrm{t})}{\overline{\mathrm{C}_{\mathrm{T}, \text { avg }}}} \\
\overline{\mathrm{X}}_{\mathrm{p}, \mathrm{i}}(\overline{\mathrm{r}}, \overline{\mathrm{z}}, \mathrm{T})=\frac{\mathrm{C}_{\mathrm{p}, \mathrm{i}}(\mathrm{r}, \mathrm{z}, \mathrm{t})}{\overline{\mathrm{C}_{\mathrm{T}, \text { avg }}}} \\
\overline{\mathrm{C}_{\mathrm{T}}}(\overline{\mathrm{z}}, \mathrm{T})=\frac{\mathrm{C}_{\mathrm{T}}(\mathrm{z}, \mathrm{t})}{\overline{\mathrm{C}}_{\mathrm{T}, \text { avg }}}
\end{gathered}
$$

Defining total particle loading $\left(Y_{i}\right)$ allows us to calculate reduced particle loading $\left(\bar{Y}_{i}\right)$ :

$$
\begin{gathered}
Y_{i}(r, z, t)=q_{i}(r, z, t)+\frac{\varepsilon_{p}}{\rho_{a}} C_{p, i}(r, z, t) \\
\bar{Y}_{i}(\bar{r}, \bar{z}, T)=\frac{Y_{i}(r, z, t)}{Y_{T}}
\end{gathered}
$$

For partial derivatives, the following expressions are used:

$$
\begin{gathered}
\frac{\partial}{\partial r}=\frac{1}{R} \frac{\partial}{\partial \bar{r}} \\
\frac{\partial}{\partial z}=\frac{1}{L} \frac{\partial}{\partial \bar{z}} \\
\frac{\partial}{\partial t}=\frac{1}{\tau\left(\operatorname{Dg}_{T}+1\right)} \frac{\partial}{\partial T}
\end{gathered}
$$


Dimensionless parameters used in the development are:

$$
\begin{aligned}
\mathrm{Dg}_{\mathrm{s}} & =\frac{\rho_{\mathrm{a}} \mathrm{q}_{\mathrm{T}}(1-\varepsilon)}{\varepsilon \overline{\mathrm{C}_{\mathrm{T}, \mathrm{avg}}}} \\
\mathrm{Dg} \mathrm{p}_{\mathrm{p}} & =\frac{\varepsilon_{\mathrm{p}}(1-\varepsilon)}{\varepsilon} \\
\mathrm{Dg}_{\mathrm{T}} & =\mathrm{Dg} \mathrm{g}_{\mathrm{s}}+\mathrm{Dg} \mathrm{g}_{\mathrm{p}} \\
\mathrm{St}_{\mathrm{i}} & =\frac{\mathrm{k}_{\mathrm{f}, \mathrm{\tau}} \tau(1-\varepsilon)}{\mathrm{R} \varepsilon} \\
\mathrm{Ed}_{\mathrm{p}, \mathrm{i}} & =\frac{\mathrm{D}_{\mathrm{p}, \mathrm{\tau}} \tau(1-\varepsilon)_{\varepsilon_{\mathrm{p}}}}{\mathrm{R}^{2} \varepsilon}
\end{aligned}
$$

\section{Liquid-Phase Equivalent Balance}

The dimensioned equation for the liquid phase equivalent balance was given in Equation XI-5. Applying the dimensionless variables and parameters yields the following:

$$
-\frac{\partial \bar{X}_{i}(\bar{z}, T)}{\partial \bar{z}}=\frac{1}{\left(D g_{T}+1\right)} \frac{\partial \bar{X}_{i}(\bar{z}, T)}{\partial T}+3 S_{i}\left[\bar{X}_{i}(\bar{z}, T)-\bar{X}_{p, i}(\bar{r}=1, \bar{z}, T)\right]
$$

The dimensionless initial and boundary conditions are given below. The dimensionless initial condition (converted from Equation $\mathrm{XI}-6$ ) is:

$$
\bar{X}_{i}(0 \leq \bar{Z} \leq 1, T=0)=0
$$

The dimensionless boundary condition (converted from Equation $\mathrm{XI}-7$ ) is:

$$
\bar{X}_{i}(\bar{z}=0, T \geq 0)=\frac{C_{0, i}(t)}{\overline{C_{T, a v g}}}
$$

\section{Intraparticle-Phase Equivalent Balance}

The dimensional equation for the intraparticle-phase equivalent balance was given in Equation XI-10. Applying the dimensionless variables and parameters yields the following:

$$
\frac{1}{\bar{r}^{2}} \frac{\partial}{\partial \bar{r}}\left[\bar{r}^{2} \operatorname{Ed}_{p, i} \frac{\partial \bar{X}_{p, i}(\bar{r}, \bar{z}, T)}{\partial \bar{r}}\right]=\left(\frac{D g_{T}}{D g_{T}+1}\right) \frac{\partial \bar{Y}_{i}(\bar{r}, \bar{z}, T)}{\partial T}
$$


The dimensionless initial and boundary conditions for the intraparticle equivalent balance are shown in Equations $\mathrm{XI}-42, \mathrm{XI}-43$, and $\mathrm{XI}-44$ with the exception that the solid-phase presaturant concentration is equal to the total resin capacity at $T$ equal to zero. The dimensionless initial condition (converted from Equation $\mathrm{XI}-11$ ) is:

$$
\bar{Y}_{i}(0 \leq \bar{r} \leq 1,0 \leq \bar{z} \leq 1, T=0)=0
$$

The dimensionless boundary conditions (converted from Equations $\mathrm{XI}-12$ and $\mathrm{XI}-16$ , respectively) are:

$$
\begin{gathered}
\frac{\partial}{\partial \bar{r}}\left[\bar{Y}_{i}(\bar{r}=0,0 \leq \bar{z} \leq 1, T)\right]=0 \\
\left(\frac{D g_{T}}{D g_{T}+1}\right) \frac{\partial}{\partial T} \int_{0}^{1} \bar{Y}_{i}(\bar{r}, \bar{z}, T) r^{2} d \bar{r}=S_{i}\left[\bar{X}_{i}(\bar{z}, T)-\bar{X}_{p, i}(\bar{r}=1, \bar{z}, T)\right]
\end{gathered}
$$

\section{Coupling Equation}

The coupling equation which relates the equivalent fraction of component $i$ in the liquid in the resin pores to the equivalent fraction exchanged on the resin surface was given in dimensioned form in Equation XI-17. Applying the dimensionless variables and parameters yields the following:

$$
\bar{X}_{p, i}(\bar{r}, \bar{z}, T)=\frac{\overline{C_{T}}(\bar{z}, T)\left[\bar{Y}_{i}(\bar{r}, \bar{z}, T) Y_{T}-\frac{\varepsilon_{p}}{\rho_{a}} \overline{C_{T, a v g}} \bar{X}_{p, i}(\bar{r}, \bar{z}, T)\right]}{\sum_{j} \alpha_{j}^{i}\left[\bar{Y}_{j}(\bar{r}, \bar{z}, T) Y_{T}-\frac{\varepsilon_{p}}{\rho_{a}} \overline{C_{T, a v g}} \bar{X}_{p, j}(\bar{r}, \bar{z}, T)\right]}
$$

Substituting Equation $\mathrm{XI}-24$ into Equation $\mathrm{XI}-45$ and dividing both the numerator and denominator by $\mathrm{q}_{\mathrm{T}}$ results in:

$$
\overline{\mathrm{X}}_{\mathrm{p}, \mathrm{i}}(\overline{\mathrm{r}}, \overline{\mathrm{z}}, \mathrm{T})=\frac{\overline{\mathrm{C}_{\mathrm{T}}}(\overline{\mathrm{z}}, \mathrm{T})\left[\overline{\mathrm{Y}}_{\mathrm{i}}(\overline{\mathrm{r}}, \overline{\mathrm{z}}, \mathrm{T})\left(1+\frac{\varepsilon_{\mathrm{p}} \overline{\mathrm{C}_{\mathrm{T}, \text { avg }}}}{\rho_{\mathrm{a}} \mathrm{q}_{\mathrm{T}}}\right)-\frac{\varepsilon_{\mathrm{p}} \overline{\mathrm{C}}_{\mathrm{T}, \text { avg }}}{\rho_{\mathrm{a}} \mathrm{q}_{\mathrm{T}}} \overline{\mathrm{X}}_{\mathrm{p}, \mathrm{i}}(\overline{\mathrm{r}}, \overline{\mathrm{z}}, \mathrm{T})\right]}{\sum_{\mathrm{j}} \alpha_{\mathrm{j}}^{\mathrm{i}}\left[\overline{\mathrm{Y}}_{\mathrm{j}}(\overline{\mathrm{r}}, \overline{\mathrm{z}}, \mathrm{T})\left(1+\frac{\varepsilon_{\mathrm{p}} \overline{\mathrm{C}}_{\mathrm{T}, \text { avg }}}{\rho_{\mathrm{a}} \mathrm{q}_{\mathrm{T}}}\right)-\frac{\varepsilon_{\mathrm{p}} \overline{\mathrm{C}}_{\mathrm{T}, \text { avg }}}{\rho_{\mathrm{a}} \mathrm{q}_{\mathrm{T}}} \overline{\mathrm{X}}_{\mathrm{p}, \mathrm{j}}(\overline{\mathrm{r}}, \overline{\mathrm{z}}, \mathrm{T})\right]}
$$


With some rearrangement and by substituting in Equations $\mathrm{XI}-33$ and $\mathrm{XI}-34$, the term $\left(\frac{\varepsilon_{\mathrm{p}} \overline{\mathrm{C}_{\mathrm{T}, \text { avg }}}}{\rho_{\mathrm{a}} \mathrm{q}_{\mathrm{T}}}\right)$ can be rewritten as:

$$
\frac{\varepsilon_{\mathrm{p}} \overline{\mathrm{C}_{\mathrm{T}, \text { avg }}}}{\rho_{\mathrm{a}} \mathrm{q}_{\mathrm{T}}}=\left[\frac{\varepsilon_{\mathrm{p}}(1-\varepsilon)}{\varepsilon}\right]\left[\frac{\varepsilon \overline{\mathrm{C}_{\mathrm{T}, \text { avg }}}}{\rho_{\mathrm{a}} \mathrm{q}_{\mathrm{T}}(1-\varepsilon)}\right]=\frac{\mathrm{Dg}_{\mathrm{p}}}{\mathrm{Dg}_{\mathrm{s}}}
$$

Substituting Equation XI-47 into Equation XI-46, multiplying the numerator and the denominator by $\mathrm{Dg}_{\mathrm{s}}$, and then substituting in Equation XI-35 results in the final form of the dimensionless coupling equation:

$$
\overline{\mathrm{X}}_{\mathrm{p}, \mathrm{i}}(\overline{\mathrm{r}}, \overline{\mathrm{z}}, \mathrm{T})=\frac{\overline{\mathrm{C}_{\mathrm{T}}}(\overline{\mathrm{z}}, \mathrm{T})\left[\overline{\mathrm{Y}}_{\mathrm{i}}(\overline{\mathrm{r}}, \overline{\mathrm{z}}, \mathrm{T}) D g_{\mathrm{T}}-\mathrm{Dg}_{\mathrm{p}} \overline{\mathrm{X}}_{\mathrm{p}, \mathrm{i}}(\overline{\mathrm{r}}, \overline{\mathrm{z}}, \mathrm{T})\right]}{\sum_{\mathrm{j}} \alpha_{\mathrm{j}}^{\mathrm{i}}\left[\overline{\mathrm{Y}}_{\mathrm{j}}(\overline{\mathrm{r}}, \overline{\mathrm{z}}, \mathrm{T}) D g_{\mathrm{T}}-\mathrm{Dg}_{\mathrm{p}} \overline{\mathrm{X}}_{\mathrm{p}, \mathrm{j}}(\overline{\mathrm{r}}, \overline{\mathrm{z}}, \mathrm{T})\right]}
$$




\section{Transferring the Dimensionless Plug Flow Pore Diffusion Model (PFPDM) Equations from Partial Differential Equations into Ordinary Differential Equations Using Orthogonal Collocation}

In order to solve the dimensionless PFPDM equations derived above, it is necessary to transfer them from partial differential equations into ordinary differential equations using the method of orthogonal collocation. The ordinary differential equations obtained after applying orthogonal collocation are presented below.

\section{Liquid-Phase Equivalent Balance}

This equation was presented in dimensionless form in Equation XI-38. Applying orthogonal collocation results in:

$$
\begin{gathered}
-\sum_{\mathrm{k}=1}^{M C} A_{j k}^{z} \bar{X}_{i k}=\left(\frac{1}{D g_{T}+1}\right) \frac{d \bar{X}_{i j}}{d T}+3 S t_{i}\left[\bar{X}_{i j}-\bar{X}_{p, i j N C}\right] \Rightarrow \\
\frac{d \bar{X}_{i j}}{d T}=\left(D g_{T}+1\right)\left[-\sum_{k=1}^{M C} A_{j k}^{z} \bar{X}_{i k}-3 S t_{i}\left(\bar{X}_{i j}-\bar{X}_{p, j N C}\right)\right]
\end{gathered}
$$

Valid for: $\mathrm{j}=2$ to $\mathrm{MC}$

$$
\mathrm{i}=1 \text { to NCOMP }
$$

The initial condition for the liquid-phase equivalent balance was given in dimensionless form in Equation XI-39. Applying orthogonal collocation to this equation results in:

$$
\overline{\mathrm{X}}_{\mathrm{ij}}=0 \text { at } \mathrm{T}=0 \text { for } \mathrm{j}=1 \text { to } \mathrm{MC}
$$

The boundary condition was given in dimensionless form in Equation XI-40.

Applying orthogonal collocation to this expression results in:

$$
\overline{\mathrm{X}}_{\mathrm{i} 1}=\frac{\mathrm{C}_{0, \mathrm{i}}(\mathrm{t})}{\overline{\mathrm{C}}_{\mathrm{T}, \mathrm{avg}}}
$$

\section{Intraparticle-Phase Equivalent Balance}

The dimensionless form of this equation was shown in Equation XI-41.

Applying orthogonal collocation results in:

$$
E d_{p, i} \sum_{q=1}^{N C} B_{k q}^{r} \bar{X}_{p, j q}=\left(\frac{D g_{T}}{D g_{T}+1}\right) \frac{d \bar{Y}_{i}(\bar{r}, \bar{z}, T)}{d T} \Rightarrow
$$




$$
\frac{d \bar{Y}_{i j k}}{d T}=\left(\frac{D g_{T}+1}{D g_{T}}\right) E d_{p, i} \sum_{q=1}^{N C} B_{k q}^{r} \bar{X}_{p, j i q}
$$

Valid for: $j=1$ to $M C$

$$
\begin{aligned}
& k=1 \text { to ND } \\
& i=1 \text { to NCOMP }
\end{aligned}
$$

The initial condition was given in dimensionless form in Equation XI-42. Applying orthogonal collocation to this equation results in:

$$
\overline{\mathrm{Y}}_{\mathrm{ijk}}=0 \text { at } \mathrm{T}=0
$$

Valid for: $\mathrm{i}=1$ to NCOMP

$$
\begin{aligned}
& j=1 \text { to } M C \\
& k=1 \text { to } N C
\end{aligned}
$$

The first boundary condition was given in dimensionless form in Equation XI-43. Applying orthogonal collocation results in:

$$
\frac{d \bar{Y}_{i j}}{d \bar{r}}=0 \text { at } \bar{r}=0,1 \leq j \leq M C
$$

This boundary condition arises from symetry of the polynomials so it is already accounted for in orthogonal collocation and does not need to be explicitly programmed. The second boundary condition was given in Equation XI-44. Applying orthogonal collocation to this equation results in:

$$
\begin{gathered}
\left(\frac{D g_{T}}{D g_{T}+1}\right) \frac{d}{d T}\left[\sum_{k=1}^{N C} W_{k}^{r} \bar{Y}_{i j k}\right]=S t_{i}\left[\bar{X}_{i j}-\bar{X}_{p, j N C}\right] \Rightarrow \\
\frac{d \bar{Y}_{i j N C}}{d T}=\frac{\left(\frac{D g_{T}+1}{D g_{T}}\right) S t_{i}\left[\bar{X}_{i j}-\bar{X}_{p, j N C}\right]-\sum_{k=1}^{N D} W_{k}^{r} \frac{d \bar{Y}_{i j k}}{d T}}{W_{N C}^{r}} \\
\text { Valid for: } i=1 \text { to NCOMP } \\
j=1 \text { to MC }
\end{gathered}
$$

\section{Coupling Equation}

The non-linear coupling equation was presented in dimensionless form in Equation $\mathrm{XI}-48$. It can be assumed for this equation that the pore contribution is negligible compared to the surface contribution, which results in the following simplified equation: 


$$
\overline{\mathrm{X}}_{\mathrm{p}, \mathrm{i}}(\overline{\mathrm{r}}, \overline{\mathrm{z}}, \mathrm{T})=\frac{\overline{\mathrm{C}_{\mathrm{T}}}(\overline{\mathrm{z}}, \mathrm{T})\left[\overline{\mathrm{Y}}_{\mathrm{i}}(\overline{\mathrm{r}}, \overline{\mathrm{z}}, \mathrm{T})\right]}{\sum_{\mathrm{j}} \alpha_{\mathrm{j}}^{\mathrm{i}}\left[\overline{\mathrm{Y}}_{\mathrm{j}}(\overline{\mathrm{r}}, \overline{\mathrm{z}}, \mathrm{T})\right]}
$$

Applying orthogonal collocation to this equation results in:

$$
\overline{\mathrm{X}}_{\mathrm{p}, \mathrm{jk}}=\frac{\overline{\mathrm{C}_{\mathrm{T}, \mathrm{j}}}\left[\overline{\mathrm{Y}}_{\mathrm{ijk}}\right]}{\sum_{\mathrm{p}=1}^{m} \alpha_{\mathrm{p}}^{\mathrm{i}}\left[\overline{\mathrm{Y}}_{\mathrm{pjk}}\right]}
$$

Valid for: $j=1$ to $M C$

$k=1$ to $N C$

$\mathrm{i}=1$ to NCOMP

\section{Notes on Application of Orthogonal Collocation}

To completely describe any fixed-bed system, there will be NC resin-phase concentrations plus one liquid-phase concentration at each axial position in the bed (except at the inlet) for each component. This results in the following calculation for the total number of differential equations to be solved:

$$
\begin{aligned}
&\{\text { Total Number of Equations }\}=\left\{\left[(\mathrm{NC}+1)^{*} \mathrm{MC}\right]-1\right\}^{*} \mathrm{NCOMP} \\
& \text { where: } \mathrm{NC}=\text { Number of radial collocation points } \\
& \mathrm{MC}=\text { Number of axial collocation points } \\
& \mathrm{NCOMP}=\text { Number of components }
\end{aligned}
$$

\section{Appendix XI.A Nomenclature}

A

$A_{p}$

$A_{j k}^{z}$

$\mathrm{B}_{\mathrm{kq}}^{\mathrm{r}}$

$C_{i}(z, t)$
Cross-sectional area of exchange column $\left(\mathrm{L}^{2}\right)$

Total external surface area of the resin particle $\left(\mathrm{L}^{2}\right)$

Orthogonal collocation matrix that approximates first derivative in the axial direction

Orthogonal collocation matrix that approximates second derivative in the radial direction

Equivalent liquid-phase concentration of ion $i\left(\mathrm{eqL}^{-3}\right)$ 
$\mathrm{C}_{0, \mathrm{i}}(\mathrm{t}) \quad$ Equivalent time-variable influent liquid-phase concentration of ion $\mathrm{i}$ $\left(e q L^{-3}\right)$

$\overline{\mathrm{C}_{0, i}} \quad$ Equivalent time-averaged influent liquid-phase concentration of ion $i$ $\left(e^{-3} L^{-3}\right)$

$\mathrm{C}_{p, \text { ave, } i}(\mathrm{z}, \mathrm{t}) \quad$ Average equivalent resin phase concentration of ion $i$ in the resin pores in equilibrium with the initial liquid phase concentration as a function of axial position and time $\left(\mathrm{eqL}^{-3}\right)$

$\mathrm{C}_{\mathrm{p}, \mathrm{i}}(\mathrm{r}, \mathrm{z}, \mathrm{t}) \quad$ Equivalent ion concentration in the resin pores as a function of radial and axial position and time $\left(\mathrm{eqL}^{-3}\right)$

$\overline{\mathrm{C}_{\mathrm{T}, \text { avg }}} \quad$ Total equivalent time-averaged influent liquid-phase concentration of all ions $\left(\mathrm{eqL}^{-3}\right)$

$\mathrm{C}_{\mathrm{T}}(\mathrm{z}, \mathrm{t}) \quad$ Total equivalent time-variable influent liquid-phase concentration of all ions at time $\mathrm{t}\left(\mathrm{eqL}^{-3}\right)$

$\overline{\mathrm{C}_{\mathrm{T}}}(\overline{\mathrm{z}}, \mathrm{T}) \quad$ Reduced total equivalent time-variable influent liquid-phase concentration of all ions (dimensionless)

$\mathrm{Dg}_{\mathrm{p}} \quad$ Equivalent pore distribution parameter (dimensionless)

$\mathrm{Dg}_{\mathrm{s}} \quad$ Equivalent surface distribution parameter (dimensionless)

$\mathrm{Dg}_{\mathrm{T}} \quad$ Total equivalent distribution parameter (dimensionless)

$D_{0} \quad$ Dosage of resin $(M)$

$D_{p, i} \quad$ Pore diffusivity of ion $i$ based on pore volume fraction $\left(L^{2} T^{-1}\right)$

Ed $_{\mathrm{p}, \mathrm{i}} \quad$ Pore diffusion modulus of ion $\mathrm{i}$ (dimensionless)

$\mathrm{J}_{\mathrm{i}} \quad$ Equivalent ion flux $\left(\mathrm{ML}^{-2} \mathrm{~T}^{-1}\right)$

$k_{f, i} \quad$ lonic transport coefficient of ion $i\left(L^{-1}\right)$

$L \quad$ Length of the resin bed $(L)$

m Number of ions in the system

M Mass of Resin (M) 
MC Number of axial collocation points

NC Number of radial collocation points

NCOMP Number of ions in the system

ND Number of radial collocation points $-1=(\mathrm{NC}-1)$

$\mathrm{q}_{\mathrm{ave}, \mathrm{i}}(\mathrm{z}, \mathrm{t}) \quad$ Average equivalent resin phase concentration of ion $i$ on the resin

surface in equilibrium with the initial liquid phase concentration as a function of axial position and time $\left(\mathrm{eqM}^{-1}\right)$

$q_{i}(r, z, t) \quad$ Equivalent resin phase concentration of ion $i$ on the resin surface as a function of radial and axial position and time $\left(\mathrm{eqM}^{-1}\right)$

$\mathrm{q}_{\mathrm{T}} \quad$ Total resin capacity $\left(\mathrm{eqM}^{-1}\right)$

$r \quad$ Radial coordinate (L)

$\bar{r} \quad$ Reduced radial coordinate (dimensionless)

$\mathrm{R} \quad$ Resin radius ( $\mathrm{L}$ )

$\mathrm{St}_{\mathrm{i}} \quad$ Modified Stanton number (dimensionless)

$\mathrm{t} \quad$ Elapsed time $(\mathrm{T})$

T Dimensionless time

$\mathrm{V} \quad$ Interstitial velocity $\left(\mathrm{LT}^{-1}\right)$

$V_{B} \quad$ Resin bed volume $\left(\mathrm{L}^{3}\right)$

$\mathrm{W}_{\mathrm{k}}^{\mathrm{r}} \quad$ Orthogonal collocation vector that approximates an integral in the radial direction

$\bar{X}_{i}(\bar{z}, T) \quad$ Reduced equivalent concentration in the liquid phase of ion $i$ as a function of dimensionless axial position and dimensionless time (dimensionless)

$\bar{X}_{p, i}(\bar{r}, \bar{z}, T) \quad$ Reduced concentration in liquid phase in the resin pores of ion $\mathrm{i}$ as a function of dimensionless radial and axial position and dimensionless time (dimensionless) 

$Y_{i}(r, z, T) \quad$ Total equivalent resin phase concentration of ion $i$ as a function of radial and axial position and time $\left(\mathrm{eqM}^{-1}\right)$
$\bar{Y}_{i}(\bar{r}, \bar{z}, T) \quad$ Reduced total equivalent concentration in the resin phase of ion i as a function of dimensionless radial and axial position and dimensionless time (dimensionless)
$\mathrm{Y}_{\mathrm{T}} \quad$ Total equivalent concentration in the resin phase of all ions $\left(\mathrm{eqM}^{-1}\right)$
z Axial coordinate $(L)$
$\bar{z} \quad$ Reduced axial coordinate (dimensionless)

\section{Greek letters}
$\varepsilon \quad$ Fraction of volumetric space in exchange column unoccupied by resin, or void fraction (dimensionless)
$\varepsilon_{\mathrm{p}} \quad$ Fraction of volumetric space in resin phase unoccupied by adsorbent (dimensionless)
$\rho_{\mathrm{a}} \quad$ Adsorbent density which includes pore volume $\left(\mathrm{ML}^{-3}\right)$
$\tau \quad$ Fluid residence time in resin column, or packed bed contact time ( $\mathrm{T}$ ) 